\title{
SELF-ASSEMBLING QUATERNARY AMMONIUM SULFONAMIDE ANTIMICROBIALS
}

by

\author{
Kamlesh Mistry \\ Bachelor of Science in Chemistry \\ Ryerson University, Toronto, Canada 2011
}

A thesis presented to Ryerson University in partial fulfillment of the requirements for the Master of Science degree in the Program of Molecular Science

Toronto, Ontario, Canada, 2016

OKamlesh Mistry 2016 


\section{AUTHOR'S DECLARATION}

I hereby declare that I am the sole author of this thesis. This is a true copy of the thesis, including any required final revisions, as accepted by my examiners.

I authorize Ryerson University to lend this thesis to other institutions or individuals for the purpose of scholarly research.

I further authorize Ryerson University to reproduce this thesis by photocopying or by other means, in total or in part, at the request of other institutions or individuals for the purpose of scholarly research.

I understand that my thesis may be made electronically available to the public. 


\title{
SELF-ASSEMBLING QUATERNARY AMMONIUM SULFONAMIDE ANTIMICROBIALS
}

M.Sc., Kamlesh Mistry, Molecular Science, Ryerson University, 2016

\begin{abstract}
A series of novel sulfonamide based quaternary ammonium (QUAT's) antimicrobials containing a variety of chemical anchors $\mathrm{R}-\mathrm{SO}_{2}-\mathrm{NH}-\left(\mathrm{CH}_{2}\right)_{3}-\mathrm{N}\left(\mathrm{CH}_{3}\right)_{2}-(\mathrm{CH} 2)_{3}-\mathrm{Y}($ where $\mathrm{R}=$ alkyl or aryl and $\mathrm{Y}=$ organosilane $\left(\mathrm{Si}(\mathrm{OMe})_{3}\right)$, organophosphorus $\left(\mathrm{P}(\mathrm{O})\left(\mathrm{OR}^{1}\right)\right)$ and benzophenone $(-\mathrm{O}-$ $\left.\mathrm{C}_{6} \mathrm{H}_{4}-\mathrm{C}(\mathrm{O})-\mathrm{C}_{6} \mathrm{H}_{5}\right)$ ) were used to immobilize them on different substrates. Sulfonamide organosilane QUAT's were immobilized on to textiles substrates, whereas benzophenone QUAT's were used to exclusively coat plastic surfaces (polyethylene (PE), and polyvinylchloride (PVC)), and organophosphorus QUAT's were prepared for testing on metal surfaces (stainless steel). The covalently attached antimicrobial coatings were found to kill gram +ve and -ve bacteria on contact, hindering their attachment and colonization without any leachate. The partially water soluble sulfonamide QUAT's presented are readily prepared, easy to apply and are relatively inexpensive.

Textile samples were prepared by immersion in a $\mathrm{MeOH}: \mathrm{H}_{2} \mathrm{O}$ (30:70) solution of organosilane QUAT's followed by curing/drying at room temperature for $2-24$ hours. Plastic samples were prepared by electrospraying an EtOH: $\mathrm{H}_{2} \mathrm{O}$ (10:90) solution containing benzophenone QUAT's followed by UV curing using for $2-5$ minutes. All samples showed a $100 \%$ reduction $\left(10^{7}-10^{6}\right.$ cells) of viable Arthrobacter, S. aureus, and E.coli after 3 hours of contact time and maintained their activity over 24 hours versus the control (untreated) samples.
\end{abstract}




\section{ACKNOWLEDGEMENTS}

First and foremost, I would like to thank my supervisor, Dr. Daniel Foucher for this research opportunity. Secondly, I would like to thank Bioshield Technologies Canada Ltd. for collaborating with Ryerson University and providing the necessary funding to keep the project active and running successfully. Special recognition goes to my committee members Dr. Andrew McWilliams and Dr. Derick Rousseau for their guidance, insights and thesis corrections. I would also like to specially recognize Dr. Lukasz Porosa for training and guiding me over the years, and a special thanks to Dr. Aman Khan for help in synthesis and providing guidance and listening.

I would also like to thank former undergraduate student Alexander Caschera, whom I had pleasure working with and provided guidance to whenever necessary. Alexander provided aid in coating of antimicrobial compounds on to the plastic surfaces, and conducted the bio-testing along with Evan Ronan and Lindsay Jackson. I would also like to thank them for spending countless hours inoculating various pathogens/bugs on plastic, fabric, and metal surfaces treated with the sulfonamide based QUAT antimicrobials in the Wolfaardt lab. As well thanks to all graduate students (Khrystyna, Michelle, Grace, Shane, Devin, Omar, Burhan, Yousaf, Christian, Alejhandro, and GM Islam) and undergraduate students (Brad Jacobs and Jeffery Pau) for their moral support and putting up with me over the years.

Most importantly, I would like to thank my loving late grandfather Kalyanjibhai Mistry for instilling the values, upbringing and encouragement towards my studies. I would also like to thank my loving, supporting and patient parents, Balvant Mistry, Hemlata Mistry, and grandmother Kamuben Mistry who supported me through my ups and downs, throughout my studies, and the reason for my accomplishments. Lastly, I would like to thank my younger brother Jignesh Mistry for putting up with me. 


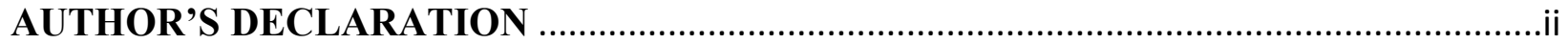

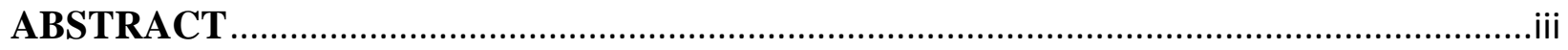

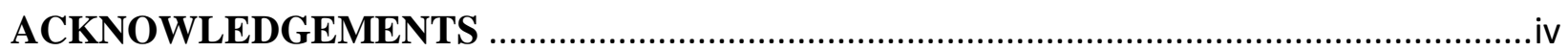

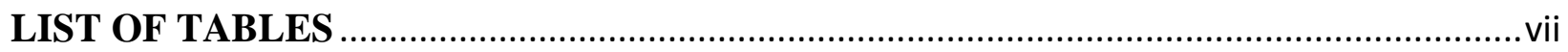

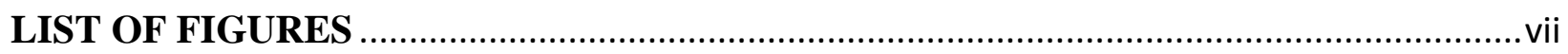

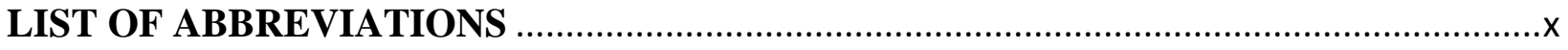

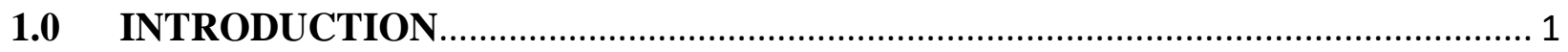

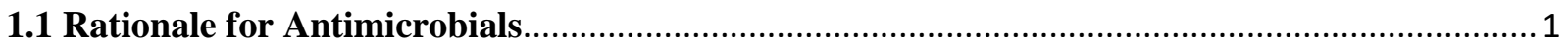

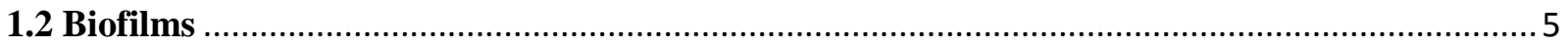

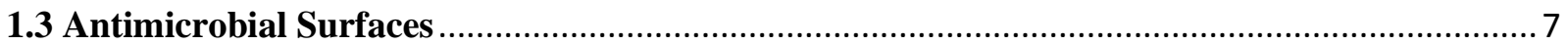

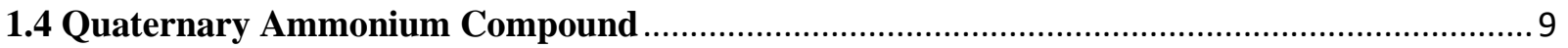

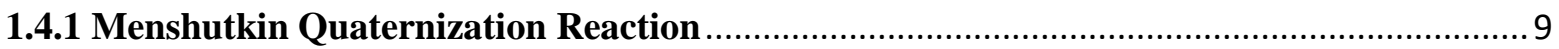

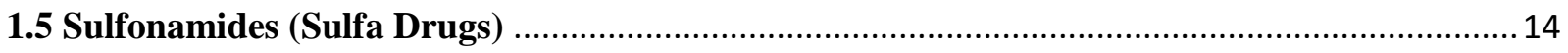

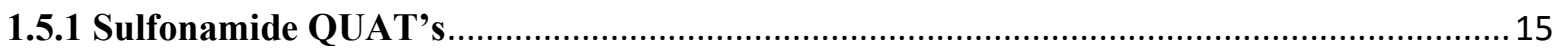

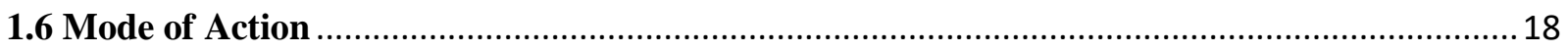

1.6.1 Quaternary Ammonium Compound Mode of Action.......................................................18

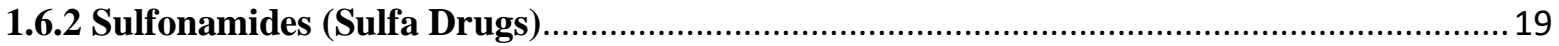

1.7 Literature Examples of Contact Active Quaternary Ammonium Antimicrobial Surfaces .....20

1.7.1 Organosilanes (Textiles, Silica, and Glass) …............................................................ 20

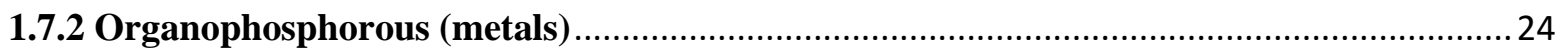

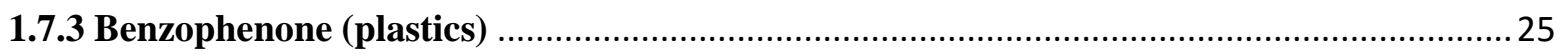

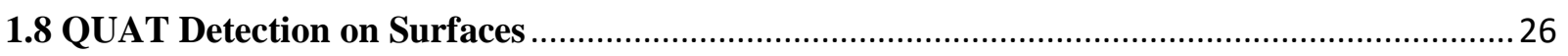

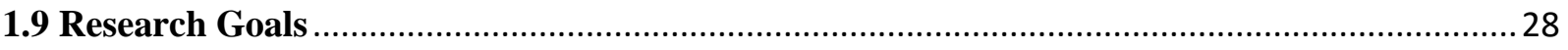

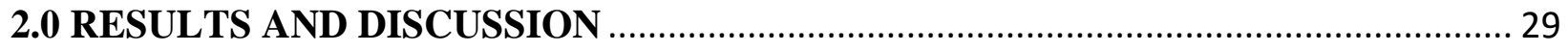

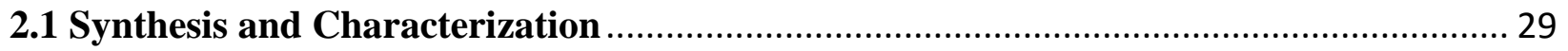

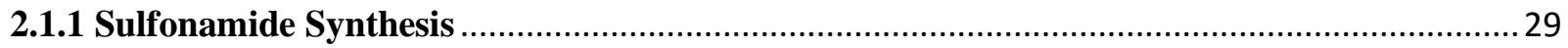

2.1.1.1 Characterization of Aromatic Sulfonamide Precursors ............................................... 32

2.1.1.2 Characterization of Aliphatic Sulfonamide Precursors ............................................ 34

2.1.2 Organosilane Functionalized Quaternary Ammonium Sulfonamide Antimicrobial.............35

2.1.2.1 Characterization of Organosilane Functionalized Sulfonamide QUAT's .....................37

2.1.3 Organophosphorous Functionalized Quaternary Ammonium Antimicrobials ....................39

2.1.3.1 Characterization of Organophosphorous Functionalized Sulfonamide QUAT's ...........40 
2.1.4 Benzophenone Functionalized Quaternary Ammonium Antimicrobials

2.1.4.1 Characterization of Benzophenone Functionalized Sulfonamide QUAT's ................... 44

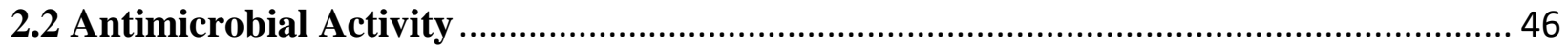

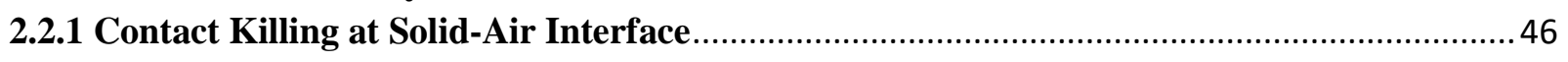

2.2.1 Solution Killing at Solid-Liquid Interface ................................................................... 49

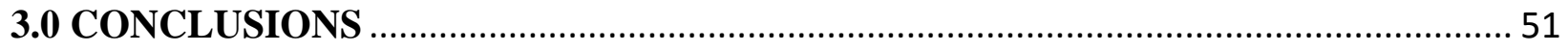

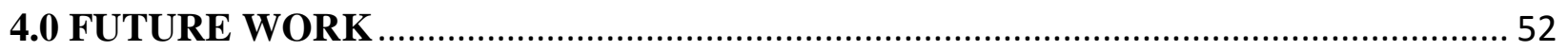

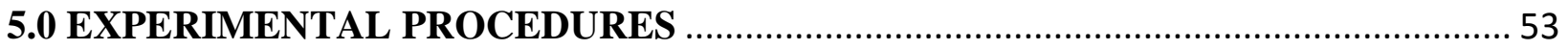

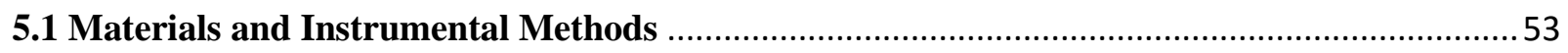

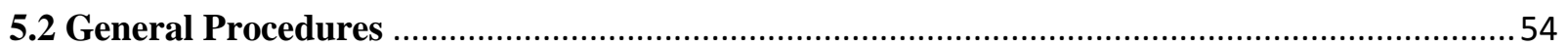

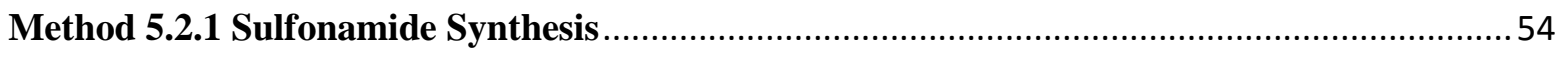

Method 5.2.1a Aromatic Sulfonamides General Synthesis .................................................. 54

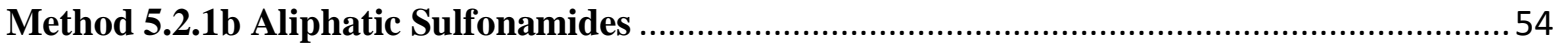

Method 5.2.2 General Synthesis for Sealed Tube Reactions ....................................................55

Method 5.2.3 Antimicrobial Testing and Detection ..............................................................55

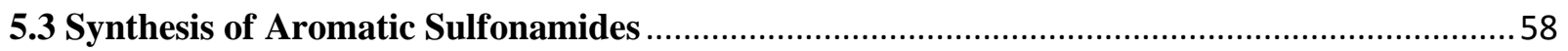

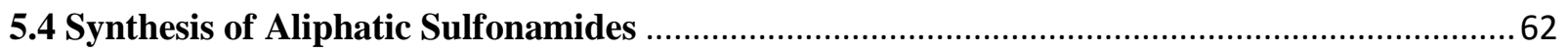

5.5 General Procedure for the Menschutkin Quaternization .....................................................64

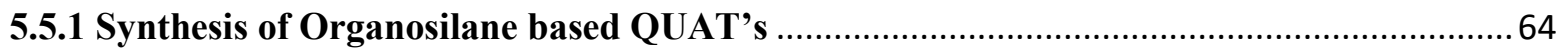

5.5.2 Synthesis of Organophosphosophorus based QUAT ….................................................69

5.5.3 Synthesis of Benzophenone based QUAT …................................................................. 76

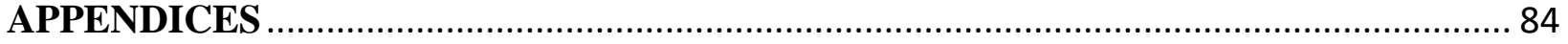

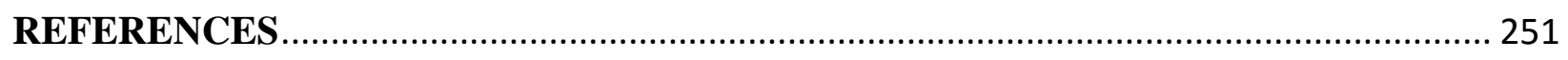




\section{LIST OF TABLES}

Table 1.1: Persistence of different nosocomial pathogens on surfaces (adapted from Ref. ${ }^{2,3}$ )...... 2 Table 1.2: Typical bacterial loads on surfaces related to healthcare and food industry $\left(\mathrm{cfu} / \mathrm{cm}^{2}\right)$

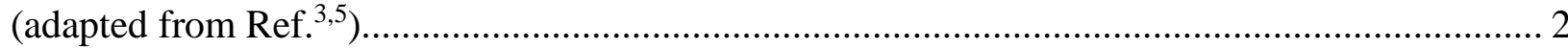

Table 1.3: Discovery and introduction of biocides (adapted from ref. ${ }^{6}$ ). .................................. 3

Table 1.4: Introduction of antibiotics for clinical use (adapted from ref. $\left.{ }^{6}\right)$................................. 4

Table 1.5: Rate of reaction for Menschutkin quaternization in various solvents (adapted from ref. $\left.^{3}\right)^{26}$ 10

Table 1.6: Literature examples of Menschutkin quaternization reaction (adapted from ref. ${ }^{3}$ ).... 11 Table 1.7: Initiators used in "grafting from" technique for growing antimicrobial polymers. ${ }^{3}$.. 14

\section{LIST OF FIGURES}

Figure 1.1: Schematic of bacterial adhesion and biofilm formation (adapted from ref. ${ }^{3,13}$ and used with permission from ref. ${ }^{13}$ )

Figure 1.2: Prevention of the nosocomial infection loop with the application of anantimicrobial coating (adapted from ref. $\left.{ }^{3}\right)^{2,5}$.....

Figure 1.3: Literature example of various types of antimicrobial surfaces. (adapted from ref. ${ }^{3}$ and used with permission).

Figure 1.4: Phosphorylcholine zwitterionic compound inhibiting biofilm adhesion (adapted from ref. $\left.{ }^{16}\right) .{ }^{23}$

Figure 1.5: The Menshutkin quaternization reaction. ${ }^{24}$ 10

Figure 1.6: Various anchor/linker functionalities used to form self-assembled monolayers on various substrates (adapted from ref., ${ }^{3,34}$ ).

Figure 1.7: Various biocide immobilization strategies: (A) Polymeric thin film coatings are adsorbed on to the surfaces; (B) Self assembled polymers or monolayers of small molecule; (C) Surface grown biocidal polymer via (ATRP) initiator, and (D) Polymer based surfaces where biocide is either attached to monomer prior to or added during the polymerization process (adapted from ref. ${ }^{3,34}$ ).

Figure 1.8: The in vivo conversion of Prontosil to its substituent form (adapted from ref. ${ }^{49}$ ). ${ }^{50} 15$

Figure 1.9: Ionic sulfonamide quaternary ammonium compound for chemotherapeutics applications. ${ }^{51}$.

Figure 1.10: Literature examples of known sulfonamide quaternary ammonium compounds. PE $=$ polyethylene.

Figure 1.11: Mechanism of immobilized contact active QUAT (adapted from ref. ${ }^{3,17}$ ) ............. 18

Figure 1.12: Biosynthetic pathway for folic acid in microorganisms....................................... 19

Figure 1.13: Structural analogs: $p$-aminobenzoic acid and sulfonamide................................... 19

Figure 1.14: Competitive inhibition of sulfonamide for the pteridine precursor. ...................... 20

Figure 1.15: Literature examples of organosilane based antimicrobials (adapted from ref. ${ }^{3}$ )..... 22

Figure 1.16: Anchoring process of alkoxysilane onto polyhydroxylated surfaces...................... 23 
Figure 1.17: Literature examples of organophosphorus QUAT's made in the Foucher lab. ${ }^{3,71}$.. 24 Figure 1.18: Benzophenone "grafted from" the surface of polypropylene upon UV irradiation. ${ }^{73}$

Figure 1.19: Literature examples of benzophenones used to prepare antimicrobial plastic

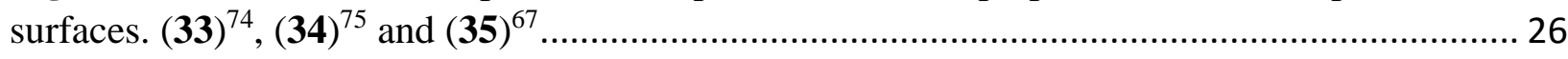

Figure 1.20: Bromophenol blue ion pair formation with silyl based QUAT (adapted from ref. ${ }^{3}$ ).

Figure 1.21: Linkers with the fluorescent dansyl tag previously synthesized in the Foucher lab

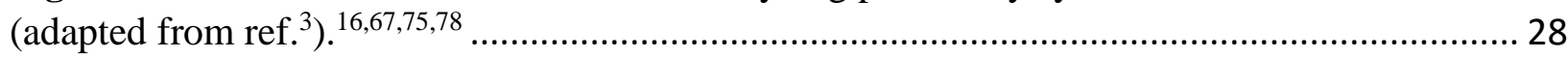

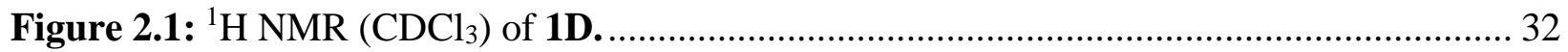

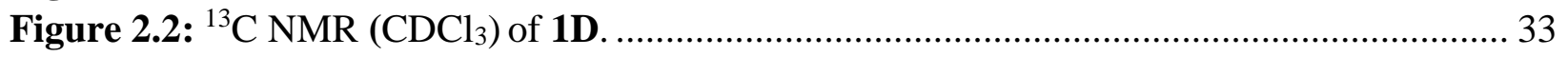

Figure 2.3: ${ }^{1} \mathrm{H}$ NMR $\left(\mathrm{CDCl}_{3}\right)$ comparison of $\mathbf{6 D}-\mathbf{8 D}$. ................................................. 34

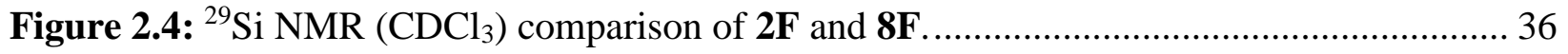

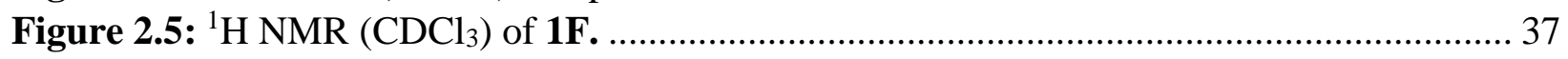

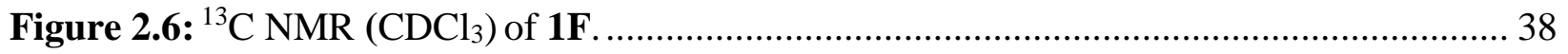

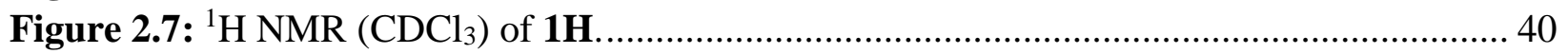

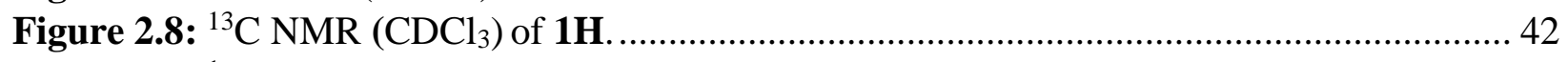

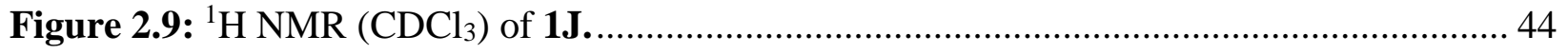

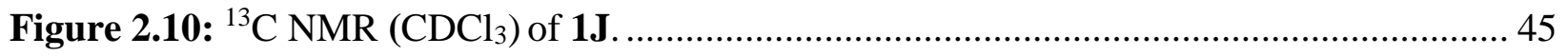

Figure 2.11: Antimicrobial efficacy of benzophenone functionalized 3J on polystyrene and organosilane functionalized 2F on cotton against Arthrobacter spp ....................................... 48

Figure 2.12: Antimicrobial efficacy of organosilane functionalized sulfonamide QUAT's 1F- 3F

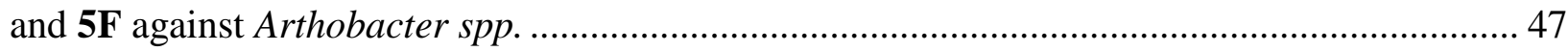

Figure 2.13: Antimicrobial efficacy of benzophenone functionalized sulfonamide QUAT's 5J

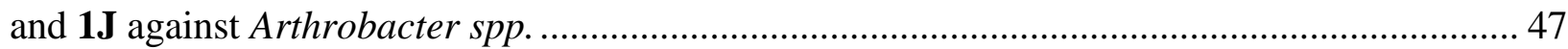

Figure 2.14: Antimicrobial efficacy of $\mathbf{3 J}$ on polyethylene against gram negative $E$. coli and

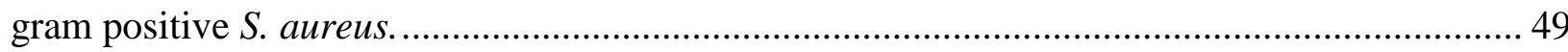

Figure 2.15: Efficacy of 3J against planktonic cells at solid-liquid interface under static

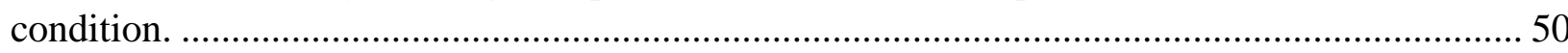

Figure 2.16: Efficacy of 3J against Arthrobacter spp. at solid-liquid interface....................... 50

Figure 4.1: Possible sulfonates/sulfonic acids as starting material.................................... 52

Figure 5.1: Coating procedure of QUAT's onto textiles (cotton) sample. ${ }^{68}$............................. 55 Figure 5.2: Antimicrobial testing method for Solid-Air interface developed by Evan Roan in the Wolfaardt Lab. (i) $1 \times 10^{8} \mathrm{CFU} / \mathrm{mL}$ (inoculum), (ii) $1 \mathrm{~mL}$ inoculum added to $1 \mathrm{~cm} \times 1 \mathrm{~cm}$ solid sample and left to dry for appropriate time $2-24 \mathrm{hrs}$, (iii) sample is added to $0.9 \%$ saline solution, (iv) vortex saline solution to remove attached cells, (v) serial dilutions and agar plating, (vi)

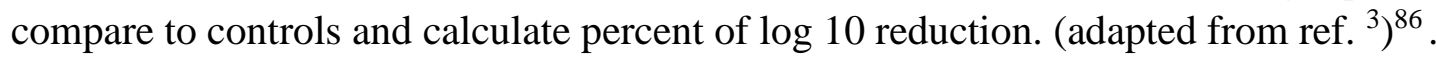
57 


\section{LIST OF SCHEMES}

Scheme 2.1: General Reaction for Aromatic Sulfonamides. .............................................. 29

Scheme 2.2: General Reaction for Aliphatic Sulfonamides................................................. 31

Scheme 2.3: General Reaction for Organosilane Functionalized QUAT's .............................. 35

Scheme 2.4: General Reaction for Organophosphorus Functionalized QUAT's. ..................... 39

Scheme 2.5: General Reaction for Benzophenone Functionalized QUAT's. .......................... 43

Scheme 4. 1: Microwave assisted sulfonamide synthesis using sulfonates or sulfonic acids...... 52 


\section{LIST OF ABBREVIATIONS}

cfu. Colony forming units

MIC Minimum Inhibitory Concentration

EPS Exopolysaccharides

WHO World Health Organization

HAI's Hospital Acquired Infections

IAI's Implant Associated Infections

QUAT's Quaternary Ammonium Compound

SAM Self-Assembled Monolayers

DCM Dichloromethane

iPr iso-propanol

MeOH Methanol

$\mathrm{MeCN} \quad$ Acetonitrile

$\mathbf{E t}_{3} \mathbf{N} \quad$ Triethylamine

HCl Hydrochloric acid

$\mathrm{K}_{2} \mathrm{CO}_{3} \quad$ Potassium carbonate

$\mathbf{E t}_{2} \mathrm{O}$ Diethylether

$\mathrm{CDCl}_{3}$ Deuterated Chloroform

PABA $\quad p$-Aminobenzoic acid

ATMP aminotris(methylene phosphonic acid)

EDTMP ethylenediamine tetra(methylene phosphonic acid)

DTPMP diethylenetriamine penta(methylene phosphonic acid)

PE Polyethylene

PEI Polyethylene imine

PEG Polyethylene glycol

PP Polypropylene

PET Polyethylene terephthalate

PVC Polyvinyl chloride

ATRP Atom Transfer Radical Polymerization

NMR Nuclear Magnetic Resonance spectroscopy

HRMS High Resolution Mass Spectrum

wks. Weeks 


$\begin{array}{ll}\text { yrs. } & \text { Years } \\ \text { hrs. } & \text { Hours } \\ \text { mon. } & \text { Months } \\ \text { d. } & \text { Days }\end{array}$




\subsection{INTRODUCTION}

\subsection{Rationale for Antimicrobials}

Common surfaces that are frequently handled are called "touch surfaces". Touch surfaces are inhabited by various microorganisms such as bacteria, viruses and fungi which can persist in the right environment for a prolonged period (Table 1.1). ${ }^{1-3}$ Both pathogenic and non-pathogenic microorganisms can persist on touch surfaces such as door knobs, elevator buttons, staircase railings, stethoscopes, uniforms, food preparation and packaging surfaces (Table 1.2). ${ }^{2-5}$

For centuries antibiotics and biocides have been used in variety of applications. ${ }^{6}$ Antibiotics have been administered to patients due to their selective toxicity whereas, biocides have been regarded as antiseptics, disinfectants and preservatives and are used more generally. The concept of biocides dates back to early empirical approaches of using copper or silver based utensils for water storage; salting as a process of preservation of meat products and the use of vinegar and honey as wound cleansing agents. ${ }^{6}$ A library of common biocides and antibiotics for prevention against a wide variety of infections and diseases is shown in Tables 1.3 and 1.4 respectively.

Even with advances in the science of antibiotics and biocides, the healthcare and food industries continue to face an ever-growing microbial contamination problem. Contamination of food packaging, storage containers, medical devices, garments and hygiene products pose a real threat to public safety and are costly. ${ }^{7}$ To date, standard hygiene procedures (hand washing, personal hygiene products, and masks) and the use of disinfectants on medical devices and hospital environments have been widely used as stopgap solutions to prevent infectious outbreaks. However, these efforts have not been fully successful due to the evolution and development of 
resistance by microorganisms and the lack of compliance to safety protocols by health care professionals. $^{8}$

Table 1.1: Persistence of different nosocomial pathogens on surfaces (adapted from Ref. ${ }^{2,3}$ ).

\begin{tabular}{|c|c|c|c|c|c|}
\hline $\begin{array}{c}\text { Type of } \\
\text { Bacterium }\end{array}$ & $\begin{array}{l}\text { Duration of } \\
\text { persistence }\end{array}$ & $\begin{array}{l}\text { Type of } \\
\text { Virus }\end{array}$ & $\begin{array}{l}\text { Duration of } \\
\text { persistence }\end{array}$ & $\begin{array}{l}\text { Type of } \\
\text { Fungi }\end{array}$ & $\begin{array}{l}\text { Duration of } \\
\text { persistence }\end{array}$ \\
\hline $\begin{array}{c}\text { Acinetobacter } \\
\text { spp. }\end{array}$ & 3 d. -5 mon. & Adenovirus & 7 d. -3 mon. & $\begin{array}{l}\text { Candida } \\
\text { albicans }\end{array}$ & $1-20 \mathrm{~d}$ \\
\hline $\begin{array}{c}\text { Clostridium } \\
\text { difficle (spores) }\end{array}$ & 5 mon. & Astrovirus & $7-90 \mathrm{~d}$ & $\begin{array}{c}\text { Candida } \\
\text { parapsilosis }\end{array}$ & $14 \mathrm{~d}$. \\
\hline $\begin{array}{c}\text { Corynebacterium } \\
\text { diphtheride }\end{array}$ & $7 \mathrm{~d} .-6$ mon. & SARS & $72-96 \mathrm{hrs}$ & $\begin{array}{c}\text { Torulopsis } \\
\text { glabrata }\end{array}$ & $102-150 \mathrm{~d}$ \\
\hline E. Coli & $\begin{array}{l}1.5 \text { hrs. }-16 \\
\text { mon. }\end{array}$ & HAV & 2 hrs. $-60 \mathrm{~d}$ & & \\
\hline Listeria spp. & $1 \mathrm{~d} .-$ mon. & HIV & $7 \mathrm{~d}$. & & \\
\hline P. aeruginosa & $\begin{array}{l}6 \text { hrs. }-16 \\
\text { mon. }\end{array}$ & Rotavirus & $6-30 \mathrm{~d}$ & & \\
\hline $\begin{array}{l}\text { Salmonella } \\
\text { typhimurium }\end{array}$ & $\begin{array}{c}10 \mathrm{~d} .-4.2 \\
\text { yrs. }\end{array}$ & Vacciniavirus & $\begin{array}{c}3 \text { wks. }-20 \\
\text { wks. }\end{array}$ & & \\
\hline
\end{tabular}

Table 1.2: Typical bacterial loads on surfaces related to healthcare and food industry $\left(\mathrm{cfu} / \mathrm{cm}^{2}\right)$ (adapted from Ref. ${ }^{3,5}$ ).

\begin{tabular}{ccc}
\hline Field of study & Site & Bacterial load $\left(\mathbf{c f u} / \mathbf{c m}^{2}\right)$ \\
\hline Healthcare & Hospital ward surfaces & 2.5 to 40 \\
Healthcare & Hospital kitchen surfaces & 2 to 294 \\
Healthcare & Stethoscope membrane & In $>54 \%$ of cases $>5 ;$ in \\
$18 \%$ of cases $>29$ & $<9$ \\
Healthcare & Nurse workstation & $<25$ \\
Healthcare & Under ward bed & $10^{5}$ \\
Food & Meat preparation surfaces & $>10^{5}$ \\
Food & Vegetable preparation & surfaces \\
Food & Refrigerator surfaces & 813 to $6 \times 10^{8}$ \\
Food & Food contact surfaces & 630 to $1.8 \times 10^{9}$ \\
\hline
\end{tabular}


Table 1.3: Discovery and introduction of biocides (adapted from ref. ${ }^{6}$ ).

\begin{tabular}{ccc}
\hline $\begin{array}{c}\text { Biocide (Antiseptic or } \\
\text { disinfectant) }\end{array}$ & Discovery & Introduction \\
\hline Alcohols & BC & Early AD \\
Chlorine & 1774 & 1847 \\
Sodium hypochlorite & 1789 & 1827 \\
Chlorine dioxide & 1925 & 1946 \\
Iodine & 1812 & 1816 \\
Phenols & & \\
Phenol & 1834 & 1867 \\
Cresol & 1842 & 1890 \\
Triclosan & 1906 & 1908 \\
QUAT's & 1916 & 1933 \\
Amphoterics & 1952 & 1954 \\
Acridines & 1870 & 1913 \\
\hline
\end{tabular}


Table 1.4: Introduction of antibiotics for clinical use (adapted from ref. ${ }^{6}$ ).

\begin{tabular}{|c|c|}
\hline Decade & Introduction \\
\hline 1930s/1940s & Sulphonamides \\
\hline \multirow{2}{*}{ 1940s } & Benzylpenicillin \\
\hline & Streptomycin \\
\hline \multirow{3}{*}{ 1950s } & Erythromycin \\
\hline & Chloramphenicol \\
\hline & Vancomycin \\
\hline \multirow{3}{*}{ 1960s } & Cephalosporin's \\
\hline & Gentamicin \\
\hline & Broad-spectrum penicillin's \\
\hline \multirow{2}{*}{ 1970s } & Clindamycin \\
\hline & Trimethoprim-sulphamethoxazole \\
\hline \multirow{2}{*}{ 1980s } & Fluoroquninolones \\
\hline & $\beta$-lactams \\
\hline \multirow{4}{*}{ 1990s, 2000s } & Pristinamycin derivatives \\
\hline & New macrolides \\
\hline & New $\beta$-lactams \\
\hline & Oxazolidinones \\
\hline \multirow{4}{*}{2000 onwards } & Everninomycins, \\
\hline & Glycylcyclines \\
\hline & Ketolides \\
\hline & Moxifloxacin \\
\hline
\end{tabular}

Based on several studies conducted by World Health Organization (WHO) and the Auditor Generals of Ontario and British Columbia, hospital-acquired infections (HAIs) or nosocomial infections have become an economic burden due to prolonged hospitalization and in some cases, have led to death due to severe infection related complications. ${ }^{9-11}$ Specifically in North America, approximately 220,000 Canadians and 2 million people in the United States contract pathogen related HAIs. This has resulted in 8000 deaths in Canada and over 100,000 deaths in the U.S. each 
year. ${ }^{8-11}$ HAI related infections result on average $10-20$ days of additional hospitalization for the patient, costing the health system billions of dollars..$^{8-10}$ Alongside HAIs, Implant Associated Infections (IAIs) have also strained healthcare systems. For example, approximately 500,000 patients in the U.S. contract urinary tract infections related to catheter implants, which incur an additional $\$ 25,000-\$ 30,000$ treatment cost per infection resulting in approximately $\$ 3$ billion healthcare associated costs. ${ }^{7}$ The increased severity and rate of infections (HAIs and IAIs) can be associated with decreased antibiotic efficacy and drug-resistance by pathogens that are found in surface biofilms. ${ }^{3,7,12}$

\subsection{Biofilms}

Biofilms are complex communities of bacteria which involve three phases for its formation. The first phase is a rapid nonspecific, reversible adhesion to the surfaces via adhesin proteins secreted by the bacterial membrane structures fimbriae or pilli (Stage I, Figure 1.1), followed by a second phase which occurs over several hours allowing the bacteria to irreversibly bind to a surface via adhesive ligand-receptor complexes (Stage II, Figure 1.1). ${ }^{13}$ Once permanently bound, the bacteria begins to synthesize a protective (slime like) peptidoglycan matrix consisting of DNA, proteins and polysaccharides such as exopolysaccharide (EPS). ${ }^{14}$ With increased accumulation of constituents in the matrix, bacterial colonies proliferate into mature biofilms which are resistant to strong antibiotic doses and are difficult to eradicate. ${ }^{15}$ Therefore, to prevent infectious outbreak caused by biofilms, strategies have been explored to prevent the bacterial adhesion to surfaces or destroy the microorganisms upon adsorption. ${ }^{13-16}$ 


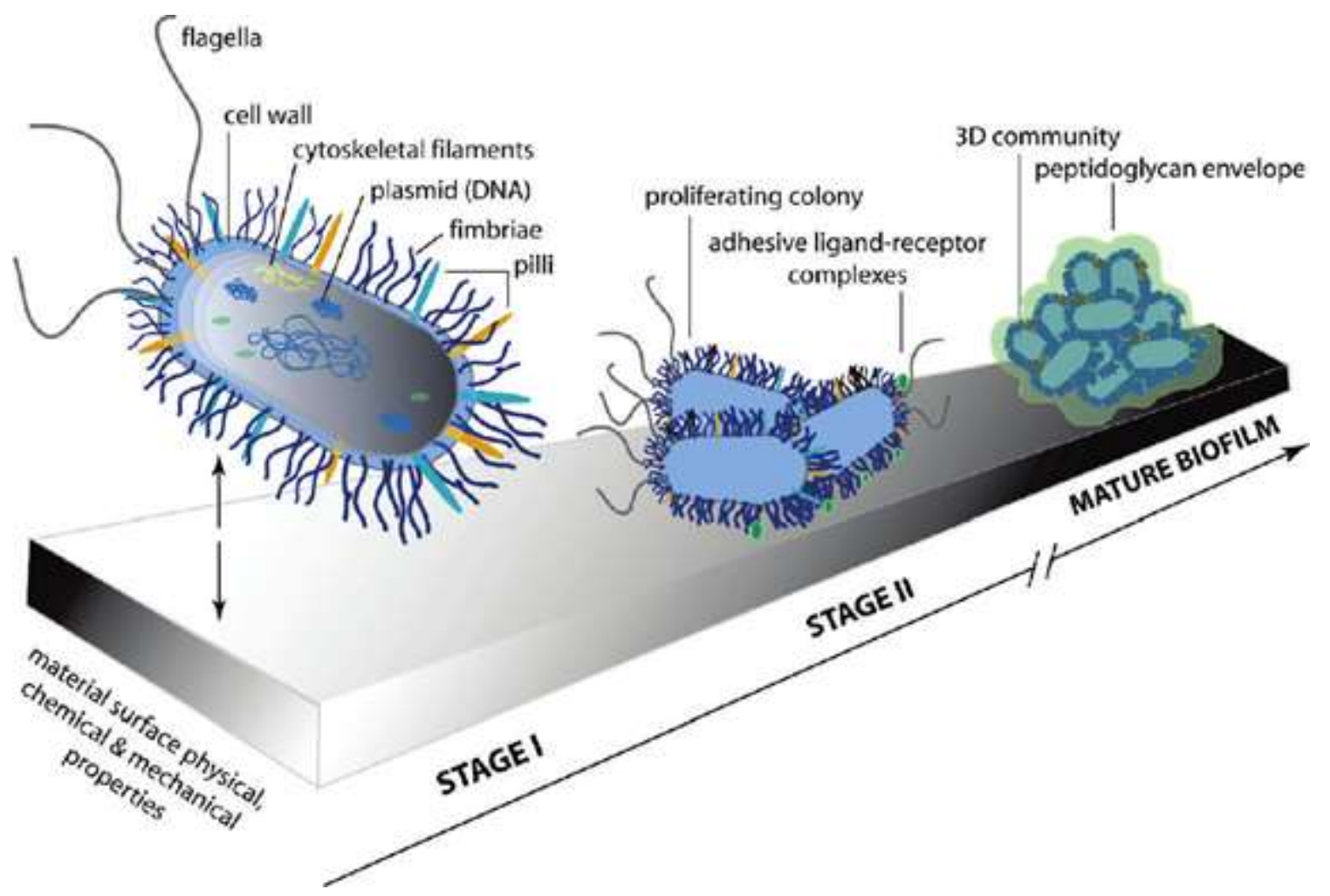

Figure 1.1: Schematic of bacterial adhesion and biofilm formation (adapted from ref. ${ }^{3,13}$ and used with permission from ref. ${ }^{13}$ )

Persistent biofilms pose a great threat for the medical, food, oil refining and water treatment industries which directly impact a mass populous. Antimicrobial textiles have been integrated widely in to different work sectors as preventive measures. Treated textiles work well with daily consumer use, but cannot prevent biofilm formation on nonporous surfaces (eg. instrumentation, equipment and structural features in industries). Therefore, medical device makers along with medical and food industries are keen to introduce antimicrobial coatings as part of an infection control strategy along with proper hygiene and disinfection protocols. ${ }^{3}$ Introducing the antimicrobial coatings on surfaces would help prevent biofilm formation and thus reduce the spread of pathogenic infections between surfaces, patients and healthcare workers (nosocomial infection loop, Figure 1.2)..$^{2,3,5}$ 


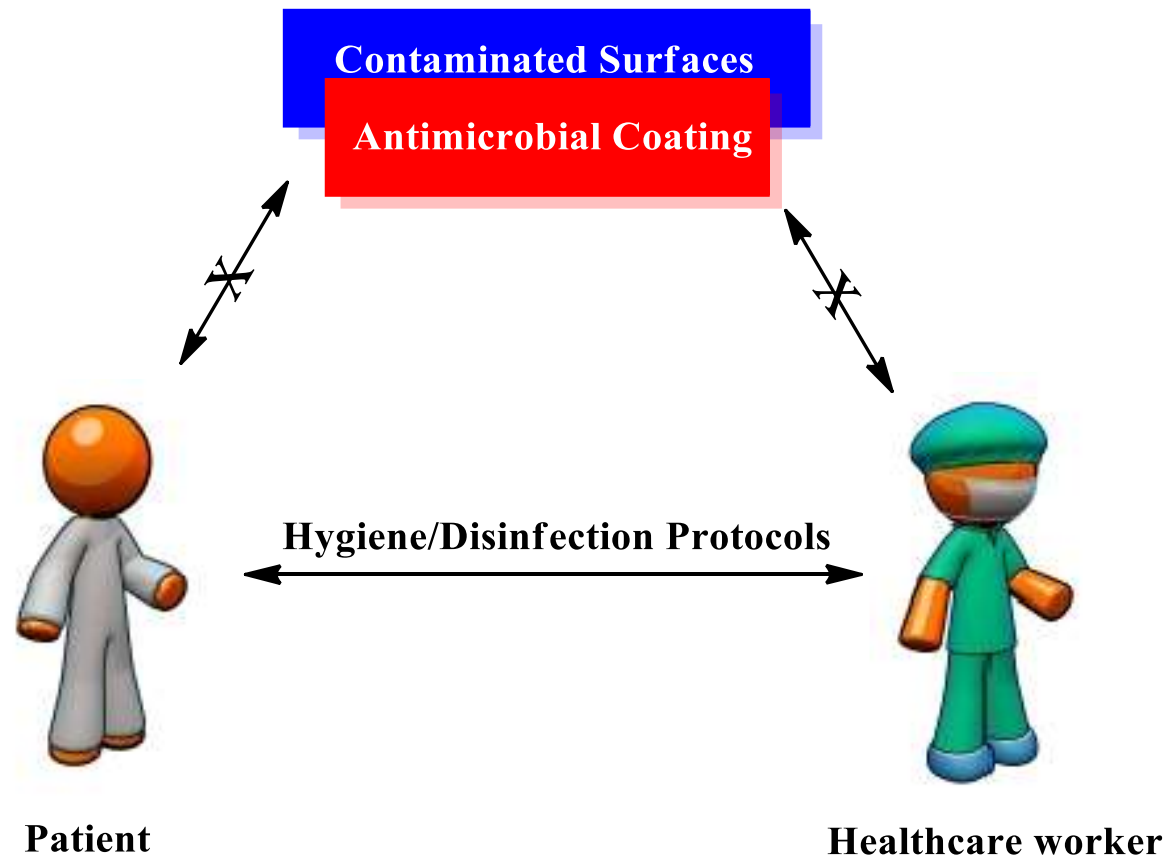

Figure 1.2: Prevention of the nosocomial infection loop with the application of anantimicrobial coating (adapted from ref. $\left.{ }^{3}\right)^{2,5}$

\subsection{Antimicrobial Surfaces}

Porous and non-porous surfaces are common sites of microbial infestation, proliferation and biofilm formation. One common strategy being employed to prevent microbial infection is the use of disinfectants; however, they are often a source of environmental pollution and have been a major contributor for the resistance development in microbial strains. ${ }^{17}$ An alternative strategy to the use of chemical poisons was the development of surface attached antimicrobials. Since the late 1960's, polymer based thin films or self-assembling monolayers have been widely investigated and used to render surfaces antimicrobial. Different approaches have been used to prepare these antimicrobial surfaces, but they can be mainly categorized as being either antibiofouling or bacteriostatic. $^{17,18}$ Antibiofouling coatings include thin film coatings that are hydrophobic in nature, have low surface tension, and/or pack tightly together. This prevents bacterial adhesion, but does not kill them. Bacteriostatic coatings are classified in two main categories; one that kills 
microbes on contact by releasing a biocide that is adsorbed by the organism and poison it, and the second being a contact active biocide which contains a biocidal component within the coating that kills microbes upon contact (Figure 1.3). ${ }^{17,18}$

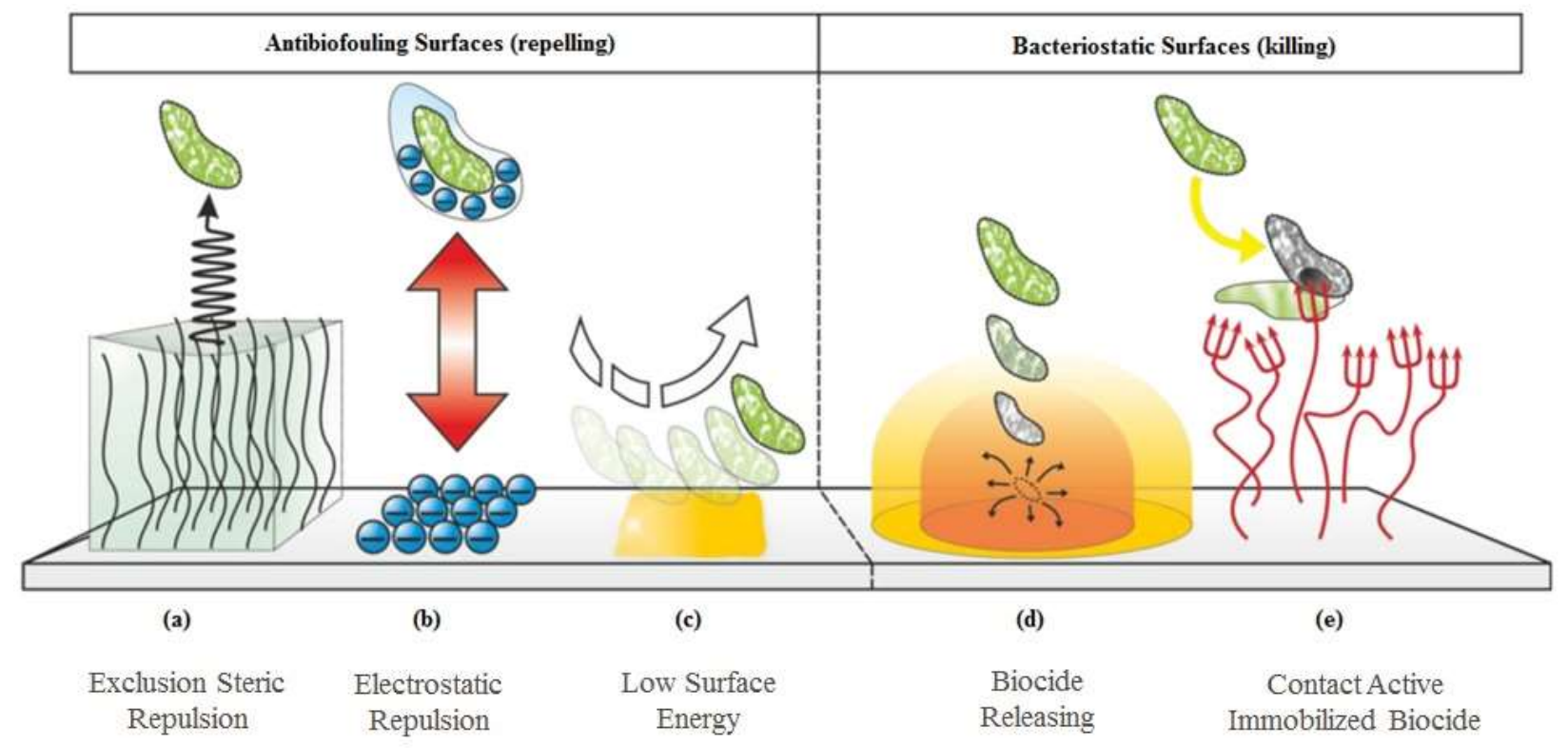

Figure 1.3: Literature example of various types of antimicrobial surfaces. (adapted from ref. ${ }^{3}$ and used with permission from ref. ${ }^{17,18}$ ).

Older approaches for preventing biofilm formation on the surfaces relied heavily on biocide (active) releasing antimicrobial coatings. These coatings consist of a polymer matrix in which the biocide is impregnated. The biocide is gradually released from the matrix and kills the microorganisms through its mode of action (biocide specific). ${ }^{6}$ Examples of a leachable biocide includes copper ${ }^{1}$ or silver ions, the latter being the most preferable. ${ }^{19,20}$ Eventually the biocide depletes from the coatings and these surfaces are once again prone to biofilm formation due to the loss of antimicrobial activity. Currently, there is no known method/procedure to regenerate the biocide on the applied coatings. An alternative to the leaching of biocides is the use of quaternary ammonium compounds (QUAT's). These active materials are immobilized onto the surfaces and provide contact based killing with no leachable agent/biocide. The non-leaching immobilized 
QUAT's provide a prolonged antimicrobial efficacy, have a minimized risk of bacteria developing resistance, and are significantly more environmentally friendly. $3,12,14$

\subsection{Quaternary Ammonium Compound}

Cationic surface-active agents and polymers containing a zwitterionic head have been extensively studied due to their biocompatibility and biocidal properties. ${ }^{15,21}$ Studies by Cheng $e t$ $a l .{ }^{15}$ and Rose et $a l .{ }^{22}$ found that the polar zwitterionic head plays a key role in prevention of biofilm formation and/or adhesion (Figure 1.4).

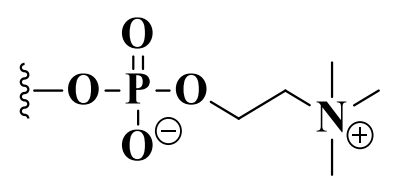

Figure 1.4: Phosphorylcholine zwitterionic compound inhibiting biofilm adhesion (adapted from ref. $\left.^{16}\right) .^{23}$

Solutions containing cationic compounds includes Quaternary Ammonium Cations are widely used due to their biocidal properties in both clinical and industrial settings. ${ }^{16}$ In general antimicrobial QUAT's consist of a positively charged nitrogen atom attached to one or more hydrophobic alkyl chains and are synthesized using the Menshutkin reaction.

\subsubsection{Menshutkin Quaternization Reaction}

The quaternization formation reaction was first discovered in 1865 by Russian chemist Nikolai Menshutkin. ${ }^{24}$ The quaternization reaction involves the reaction between two neutral molecules, a tertiary amine with an alkylhalide. The reaction proceeds in an $\mathrm{S}_{\mathrm{N}} 2$ manner, wherein the alkylhalide is substituted by the amine producing a positively charged quaternary amine with four bonds and a negatively charged counter ion (Figure 1.5). ${ }^{3}$ 


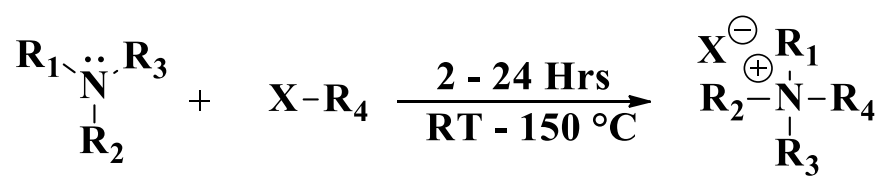

Figure 1.5: The Menshutkin quaternization reaction. ${ }^{24}$

For $\mathrm{S}_{\mathrm{N}} 2$ reactions, the reaction rate is greatly affected by the nucleophilicity of the amines, the leaving group, increased pressure and elevated temperature. Polar solvents were found to accelerate the reaction by stabilizing the charged transition state along with the leaving group (Table 1.5) and halides further down Group 17 (i.e. Br, I) serve as excellent leaving groups. When working with alkyltosyl or mesylates, polar protic solvents and lower reaction temperatures are preferred to avoid a competitive elimination reaction. ${ }^{25}$

Table 1.5: Rate of reaction for Menschutkin quaternization in various solvents (adapted from ref. $\left.{ }^{3}\right)^{26}$

\begin{tabular}{cc}
\hline Solvent & Relative Rate $\left(\mathbf{s}^{\mathbf{1}}\right)$ \\
\hline $\mathrm{CH}_{3}\left(\mathrm{CH}_{2}\right)_{4} \mathrm{CH}_{3}$ & 1 \\
$\mathrm{Et}_{2} \mathrm{O}$ & 4 \\
$\mathrm{C}_{6} \mathrm{H}_{6}$ & 38 \\
$n-\mathrm{BuOH}$ & 70 \\
$\mathrm{CHCl}_{3}$ & 100 \\
$\mathrm{EtOH}$ & 200 \\
$\mathrm{MeOH}$ & 285 \\
$\mathrm{ACN}$ & 375 \\
$\mathrm{DMF}$ & 900 \\
\hline
\end{tabular}

For the purpose of this thesis, all quaternary ammonium compounds described in this work will be synthesized using the Menschutkin reaction. A typical reaction would be carried out at refluxing temperature in polar anhydrous solvents and in a closed environment (vials). Often the 
resulting product can be recovered by precipitation from $\mathrm{Et}_{2} \mathrm{O}$. Select literature examples portraying the reaction conditions for the formation of QUAT's have been tabulated in Table 1.6.

Table 1.6: Literature examples of Menschutkin quaternization reaction (adapted from ref. ${ }^{3}$ ).

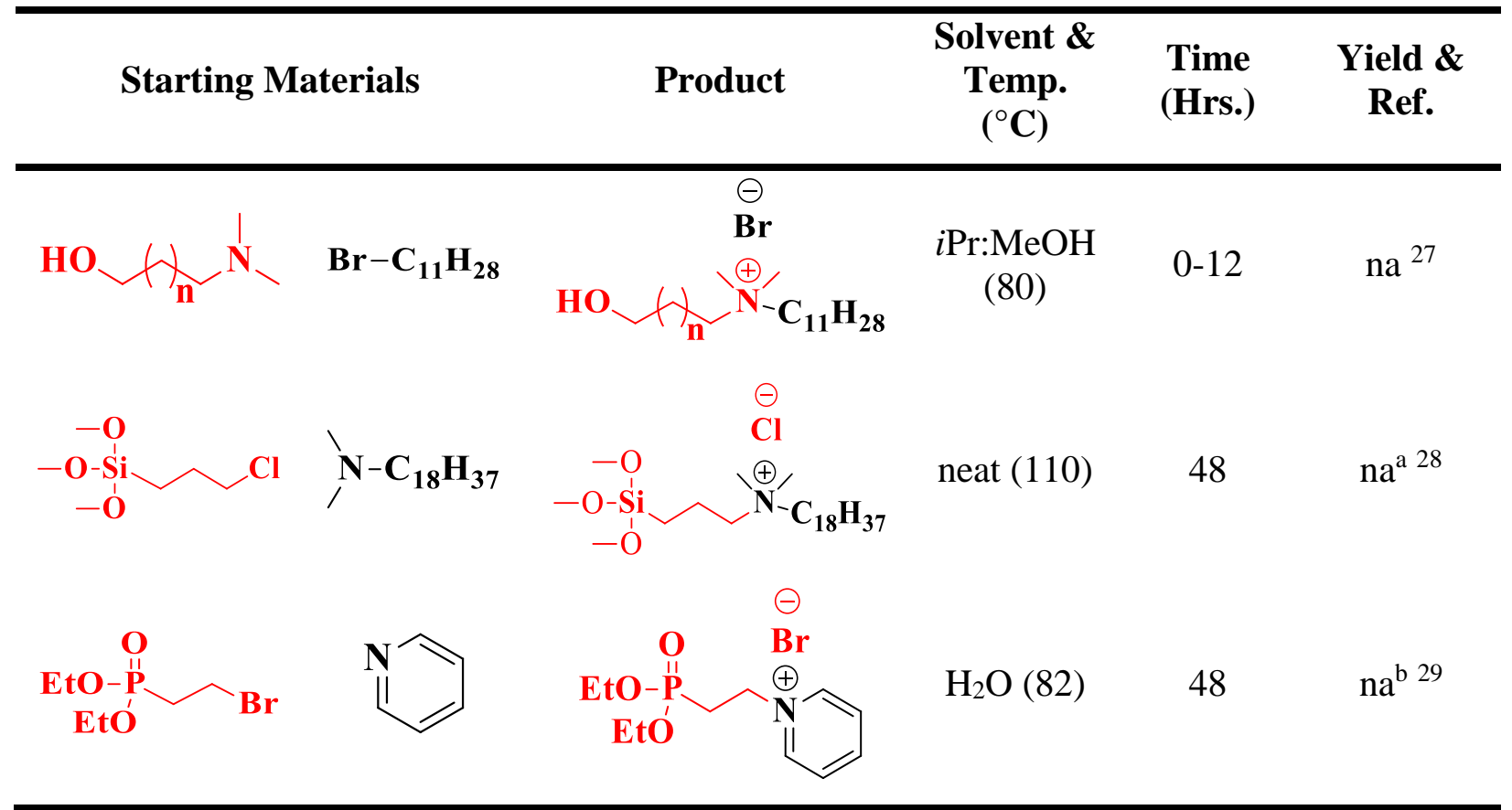

(a) Diluted directly to 50\% w/v in $\mathrm{MeOH}$, and (b) used directly following hydrolysis with $\mathrm{HCl}$.

Various surfaces can be treated by immobilizing small size quaternary ammonium compounds containing linker groups such as thiol ${ }^{30}$, phosphonate ${ }^{31,32}$, organosilane ${ }^{33}$, catechol $^{34}$ or as polymers (Figure 1.6). ${ }^{33,35}$ 

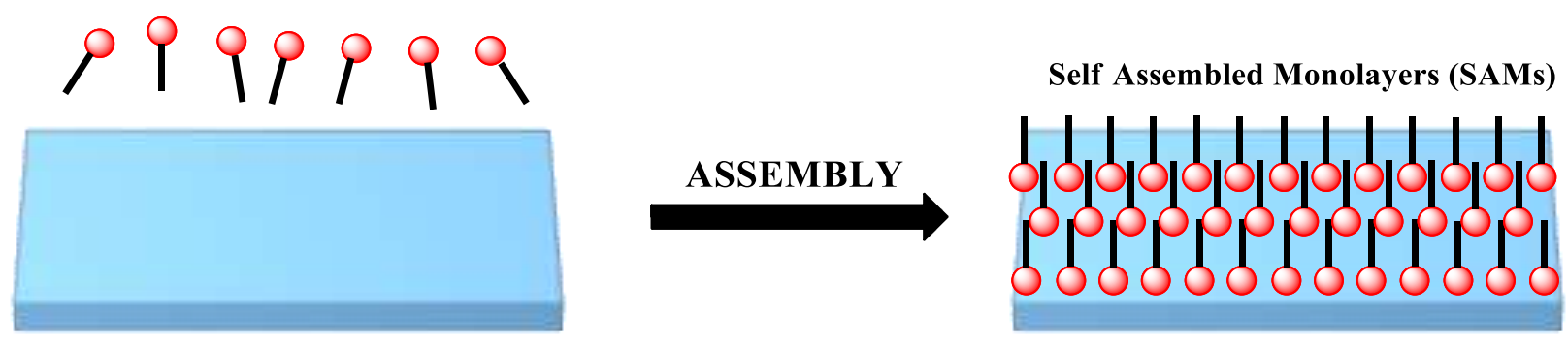

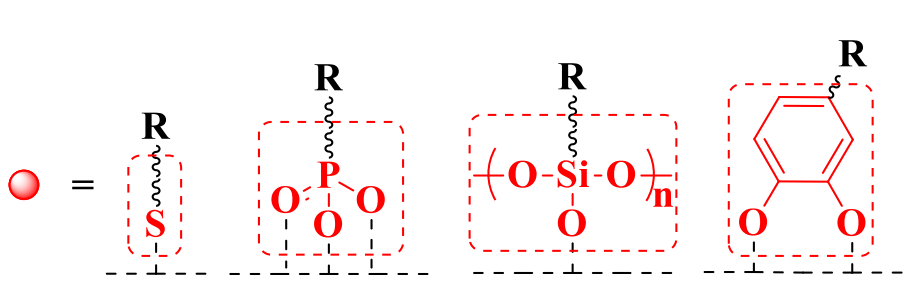

Thiol Phosphonate Organosilane Catechol

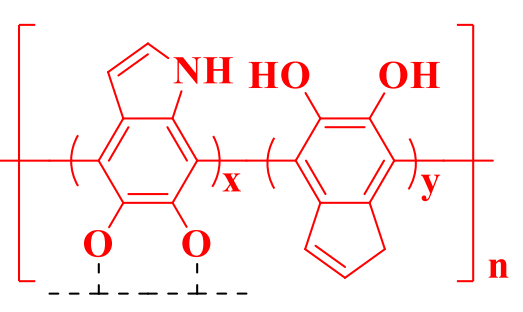

Polydopamine

Figure 1.6: Various anchor/linker functionalities used to form self-assembled monolayers on various substrates (adapted from ref., ${ }^{3,34}$ ).

Surfaces treated with a polymeric coating are prepared using either a "grafting to" or "grafting from" strategy. A grafting to strategy attaches biocides by adsorption of the polymer to the surface (Figure $1.7 \mathrm{~A})^{36,37}$ or through covalent bond formation between a linker group and complementary functional group on the substrate (Figure 1.7B) ${ }^{38,39}$; whereas the grafting from strategy employs growth of polymeric brushes directly from the substrate. This can be accomplished using Atom Transfer Radical Polymerization (ATRP) (Figure 1.7C), ${ }^{40,41}$ which requires an initiator directly bound to surfaces or to an immobilized anchor (Table 1.7). ${ }^{36}$ 
(A) Adsorption
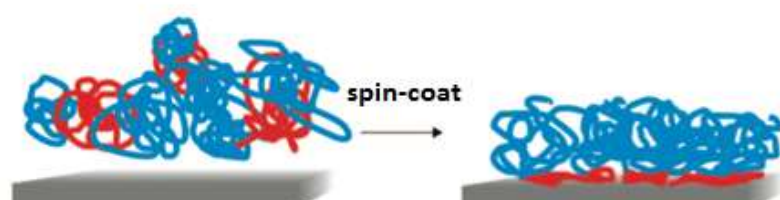

(C) "Graft From"

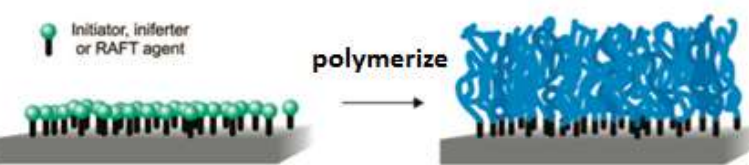

(B) "Graft To"

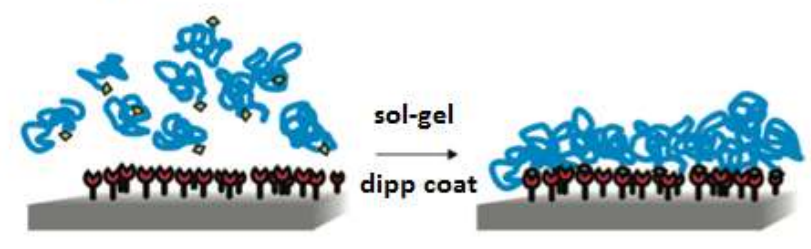

(D) Polymer Blends

Biocide added as

additive of part of polymer

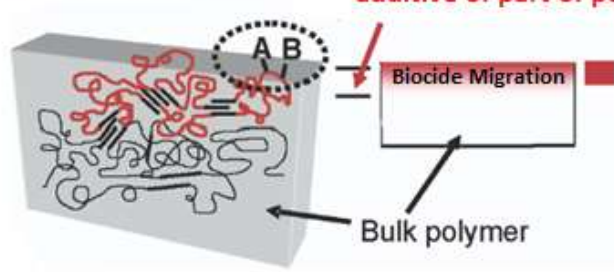

Figure 1.7: Various biocide immobilization strategies: (A) Polymeric thin film coatings are adsorbed on to the surfaces; (B) Self assembled polymers or monolayers of small molecule; (C) Surface grown biocidal polymer via (ATRP) initiator, and (D) Polymer based surfaces where biocide is either attached to monomer prior to or added during the polymerization process (adapted from ref. ${ }^{3,34}$ ). 
Table 1.7: Initiators used in "grafting from" technique for growing antimicrobial polymers. ${ }^{3}$

\begin{tabular}{|c|c|c|c|}
\hline Anchoring Group & $\chi^{\mathrm{Br}}$ Initi & $\rightarrow \quad$ Anchor ${ }_{2}$ & $\gamma$ \\
\hline Substrate & Anchoring Group & Surface Grafted Initiator & Reference \\
\hline PET (Film) & $\mathrm{H}_{2} \mathrm{~N} \frown \mathrm{NH}_{2}$ & & 42 \\
\hline $\begin{array}{l}\text { Gold coated Ti } \\
\text { (wafer) }\end{array}$ & $\mathrm{HS}_{\widehat{\gamma} / 9} \mathrm{OH}$ & & 43 \\
\hline $\begin{array}{c}\text { Magnetite } \\
\text { (nanoparticles) }\end{array}$ & 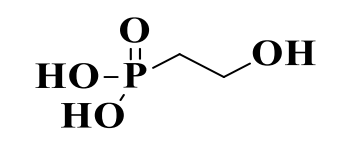 & HO' & 16 \\
\hline Silicone (wafer) & $\begin{array}{l}-\mathrm{O} \\
-\mathrm{O}-\mathrm{Si} \\
-\mathrm{O}\end{array}$ & $\begin{array}{l}-\mathbf{O} \\
-\mathbf{O}-\mathbf{S i} \\
-\mathbf{O}\end{array}$ & 44 \\
\hline PP (wafer) & & & 45 \\
\hline
\end{tabular}

$\overline{\mathbf{P E T}}=$ Polyethylene and $\mathbf{P P}=$ Polypropylene

\subsection{Sulfonamides (Sulfa Drugs)}

Sulfonamide based drugs were the first widely prescribed antibiotics that helped revolutionize the medical industry. ${ }^{6}$ Sulfonamides are synthetic agents containing a $\mathrm{S}(\mathrm{O})_{2}=\mathrm{N}$ linkage (see Figure 1.8) which acts as antimicrobial agent. ${ }^{46}$ The first known sulfonamide was sulfanilamide synthesized in 1908 by German chemist Paul Gelmo ${ }^{47}$ and was later patented as the prodrug Prontosil by Bayer AG in 1909. Applications of Prontosil were not widely researched until the 1930 's. ${ }^{48}$

Around the same time Bayer AG was also investigating the use of coal-tar dyes that were able to bind and harm parasites and bacteria. In 1935, under the direction of German chemist Gerhard Domagk the group found that Prontosil was able to treat a range of streptococcal 
infections. ${ }^{48,49}$ Studies by Trefouels et al. ${ }^{50}$ found that Prontosil (1) was metabolized in the body to give sulfanilamide (2) and 1,2,4-triaminobenzene (3). Further examination of individual components revealed that the activity of $\mathbf{1}$ was entirely dependent on its in vivo reduction to $\mathbf{2}$ (see Section 1.6.2). ${ }^{49,50}$<smiles>Nc1ccc(N=Nc2ccc(S(N)(=O)=O)cc2)c(N)c1</smiles>

Prontosil

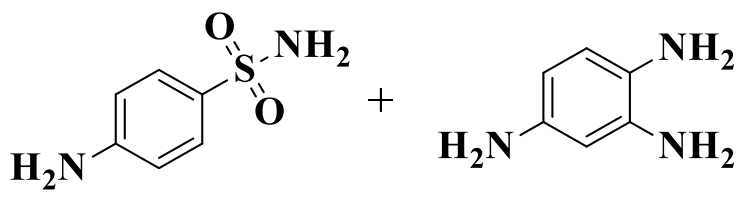

Sulf anilamide

(2)

\section{1,2,4-triaminobenzene}

(3)

Figure 1.8: The in vivo conversion of Prontosil to its substituent form (adapted from ref. $\left.{ }^{49}\right){ }^{50}$

\subsubsection{Sulfonamide QUAT's}

For more than 100 years sulfonamide based antibiotics and QUAT based antimicrobials have been shown individually to play important roles in the control of illness and the spread of diseases. Researchers have long desired to design a compound that was bactericidal and possessed the functional properties of antibiotics. The work by Barry and Puetzer resulted in the preparation of a salt that comprised a QUAT cation and a sulfonamide radical anion, yielding a dual natured compound (Figure 1.10). ${ }^{51}$

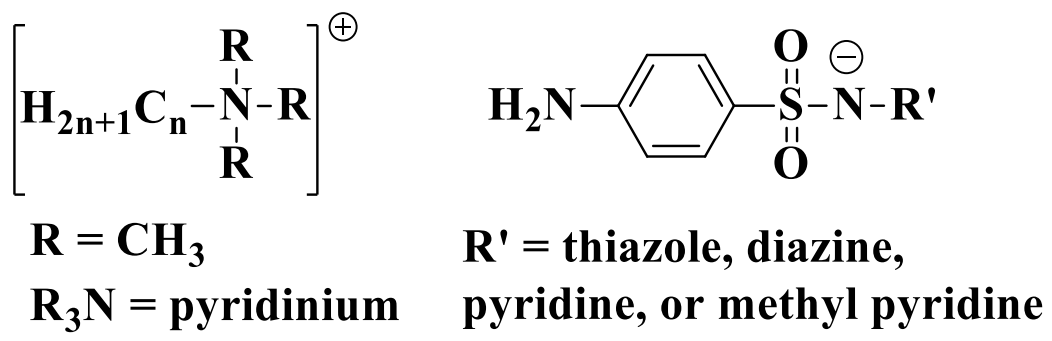

Figure 1.9: Ionic sulfonamide quaternary ammonium compound for chemotherapeutics applications. $^{51}$ 
Barry and Puetzer's ionic sulfonamide QUAT's were found to be highly bactericidal against E. Coli and S. Auereus. Lawrence et $a .^{52}$ furthered this research by synthesizing compounds 4-9 (Figure 1.10) where the QUAT and the sulfonamide moiety are within the same molecule with a halogen acting as the counter-ion. These compounds featured the benzylsulfonamide group within the backbone and standard phenolic coefficient testing of these compounds were conducted. The test indicated that compounds $\mathbf{4}$ and $\mathbf{5}$ were highly biocidal, compound 7 was moderately biocidal, and the remainder of compounds provided only bacteriostatic effect. ${ }^{53}$

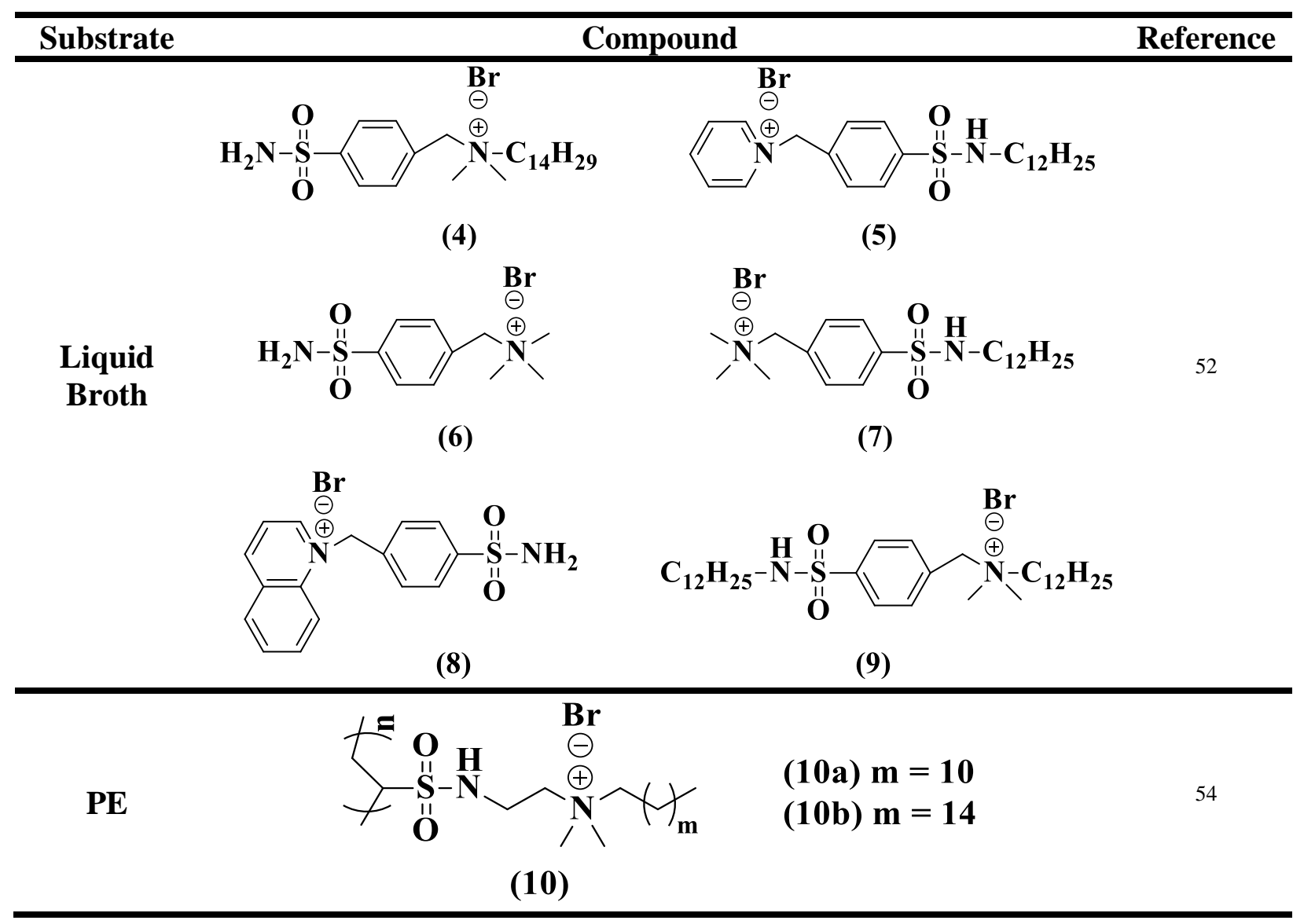




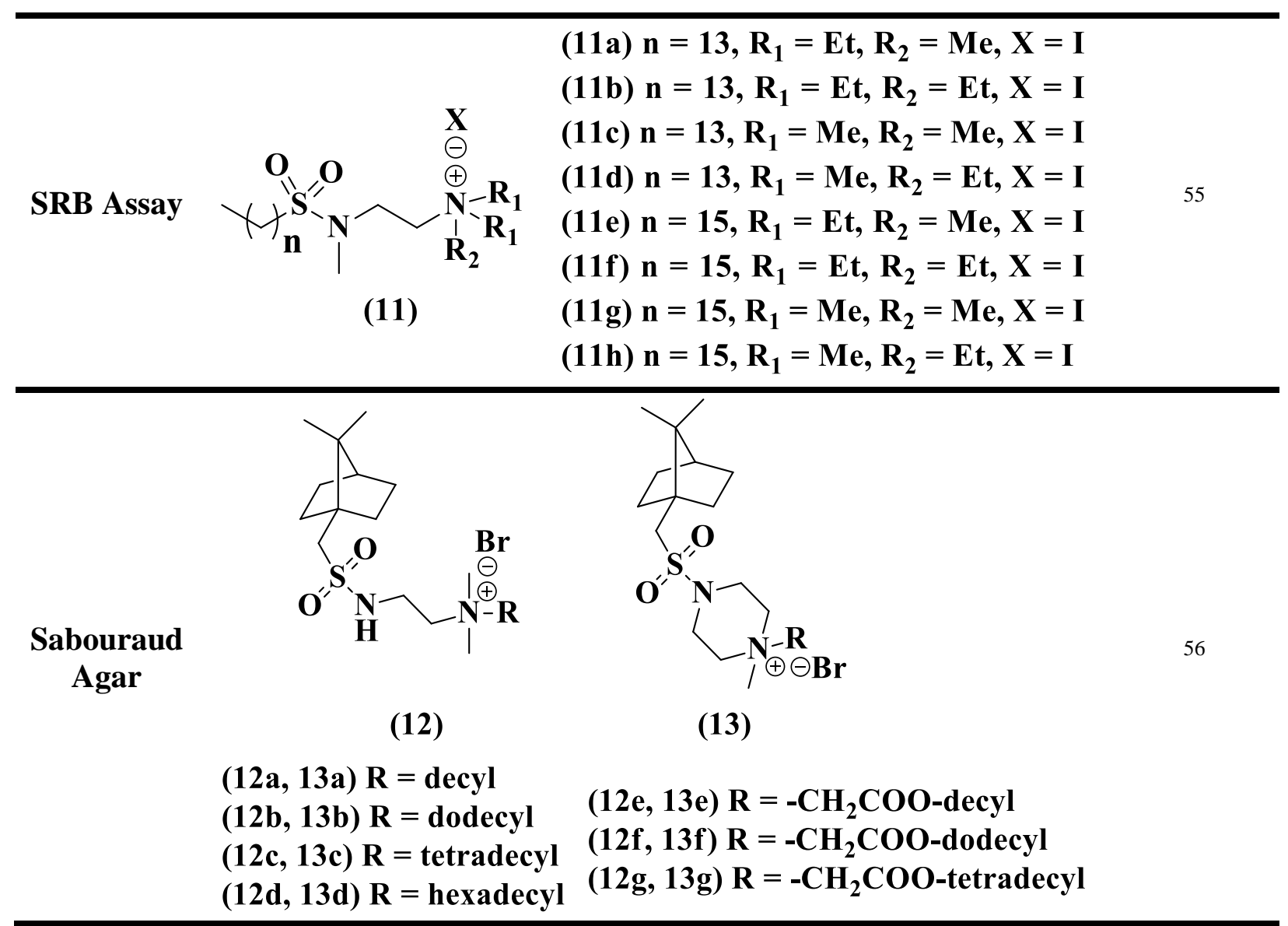

Figure 1.10: Literature examples of known sulfonamide quaternary ammonium compounds. PE $=$ polyethylene.

Aliphatic sulfonamide QUAT's consisting of 13 - 15 hydrocarbon chain tails (11) were widely investigated by Song et al. for their use as anticancer chemotherapeutic agents. ${ }^{55}$ On the other hand, Mikláš et al. developed bicyclic camphor based sulfonamide QUAT's to enhance bioactivity. ${ }^{56}$ All of these specialty QUAT's were designed to work in liquid mediums and were not surface bound. U.S. Patent No. 5,104,649 illustrates a multistep process to develop biocidetreated polymers and surfaces such as polyvinylchloride (PVC) and polyvinylbenzylchloride (PVBC) using compound 10, where the biocide is directly linked to the surface. ${ }^{54}$ The surfaces were functionalized with sulfonyl group by heat and UV irradiation followed by a sequential synthetic process using an alkyl amine and alkyl bromide to obtain $\mathbf{1 0 .}$ 


\subsection{Mode of Action}

\subsubsection{Quaternary Ammonium Compound Mode of Action}

The mode of Action of QUAT's has been extensively investigated but no firm mechanism could be elucidated, hence only proposed pathways have been widely reported. ${ }^{57}$ One of the proposed mechanisms that has been more broadly accepted is that the treated surfaces adsorb the negative net charge on microbes, causing cells to be pulled towards the cationic surface which eventually leads to the destruction of cell envelope and loss of essential cytoplasmic fluids, and finally cell death (Figure 1.11). ${ }^{17}$

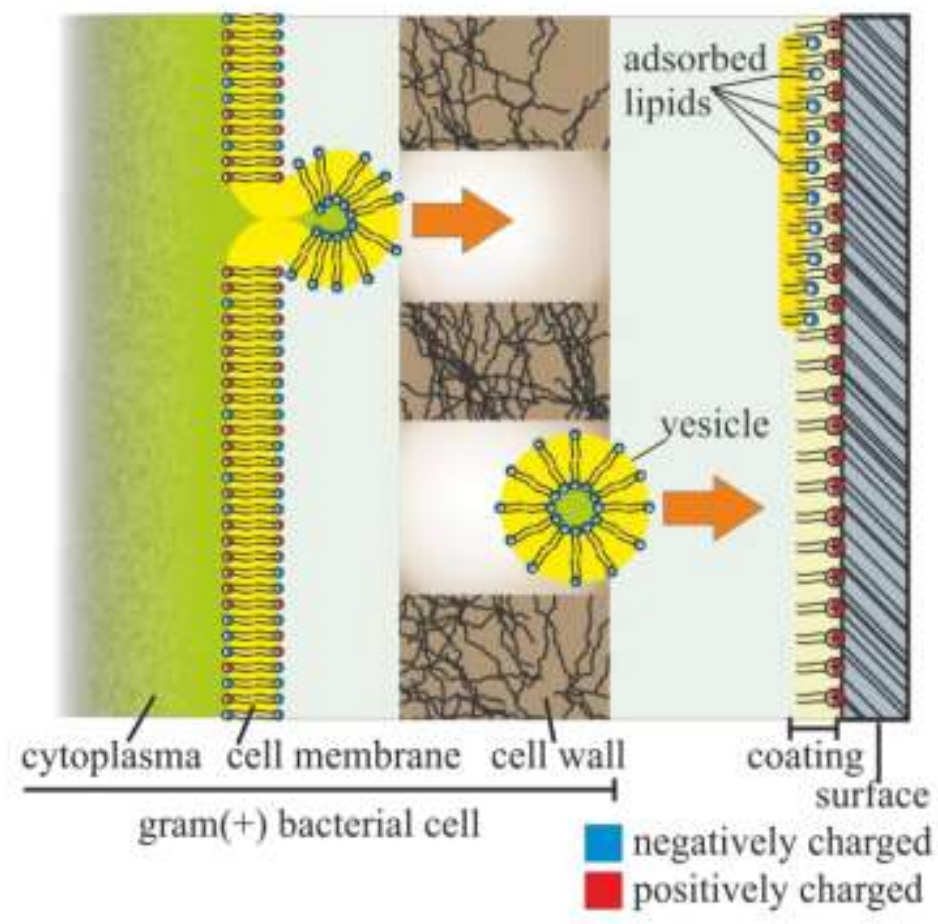

Figure 1.11: Mechanism of immobilized contact active QUAT (adapted from ref. ${ }^{3,17}$ ) 


\subsubsection{Sulfonamides (Sulfa Drugs)}

All cells, prokaryotic and eukaryotic, require folic acid for development of individual cellular components. ${ }^{58}$ Human beings obtain folic acid through diet and supplements whereas microorganisms acquire folic acid through a specific metabolic pathway. Microorganisms use a pteridine based precursor along with $p$-benzoic acid in presence of dihydropteroate synthatase enzyme to generate the required folic acid for its nourishment (Figure 1.12). ${ }^{59}$

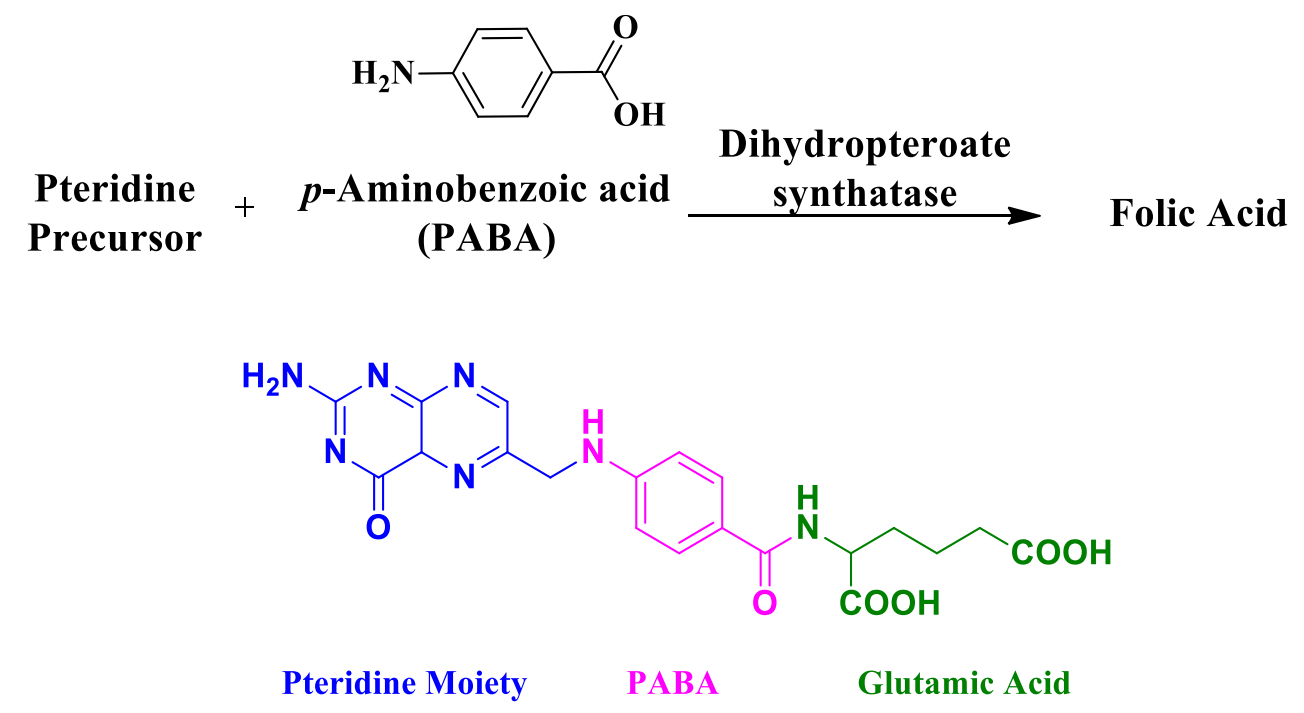

Figure 1.12: Biosynthetic pathway for folic acid in microorganisms.

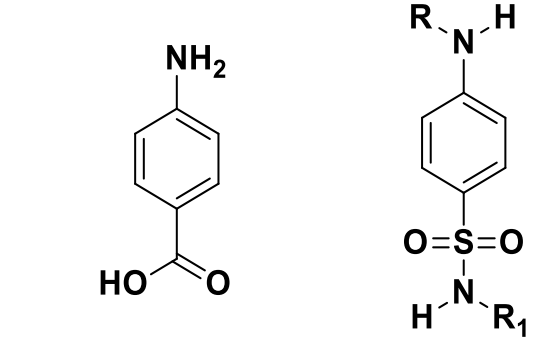

\section{p-Aminobenzoic acid Sulfonamide}

Figure 1.13: Structural analogs: $p$-aminobenzoic acid and sulfonamide.

Sulfonamides and/or sulfa drugs are analogs of $p$-aminobenzoic acid (PABA) (Figure 1.13) having two tertiary amine sites where $\mathrm{R}$ and $\mathrm{R}_{1}$ can be either a hydrogen atom or a methyl group. When introduced in to the microorganism's folic acid pathway, the sulfonamide competitively inhibits 
the binding of PABA molecule to form folic acid, which results in inhibiting the microorganisms growth and reproduction cycles (Figure 1.14). ${ }^{58,60,61}$

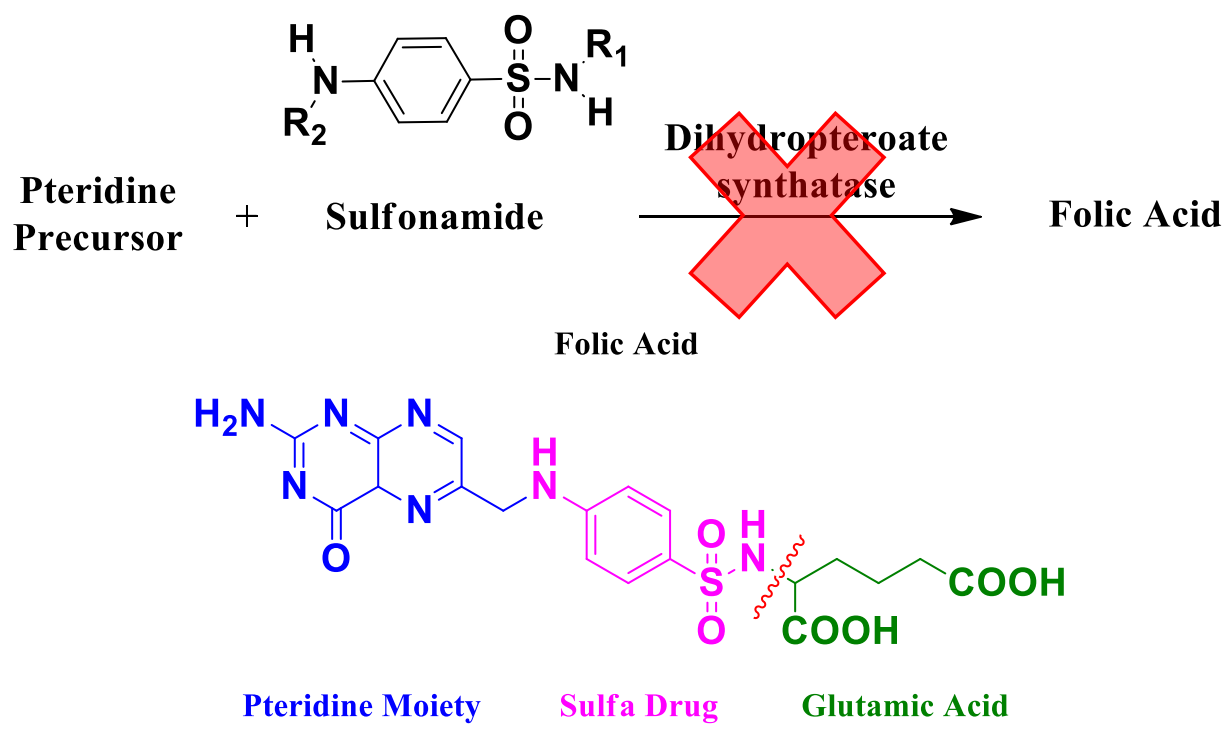

Figure 1.14: Competitive inhibition of sulfonamide for the pteridine precursor.

The absence of a similar biosynthetic pathway in mammals and its exclusiveness in pathogenic microorganisms suggests that the folate biosynthetic pathway is a natural target for antimicrobial drug development. ${ }^{58}$

\subsection{Literature Examples of Contact Active Quaternary Ammonium Antimicrobial Surfaces}

\subsubsection{Organosilanes (Textiles, Silica, and Glass)}

Surface attached antimicrobial technology was first widely investigated in the late 1960's using alkoxysilanes and catecholamines as anchoring groups. The first surface bound contact active molecule that presented antimicrobial activity on contat was reported by Isquith et al. in 1972 at DOW Corning. Isquith et al. successfully functionalized cotton and glass samples with octadecyldimethyl(3-trimethoxysilylpropyl) ammonium chloride (Si-QUAT's) (22). ${ }^{28}$ This work was a continuation of Abbot's work, who was the first to investigate alkoxysilane based 
compounds for antimicrobial activity in solution. In solution, silane based QUAT's were observed to have very low values ( $\mathrm{cfu} \approx 0$ ) for minimum inhibitory concentration (MIC). As a result, it was postulated that the active Si-QUAT was being adsorbed on to the equipment walls. ${ }^{62}$ Further investigation demonstrated that a series of (3-(trimethoxysilyl)propyldimethyl-alkyl ammonium chlorides with chain lengths of 6 to 22 showed antimicrobial activity against gram +ve/-ve bacteria and were patented by DOW Corning (Figure Compound 14-24). ${ }^{62,63}$

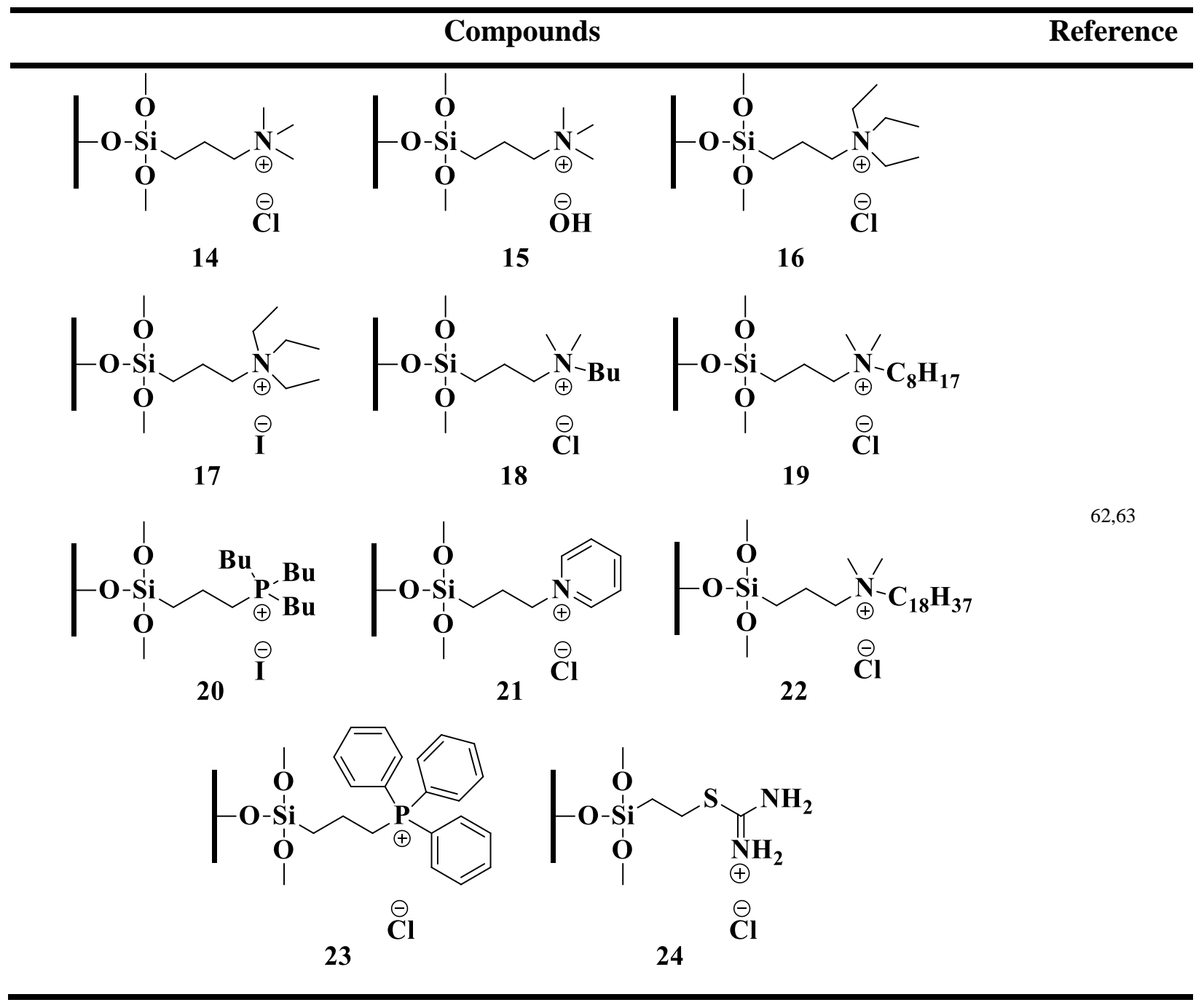




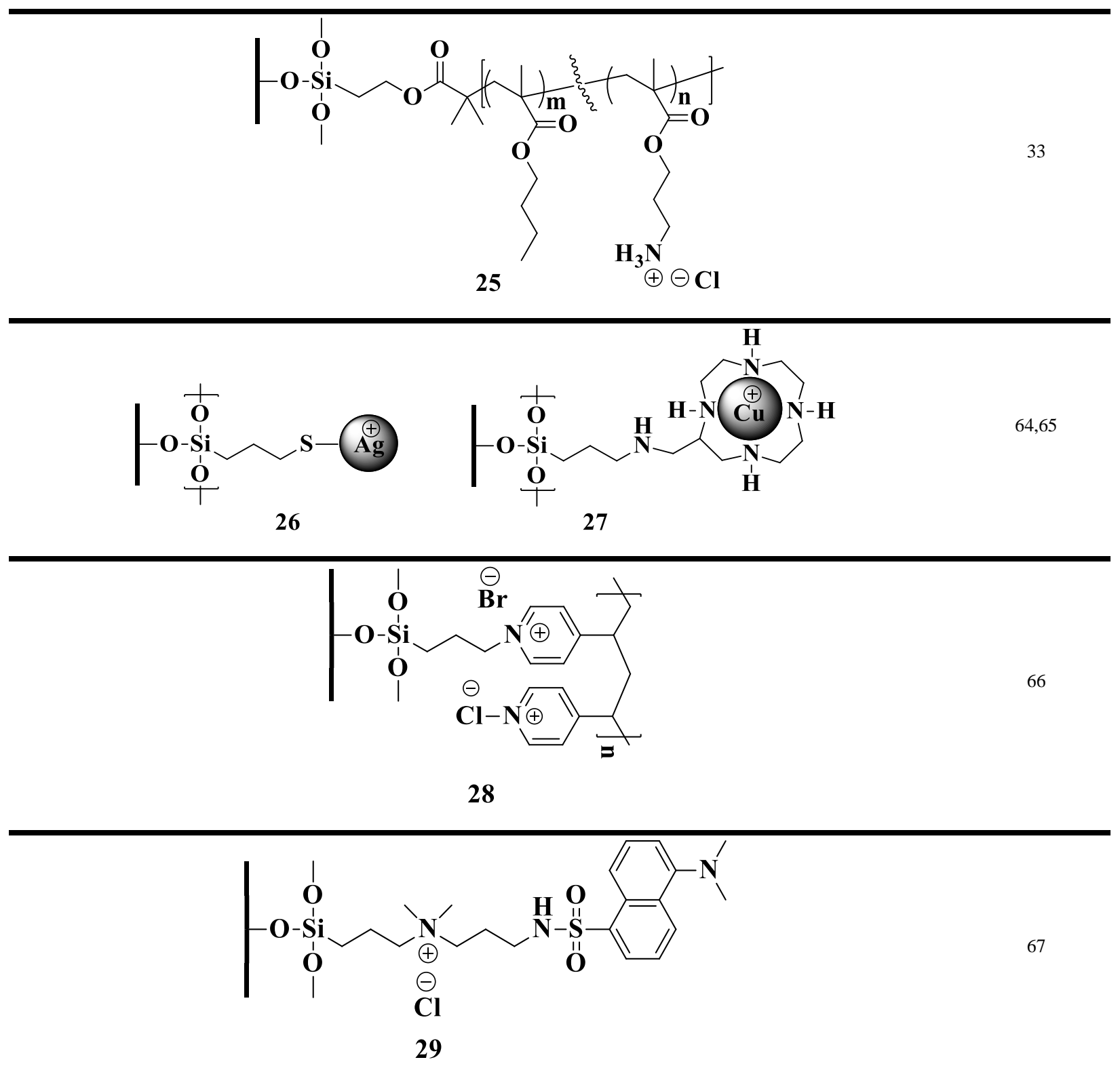

Figure 1.15: Literature examples of organosilane based antimicrobials (adapted from ref. ${ }^{3}$ ).

After extensive experimentation and analysis, Si-QUAT 22 was approved by the EPA in 1977 and was commercially sold as an antimicrobial finish for textiles. ${ }^{4}$ Si-QUAT 9 is commercially available as $40-72 \%$ methanolic solution or $0.75-5 \%$ water solution from DOW Corning® (9-6346), Microban (Liquid solution and treated textiles), Innovative Chemical Technologies (Flexipel MMP-25), Piedmont Chemical Industries (Ztrex 72, Pomofresh 42, 
Pomofresh 4850, Pomofresh X 105), and SiShield (SiS 7200, SiSAM500, SiS AM150, SiS AM75).

Isquith et.al. were the first to apply Si-QUAT (72\%) as $0.1 \%(\mathrm{w} / \mathrm{v})$ solution in water on pretreated glass or cotton surfaces, followed by $30 \mathrm{~min}$. annealing process at $70{ }^{\circ} \mathrm{C}$ to allow siloxane linkages to form on the pretreated substrate. However, the industrial application was limited by the rapid polymerization of the neighboring silanes in water, causing it to precipitate over time in storage or form a gel like layer on the substrate upon drying. In aqueous environments the alkoxy silanes undergo rapid hydrolyzation, followed by condensation of the neighbouring silanols, forming a polymeric linkage with the substrate (Figure 1.16). Compound 22 is commercially available as a methanol based solution which is undesirable for large scale production due to toxicity and flammability.

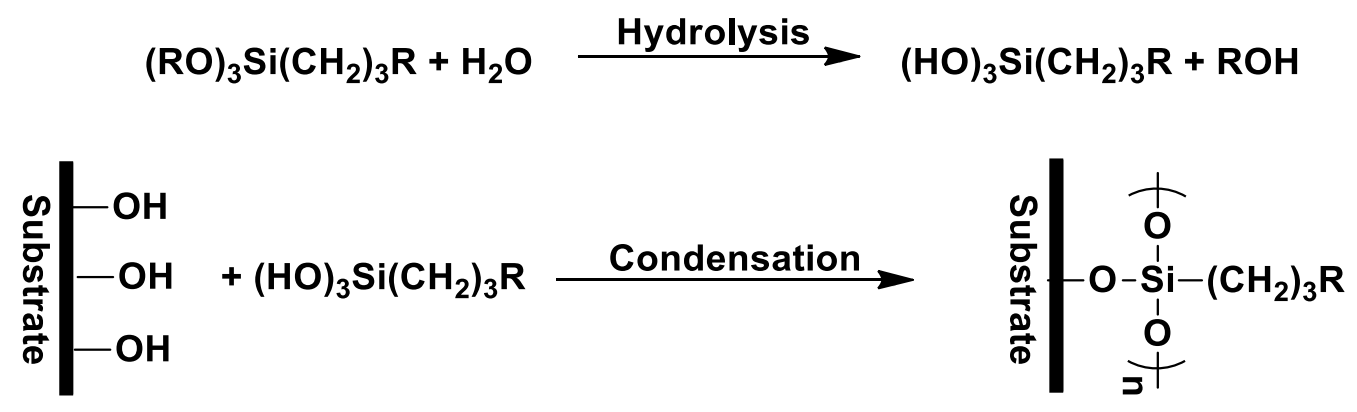

Figure 1.16: Anchoring process of alkoxysilane onto polyhydroxylated surfaces.

Organosilanes have been widely studied in literature as a treatment to polyhydroxylated substrates. Isquith et al. reported that immobilized Si-QUAT on natural fibers, metals and siliceous surfaces have great antimicrobial activity. ${ }^{68}$ Other published work include surfaces such as cotton gauze, cotton textile, polyester fabrics, titanium and silica nanoparticels. These materials were treated mostly using trialkoxysilane $\mathbf{1}$, which possessed great antimicrobial activity. 


\subsubsection{Organophosphorous (metals)}

Robust surface modifications on metal oxide surfaces can be achieved by covalent attachment of phosphonate monolayers. Such monolayers form tenacious M-O-P bonds and allow for various surface tuning properties. Phosphonates may either be naturally occurring and isolated from plants where they are part of membranes, i.e. 2-aminoethylphosphonic acid, or synthesized for applications as corrosion inhibition/scale inhibititors, or contact killing mircobiostatic coatings. ${ }^{69}$ Commonly used organic phosphoric acids in corrosion inhibition tests include: aminotris(methylenephosphonic acid) (ATMP), ethylenediamine tetra(methylene phosphoric acid) (EDTMP) and diethylenetriamine penta(methylene phosphoric acid) (DTPMP). ${ }^{70}$

Antimicrobial attachment via phosphonate linkers was performed by Porosa et al. in the Foucher group, who utilized a three step microwave procedure (Arbuzov, Menshutkin and bisdealkylation reactions) for the synthesis of $\gamma$-phosphonic acid quaternary ammonium antimicrobials possessing great antimicrobial efficacy. ${ }^{71}$

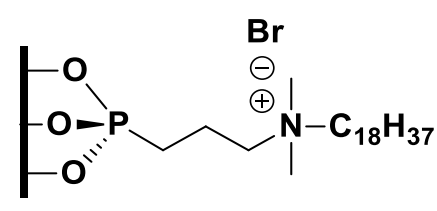

30

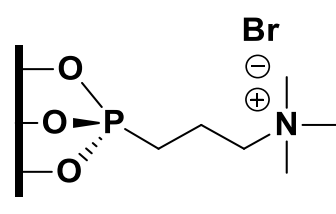

31

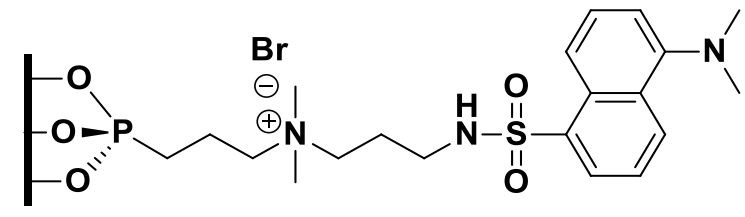

32

Figure 1.17: Literature examples of organophosphorus QUAT's made in the Foucher lab. 3,71 


\subsubsection{Benzophenone (plastics)}

Plastic-based products have been well integrated in to various industries; specifically, the medical and food industries where plastic serves as an essential packaging material. However, plastic surfaces are prone to biofilm colonization. ${ }^{72}$ Unlike the organosilane and organophosphorous coatings that require hydroxylated surfaces, plastics lack the initiation/anchoring site for coating purposes. Recent studies have shown that when exposed to UV light benzophenone forms a di-radical which acts as a cross-linker for coating plastic surfaces. The di-radical benzophenone group abstracts a hydrogen atom from the polymeric surface $(\mathrm{C}-\mathrm{H})$ forming a strong $(\mathrm{C}-\mathrm{C})$ bond (Figure 1.18). ${ }^{73}$
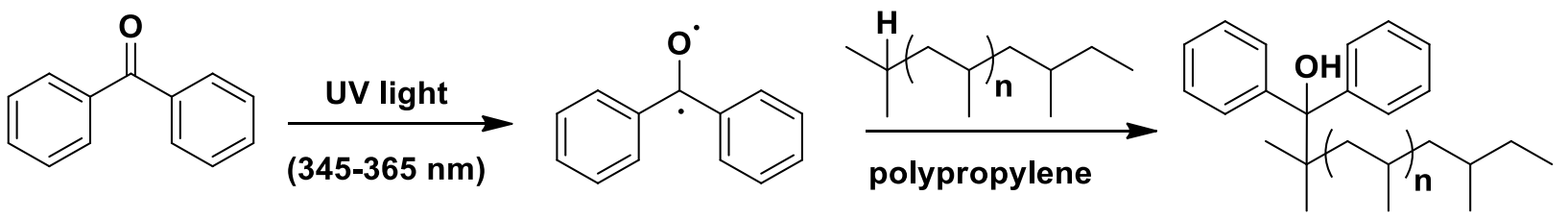

Figure 1.18: Benzophenone "grafted from" the surface of polypropylene upon UV irradiation. ${ }^{73}$

Dhende et al. were the first to report covalent attachment of quaternized polyethyleneimine (PEI) polymer on various surfaces ( Figure 1.19). ${ }^{74}$ The Foucher group recently reported successful synthesis of a benzophenone functionalized QUAT comprising a $\mathrm{C}_{18}$ carbon chain and/or Dansyl fluorescent tag (Figure 1.19, Compounds 34 and 35) which were coated on different surfaces (PP, PVC, and silicone tubing) exhibiting a complete reduction of E.coli amd S. aureus. 


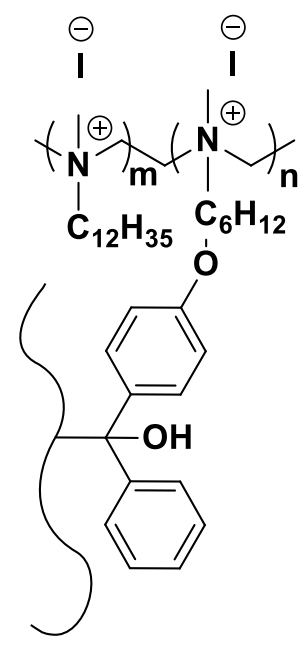

33

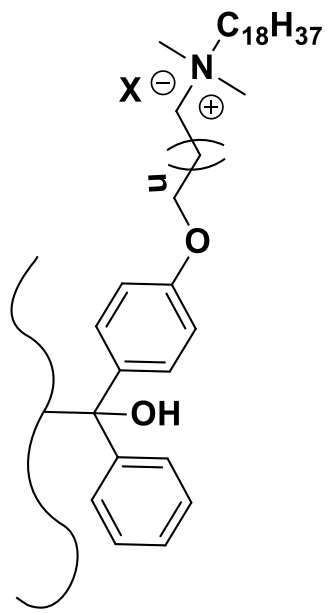

34

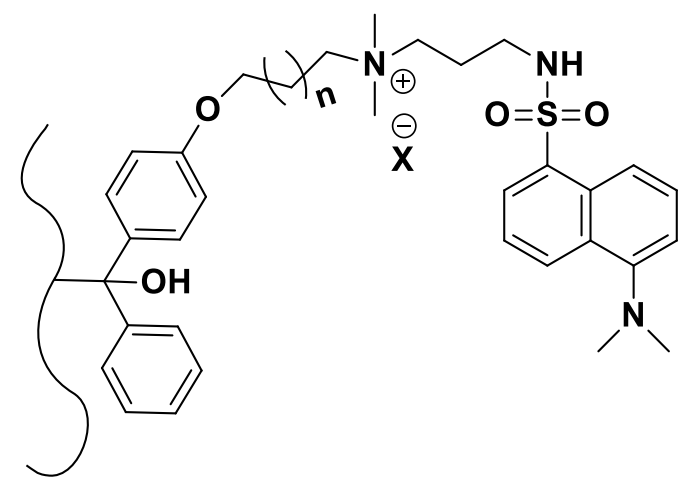

35

$$
\begin{gathered}
X=\mathrm{Cl}^{-}, \mathrm{Br}^{-}, \mathrm{I}^{-} \\
\mathrm{n}=1,2,3
\end{gathered}
$$

Figure 1.19: Literature examples of benzophenones used to prepare antimicrobial plastic surfaces. $(\mathbf{3 3})^{74},(\mathbf{3 4})^{75}$ and $(\mathbf{3 5})^{67}$

\subsection{QUAT Detection on Surfaces}

With the widespread application of QUAT's as disinfectants and sanitizers in various environments (households, hospital, food production, water processing, and public institutions), it is essential to quantify/assay the presence of residual QUAT's for safety and environmental risks that may arise. Over the years, various titration, colorimetric and LC - GC spectrum methods using dyes have been employed to quantify the amount of QUAT present in consumer products and waste water. ${ }^{76}$ The most commonly used qualitative method involves a water soluble bromophenol blue dye that binds to the QUAT through ionic interactions (Figure 1.20) allowing for visual conformation of a QUAT molecule bound to porous (fabrics) and non-porous surfaces (plastics, and glass). ${ }^{77}$ 


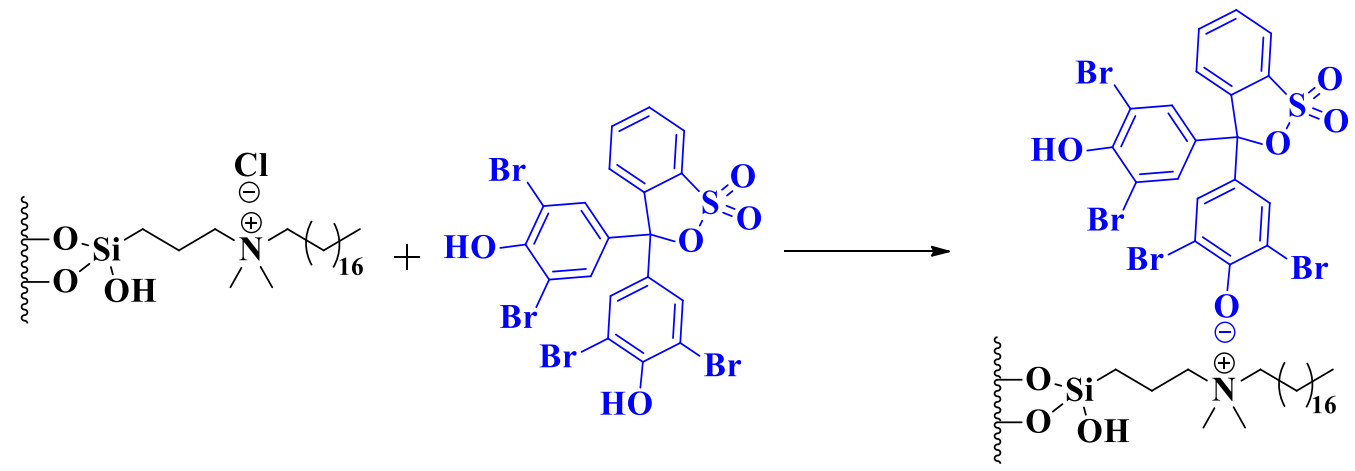

22

Bromophenol blue dye

Bromophenol blue ion pair with Si-QUAT

Figure 1.20: Bromophenol blue ion pair formation with silyl based QUAT (adapted from ref. ${ }^{3}$ ).

The bromophenol blue dye complexes with the surface bound QUAT resulting in a blue stain. Once complexed, the material is permanently stained, damaged and unusable. An alternative to the bromophenol blue detection method is fluorescent incorporation; once treated, the surfaces containing a small amount of an attachable fluorophore would fluoresce (glow) upon exposure to a low intensity/power UV lamp. The fluorescent detection method allows for easy visibility of poorly coated areas as well as missed areas during the application process. Fluorescent detection could be implied as unique identifier and as security feature for treated surfaces when added in trace amounts to an antimicrobial solution. Previously, the Foucher group demonstrated the use of fluorescent detection by incorporating dansyl moiety/tags into the structures of organosilanes ${ }^{16}$, phosphonates ${ }^{16}$, benzophenones ${ }^{75}$, and vinyl ${ }^{78}$ functionalities (Figure 1.21). ${ }^{67}$ 

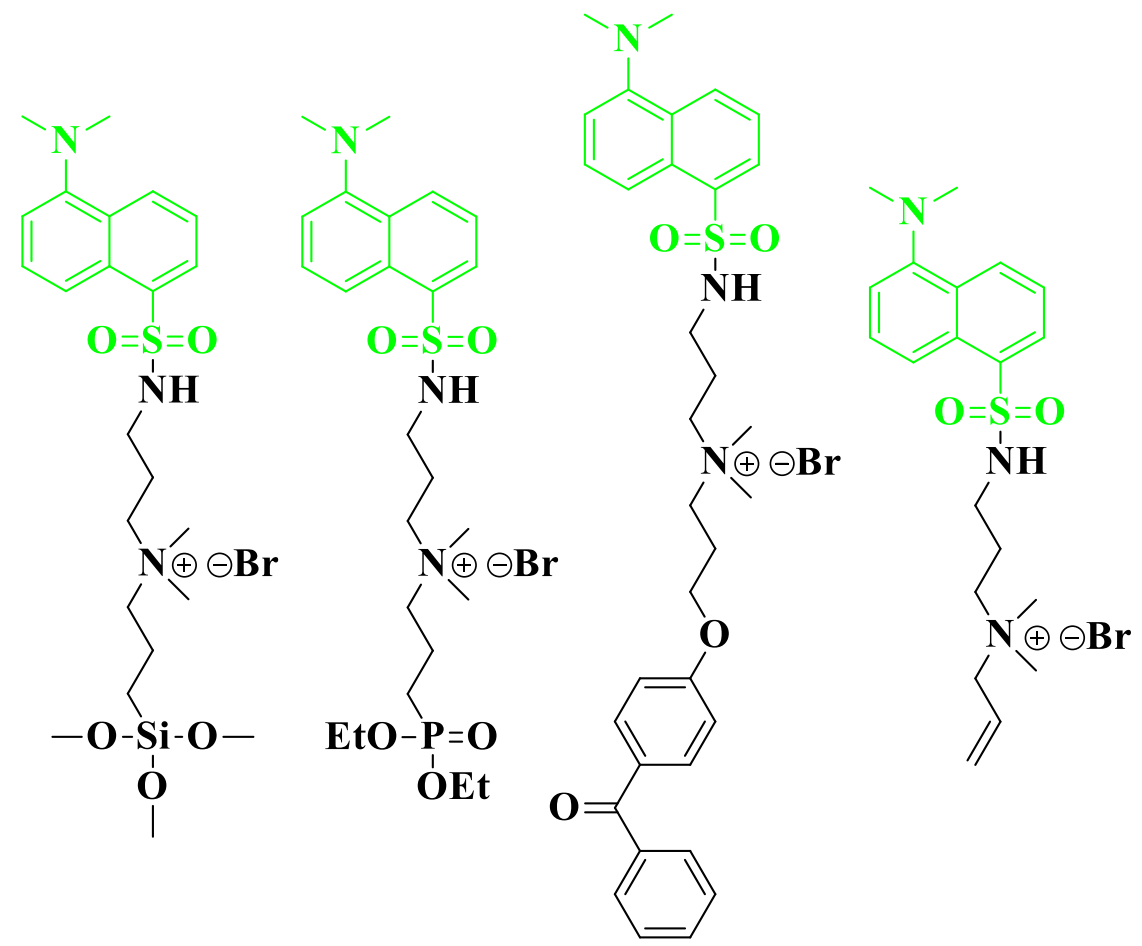

29

Figure 1.21: Linkers with the fluorescent dansyl tag previously synthesized in the Foucher lab (adapted from ref. $\left.{ }^{3}\right){ }^{16,67,75,78}$

\subsection{Research Goals}

The aim of this thesis project was to develop new generation of QUAT's that are more water soluble and relatively safe in comparison to commercially available products which are sold as methanolic solutions. Another aspect of this project was to combine the already known sulfonamide chemistry with the modern chemistry of QUAT's to provide enhanced antimicrobial activity. This project involves synthesis and characterization of sulfonamide based QUAT's that are water soluble and can attach to any designed surface. 


\subsection{RESULTS AND DISCUSSION}

\subsection{Synthesis and Characterization}

\subsubsection{Sulfonamide Synthesis}

A series of sulfonamide derivatives 1 - 9 (aromatic 1D - 5D, aliphatic 6D - 9D) were prepared using Method 5.2.1a and Method 5.2.1b respectively (Scheme 2.1 and 2.2) as precursors for Menshutkin Quaternization reactions with various linking functionalities. These compounds are commercially available (although rather expensive), with the synthetic summary, commercial source and pricing tabulated below (Table 2.1 and 2.2).

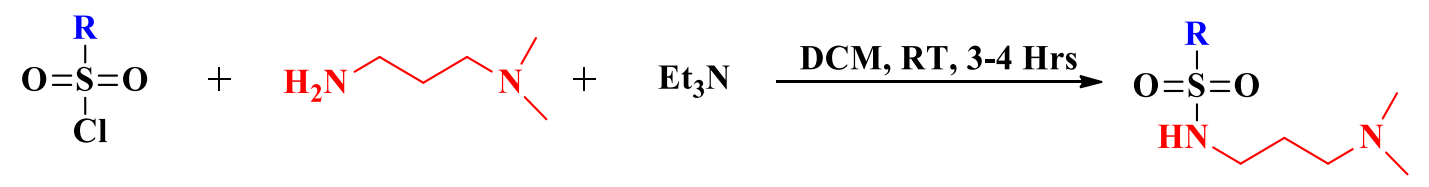
A
B
$\mathbf{C}$
D

Scheme 2.1: General reaction for aromatic sulfonamides.

\begin{tabular}{|c|c|c|c|c|c|c|}
\hline Compound & $\begin{array}{c}\text { Sulfonyl } \\
\text { Chloride (R) }\end{array}$ & $\begin{array}{c}\text { Reagents } \\
(\mathbf{A}: \mathbf{B}: \mathbf{C})\end{array}$ & $\begin{array}{c}\text { Time } \\
\text { (hrs.) }\end{array}$ & $\begin{array}{c}\text { Yield } \\
(\mathbf{\%})\end{array}$ & Pricing & $\begin{array}{c}\text { Commercial } \\
\text { Source }\end{array}$ \\
\hline $\mathbf{1}$ & $1: 1.5: 1.5$ & 4 & 98 & $\begin{array}{c}\$ 25.50 / 1 \\
\mathrm{mg}\end{array}$ & $\begin{array}{c}\text { LabNetwork } \\
\text { Compounds }\end{array}$ \\
\hline $\mathbf{2}$ & $1: 1.5: 1.5$ & 4 & 96 & $\$ 105 / 5 \mathrm{mg}$ & $\begin{array}{c}\text { TimTec } \\
\text { Building } \\
\text { Blocks and } \\
\text { Screening } \\
\text { Compounds }\end{array}$ \\
\hline $\mathbf{3}$ & & $1: 1.5: 1.5$ & 3 & 99 & $\$ 40 / 1 \mathrm{mg}$ & $\begin{array}{c}\text { Combridge } \\
\text { Cheming } \\
\text { Sibrary }\end{array}$ \\
\hline
\end{tabular}




\begin{tabular}{|l|l|l|l|l|l|}
\hline 4 & $1: 1.5: 1.5$ & 3 & 97 & $\$ 45 / 5 \mathrm{mg}$ & $\begin{array}{c}\text { Zelinsky } \\
\text { Institute Inc. } \\
\text { HTS Stock } \\
\text { Compounds }\end{array}$ \\
\hline $\mathbf{5}$ & $1: 1.5: 1.5$ & 3 & 95 & $\begin{array}{c}\text { Screening } \\
\text { amounts }\end{array}$ & $\begin{array}{c}\text { Otava Stock } \\
\text { Chemicals }\end{array}$ \\
\hline
\end{tabular}

Table 2.1: Summary and commercial pricing of aromatic sulfonamide precursors.

Sulfonamides have been widely studied since the late $20^{\text {th }}$ century. Compound $2 \mathrm{D}$ was previously synthesized by Rosatelli et al. in a single step process using a flow mesoreactor equipped with two-loop injection system, solvent pumps, a reactor, a back pressure regulator, UV detector and a fraction collector. The synthesis was carried out using acetone and water as solvents and PEG 400 as co-solvent in 1:2:1 ratio (v/v/v). The reagents were injected into the loop, and collected as crude mixtures followed by quenching with $3 \mathrm{~N} \mathrm{HCl}$ and $\mathrm{Et}_{2} \mathrm{O}$ extraction workup to obtain a pure product in $91 \%$ yield. ${ }^{79,80}$ While the Rosatelli et al. synthetic process is rather intricate, by comparison, the current research provides a simpler approach for thesynthesis and recovery of the sulfonamide derivatives. Compounds 1D-5D were initially synthesized as shown in Scheme 2.1, followed by a $\mathrm{K}_{2} \mathrm{CO}_{3}(1 \mathrm{~N})$ wash to yield viscous oils as products. Several later synthetic attempts have shown that washing the reaction mixture with only distilled water results in a similar yields and recovered as viscous oil that readily solidify over time ( $2-3$ days) or under high vacuum ( $4-12 \mathrm{hrs}$.). These sulfonamides were later isolated as a waxy solid product upon addition of hexanes $10 \%(\mathrm{v} / \mathrm{v})$ to the extracted organic phase and drying over high vacuum $(5-15$ $\min$. .).

The synthesis of 1D was initially described in patent DE 2744137 A1, but lacked any characterization detail. ${ }^{81}$ Similarly, compounds $\mathbf{3 D}-\mathbf{5 D}$ are commercially available but there is 
no known published processes or characterization data available. In this work, compounds $\mathbf{1 D}$ 5D were obtained in high yields $(>90 \%)$ and high purity based on NMR $\left({ }^{1} \mathrm{H}\right.$ and $\left.{ }^{13} \mathrm{C}\right)$ spectroscopy and mass spectrometry.

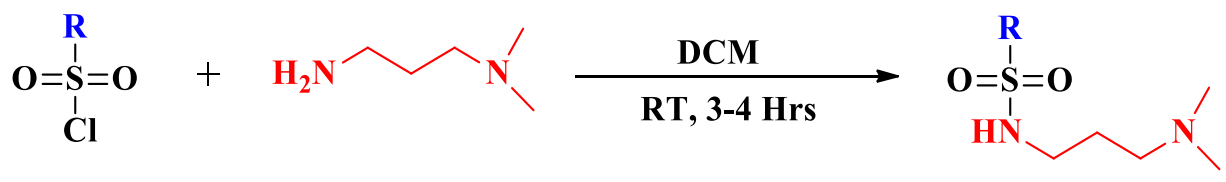

A

B

D

Scheme 2.2: General reaction for aliphatic sulfonamides.

\begin{tabular}{|c|c|c|c|c|c|c|}
\hline Compound & $\begin{array}{c}\text { Sulfonyl } \\
\text { Chloride (R) }\end{array}$ & $\begin{array}{c}\text { Reagents } \\
\text { (A:B) }\end{array}$ & $\begin{array}{l}\text { Time } \\
\text { (hrs.) }\end{array}$ & $\begin{array}{c}\text { Yield } \\
(\%)\end{array}$ & Pricing & $\begin{array}{c}\text { Commercial } \\
\text { Source }\end{array}$ \\
\hline 6 & $-\xi$ & $1: 1.5$ & 4 & 65 & $\$ 105 / 5 \mathrm{mg}$ & $\begin{array}{c}\text { TimTec } \\
\text { Building } \\
\text { Blocks and } \\
\text { Screening } \\
\text { Compounds }\end{array}$ \\
\hline 7 & & $1: 1.5$ & 4 & 61 & $\begin{array}{c}\text { EUR 459/ } \\
1 \mathrm{~g}\end{array}$ & $\begin{array}{c}\text { UORSY } \\
\text { Building } \\
\text { Blocks } \\
\text { Library }\end{array}$ \\
\hline 8 & & $1: 1.5$ & 4 & 81 & - & $\begin{array}{c}\text { AKos Out of } \\
\text { Stock } \\
\text { Catalog }\end{array}$ \\
\hline 9 & $\mathrm{~N}-\xi$ & $1: 1.5$ & 4 & 80 & - & - \\
\hline
\end{tabular}

Table 2. 2: Summary and commercial pricing of aliphatic sulfonamide precursors.

Compounds (6D - 9D) where synthesized according to Scheme 2.1 and Method 5.2.1a, and formed a salt upon addition of $\mathrm{Et}_{3} \mathrm{~N}$ or diamine $\mathbf{B}$ to the reaction, and following washes with $\mathrm{K}_{2} \mathrm{CO}_{3}(1 \mathrm{~N})$ resulted in only very low yield $(<5 \%)$. In later attempts, $\mathrm{Et}_{3} \mathrm{~N}$ was eliminated from reaction, and the addition of reagents $\mathbf{A}$ and $\mathbf{B}$ was reversed and the workup was conducted with $\mathrm{K}_{2} \mathrm{CO}_{3}(0.05 \mathrm{M})$ resulting yielding the desired product as clear to pale yellow coloured viscous oil. For compounds 6D - 9D there is no published processes or characterization data currently available, however 6D and 7D are commercially available. 


\subsubsection{Characterization of Aromatic Sulfonamide Precursors}

The ${ }^{1} \mathrm{H}$ and ${ }^{13} \mathrm{C}$ NMR spectra of the aromatic sulfonamides $1 \mathrm{D}-\mathbf{5 D}$ were collected and peak assignments made using 2D HSQC and COSY NMR experiments. Analysis for $1 D$ will serve as a template for compounds $\mathbf{2 D}-\mathbf{5 D}$.

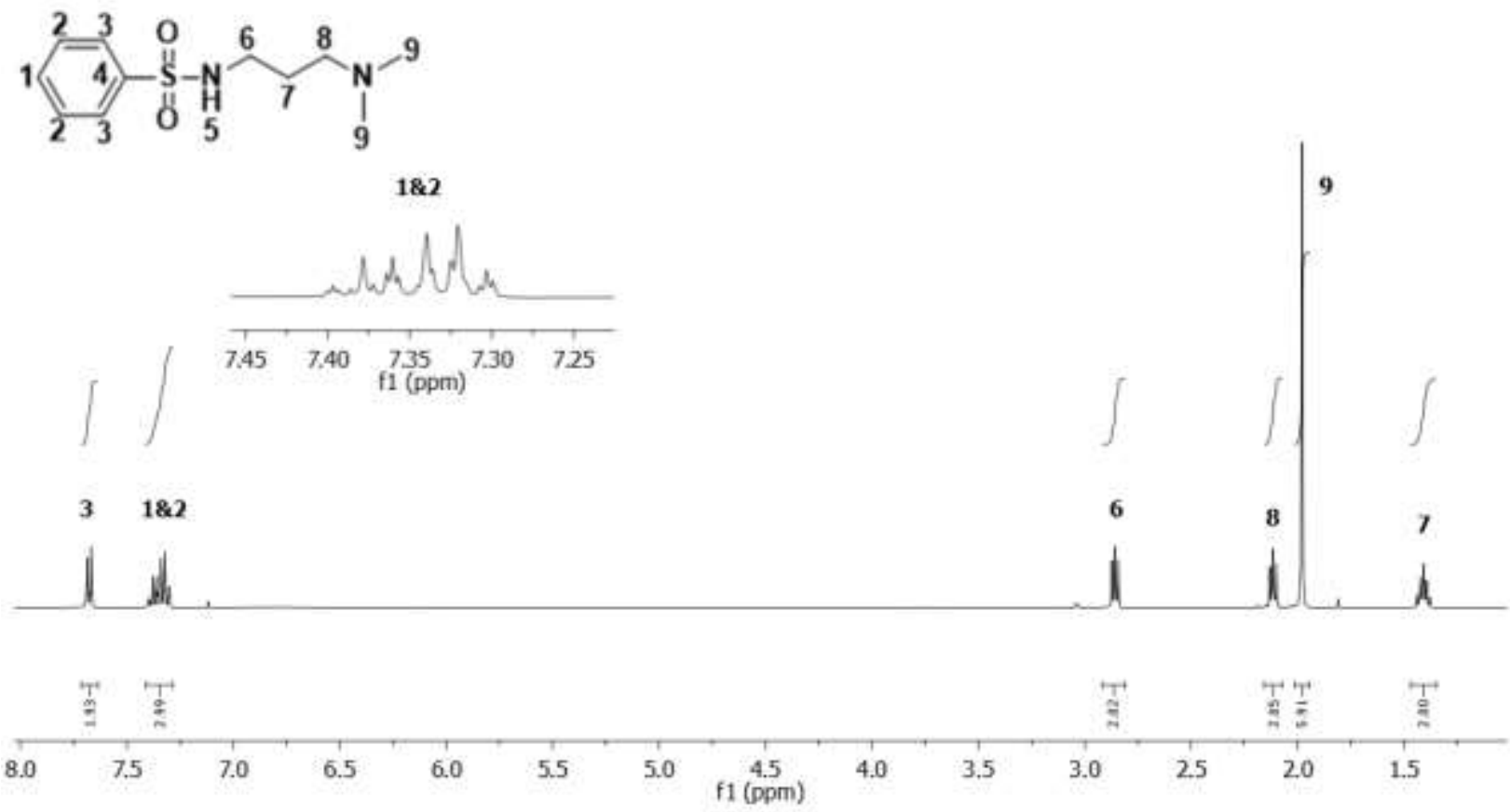

Figure 2.1: ${ }^{1} \mathrm{H} \mathrm{NMR}\left(\mathrm{CDCl}_{3}\right)$ of $\mathbf{1 D}$.

In the ${ }^{1} \mathrm{H}$ NMR of $1 D$ (Figure 2.1), the doublet at 7.68 ppm integrates for two hydrogens (H3) and corresponds to the hydrogen on the ortho-carbons from the sulfonyl group, followed by an overlap of peaks for hydrogens $(\mathrm{H} 1 \& \mathrm{H} 2)$ corresponding to the meta and para positions respectively. The singlet at $1.98 \mathrm{ppm}$ (H9) integrating for six hydrogens corresponds to the methyl groups attached to nitrogen. The downfield triplet at $2.86 \mathrm{ppm}$ integrates for two hydrogens has coupling $\left({ }^{3} J_{\mathrm{H} 6-\mathrm{H} 7}=5.8 \mathrm{~Hz}\right)$ to the upfield multiplet is the methylene group bound to the amide of sulfonyl group. The second triplet signal at $2.11 \mathrm{ppm}$ (H8) also couples to the upfield multiplet indicating that it is the methylene group bound to the nitrogen atom with dimethyl substitution and hence the multiplet $(\mathrm{H} 7)$ corresponds to intermediary methylene group. 

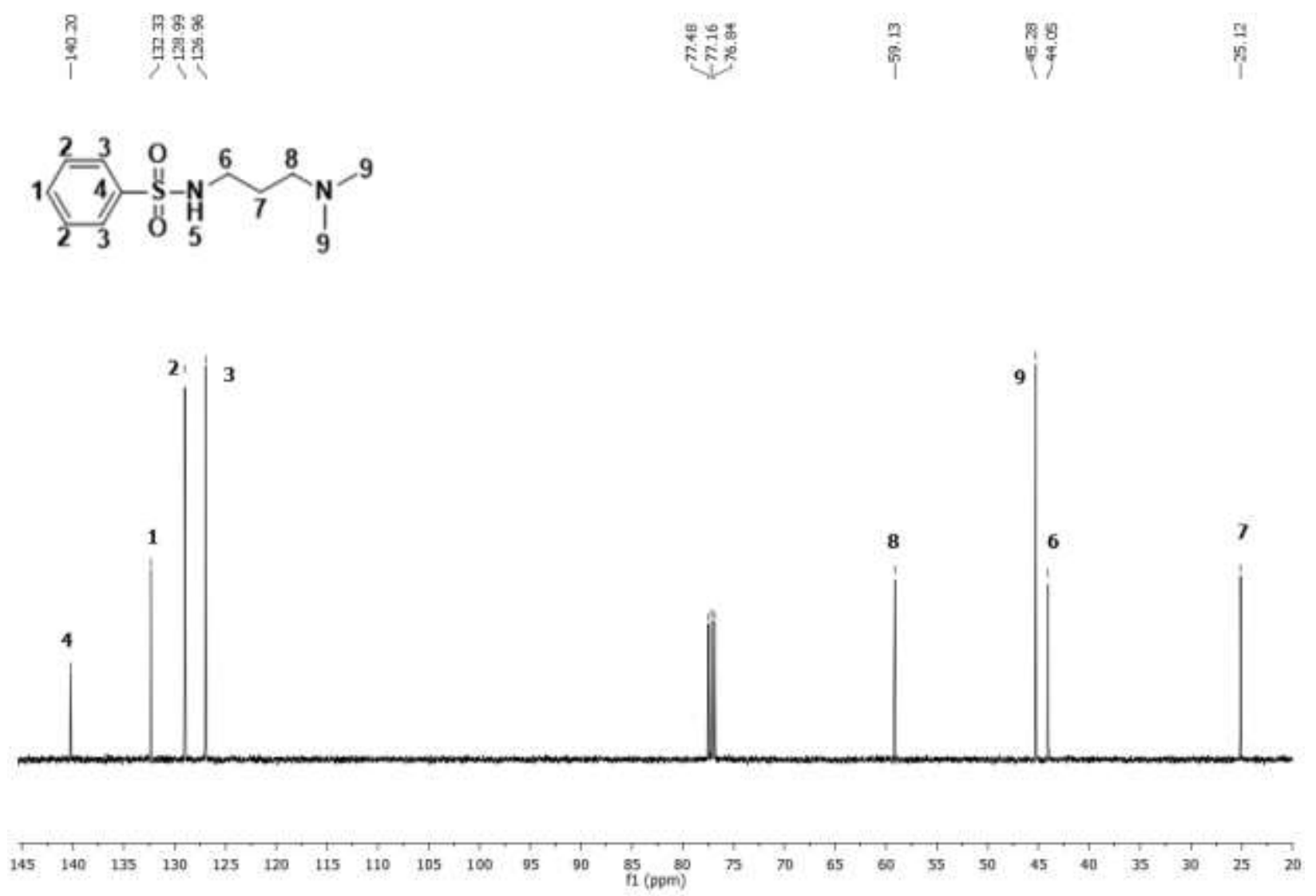

Figure 2.2: ${ }^{13} \mathrm{C} \mathrm{NMR}\left(\mathrm{CDCl}_{3}\right)$ of $\mathbf{1 D}$.

The ${ }^{13} \mathrm{C}$ NMR assignments were made in conjunction with 2D HSQC NMR (Appendix Figure A4), where the peaks from 140.20 - 132.33 ppm (C1-C4) were attributed to the aromatic ring. The furthest downfield resonance at 140.20 (C4) ppm was identified as the ipso carbon bound to the sulfonyl group due to the absence of coupling in 2D HSQC NMR spectrum. The peak at $45.28 \mathrm{ppm}$ (C9) was attributed to the methyl groups of the tertiary amine whereas the peaks at $\delta=$ $59.13,44.05,25.12 \mathrm{ppm}(\mathrm{C} 6-\mathrm{C} 8)$ were attributed to the propylene carbons between the two nitrogen centers. For compounds 2D - 5D, the ${ }^{1} \mathrm{H}$ and ${ }^{13} \mathrm{C}$ NMR are differentiated from $\mathbf{1 D}$ based on the substitution on the aromatic ring (2D - 4D) and the different substituent on the sulfonyl group (5D). 


\subsubsection{Characterization of Aliphatic Sulfonamide Precursors}

The ${ }^{1} \mathrm{H}$ and ${ }^{13} \mathrm{C}$ NMR spectra of aliphatic sulfonamide 6D - 9D were collected and peak assignments were made using 2D HSQC and COSY NMR experiments. The ${ }^{1} \mathrm{H}$ and ${ }^{13} \mathrm{C}$ NMR spectrums of 6D - 9D have a similar trend to aromatic sulfonamides (1D-5D) for the $N, N$ dimethylpropylamine end bound to the sulfonyl group (Figure 2.3). The ${ }^{1} \mathrm{H}$ NMR of 9D was similar to that of $6 \mathrm{D}$ with the absence of a methyl peak at $2.91 \mathrm{ppm}(\mathrm{H} 1, \mathbf{6 D})$ and the presence of additional singlet peak at $2.75 \mathrm{ppm}(\mathrm{H} 1,9 \mathrm{9D})$. Similar patterns were observed for the ${ }^{13} \mathrm{C}$ NMR spectra of 6D-9D.

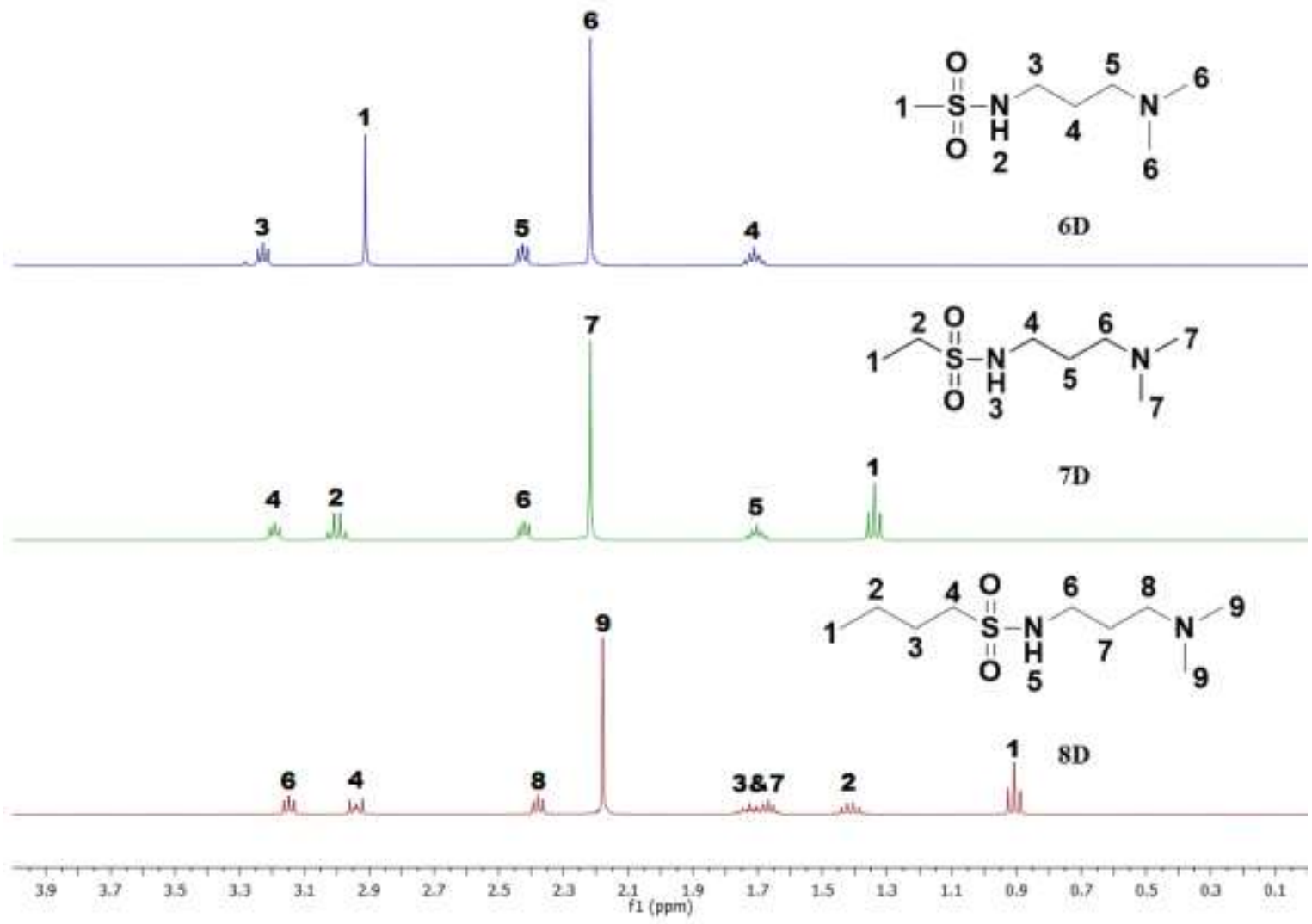

Figure 2.3: ${ }^{1} \mathrm{H}$ NMR $\left(\mathrm{CDCl}_{3}\right)$ comparison of $6 \mathrm{D}-\mathbf{8 D}$. 


\subsubsection{Organosilane Functionalized Quaternary Ammonium Sulfonamide Antimicrobial}

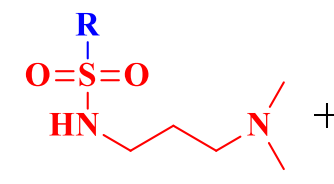

D

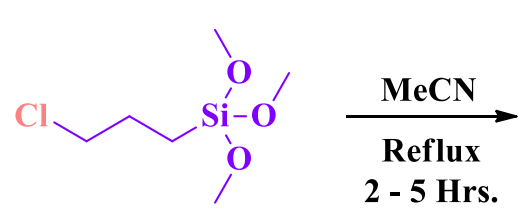

$\mathbf{E}$

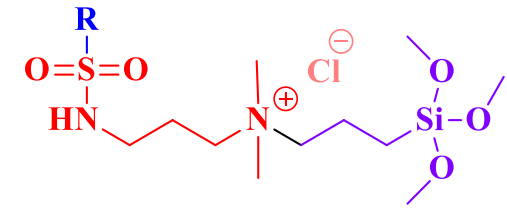

$\mathbf{F}$

Scheme 2.3: General Reaction for Organosilane Functionalized QUAT's

\begin{tabular}{|c|c|c|c|c|}
\hline Compound (D) & Reagents (D:E) & Time (hrs.) & Yield (\%) & $\begin{array}{c}{ }^{29} \mathbf{S i ~ N M R ~} \\
\boldsymbol{\delta}(\mathbf{p p m})\end{array}$ \\
\hline $\mathbf{1}$ & $1: 1.5$ & 4 & 82 & -44.49 \\
\hline $\mathbf{2}$ & $1: 1.5$ & 3.5 & 97 & -44.43 \\
\hline $\mathbf{3}$ & $1: 1.5$ & 4.5 & 93 & -44.70 \\
\hline $\mathbf{4}$ & $1: 1.5$ & $3-5$ & - & - \\
\hline $\mathbf{5}$ & $1: 1.5$ & 5 & 80 & -44.50 \\
\hline $\mathbf{6}$ & $1: 1.5$ & $2-5$ & - & - \\
\hline $\mathbf{7}$ & $1: 1.5$ & 5 & 86 & -44.45 \\
\hline $\mathbf{8}$ & $1: 1.5$ & 5 & 60 & -44.50 \\
\hline $\mathbf{9}$ & $1: 1.5$ & $3-4.5$ & - & - \\
\hline
\end{tabular}

Table 2.3: Synthesis summary of organosilane functionalized sulfonamide QUAT's.

Organosilane functionalized QUAT's have been widely investigated for their antimicrobial properties $(\mathbf{1 4}$ - 29, Figure 1.15). Porosa et al. were the first to prepare a sulfonamide based organosilane QUAT (29), wherein the substituent of the sulfonyl group served as a fluorescent detector/indicator. ${ }^{67}$ Other than $\mathbf{2 9}$, there is no published literature on sulfonamide based QUAT's possessing a terminal binding group. Compounds 1F - 9F were synthesized according to Scheme 2.3 to yield the desired products as clear pale brown to pale yellow coloured gummy/viscous oils in moderate to high yields $(60-97 \%)$ (Table 2.3$)$. The purity of these compounds was confirmed based on the mass spectrometry, ${ }^{1} \mathrm{H},{ }^{13} \mathrm{C}$, and ${ }^{29} \mathrm{Si}$ NMR experiments. ${ }^{29} \mathrm{Si}$ NMR signal of $\mathbf{E}(-$ $46.56 \mathrm{ppm}$ ) was used as a reference to confirm formation of $\mathbf{1 F}-\mathbf{9 F}$; a downfield shift of $\sim 2 \mathrm{ppm}$ was seen for the synthesized products (Figure 2.4 and Table 2.3). 
Several attempts to synthesize compounds $4 \mathbf{F}, 6 \mathbf{F}$, and $9 \mathbf{F}$ were made; $4 \mathbf{F}$ could not be isolated employing Method 5.2.2, whereas as the synthesis of $\mathbf{5 F}$ and $\mathbf{9 F}$ was unsuccessful based on the absence of a distinguishable ${ }^{29} \mathrm{Si}$ NMR resonance or the presence of the expected resonances in the respective ${ }^{1} \mathrm{H}$ and ${ }^{13} \mathrm{C}$ NMR spectra. Initially the synthesis of $\mathbf{1 F}-\mathbf{9 F}$ was conducted using published methods by Porosa et al. uses conventional thermal methods which took up to 48 hours and resulted either a moderate yield $(<60 \%)$ or in no product formation. Attempts to prepare these products by microwave processing failed. In this research it was established that the use of a minimum amount of solvent (anhydrous ACN) allowed the reactions to proceed towards completion in less time than conventional Menshutkin reactions.
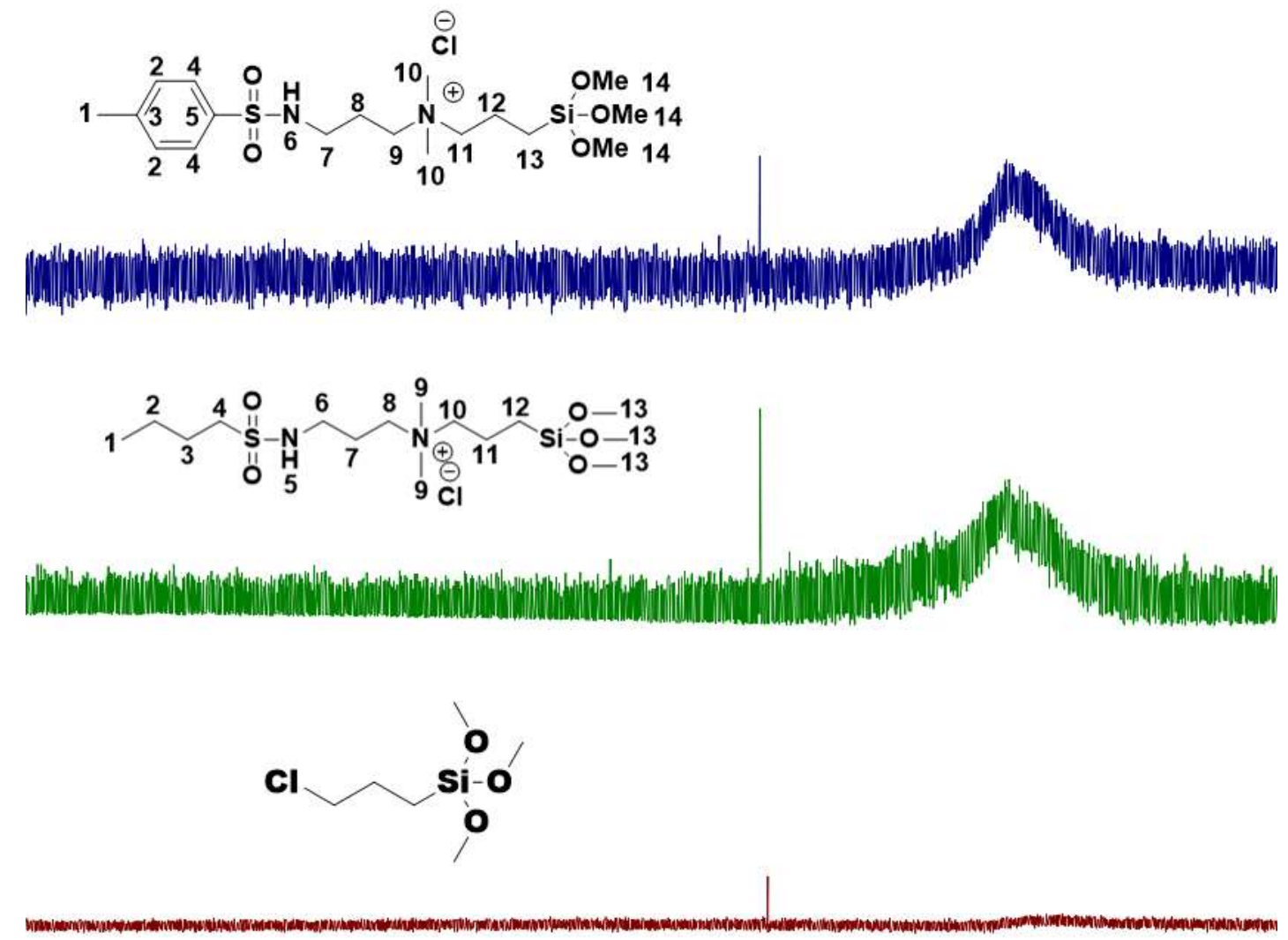

\begin{tabular}{|c|c|c|c|c|c|c|c|c|c|c|c|c|c|c|}
\hline 71 & $T$ & $T$ & $T$ & 1 & 1 & 1 & $1,1,1$ & $T$ & $T$ & 1 & $T$ & $T$ & 1 & 11 \\
\hline 140 & 120 & 100 & 80 & 60 & 40 & 20 & $\begin{array}{cc}0 & -10 \\
\mathrm{f} 1 & (\mathrm{ppm})\end{array}$ & -30 & -50 & -70 & -90 & -120 & -150 & -18 \\
\hline
\end{tabular}

Figure 2.4: ${ }^{29} \mathrm{Si} \mathrm{NMR}\left(\mathrm{CDCl}_{3}\right)$ comparison of $\mathbf{2 F}, \mathbf{8 F}$, and the starting material. 


\subsubsection{Characterization of Organosilane Functionalized Sulfonamide QUAT's}

The ${ }^{1} \mathrm{H},{ }^{13} \mathrm{C}$ and ${ }^{29} \mathrm{Si}$ NMR spectra of the organosilane functionalized sulfonamide QUAT's 1F - 9F were collected and peak assignments were made using 2D HSQC and COSY NMR experiments. Analysis for $\mathbf{1 F}$ will serve as a template for compounds $\mathbf{2 F}-\mathbf{9 F}$.
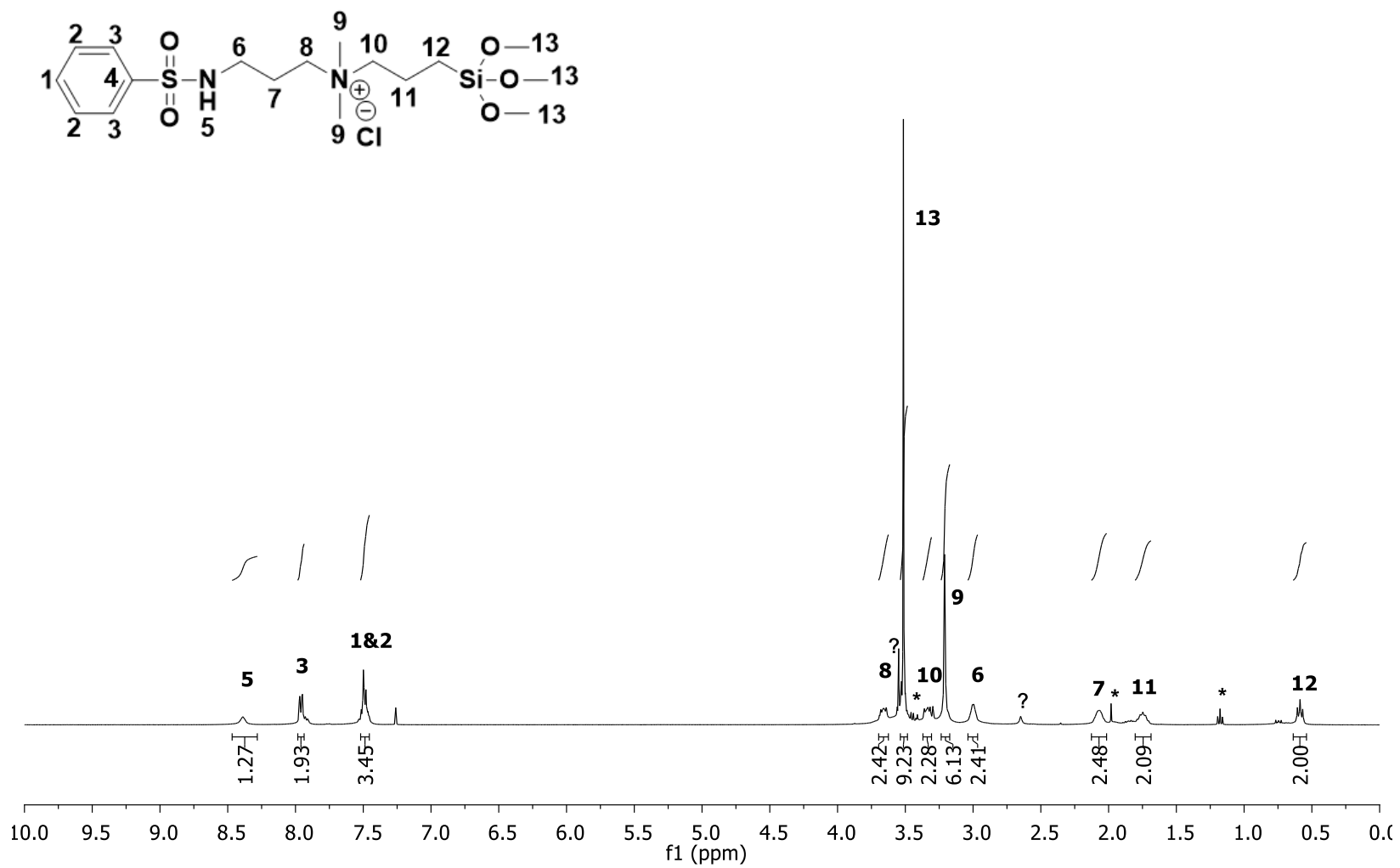

Figure 2.5: ${ }^{1} \mathrm{H} \mathrm{NMR}\left(\mathrm{CDCl}_{3}\right)$ of $\mathbf{1 F}$.

In the ${ }^{1} \mathrm{H}$ NMR of $\mathbf{1 F}$ (Figure 2.5), the peak at 7.96 ppm (H3) and multiplet from $7.54-7.34 \mathrm{ppm}$ ( $\mathrm{H} 1$ and $\mathrm{H} 2$ ) were attributed to that of the phenyl moeity bound to the sulfonamide group as was observed in ${ }^{1} \mathrm{H}$ NMR of 1D. The upfield triplet at $0.59 \mathrm{ppm}(\mathrm{H} 12)$ integrating for two hydrogens corresponds to the methylene group directly bound to the silane functional group. The broad singlet at $1.75 \mathrm{ppm}$ (H11) integrating for two hydrogens corresponds to the hydrogens of $\beta$-methylene group from the silane group and the multiplet at $3.66 \mathrm{ppm}$ (H8) corresponds to hydrogens bound to methylene group bound to QUAT as established by 2D COSY NMR. The upfield broad singlet 
at $8.39 \mathrm{ppm}$ (H5) integrating for one hydrogen corresponds to the hydrogen of the amide bound to the sulfonyl group. The singlet at $3.51 \mathrm{ppm}$ (H13) integrating for nine hydrogens corresponds to the hydrogens of the methoxy group directly bound to silane group, whereas the singlet at 3.21 ppm (H9) integrating for six hydrogens belongs to the two methyl groups bound to the quaternized amine. The broad singlet at $3.01 \mathrm{ppm}$ (H6) couples with the amide proton (H5) and integrates for two hydrogens and corresponds to the methylene group bound to sulfonamide whereas assignments for $\mathrm{H} 7, \mathrm{H} 8$, and $\mathrm{H} 10$ were assigned based on observed coupling in 2D COSY NMR. The peaks at $3.45 \mathrm{ppm}, 1.98 \mathrm{ppm}$ and 1.18 corresponds to trace solvents $\mathrm{ACN}$ and $\mathrm{Et}_{2} \mathrm{O}(*)$, and one other unassigned unknown impurities.

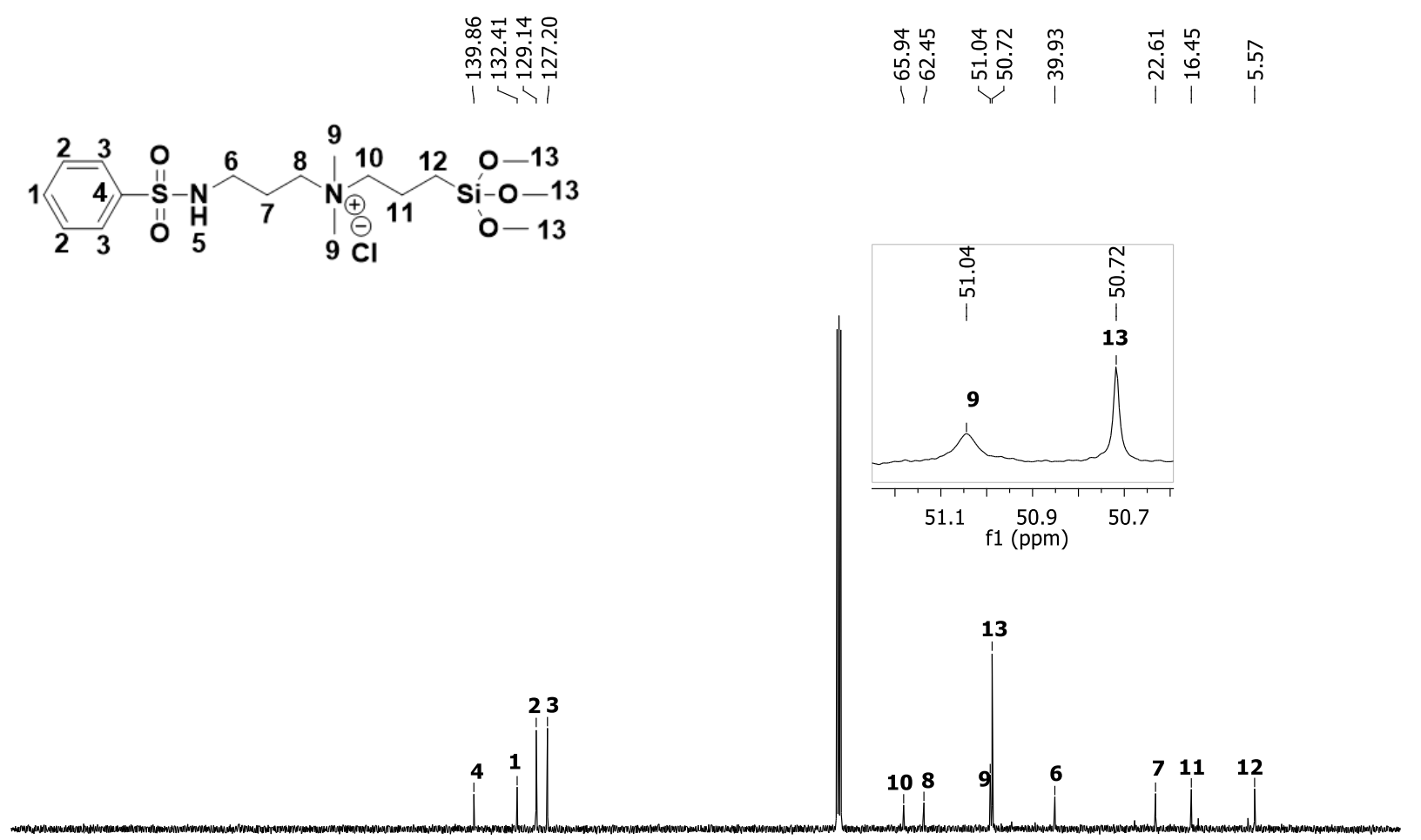

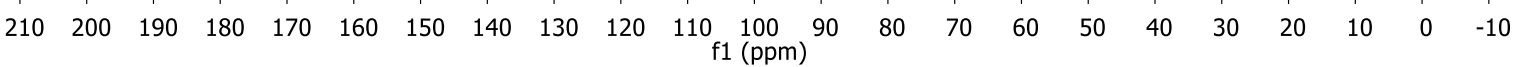

Figure 2.6: ${ }^{13} \mathrm{C} \mathrm{NMR}\left(\mathrm{CDCl}_{3}\right)$ of $\mathbf{1 F}$. 
The ${ }^{13} \mathrm{C}$ NMR assignments were made in conjunction with 2D HSQC NMR (Appendix Figure A49), where the aromatic resonance for the phenyl moiety bound to the sulfonamide are similar to 1D. The peaks at $65.94 \mathrm{ppm}(\mathrm{C} 10)$ and $62.45 \mathrm{ppm}(\mathrm{C} 8)$ belong to the methylene carbons bound to the central QUAT amine, whereas the downfield peak at $5.57 \mathrm{ppm}(\mathrm{C} 12)$ corresponds to the carbon bound directly to the silane functionality. The peaks at $51.04 \mathrm{ppm}(\mathrm{C} 9)$ and $50.72 \mathrm{ppm}$ (C13) corresponds to the methyl groups on QUAT and the methoxy carbons bound to silane respectively. The methylene carbon bound to amide group was observed at $39.93 \mathrm{ppm}$ (C6), similar to chemical shifts for similar compounds found in the literature. ${ }^{67}$ Peak assignments for C7 and C11 were made based on the 2D HSQC NMR experiment. For compounds $\mathbf{2 F}, \mathbf{3 F}, \mathbf{5 F}, \mathbf{7 F}$ and $\mathbf{8 F}$, the ${ }^{1} \mathrm{H}$ and ${ }^{13} \mathrm{C}$ NMR are differentiated from $\mathbf{1 F}$ based on the substitution of the aromatic ring (2F, $\mathbf{3 F}$, and $\mathbf{5 F}$ ) and the different substituent on the sulfonyl group (7F and $\mathbf{8 F}$ ).

\subsubsection{Organophosphorous Functionalized Quaternary Ammonium Antimicrobials}<smiles>[R]S(=O)(=O)NCCCN(C)C</smiles>

D

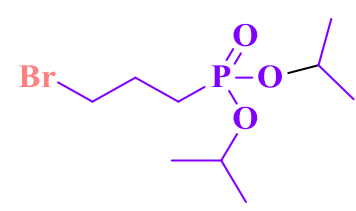

G

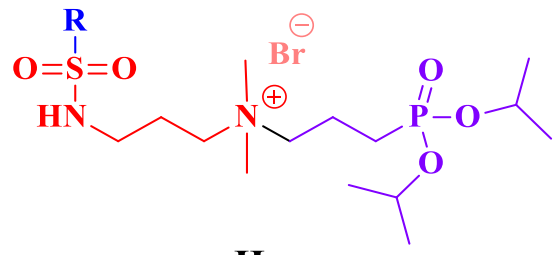

H

Scheme 2.4: General Reaction for Organophosphorus Functionalized QUAT’s.

\begin{tabular}{|c|c|c|c|c|}
\hline Compound (D) & Reagents (D:G) & Time (hrs.) & Yield (\%) & $\begin{array}{c}\text { 31P NMR } \\
\text { f (ppm) }\end{array}$ \\
\hline $\mathbf{1}$ & $1: 1$ & 4 & 68 & 27.08 \\
\hline $\mathbf{2}$ & $1: 1$ & 3 & 89.5 & 27.15 \\
\hline $\mathbf{3}$ & $1: 1$ & 4 & 70.5 & 27.13 \\
\hline $\mathbf{4}$ & $1: 1$ & $4-6$ & - & - \\
\hline $\mathbf{5}$ & $1: 1$ & 5.5 & 77.5 & 27.19 \\
\hline $\mathbf{6}$ & $1: 1$ & $3-5$ & - & - \\
\hline $\mathbf{7}$ & $1: 1$ & 5 & 86 & 27.05 \\
\hline $\mathbf{8}$ & $1: 1$ & 3 & 82 & 27.22 \\
\hline $\mathbf{9}$ & $1: 1$ & 3 & 91.7 & 27.27 \\
\hline
\end{tabular}

Table 2.4: Synthesis summary of organophosphorus functionalized sulfonamide QUAT's. 
Compounds 1H -9H were synthesized according to Scheme 2.6 employing Method 5.2.2. Initial attempts using conventional method (reflux for 48 hrs.) and reagents D:G in ratio 1:1.5 resulted in mixed product formation based on multiple ${ }^{31} \mathrm{P}$ NMR peaks. Later attempts using reagents D:G in 1:1 ratio and minimum solvent resulted in white/pale yellow coloured gummy powder in moderate to high yields of product. The products were recovered in high purity based on mass spectrometry, as well as ${ }^{31} \mathrm{P},{ }^{1} \mathrm{H}$ and ${ }^{13} \mathrm{C}$ NMR spectrometry (Table 2.4). Product $\mathbf{4 H}$ could not be isolated employing Method 5.2.2, whereas synthesis of $\mathbf{6 H}$ was unsuccessful based on analysis by ${ }^{31} \mathrm{P}$ NMR spectroscopy.

\subsubsection{Characterization of Organophosphorous Functionalized Sulfonamide QUAT's}

The ${ }^{1} \mathrm{H},{ }^{13} \mathrm{C}$ and ${ }^{31} \mathrm{P}$ NMR spectra of the organophosphorous functionalized sulfonamide QUAT's 1H - 9H were collected and peak assignments were made using 2D HSQC and COSY NMR experiments. Analysis for $\mathbf{1 H}$ will serve as a template for compounds $\mathbf{2 H} \mathbf{- 9 H}$.
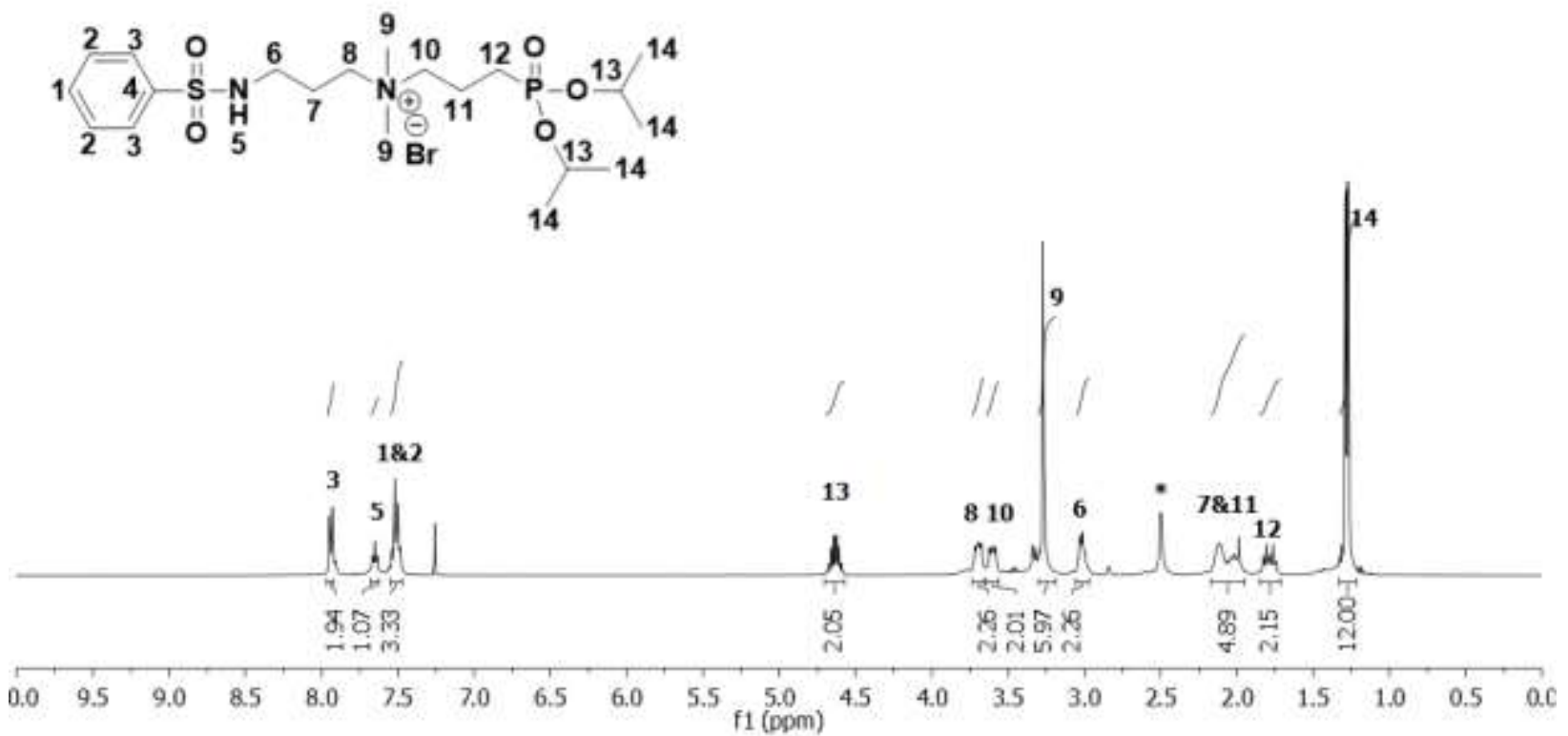

Figure 2.7: ${ }^{1} \mathrm{H} \mathrm{NMR}\left(\mathrm{CDCl}_{3}\right)$ of $\mathbf{1 H}$. 
In the ${ }^{1} \mathrm{H}$ NMR of $\mathbf{1 H}$ (Figure 2.7), the shifts in aromatic region were similar to that of precursor 1D and organosilane 1F. The triplet at $7.65 \mathrm{ppm}$ (H5) integrates for one hydrogen and corresponds to the amide hydrogen, which couples with the methylene hydrogens (H6) of the carbon bound to the amide group with a coupling constant of ${ }^{3} J_{5-6}=5.9 \mathrm{~Hz}$. The signal at $1.79 \mathrm{ppm}(\mathrm{H} 12)$ displays a splitting of doublets of triplets integrating for two hydrogens are of methylene group directly bound to the phosphorous group with coupling constant of ${ }^{1} J_{12-\mathrm{P}}=17.7 \mathrm{~Hz}$. The downfield peak at $1.28 \mathrm{ppm}(\mathrm{H} 14)$ integrating for twelve hydrogens corresponds to the terminal methyl hydrogens of the isopropyl group, which gives rise to a doublet of doublets with a splitting due to far range coupling of ${ }^{3} J_{14-\mathrm{P}}=6.2 \mathrm{~Hz}$ with phosphorous through the oxygen bond. The multiplet at $4.63 \mathrm{ppm}$ (H13) integrating for two hydrogens displays coupling with the resonance for H14, corresponding to the hydrogen on the central carbons of the terminal isopropyl groups bound to oxygen. The singlet at $3.27 \mathrm{ppm}$ corresponds to the methyl groups bound to the QUAT amine, whereas the multiplet from $2.16-1.94 \mathrm{ppm}(\mathrm{H} 7, \mathrm{H} 11$, and $\mathrm{ACN})$ is the overlap of peaks corresponding to the hydrogens bound to $\beta$-carbons on both sides of the central QUAT. The multiplets at $3.70 \mathrm{ppm}(\mathrm{H} 8)$ and $3.60 \mathrm{ppm}$ (H10) were assigned to the methylene hydrogens on the $\alpha$-carbons alongside the central QUAT based on coupling observed in 2D COSY NMR. 


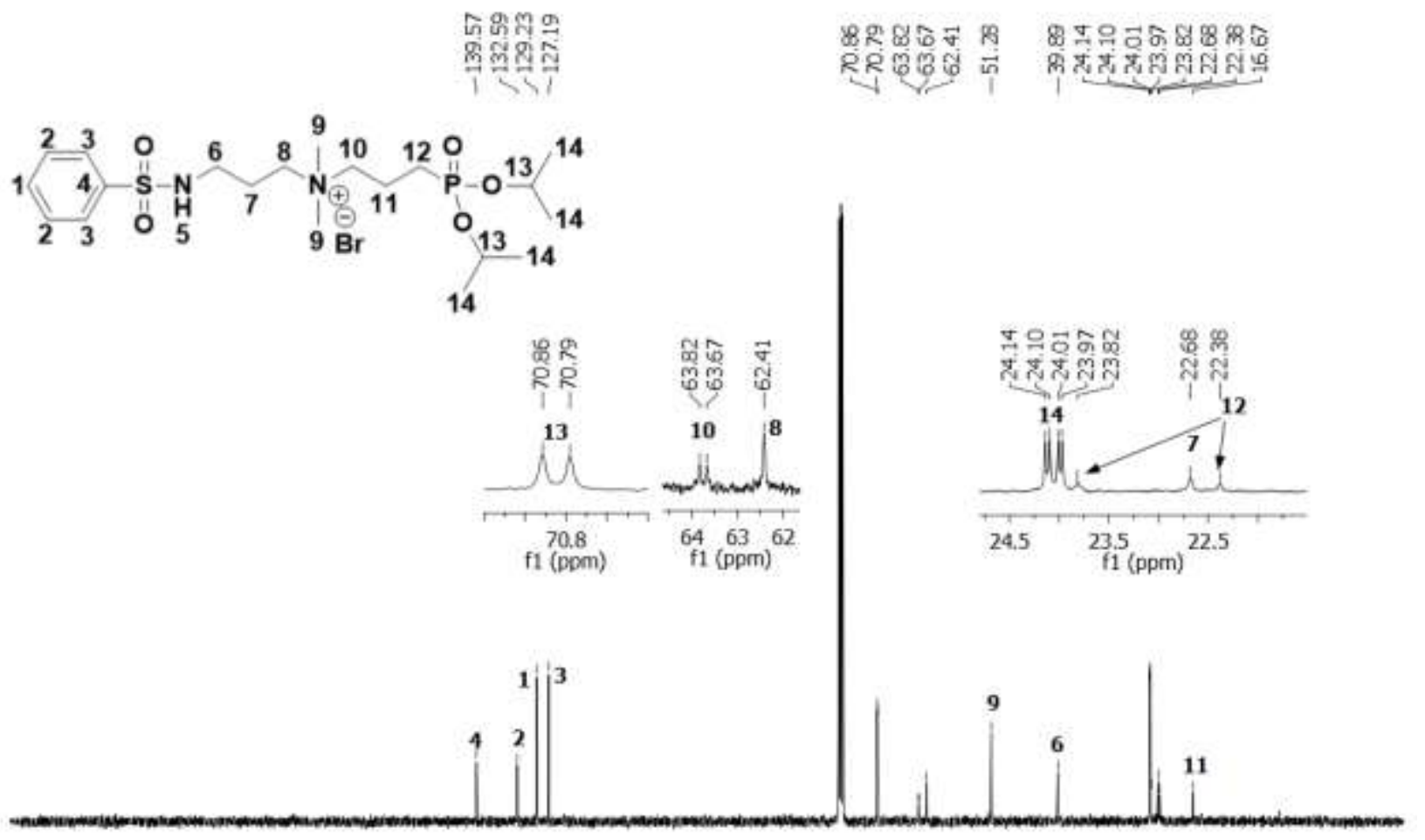

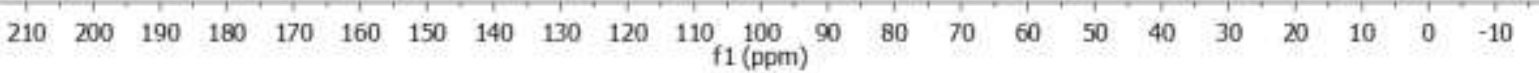

Figure 2.8: ${ }^{13} \mathrm{C} \mathrm{NMR}\left(\mathrm{CDCl}_{3}\right)$ of $\mathbf{1 H}$.

The ${ }^{13} \mathrm{C}$ NMR assignments were made in conjunction with 2D HSQC NMR (Appendix Figure 85), where the aromatic region bears essentially the same shifts as the precursor 1D. The doublet at $70.82 \mathrm{ppm}(\mathrm{C} 13)$ corresponds to the central carbon of the isopropyl moiety bound to phosphorus through oxygen linkage with coupling of ${ }^{2} J_{13-\mathrm{P}}=6.7 \mathrm{~Hz}$. The peak at $62.41 \mathrm{ppm}(\mathrm{C} 8)$ corresponds to the carbon bound to QUAT on the sulfonamide side, whereas the carbon bound to the QUAT towards the terminal organophosphorus moiety yields a doublet at $63.74 \mathrm{ppm}(\mathrm{C} 10)$ which couples with phosphorus through ethyl linkage with coupling constant of ${ }^{3} J_{10-\mathrm{P}}=15.1 \mathrm{~Hz}$. The terminal methyl carbons of the isopropyl gives rise to a sets of doublets at 24.12 and $23.99 \mathrm{ppm}(\mathrm{C} 14)$ with coupling constants of ${ }^{3} J_{14-\mathrm{P}}=4.5$ and $4.0 \mathrm{~Hz}$ respectively. This scenario was attributed to a slight offset in spatial arrangement of the terminal isopropyl moiety. The peaks at $23.10 \mathrm{ppm}(\mathrm{C} 12)$ 
corresponds to carbon bound directly to phosphorus group with a coupling constant of ${ }^{1} J_{12-\mathrm{P}}=$ 144.3 $\mathrm{Hz}$ based on the 2D HSQC NMR spectra. For compounds $\mathbf{2 H}, \mathbf{3 H}, \mathbf{5 H}$, and $\mathbf{7 H}-\mathbf{9 H}$, the ${ }^{1} \mathrm{H}$ and ${ }^{13} \mathrm{C}$ NMR are differentiated by $\mathbf{1 H}$ based on the substitution of the aromatic ring $(\mathbf{2 H}, \mathbf{3 H}$, and $5 \mathbf{H})$ and the different substituent on the sulfonyl group (7F - 9F).

\subsubsection{Benzophenone Functionalized Quaternary Ammonium Antimicrobials}

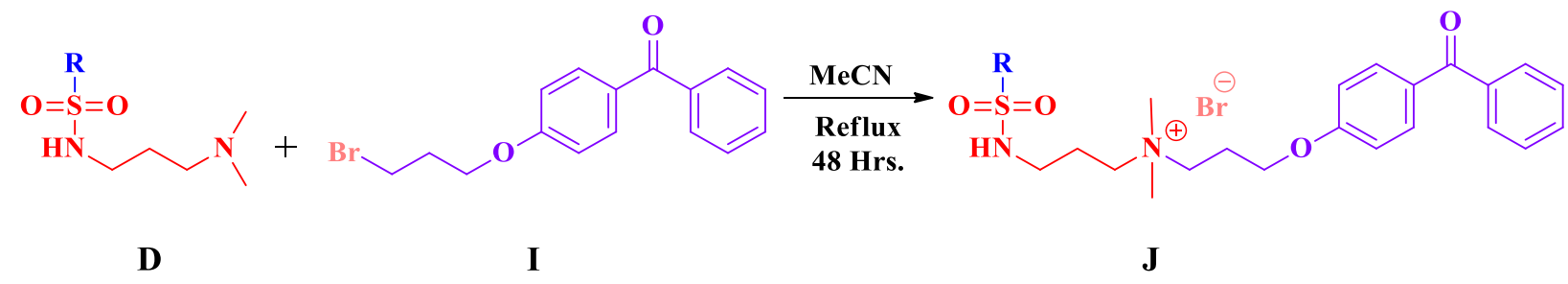

Scheme 2.5: General Reaction for Benzophenone Functionalized QUAT’s.

\begin{tabular}{|c|c|c|c|}
\hline Compound (D) & Reagents (D:I) & Time (hrs.) & Yield (\%) \\
\hline $\mathbf{1}$ & $1: 1$ & 48 & 82 \\
\hline $\mathbf{2}$ & $1: 1$ & 48 & 80 \\
\hline $\mathbf{3}$ & $1: 1$ & 48 & 67 \\
\hline $\mathbf{4}$ & $1: 1$ & 48 & 92 \\
\hline $\mathbf{5}$ & $1: 1$ & 48 & 82 \\
\hline $\mathbf{6}$ & $1: 1$ & 48 & - \\
\hline $\mathbf{7}$ & $1: 1$ & 48 & 77 \\
\hline $\mathbf{8}$ & $1: 1$ & 48 & 73 \\
\hline $\mathbf{9}$ & $1: 1$ & 48 & 60 \\
\hline
\end{tabular}

Table 2.5: Synthesis summary of benzophenone functionalized sulfonamide QUAT's.

Compounds 1J - 9J were synthesized according to Scheme 2.6 employing Method 5.2.2. Initial experiments followed methodology similar to those used to prepare organosilane and organophosphorus QUAT's (Section 2.2 and 2.3). This methodology resulted in very low yields or no product formation based on ${ }^{1} \mathrm{H}$ and ${ }^{13} \mathrm{C}$ NMR experiments. Hence $\mathbf{1 J}-\mathbf{9 J}$ were synthesized using method described by Porosa et al. ${ }^{67}$ to yield fluffy pale white to pale yellow coloured powders. The identity and purity of these compounds was confirmed using mass spectrometry and 
${ }^{1} \mathrm{H}$ and ${ }^{13} \mathrm{C}$ NMR spectroscopy. Synthesis of $\mathbf{6 J}$ was unsuccessful, similar to its counterpart in organosilane and organophosphorus QUAT's.

\subsubsection{Characterization of Benzophenone Functionalized Sulfonamide QUAT's}

The ${ }^{1} \mathrm{H}$ and ${ }^{13} \mathrm{C}$ NMR spectra of the benzophenone functionalized sulfonamide QUAT's 1H - 9H were collected and peak assignments were made using 2D HSQC and COSY NMR experiments. Analysis for $\mathbf{1 H}$ will serve as a template for compounds $\mathbf{2 H}-\mathbf{9 H}$.
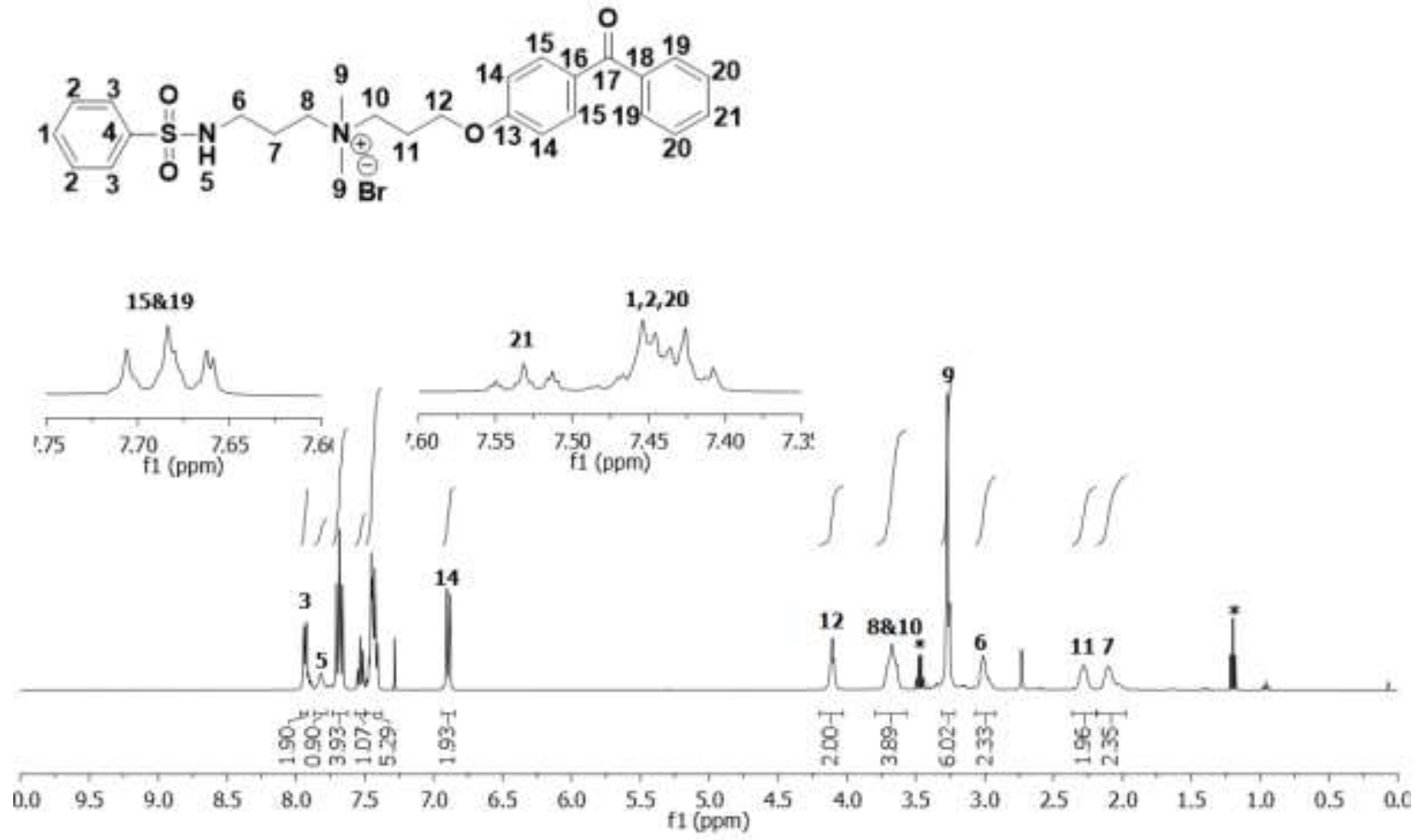

Figure 2.9: ${ }^{1} \mathrm{H} \mathrm{NMR}\left(\mathrm{CDCl}_{3}\right)$ of $\mathbf{1 J}$.

In the ${ }^{1} \mathrm{H}$ NMR of $\mathbf{1 J}$ (Figure 2.9), the singlet at $3.27 \mathrm{ppm}(\mathrm{H} 9)$ integrating for six hydrogen corresponds to the two methyl groups on the QUAT nitrogen, whereas the multiplet from 7.86 $7.77 \mathrm{ppm}$ (H5) integrating for one hydrogen of the amide of the sulfonyl group as seen in the ${ }^{1} \mathrm{H}$ NMR of 1D. The upfield triplet at $4.11 \mathrm{ppm}$ (H12) integrating for two hydrogen corresponds to the methylene hydrogens bound to oxygen of the benzophenone moiety, which also couples to the 
multiplet from $2.36-2.19 \mathrm{ppm}$ (H11) also integrating for two hydrogens corresponding to the hydrogens of the adjoining carbon. Based on 2D COSY NMR multiplet from $3.06-2.92$ ppm (H6) integrating for two corresponds to the methylene hydrogens coupling to the amide group proton (H5). The downfield multiplet at 2.19-1.97 ppm (H7) integrating for two hydrogens with coupling to the multiple of (H6). The multiplet at 3.79 - $3.56 \mathrm{ppm}$ (H8 \& H10) integrating for four hydrogens was assigned to hydrogens on methylene carbons bound to the central QUAT nitrogen with coupling to (H7) and (H11). For the aromatic region the peaks for H1 - H3 follow a similar trend to its precursor 1D. The triplet at $6.89 \mathrm{ppm}$ (H14) integrating for two hydrogen and corresponds to the hydrogen on the ortho carbons of the benzophenone group closer to the oxygen linkage. The peak assignments for H15, H19 and H20 were made using 2D COSY NMR experiment.
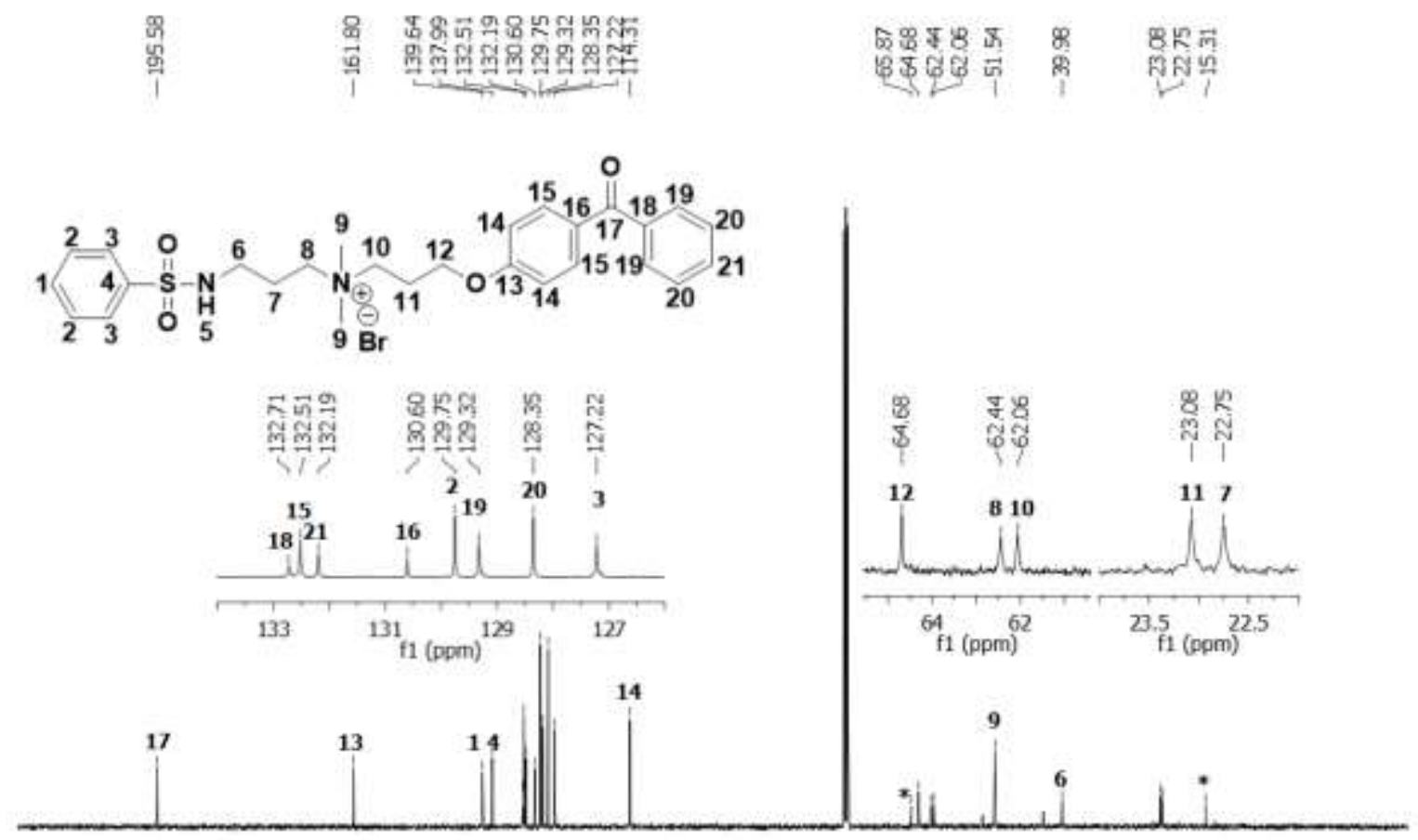

$\begin{array}{lllllllllllllllllllllllll}210 & 200 & 190 & 180 & 170 & 160 & 150 & 140 & 130 & 120 & 110 & 100 & 90 & 80 & 70 & 60 & 50 & 40 & 30 & 20 & 10 & 0 & -10\end{array}$

Figure 2.10: ${ }^{13} \mathrm{C} \mathrm{NMR}\left(\mathrm{CDCl}_{3}\right)$ of $\mathbf{1 J}$. 
The ${ }^{13} \mathrm{C}$ NMR assignments were made in conjunction with 2D HSQC NMR (Appendix Figure A126), where the peak at $195.58 \mathrm{ppm}(\mathrm{C} 17)$ corresponds to the carbonyl carbon of the benzophenone moiety and the peak at $161.87 \mathrm{ppm}(\mathrm{C} 13)$ corresponds to the para carbon bound to the oxygen atom. The peaks at $139.64(\mathrm{C} 1), 137.99(\mathrm{C} 4), 129.75(\mathrm{C} 2)$, and $127.22(\mathrm{C} 3)$ ppm were attributed to the aromatic carbons of the phenyl moiety bound to sulfonamide group based on the ${ }^{13} \mathrm{C}$ NMR of 1D. The aromatic peak assignments for the benzophenone moiety was assigned based on 2D HSQC NMR experiment. The peak at $64.68 \mathrm{ppm}(\mathrm{C} 12)$ corresponds to the propoxy carbon, whereas the peaks at $62.44(\mathrm{C} 8)$ and $62.06(\mathrm{C} 10)$ corresponds to the carbon directly bound to the QUAT. The peak at $39.98 \mathrm{ppm}$ (C6) corresponds to the carbon directly bound to the sulfonamide group. For compounds $\mathbf{2 J}-\mathbf{5 J}$ and $\mathbf{7 J}-\mathbf{9 J}$, the ${ }^{1} \mathrm{H}$ and ${ }^{13} \mathrm{C}$ NMR are differentiated from $\mathbf{1 J}$ based on the substitution of the aromatic ring (2D - 5D) and the different substituent on the sulfonyl group (7J-9J).

\subsection{Antimicrobial Activity}

\subsubsection{Contact Killing at Solid-Air Interface}

Organosilicon functionalized sulfonamide QUAT's $\mathbf{1 F}-\mathbf{3 F}$ and $\mathbf{5 F}$ were prepared using Method 5.2.3.1a and tested together for comparison purposes. After $3 \mathrm{hrs}$. of inoculation, the test samples showed complete reduction in viable bacteria versus the control (Figure 2.11). Similarly, the benzophenone QUAT's 1J and 5J were evaluated and resulted in completed reduction in viable bacteria (Figure 2.12). Regardless of the aromatic ring size and substitution it was evident from the test that sulfonamide based QUAT's resulted in complete reduction of bacteria after 3 hrs. in comparison to controls. 


\section{Efficacay of organosilane functionizaed sulfonamide QUAT's (1F - 5F)on cotton samples against Arthrobacter spp.}

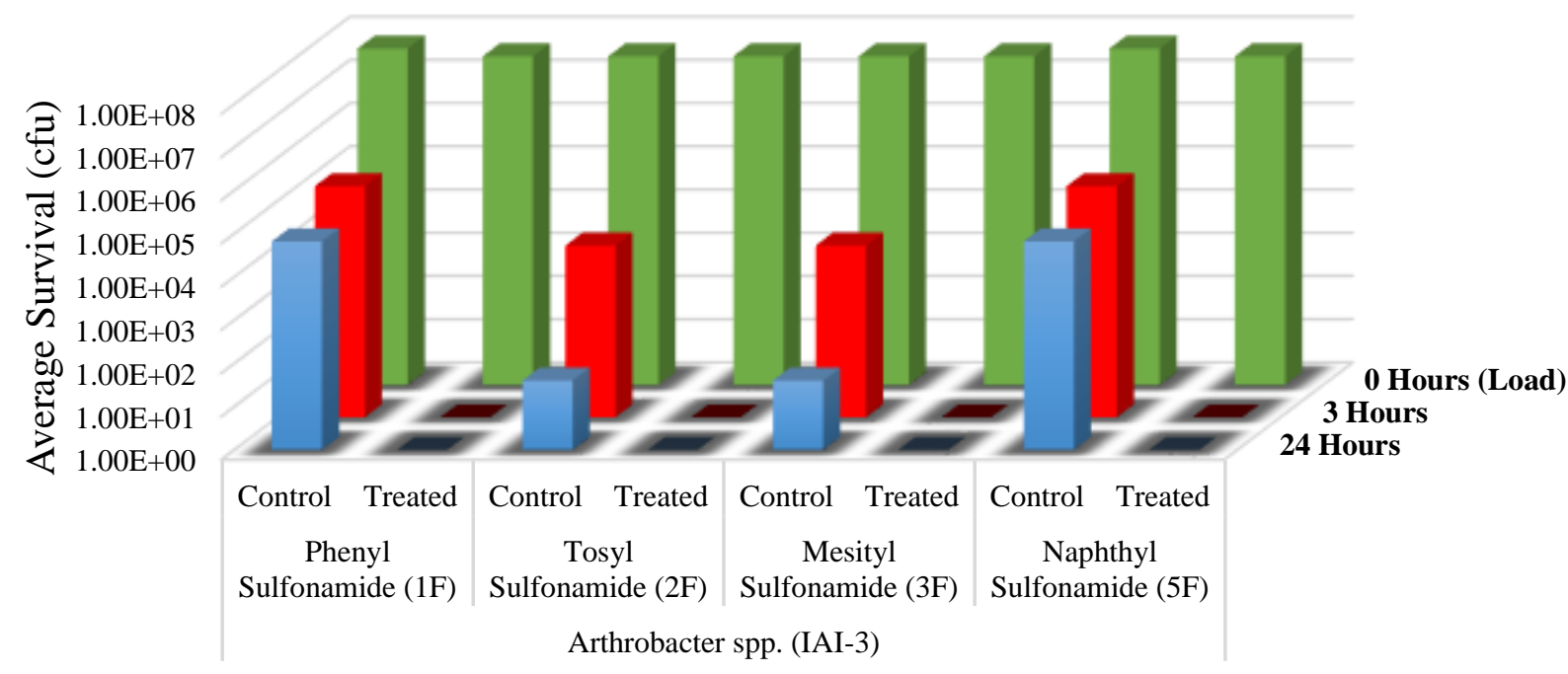

Figure 2.11: Antimicrobial efficacy of organosilane functionalized sulfonamide QUAT's 1F- 3F and $\mathbf{5 F}$ against Arthobacter spp.

\section{Efficacy of benzophenone functionalized sulfonamide QUAT on polyethylene samples against Arthrobacter spp.}
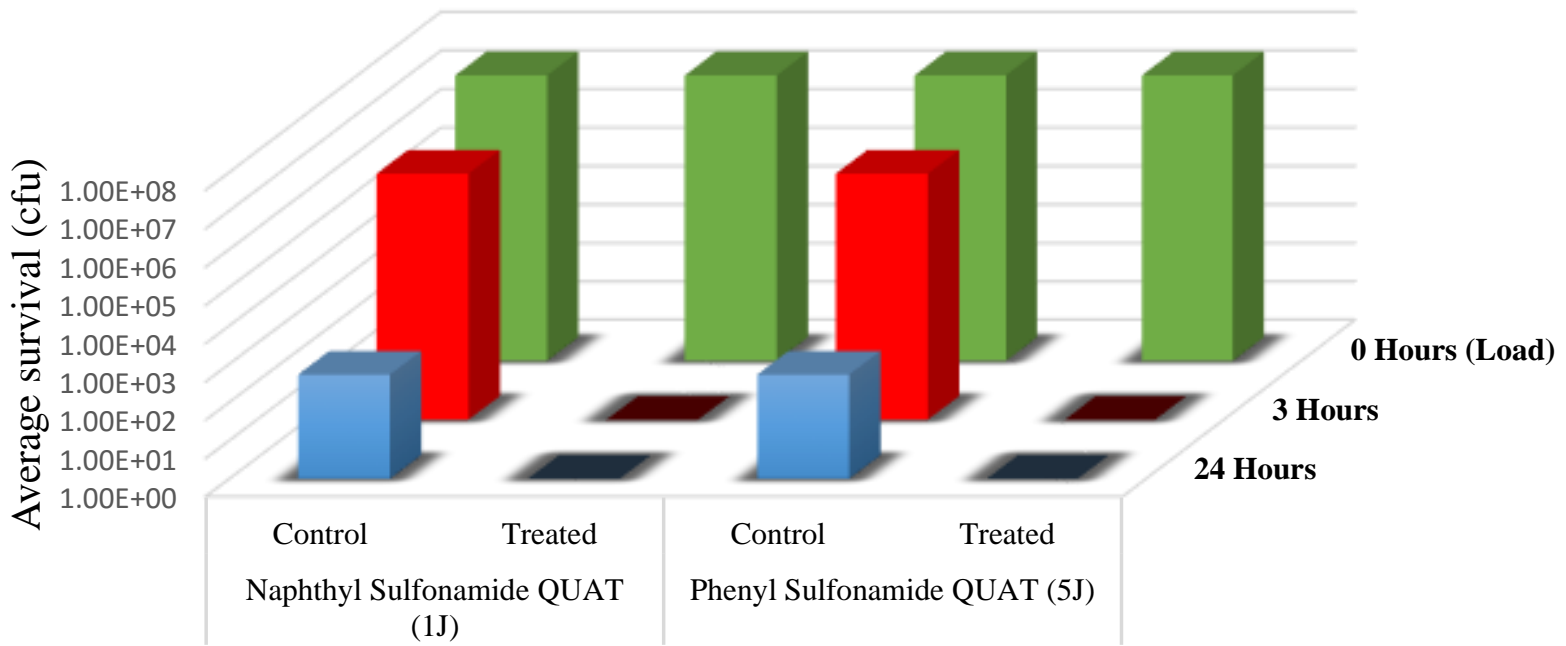

Figure 2.12: Antimicrobial efficacy of benzophenone functionalized sulfonamide QUAT's 5J and 1J against Arthrobacter spp. 
Antimicrobial activity of sulfonamide based benzophenone QUAT 3J and the silane QUAT 2F for comparison purposes were prepared on polystyrene and cotton using Method 5.2.3.1b and 5.2.3.1a respectively. The antimicrobial activity was tested by the enumeration method developed in the Wolfaardt lab against lab grown gram positive Arthrobacter spp. strain. The inoculated samples were sampled after 3 hrs. of drying and showed $100 \%$ reduction in viable bacteria versus the control (Figure 2.13).

\section{Efficacy of 3J and 2F against Arthrobactor spp. on different surfaces}

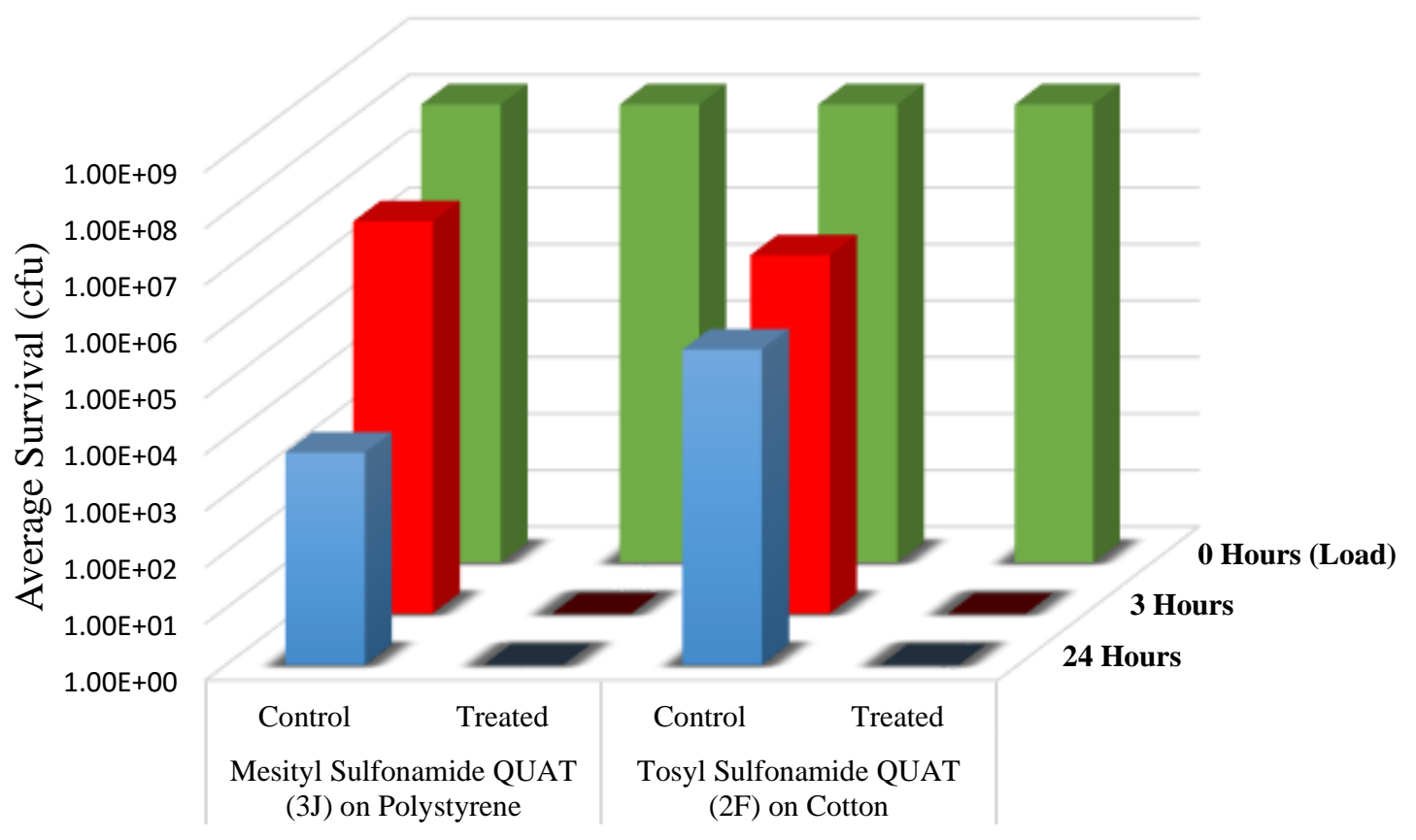

Figure 2.13: Antimicrobial efficacy of benzophenone functionalized 3J on polystyrene and organosilane functionalized $\mathbf{2 F}$ on cotton against Arthrobacter spp. 


\section{Efficacy of 3J on polyethylene samples against $E$. coli and $S$. aureus}

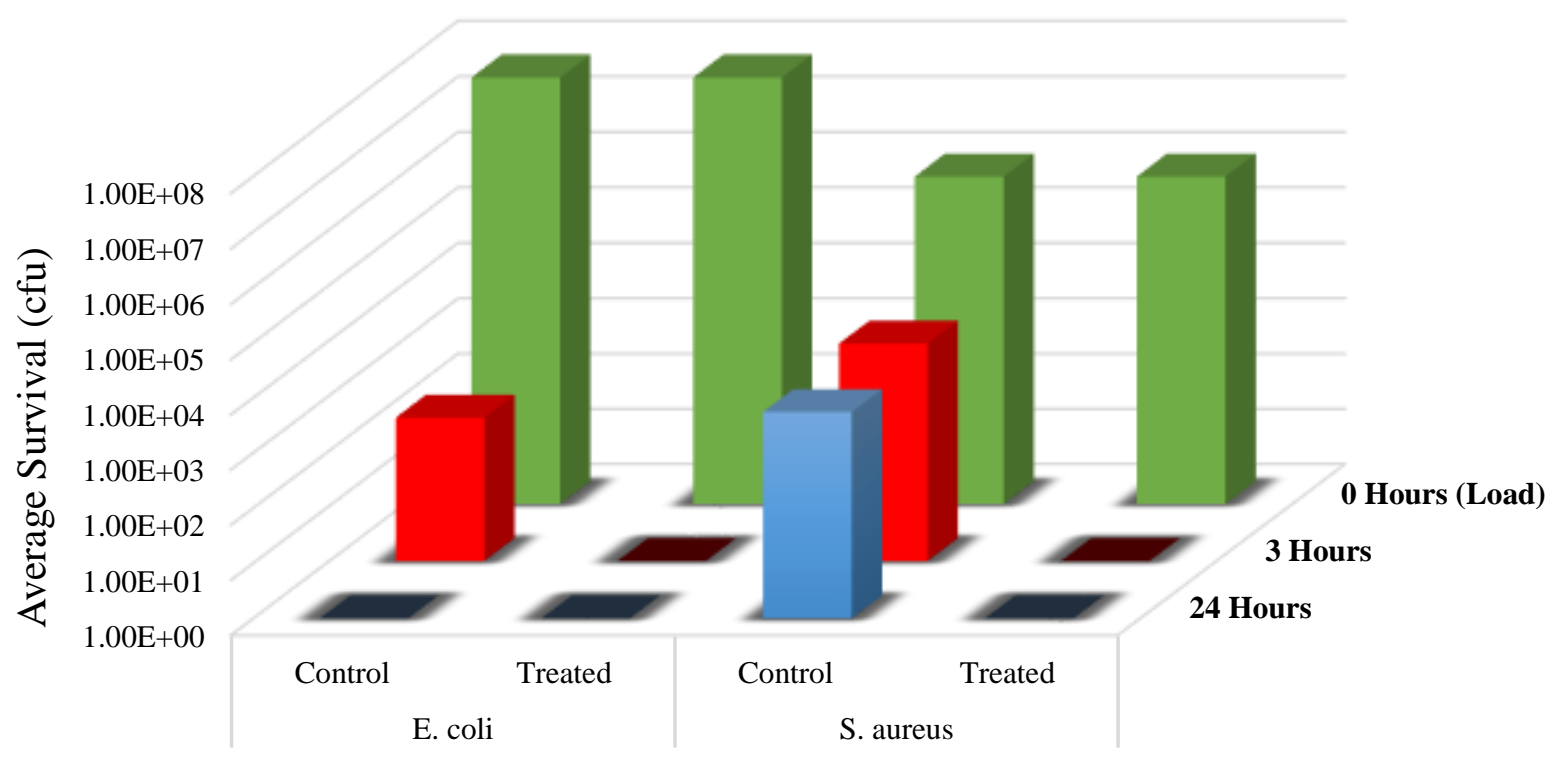

Figure 2.14: Antimicrobial efficacy of $\mathbf{3 J}$ on polyethylene against gram negative E. coli and gram positive S. aureus.

To test the range of antimicrobial activity benzophenone functionalized QUAT 3J was tested against gram positive $S$. aureus and gram negative $E$. coli using Method 5.2.3.2a. A test sample taken after $3 \mathrm{hrs}$. of drying showed complete reduction of both gram positive and negative bacteria (Figure 2.14).

\subsubsection{Solution Killing at Solid-Liquid Interface}

Benzophenone QUAT 3J was treated on the inside of polyethylene tubes using method 5.3.2.1a and tested according to Method 5.2.3.2b against planktonic cell and Arthrobacter spp. bacterial culture. After 48 hrs. enumeration of both bacterial strains showed complete reduction at the solid-liquid interface; hence a rechallenge was performed without reapplying the antimicrobial coating to ensure the efficacy (Figures 2.15 and 2.16). 


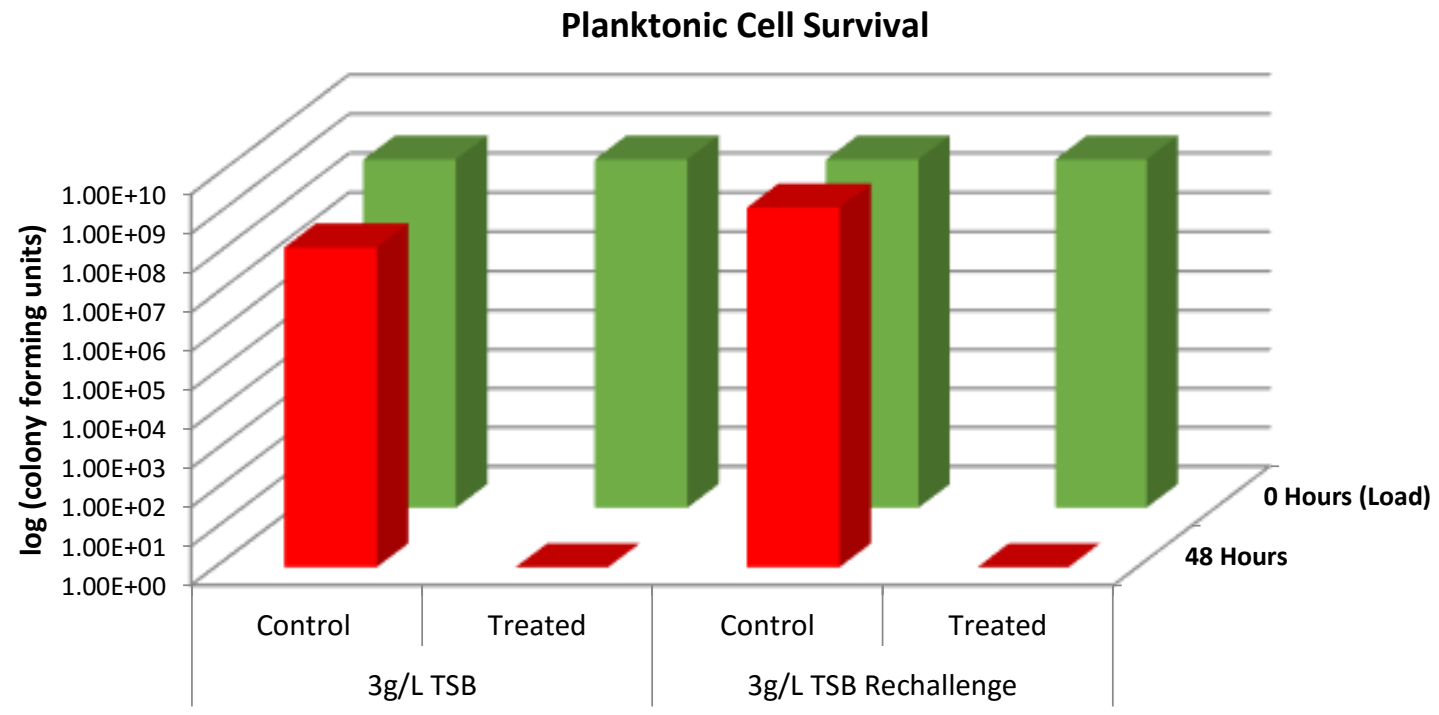

Figure 2.15: Efficacy of 3J against planktonic cells at solid-liquid interface under static condition.

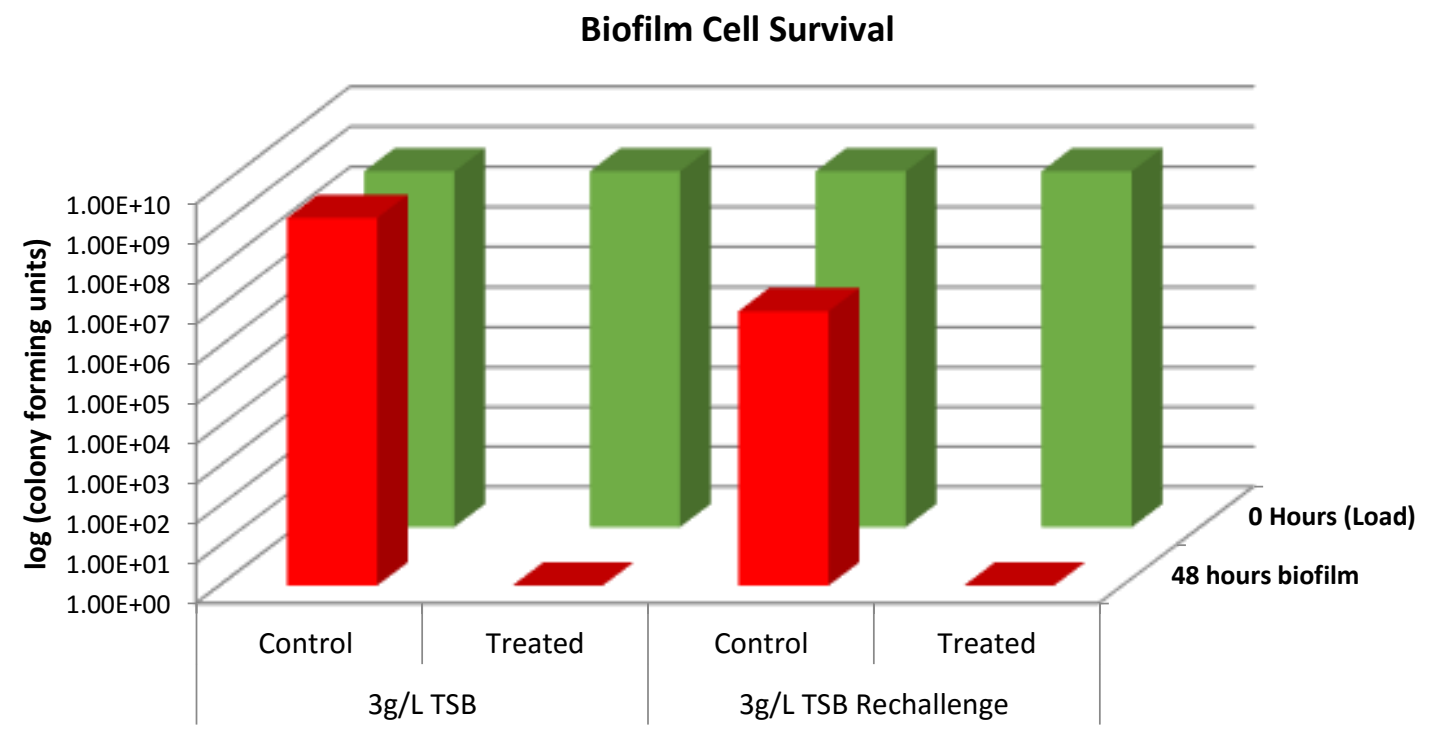

Figure 2.16: Efficacy of 3J against Arthrobacter spp. at solid-liquid interface. 


\subsection{CONCLUSIONS}

Sulfonamide QUAT's with specific anchoring functionalities such as organosilanes (textiles), phosphonates (metals), and benzophenone (plastics) were synthesized using the Menshutkin reaction and were used to prepare antimicrobial coatings for surfaces. The majority of the sulfonamides synthesized are commercially available but rather expensive, and there is no available synthetic and characterization data. Sulfonamides 1D - 9D were synthesized using a simplified approach and obtained in high yields and purity. All compounds were successfully characterized by NMR spectroscopy $\left({ }^{1} \mathrm{H},{ }^{13} \mathrm{C}\right.$, COSY, HSQC, ${ }^{29} \mathrm{Si}$, and $\left.{ }^{31} \mathrm{P}\right)$, and HRMS spectrometry.

The synthesized QUAT's were found to be more water soluble with only a minimum amount of $\mathrm{EtOH} / \mathrm{MeOH}$ reuired for complete solvation in comparison to available organosilanes. Organosilane functionalized QUAT's (1D - 3D and 5D) were physically attached to cotton textiles by immersion in $\mathrm{EtOH} / \mathrm{H}_{2} \mathrm{O}$ solutions containing the active QUAT, whereas the solutions of benzophenone functionalized QUAT's (1J - 3J, and 5J) were UV cured on to plastic substrates (PE, PS, PEEK, and PVC) and visualized using bromophenol blue test.

Antimicrobial activity was evaluated at solid-air interfaces (cotton and plastics) by growth enumeration in the dry state and at solid-liquid interface by determining MIC. Both the organosilane functionalized QUAT's (1D - 3D and 5D) and benzophenone functionalized QUAT's (1J - 3J, and $\mathbf{5 J})$ showed excellent antimicrobial efficacy and were able to reduce initial concentration of Arthrobacter spp, E. coli, and S. aureus by a factor of $10^{9} / 10^{7}$ after $3 \mathrm{hrs}$. Compound 3J subjected to solid-liquid interface antimicrobial testing showed reduction of $10^{9}$ (100\%) over 48 hrs. against planktonic cells and Arthrobacter spp. The same substrates were rechallenged without reapplication of coatings showed complete reduction over $48 \mathrm{hrs}$. 


\subsection{FUTURE WORK}

Sulfonyl chlorides are commercially available but rather expensive due to extensive synthesis and purification process. Alternatively, sulfonates and sulfonic acid analogs cost less and are readily available in large quantities. Sulfonamide precursors of these sulfonates and sulfonic acids can be synthesized using microwave irradiation as described in Scheme 4.1.

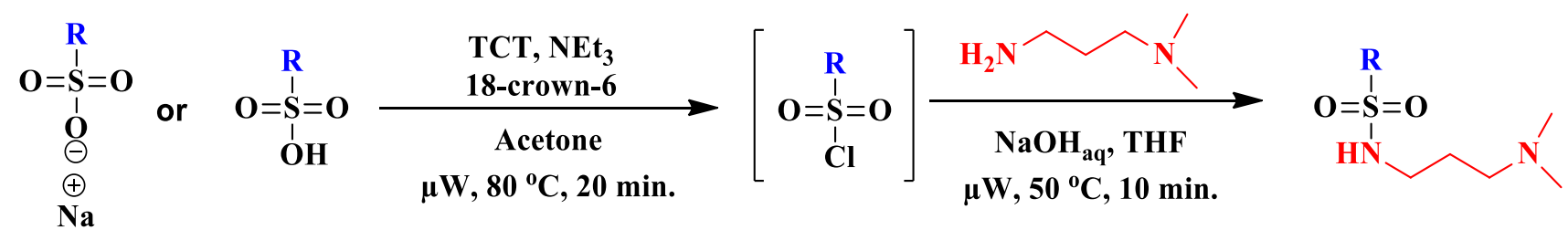

Scheme 4. 1: Microwave assisted sulfonamide synthesis using sulfonates or sulfonic acids. Luca et al. reported successful synthesis of various analogs of sulfonic acids/sulfonates using this process. ${ }^{82}$ In this work it was found that it was not necessary to isolate the sulfonyl chloride intermediate, since they were readily converted into the corresponding sulfonamides in presence of an amine. For future, this process could be used to synthesize sulfonamide precursors required for quaternization reactions. Some of the possible starting sulfonates and sulfonic acids are illustrated in Figure 4.1, which are believed to provide great antimicrobial activity.

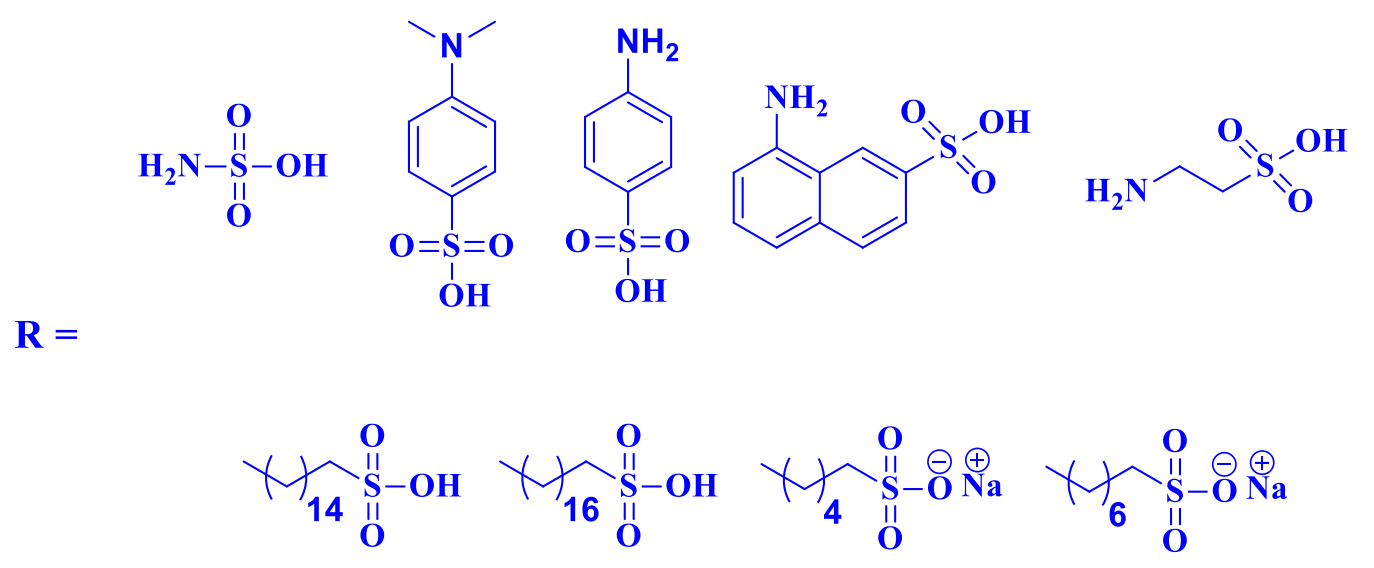

Figure 4.1: Possible sulfonates/sulfonic acids as starting material. 


\subsection{EXPERIMENTAL PROCEDURES}

\subsection{Materials and Instrumental Methods}

The reagents used consist of $p$-Toluenesulfonyl chloride, Benzenesulfonyl chloride, 2Mesitylenesulfonyl chloride, 2,4,6-Triisopropylbenzenesulfonyl chloride, Methanesulfonyl chloride, Ethanesulfonyl chloride, 1-Butanesulfonyl chloride, $N, N$-Dimethylsulfamoyl chloride, 1Napthalenesulfonyl chloride, Triethylamine, 3-(Dimethylamino)-1-propylamine, 4hydroxybenzophenone, and 1,3-dibromopropane were used as received from Sigma-Aldrich, Triisopropyl phosphite received from Alfa Aesar was distilled prior to use. Dichloromethane $\left(\mathrm{CH}_{2} \mathrm{Cl}_{2}\right)$ and Diethyl ether $\left(\mathrm{Et}_{2} \mathrm{O}\right)$ used was pre-dried using an $\mathrm{M}$ Braun solvent system under nitrogen environment. Acetonitrile $(99.8 \%, \rho=0.782 \mathrm{~g} / \mathrm{mL})$ from Sigma-Aldrich was distilled and stored under nitrogen environment prior to use.

Nuclear magnetic resonance (NMR) experiments were recorded on a $400 \mathrm{MHz}$ Bruker Avance II Spectrometer (Ryerson University) using deuterated chloroform $\left(\mathrm{CDCl}_{3}\right)$ as the solvent. ${ }^{1} \mathrm{H}$ and ${ }^{13} \mathrm{C}\left\{{ }^{1} \mathrm{H}\right\}$ NMR spectra were referenced to an internal TMS standard or the residual $\mathrm{CDCl}_{3}$ $\left(\delta_{\mathrm{H}}=7.26 \mathrm{ppm}\right.$ and $\left.\delta_{\mathrm{C}}=77.0 \mathrm{ppm}\right)$ solvent signal. The ${ }^{31} \mathrm{P}\left\{{ }^{1} \mathrm{H}\right\}$ spectra were referenced externally to $85 \%$ phosphoric acid $\left(\delta_{\mathrm{P}}=0.00 \mathrm{ppm}\right) \cdot{ }^{67} \mathrm{In}$ all cases ${ }^{1} \mathrm{H}$ and ${ }^{13} \mathrm{C}$ assignments were interpreted with the aid of the corresponding COSY and HSQC spectra respectively (see appendix). High resolution mass spectra (MS) were recorded by electron spray ionization in real time by ESI-TOF at the University of Toronto. 


\subsection{General Procedures}

Precursors 4-(3-bromopropyoxy)benzophenone ${ }^{67}$ and diisopropyl(3bromopropyl)phosphonate ${ }^{71}$ were synthesized according to published work and NMR spectra $\left({ }^{1} \mathrm{H}\right.$ and ${ }^{13} \mathrm{C}$ ) corresponded well with previously published NMR data.

\section{Method 5.2.1 Sulfonamide Synthesis}

\section{Method 5.2.1a Aromatic Sulfonamides General Synthesis}

To a flame dried, round bottom flask in an ice bath equipped with a stir bar containing an appropriate amount of anhydrous DCM an adequate amount of respective sulfonyl chloride was added followed by an equimolar amount of $\mathrm{Et}_{3} \mathrm{~N}$, and dropwise addition of a stoichiometric quantity of 3-(dimethylamino)propylamine. After $30 \mathrm{~min}$. the reaction mixture was removed from the ice bath and allowed to stir at room temperature for the indicated time. The reaction was then transferred to a separatory funnel and extracted with an appropriate amount of distilled water. Volatiles and/or solvent were removed from the organic phase using a rotary evaporator followed by drying under high vacuum.

\section{Method 5.2.1b Aliphatic Sulfonamides}

To a flame dried, round bottom flask in an ice bath equipped with a stir bar containing appropriate amount of anhydrous DCM a stoichiometric amount of 3(dimethylamino)propylamine was added followed by the dropwise addition of the respective sulfonyl chlorides. The reaction mixture was removed from the ice bath and allowed to stir for the indicated time at room temperature. Upon completion, the reaction solvent was evaporated using a rotary evaporator. The resultant residue was then dissolved in an appropriate amount of potassium carbonate solution $(0.05 \mathrm{M})$ and extracted using appropriate amount of DCM. Volatiles 
and/or solvent were removed from the organic phase using a rotary evaporator followed by drying under high vacuum.

\section{Method 5.2.2 General Synthesis for Sealed Tube Reactions}

In a $20 \mathrm{~mL}$ scintillation / microwave vial the appropriate reagents were added along with a magnetic stir bar and sealed with a screw cap. The reaction mixture was heated using an oil bath at $110^{\circ} \mathrm{C}$ for the indicated time. The crude material was purified by addition of $\mathrm{Et}_{2} \mathrm{O}$ directly into the reaction mixture followed by decanting $\left(\mathrm{Et}_{2} \mathrm{O}\right.$ wash $\left.x 3\right)$ and dried under high vacuum.

\section{Method 5.2.3 Antimicrobial Testing and Detection}

Antimicrobial activity tests of the synthesized QUAT's was carried out by Alexander Caschera in the Wolfaardt lab at Ryerson University. The testing was conducted at solid - air interface as well as solid - liquid interface to determine sulfonamide based QUAT's efficacy in both environments. The presence of the sulfonamide QUAT's was visualized with the aid of bromophenol blue dye (Section 1.8).

\section{Method 5.2.3.1 Surface treatment}

Method 5.3.2.1a Textiles

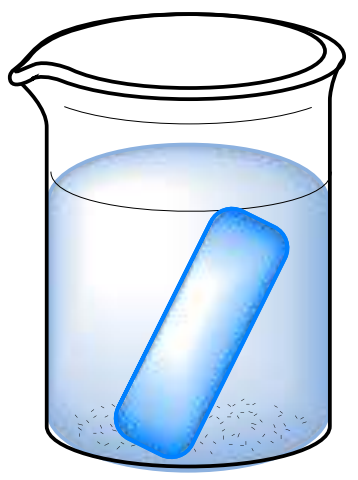

(1) Dip Coat (1-10 min.)

(2) Curing/Drying (2-24 hrs.)

(3) Rinsing

Antimicrobial Surface

1\% in $\mathrm{MeOH}: \mathrm{H}_{2} \mathrm{O}$

Figure 5.1: Coating procedure of QUAT's onto textiles (cotton) sample. ${ }^{67}$ 
Cotton textile samples were dipcoated with 1\% (w/v) of sulfonamide organosilane QUAT's in luke warm methanol:water mixture (30:70 ratio) with mild agitation. After application, the treated samples were allowed to dry for $2-24 \mathrm{hrs}$.; followed by water rinsing. The quality/presence of QUAT's coating was visualized/confirmed with bromophenol blue dye.

\section{Method 5.3.2.1b Plastics}

$1 \%(\mathrm{w} / \mathrm{v})$ solution of sulfonamide QUAT's with benzophenone functionality were prepared in EtOH:Water solution (10:90 - 40:60 ratio). Test samples consisted of $25 \mathrm{~mm}( \pm 5 \mathrm{~mm}) \times 25$ $\mathrm{mm}( \pm 5 \mathrm{~mm}) \times 1 \mathrm{~mm}$ coupons of polystyrene (PS), polyvinyl chloride (PVC), and polyether ether ketone (PEEK). The coupons were coated using an ESS AD - LG electrospray apparatus set to $150 \mathrm{kPa}$. After application, coupons were air dried followed by UV curing using EFOS N2001-A1 Novacure Ultraviolet spot curing light source set at $5000 \mathrm{~mW}$ intensity for $1 \mathrm{~min}$. (repeated 2 times).

\section{Method 5.2.3.2 Antimicrobial Testing Interfaces}

\section{Method 5.2.3.2a Solid-Air Interface}

Antimicrobial testing at solid - air interface was conducted using modified ISO 22196 large-droplet $(50 \mu \mathrm{L})$ inoculation method developed by Evan Ronan in Dr. Wolfaardt's lab at Ryerson University. The method allows for the droplet of inoculum to dry directly on to the coated surface. Once dried, the surface is washed with saline to remove unbound cells followed by serial dilutions and enumeration (Figure 5.2). ${ }^{3,83}$ 


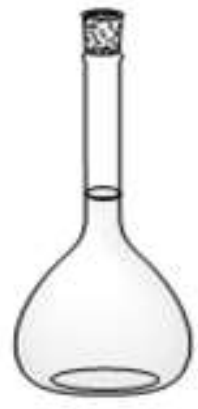

i

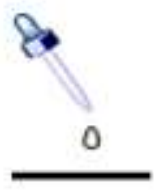

ii

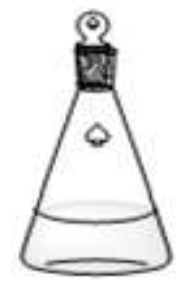

iii

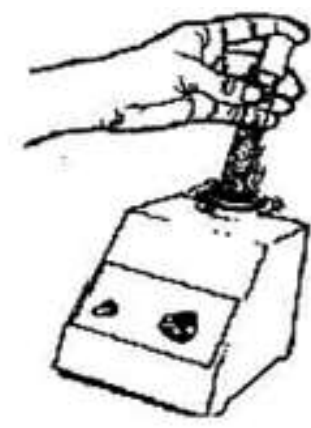

iv

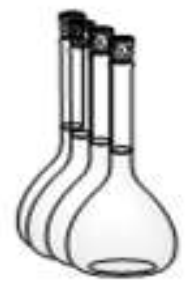

v

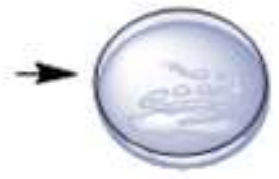

vi

Figure 5.2: Antimicrobial testing method for Solid-Air interface developed by Evan Roan in the Wolfaardt Lab. (i) $1 \times 10^{8} \mathrm{CFU} / \mathrm{mL}$ (inoculum), (ii) $1 \mathrm{~mL}$ inoculum added to $1 \mathrm{~cm} \times 1 \mathrm{~cm}$ solid sample and left to dry for appropriate time $2-24 \mathrm{hrs}$, (iii) sample is added to $0.9 \%$ saline solution, (iv) vortex saline solution to remove attached cells, (v) serial dilutions and agar plating, (vi) compare to controls and calculate percent of log 10 reduction. (adapted from ref. $\left.{ }^{3}\right)^{83}$

\section{Method 5.2.3.2b Solid-Liquid Interface}

The pretreated tubes were filled with growth media $(3 \mathrm{~g} / \mathrm{L}$ TSB) containing $300 \mu \mathrm{L}$

inoculation of Arthobacter spp. bacterial culture and were compared against planktonic cell

culture. After $48 \mathrm{hrs}$. of incubation the tubes were emptied and gently washed with saline

solution to remove unbound planktonic or Arthobacter spp. Cells. $1 \mathrm{~mL}$ of saline was added to

tubes and vortexed for $1 \mathrm{~min}$. (Figure 5.2, iv) and transferred to the collection liquid (Figure 5.2,

iii) followed by serial dilutions and enumeration. ${ }^{83}$ 


\subsection{Synthesis of Aromatic Sulfonamides}

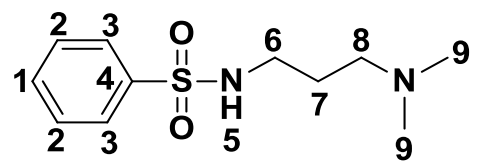

$N$-(3-(dimethylamino)propyl)benzenesulfonamide (1D): ${ }^{81}$

This compound was synthesized according to Method 5.1.1a with benzenesulfonyl chloride (1.4 $\mathrm{mL}, \quad 11.32 \mathrm{mmol})$, triethylamine $(2.4 \mathrm{~mL}, \quad 16.99 \mathrm{mmol}, \quad 1.5 \quad$ eqv. $)$, and 3(dimethylamino)propylamine $(2.1 \mathrm{~mL}, 16.99 \mathrm{mmol}, 1.5 \mathrm{eqv}$.$) in DCM (30 mL) for 4$ hours yielding a clear solution. The solution was then washed using distilled water $(40 \mathrm{~mL})$, and the organic layer was evaporated using a rotary evaporater to yield a green yellow coloured oil. The product was further dried under reduced pressure using a schlenk line yielding a pale yellow coloured waxy solid. Yield $98 \%(2.69 \mathrm{~g}) .{ }^{1} \mathrm{H} \mathrm{NMR}\left(\mathrm{CDCl}_{3}, 400 \mathrm{MHz}, \delta\right): 7.68\left(\mathrm{~d}, 2 \mathrm{H},{ }^{3} J_{\mathrm{H} 3-\mathrm{H} 2}=\right.$ $8.3 \mathrm{~Hz}, \mathrm{H} 3), 7.35(\mathrm{~m}, 3 \mathrm{H}, \mathrm{H} 1$ and $\mathrm{H} 2), 2.86\left(\mathrm{t}, 2 \mathrm{H},{ }^{3} J_{\mathrm{H} 6-\mathrm{H} 7}=5.8 \mathrm{~Hz}, \mathrm{H} 6\right), 2.11\left(\mathrm{t}, 2 \mathrm{H},{ }^{3} J_{\mathrm{H} 8-\mathrm{H} 7}=5.9\right.$ $\mathrm{Hz}, \mathrm{H} 8), 1.98$ (s, 6H, H9), $1.41\left(\mathrm{tt}, 2 \mathrm{H},{ }^{3} J_{\mathrm{H} 7-\mathrm{H} 6}=9.0 \mathrm{~Hz},{ }^{3} J_{\mathrm{H} 7-\mathrm{H} 8}=3.1 \mathrm{~Hz}, \mathrm{H} 7\right) \mathrm{ppm} ;{ }^{13} \mathrm{C}\left\{{ }^{1} \mathrm{H}\right\} \mathrm{NMR}$ $\left(\mathrm{CDCl}_{3}, 100 \mathrm{MHz}, \delta\right): 140.20$ (C4), 132.33 (C1), 128.99 (C2), 126.96 (C3), 59.13 (C8), 45.28 (C9), 44.05 (C6), 25.12 (C7) ppm. HRMS-ESI-TOF (m/z): $\left[\mathrm{M}^{+}+\mathrm{H}^{+}\right]$calculated for $\mathrm{C}_{11} \mathrm{H}_{19} \mathrm{~N}_{2} \mathrm{O}_{2} \mathrm{~S}_{1}$, 243.1162, found, 243.1170 .

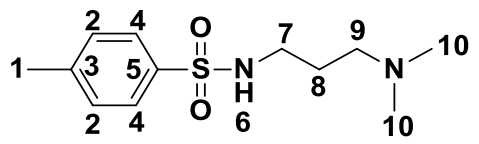

N-(3-(dimethylamino)propyl)-4-methylbenzenesulfonamide (2D): ${ }^{79,84}$

This compound was synthesized according to Method 5.1.1a with $p$-toluenesulfonyl chloride (10.505 g, $55.10 \mathrm{mmol})$, triethylamine (11.5 mL, $82.65 \mathrm{mmol}, 1.5$ eqv.), and 3(dimethylamino)propylamine (10.4 mL, $82.65 \mathrm{mmol}, 1.5 \mathrm{eqv}$.$) in DCM (100 mL) for 4$ hours 
yielding a milky white solution. The solution was then washed using distilled water $(100 \mathrm{~mL})$, and the volatile organic layer removed using a rotary evaporater to yield a pale yellow coloured oil. The product was further dried under reduced pressure using schlenk line yielding a pale white coloured waxy solid. Yield $98 \%(13.85 \mathrm{~g}) .{ }^{1} \mathbf{H} \mathbf{~ N M R}\left(\mathrm{CDCl}_{3}, 400 \mathrm{MHz}, \delta\right): 7.73\left(\mathrm{~d}, 2 \mathrm{H},{ }^{3} \mathrm{~J}_{\mathrm{H} 4-\mathrm{H} 2}=\right.$ $8.3 \mathrm{~Hz}, \mathrm{H} 4), 7.29\left(\mathrm{~d}, 2 \mathrm{H},{ }^{3} \mathrm{~J}_{\mathrm{H} 2-\mathrm{H} 4}=7.9 \mathrm{~Hz}, \mathrm{H} 2\right), 3.03\left(\mathrm{t}, 2 \mathrm{H},{ }^{3} J_{\mathrm{H} 7-\mathrm{H} 8}=5.8 \mathrm{~Hz}, \mathrm{H} 7\right), 2.42(\mathrm{~s}, 3 \mathrm{H}, \mathrm{H} 1)$, $2.29\left(\mathrm{t}, 2 \mathrm{H},{ }^{3} J_{\mathrm{H} 9-\mathrm{H} 8}=5.8 \mathrm{~Hz}, \mathrm{H} 9\right), 2.16(\mathrm{~s}, 6 \mathrm{H}, \mathrm{H} 10), 1.58\left(\mathrm{tt}, 2 \mathrm{H},{ }^{3} J_{\mathrm{H} 8-\mathrm{H} 7}=9.2 \mathrm{~Hz},{ }^{3} J_{\mathrm{H} 8-\mathrm{H} 9}=2.5\right.$ $\mathrm{Hz}, \mathrm{H} 8) \mathrm{ppm} ;{ }^{13} \mathbf{C}\left\{{ }^{1} \mathbf{H}\right\} \mathbf{N M R}\left(\mathrm{CDCl}_{3}, 100 \mathrm{MHz}, \delta\right): 142.83$ (C5), 137.11 (C3), 129.44 (C2), 126.88 (C4), 58.76 (C9), 45.15 (C10), 43.65 (C7), 25.23 (C8), 21.32 (C1) ppm. HRMS-ESI-TOF $(\mathrm{m} / z):\left[\mathrm{M}^{+}+\mathrm{H}^{+}\right]$calculated for $\mathrm{C}_{12} \mathrm{H}_{21} \mathrm{~N}_{2} \mathrm{O}_{2} \mathrm{~S}_{1}, 257.1318$, found, 257.1322 .

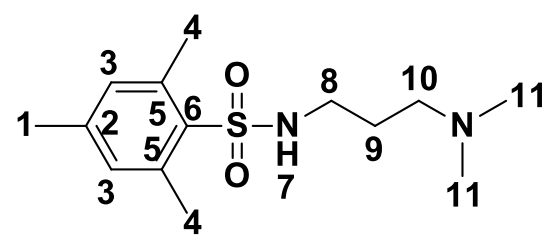

\section{$N$-(3-(dimethylamino)propyl)-2,4,6-trimethylbenzenesulfonamide (3D):}

This compound was synthesized according to Method 5.1.1a with 2,4,6-trimethylbenzene-1sulfonyl chloride ( $2 \mathrm{~g}, 9.14 \mathrm{mmol})$, triethylamine (1.9 mL, $13.72 \mathrm{mmol}, 1.5 \mathrm{eqv}$.$) , and 3$ (dimethylamino)propylamine (1.7 mL, $13.72 \mathrm{mmol}, 1.5$ eqv.) in DCM $(50 \mathrm{~mL})$ for 3 hours yielding a clear solution. The solution was then washed using distilled water $(75 \mathrm{~mL})$, and the volatile organic layer evaporated using a rotary evaporater to yield a clear oil. The product was dried under reduced pressure using a schlenk line yielding a pale white coloured waxy solid. Yield $98.5 \%$ (2.56 g). ${ }^{1} \mathbf{H}$ NMR $\left(\mathrm{CDCl}_{3}, 400 \mathrm{MHz}, \delta\right): 7.04$ (br s, 1H, H7), 6.93 (s, 2H, H3), 2.94 (t, 2H, $\left.{ }^{3} J_{\mathrm{H} 8-\mathrm{H} 9}=5.7 \mathrm{~Hz}, \mathrm{H} 8\right), 2.61(\mathrm{~s}, 6 \mathrm{H}, \mathrm{H} 4), 2.32\left(\mathrm{t}, 2 \mathrm{H},{ }^{3} J_{\mathrm{H} 10-\mathrm{H} 9}=5.6 \mathrm{~Hz}, \mathrm{H} 10\right), 2.27$ (s, 3H, H1), 2.18 $(\mathrm{s}, 6 \mathrm{H}, \mathrm{H} 11), 1.62\left(\mathrm{tt}, 2 \mathrm{H},{ }^{3} J_{\mathrm{H} 9-\mathrm{H} 8}=9.5 \mathrm{~Hz},{ }^{3} J_{\mathrm{H} 9-\mathrm{H} 10}=2.2 \mathrm{~Hz}, \mathrm{H} 9\right) \mathrm{ppm} ;{ }^{13} \mathbf{C}\left\{{ }^{1} \mathbf{H}\right\} \mathbf{~ N M R}\left(\mathrm{CDCl}_{3}\right.$, $100 \mathrm{MHz}, \delta): 141.74$ (C6), 139.07 (C2), 133.80 (C5), 131.87 (C3), 59.66 (C10), 45.48 (C11), 
43.72 (C8), 24.99 (C9), 22.88 (C4), 20.95 (C1) ppm. HRMS-ESI-TOF ( $/ 2 / z):\left[\mathrm{M}^{+}+\mathrm{H}^{+}\right]$calculated for $\mathrm{C}_{14} \mathrm{H}_{25} \mathrm{~N}_{2} \mathrm{O}_{2} \mathrm{~S}_{1}, 285.1631$, found, 285.1643.

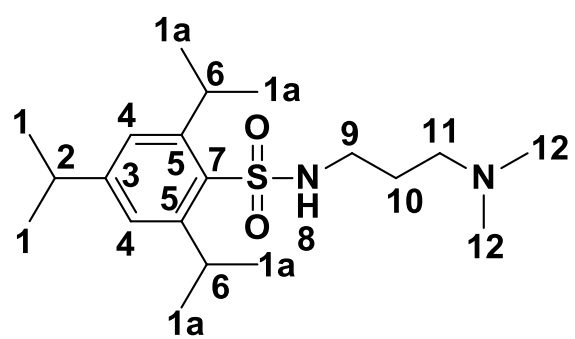

\section{$N$-(3-(dimethylamino)propyl)-2,4,6-triisopropylbenzenesulfonamide (4D):}

This compound was synthesized according to Method 5.1.1a with 2,4,6-triisopropylbenzene-1sulfonyl chloride (2 g, $6.60 \mathrm{mmol})$, triethylamine (1.4 mL, $9.91 \mathrm{mmol}, 1.5 \mathrm{eqv}$.$) , and 3$ (dimethylamino)propylamine (1.2 mL, $9.91 \mathrm{mmol}, 1.5 \mathrm{eqv}$.) in DCM $(50 \mathrm{~mL})$ for 3 hours yielding a clear solution. The solution was then washed using distilled water $(75 \mathrm{~mL})$, and the volatile organic layer removed using a rotary evaporater to yield a faint green coloured oil. The product was further dried under reduced pressure using schlenk line yielding a pale white coloured waxy solid. Yield $97 \%$ (2.36 g). ${ }^{1} \mathbf{H}$ NMR $\left(\mathrm{CDCl}_{3}, 400 \mathrm{MHz}, \delta\right.$ ): 7.15 (s, 2H, H4), 4.17 (sep., 2H, ${ }^{3} \mathrm{~J}_{\mathrm{H} 6-}$ $\mathrm{H} 1 \mathrm{a}=6.8 \mathrm{~Hz}, \mathrm{H} 6), 3.08$ (t, 2H, $\left.J_{\mathrm{H} 9-\mathrm{H} 10}=5.9 \mathrm{~Hz}, \mathrm{H} 9\right), 2.89$ (sep., $\left.1 \mathrm{H},{ }^{3} J_{\mathrm{H} 2-\mathrm{H} 1}=7.0 \mathrm{~Hz}, \mathrm{H} 2\right), 2.50(\mathrm{br}$ s, 2H, H11), 2.30 (br s, 6H, H12), 1.75 (br s, 2H, H10), 1.26 (br m, 18H, H1 and H1a) ppm; ${ }^{13} \mathrm{C}$ \{'H\} NMR ( $\left.\mathrm{CDCl}_{3}, 100 \mathrm{MHz}, \delta\right): 152.48$ (C7), 150.45 (C5), 132.57 (C3), 123.79 (C4), 59.03 (C11), 45.28 (C12), 42.93 (C9), 34.25 (C2), 29.74 (C6), 25.61 (C10), 25.10 (C1a), 23.73 (C1) ppm. HRMS-ESI-TOF $(\mathrm{m} / z)$ : $\left[\mathrm{M}^{+}+\mathrm{H}^{+}\right]$calculated for $\mathrm{C}_{20} \mathrm{H}_{37} \mathrm{~N}_{2} \mathrm{O}_{2} \mathrm{~S}_{1}, 369.2570$, found, 369.2570 . 


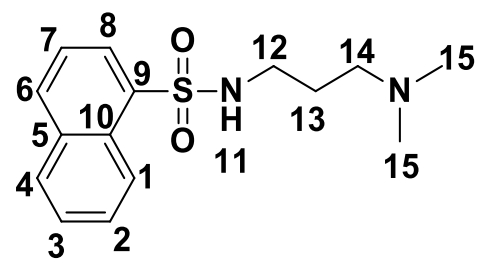

\section{$N$-(3-(dimethylamino)propyl)naphthalene-1-sulfonamide (5D):}

This compound was synthesized according to Method 5.1.1a with naphthalene-1-sulfonyl chloride (4 g, $18.04 \mathrm{mmol}$ ), triethylamine $(3.8 \mathrm{~mL}, 27.06 \mathrm{mmol}, \quad 1.5$ eqv.), and 3 (dimethylamino)propylamine $(3.4 \mathrm{~mL}, 27.06 \mathrm{mmol}, 1.5$ eqv.) in DCM $(50 \mathrm{~mL})$ for 3 hours yielding a clear solution. The solution was then washed using distilled water $(50 \mathrm{~mL})$, and the organic layer was evaporated using a rotary evaporater to yield a greenish yellow coloured oil. The product was further dried under reduced pressure using a schlenk line yielding a pale white coloured waxy solid product. Yield $99.7 \%(5.27 \mathrm{~g}) .{ }^{1} \mathbf{H} \mathbf{~ N M R}\left(\mathrm{CDCl}_{3}, 400 \mathrm{MHz}, \delta\right): 8.67(\mathrm{~d}, 1 \mathrm{H}$, $\left.{ }^{3} J_{\mathrm{H} 1-\mathrm{H} 2}=8.5 \mathrm{~Hz}, \mathrm{H} 1\right), 8.25\left(\mathrm{~d}, 1 \mathrm{H},{ }^{3} J_{\mathrm{H} 8-\mathrm{H} 7}=6.2 \mathrm{~Hz}, \mathrm{H} 8\right), 8.05\left(\mathrm{~d}, 1 \mathrm{H},{ }^{3} J_{\mathrm{H} 6-\mathrm{H} 7}=8.2 \mathrm{~Hz}, \mathrm{H} 6\right), 7.95$ $\left(\mathrm{d}, 1 \mathrm{H},{ }^{3} \mathrm{~J}_{\mathrm{H} 4-\mathrm{H} 3}=7.8 \mathrm{~Hz}, \mathrm{H} 4\right), 7.65(\mathrm{~m}, 1 \mathrm{H}, \mathrm{H} 2), 7.59(\mathrm{~m}, 1 \mathrm{H}, \mathrm{H} 3), 7.52(\mathrm{~m}, 1 \mathrm{H}, \mathrm{H} 7), 2.95(\mathrm{t}, 2 \mathrm{H}$, $\left.{ }^{3} J_{\mathrm{H} 12-\mathrm{H} 13}=5.6 \mathrm{~Hz}, \mathrm{H} 12\right), 2.21\left(\mathrm{t}, 2 \mathrm{H},{ }^{3} J_{\mathrm{H} 14-\mathrm{H} 13}=5.6 \mathrm{~Hz}, \mathrm{H} 14\right), 2.12(\mathrm{~s}, 6 \mathrm{H}, \mathrm{H} 15), 1.55(\mathrm{~m}, 2 \mathrm{H}$, H13) ppm; ${ }^{13} \mathbf{C}\left\{{ }^{1} \mathbf{H}\right\}$ NMR $\left(\mathrm{CDCl}_{3}, 100 \mathrm{MHz}, \delta\right): 134.85$ (C9), 134.45 (C5), 133.96 (C4), 129.79 (C6), 129.16 (C2), 128.42 (C10), 128.21 (C3), 126.82 (C8), 124.76 (C7), 124.28 (C1), 59.80 (C14), 45.56 (C15), 44.77 (C12), 24.68 (C13) ppm. HRMS-ESI-TOF ( $/ 2 / z):\left[\mathrm{M}^{+}+\mathrm{H}^{+}\right]$calculated for $\mathrm{C}_{15} \mathrm{H}_{21} \mathrm{~N}_{2} \mathrm{O}_{2} \mathrm{~S}_{1}, 293.1318$, found, 293.1319. 


\subsection{Synthesis of Aliphatic Sulfonamides}

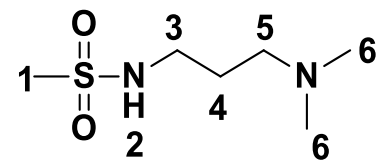

\section{$N$-(3-(dimethylamino)propyl)methanesulfonamide (6D): ${ }^{85}$}

This compound was synthesized according to Method 5.1.1b with methanesulfonyl chloride (1.4 $\mathrm{mL}, 17.46 \mathrm{mmol})$ and 3-(dimethylamino)propylamine $(2.2 \mathrm{~mL}, 17.46 \mathrm{mmol}, 1.5 \mathrm{eq}$.$) in DCM (50$ $\mathrm{mL})$ for 4 hours. The solution was washed with $\mathrm{K}_{2} \mathrm{CO}_{3}(0.05 \mathrm{M}, 40 \mathrm{~mL})$, and the volatile organic layer was removed using a rotary evaporator yielding in clear oil. Yield: $65 \%$ (2.05 g). ${ }^{\mathbf{1}} \mathbf{H}$ NMR $\left(\mathrm{CDCl}_{3}, 400 \mathrm{MHz}, \delta\right): 3.23\left(\mathrm{t}, 2 \mathrm{H},{ }^{3} J_{\mathrm{H} 3-\mathrm{H} 4}=5.8 \mathrm{~Hz}, \mathrm{H} 3\right), 2.91(\mathrm{~s}, 3 \mathrm{H}, \mathrm{H} 1), 2.43\left(\mathrm{t}, 2 \mathrm{H},{ }^{3} J_{\mathrm{H} 5-\mathrm{H} 4}=5.8\right.$ Hz, H5), 2.22 (s, 6H, H6), $1.71(\mathrm{~m}, 2 \mathrm{H}, \mathrm{H} 4) \mathrm{ppm} ;{ }^{13} \mathbf{C}\left\{{ }^{1} \mathbf{H}\right\} \mathbf{N M R}\left(\mathrm{CDCl}_{3}, 100 \mathrm{MHz}, \delta\right): 59.26$ (C5), 45.37 (C6), 44.08 (C3), 39.70 (C1), 25.72 (C4) ppm. HRMS-ESI-TOF (m/z): $\left[\mathrm{M}^{+}+\mathrm{H}^{+}\right]$ calculated for $\mathrm{C}_{6} \mathrm{H}_{17} \mathrm{~N}_{2} \mathrm{O}_{2} \mathrm{~S}_{1}, 181.1005$, found, 181.1005 .

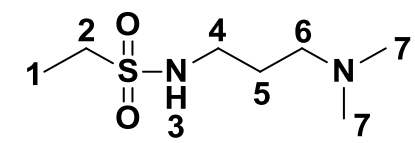

\section{$N$-(3-(dimethylamino)propyl)ethanesulfonamide (7D): ${ }^{86}$}

This compound was synthesized according to Method 5.1.1b with ethanesulfonyl chloride $(0.7$ $\mathrm{mL}, 7.78 \mathrm{mmol})$ and 3-(dimethylamino)propylamine (1.5 mL, $11.67 \mathrm{mmol}, 1.5 \mathrm{eq}$.$) in DCM (50$ $\mathrm{mL})$ for 4 hours. The solution was washed with $\mathrm{K}_{2} \mathrm{CO}_{3}(0.05 \mathrm{M}, 50 \mathrm{~mL})$, and the volatile organic layer was removed using a rotary evaporator yielding in clear oil. Yield: $61 \%$ (0.92 g). ${ }^{\mathbf{1}} \mathbf{H}$ NMR $\left(\mathrm{CDCl}_{3}, 400 \mathrm{MHz}, \delta\right): 3.19\left(\mathrm{t}, 2 \mathrm{H},{ }^{3} J_{\mathrm{H} 4-\mathrm{H} 5}=5.8 \mathrm{~Hz}, \mathrm{H} 4\right), 3.0\left(\mathrm{q}, 2 \mathrm{H}, J_{\mathrm{H} 2-\mathrm{H} 1}=7.4 \mathrm{~Hz}, \mathrm{H} 2\right), 2.42(\mathrm{t}$, $\left.2 \mathrm{H}, J_{\mathrm{H} 6-\mathrm{H} 5}=5.8 \mathrm{~Hz}, \mathrm{H} 6\right), 2.22(\mathrm{~s}, 6 \mathrm{H}, \mathrm{H} 7), 1.70(\mathrm{~m}, 2 \mathrm{H}, \mathrm{H} 5), 1.34\left(\mathrm{t}, 3 \mathrm{H},{ }^{3} J_{\mathrm{H} 1-\mathrm{H} 2}=7.4 \mathrm{~Hz}, \mathrm{H} 1\right)$ ppm; ${ }^{13} \mathbf{C}\left\{{ }^{1} \mathbf{H}\right\}$ NMR $\left(\mathrm{CDCl}_{3}, 100 \mathrm{MHz}, \delta\right): 59.33$ (C6), 46.05 (C2), 45.41 (C7), 44.11 (C4), 25.91 
(C5), 8.35 (C1) ppm. HRMS-ESI-TOF $(\mathrm{m} / z):\left[\mathrm{M}^{+}+\mathrm{H}^{+}\right]$calculated for $\mathrm{C}_{9} \mathrm{H}_{23} \mathrm{~N}_{2} \mathrm{O}_{2} \mathrm{~S}_{1}, 223.1475$, found, 223.1480.

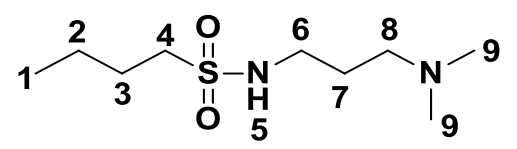

$N$-(3-(dimethylamino)propyl)butane-1-sulfonamide (8D): ${ }^{87,88}$

This compound was synthesized according to Method 5.1.1b with butanesulfonyl chloride (1.7 $\mathrm{mL}, 12.77 \mathrm{mmol}$ ) and 3-(dimethylamino)propylamine (2.4 mL, $19.15 \mathrm{mmol}, 1.5 \mathrm{eq}$.$) in DCM (50$ $\mathrm{mL})$ for 4 hours. The solution was washed with $\mathrm{K}_{2} \mathrm{CO}_{3}(0.05 \mathrm{M}, 50 \mathrm{~mL})$, and the volatile organic layer was removed using a rotary evaporater yielding in a clear oil. Yield: $81 \%(2.31 \mathrm{~g}) .{ }^{\mathbf{1}} \mathbf{H} \mathbf{N M R}$ $\left(\mathrm{CDCl}_{3}, 400 \mathrm{MHz}, \delta\right): 3.15\left(\mathrm{t}, 2 \mathrm{H},{ }^{3} \mathrm{~J}_{6-7}=5.9 \mathrm{~Hz}, \mathrm{H} 6\right), 2.94\left(\mathrm{t}, 2 \mathrm{H},{ }^{3} J_{4-3}=7.9 \mathrm{~Hz}, \mathrm{H} 4\right), 2.38(\mathrm{t}, 2 \mathrm{H}$, $\left.{ }^{3} J_{8-7}=5.9 \mathrm{~Hz}, \mathrm{H} 8\right), 2.18(\mathrm{~s}, 6 \mathrm{H}, \mathrm{H} 9), 1.78-1.61(\mathrm{~m}, 4 \mathrm{H}, \mathrm{H} 3$ and H7), 1.48-1.34 (m, 2H, H2), 0.91 $\left(\mathrm{t}, 3 \mathrm{H},{ }^{3} J_{1-2}=7.3 \mathrm{~Hz}, \mathrm{H} 1\right) \mathrm{ppm} ;{ }^{13} \mathbf{C}\left\{{ }^{1} \mathbf{H}\right\} \mathbf{N M R}\left(\mathrm{CDCl}_{3}, 100 \mathrm{MHz}, \delta\right): 59.08$ (C8), $51.56(\mathrm{C} 4)$, 45.38 (C9), 43.83 (C6), 26.05 (C3), 25.70 (C7), 21.54 (C2), 13.63 (C1) ppm. HRMS-ESI-TOF $(m / z):\left[\mathrm{M}^{+}+\mathrm{H}^{+}\right]$calculated for $\mathrm{C}_{7} \mathrm{H}_{10} \mathrm{~N}_{3} \mathrm{O}_{2} \mathrm{~S}_{1}, 210.1271$, found, 210.1276.

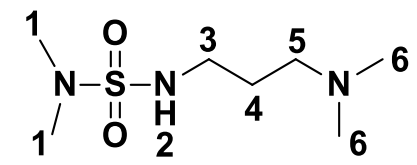

\section{$N$-(2-(dimethylamino)propyl)-N,N-Dimethyl-sulfamide (9D):}

This compound was synthesized according to Method 5.1.1b using $N, N$-Dimethylsulfamoyl chloride (1.5 mL, $13.93 \mathrm{mmol})$ and 3-(dimethylamino)propylamine (2.6 mL, $20.89 \mathrm{mmol}, 1.5 \mathrm{eq}$. in DCM (50 mL) for 4 hours and extracted using $\mathrm{K}_{2} \mathrm{CO}_{3}(0.05 \mathrm{M}, 50 \mathrm{~mL})$ yielding in clear oil. Yield: $79.8 \%\left(2.33\right.$ g). ${ }^{1} \mathbf{H}$ NMR $\left(\mathrm{CDCl}_{3}, 400 \mathrm{MHz}, \delta\right): 3.11\left(\mathrm{t}, 2 \mathrm{H},{ }^{3} J_{3-4}=6.0 \mathrm{~Hz}, \mathrm{H} 3\right), 2.75(\mathrm{~s}$, 
$6 \mathrm{H}, \mathrm{H} 1), 2.38\left(\mathrm{t}, 2 \mathrm{H}, J_{5-4}=6.0 \mathrm{~Hz}, \mathrm{H} 5\right), 2.19(\mathrm{~s}, 6 \mathrm{H}, \mathrm{H} 6), 1.66(\mathrm{~m}, 2 \mathrm{H}, \mathrm{H} 4) \mathrm{ppm} .{ }^{13} \mathbf{C}\left\{{ }^{1} \mathbf{H}\right\} \mathbf{N M R}$ $\left(\mathrm{CDCl}_{3}, 100 \mathrm{MHz}, \delta\right): 59.24$ (C5), 45.39 (C6), 44.31 (C3), 38.00 (C1), 25.62 (C4) ppm.

\subsection{General Procedure for the Menschutkin Quaternization}

An appropriate amount of sulfonamide containing a tertiary amine and a trimethoxy silane, diallyl phosphonate or benzophenone (silane, phosphprus or benzophenone) along with alkyl halide were mixed with ACN using Method 5.2 and heated for the indicated time. The reaction vial was allowed to cool to RT and the crude product purified as indicated in Method 5.2.

\subsubsection{Synthesis of Organosilane based QUAT's}

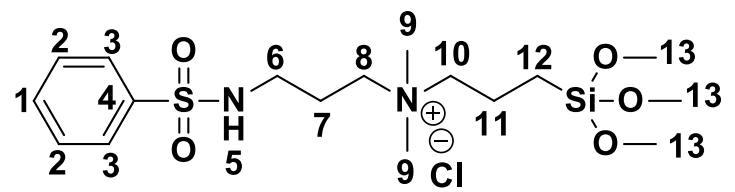

$N, N$-dimethyl-3-(phenylsulfonamido)- $N$-(3-(trimethoxysilyl)propyl)propan-1-aminium chloride (1F):

This compound was synthesized using $N$-(3-(dimethylamino)propyl)benzenesulfonamide (1.0 g, $4.13 \mathrm{mmol})$ and (3-chloropropyl)trimethoxysilane (1.1 mL, $6.19 \mathrm{mmol}, 1.5$ eq.) in ACN (3 mL) for 4 hours resulting in viscous golden yellow brown solution. The product was purified using $\mathrm{Et}_{2} \mathrm{O}(10 \mathrm{~mL} \times 3)$ and obtained as clear golden brown coloured gummy oil. Yield: $97.5 \%$ (1.77 g). ${ }^{1} \mathbf{H}$ NMR $\left(\mathrm{CDCl}_{3}, 400 \mathrm{MHz}, \delta\right): 8.39$ (br s, 1H, H5), 7.96 (d, 2H, H3), 7.54 - 7.341 (m, 3H, H1 \& H2), 3.66 (m, 2H, H8), $3.51(\mathrm{~s}, 9 \mathrm{H}, \mathrm{H} 13), 3.34$ (m, 2H, H10), 3.21 (s, 6H, H9), 3.00 (m, 2H, H6), $2.06(\mathrm{~m}, 2 \mathrm{H}, \mathrm{H} 7), 1.75(\mathrm{~m}, 2 \mathrm{H}, \mathrm{H} 11), 0.59\left(\mathrm{t}, 2 \mathrm{H},{ }^{3} J_{12-11}=7.8 \mathrm{~Hz}, \mathrm{H} 12\right) \mathrm{ppm} .{ }^{13} \mathbf{C}\left\{{ }^{1} \mathbf{H}\right\} \mathbf{N M R}$ $\left(\mathrm{CDCl}_{3}, 100 \mathrm{MHz}, \delta\right): 139.86$ (C4), 132.41 (C1), 129.14 (C2), 127.20 (C3), 65.94 (C10), 62.45

(C8), 51.10 (C9), 50.72 (C13), 39.93 (C6), 22.61 (C7), 16.45 (C11), 5.57 (C12) ppm. ${ }^{29}$ Si $\left\{{ }^{1} \mathbf{H}\right\}$ 
NMR (79.4 MHz, $\left.\mathrm{CDCl}_{3}, \delta\right)$ : $44.41 \mathrm{ppm}$. HRMS-ESI-TOF $(\mathrm{m} / \mathrm{z})$ : $\left[\mathrm{M}^{+}-\mathrm{Cl}^{-}\right]$calculated for $\mathrm{C}_{17} \mathrm{H}_{33} \mathrm{~N}_{2} \mathrm{O}_{5} \mathrm{~S}_{1} \mathrm{Si}_{1}, 405.1874$, found, 405.8166 .

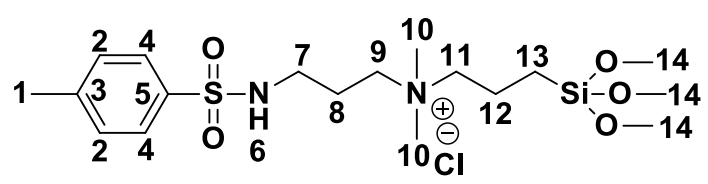

$N, N$-dimethyl-3-(4-methylphenylsulfonamido)- $N$-(3-(trimethoxysilyl)propyl)propan-1aminium chloride (2F):

This compound was synthesized using $\quad N$-(3-(dimethylamino)propyl)-4methylbenzenesulfonamide (1.0 g, $3.9 \mathrm{mmol})$ and (3-chloropropyl)trimethoxysilane (1.1 mL, 5.85 mmol, 1.5 eq.) in $\mathrm{ACN}(3 \mathrm{~mL}$ ) for 3.5 hours resulting in viscous golden yellow brown coloured solution. The product was purified using $\mathrm{Et}_{2} \mathrm{O}(10 \mathrm{~mL} \times 3)$ and obtained as clear golden brown gummy oil. Yield: 97 \% (1.67 g). ${ }^{1} \mathbf{H}$ NMR $\left(\mathrm{CDCl}_{3}, 400 \mathrm{MHz}, \delta\right): 8.18$ (br s, 1H, H6), 7.85 (d, $\left.2 \mathrm{H},{ }^{3} J_{4-2}=7.9 \mathrm{~Hz}, \mathrm{H} 4\right), 7.29\left(\mathrm{~d}, 2 \mathrm{H},{ }^{3} J_{2-4}=7.7 \mathrm{~Hz}, \mathrm{H} 2\right), 3.69$ (m, 2H, H9), 3.55 (s, 9H, H14), 3.37 (m, 2H, H11), 3.25 (s, 6H, H10), 3.01 (m, 2H, H7), 2.40 (s, 3H, H1), 2.10 (m, 2H, H8), 1.79 (m, 2H, H12), $0.63\left(\mathrm{t}, 2 \mathrm{H},{ }^{3} \mathrm{~J}_{13-12}=7.7 \mathrm{~Hz}, \mathrm{H} 13\right) \mathrm{ppm} .{ }^{13} \mathbf{C}\left\{{ }^{1} \mathbf{H}\right\} \mathbf{N M R}\left(\mathrm{CDCl}_{3}, 100 \mathrm{MHz}, \delta\right): 143.08$ (C5), 136.85 (C3), 129.70 (C2), 127.85 (C4), 65.82 (C11), 62.45 (C9), 51.10 (C14), 50.70 (C10), 39.91 (C7), 22.66 (C1), 21.46 (C8), 16.44 (C12), 5.57 (C13) ppm. ${ }^{29} \mathrm{Si}\left\{{ }^{1} \mathbf{H}\right\}$ NMR (79.4 MHz, $\left.\mathrm{CDCl}_{3}, \delta\right):-44.37$ ppm. HRMS-ESI-TOF $(\mathrm{m} / z)$ : $\left[\mathrm{M}^{+}-\mathrm{Cl}^{-}\right]$calculated for $\mathrm{C}_{18} \mathrm{H}_{35} \mathrm{~N}_{2} \mathrm{O}_{5} \mathrm{~S}_{1} \mathrm{Si}_{1}$, 419.2030, found, 419.2026 . 


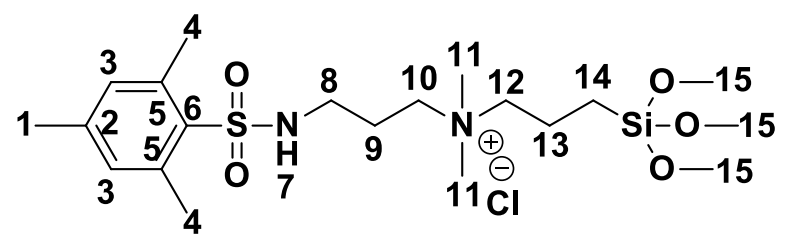

$N, N$-dimethyl-3-(trimethoxysilyl)- $N$-(3-(2,4,6-trimethylphenylsulfonamido)propyl)propan1-aminium chloride (3F):

This compound was synthesized using $N$-(3-(dimethylamino)propyl)-2,4,6trimethylbenzenesulfonamide $(2.0 \mathrm{~g}, 7.03 \mathrm{mmol})$ and (3-chloropropyl)trimethoxysilane $(1.9 \mathrm{~mL}$, $10.55 \mathrm{mmol}, 1.5$ eq.) in $\mathrm{ACN}$ ( $3 \mathrm{~mL}$ ) for 4.5 hours resulting in viscous golden yellow brown solution. The product was purified using $\mathrm{Et}_{2} \mathrm{O}(10 \mathrm{~mL} \times 3)$ and obtained as clear golden brown colouredgummy oil. Yield: $92.6 \%(3.27 \mathrm{~g}) .{ }^{1} \mathbf{H} \mathbf{N M R}\left(\mathrm{CDCl}_{3}, 400 \mathrm{MHz}, \delta\right): 7.74\left(\mathrm{t}, 1 \mathrm{H},{ }^{3} \boldsymbol{J}_{7-8}=\right.$ $6.0 \mathrm{~Hz}, \mathrm{H} 7), 6.90$ (s. 2H, H3), 3.70 (m, 2H, H8), 3.53 (s, 9H, H15), 3.37 (m, 2H, H12), 3.25 (s, 6H, H11), 2.98 (m, 2H, H10), 2.62 (br s, 6H, H4), 2.25 (s, 3H, H1), 2.09 (m, 2H, H9), 1.78 (m, 2H, H13), $0.62\left(\mathrm{t}, 2 \mathrm{H},{ }^{3} J_{14-13}=7.9 \mathrm{~Hz}, \mathrm{H} 14\right) \mathrm{ppm} .{ }^{13} \mathbf{C}\left\{{ }^{1} \mathbf{H}\right\} \mathbf{N M R}\left(\mathrm{CDCl}_{3}, 100 \mathrm{MHz}, \delta\right): 142.01$ (C6), 139.22 (C5), 133.83 (C2), 132.01 (C3), 66.06 (C12), 62.51 (C10), 51.22 (C11), 50.81 (C15), 39.33 (C8), 23.28 (C4), 22.88 (C1), 20.95 (C9), 16.57 (C13), 5.70 (C14) ppm. ${ }^{29} \mathbf{S i}\left\{{ }^{1} \mathbf{H}\right\}$ NMR (79.4 MHz, $\left.\mathrm{CDCl}_{3}, \delta\right):-44.43$ ppm. HRMS-ESI-TOF $(\mathrm{m} / z):\left[\mathrm{M}^{+}-\mathrm{Cl}^{-}\right]$calculated for $\mathrm{C}_{20} \mathrm{H}_{39} \mathrm{~N}_{2} \mathrm{O}_{5} \mathrm{~S}_{1} \mathrm{Si}_{1}, 447.2343$, found, 447.2357. 


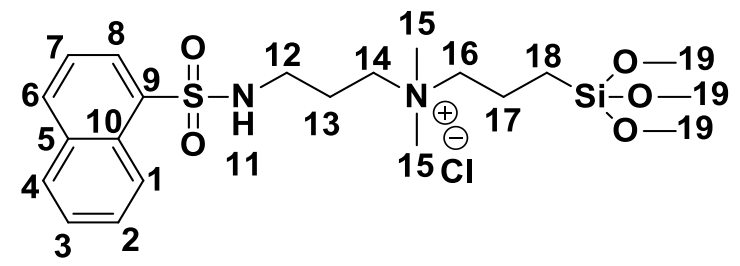

$N, N$-dimethyl-3-(naphthalene-1-sulfonamido)- $N$-(3-(trimethoxysilyl)propyl)propan-1aminium chloride (5F):

This compound was synthesized using $N$-(3-(dimethylamino)propyl)naphthalene-1-sulfonamide $(0.5 \mathrm{~g}, 2.21 \mathrm{mmol})$ and (3-chloropropyl)trimethoxysilane $(0.6 \mathrm{~mL}, 3.31 \mathrm{mmol}, 1.5 \mathrm{eq}$.$) in ACN (3$ $\mathrm{mL}$ ) for 5 hours resulting in viscous golden yellow brown solution. The product was purified using $\mathrm{Et}_{2} \mathrm{O}(10 \mathrm{~mL} \times 3)$ and obtained as clear golden brown coloured gummy oil. Yield: $78.8 \%(0.85$ g). ${ }^{1} \mathbf{H}$ NMR $\left(\mathrm{CDCl}_{3}, 400 \mathrm{MHz}, \delta\right): 8.83\left(\mathrm{~d}, 1 \mathrm{H},{ }^{3} J_{8-7}=8.6 \mathrm{~Hz}, \mathrm{H} 8\right), 8.47\left(\mathrm{t}, 1 \mathrm{H},{ }^{3} J_{11-12}=5.7 \mathrm{~Hz}\right.$, H11), $8.20\left(\mathrm{~d}, 1 \mathrm{H},{ }^{3} J_{6-7}=7.3 \mathrm{~Hz}, \mathrm{Hs} 6\right), 7.99\left(\mathrm{~d}, 1 \mathrm{H},{ }^{3} J_{1-2}=8.1 \mathrm{~Hz}, \mathrm{H} 1\right), 7.87\left(\mathrm{~d}, 1 \mathrm{H},{ }^{3} J_{4-3}=8.1\right.$ Hz, H4), 7.69 (m, 1H, H7), 7.55 - 7.46 (m, 2H, H3 \& H2), 3.49 (br s, 11H, H14 \& H19), 3.20 (m, 2H, H16), 3.06 (br s, 8H, H12 \& H15), 1.98 - 1.86 (m, 2H, H13), 1.68 - 1.54 (m, 2H, H17), 0.51 $\left(\mathrm{t}, 2 \mathrm{H},{ }^{3} J_{18-17}=7.8 \mathrm{~Hz}, \mathrm{H} 18\right) \mathrm{ppm} .{ }^{13} \mathbf{C}\left\{{ }^{1} \mathbf{H}\right\} \mathbf{N M R}\left(\mathrm{CDCl}_{3}, 100 \mathrm{MHz}, \delta\right): 135.12(\mathrm{C} 9), 134.16$ (C5), 133.91 (C1), 129.07 (C6), 128.8 (C4), 128.56 (C7), 128.12 (C10), 127.02 (C3), 125.30 (C8), 124.31 (C2), 65.84 (C16), 62.32 (C14), 50.92 (C15), 50.69 (C19), 39.79 (C12), 22.81 (C13), 16.33 (C17), 5.48 (C18) ppm. ${ }^{29} \mathrm{Si}\left\{{ }^{1} \mathbf{H}\right\}$ NMR $\left(79.4 \mathrm{MHz}, \mathrm{CDCl}_{3}, \delta\right):-44.49$ ppm. HRMS-ESI-TOF (m/z): $\left[\mathrm{M}^{+}-\mathrm{Cl}^{-}\right]$calculated for $\mathrm{C}_{21} \mathrm{H}_{35} \mathrm{~N}_{2} \mathrm{O}_{2} \mathrm{~S}_{1} \mathrm{Si}_{1}, 455.2030$, found, 455.2018. 


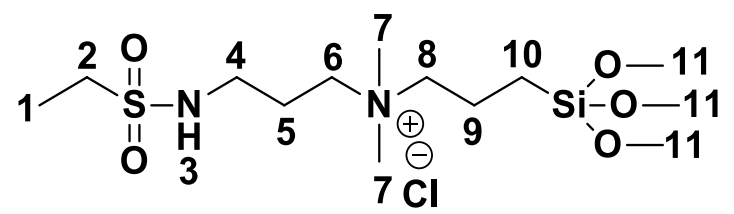

\section{3-(ethylsulfonamido)- $N, N$-dimethyl- $N$-(3-(trimethoxysilyl)propyl)propan-1-aminium} chloride (7F):

This compound was synthesized using $N$-(3-(dimethylamino)propyl)ethanesulfonamide (1.0 g, $5.15 \mathrm{mmol})$ and (3-chloropropyl)trimethoxysilane $(1.4 \mathrm{~mL}, 7.72 \mathrm{mmol}, 1.5$ eq.) in ACN (3 mL) for 5 hours resulting in viscous golden yellow brown solution. The product was purified using $\mathrm{Et}_{2} \mathrm{O}(10 \mathrm{~mL} \times 3)$ and obtained as clear golden brown coloured gummy oil. Yield: $86.0 \%$ (1.73 g). ${ }^{1} \mathbf{H}$ NMR $\left(\mathrm{CDCl}_{3}, 400 \mathrm{MHz}, \delta\right): 7.63$ (s, 1H, H3), 3.66 (m, 2H, H6), 3.53 (m, 9H, H11), 3.36 (m, 2H, H8), 3.25 - 3.15 (m, 8H, H7 \& H4), 3.03 (m, 2H, H2), 2.12 (m, 2H, H5), 1.78 (m, 2H, H9), $1.31(\mathrm{~m}, 3 \mathrm{H}, \mathrm{H1}), 0.62\left(\mathrm{t}, 2 \mathrm{H},{ }^{3} J_{10-9}=7.8 \mathrm{~Hz}, \mathrm{H} 10\right) \mathrm{ppm} .{ }^{13} \mathbf{C}\left\{{ }^{1} \mathbf{H}\right\} \mathbf{N M R}\left(\mathrm{CDCl}_{3}, 100 \mathrm{MHz}\right.$, ठ): 65.89 (C8), 62.40 (C6), 51.18 (C7), 50.81 (C11), 46.37 (C2), 40.09 (C4), 23.58 (C5), 16.54 (C9), 8.28 (C1), 5.73 (C10) ppm. ${ }^{29} \mathrm{Si}\left\{{ }^{1} \mathbf{H}\right\}$ NMR (79.4 MHz, $\left.\mathrm{CDCl}_{3}, \delta\right):-44.51 \mathrm{ppm}$.

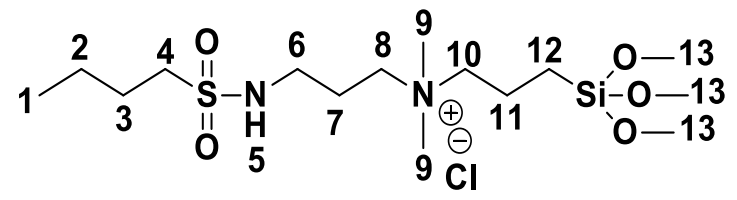

\section{3-(butylsulfonamido)- $N, N$-dimethyl- $N$-(3-(trimethoxysilyl)propyl)propan-1-aminium chloride (8F):}

This compound was synthesized using $N$-(3-(dimethylamino)propyl)butanesulfonamide (1.0 g, $4.50 \mathrm{mmol})$ and (3-chloropropyl)trimethoxysilane $(1.2 \mathrm{~mL}, 6.75 \mathrm{mmol}, 1.5$ eq.) in ACN (3 mL) for 5 hours resulting in viscous golden yellow brown solution. The product was purified using 
$\mathrm{Et}_{2} \mathrm{O}(10 \mathrm{~mL} \times 5)$ and obtained as clear golden brown coloured gummy oil. Yield: $60.0 \%$ (1.13 g). ${ }^{1} \mathbf{H}$ NMR $\left(\mathrm{CDCl}_{3}, 400 \mathrm{MHz}, \delta\right): 7.62$ (br s, 1H, H5), 3.64 (m, 2H, H8), 3.51 (s, 9H, H13), 3.34 (m, 2H, H4), $3.24-3.12$ (m, 8H, H9 and H6), 2.98 (m, 2H, H4), 2.09 (m, 2H, H7), $1.83-1.66$ (m, 4H, H11 \& H3), 1.38 (m, 2H, H2), $0.86(\mathrm{~m}, \mathrm{H} 1), 0.60$ (t, 2H, $\left.{ }^{3} \mathrm{~J}_{12-11}=7.3 \mathrm{~Hz}, \mathrm{H} 12\right) \mathrm{ppm} .{ }^{13} \mathbf{C}$ $\left\{{ }^{1} \mathrm{H}\right\}$ NMR $\left(\mathrm{CDCl}_{3}, 100 \mathrm{MHz}, \delta\right): 65.82$ (C10), 51.81 (C4), 51.12 (C9), 50.74 (C13), 40.04 (C6), 25.38 (C3), 23.50 (C7), 21.58 (C2), 16.50 (C11), $13.62(\mathrm{C} 1), 5.68$ (C12) ppm. ${ }^{29} \mathrm{Si}\left\{{ }^{1} \mathbf{H}\right\}$ NMR (79.4 MHz, $\left.\mathrm{CDCl}_{3}, \delta\right):-44.50 \mathrm{ppm}$. HRMS-ESI-TOF $(\mathrm{m} / z):\left[\mathrm{M}^{+}-\mathrm{Cl}^{-}\right]$calculated for $\mathrm{C}_{15} \mathrm{H}_{37} \mathrm{~N}_{2} \mathrm{O}_{5} \mathrm{~S}_{1} \mathrm{Si}_{1}, 385.2187$, found, 385.2185.

\subsubsection{Synthesis of Organophosphosophorus based QUAT}

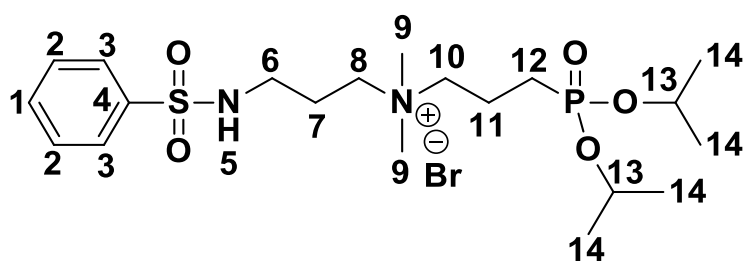

3-(diisopropoxyphosphoryl)- $N, N$-dimethyl- $N$-(3-(phenylsulfonamido)propyl)propan-1aminium bromide (1H):

This compound was synthesized using $N$-(3-(dimethylamino)propyl)benzenesulfonamide (1.0 g, $4.13 \mathrm{mmol}$ ) and diisopropyl (3-bromopropyl)phosphonate ( $1.10 \mathrm{~mL}, 4.13 \mathrm{mmol}, 1$ eq.) in ACN (3 $\mathrm{mL}$ ) for 4 hours resulting in viscous golden yellow brown solution. The product was purified using $\mathrm{Et}_{2} \mathrm{O}(10 \mathrm{~mL}$ X 3$)$ and obtained as pale yellow coloured fluffy/gummy powder. Yield: $86.0 \%$ $(1.87 \mathrm{~g}) .{ }^{1} \mathbf{H}$ NMR $\left(\mathrm{CDCl}_{3}, 400 \mathrm{MHz}, \delta\right): 7.94\left(\mathrm{~d}, 2 \mathrm{H},{ }^{3} J_{3-2}=6.5 \mathrm{~Hz}, \mathrm{H} 3\right), 7.65\left(\mathrm{t}, 1 \mathrm{H},{ }^{3} J_{5-6}=5.9\right.$ Hz, H5), 7.54 - 7.46 (m, 3H, H1 \& H2), 4.63 (m, 2H, H13), 3.70 (m, 2H, H8), 3.60 (m, 2H, H10), 3.27 (s, 6H, H9), 3.01 (m, 2H, H6), $2.16-1.94$ (m, 4H, (H7, H11, \& ACN), 1.79 (dt, 2H, ${ }^{2} J_{12-\mathrm{P}}=$ $\left.17.7 \mathrm{~Hz}, \mathrm{H} 8,{ }^{3} J_{12-11}=7.2 \mathrm{~Hz}, \mathrm{H} 12\right), 1.28\left(\mathrm{dd}, 12 \mathrm{H},{ }^{4} J_{14-\mathrm{P}}=6.2 \mathrm{~Hz}, \mathrm{H} 8,{ }^{3} J_{14-13}=1.7 \mathrm{~Hz}, \mathrm{H} 14\right) \mathrm{ppm}$. ${ }^{13} \mathbf{C}\left\{{ }^{1} \mathbf{H}\right\}$ NMR $\left(\mathrm{CDCl}_{3}, 100 \mathrm{MHz}, \delta\right): 139.57$ (C4), 132.59 (C2), 129.23 (C1), 127.19 (C3), 70.82 
$\left(\mathrm{d},{ }^{2} J_{13-\mathrm{P}}=6.7 \mathrm{~Hz}, \mathrm{C} 13\right), 63.74\left(\mathrm{~d},{ }^{3} J_{10-\mathrm{P}}=15.1 \mathrm{~Hz}, \mathrm{C} 10\right), 62.41$ (C8), 51.28 (C9), 39.89 (C6), $24.12\left(\mathrm{~d},{ }^{3} J_{14-\mathrm{P}}=4.5 \mathrm{~Hz}, \mathrm{C} 14\right), 23.99\left(\mathrm{~d},{ }^{3} J_{14-\mathrm{P}}=4.0 \mathrm{~Hz}, \mathrm{C} 14\right), 23.10\left(\mathrm{~d},{ }^{1} J_{12-\mathrm{P}}=144.3 \mathrm{~Hz}, \mathrm{C} 12\right)$, 22.68 (C7), 16.67 (C11) ppm. ${ }^{31} \mathbf{P}\left\{{ }^{1} \mathbf{H}\right\}$ NMR $\left(\mathrm{CDCl}_{3}, 121.45 \mathrm{MHz}, \delta\right): 27.36$ ppm. HRMS-ESITOF $(m / z):\left[\mathrm{M}^{+}-\mathrm{Br}^{-}\right]$calculated for $\mathrm{C}_{20} \mathrm{H}_{38} \mathrm{~N}_{2} \mathrm{O}_{5} \mathrm{P}_{1} \mathrm{~S}_{1}$, 449.2234, found, 449.2232.

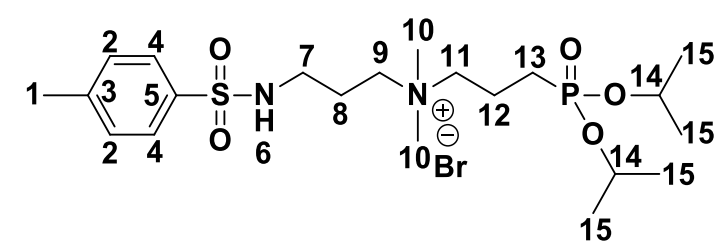

\section{3-(diisopropoxyphosphoryl)- $N, N$-dimethyl- $N$-(3-(4-}

methylphenylsulfonamido)propyl)propan-1-aminium bromide (2H):

This compound was synthesized using $N$-(3-(dimethylamino)propyl)-4methylbenzenesulfonamide ( $0.50 \mathrm{~g}, 1.95 \mathrm{mmol})$ and diisopropyl (3-bromopropyl)phosphonate $(0.50 \mathrm{~mL}, 1.95 \mathrm{mmol}, 1$ eq.) in $\mathrm{ACN}(3 \mathrm{~mL})$ for 3 hours resulting in pale yellow solution with some precipitate formation. The product was purified using $\mathrm{Et}_{2} \mathrm{O}(10 \mathrm{~mL} \times 3)$ and obtained as white puffy powder. Yield: $89.5 \%(0.95 \mathrm{~g}) .{ }^{1} \mathbf{H} \mathbf{~ N M R}\left(\mathrm{CDCl}_{3}, 400 \mathrm{MHz}, \delta\right): 7.78\left(\mathrm{~d}, 2 \mathrm{H},{ }^{3} \mathrm{~J}_{4-2}=\right.$ $8.2 \mathrm{~Hz}, \mathrm{H} 4), 7.55\left(\mathrm{t}, 1 \mathrm{H},{ }^{3} \mathrm{~J}_{6-7}=5.8 \mathrm{~Hz}, \mathrm{H} 6\right), 7.28-7.23\left(\mathrm{~m}, 2 \mathrm{H}, \mathrm{H} 2\right.$ and $\left.\mathrm{CDCl}_{3}\right), 4.61(\mathrm{~m}, 2 \mathrm{H}$, H14), 3.67 (m, 2H, H9), 3.59 (m, 2H, H11), 3.25 (s, 6H, H10), 2.95 (m, 2H, H7), 2.36 (s, 3H, H1), $2.16-1.90(\mathrm{~m}, 4 \mathrm{H}, \mathrm{H} 8 \& \mathrm{H} 12), 1.75\left(\mathrm{dt}, 2 \mathrm{H},{ }^{2} J_{13-\mathrm{P}}=17.8 \mathrm{~Hz},{ }^{3} J_{13-12}=7.1 \mathrm{~Hz}, \mathrm{H} 13\right), 1.25(\mathrm{dd}$, $\left.12 \mathrm{H},{ }^{4} J_{15-\mathrm{P}}=56.15 \mathrm{~Hz},{ }^{3} J_{15-14}=2.1 \mathrm{~Hz}, \mathrm{H} 15\right) \mathrm{ppm} .{ }^{13} \mathbf{C}\left\{{ }^{1} \mathbf{H}\right\} \mathbf{N M R}\left(\mathrm{CDCl}_{3}, 100 \mathrm{MHz}, \delta\right): 143.25$ (C5), $136.46(\mathrm{C} 3), 129.74(\mathrm{C} 2), 127.22(\mathrm{C} 4), 70.71\left(\mathrm{~d},{ }^{2} J_{14-\mathrm{P}}=6.7 \mathrm{~Hz}, \mathrm{C} 14\right), 63.67\left(\mathrm{~d},{ }^{3} J_{11-\mathrm{P}}=15.8\right.$ Hz, C11), 62.42 (C9), 51.17 (C10), 39.86 (C7), 24.10 (d, $\left.{ }^{3} J_{15-\mathrm{P}}=4.5 \mathrm{~Hz}, \mathrm{C} 15\right), 23.97$ (d, J15-P = 4.0 Hz, C15), 23.07 (d, $\left.{ }^{1} J_{13-\mathrm{P}}=144.1 \mathrm{~Hz}, \mathrm{C} 13\right), 22.52(\mathrm{C} 8), 21.47(\mathrm{C} 1), 16.69\left(\mathrm{~d},{ }^{2} J_{12-\mathrm{P}}=4.1 \mathrm{~Hz}\right.$, C12) ppm. ${ }^{31} \mathbf{P}\left\{{ }^{1} \mathbf{H}\right\} \mathbf{N M R}\left(\mathrm{CDCl}_{3}, 121.45 \mathrm{MHz}, \delta\right): 27.15 \mathrm{ppm}$. HRMS-ESI-TOF $(\mathrm{m} / \mathrm{z}):\left[\mathrm{M}^{+}-\mathrm{Br}^{-}\right.$ ] calculated for $\mathrm{C}_{21} \mathrm{H}_{40} \mathrm{~N}_{2} \mathrm{O}_{5} \mathrm{P}_{1} \mathrm{~S}_{1}, 463.2390$, found, 463.2394. 


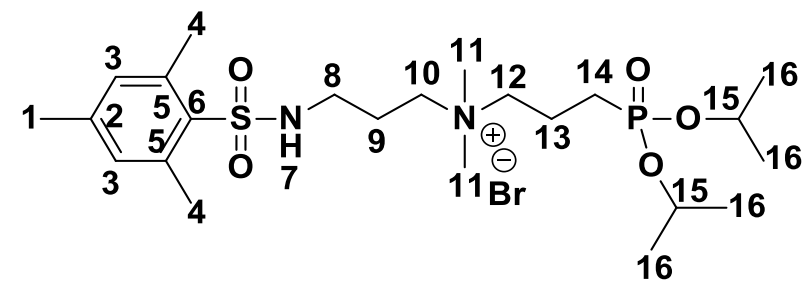

3-(diisopropoxyphosphoryl)- $N, N$-dimethyl- $N$-(3-(2,4,6-

trimethylphenylsulfonamido)propyl)propan-1-aminium bromide (3H):

This compound was synthesized using $N$-(3-(dimethylamino)propyl)-2,4,6trimethylbenzenesulfonamide $(0.50 \mathrm{~g}, 1.76 \mathrm{mmol})$ and diisopropyl (3-bromopropyl)phosphonate (0.40 mL, $1.76 \mathrm{mmol}, 1$ eq.) in $\mathrm{ACN}(3 \mathrm{~mL})$ for 4 hours resulting in viscous golden yellow brown solution. The product was purified using $\mathrm{Et}_{2} \mathrm{O}(10 \mathrm{~mL} \times 3)$ and obtained as pale yellow coloured fluffy/gummy powder. Yield: $71.0 \%(0.71 \mathrm{~g}) .{ }^{1} \mathbf{H}$ NMR $\left(\mathrm{CDCl}_{3}, 400 \mathrm{MHz}, \delta\right): 7.14$ (t, $1 \mathrm{H},{ }^{3} J_{7-8}$ = $6.0 \mathrm{~Hz}, \mathrm{H} 7), 6.92(\mathrm{~s}, 2 \mathrm{H}, \mathrm{H} 3), 4.65(\mathrm{~m}, 2 \mathrm{H}, \mathrm{H} 15), 3.80(\mathrm{~m}, 2 \mathrm{H}, \mathrm{H} 10), 3.67(\mathrm{~m}, 2 \mathrm{H}, \mathrm{H} 12), 3.32$ (s, 6H, H11), $3.01\left(\mathrm{dd}, 2 \mathrm{H},{ }^{3} J_{8-7}=11.2 \mathrm{~Hz},{ }^{3} J_{8-9}=5.6 \mathrm{~Hz}, \mathrm{H} 8\right), 2.63(\mathrm{~s}, 6 \mathrm{H}, \mathrm{H} 4), 2.27$ (s, 3H, H1), $2.22-2.00(\mathrm{~m}, 4 \mathrm{H}, \mathrm{H} 9 \& \mathrm{H} 13), 1.81\left(\mathrm{dt}, 2 \mathrm{H},{ }^{2} J_{14-\mathrm{P}}=17.8 \mathrm{~Hz},{ }^{3} J_{14-13}=7.0 \mathrm{~Hz}, \mathrm{H} 14\right), 1.30(\mathrm{~d}, 12 \mathrm{H}$, $\left.{ }^{3} J_{16-15}=6.2 \mathrm{~Hz}, \mathrm{H} 16\right) \mathrm{ppm} .{ }^{13} \mathbf{C}\left\{{ }^{1} \mathbf{H}\right\}$ NMR $\left(\mathrm{CDCl}_{3}, 100 \mathrm{MHz}, \delta\right): 142.11$ (C6), 139.07 (C2), 133.33 (C5), 132.00 (C3), $70.80\left(\mathrm{~d},{ }^{2} J_{15-\mathrm{P}}=6.7 \mathrm{~Hz}, \mathrm{C} 15\right), 63.68\left(\mathrm{~d},{ }^{3} J_{12-\mathrm{P}}=15.0 \mathrm{~Hz}, \mathrm{C} 12\right), 62.35$ (C10), 51.32 (C11), 39.20 (C8), $24.13\left(\mathrm{~d},{ }^{3} J_{16-\mathrm{P}}=4.5 \mathrm{~Hz}, \mathrm{C} 16\right), 24.00\left(\mathrm{~d},{ }^{3} J_{16-\mathrm{P}}=4.0 \mathrm{~Hz}, \mathrm{C} 16\right)$, $23.09\left(\mathrm{~d},{ }^{1} J_{14-\mathrm{P}}=144.3 \mathrm{~Hz}, \mathrm{C} 14\right), 23.22(\mathrm{C} 4), 22.68$ (C9), 20.89 (C1), 16.76 (C13) ppm. ${ }^{31} \mathbf{P}\left\{{ }^{1} \mathbf{H}\right\}$ NMR $\left(\mathrm{CDCl}_{3}, 121.45 \mathrm{MHz}, \delta\right): 27.16 \mathrm{ppm}$. HRMS-ESI-TOF $(\mathrm{m} / z):\left[\mathrm{M}^{+}-\mathrm{Br}^{-}\right]$calculated for $\mathrm{C}_{23} \mathrm{H}_{44} \mathrm{~N}_{2} \mathrm{O}_{5} \mathrm{P}_{1} \mathrm{~S}_{1}, 491.2703$, found, 491.2693. 


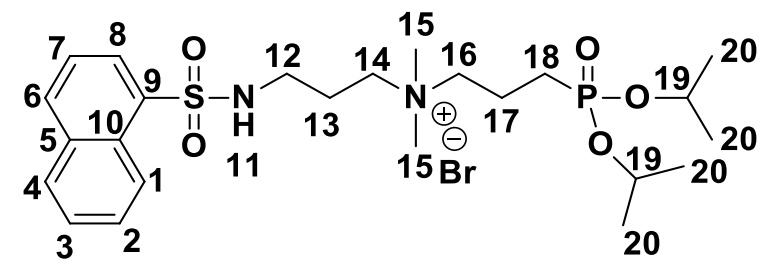

3-(diisopropoxyphosphoryl)- $N, N$-dimethyl- $N$-(3-(naphthalene-1-

sulfonamido)propyl)propan-1-aminium bromide (5H):

This compound was synthesized using $N$-(3-(dimethylamino)propyl)naphthalene-1-sulfonamide (0.50 g, $4.13 \mathrm{mmol})$ and diisopropyl (3-bromopropyl)phosphonate (0.50 mL, $3.42 \mathrm{mmol}, 1$ eq.) in ACN ( $3 \mathrm{~mL}$ ) for 5.5 hours resulting in viscous golden yellow brown solution. The product was purified using $\mathrm{Et}_{2} \mathrm{O}(10 \mathrm{~mL} \times 3)$ and obtained as pale yellow coloured fluffy/gummy powder. Yield: $77.4 \%\left(0.77\right.$ g). ${ }^{1} \mathbf{H}$ NMR $\left(\mathrm{CDCl}_{3}, 400 \mathrm{MHz}, \delta\right): 8.82\left(\mathrm{~d}, 1 \mathrm{H},{ }^{3} J_{8-7}=8.7 \mathrm{~Hz}, \mathrm{H} 8\right), 8.20$ (d, $\left.1 \mathrm{H},{ }^{3} J_{6-7}=7.3 \mathrm{~Hz}, \mathrm{H} 6\right), 8.02\left(\mathrm{~d}, 1 \mathrm{H},{ }^{3} J_{1-2}=8.3 \mathrm{~Hz}, \mathrm{H} 1\right), 7.92-7.84$ (m, 2H, H4 \& H11), 7.69 (m, 1H, H7), $7.57-7.48$ (m, 2H, H3 \& H2), 4.60 (m, 2H, H19), $3.62-3.47$ (m, 4H, H14 \& H16), $3.12(\mathrm{~s}, 6 \mathrm{H}, \mathrm{H} 15), 3.03\left(\mathrm{dd}, 2 \mathrm{H},{ }^{3} J_{12-11}=11.2 \mathrm{~Hz},{ }^{3} J_{12-13}=5.6 \mathrm{~Hz}, \mathrm{H} 12\right), 2.08-1.82(\mathrm{~m}, 7 \mathrm{H},(\mathrm{ACN}$, $\mathrm{H} 13$ \& H17)), $1.71\left(\mathrm{dt}, 2 \mathrm{H},{ }^{2} J_{18-\mathrm{P}}=17.5 \mathrm{~Hz},{ }^{3} J_{18-17}=7.2 \mathrm{~Hz}, \mathrm{H} 18\right), 1.12(\mathrm{~m}, 12 \mathrm{H}, \mathrm{H} 20)$ ppm. ${ }^{13} \mathbf{C}$ $\left\{{ }^{1} \mathbf{H}\right\} \mathbf{N M R}\left(\mathrm{CDCl}_{3}, 100 \mathrm{MHz}, \delta\right): 134.63$ (C9), 134.18 (C5), 13.14 (C1), 129.37 (C6), 128.92 (C4), 128.63 (C7), 128.03 (C10), 127.08 (C3), 125.17 (C8), 124.36 (C2), 70.80 (d, ${ }^{2} J_{19-P}=6.7 \mathrm{~Hz}$, C19), $63.60\left(\mathrm{~d},{ }^{3} J_{16-\mathrm{P}}=15.1 \mathrm{~Hz}, \mathrm{C} 16\right), 62.36(\mathrm{C} 14), 51.14(\mathrm{C} 15), 39.74(\mathrm{C} 12), 24.12\left(\mathrm{~d},{ }^{3} J_{20-\mathrm{P}}=\right.$ 4.5 Hz, C20), 23.99 (d, $\left.{ }^{3} J_{20-\mathrm{P}}=4.0 \mathrm{~Hz}, \mathrm{C} 20\right), 23.02\left(\mathrm{~d},{ }^{1} \mathrm{~J}_{18-\mathrm{P}}=144.5 \mathrm{~Hz}, \mathrm{C} 18\right), 22.68(\mathrm{C} 13), 16.65$ $\left(\mathrm{d},{ }^{2} J_{17-\mathrm{P}}=144.3 \mathrm{~Hz}, \mathrm{C} 17\right) \mathrm{ppm} .{ }^{31} \mathbf{P}\left\{{ }^{1} \mathbf{H}\right\} \mathbf{N M R}\left(\mathrm{CDCl}_{3}, 121.45 \mathrm{MHz}, \delta\right): 27.19 \mathrm{ppm}$. HRMS-ESITOF (m/z): [ $\left.\mathrm{M}^{+}-\mathrm{Br}^{-}\right]$calculated for $\mathrm{C}_{24} \mathrm{H}_{44} \mathrm{~N}_{2} \mathrm{O}_{5} \mathrm{P}_{1} \mathrm{~S}_{1}, 499.2390$, found, 499.2385. 


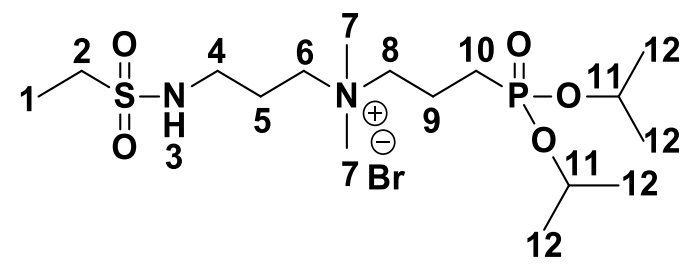

3-(diisopropoxyphosphoryl)- $N$-(3-(ethylsulfonamido)propyl)- $N, N$-dimethylpropan-1aminium bromide (7H):

This compound was synthesized using $N$-(3-(dimethylamino)propyl)ethanesulfonamide (0.25 g, $1.29 \mathrm{mmol})$ and diisopropyl (3-bromopropyl)phosphonate $(0.30 \mathrm{~mL}, 1.29 \mathrm{mmol}, 1$ eq.) in ACN (3 $\mathrm{mL}$ ) for 5 hours resulting in viscous golden yellow brown solution. The product was purified using $\mathrm{Et}_{2} \mathrm{O}(10 \mathrm{~mL} \times 3)$ and obtained as white coloured gummy powder. Yield: $86.0 \%(0.53 \mathrm{~g}) .{ }^{1} \mathbf{H}$ NMR $\left(\mathrm{CDCl}_{3}, 400 \mathrm{MHz}, \delta\right): 7.08\left(\mathrm{t}, 1 \mathrm{H}, J_{3-4}=5.8 \mathrm{~Hz}, \mathrm{H} 3\right), 4.66$ (m, 2H, H11), 3.74 (m, 2H, H6), $3.63(\mathrm{~m}, 2 \mathrm{H}, \mathrm{H} 8), 3.35-3.16(\mathrm{~m}, 8 \mathrm{H}, \mathrm{H} 7 \& \mathrm{H} 4), 3.07$ (q, 2H, $\left.{ }^{3} J_{2-1}=7.4 \mathrm{~Hz}, \mathrm{H} 2\right), 2.19(\mathrm{~m}, 2 \mathrm{H}$, H5), 2.04 (m, 2H, H9), $1.82\left(\mathrm{dt}, 2 \mathrm{H},{ }^{2} J_{10-\mathrm{P}}=17.4 \mathrm{~Hz},{ }^{3} J_{10-9}=7.2 \mathrm{~Hz}, \mathrm{H} 10\right), 1.44-1.24(\mathrm{~m}, 15 \mathrm{H}$, $\mathrm{H} 1$ \& H12) ppm. ${ }^{13} \mathbf{C}\left\{{ }^{1} \mathbf{H}\right\}$ NMR $\left(\mathrm{CDCl}_{3}, 100 \mathrm{MHz}, \delta\right): 70.74\left(\mathrm{~d},{ }^{2} J_{11-\mathrm{P}}=6.7 \mathrm{~Hz}, \mathrm{C} 11\right), 63.75(\mathrm{~d}$, $\left.{ }^{3} J_{8-\mathrm{P}}=15.7 \mathrm{~Hz}, \mathrm{C} 8\right), 62.36(\mathrm{C} 6), 51.20(\mathrm{C} 7), 46.22(\mathrm{C} 2), 39.97(\mathrm{C} 4), 24.12\left(\mathrm{~d},{ }^{3} J_{12-\mathrm{P}}=4.5 \mathrm{~Hz}\right.$, C12), $23.98\left(\mathrm{~d},{ }^{3} J_{12-\mathrm{P}}=4.0 \mathrm{~Hz}, \mathrm{C} 12\right), 23.14\left(\mathrm{~d},{ }^{1} J_{10-\mathrm{P}}=144.3 \mathrm{~Hz}, \mathrm{C} 10\right), 23.36$ (C5), 16.74 (C9), 8.24 (C1) ppm. ${ }^{31} \mathbf{P}\left\{{ }^{1} \mathbf{H}\right\}$ NMR $\left(\mathrm{CDCl}_{3}, 121.45 \mathrm{MHz}, \delta\right): 27.05$ ppm. HRMS-ESI-TOF $(\mathrm{m} / z):\left[\mathrm{M}^{+}\right.$ - $\left.\mathrm{Br}^{-}\right]$calculated for $\mathrm{C}_{16} \mathrm{H}_{38} \mathrm{~N}_{2} \mathrm{O}_{5} \mathrm{P}_{1} \mathrm{~S}_{1}, 401.2234$, found, 401.2235. 


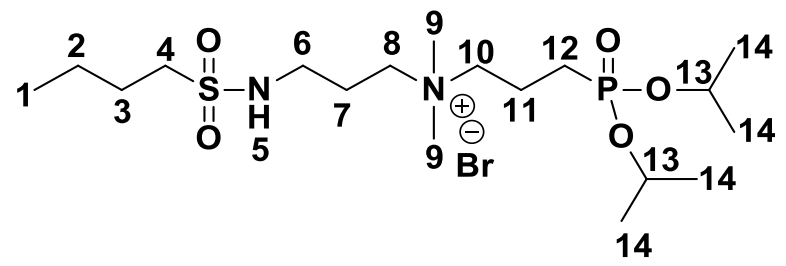

\section{3-(butylsulfonamido)- $N$-(3-(diisopropoxyphosphoryl)propyl)- $N, N$-dimethylpropan-1-} aminium bromide $(8 \mathrm{H})$ :

This compound was synthesized using $N$-(3-(dimethylamino)propyl)butane-1-sulfonamide $(0.50$ g, $2.25 \mathrm{mmol}$ ) and diisopropyl (3-bromopropyl)phosphonate ( $0.60 \mathrm{~mL}, 2.25 \mathrm{mmol}, 1$ eq.) in ACN $(3 \mathrm{~mL})$ for 3 hours resulting in viscous golden yellow brown solution. The product was purified using $\mathrm{Et}_{2} \mathrm{O}(10 \mathrm{~mL} \times 3)$ and obtained as pale yellow coloured gummy powder. Yield: $82.0 \%$ (0.94 g). ${ }^{1} \mathbf{H}$ NMR $\left(\mathrm{CDCl}_{3}, 400 \mathrm{MHz}, \delta\right): 7.07\left(\mathrm{t}, 1 \mathrm{H},{ }^{3} J_{3-4}=6.1 \mathrm{~Hz}, \mathrm{H} 5\right), 4.69(\mathrm{~m}, 2 \mathrm{H}, \mathrm{H13}), 3.78(\mathrm{~m}$, 2H, H8), 3.66 (m, 2H, H10), 3.33 (s, 6H, H9), 3.28 (m, 2H, H6), 3.29 (t, $\left.2 \mathrm{H},{ }^{3} J_{4-3}=8.4 \mathrm{~Hz}, \mathrm{H} 4\right)$, 2.21 (m, 2H, H7), 2.08 (m, 2H, H11), 1.89 - 1.75 (m, 4H, H3 \& H12), 1.45 (m, 2H, H2), 1.34 (m, 12H, H14), $0.96\left(\mathrm{t}, 3 \mathrm{H},{ }^{3} J_{1-2}=7.4 \mathrm{~Hz}, \mathrm{H1}\right) \mathrm{ppm} .{ }^{13} \mathbf{C}\left\{{ }^{1} \mathbf{H}\right\} \mathbf{N M R}\left(\mathrm{CDCl}_{3}, 100 \mathrm{MHz}, \delta\right): 70.77(\mathrm{~d}$, $\left.{ }^{2} J_{13-\mathrm{P}}=6.7 \mathrm{~Hz}, \mathrm{C} 13\right), 63.73\left(\mathrm{~d},{ }^{3} J_{10-\mathrm{P}}=15.5 \mathrm{~Hz}, \mathrm{C} 10\right), 62.36(\mathrm{C} 8), 51.72(\mathrm{C} 4), 51.25(\mathrm{C} 9), 39.98$ (C6), 25.35 (C3), $24.14\left(\mathrm{~d},{ }^{3} J_{14-\mathrm{P}}=4.5 \mathrm{~Hz}, \mathrm{C} 14\right), 24.00\left(\mathrm{~d},{ }^{3} J_{14-\mathrm{P}}=4.0 \mathrm{~Hz}, \mathrm{C} 14\right), 23.87 \& 22.43$ $\left(\mathrm{d},{ }^{1} J_{12-\mathrm{P}}=144.4 \mathrm{~Hz}, \mathrm{C} 12\right), 23.37(\mathrm{C} 7), 21.51(\mathrm{C} 2), 16.73\left(\mathrm{~d},{ }^{2} J_{11-\mathrm{P}}=4.2 \mathrm{~Hz}, \mathrm{C} 11\right), 13.62(\mathrm{C} 1)$ ppm. ${ }^{31} \mathbf{P}\left\{{ }^{1} \mathbf{H}\right\}$ NMR $\left(\mathrm{CDCl}_{3}, 121.45 \mathrm{MHz}, \delta\right): 27.22 \mathrm{ppm}$. HRMS-ESI-TOF $(\mathrm{m} / \mathrm{z}):\left[\mathrm{M}^{+}-\mathrm{Br}^{-}\right]$ calculated for $\mathrm{C}_{18} \mathrm{H}_{42} \mathrm{~N}_{2} \mathrm{O}_{5} \mathrm{P}_{1} \mathrm{~S}_{1}, 429.2547$, found, 429.2543 . 


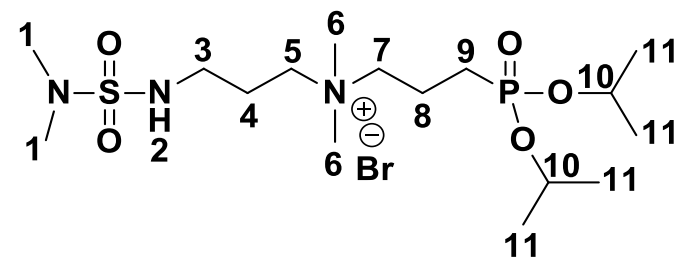

3-(diisopropoxyphosphoryl)- $N$-(3-((N,N-dimethylsulfamoyl)amino)propyl)- $N, N$ dimethylpropan-1-aminium bromide (9H):

This compound was synthesized using $N$-(2-(dimethylamino)propyl)-N,N-Dimethyl-sulfamide $(0.50 \mathrm{~g}, 2.39 \mathrm{mmol})$ and diisopropyl (3-bromopropyl)phosphonate $(0.6 \mathrm{~mL}, 2.39 \mathrm{mmol}, 1$ eq.) in ACN ( $3 \mathrm{~mL}$ ) for 3 hours resulting in viscous pale yellow solution. The product was purified using $\mathrm{Et}_{2} \mathrm{O}(10 \mathrm{~mL} \mathrm{X} 3)$ and obtained as pale yellow coloured fluffy/gummy powder. Yield: $91.7 \%$ (1.09 g). ${ }^{1} \mathbf{H}$ NMR $\left(\mathrm{CDCl}_{3}, 400 \mathrm{MHz}, \delta\right): 7.02\left(\mathrm{t}, 1 \mathrm{H}, J_{2-3}=5.9 \mathrm{~Hz}, \mathrm{H} 2\right), 4.62(\mathrm{~m}, 2 \mathrm{H}, \mathrm{H} 10), 3.66$ (m, 2H, H5), 3.59 (m, 2H, H7), 3.26 (s, 6H, H6), 3.14 (m, 2H, H3), 2.75 (s, 6H, H1), 2.12 (m, 2H, H4), $2.05-1.97(\mathrm{~m}, 2 \mathrm{H}, \mathrm{H} 8), 1.78\left(\mathrm{dt}, 2 \mathrm{H},{ }^{2} J_{9-\mathrm{P}}=17.4 \mathrm{~Hz},{ }^{3} J_{9-8}=7.2 \mathrm{~Hz}, \mathrm{H} 9\right), 1.25(\mathrm{~m}, 12 \mathrm{H}$, H11) ppm. ${ }^{13} \mathbf{C}\left\{{ }^{1} \mathbf{H}\right\}$ NMR $\left(\mathrm{CDCl}_{3}, 100 \mathrm{MHz}, \delta\right): 70.78\left(\mathrm{~d},{ }^{2} J_{10-\mathrm{P}}=6.6 \mathrm{~Hz}, \mathrm{C} 10\right), 63.74\left(\mathrm{~d},{ }^{3} J_{7-\mathrm{P}}=\right.$ 15.4 Hz, C7), 62.44 (C5), 51.24 (C6), 40.19 (C6), 38.15 (C1), 24.13 (d, $\left.{ }^{3} J_{11-\mathrm{P}}=4.5 \mathrm{~Hz}, \mathrm{C} 11\right), 24.06$ $\left(\mathrm{d},{ }^{3} J_{11-\mathrm{P}}=4.0 \mathrm{~Hz}, \mathrm{C} 11\right), 23.15\left(\mathrm{~d},{ }^{1} J_{9-\mathrm{P}}=144.0 \mathrm{~Hz}, \mathrm{C} 9\right), 22.84(\mathrm{C} 4), 16.74(\mathrm{C} 8) \mathrm{ppm} .{ }^{31} \mathbf{P}\left\{{ }^{1} \mathbf{H}\right\}$ NMR $\left(\mathrm{CDCl}_{3}, 121.45 \mathrm{MHz}, \delta\right): 27.27 \mathrm{ppm}$. HRMS-ESI-TOF $(\mathrm{m} / \mathrm{z}):\left[\mathrm{M}^{+}-\mathrm{Br}^{-}\right]$calculated for $\mathrm{C}_{16} \mathrm{H}_{39} \mathrm{~N}_{2} \mathrm{O}_{5} \mathrm{P}_{1} \mathrm{~S}_{1}, 416.2343$, found, 416.2341. 


\subsubsection{Synthesis of Benzophenone based QUAT}

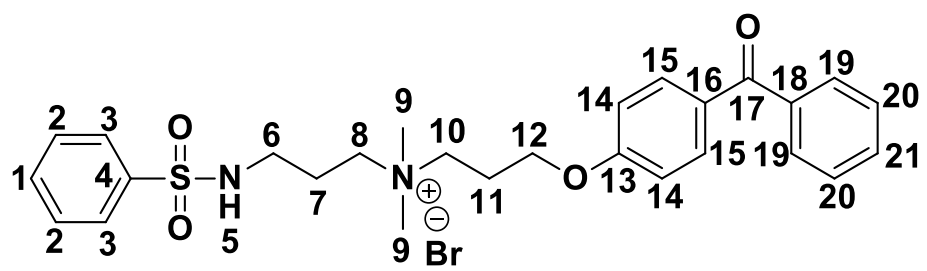

\section{3-(4-benzoylphenoxy)- $N, N$-dimethyl- $N$-(3-(phenylsulfonamido)propyl)propan-1-aminium}

bromide (1J):

This compound was synthesized using $N$-(3-(dimethylamino)propyl)phenylsulfonamide (0.921 g, $3.8 \mathrm{mmol}$ ) and 4-(3-bromopropoxy)benzophenone (1.29 $\mathrm{g}, 4.0 \mathrm{mmol})$ in $\mathrm{ACN}(10 \mathrm{~mL})$ for 48 hours; yielding in viscous pale yellow solution. The product was obtained as fluffy pale yellow coloured powder after purification. Yield: $82 \%$ (1.74 g). ${ }^{1} \mathbf{H} \mathbf{N M R}\left(\mathrm{CDCl}_{3}, 400 \mathrm{MHz}, \delta\right): 7.93(\mathrm{~m}$, 2H, H3), 7.82 (m, 1H, H5), 7.74 - 7.62 (m, 4H, H15 \& H19), 7.53 (m, 1H, H21), 7.49 - 7.37 (m, 5H, (H1, H2, \& H20)), $6.89\left(\mathrm{~d}, 2 \mathrm{H},{ }^{3} J_{14-15}=8.9 \mathrm{~Hz}, \mathrm{H} 14\right), 4.11\left(\mathrm{t},{ }^{3} J_{12-11}=5.3 \mathrm{~Hz}, \mathrm{H} 12\right), 3.79-$ 3.56 (m, 4H, H8 \& H10), 3.27 (s, 6H, H9), 3.01 (m, 2H, H6), 2.29 (m, 2H, H11), 2.10 (m, 2H, H7) ppm. ${ }^{13} \mathbf{C}\left\{{ }^{1} \mathbf{H}\right\}$ NMR $\left(\mathrm{CDCl}_{3}, 100 \mathrm{MHz}, \delta\right): 195.58$ (C17), 161.80 (C13), 139.64 (C1), 137.99 (C4), 132.71 (C18), 132.51 (C15), 132.19 (C21), 130.60 (C16), 139.75 (C2), 129.32 (C19), 128.35 (C20), 127.22 (C3), 114.31 (C14), 64.68 (C12), 62.44 (C8), 62.06 (C10), 39.98 (C6), 23.08 (C11), 22.75 (C7) ppm. HRMS-ESI-TOF (m/z): [ $\left.\mathrm{M}^{+}-\mathrm{Br}^{-}\right]$calculated for $\mathrm{C}_{27} \mathrm{H}_{33} \mathrm{~N}_{2} \mathrm{O}_{4} \mathrm{~S}, 481.2156$; found 481.2155 . 


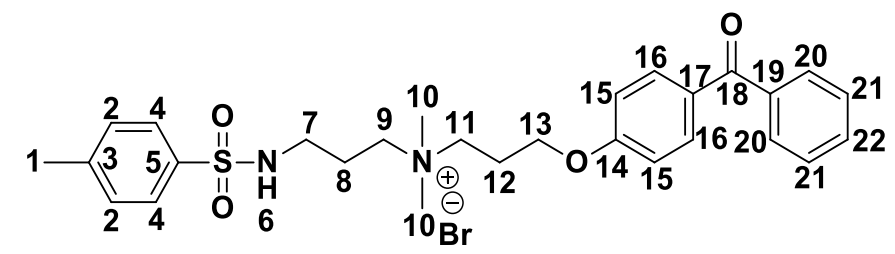

3-(4-benzoylphenoxy)- $N, N$-dimethyl- $N$-(3-(4-methylphenylsulfonamido)propyl)propan-1aminium bromide (2J):

This compound was synthesized using $N$-(3-(dimethylamino)propyl)-4methylphenyl)sulfonamide (1.05 g, $4.1 \mathrm{mmol})$ and 4-(3-bromopropoxy)benzophenone (1.417 g, $4.44 \mathrm{mmol})$ in ACN (10 mL) for 48 hours; yielding in viscous pale yellow solution. The product was obtained as fluffy white coloured powder after purification. Yield: $80 \%$ (1.88 g). ${ }^{\mathbf{1}} \mathbf{H}$ NMR $\left(\mathrm{CDCl}_{3}, 400 \mathrm{MHz}, \delta\right): 7.80\left(\mathrm{~d}, 2 \mathrm{H}, J_{4-2}=8.2 \mathrm{~Hz}, \mathrm{H} 4\right), 7.73-7.65$ (m, 4H, H16 \& H20), $7.56-$ $7.59(\mathrm{~m}, 1 \mathrm{H}, \mathrm{H} 22), 7.42\left(\mathrm{t}, J_{4-2}=7.2 \mathrm{~Hz} 2 \mathrm{H}, \mathrm{H} 22\right), 7.21\left(\mathrm{~d}, 2 \mathrm{H}, J_{2-4}=8.2 \mathrm{~Hz}, \mathrm{H} 2\right), 6.89(\mathrm{~d}, 2 \mathrm{H}$, $\left.J_{15-16}=8.8 \mathrm{~Hz}, \mathrm{H} 15\right), 4.12\left(\mathrm{t}, 2 \mathrm{H}, J_{13-12}=5.4 \mathrm{~Hz}, \mathrm{H} 13\right), 3.79-3.59(\mathrm{~m}, 4 \mathrm{H}, \mathrm{H} 9$ \& H11), 3.29 (s, 6H, H10), 3.07 - 2.90 (m, 2H, H7), 2.35 - 2.23 (m, 5H, H1 \& H12), $2.19-2.03$ (m, 2H, H8) ppm. ${ }^{13} \mathbf{C}\left\{{ }^{1} \mathbf{H}\right\}$ NMR $\left(\mathrm{CDCl}_{3}, 100 \mathrm{MHz}, \delta\right): 195.57$ (C18), 161.82 (C14), 143.50 (C3), 138.05 (C5), 136.53 (C19), 132.54 (C16), 132.19 (C22), 130.69 (C17), 129.90 (C20), 129.80 (C2), 128.36 (C21), 127.34 (C4), 114.32 (C15), 64.71 (C13), 62.53 (C9), 62.11 (C11), 51.62 (C10), 40.01 (C7), 23.15 (C12), $22.75(\mathrm{C} 8), 21.57$ (C1) ppm. HRMS-ESI-TOF (m/z): [M+ - $\left.\mathrm{Br}^{-}\right]$calculated for $\mathrm{C}_{28} \mathrm{H}_{35} \mathrm{~N}_{2} \mathrm{O}_{4} \mathrm{~S}, 495.2312$; found 495.2319. 


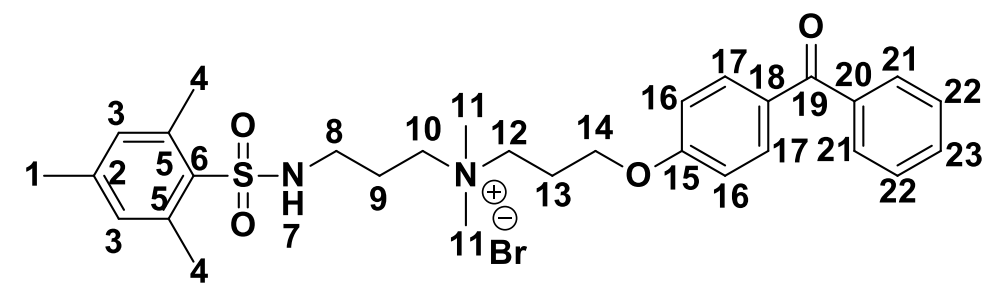

\section{3-(4-benzoylphenoxy)- $N, N$-dimethyl- $N$-(3-(2,4,6-}

trimethylphenylsulfonamido)propyl)propan-1-aminium bromide (3J):

This compound was synthesized using $N$-(3-(dimethylamino)propyl)-2,4,6trimethylphenyl)sulfonamide $(0.853 \mathrm{~g}, 3.0 \mathrm{mmol})$ and 4-(3-bromopropoxy)benzophenone $(1.0 \mathrm{~g}$, $3.13 \mathrm{mmol}$ ) in ACN (10 mL) for 48 hours; yielding in viscous pale yellow solution. The product was obtained as fluffy white coloured powder after purification. Yield: $67 \%(1.20 \mathrm{~g}) .{ }^{\mathbf{1}} \mathbf{H}$ NMR $\left(\mathrm{CDCl}_{3}, 400 \mathrm{MHz}, \delta\right): 7.76\left(\mathrm{~d}, 2 \mathrm{H}, J_{17-16}=8.7 \mathrm{~Hz}, \mathrm{H} 17\right), 7.72\left(\mathrm{~d}, 2 \mathrm{H}, J_{21-22}=7.2 \mathrm{~Hz}, \mathrm{H} 21\right), 7.56$ $\left(\mathrm{t}, 2 \mathrm{H},{ }^{3} J_{23-22}=7.4 \mathrm{~Hz}, \mathrm{H} 23\right), 7.56(\mathrm{~m}, 2 \mathrm{H}, \mathrm{H} 22), 7.22\left(\mathrm{t}, 1 \mathrm{H},{ }^{3} J_{7-8}=6.2 \mathrm{~Hz}, \mathrm{H} 7\right), 6.94\left(\mathrm{t}, 2 \mathrm{H},{ }^{3} J_{16-}\right.$ $17=6.0 \mathrm{~Hz}, \mathrm{H} 16), 6.90(\mathrm{~s}, 2 \mathrm{H}, \mathrm{H} 3), 4.21\left(\mathrm{t}, 2 \mathrm{H},{ }^{3} J_{14-13}=5.4 \mathrm{~Hz}, \mathrm{H} 14\right), 3.85(\mathrm{~m}, 2 \mathrm{H}, \mathrm{H} 10), 3.75$ (m, 2H, H12), 3.37 (s, 6H, H11), 3.04 (m, 2H, H8), 2.63 (s, 6H, H4), 2.38 (m, 2H, H13), 2.25 (s, 3H, H1), 2.20 (m, 2H, H9) ppm. ${ }^{13} \mathbf{C}\left\{{ }^{1} \mathbf{H}\right\}$ NMR $\left(\mathrm{CDCl}_{3}, 100 \mathrm{MHz}, \delta\right): 195.63$ (C19), 161.81 (C15), 142.40 (C5), 139.24 (C2), 138.15 (20), 133.41 (C6), 132.66 (C17), 132.22 (C23), 132.18 (C3), 130.91 (C18), 129.90 (C21), 128.39 (C22), 64.72 (C14), 62.68 (C10), 62.29 (C12), 51.77 (C11), 39.36 (C8), 23.42 (C4), 23.27 (C13), 23.05 (C9), 21.03 (C1) ppm. HRMS-ESI-TOF (m/z): $\left[\mathrm{M}^{+}-\mathrm{Br}^{-}\right]$calculated for $\mathrm{C}_{30} \mathrm{H}_{39} \mathrm{~N}_{2} \mathrm{O}_{4} \mathrm{~S}, 523.2625$; found 523.2636. 


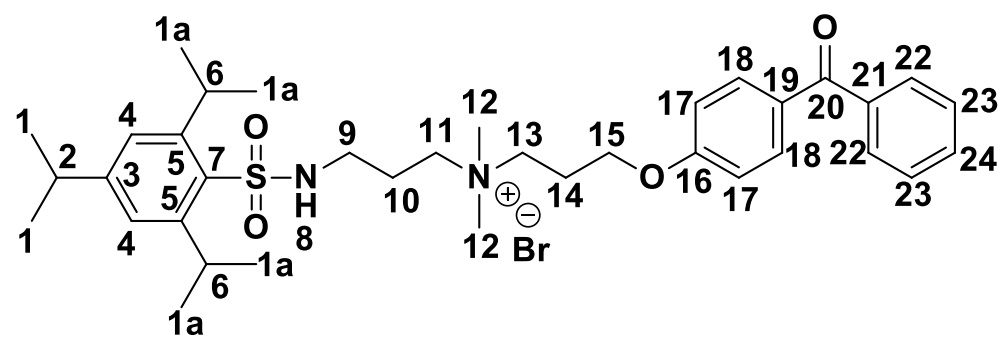

\section{3-(4-benzoylphenoxy)- $N, N$-dimethyl- $N$-(3-(2,4,6-}

triisopropylphenylsulfonamido)propyl)propan-1-aminium bromide (4J):

This compound was synthesized using $N$-(3-(dimethylamino)propyl)-2,4,6triisopropylbenzenesulfonamide $(0.379 \mathrm{~g}, 1.03 \mathrm{mmol})$ and 4-(3-bromopropoxy)benzophenone $(0.329 \mathrm{~g}, 1.03 \mathrm{mmol})$ in $\mathrm{ACN}(10 \mathrm{~mL})$ for 48 hours; yielding in viscous pale yellow solution. The product was obtained as fluffy pale white coloured powder after purification. Yield: 92\% (0.65 g). ${ }^{1} \mathbf{H}$ NMR $\left(\mathrm{CDCl}_{3}, 400 \mathrm{MHz}, \delta\right): 7.78$ - 765 (m, 4H, H18 \& H22), 7.57 - 7.49 (m, 1H, H24), 7.43 $\left(\mathrm{t}, 2 \mathrm{H},{ }^{3} J_{23-22}=7.5 \mathrm{~Hz}, \mathrm{H} 23\right), 7.12(\mathrm{~s}, 2 \mathrm{H}, \mathrm{H} 4), 7.06\left(\mathrm{t}, 1 \mathrm{H},{ }^{3} J_{8-9}=6.1 \mathrm{~Hz}, \mathrm{H} 8\right), 6.93\left(\mathrm{~d}, 2 \mathrm{H},{ }^{3} J_{17-18}\right.$ $=8.9 \mathrm{~Hz}, \mathrm{H} 17), 4.20\left(\mathrm{t}, 2 \mathrm{H},{ }^{3} J_{15-14}=5.5 \mathrm{~Hz}, \mathrm{H} 15\right), 4.12(\mathrm{~m}, 2 \mathrm{H}, \mathrm{H} 6), 3.86(\mathrm{~m}, 2 \mathrm{H}, \mathrm{H} 11), 3.75(\mathrm{~m}$, 2H, H13), 3.39 (s, 6H, H12), 3.10 (m, 1H, H9), 2.85 (m, 1H, H2), 2.37 (m, 2H, H14), 2.20 (m, 2H, H10), 1.21 (m, 18H, H1 \& H1a) ppm. ${ }^{13} \mathbf{C}\left\{{ }^{1} \mathbf{H}\right\}$ NMR $\left(\mathrm{CDCl}_{3}, 100 \mathrm{MHz}, \delta\right): 195.55$ (C20), 161.75 (C16), 152.76 (C3), 150.33 (C7), 138.01 (C21), 132.50 (C18), 132.06 (C24), 131.96 (C5), 130.66 (C19), 129.74 (C22), 128.24 (C23), 123.88 (C4), 114.22 (C17), 64.67 (C15), 62.49 (C11), 62.03 (C13), 51.66 (C12), 39.47 (C9), 34.10 (C2), 29.54 (C6), 25.12 (C1), 23.14 (C14), 23.07 (C10) ppm. HRMS-ESI-TOF (m/z): [ $\mathrm{M}^{+}$- $\left.\mathrm{Br}^{-}\right]$calculated for $\mathrm{C}_{36} \mathrm{H}_{51} \mathrm{~N}_{2} \mathrm{O}_{4} \mathrm{~S}, 607.3564$; found 607.3555. 


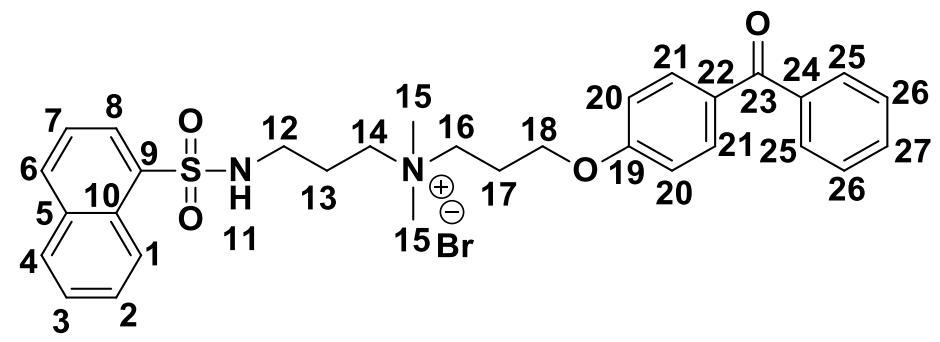

3-(4-benzoylphenoxy)- $N, N$-dimethyl- $N$-(3-(naphthalene-1-sulfonamido)propyl)propan-1aminium bromide (5J):

This compound was synthesized using $N$-(3-(dimethylamino)propyl)naphthalene-1-sulfonamide (0.584 g, $2.0 \mathrm{mmol})$ and 4-(3-bromopropoxy)benzophenone (0.702 g, $2.2 \mathrm{mmol})$ in ACN (10 mL) for 48 hours; yielding in viscous pale yellow solution. The product was obtained as fluffy white coloured powder after purification. Yield: $82 \%$ (1.0 g). ${ }^{1} \mathbf{H} \mathbf{~ N M R}\left(\mathrm{CDCl}_{3}, 400 \mathrm{MHz}, \delta\right): 8.80$ (d, $\left.1 \mathrm{H},{ }^{3} J_{1-2}=8.7 \mathrm{~Hz}, \mathrm{H} 1\right), 8.15\left(\mathrm{~d}, 1 \mathrm{H},{ }^{3} J_{8-7}=7.3 \mathrm{~Hz}, \mathrm{H} 8\right), 7.96(\mathrm{~s}, 1 \mathrm{H}, \mathrm{H} 11), 7.91\left(\mathrm{~d}, 1 \mathrm{H},{ }^{3} J_{6-7}=8.3\right.$ $\mathrm{Hz}, \mathrm{H} 6), 7.78\left(\mathrm{~d}, 1 \mathrm{H},{ }^{3} J_{4-3}=8.2 \mathrm{~Hz}, \mathrm{H} 4\right), 7.70-7.55(\mathrm{~m}, 4 \mathrm{H},(\mathrm{H} 2, \mathrm{H} 25, \& \mathrm{H} 21)), 7.51\left(\mathrm{t}, 2 \mathrm{H},{ }^{3} J_{27-}\right.$ $26=7.4 \mathrm{~Hz}, \mathrm{H} 27), 7.46-7.34\left(\mathrm{~m}, 4 \mathrm{H},(\mathrm{H} 3, \mathrm{H} 26, \& \mathrm{H} 7), 6.77\left(\mathrm{~d}, 2 \mathrm{H},{ }^{3} J_{20-21}=8.7 \mathrm{~Hz}, \mathrm{H} 20\right), 3.92\right.$ (m, 2H, H18), 3.59 - 3.37 (m, 4H, H14 \& H16), 3.19 - 2.91 (m, 8H, H15 \& H12), 2.04 (m, 2H, H17), 1.91 (m, 2H, H13) ppm. ${ }^{13} \mathbf{C}\left\{{ }^{1} \mathbf{H}\right\}$ NMR $\left(\mathrm{CDCl}_{3}, 100 \mathrm{MHz}, \delta\right): 195.59$ (C23), 161.77 (C19), 138.04 (C24), 134.85 (C9), 134.21 (C6), 132.50 (C25), 132.20 (C27), 130.56 (C10), 129.80 (C2), 129.36 (C8), 129.05 (C4), 128.76 (C21), 128.37 (C7), 128.00 (C22), 127.18 (C3), 125.20 (C1), 124.52 (C26), 114.25 (C20), 64.59 (C18), 62.42 (C14), 62.10 (C16), 51.42 (15), 39.83 (C12), 22.92 (C17 \& C13) ppm. HRMS-ESI-TOF (m/z): [ $\left.\mathrm{M}^{+}-\mathrm{Br}^{-}\right]$calculated for $\mathrm{C}_{31} \mathrm{H}_{35} \mathrm{~N}_{2} \mathrm{O}_{4} \mathrm{~S}$, 531.2312; found 531.2328. 


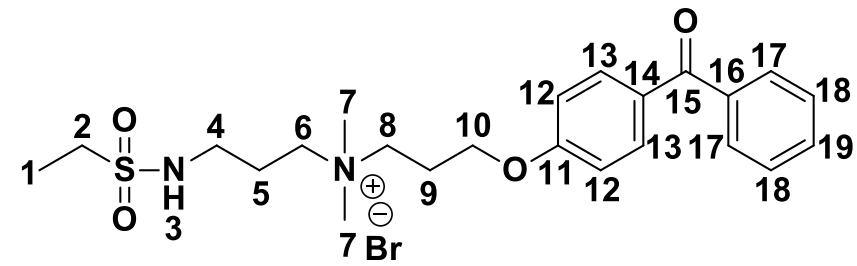

\section{3-(4-benzoylphenoxy)- $N$-(3-(ethylsulfonamido)propyl)- $N, N$-dimethylpropan-1-aminium} bromide (7J):

This compound was synthesized using $N$-(3-(dimethylamino)propyl)ethanesulfonamide $(0.250 \mathrm{~g}$, $1.29 \mathrm{mmol})$ and 4-(3-bromopropoxy)benzophenone (0.411 g, $1.29 \mathrm{mmol})$ in ACN (10 mL) for 48 hours; yielding in viscous pale yellow solution. The product was obtained as fluffy pale yellow coloured powder after purification. Yield: $77 \%(0.52 \mathrm{~g}) .{ }^{1} \mathbf{H} \mathbf{N M R}\left(\mathrm{CDCl}_{3}, 400 \mathrm{MHz}, \delta\right): 7.78$ (d, $\left.2 \mathrm{H},{ }^{3} J_{13-12}=8.7 \mathrm{~Hz}, \mathrm{H} 13\right), 7.72\left(\mathrm{~d}, 2 \mathrm{H},{ }^{3} J_{17-18}=7.4 \mathrm{~Hz}, \mathrm{H} 17\right), 7.56$ (t, $\left.2 \mathrm{H},{ }^{3} J_{19-18}=7.4 \mathrm{~Hz}, \mathrm{H} 19\right)$, $7.50-7.40(\mathrm{~m}, 2 \mathrm{H}, \mathrm{H} 18), 7.12\left(\mathrm{t}, 1 \mathrm{H},{ }^{3} J_{3-4}=6.0 \mathrm{~Hz}, \mathrm{H} 3\right), 6.98\left(\mathrm{~d}, 2 \mathrm{H},{ }^{3} J_{12-13}=8.8 \mathrm{~Hz}, \mathrm{H} 12\right), 4.21$ $\left(\mathrm{t}, 2 \mathrm{H},{ }^{3} J_{10-9}=5.3 \mathrm{~Hz}, \mathrm{H} 10\right), 3.80(\mathrm{~m}, 2 \mathrm{H}, \mathrm{H} 6), 3.71(\mathrm{~m}, 2 \mathrm{H}, \mathrm{H} 8), 3.35(\mathrm{~s}, 6 \mathrm{H}, \mathrm{H} 7), 3.31-3.22(\mathrm{~m}$, 2H, H4), 3.07 (q, 2H, $\left.J_{2-3}=7.3 \mathrm{~Hz}, \mathrm{H} 2\right), 2.37(\mathrm{~m}, 2 \mathrm{H}, \mathrm{H} 9), 2.20(\mathrm{~m}, 2 \mathrm{H}, \mathrm{H} 5), 1.34\left(\mathrm{t}, 3 \mathrm{H},{ }^{3} J_{2-3}=\right.$ $7.4 \mathrm{~Hz}, \mathrm{H1}) \mathrm{ppm} .{ }^{13} \mathbf{C}\left\{{ }^{1} \mathbf{H}\right\} \mathbf{N M R}\left(\mathrm{CDCl}_{3}, 100 \mathrm{MHz}, \delta\right): 195.55(\mathrm{C} 15), 161.66(\mathrm{C} 11), 137.94$ (C16), 132.55 (C13), 132.16 (C19), 130.83 (C14), 129.78 (C17), 128.29 (C18), 114.22 (C12), 64.57 (C10), 62.46 (C6), 62.17 (C8), 51.61 (C7), 46.44 (C2), 39.95 (C4), 23.64 (C5), 23.11 (C9), 8.27 (C1) ppm. HRMS-ESI-TOF (m/z): $\left[\mathrm{M}^{+}-\mathrm{Br}^{-}\right]$calculated for $\mathrm{C}_{23} \mathrm{H}_{33} \mathrm{~N}_{2} \mathrm{O}_{4} \mathrm{~S}$, 433.2156; found 433.2153. 


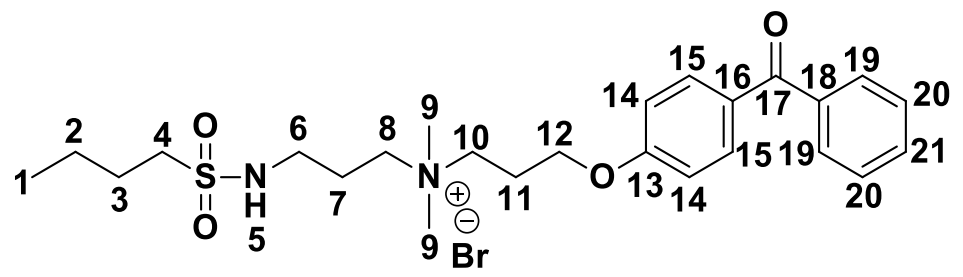

\section{3-(4-benzoylphenoxy)- $N$-(3-(butylsulfonamido)propyl)- $N, N$-dimethylpropan-1-aminium}

\section{bromide (8J):}

This compound was synthesized using $N$-(3-(dimethylamino)propyl)butane-1-sulfonamide (0.324 $\mathrm{g}, 1.46 \mathrm{mmol}$ ) and 4-(3-bromopropoxy)benzophenone (0.466 g, $1.46 \mathrm{mmol})$ in ACN (10 mL) for 48 hours; yielding in viscous pale yellow solution. The product was obtained as fluffy pale yellow coloured powder after purification. Yield: $73 \%(0.58 \mathrm{~g}){ }^{\mathbf{1}} \mathbf{H} \mathbf{N M R}\left(\mathrm{CDCl}_{3}, 400 \mathrm{MHz}, \delta\right): 7.74$ (d, $\left.2 \mathrm{H},{ }^{3} J_{15-14}=8.7 \mathrm{~Hz}, \mathrm{H} 15\right), 7.69\left(\mathrm{~d}, 2 \mathrm{H},{ }^{3} J_{19-20}=7.1 \mathrm{~Hz}, \mathrm{H} 19\right), 7.54\left(\mathrm{t}, 1 \mathrm{H},{ }^{3} J_{21-20}=7.4 \mathrm{~Hz}, \mathrm{H} 21\right)$, $7.44(\mathrm{~m}, 2 \mathrm{H}, \mathrm{H} 20), 7.10\left(\mathrm{t}, 1 \mathrm{H},{ }^{3} J_{5-6}=5.6 \mathrm{~Hz}, \mathrm{H} 5\right), 6.96\left(\mathrm{~d}, 2 \mathrm{H},{ }^{3} J_{14-15}=8.8 \mathrm{~Hz}, \mathrm{H} 14\right), 4.18(\mathrm{t}, 1 \mathrm{H}$, $\left.{ }^{3} J_{12-11}=5.2 \mathrm{~Hz}, \mathrm{H} 12\right), 3.79-3.61$ (m, 2H, H8 \& H10), 3.33 (s, 6H, H9), 3.24 (m, 2H, H6), 3.02 (m, 2H, H4), 2.33 (m, 2H, H11), 2.18 (m, 2H, H7), 1.73 (m, 2H, H3), 1.38 (m, 2H, H2), 0.87 (t, $\left.3 \mathrm{H},{ }^{3} J_{1-2}=7.3 \mathrm{~Hz}, \mathrm{H} 1\right) \mathrm{ppm} .{ }^{\mathbf{1 3}} \mathbf{C}\left\{{ }^{1} \mathbf{H}\right\} \mathbf{N M R}\left(\mathrm{CDCl}_{3}, 100 \mathrm{MHz}, \delta\right): 195.56(\mathrm{C} 17), 161.17(\mathrm{C} 13)$, 137.89 (C18), 132.50 (C15), 132.16 (C21), 130.62 (C16), 129.71 (C19), 128.29 (C20), 114.27 (C14), 64.67 (C12), 62.30 (C8), 61.96 (C10), 51.79 (C4), 51.56 (C9), 25.37 (C3), 23.55 (C7), $23.05(\mathrm{C} 11), 21.51(\mathrm{C} 2), 13.64(\mathrm{C} 1) \mathrm{ppm}$. HRMS-ESI-TOF (m/z): $\left[\mathrm{M}^{+}-\mathrm{Br}^{-}\right]$calculated for $\mathrm{C}_{25} \mathrm{H}_{37} \mathrm{~N}_{2} \mathrm{O}_{4} \mathrm{~S}, 461.2469$; found 461.2458. 


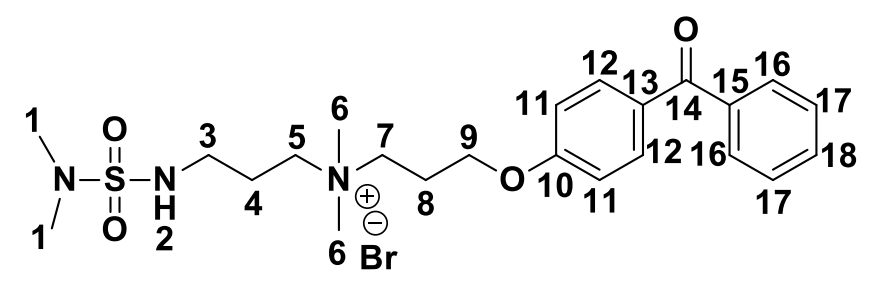

3-(4-benzoylphenoxy)- $N$-(3-(( $N, N$-dimethylsulfamoyl)amino)propyl)- $N, N$-dimethylpropan-

\section{1-aminium bromide (9J):}

This compound was synthesized using $N$-(2-(dimethylamino)propyl)-N,N-Dimethyl-sulfamide (0.232 g, $1.11 \mathrm{mmol})$ and 4-(3-bromopropoxy)benzophenone (0.354 g, $1.11 \mathrm{mmol})$ in ACN (10 $\mathrm{mL}$ ) for 48 hours; yielding in viscous pale yellow solution. The product was obtained as fluffy pale yellow coloured powder after purification. Yield: $60 \%(0.36 \mathrm{~g}) .{ }^{1} \mathbf{H} \mathbf{~ N M R}\left(\mathrm{CDCl}_{3}, 400 \mathrm{MHz}\right.$,

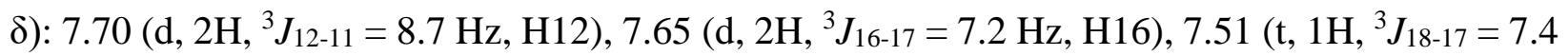
Hz, H18), 7.40 (m, 2H, H17), $7.03-6.87$ (m, 3H, H11 \& H2), 4.15 (t, 2H, J9-8 = 4.7 Hz, H9), 3.71 - 3.53 (m, 4H, H5 \& H7), 3.28 (s, 6H, H6), 3.15 (m, 2H, H3), 2.72 (s, 6H, H1), 2.29 (m, 2H, H8), $2.11(\mathrm{~m}, 2 \mathrm{H}, \mathrm{H} 4) \mathrm{ppm} .{ }^{13} \mathbf{C}\left\{{ }^{1} \mathbf{H}\right\} \mathbf{N M R}\left(\mathrm{CDCl}_{3}, 100 \mathrm{MHz}, \delta\right): 195.62$ (C14), 161.88(C9), 137.87 (C15), 132.50 (C12), 132.17 (C18), 130.49 (C13), 129.73 (C16), 128.30 (C17), 114.35 (C11), 64.82 (C9), 62.24 (C5), 61.76 (C7), 51.62 (C6), 40.18 (C3), 38.15 (C1), 23.06 (C4), 22.97 (C8) ppm. HRMS-ESI-TOF (m/z): [ $\mathrm{M}^{+}$- $\left.\mathrm{Br}^{-}\right]$calculated for $\mathrm{C}_{23} \mathrm{H}_{34} \mathrm{~N}_{2} \mathrm{O}_{4} \mathrm{~S}, 448.2265$; found 448.2262. 


\section{APPENDICES}

\section{List of Appendices Figures}

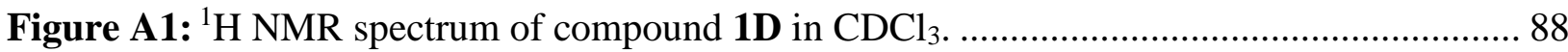

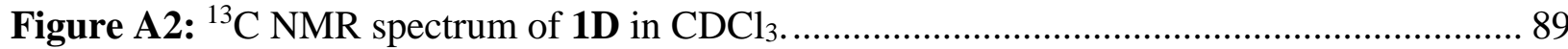

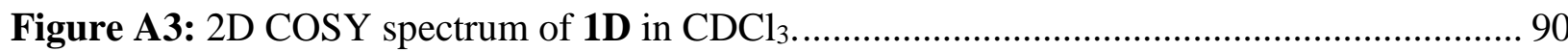

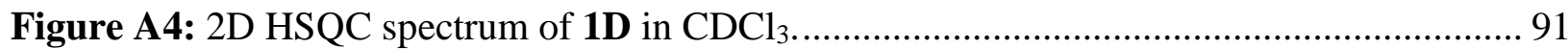

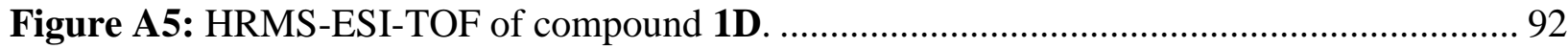

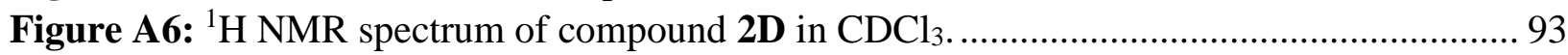

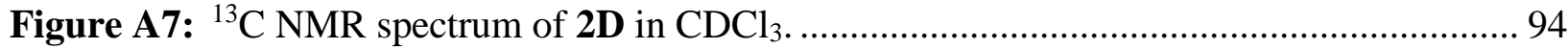

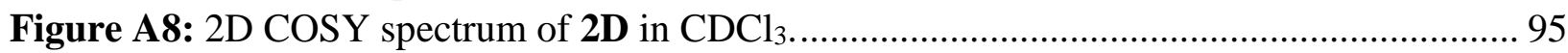

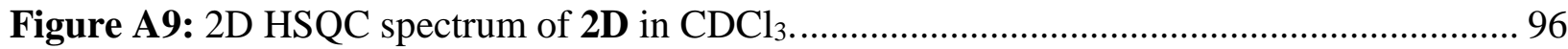

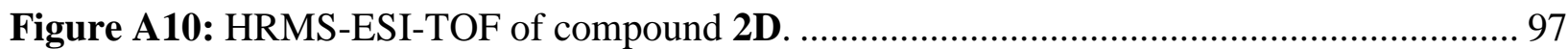

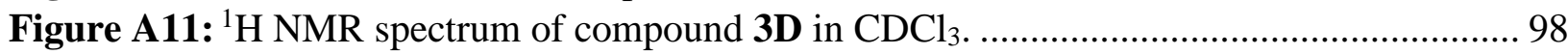

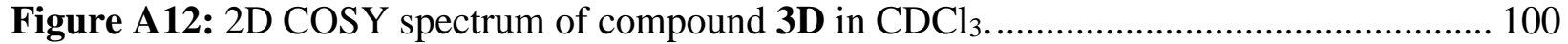

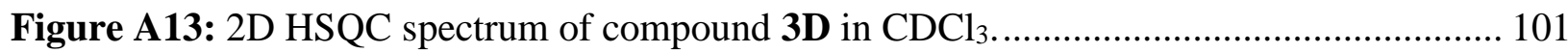

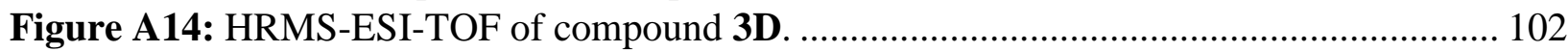

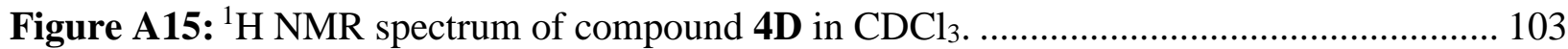

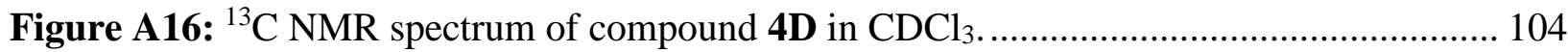

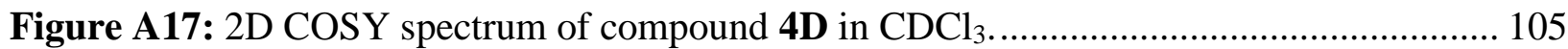

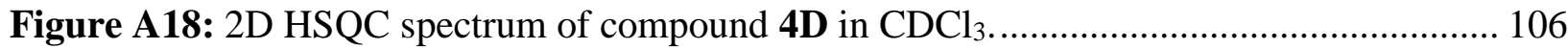

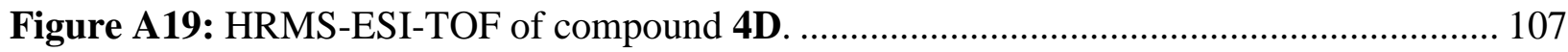

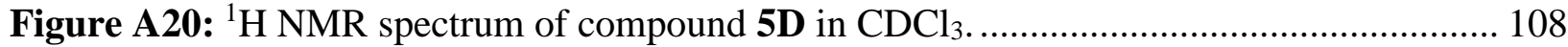

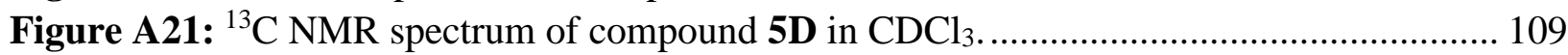

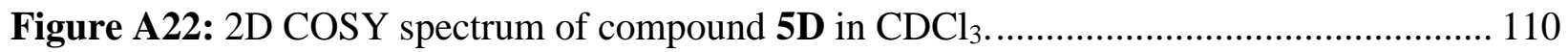

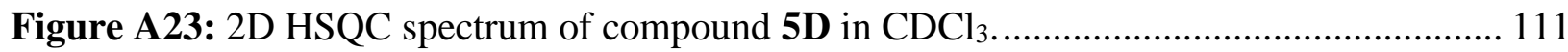

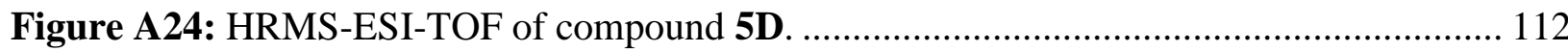

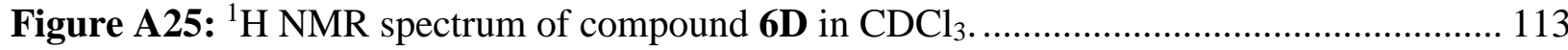

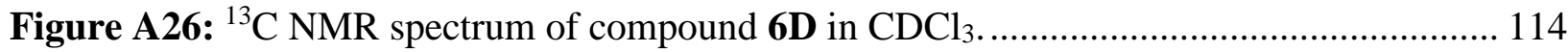

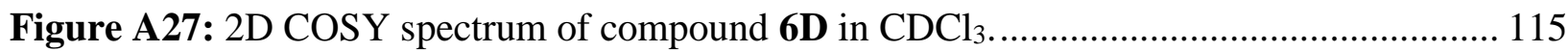

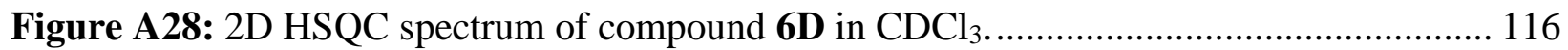

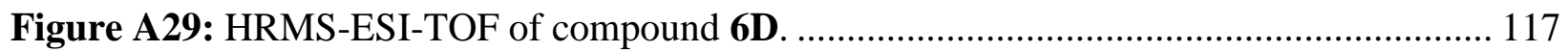

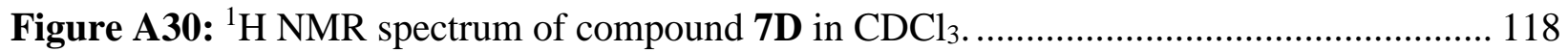

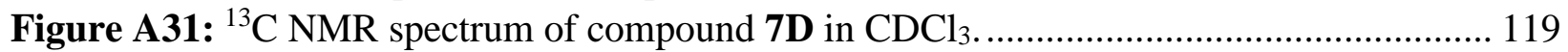

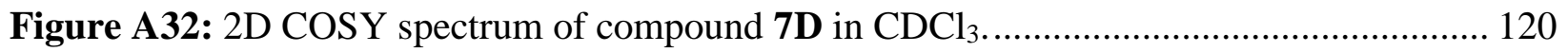

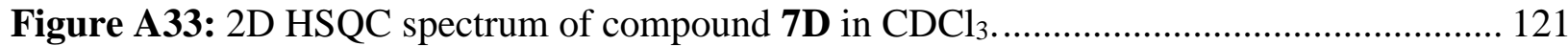

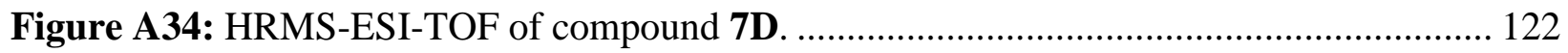

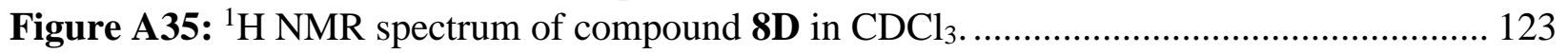

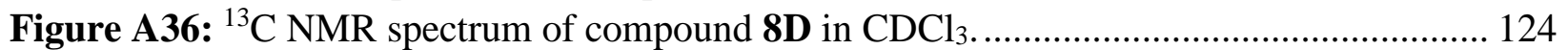

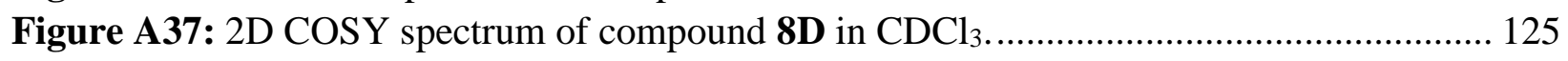

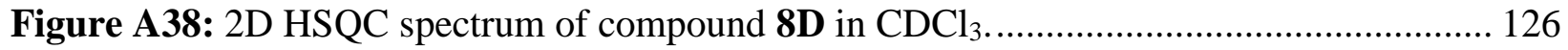

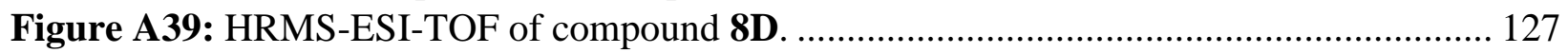




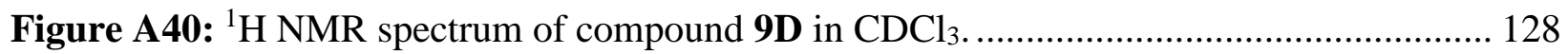

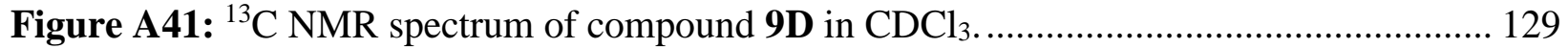

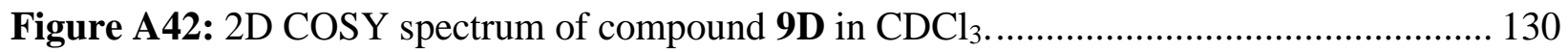

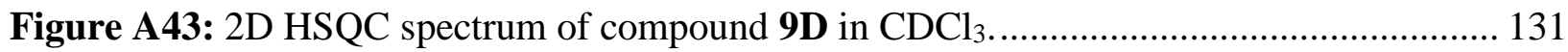

Figure A44: HRMS-ESI-TOF of compound 9D. ........................................................... 132

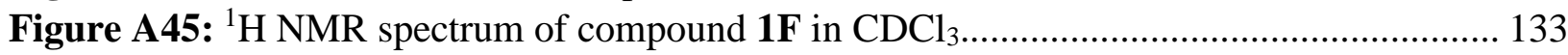

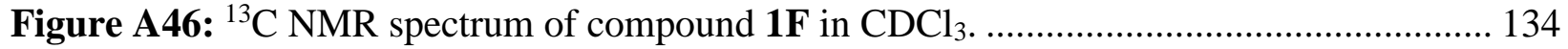

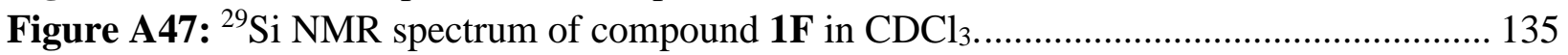

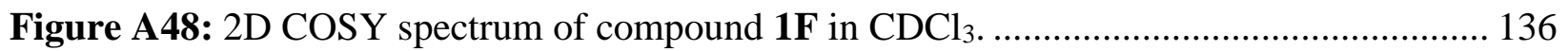

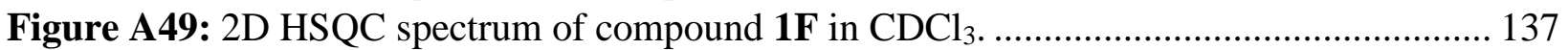

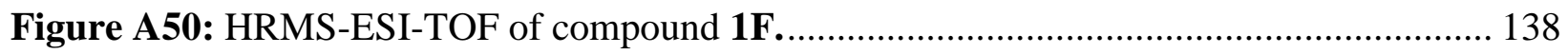

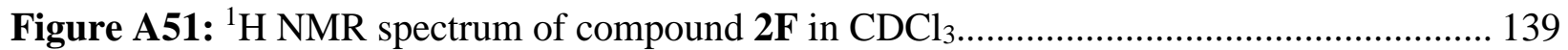

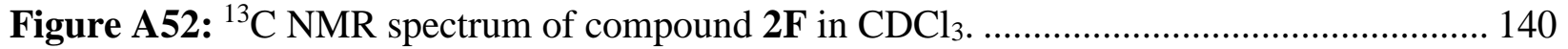

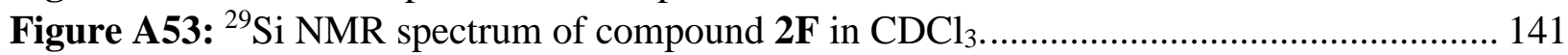

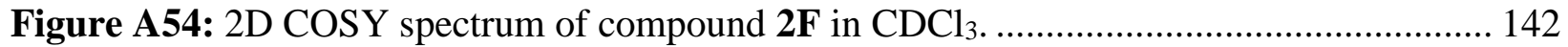

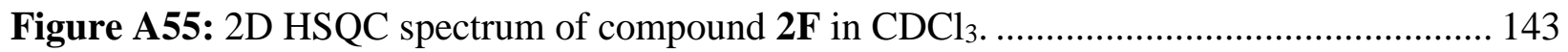

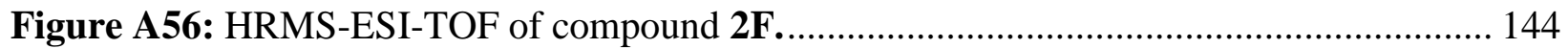

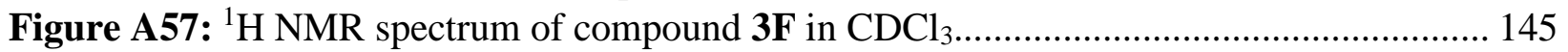

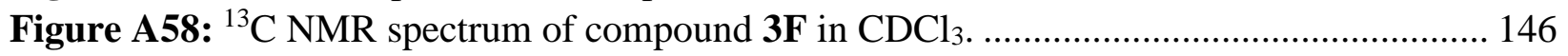

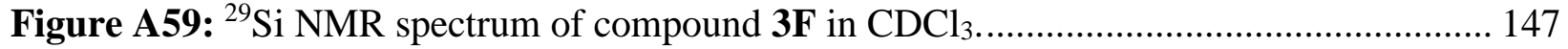

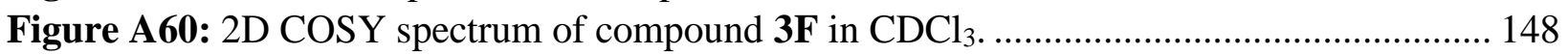

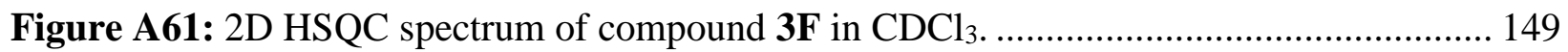

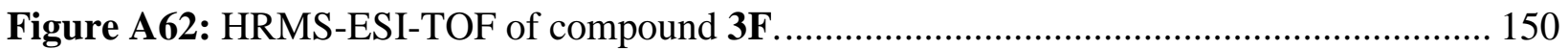

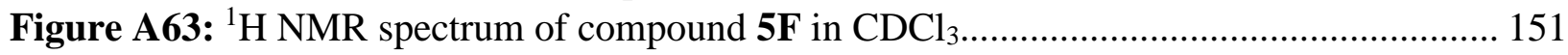

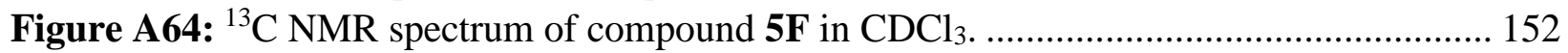

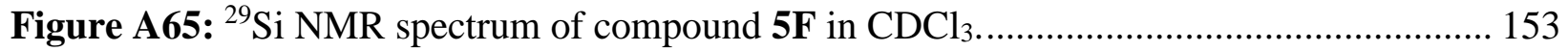

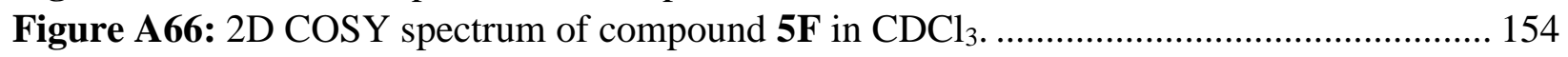

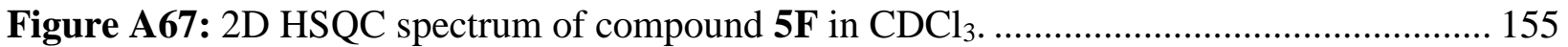

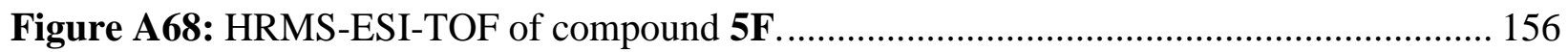

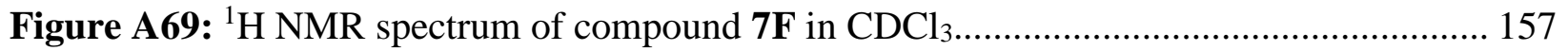

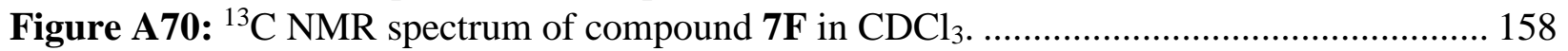

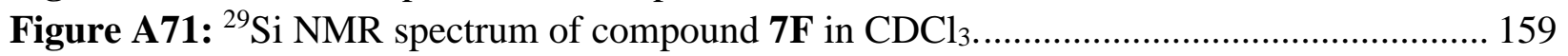

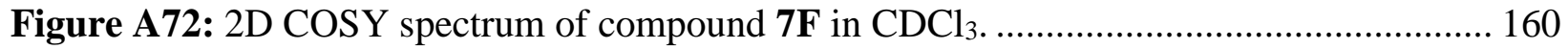

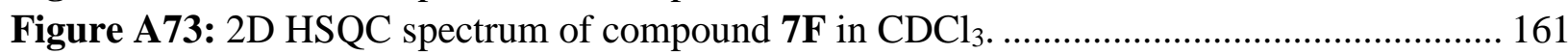

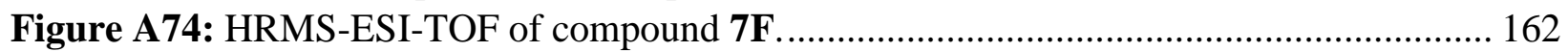

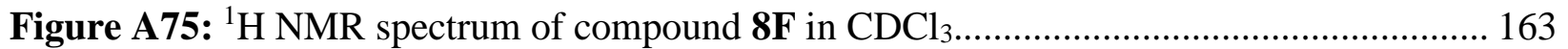

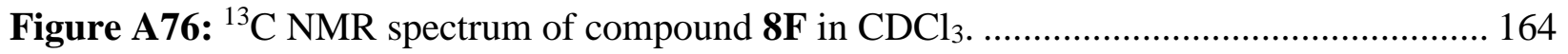

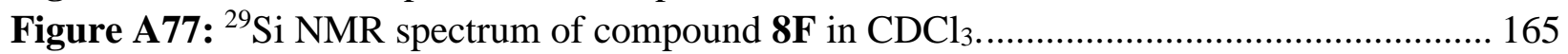

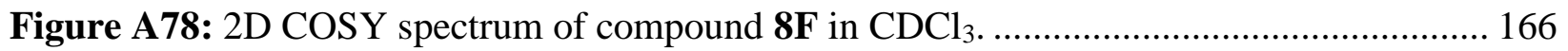

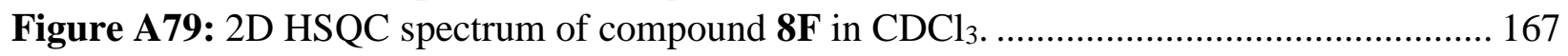

Figure A80: HRMS-ESI-TOF of compound 8F .......................................................... 168

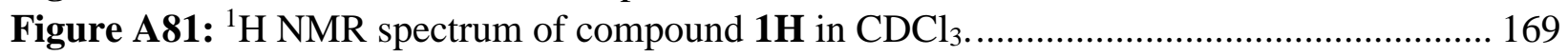

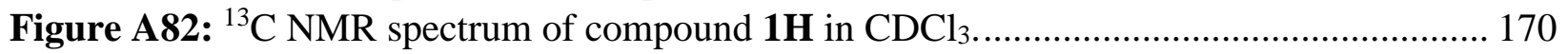




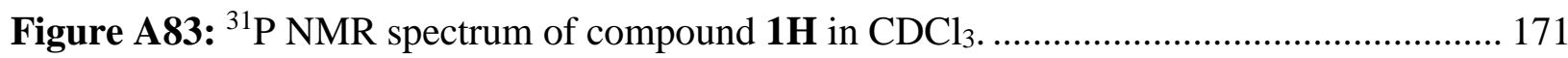

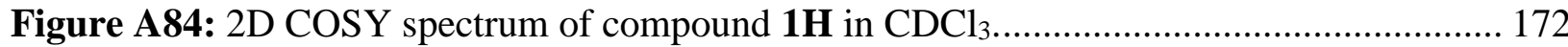

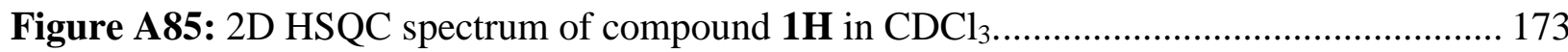

Figure A86: HRMS-ESI-TOF of compound 1H.......................................................... 174

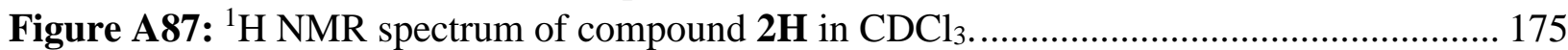

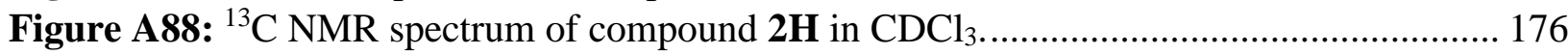

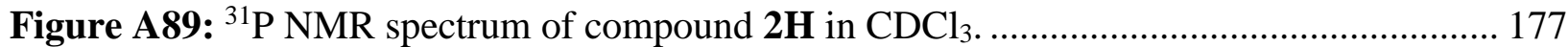

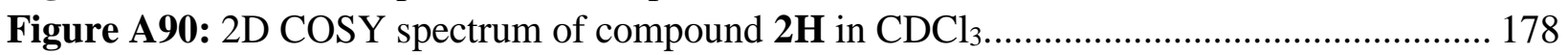

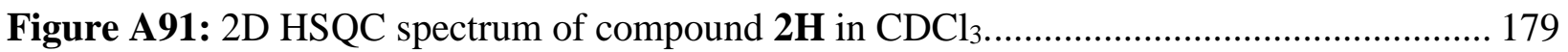

Figure A92: HRMS-ESI-TOF of compound 2H. ............................................................ 180

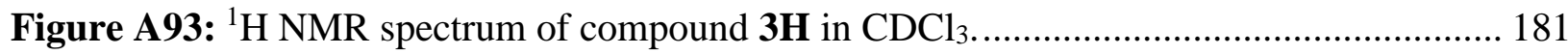

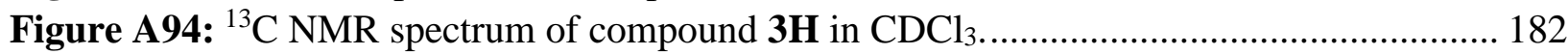

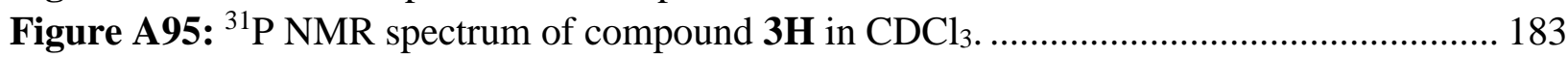

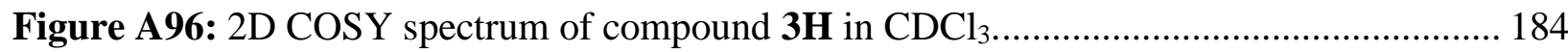

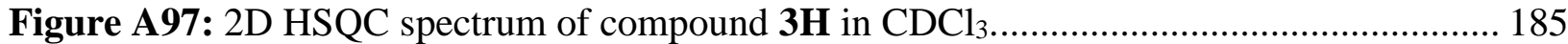

Figure A98: HRMS-ESI-TOF of compound 3H. ....................................................... 186

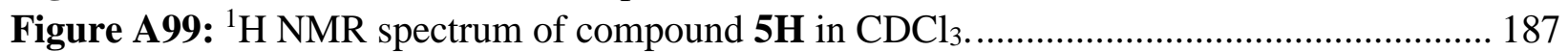

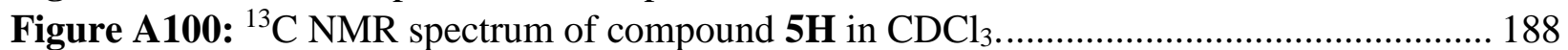

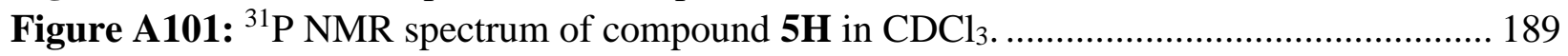

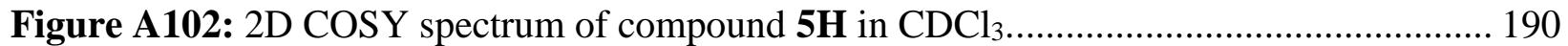

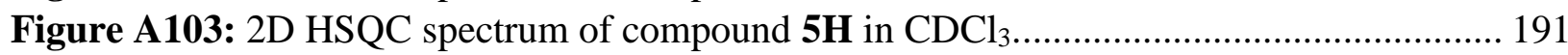

Figure A104: HRMS-ESI-TOF of compound 5H........................................................ 192

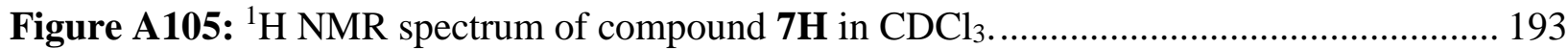

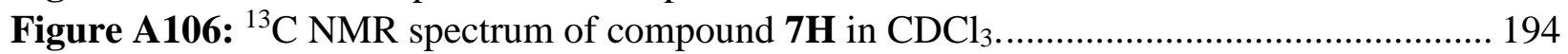

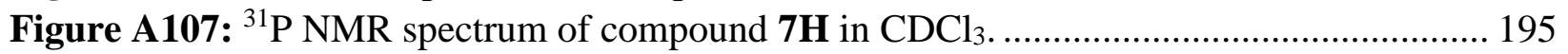

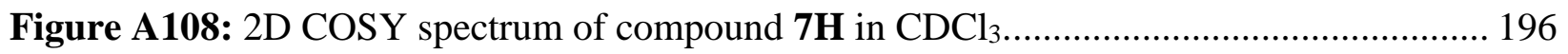

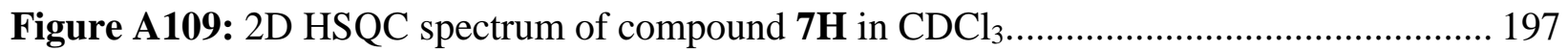

Figure A110: HRMS-ESI-TOF of compound 7H........................................................ 198

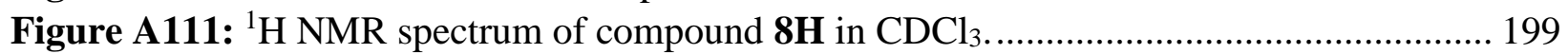

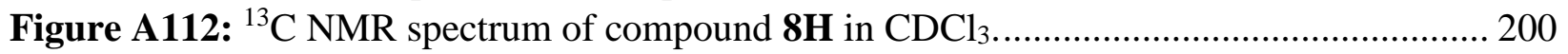

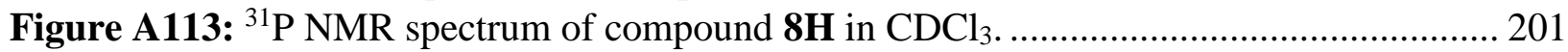

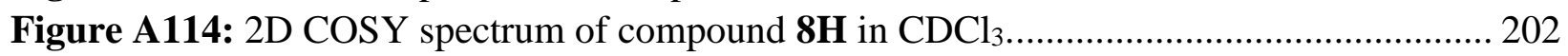

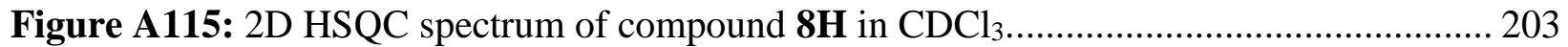

Figure A116: HRMS-ESI-TOF of compound 8H.............................................................. 204

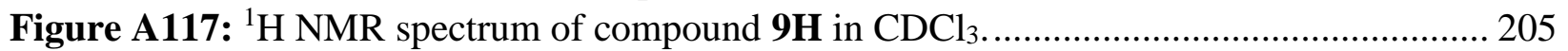

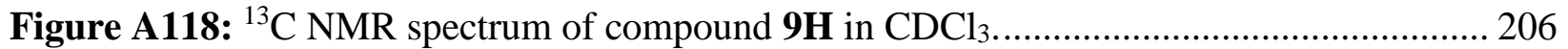

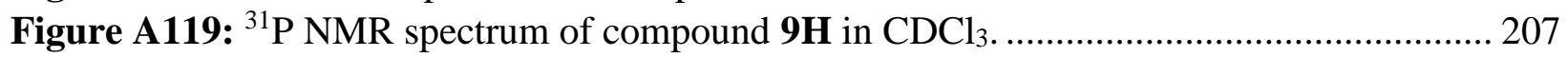

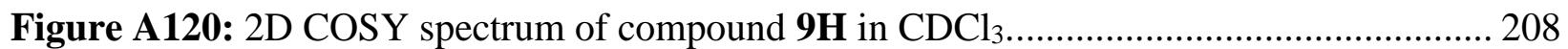

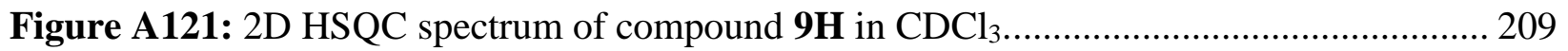

Figure A122: HRMS-ESI-TOF of compound 9H.......................................................... 210

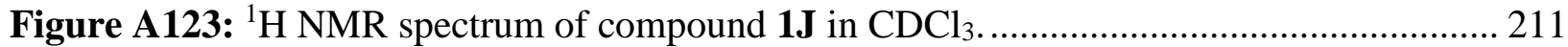

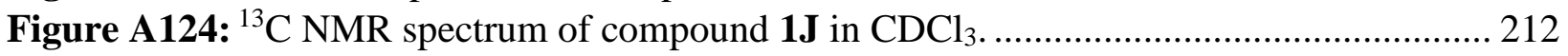

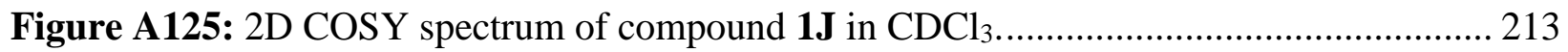




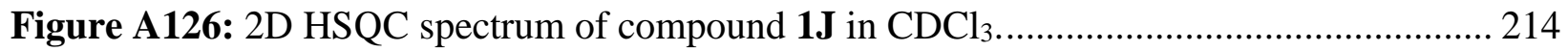

Figure A127: HRMS-ESI-TOF of compound 1J. .......................................................... 215

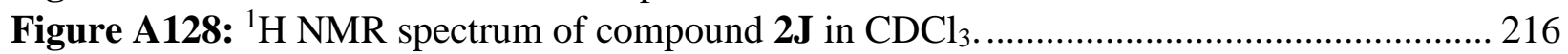

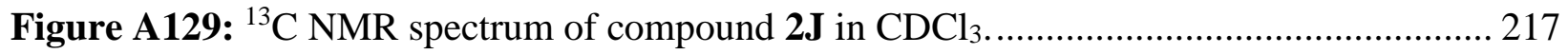

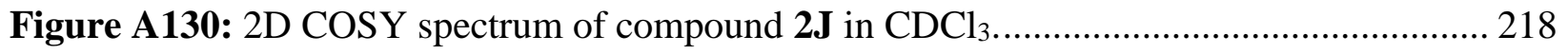

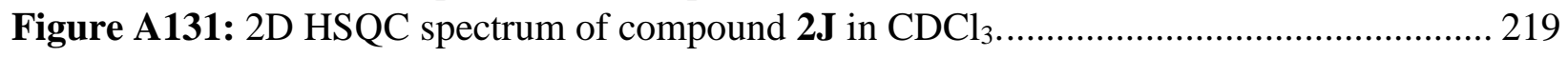

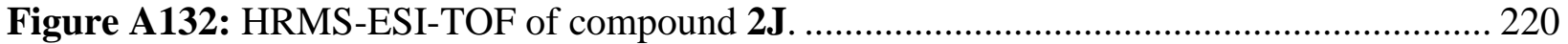

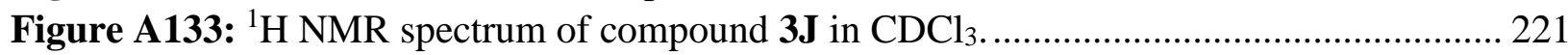

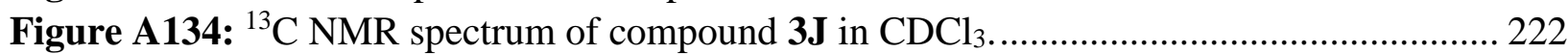

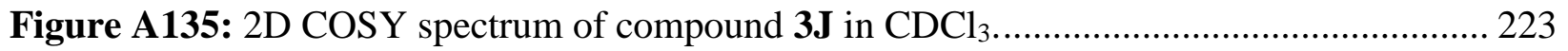

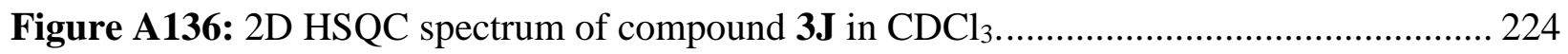

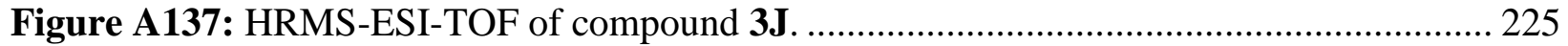

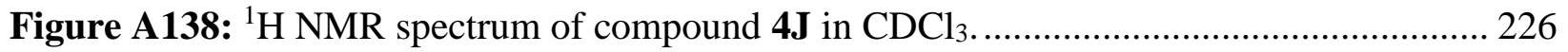

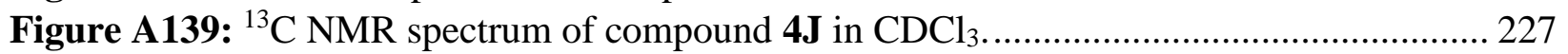

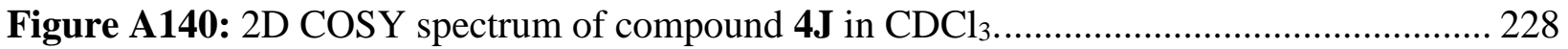

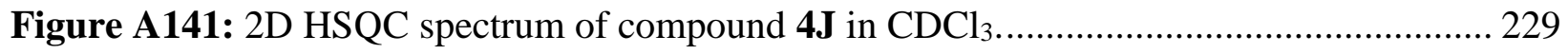

Figure A142: HRMS-ESI-TOF of compound 4J. ............................................................ 230

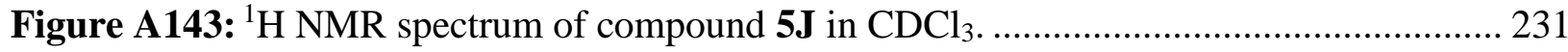

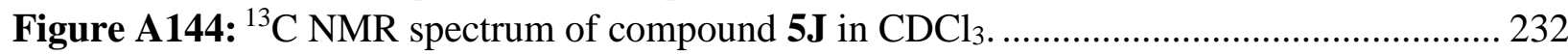

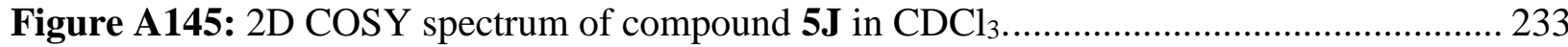

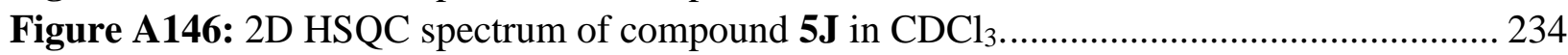

Figure A147: HRMS-ESI-TOF of compound 5J. ......................................................... 235

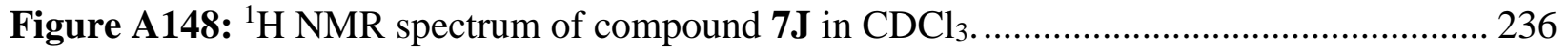

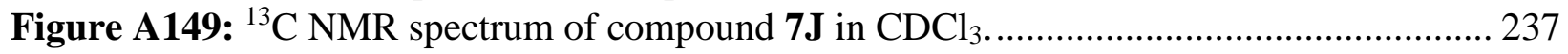

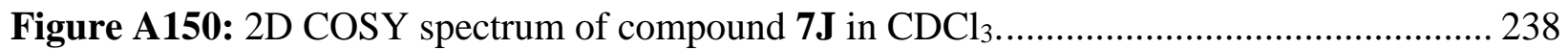

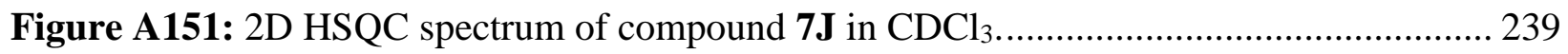

Figure A152: HRMS-ESI-TOF of compound 7J. ............................................................. 240

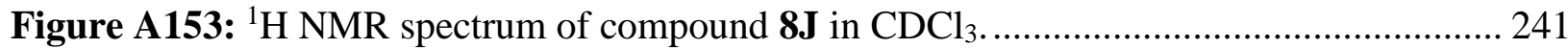

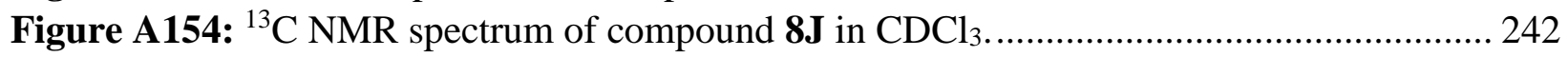

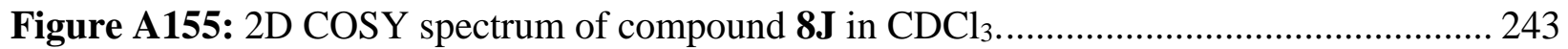

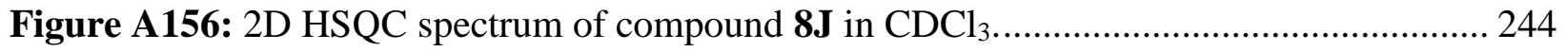

Figure A157: HRMS-ESI-TOF of compound 8J. .......................................................... 245

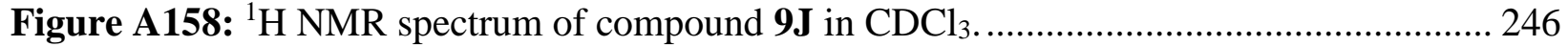

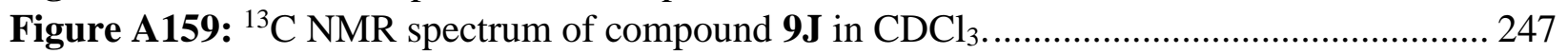

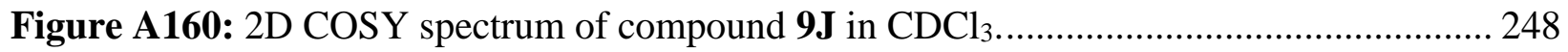

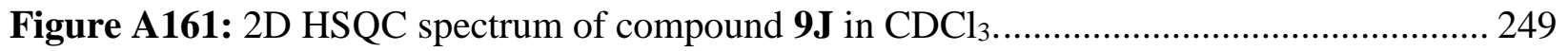

Figure A162: HRMS-ESI-TOF of compound 9J. ...................................................... 250 

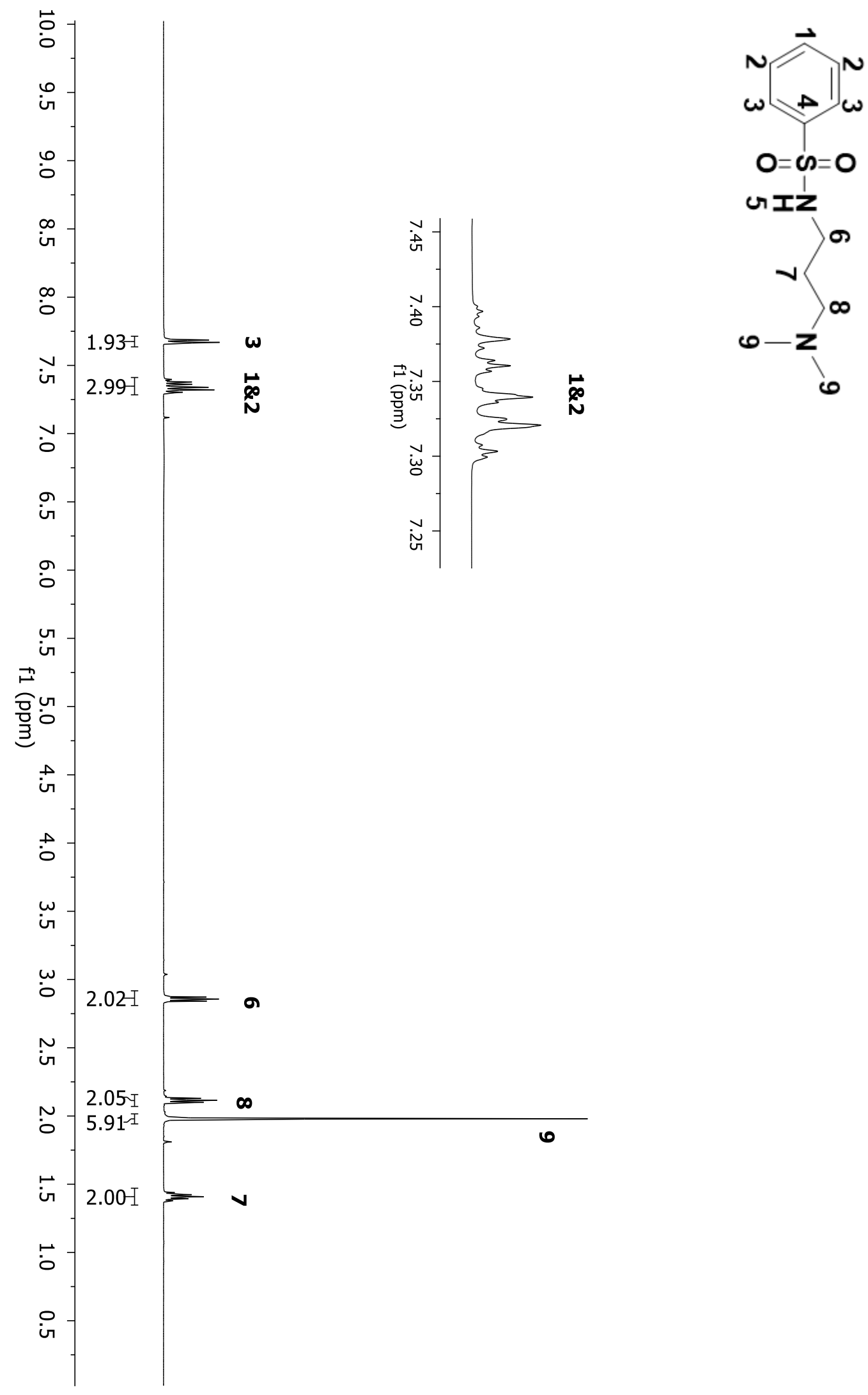

Figure A1: ${ }^{1} \mathrm{H}$ NMR spectrum of $\mathbf{1 D}$ in $\mathrm{CDCl}_{3}$. 

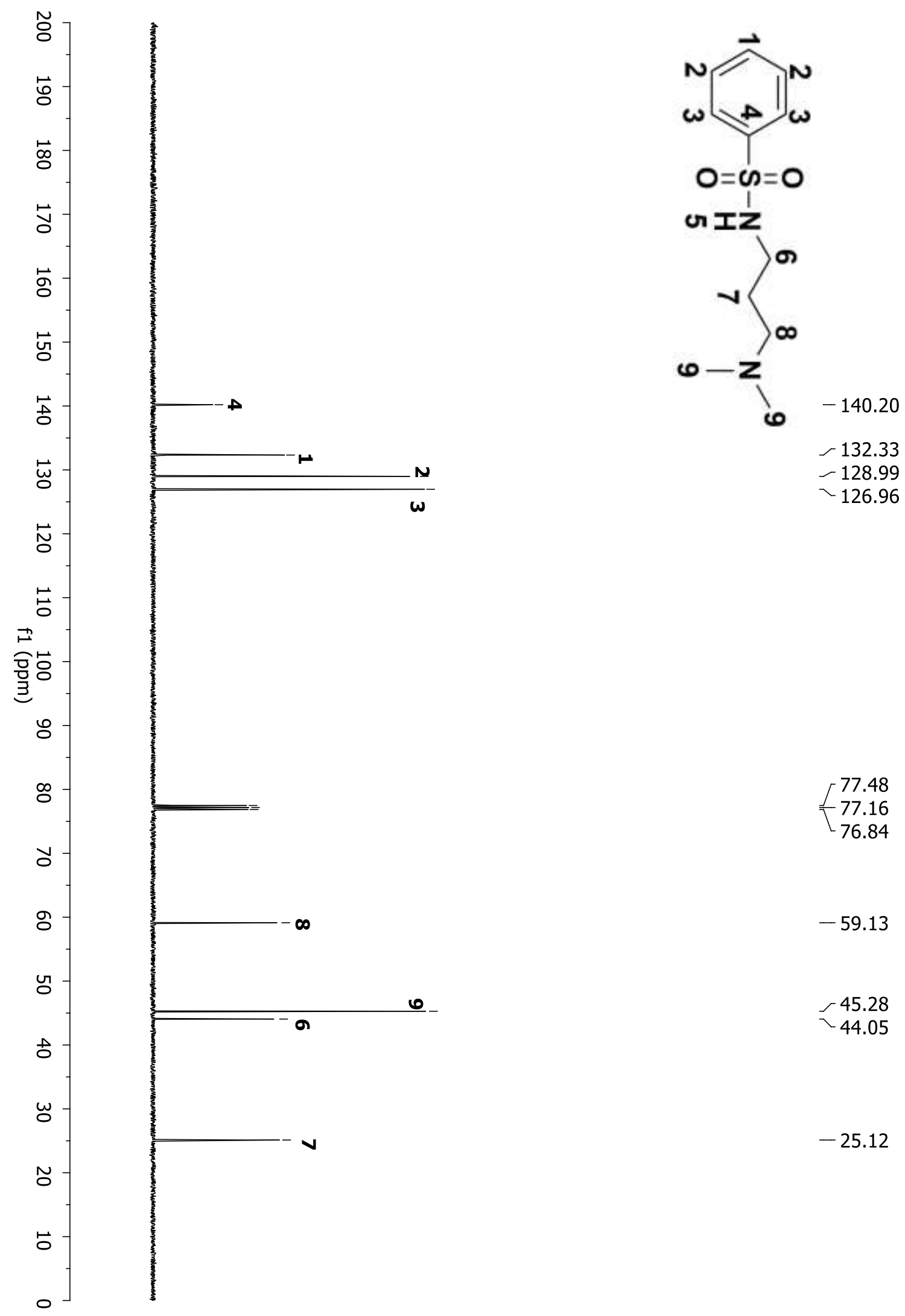

$$
\begin{array}{r}
77.48 \\
-77.16 \\
76.84
\end{array}
$$$$
-59.13
$$$$
-45.28
$$$$
\checkmark 44.05
$$

Figure A2: ${ }^{13} \mathrm{C}$ NMR spectrum of $1 \mathrm{D}$ in $\mathrm{CDCl}_{3}$. 


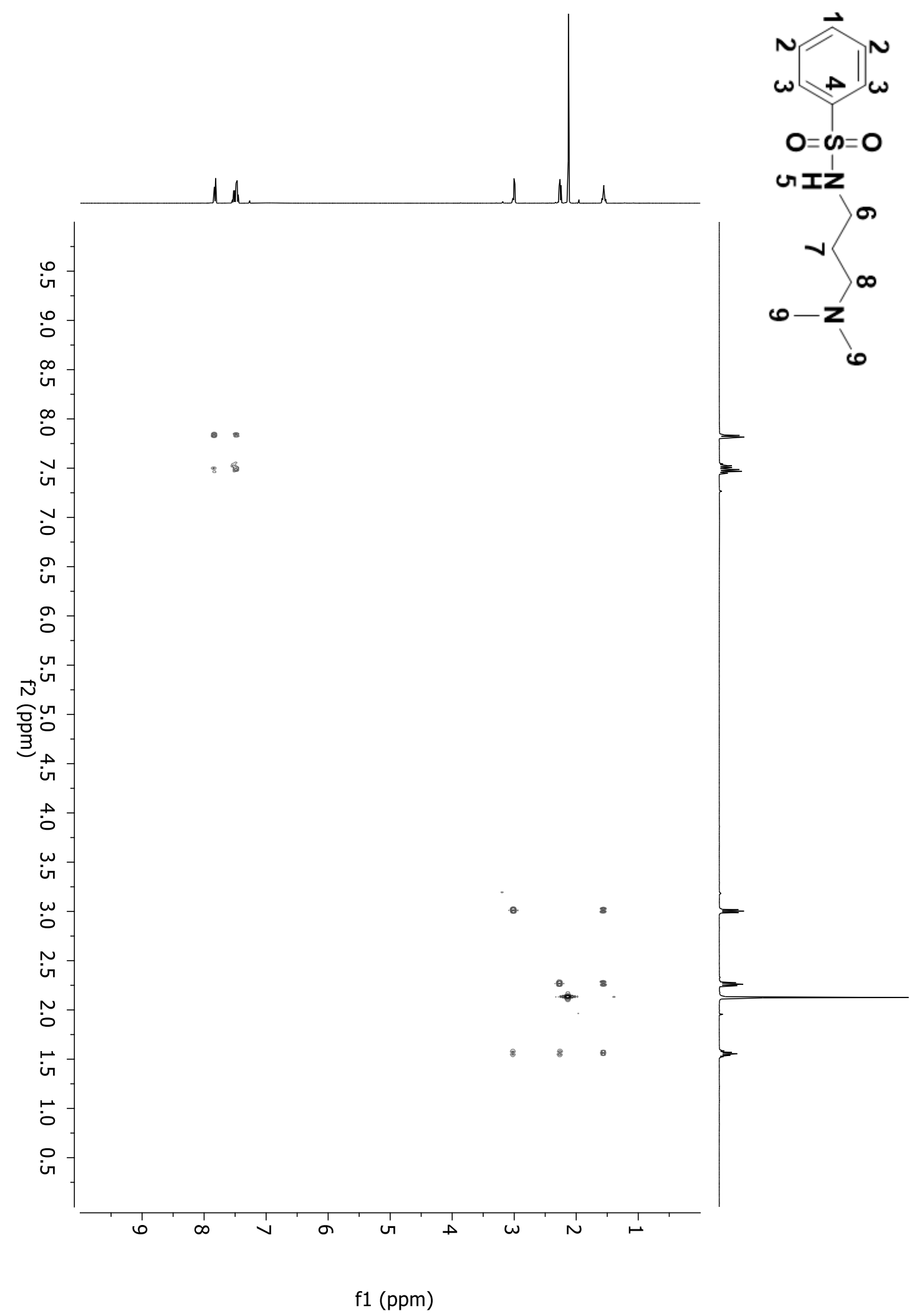

Figure A3: 2D COSY spectrum of $\mathbf{1 D}$ in $\mathrm{CDCl}_{3}$. 


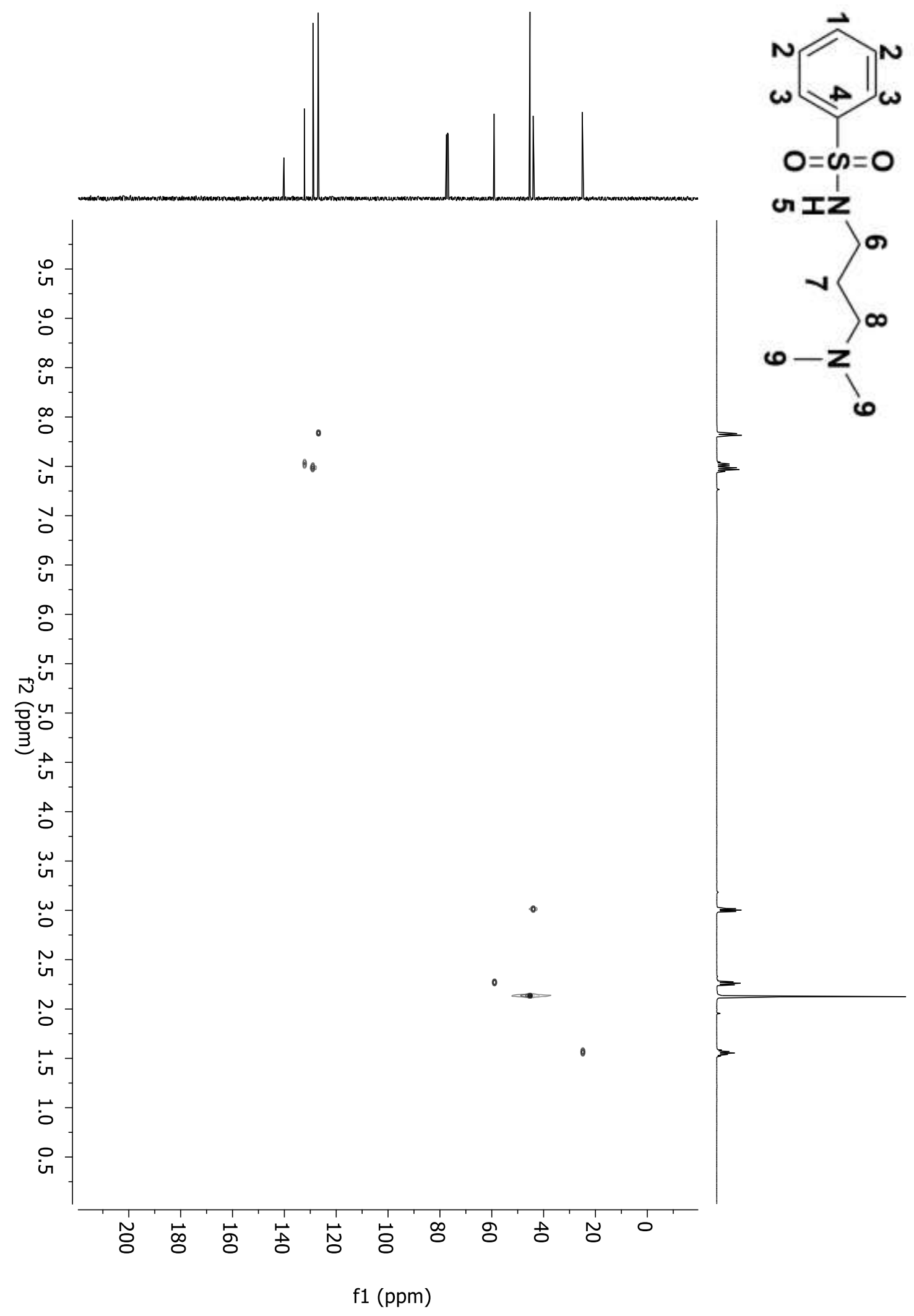

Figure A4: 2D HSQC spectrum of $1 \mathrm{D}$ in $\mathrm{CDCl}_{3}$. 


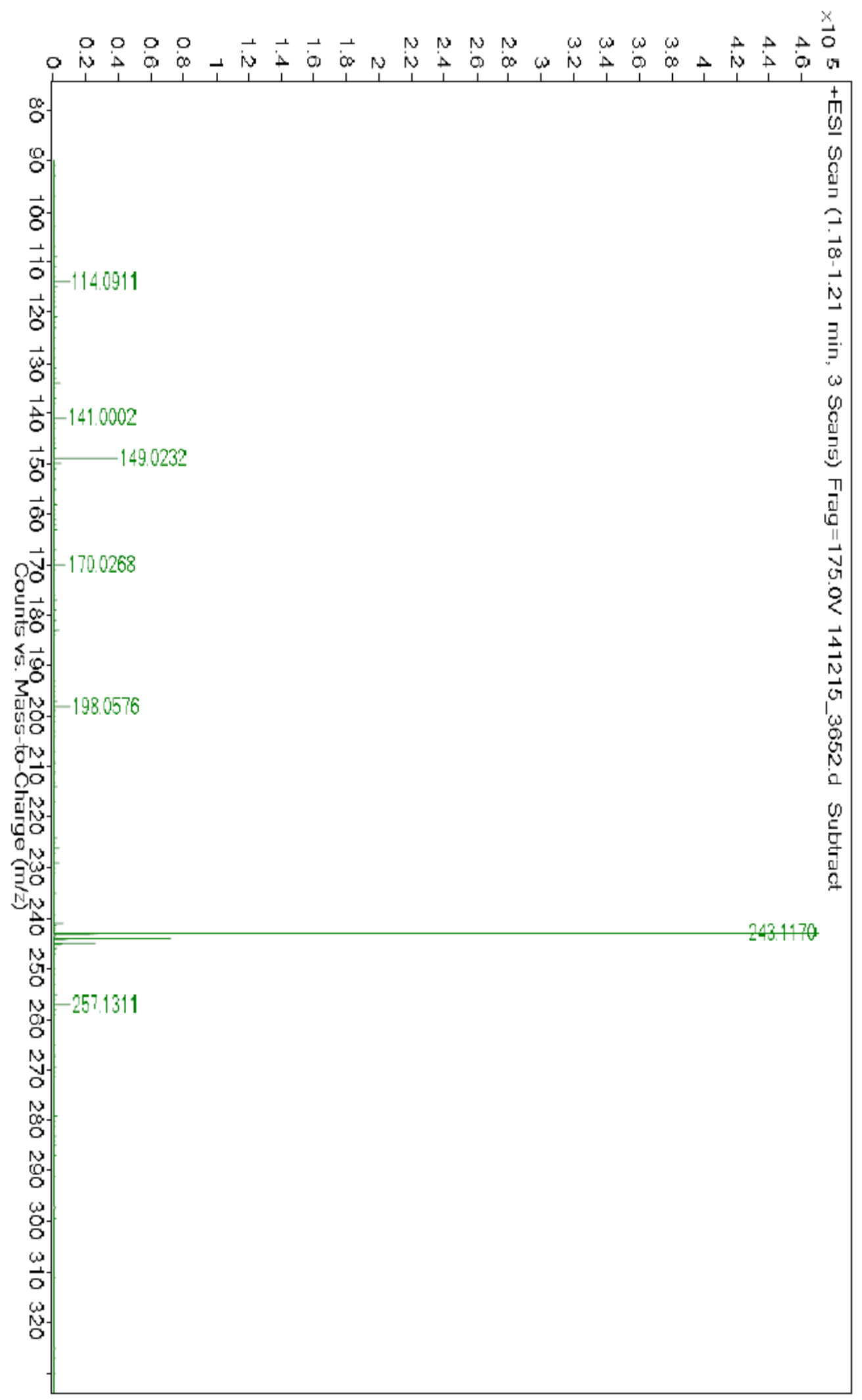

Figure A5: HRMS-ESI-TOF of compound $1 D$. 


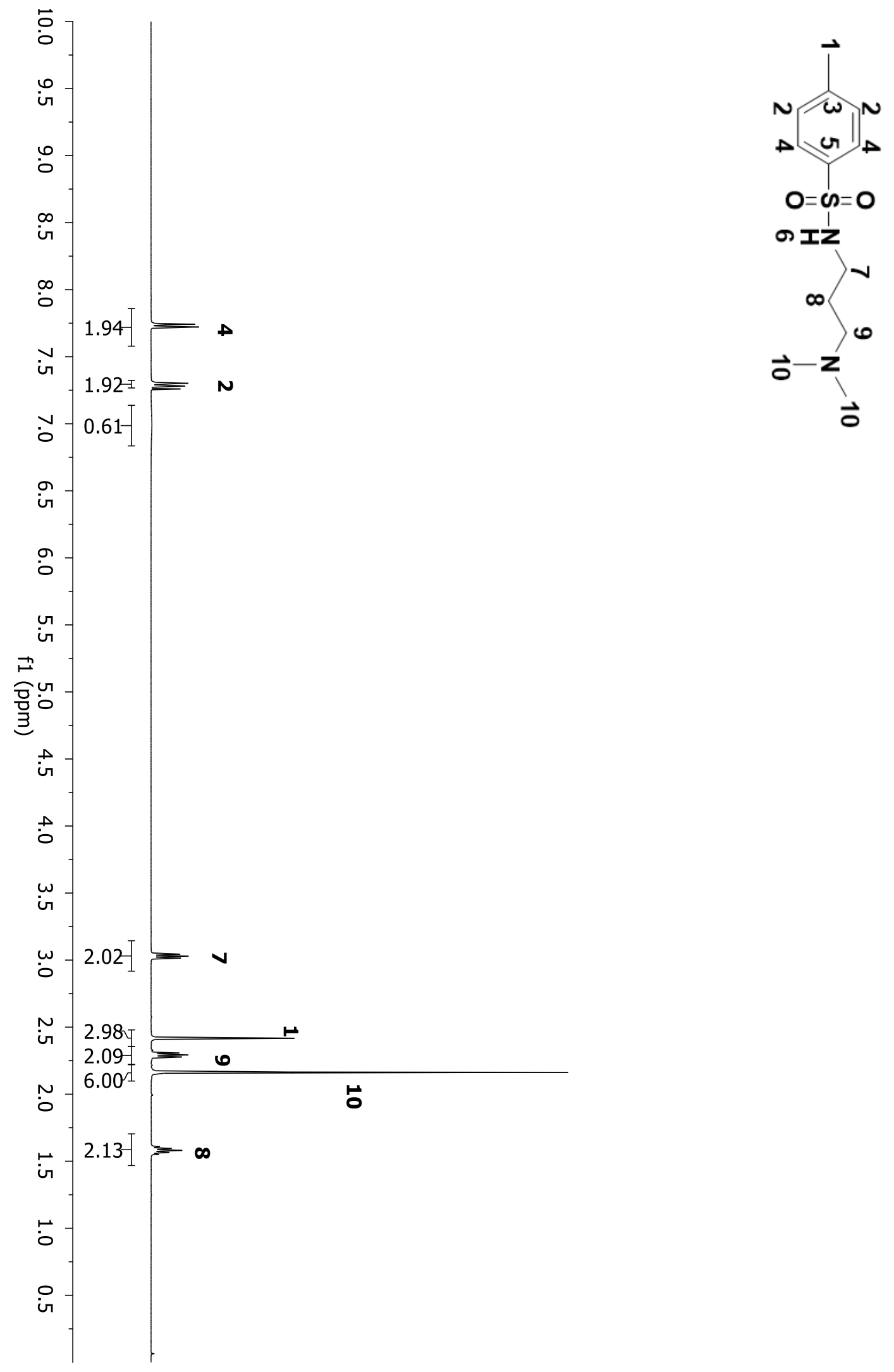

Figure A6: ${ }^{1} \mathrm{H}$ NMR spectrum of compound 2D in $\mathrm{CDCl}_{3}$. 

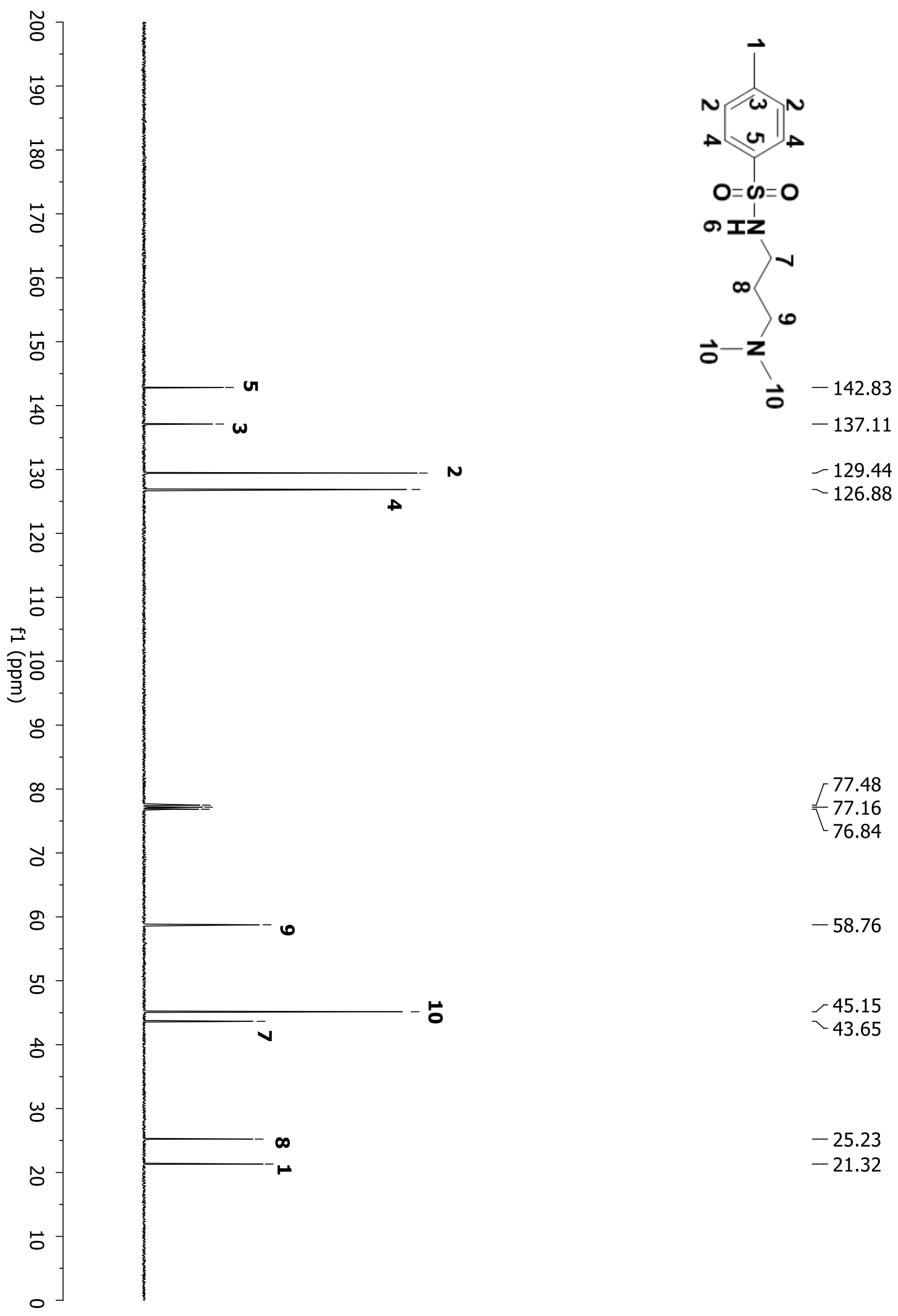

$-58.76$

$-45.15$

$\checkmark 43.65$

$-25.23$

$-21.32$

Figure A7: ${ }^{13} \mathrm{C}$ NMR spectrum of $2 \mathrm{D}$ in $\mathrm{CDCl}_{3}$. 


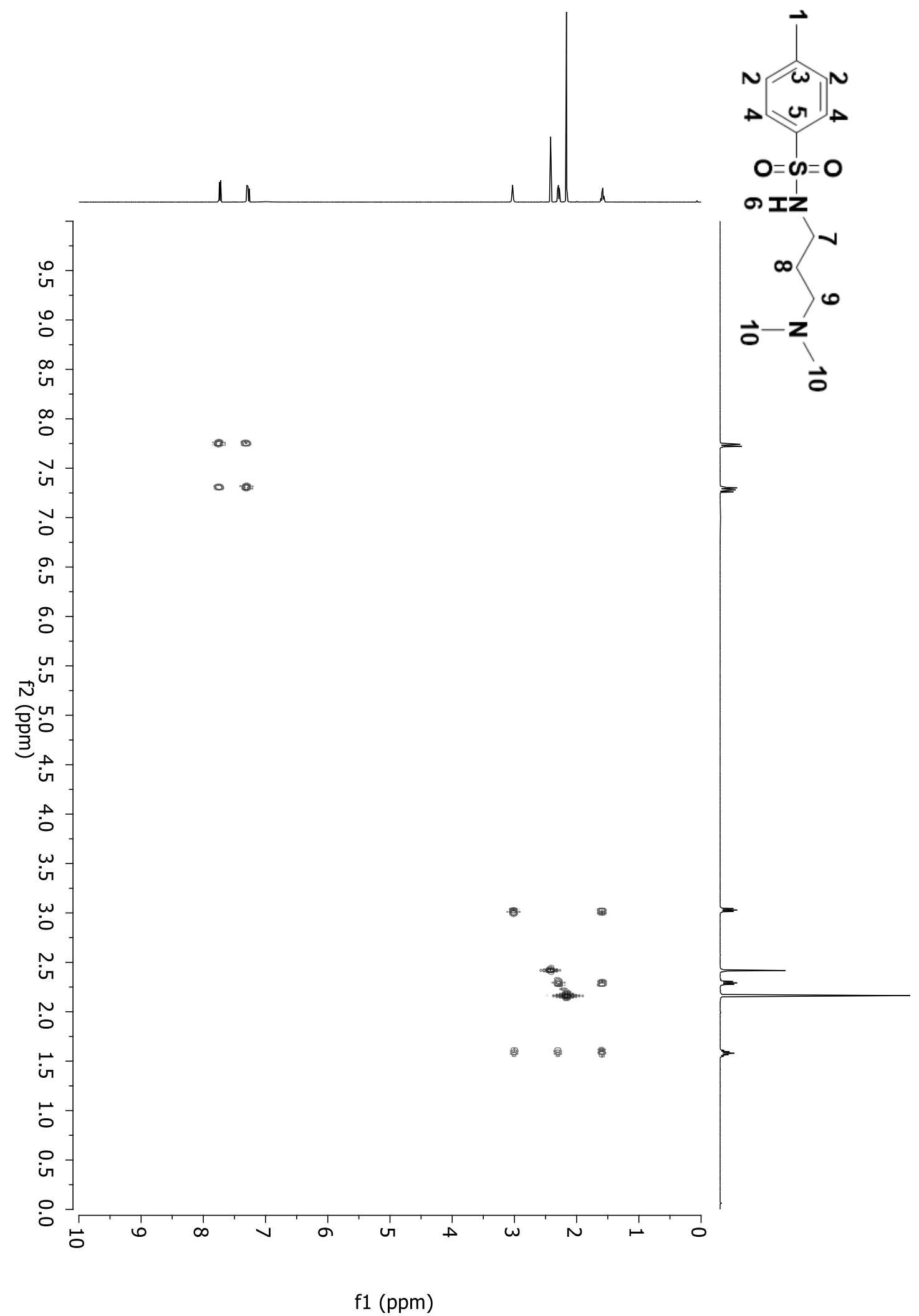

Figure A8: 2D COSY spectrum of $2 \mathrm{D}$ in $\mathrm{CDCl}_{3}$. 


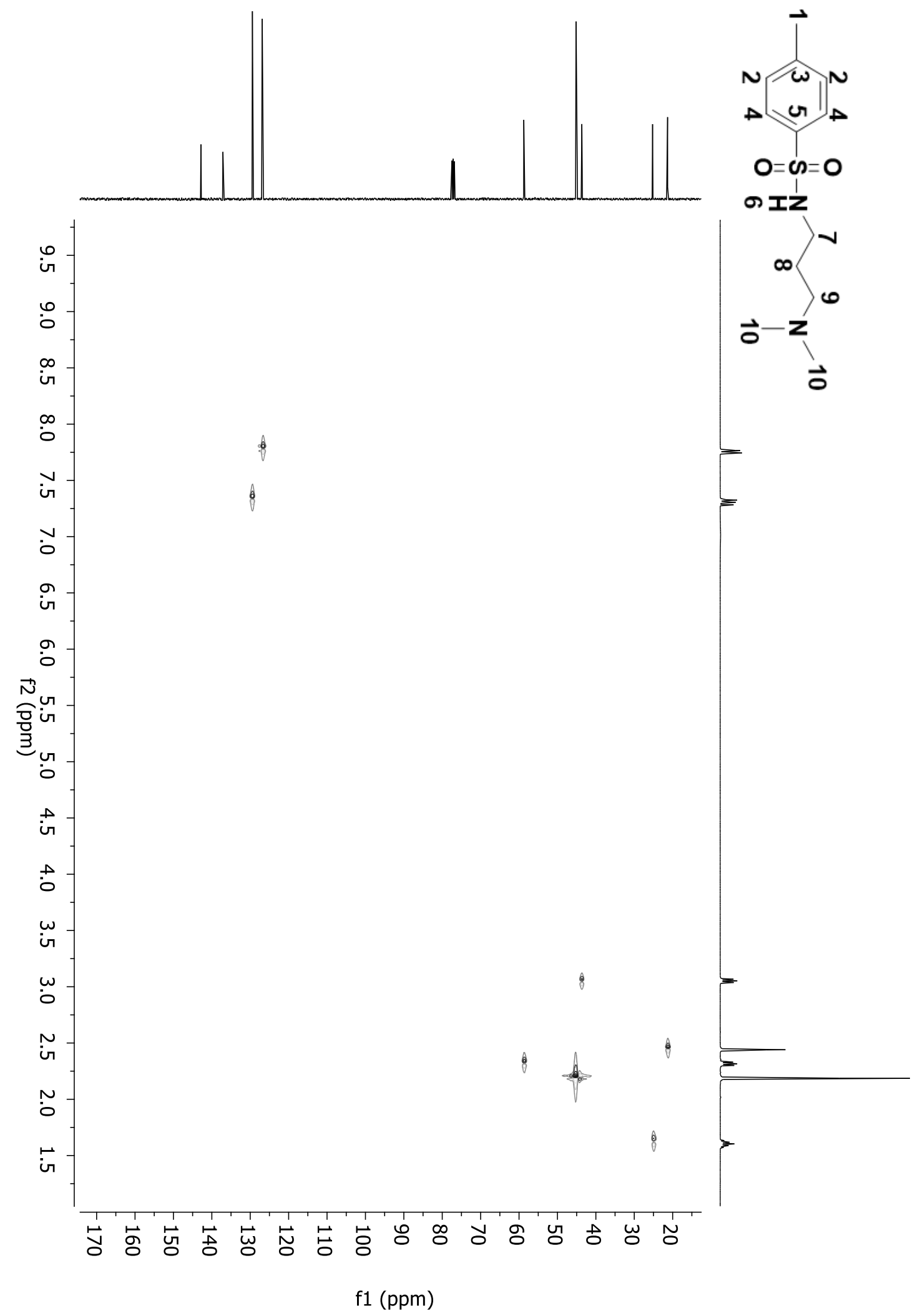

Figure A9: 2D HSQC spectrum of 2D in $\mathrm{CDCl}_{3}$. 


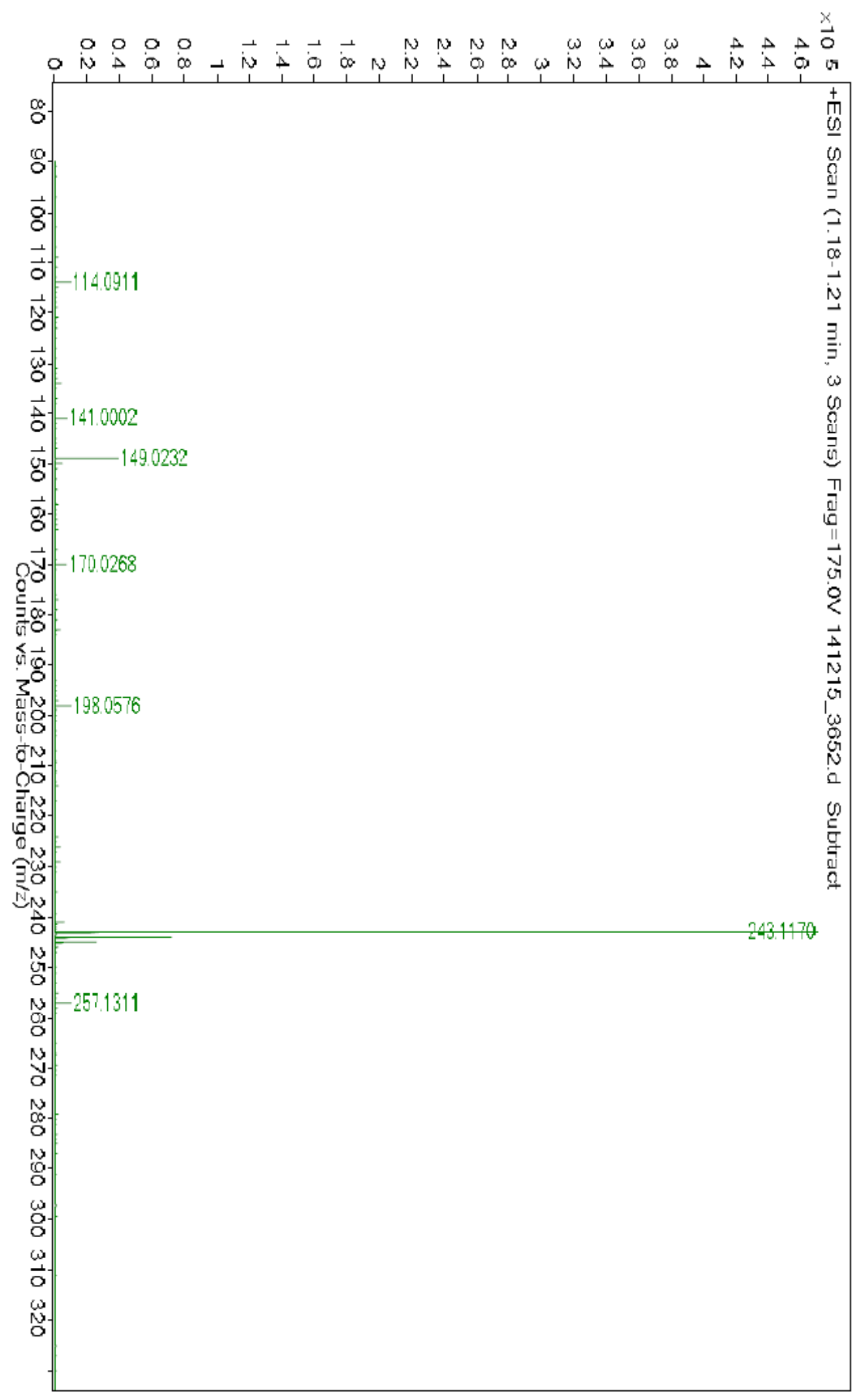

Figure A10: HRMS-ESI-TOF of compound 2D. 


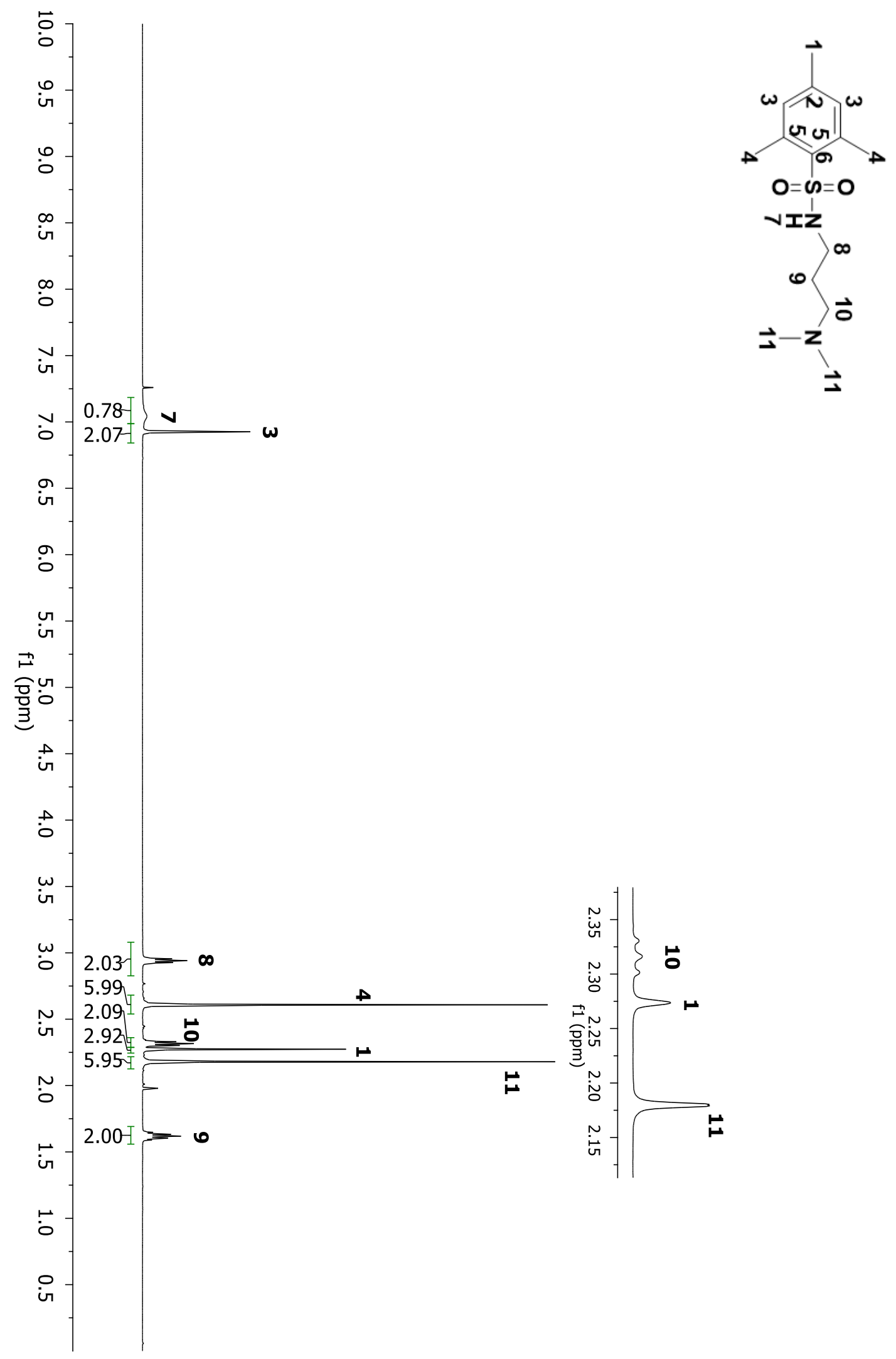

Figure A11: ${ }^{1} \mathrm{H}$ NMR spectrum of compound $3 \mathrm{D}$ in $\mathrm{CDCl}_{3}$. 


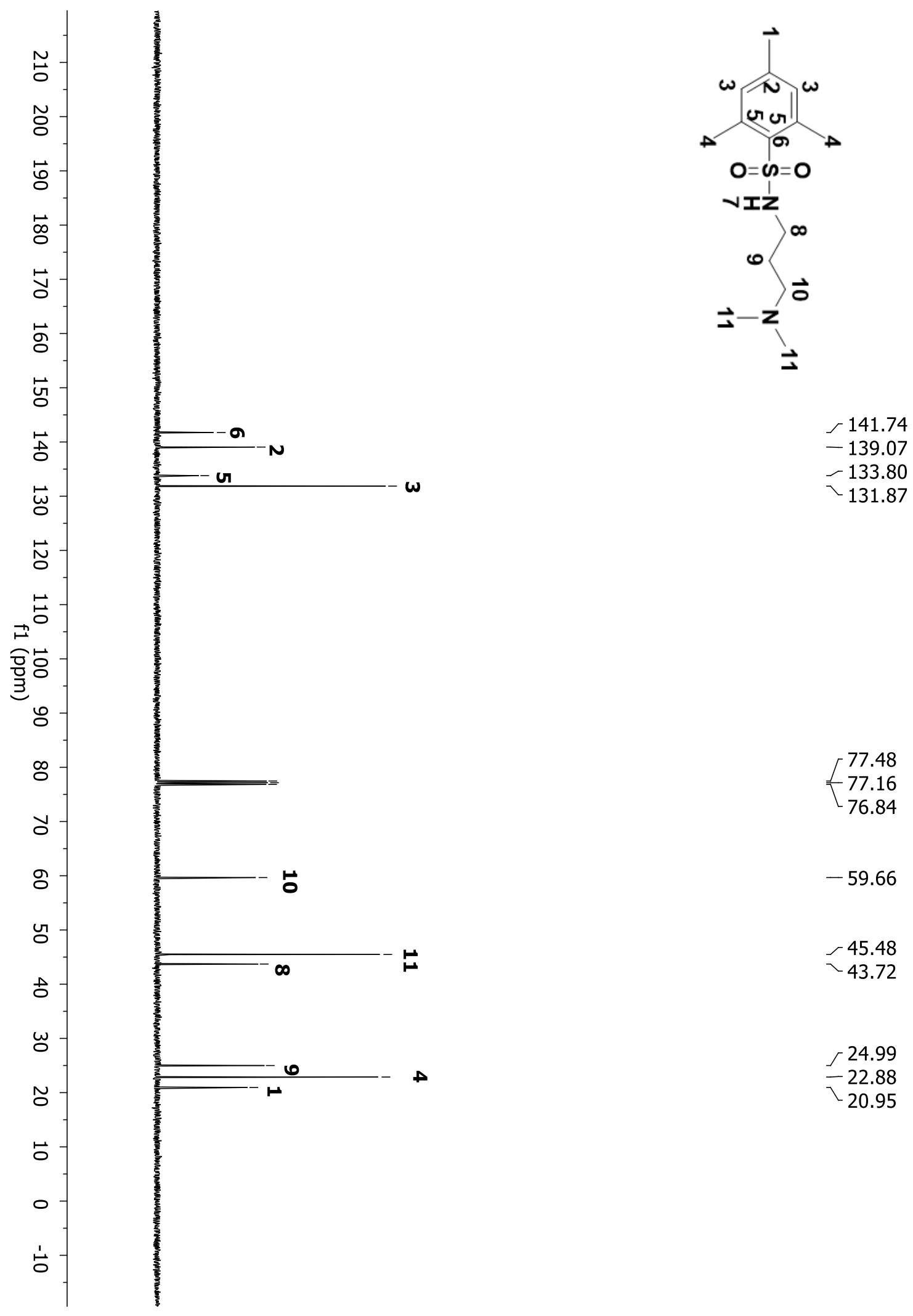

Figure A1: ${ }^{13} \mathrm{C}$ NMR spectrum of compound $3 \mathrm{D}$ in $\mathrm{CDCl}_{3}$. 


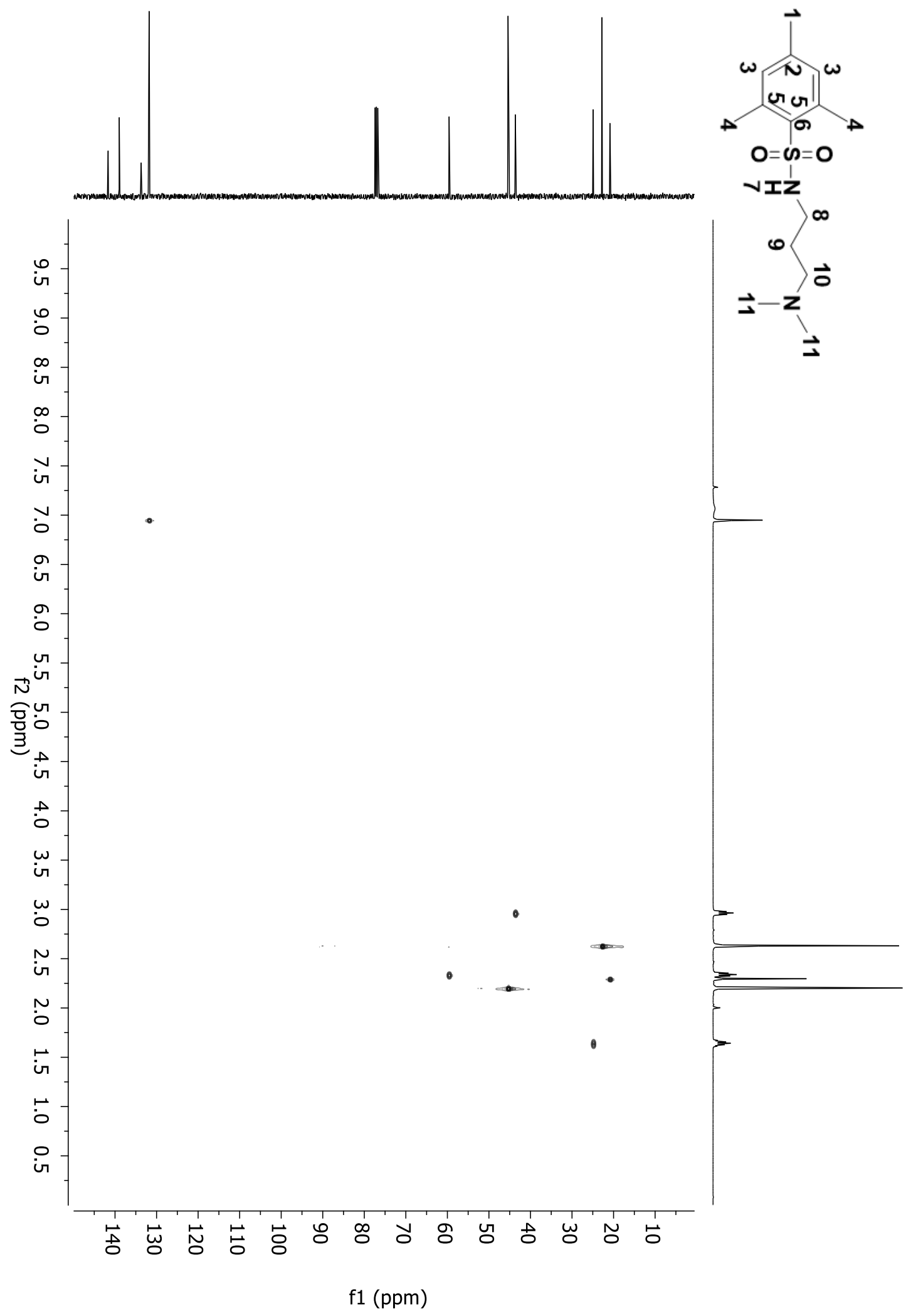

Figure A12: 2D COSY spectrum of compound 3D in $\mathrm{CDCl}_{3}$. 


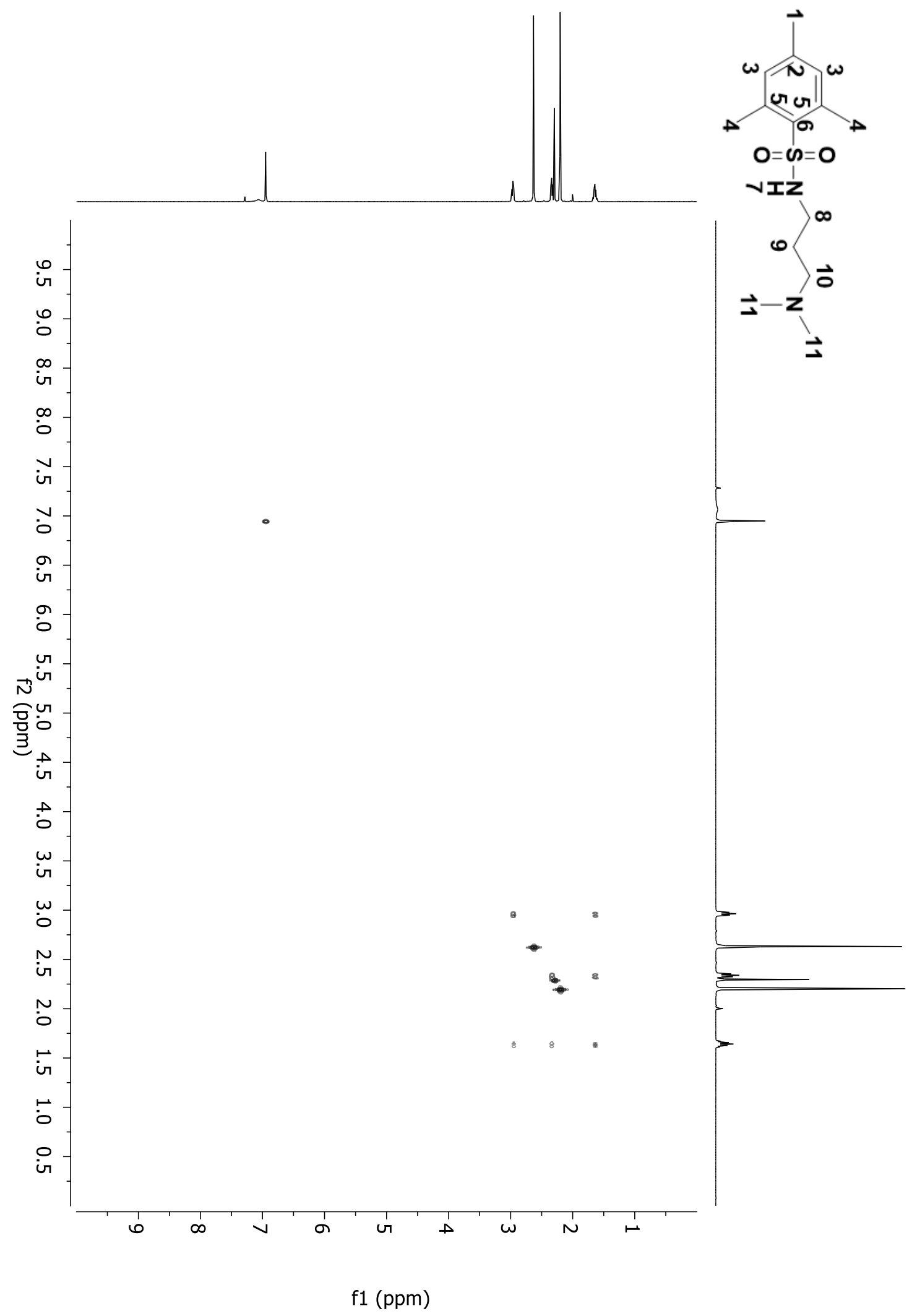

Figure A13: 2D HSQC spectrum of compound 3D in $\mathrm{CDCl}_{3}$. 


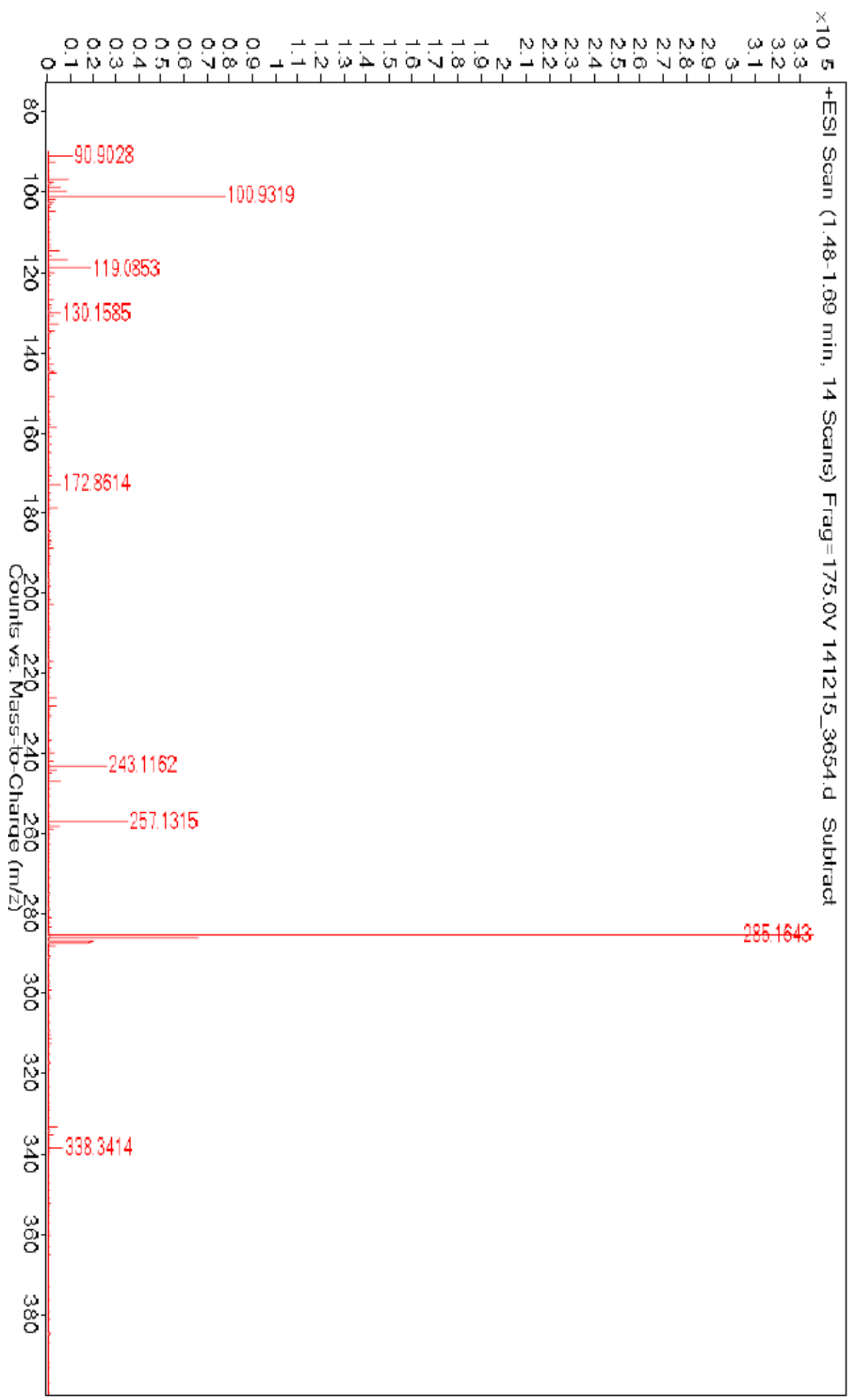

Figure A14: HRMS-ESI-TOF of compound 3D. 

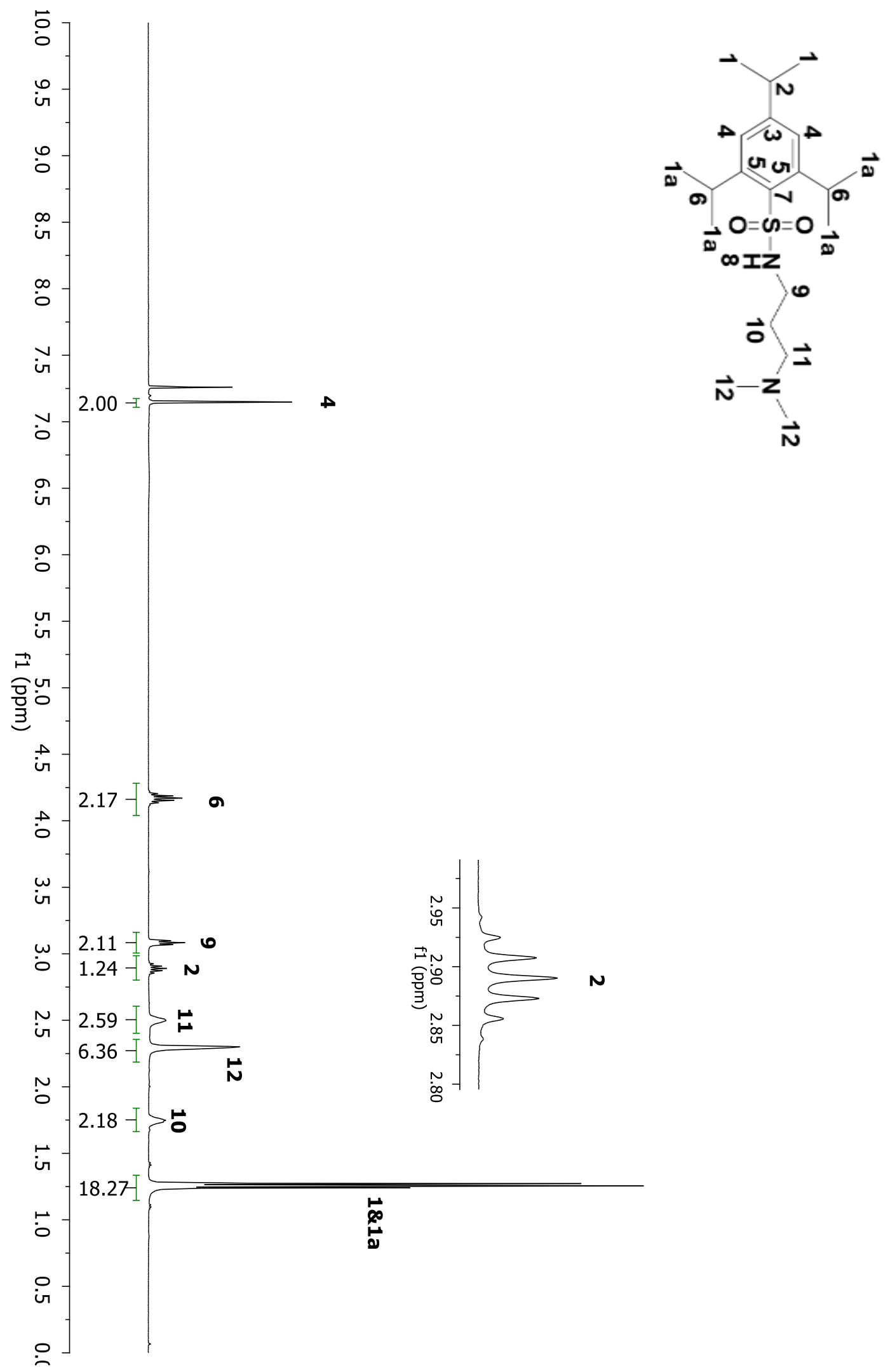

Figure A15: ${ }^{1} \mathrm{H}$ NMR spectrum of compound $4 \mathrm{D}$ in $\mathrm{CDCl}_{3}$. 


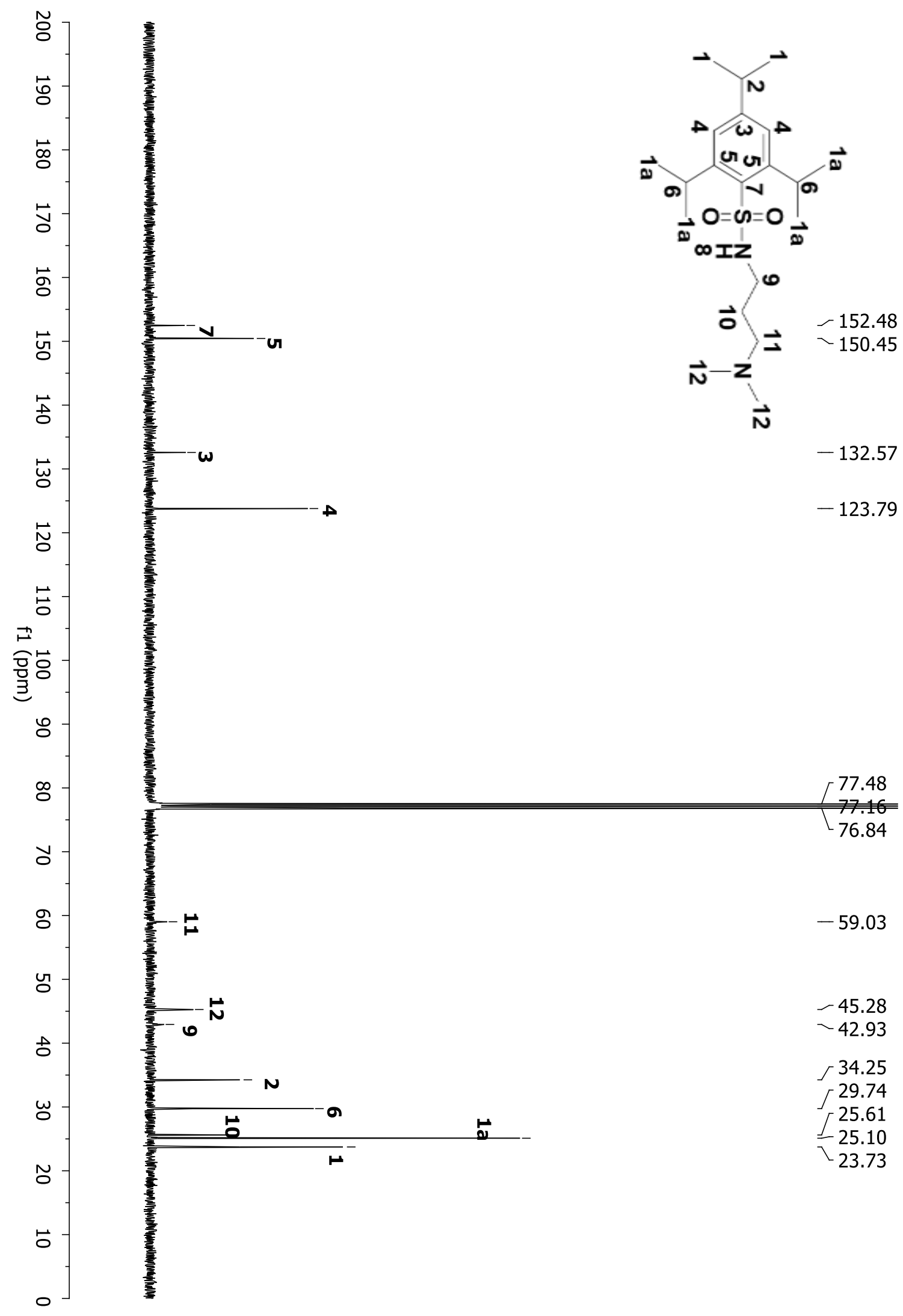

Figure A16: ${ }^{13} \mathrm{C}$ NMR spectrum of compound $4 \mathrm{D}$ in $\mathrm{CDCl}_{3}$. 


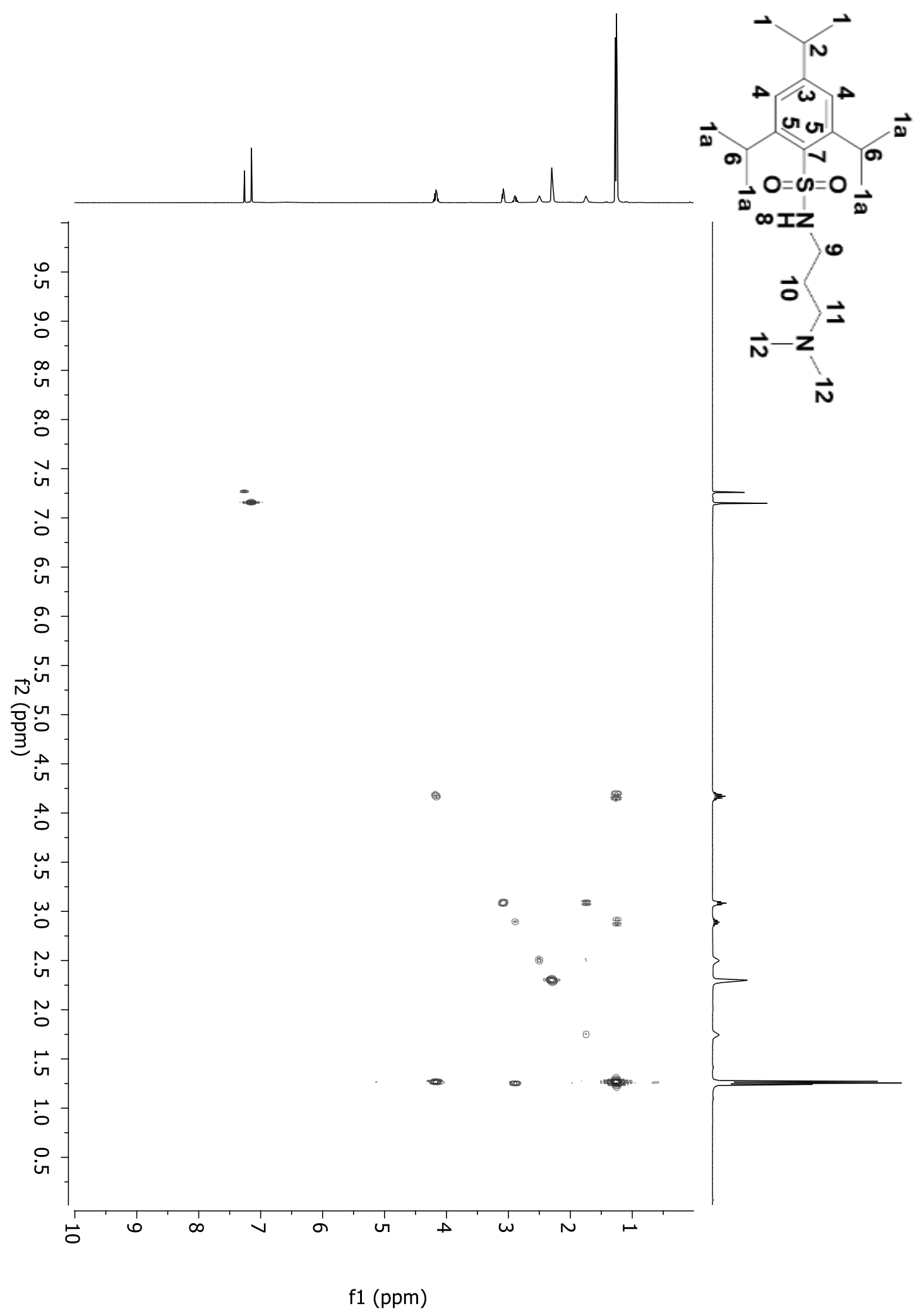

Figure A17: 2D COSY spectrum of compound 4D in $\mathrm{CDCl}_{3}$. 


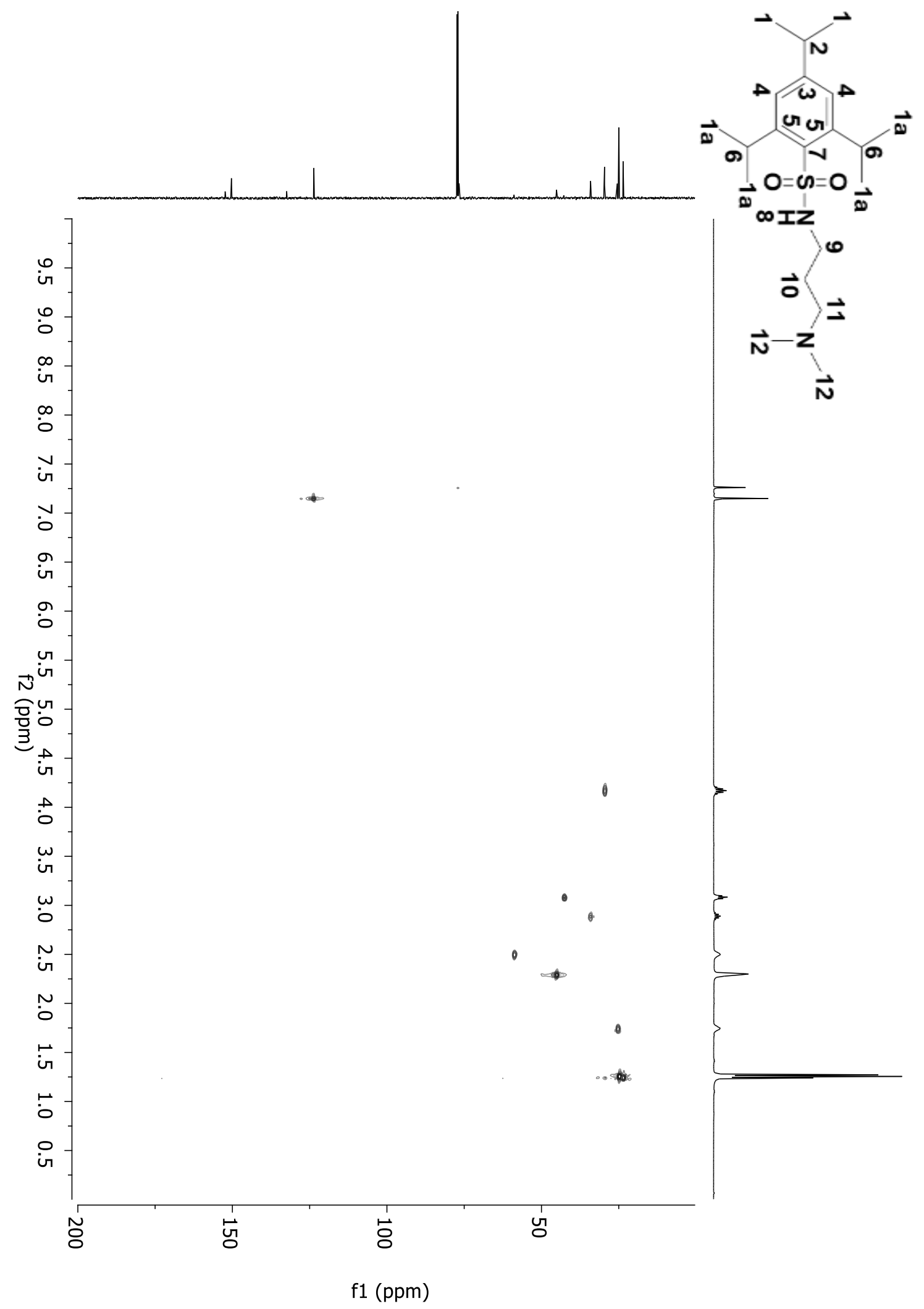

Figure A18: 2D HSQC spectrum of compound 4D in $\mathrm{CDCl}_{3}$. 


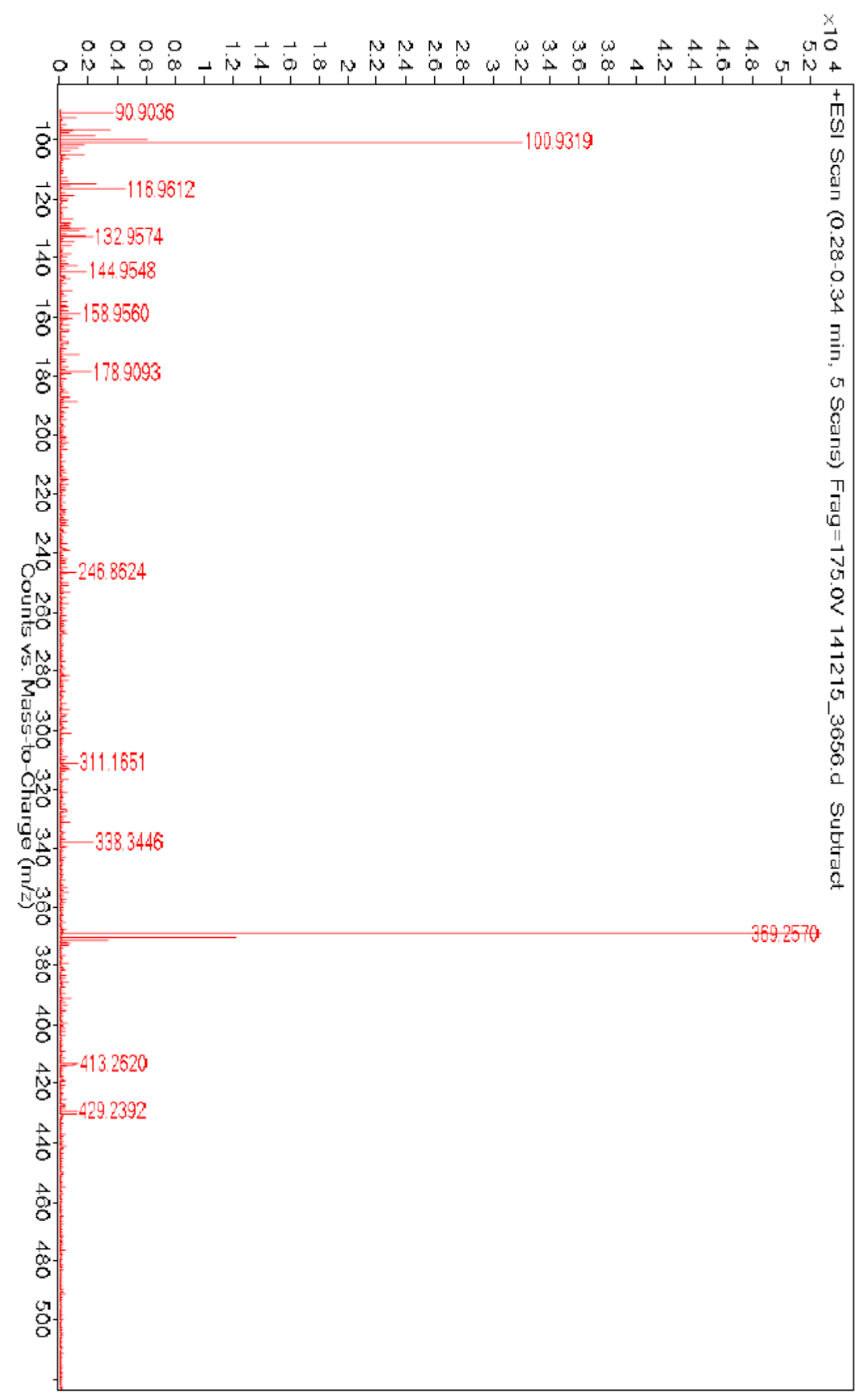

Figure A19: HRMS-ESI-TOF of compound 4D. 

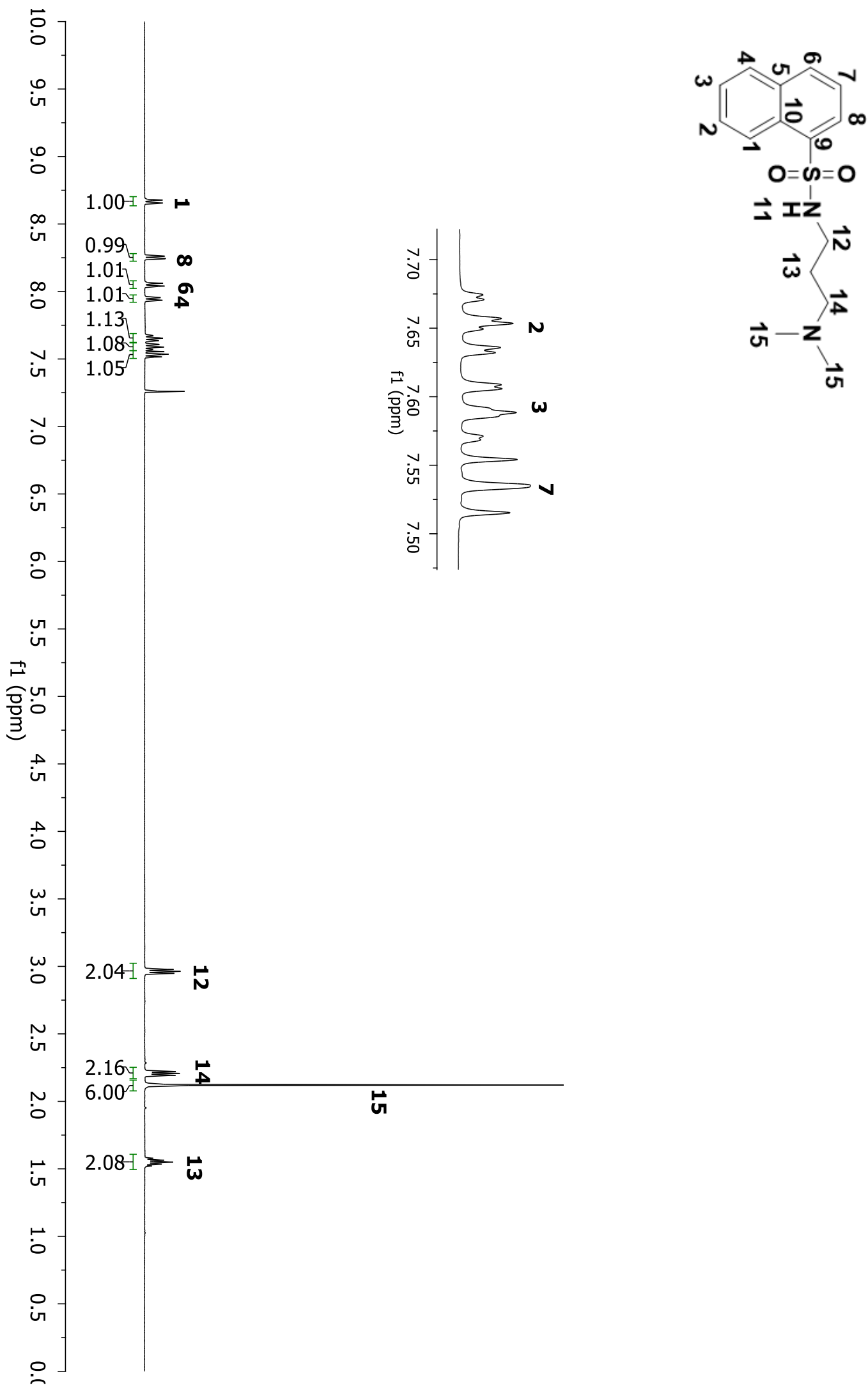

Figure A20: ${ }^{1} \mathrm{H}$ NMR spectrum of compound 5D in $\mathrm{CDCl}_{3}$. 


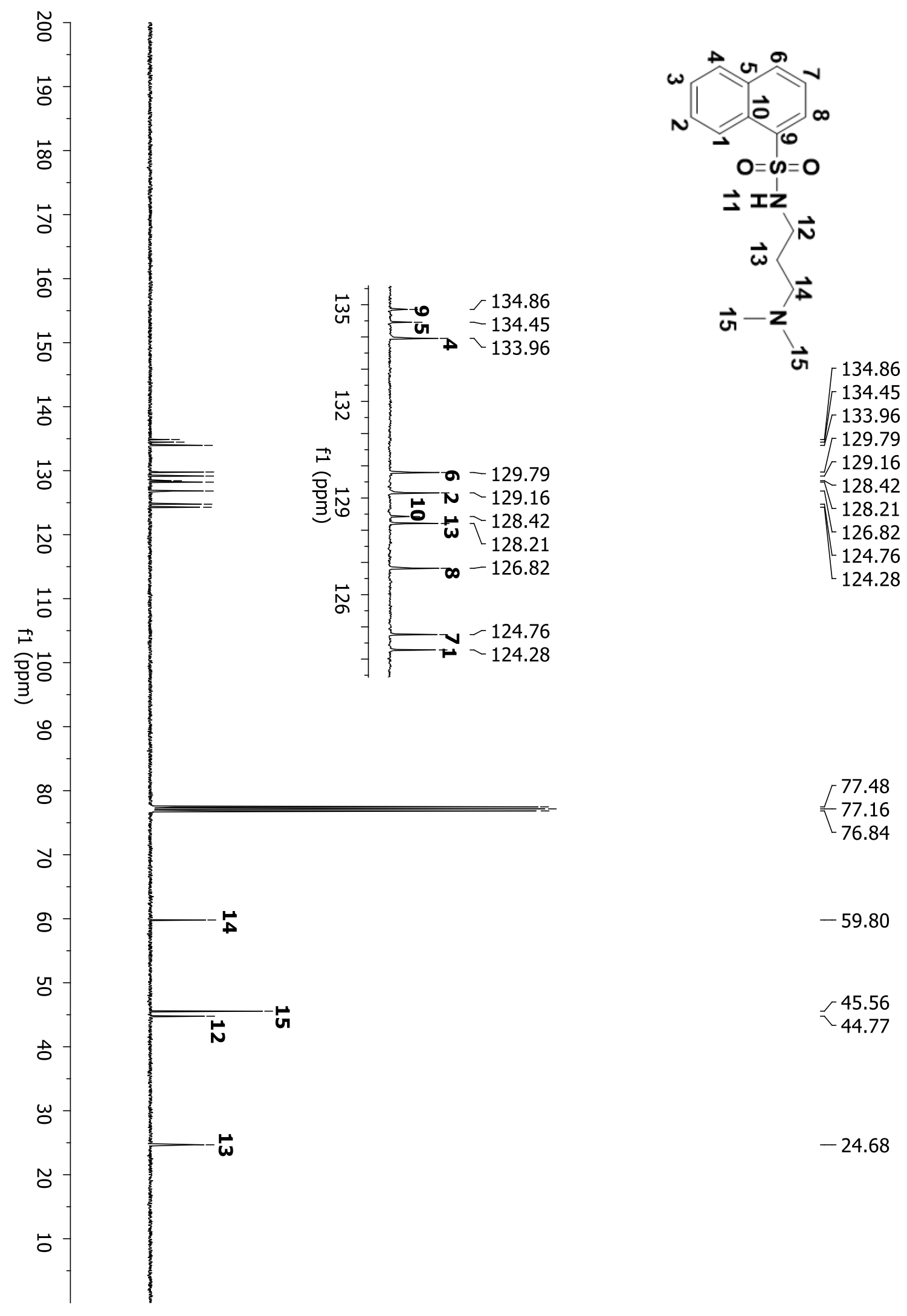

Figure A21: ${ }^{13} \mathrm{C}$ NMR spectrum of compound $5 \mathrm{D}$ in $\mathrm{CDCl}_{3}$. 


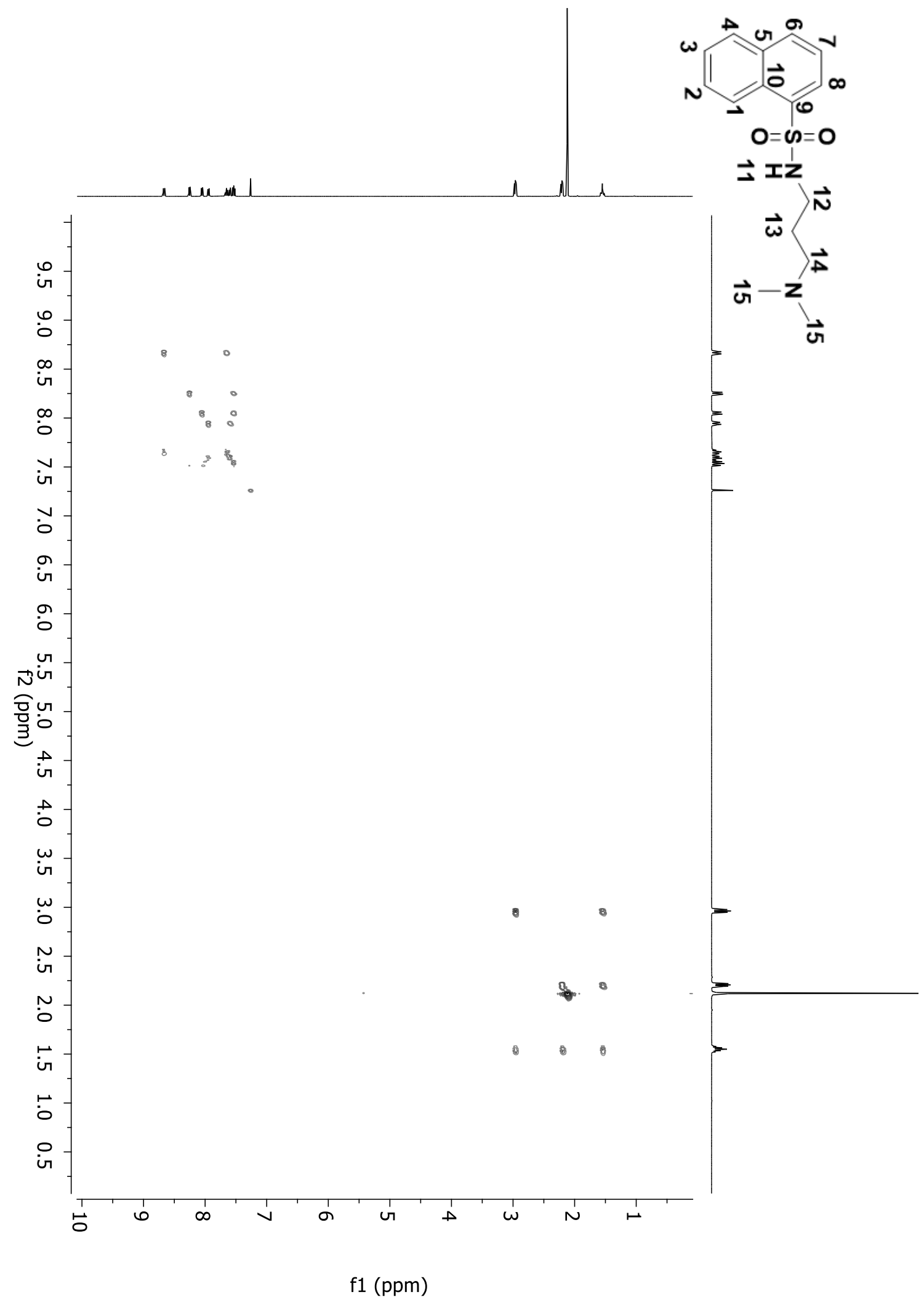

Figure A22: 2D COSY spectrum of compound 5D in $\mathrm{CDCl}_{3}$. 


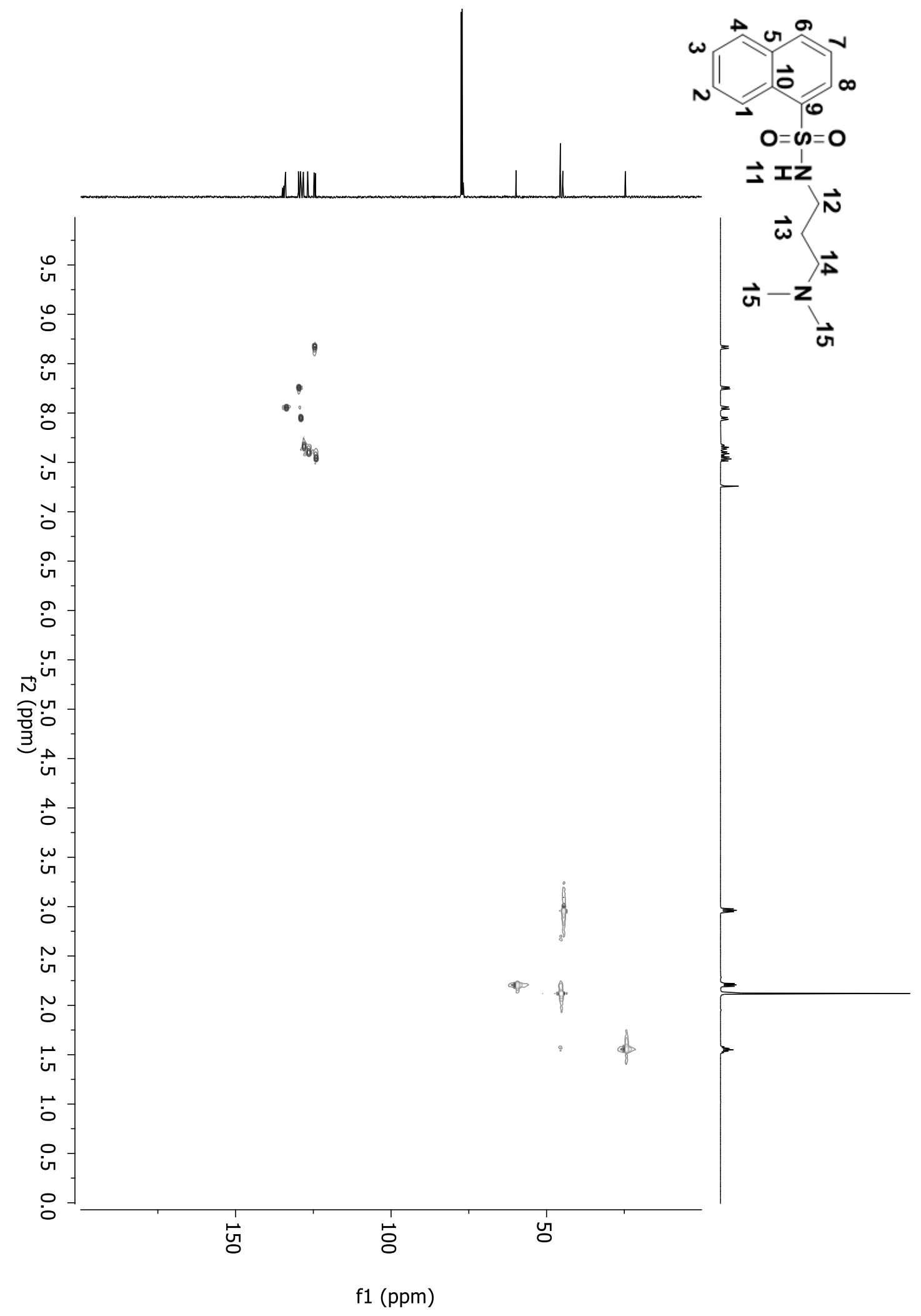

Figure A23: 2D HSQC spectrum of compound 5D in $\mathrm{CDCl}_{3}$. 


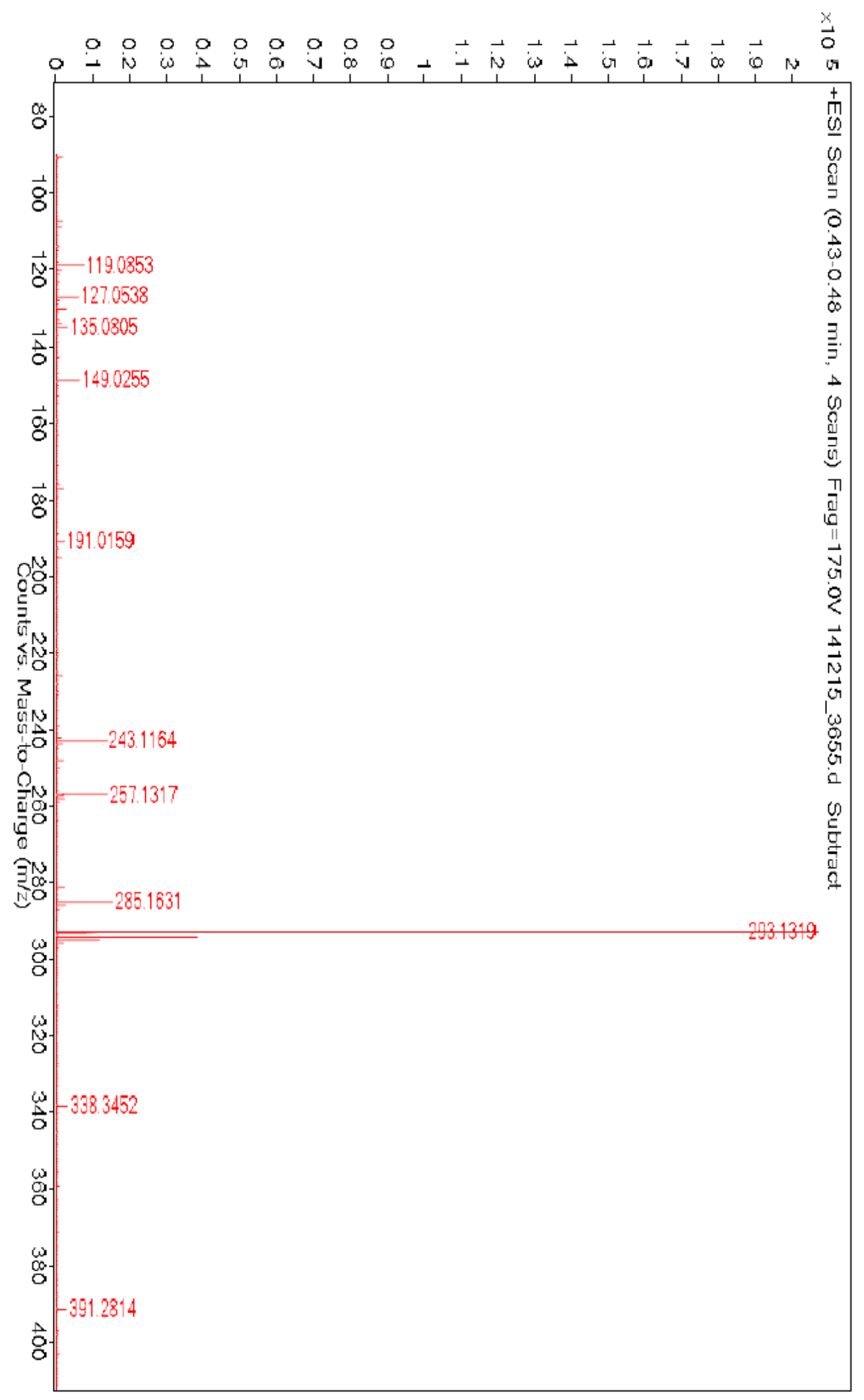

Figure A24: HRMS-ESI-TOF of compound 5D. 

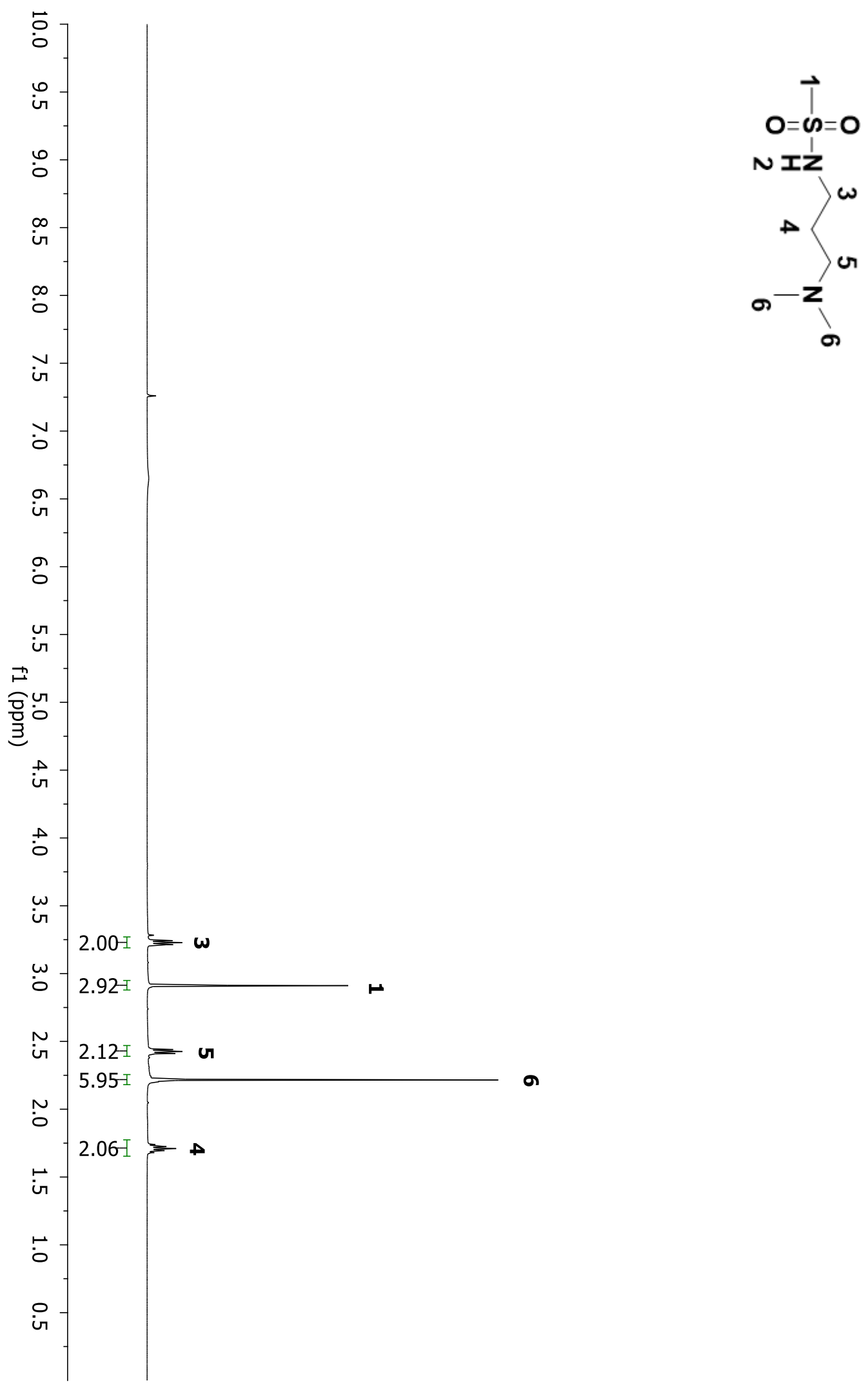

Figure A25: ${ }^{1} \mathrm{H}$ NMR spectrum of compound $6 \mathrm{D}$ in $\mathrm{CDCl}_{3}$. 


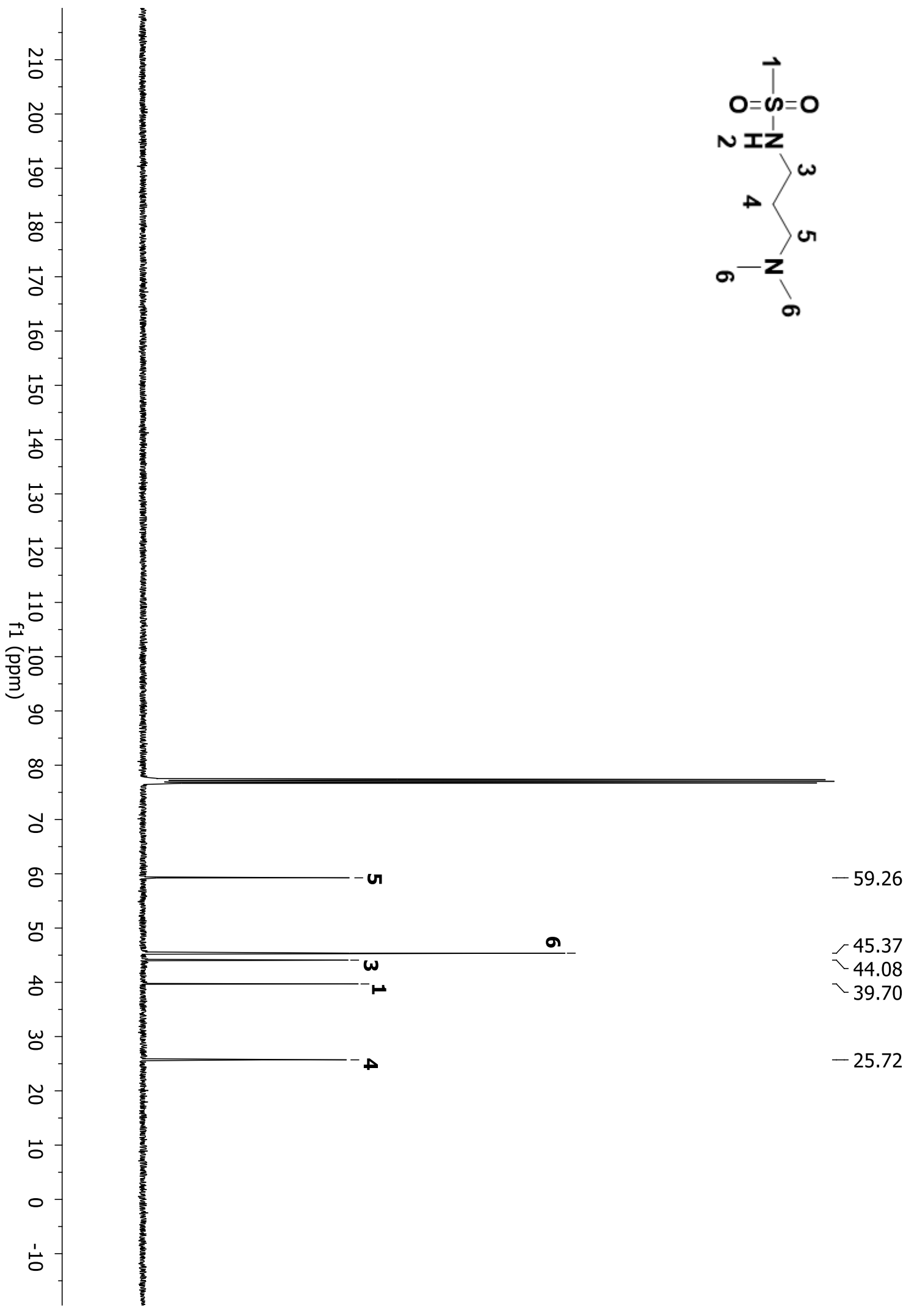

Figure A26: ${ }^{13} \mathrm{C}$ NMR spectrum of compound $6 \mathrm{D}$ in $\mathrm{CDCl}_{3}$. 


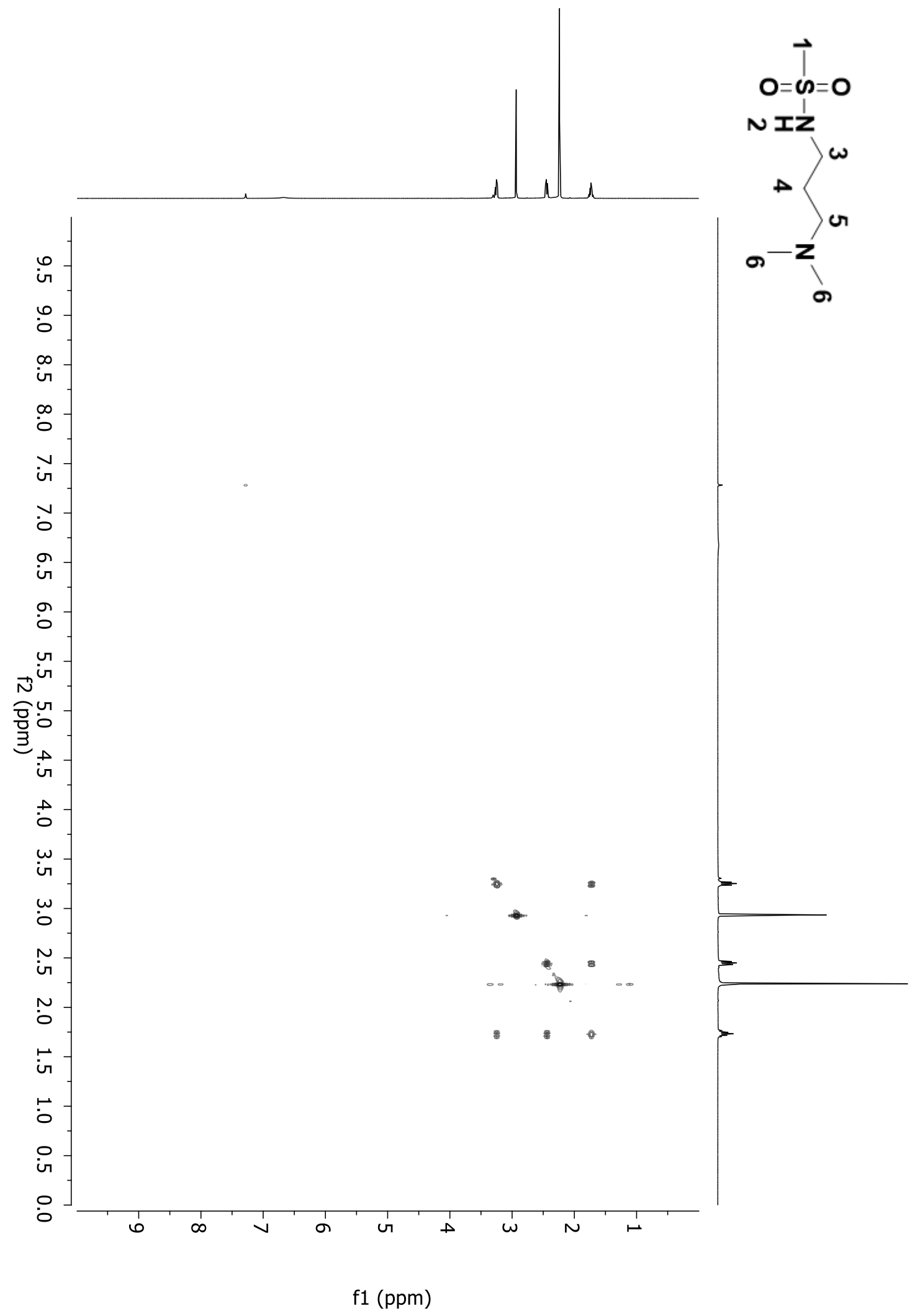

Figure A27: 2D COSY spectrum of compound $6 \mathrm{D}$ in $\mathrm{CDCl}_{3}$. 


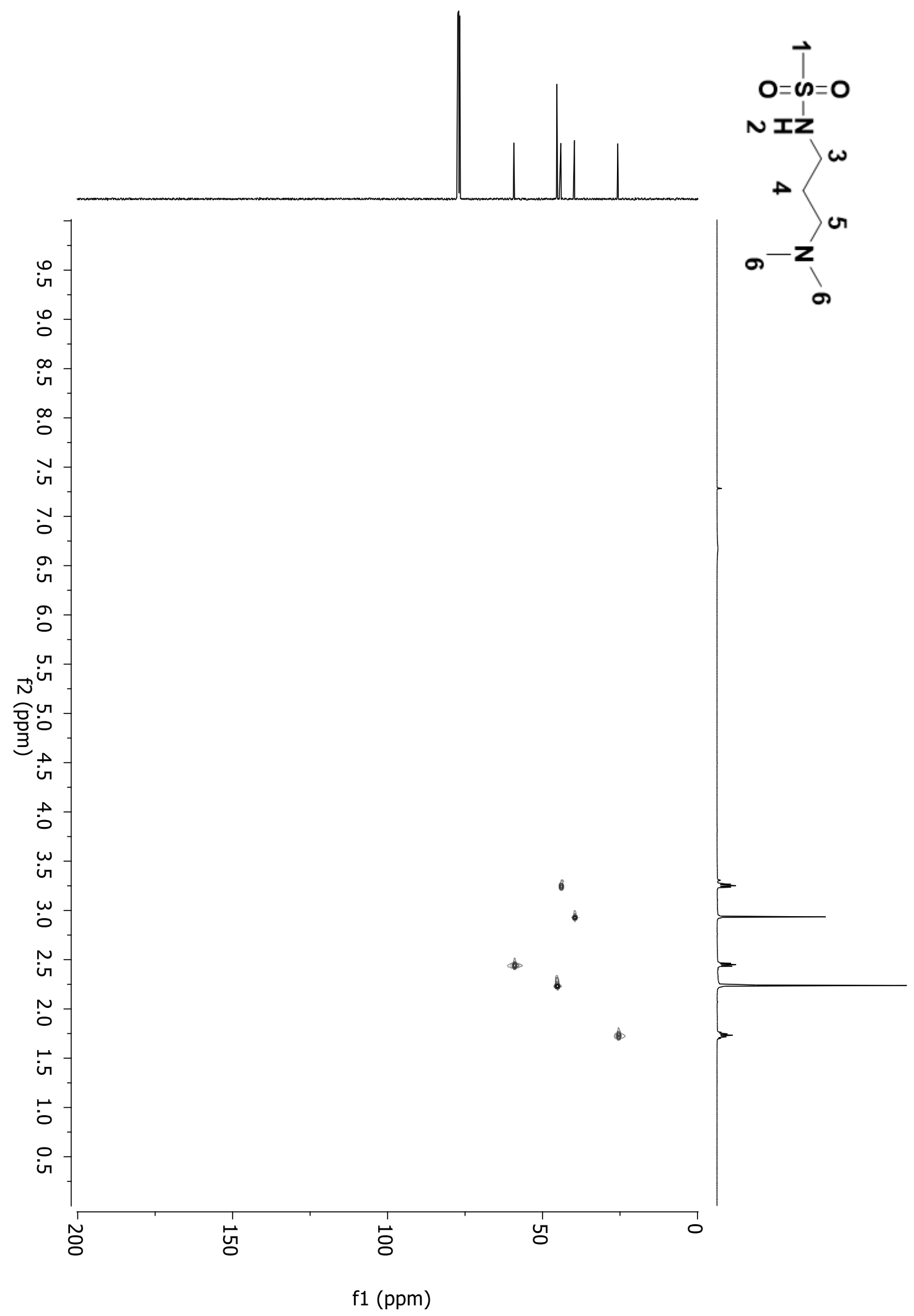

Figure A28: 2D HSQC spectrum of compound $6 \mathrm{D}$ in $\mathrm{CDCl}_{3}$. 


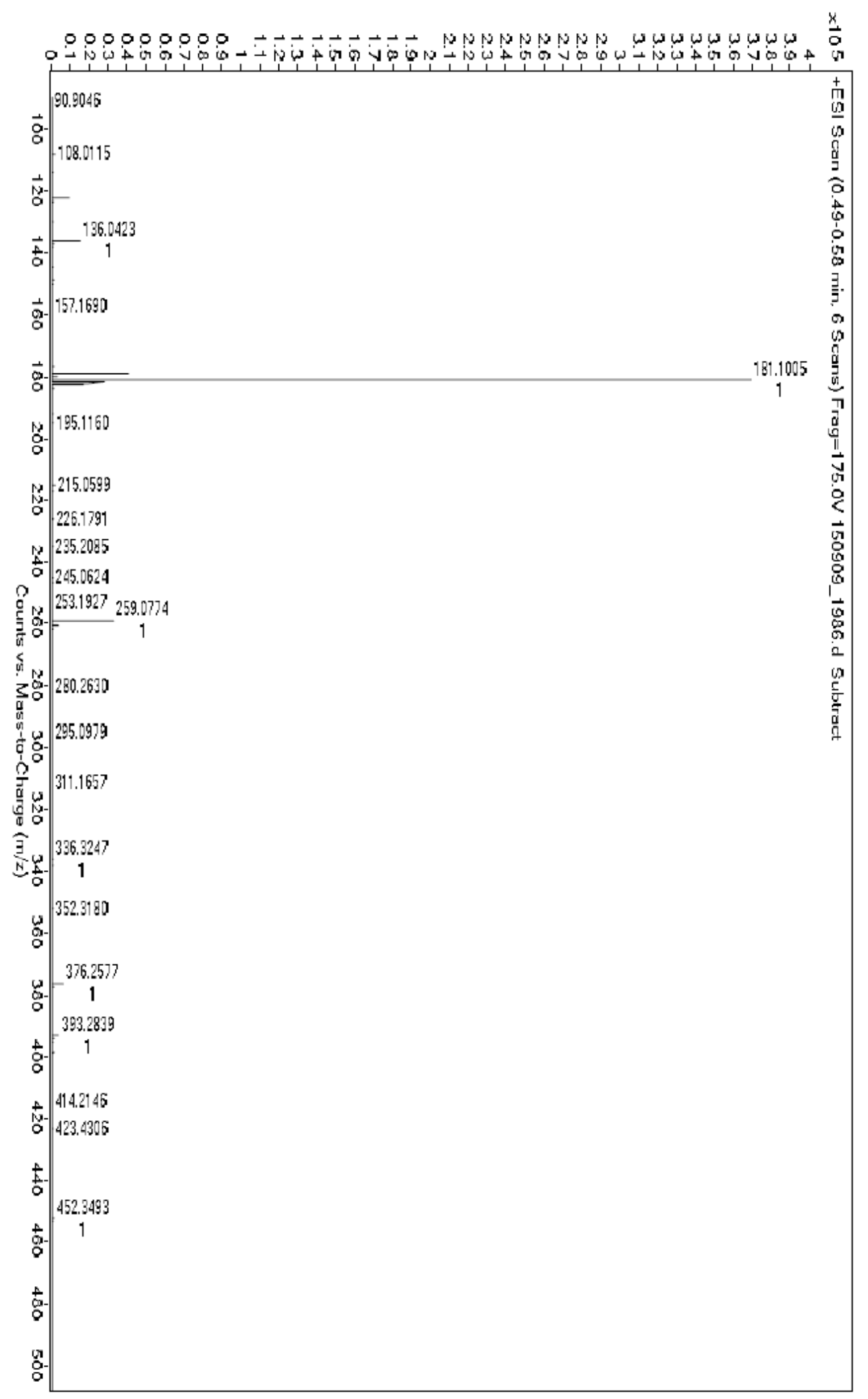

Figure A29: HRMS-ESI-TOF of compound 6D. 

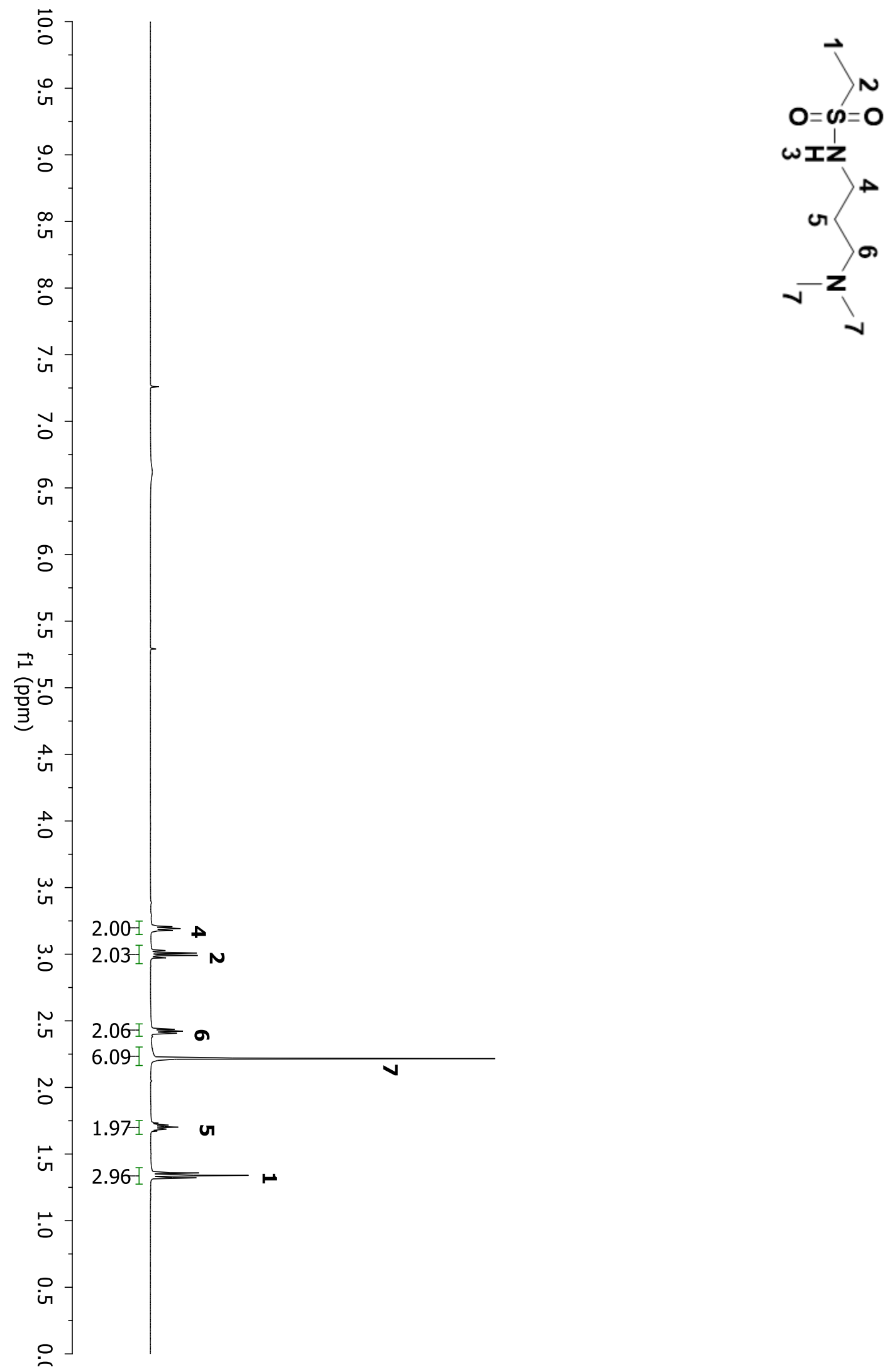

Figure A30: ${ }^{1} \mathrm{H}$ NMR spectrum of compound 7D in $\mathrm{CDCl}_{3}$. 


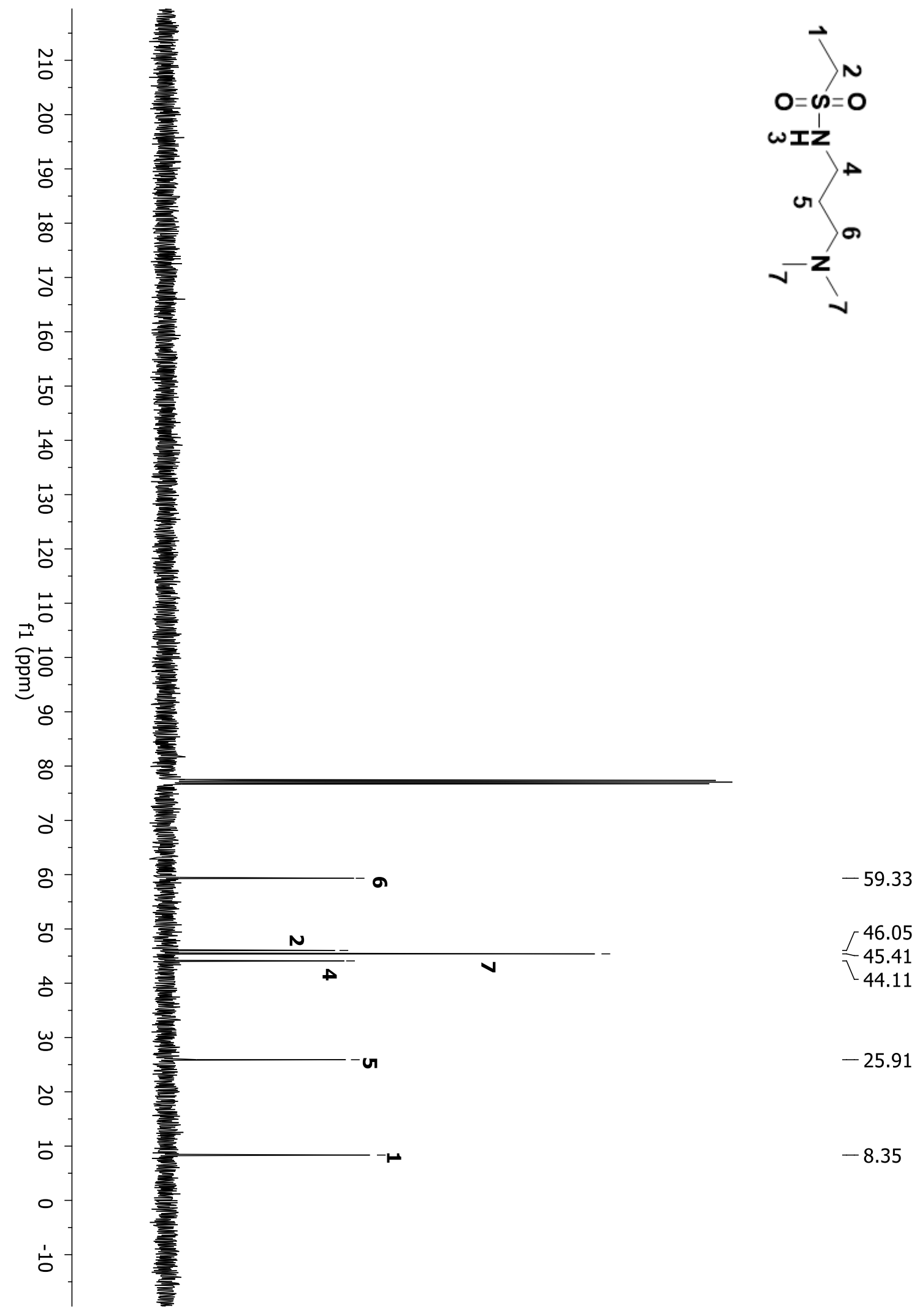

Figure A31: ${ }^{13} \mathrm{C}$ NMR spectrum of compound 7D in $\mathrm{CDCl}_{3}$. 


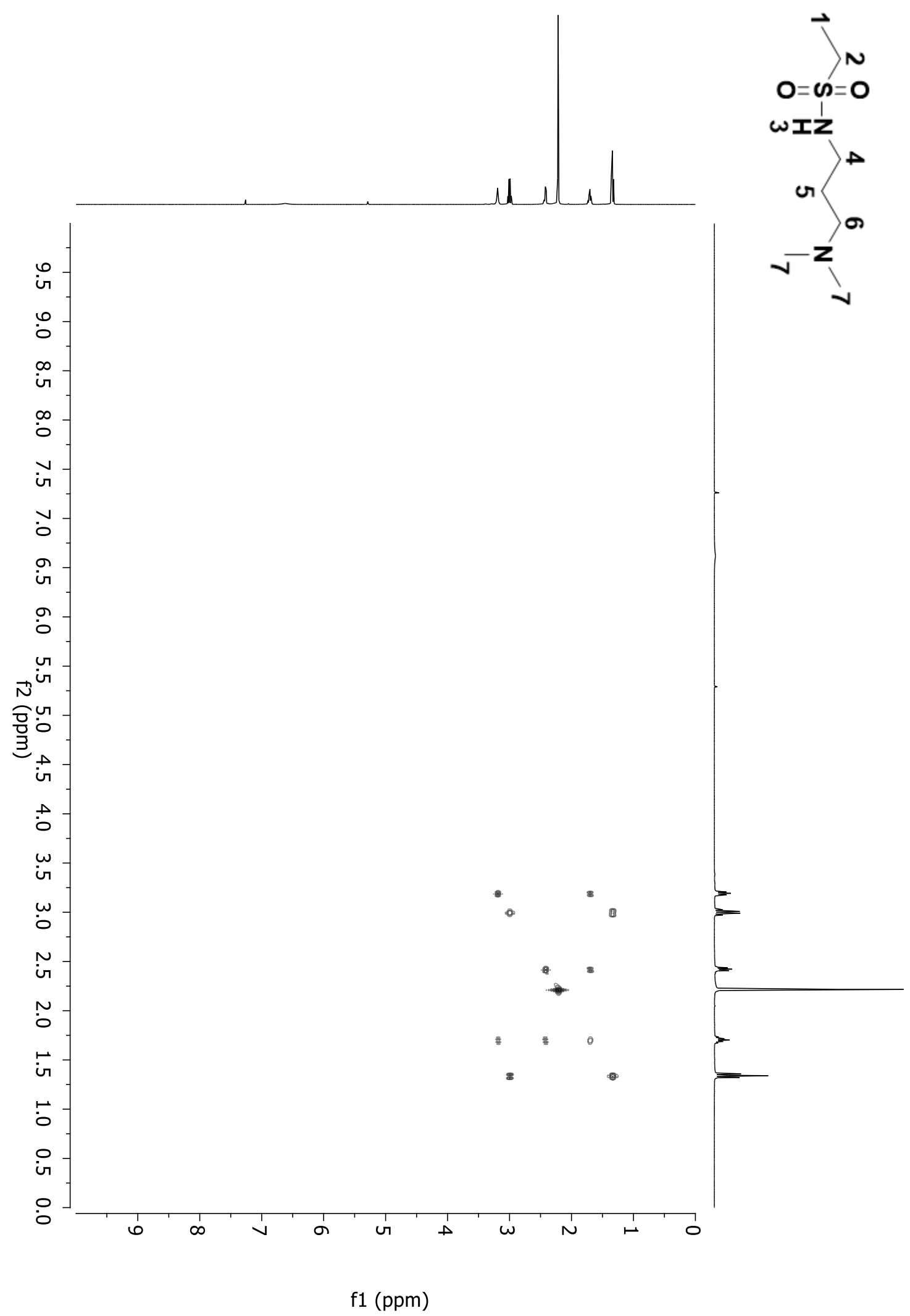

Figure A32: 2D COSY spectrum of compound 7D in $\mathrm{CDCl}_{3}$. 


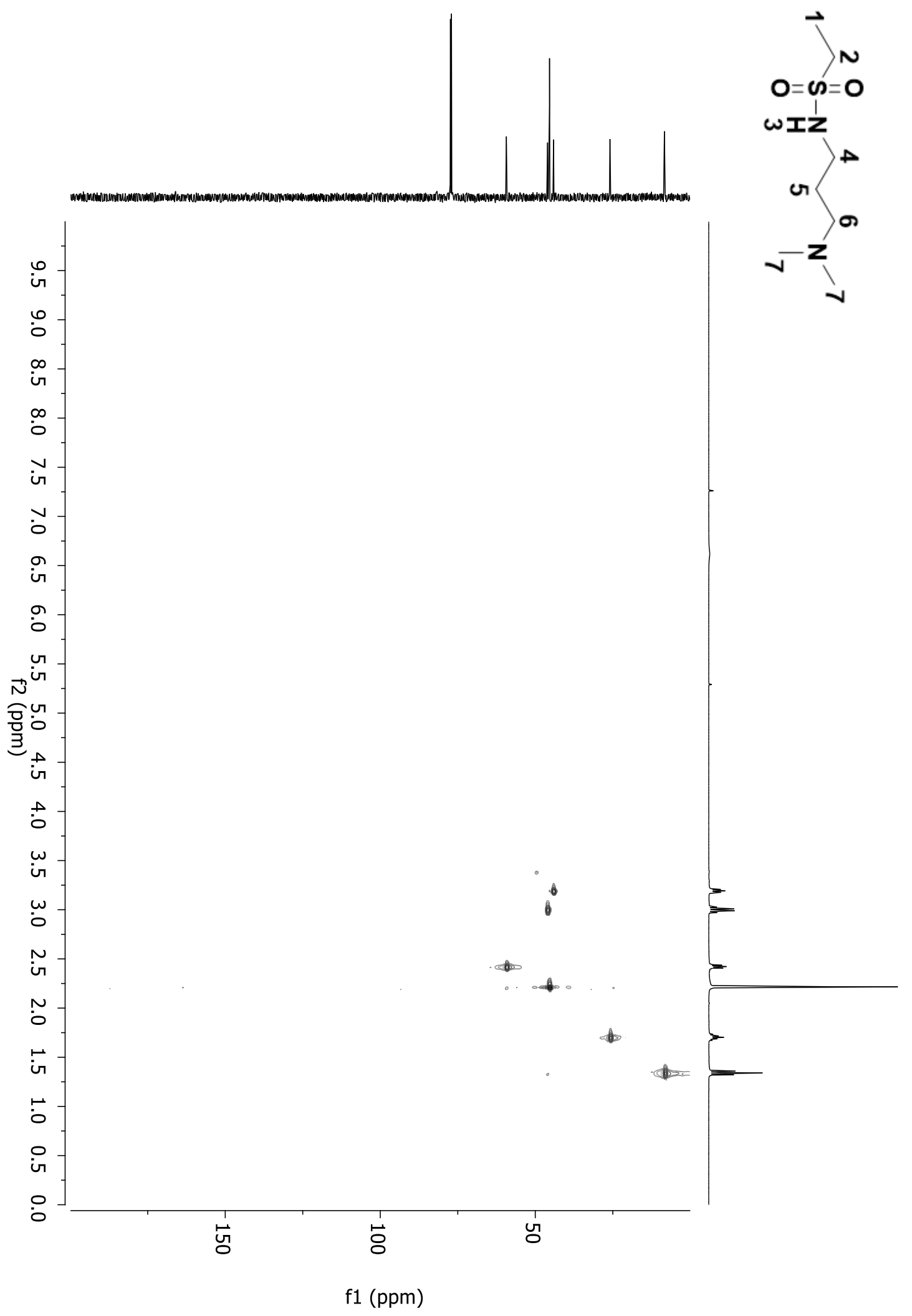

Figure A33: 2D HSQC spectrum of compound 7D in $\mathrm{CDCl}_{3}$. 


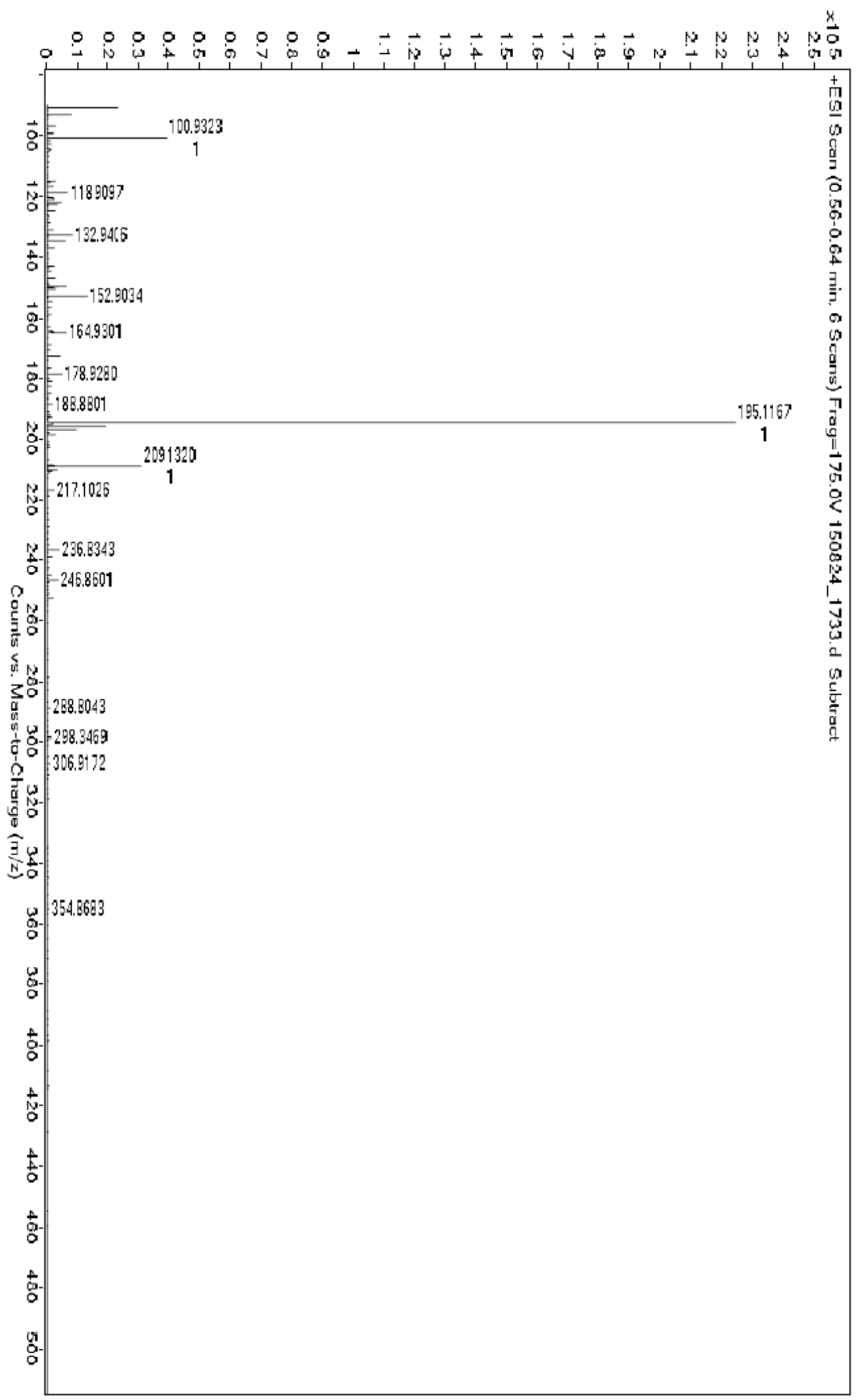

Figure A34: HRMS-ESI-TOF of compound 7D. 


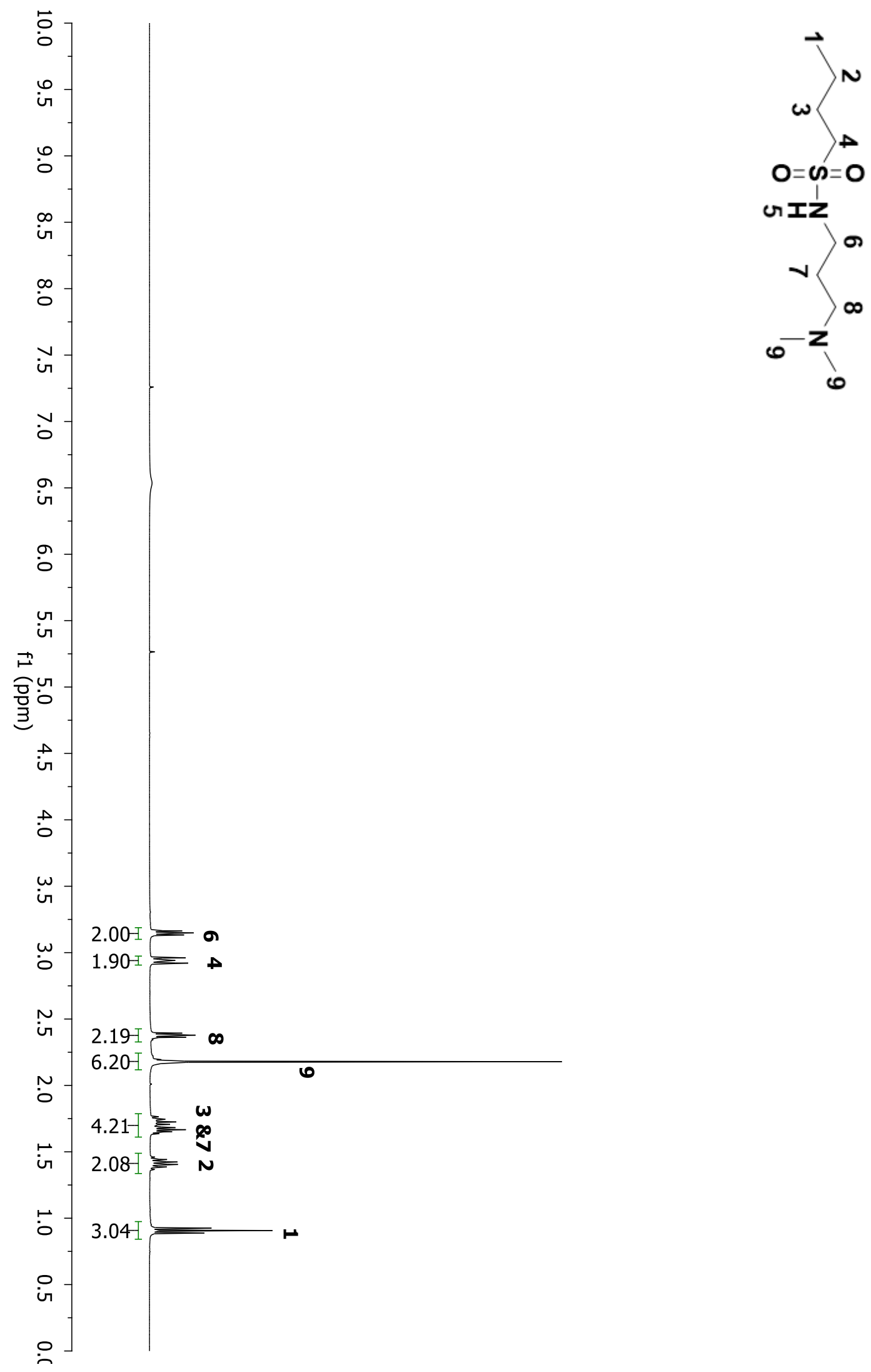

Figure A35: ${ }^{1} \mathrm{H}$ NMR spectrum of compound $\mathbf{8 D}$ in $\mathrm{CDCl}_{3}$. 


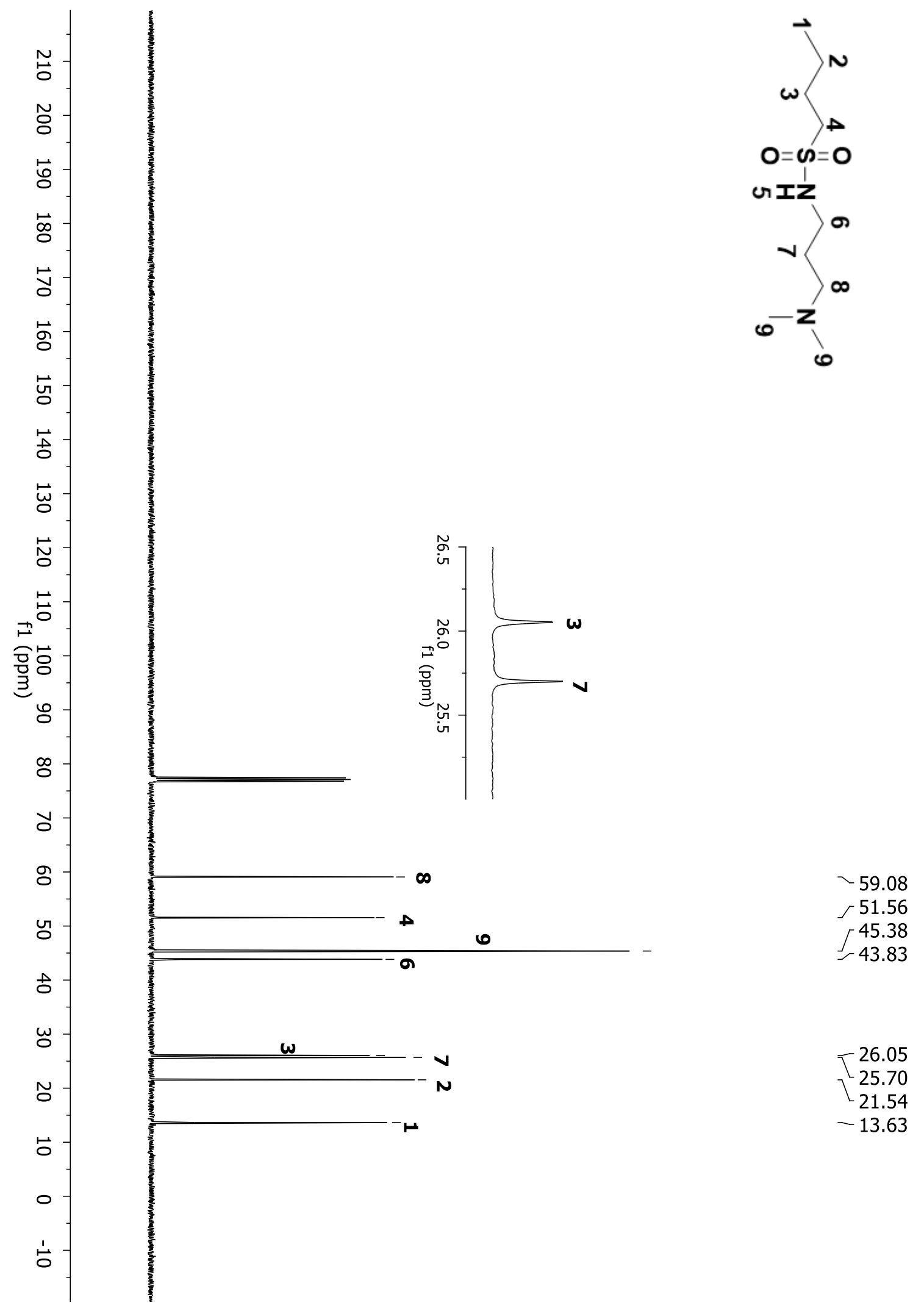

Figure A36: ${ }^{13} \mathrm{C}$ NMR spectrum of compound $\mathbf{8 D}$ in $\mathrm{CDCl}_{3}$. 


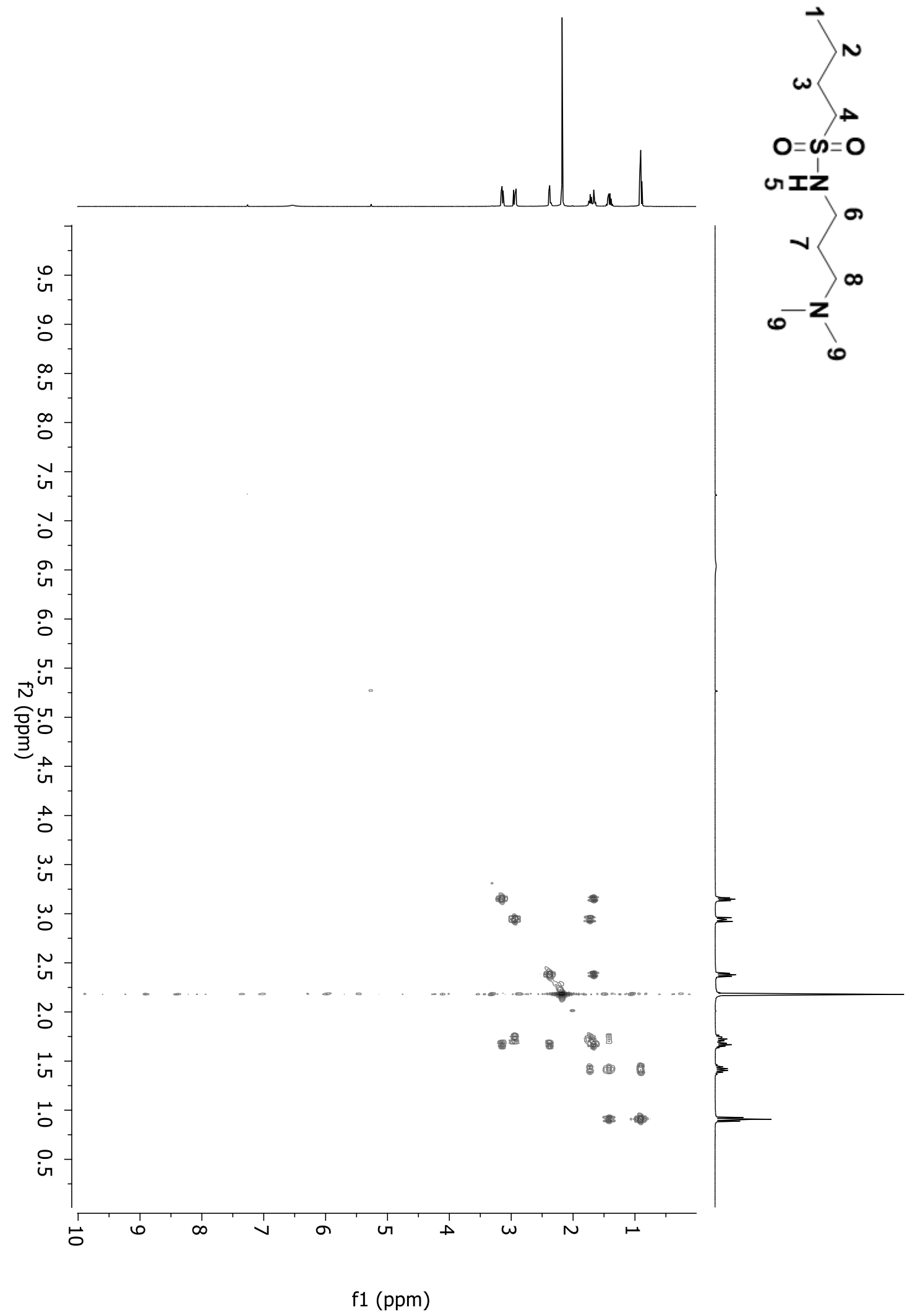

Figure A37: 2D COSY spectrum of compound $\mathbf{8 D}$ in $\mathrm{CDCl}_{3}$. 


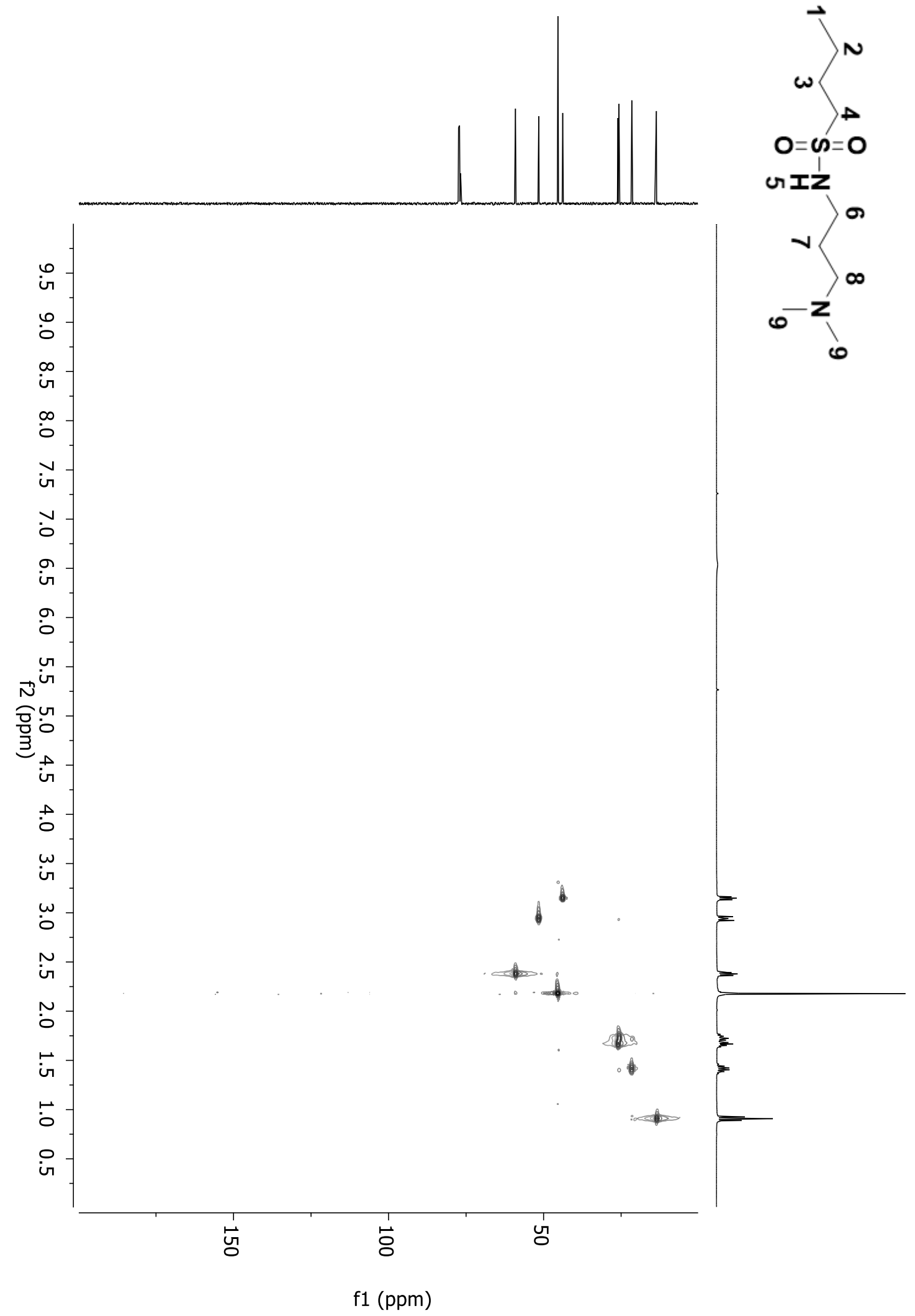

Figure A38: 2D HSQC spectrum of compound $\mathbf{8 D}$ in $\mathrm{CDCl}_{3}$. 


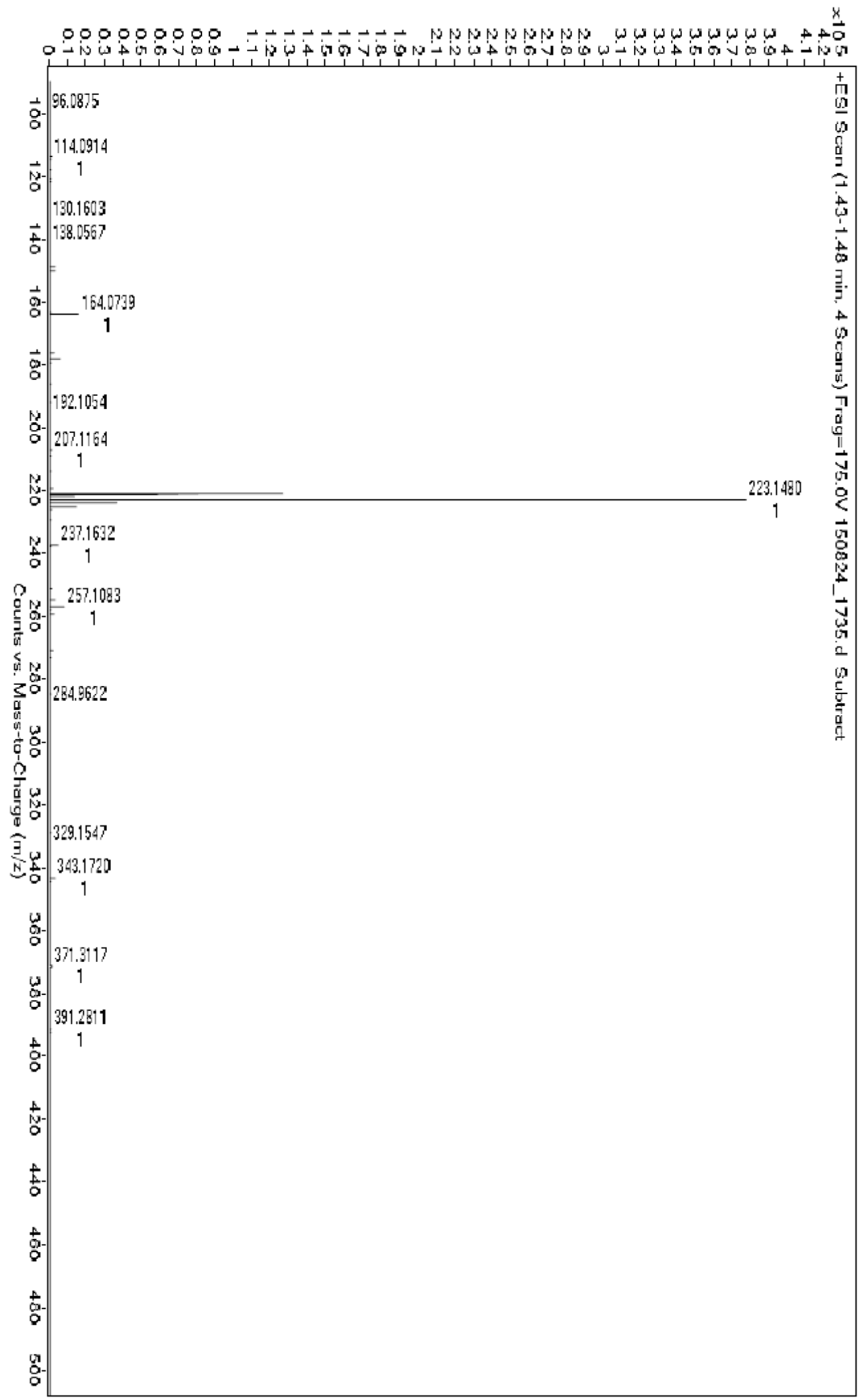

Figure A39: HRMS-ESI-TOF of compound 8D. 

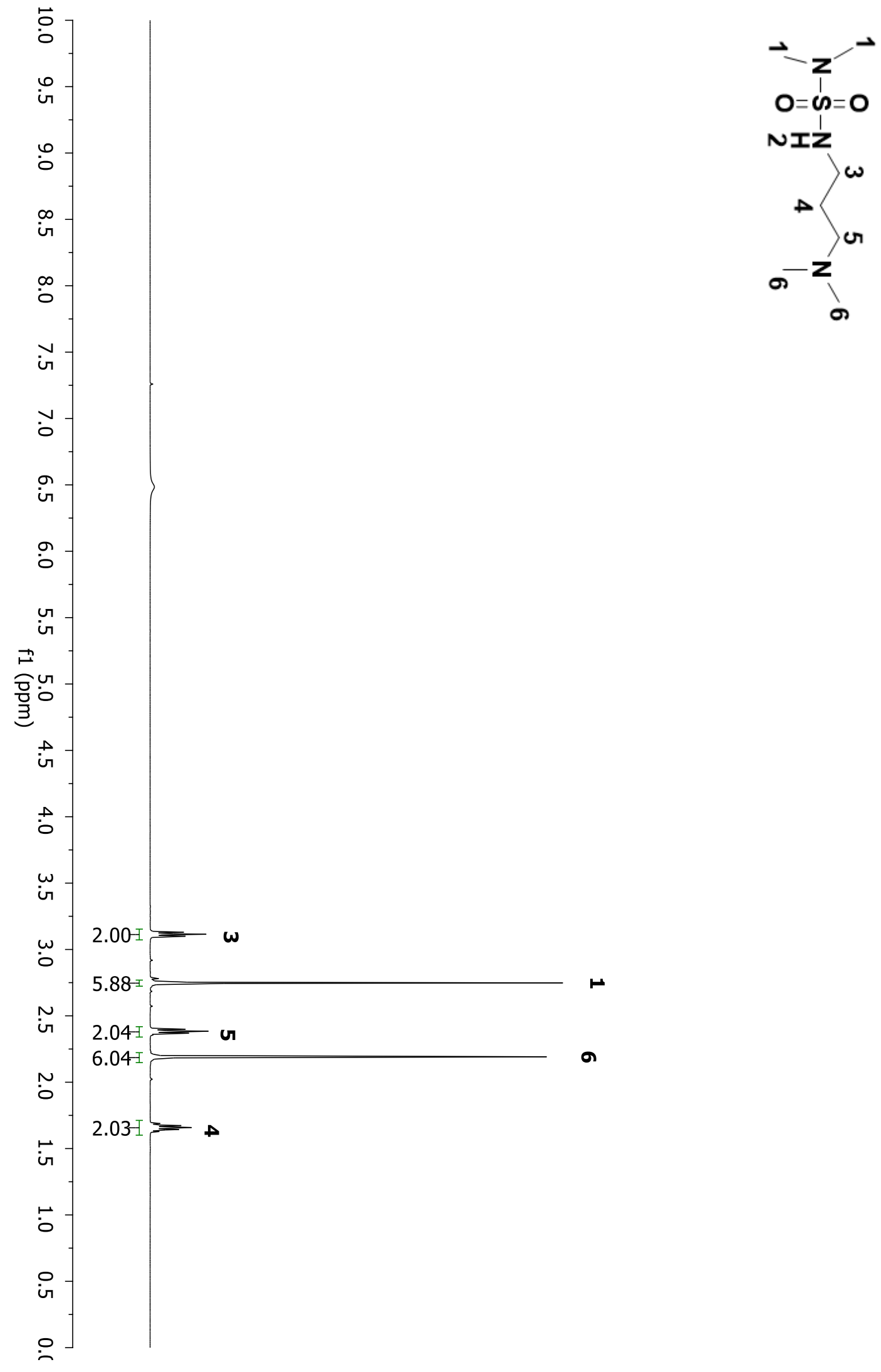

Figure A40: ${ }^{1} \mathrm{H}$ NMR spectrum of compound 9D in $\mathrm{CDCl}_{3}$. 


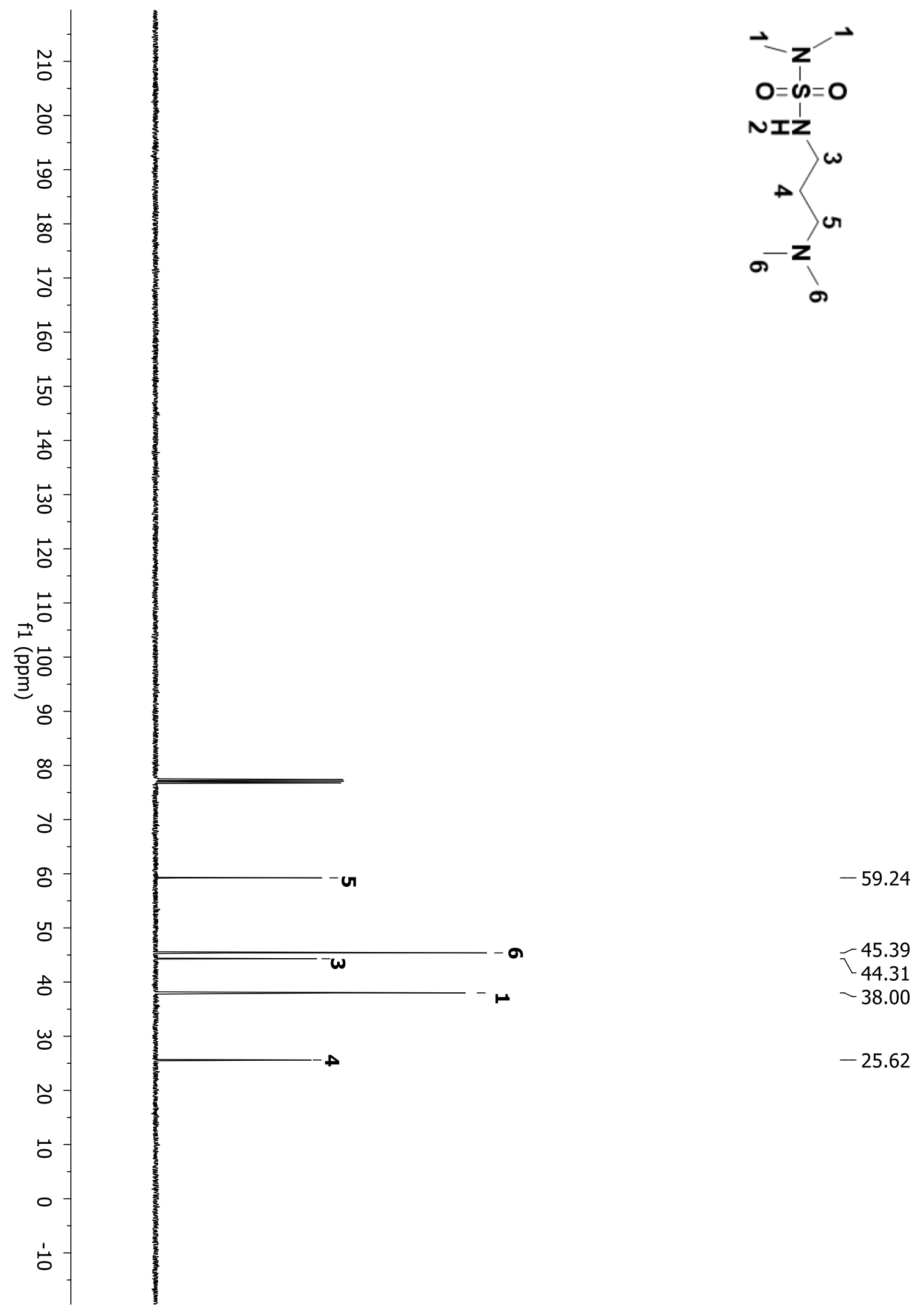

Figure A41: ${ }^{13} \mathrm{C}$ NMR spectrum of compound $9 \mathrm{D}$ in $\mathrm{CDCl}_{3}$. 


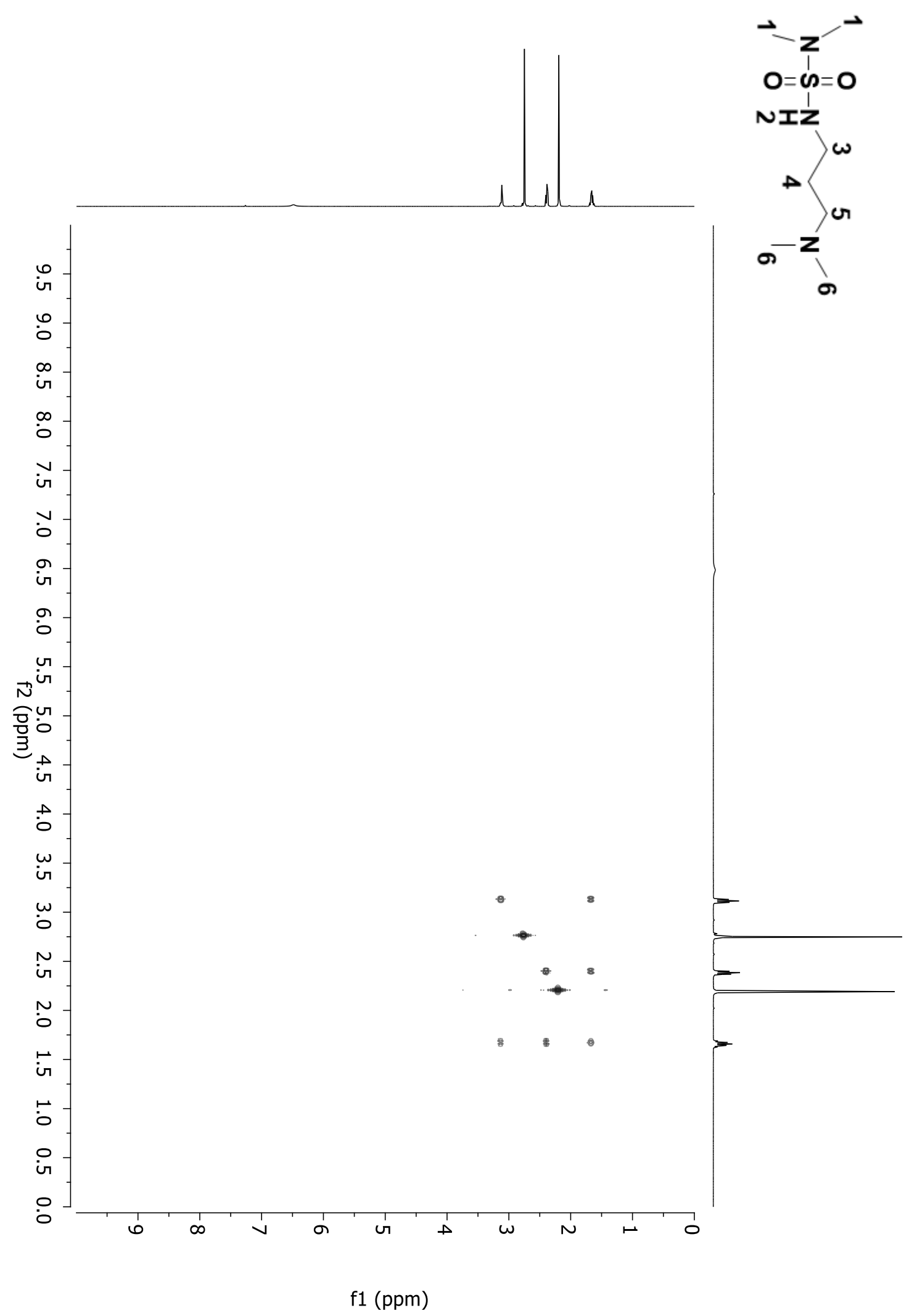

Figure A42: 2D COSY spectrum of compound 9D in $\mathrm{CDCl}_{3}$. 


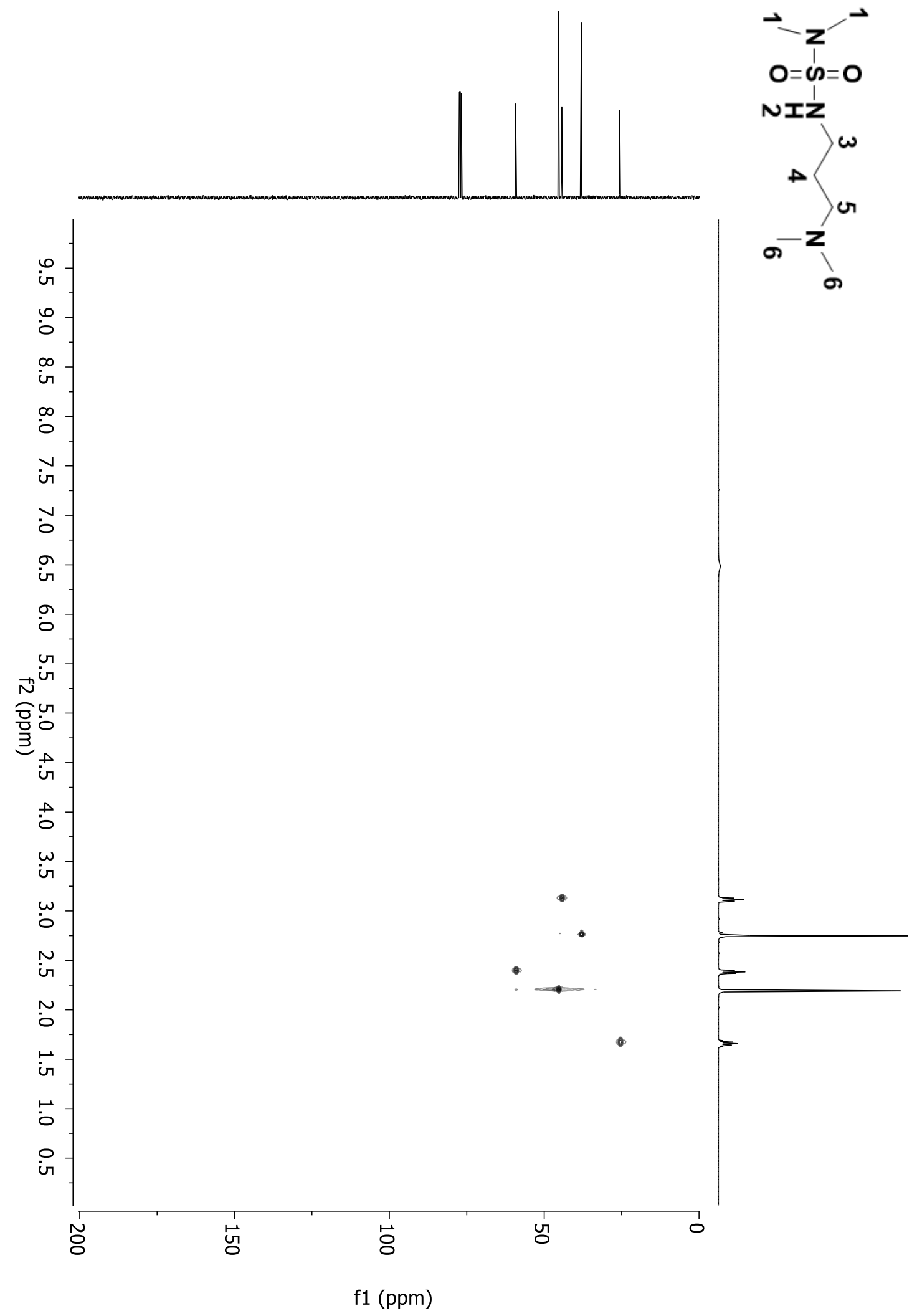

Figure A43: 2D HSQC spectrum of compound 9D in $\mathrm{CDCl}_{3}$. 


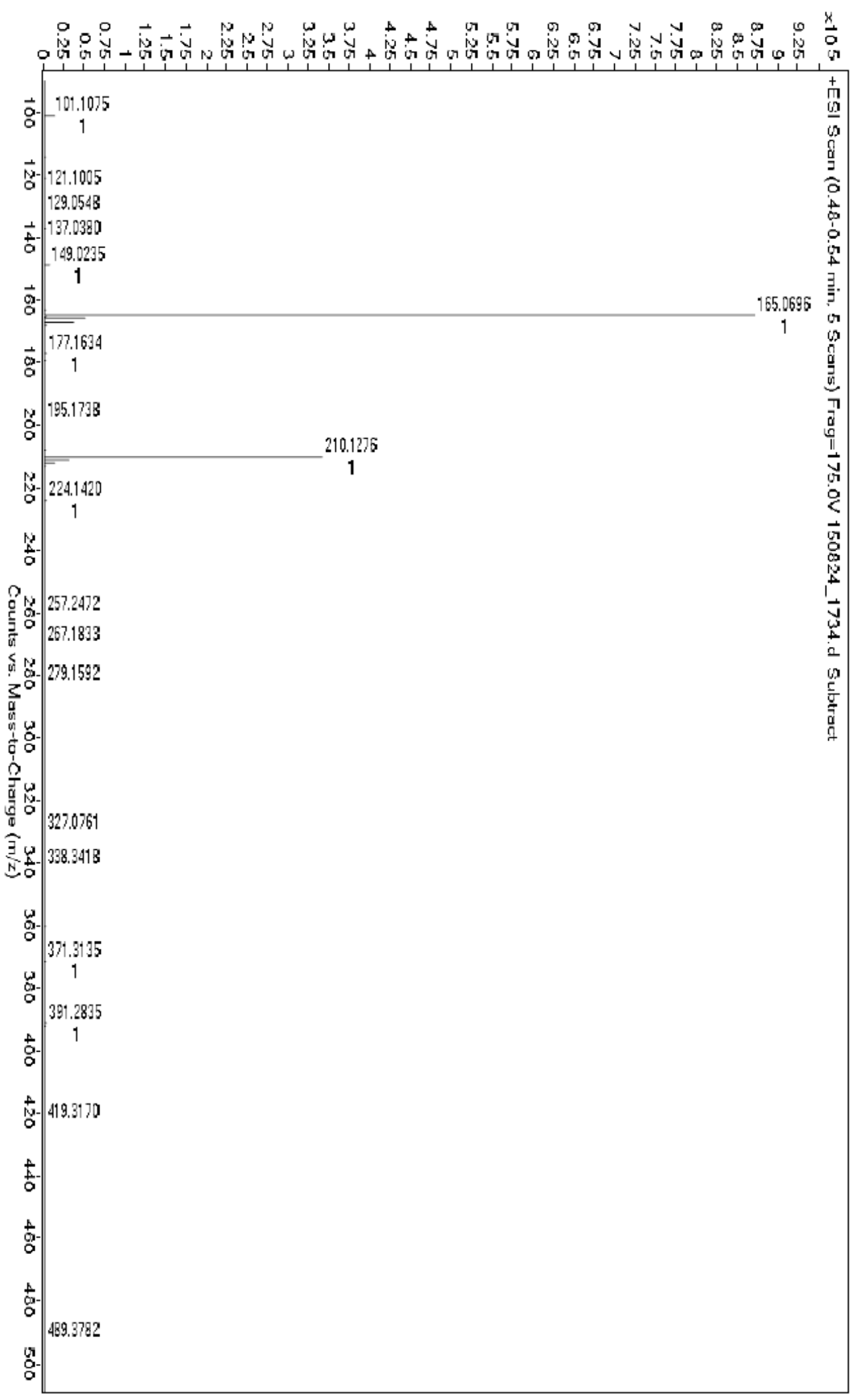

Figure A44: HRMS-ESI-TOF of compound 9D. 


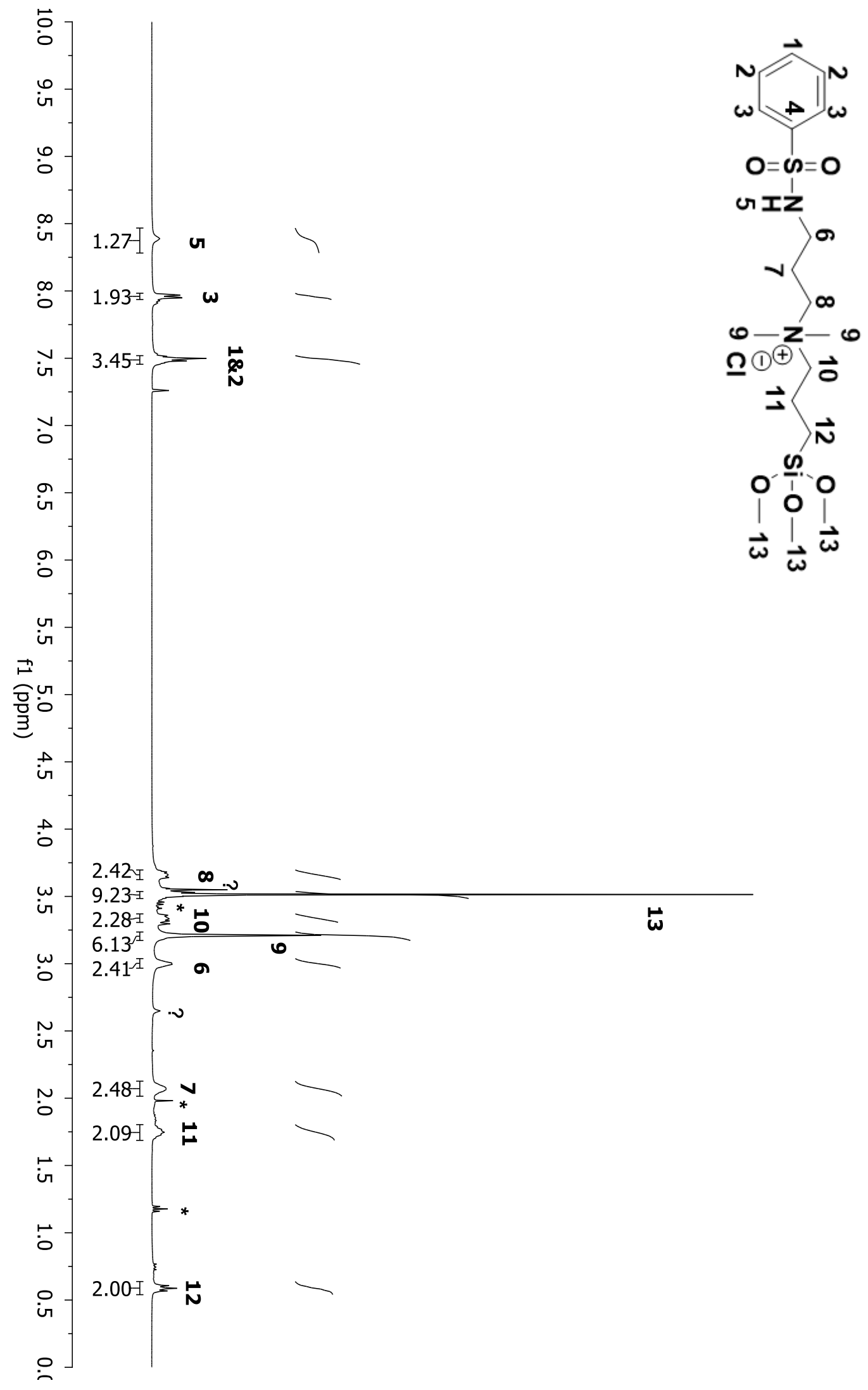

Figure A45: ${ }^{1} \mathrm{H}$ NMR spectrum of compound $1 \mathrm{~F}$ in $\mathrm{CDCl}_{3}$. 


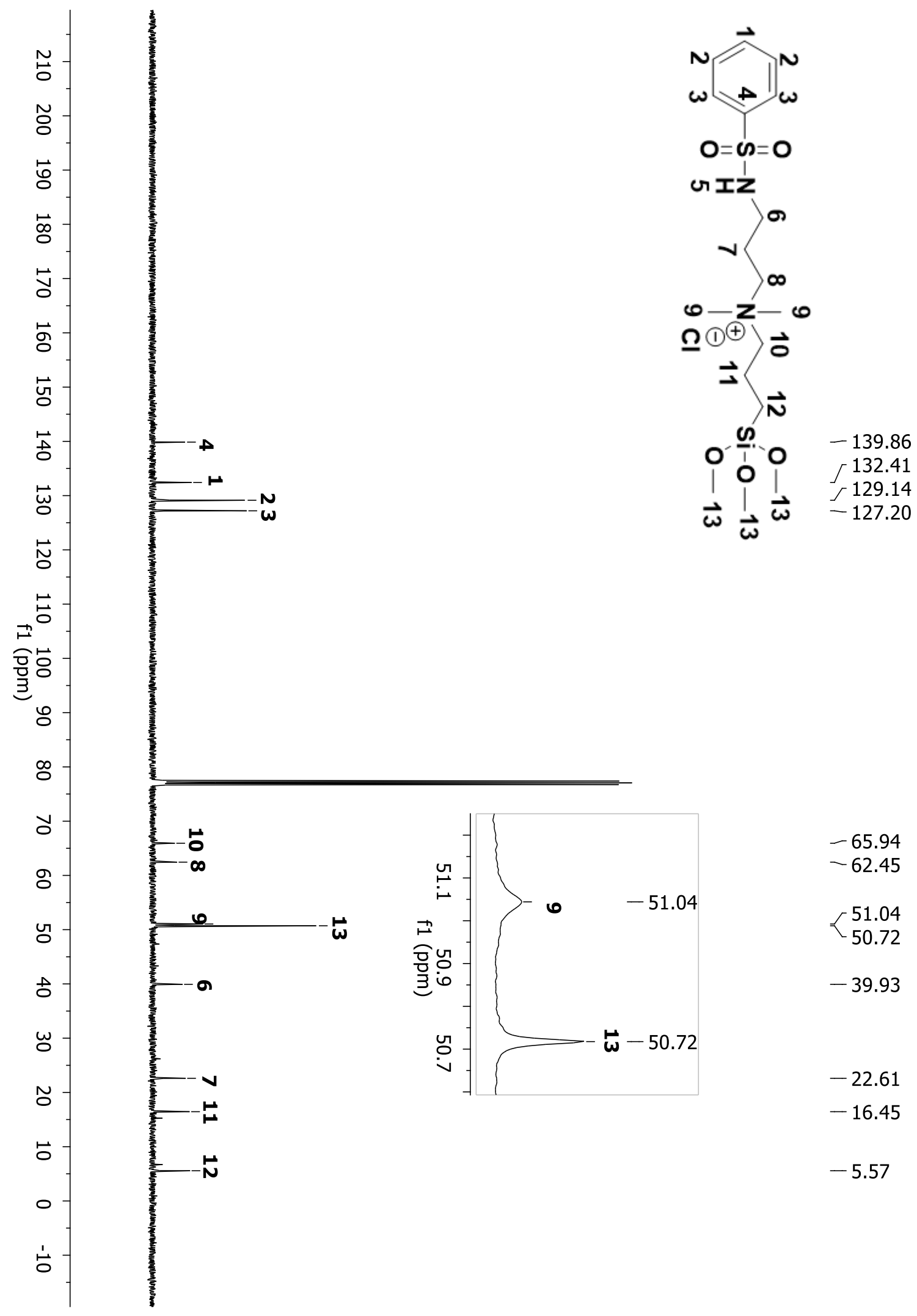

Figure A46: ${ }^{13} \mathrm{C}$ NMR spectrum of compound $1 \mathrm{~F}$ in $\mathrm{CDCl}_{3}$. 

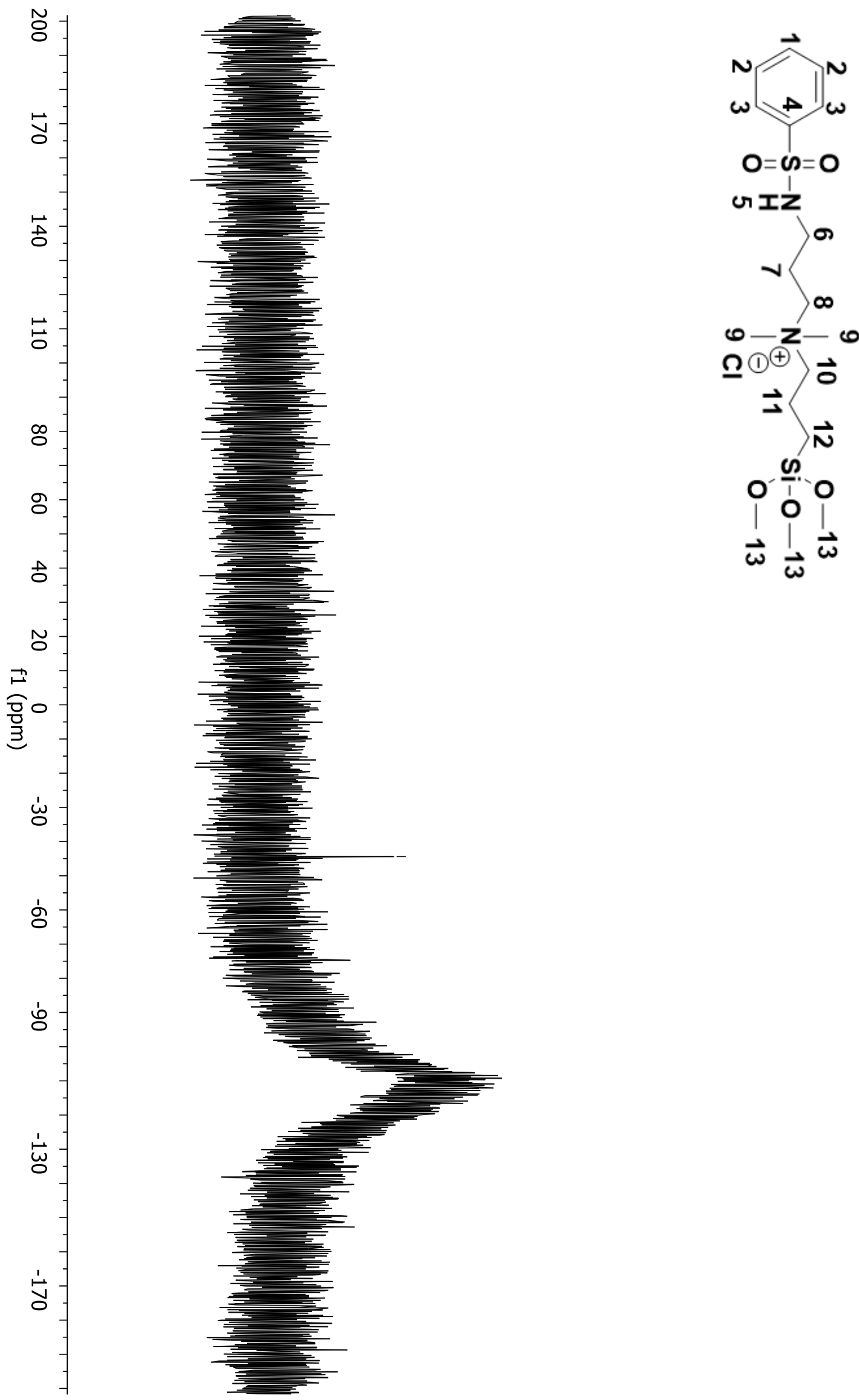

$--44.41$

Figure A47: ${ }^{29} \mathrm{Si}$ NMR spectrum of compound $1 \mathrm{~F}$ in $\mathrm{CDCl}_{3}$. 


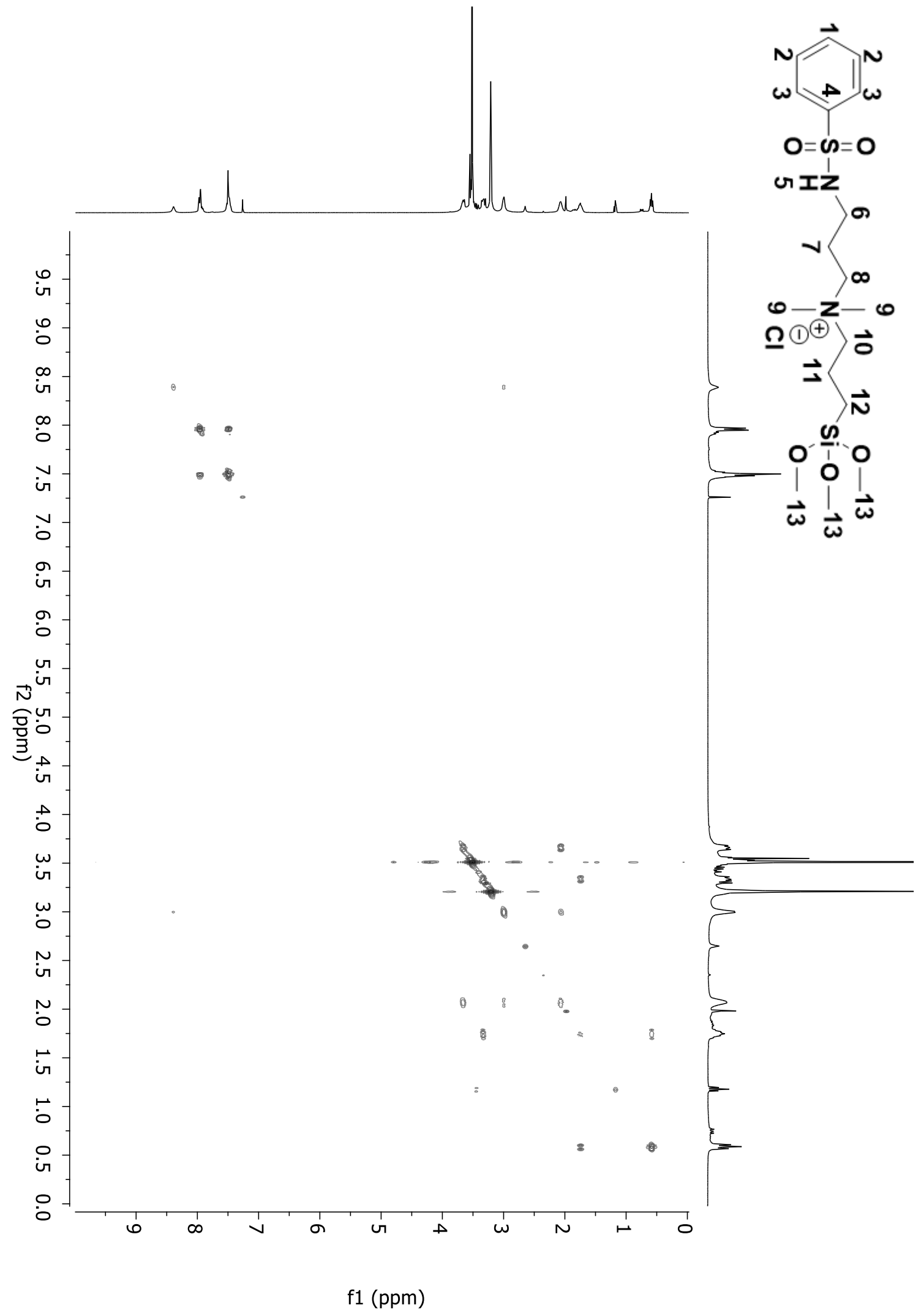

Figure A48: 2D COSY spectrum of compound $\mathbf{1 F}$ in $\mathrm{CDCl}_{3}$. 


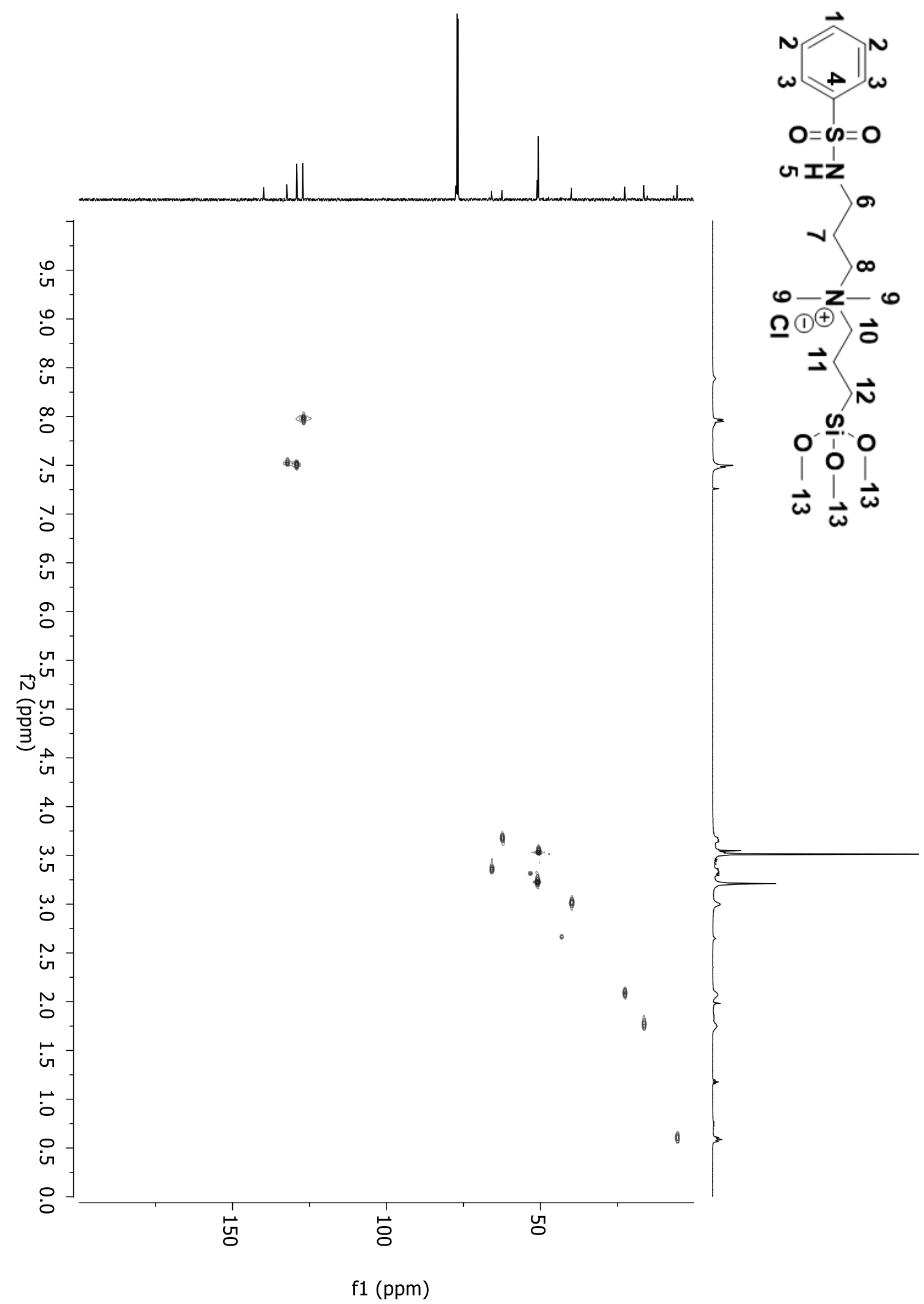

Figure A49: 2D HSQC spectrum of compound $\mathbf{1 F}$ in $\mathrm{CDCl}_{3}$. 


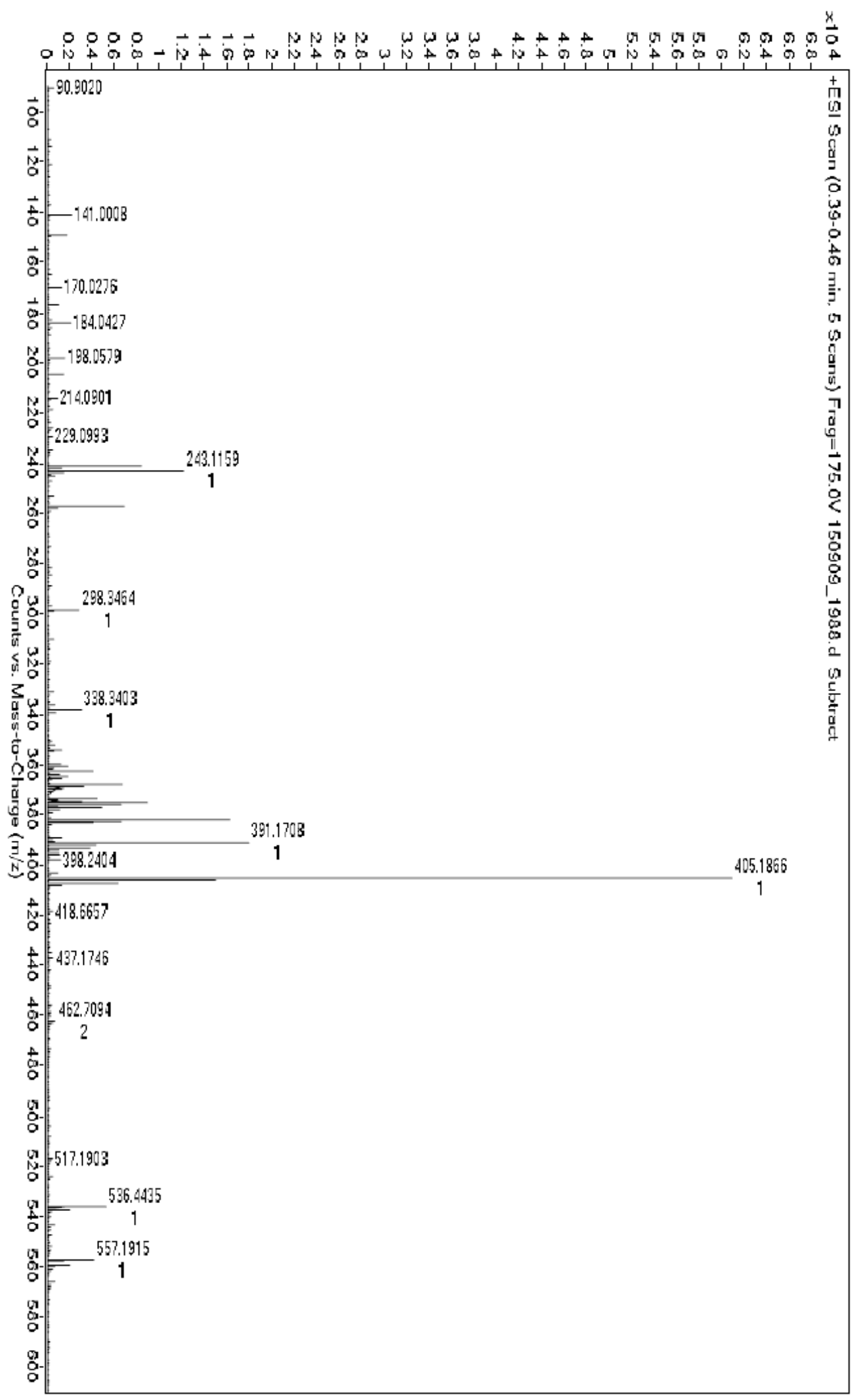

Figure A50: HRMS-ESI-TOF of compound 1F. 

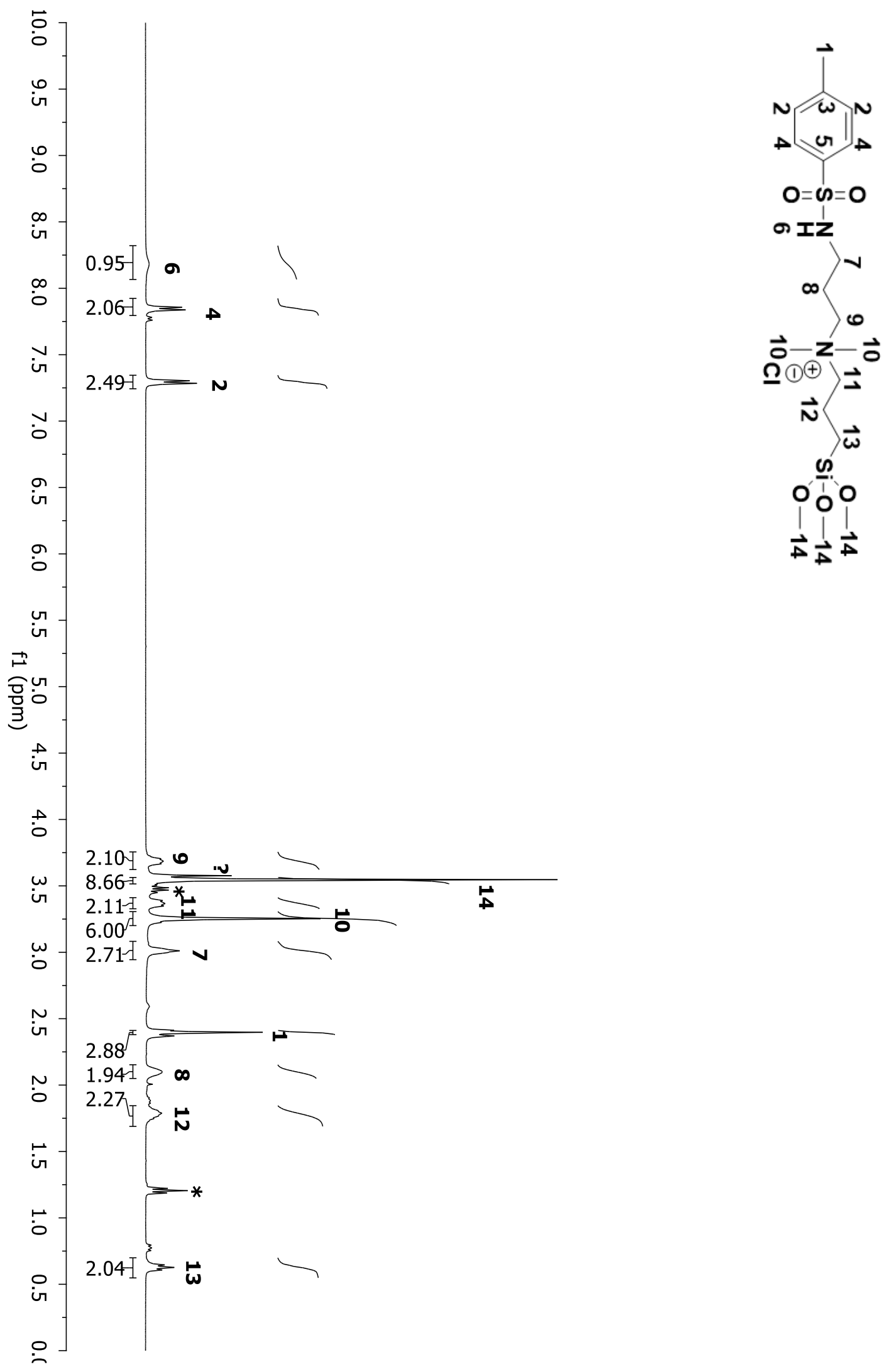

Figure A51: ${ }^{1} \mathrm{H}$ NMR spectrum of compound $2 \mathbf{F}$ in $\mathrm{CDCl}_{3}$. 


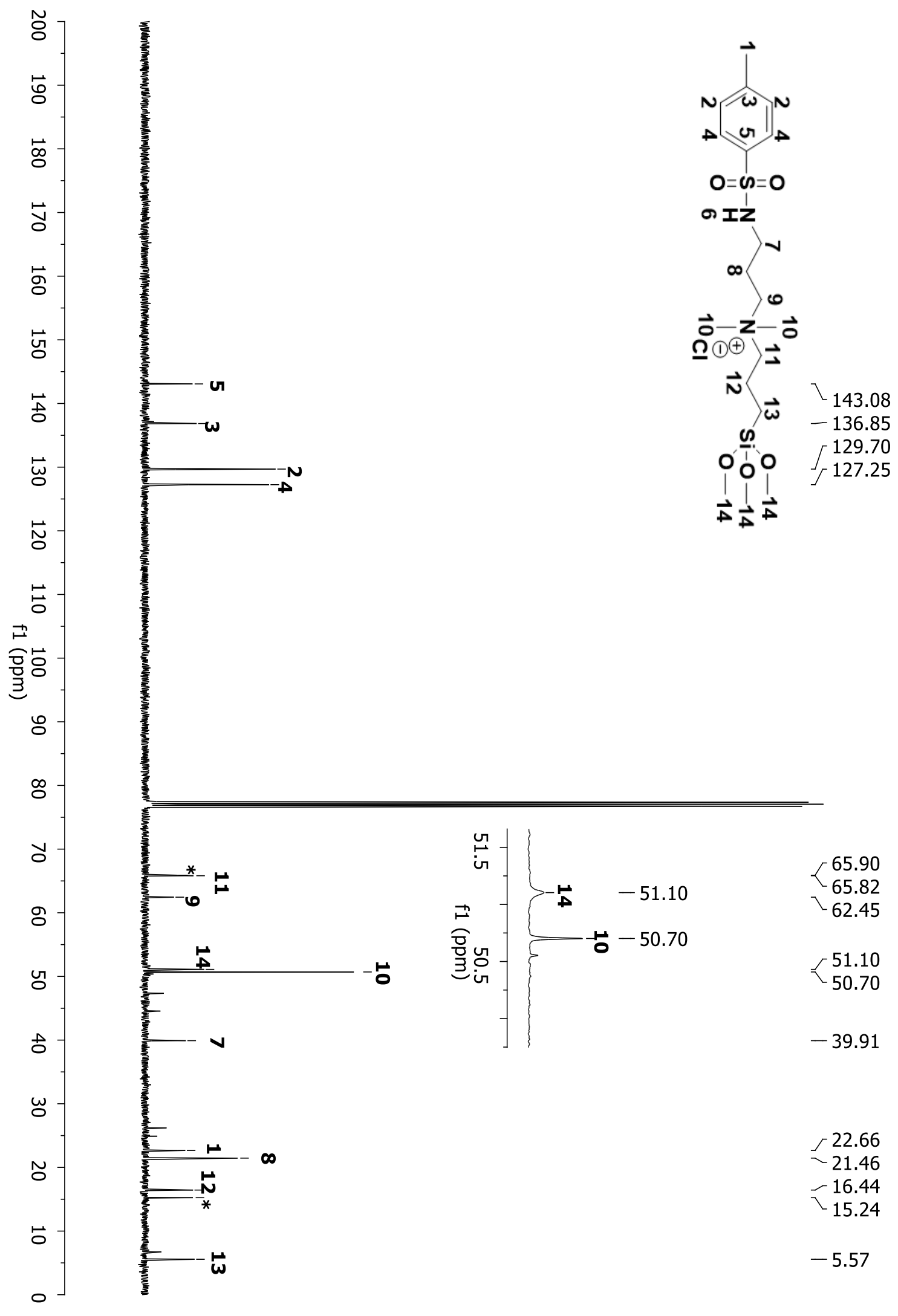

Figure A52: ${ }^{13} \mathrm{C}$ NMR spectrum of compound $2 \mathbf{F}$ in $\mathrm{CDCl}_{3}$. 

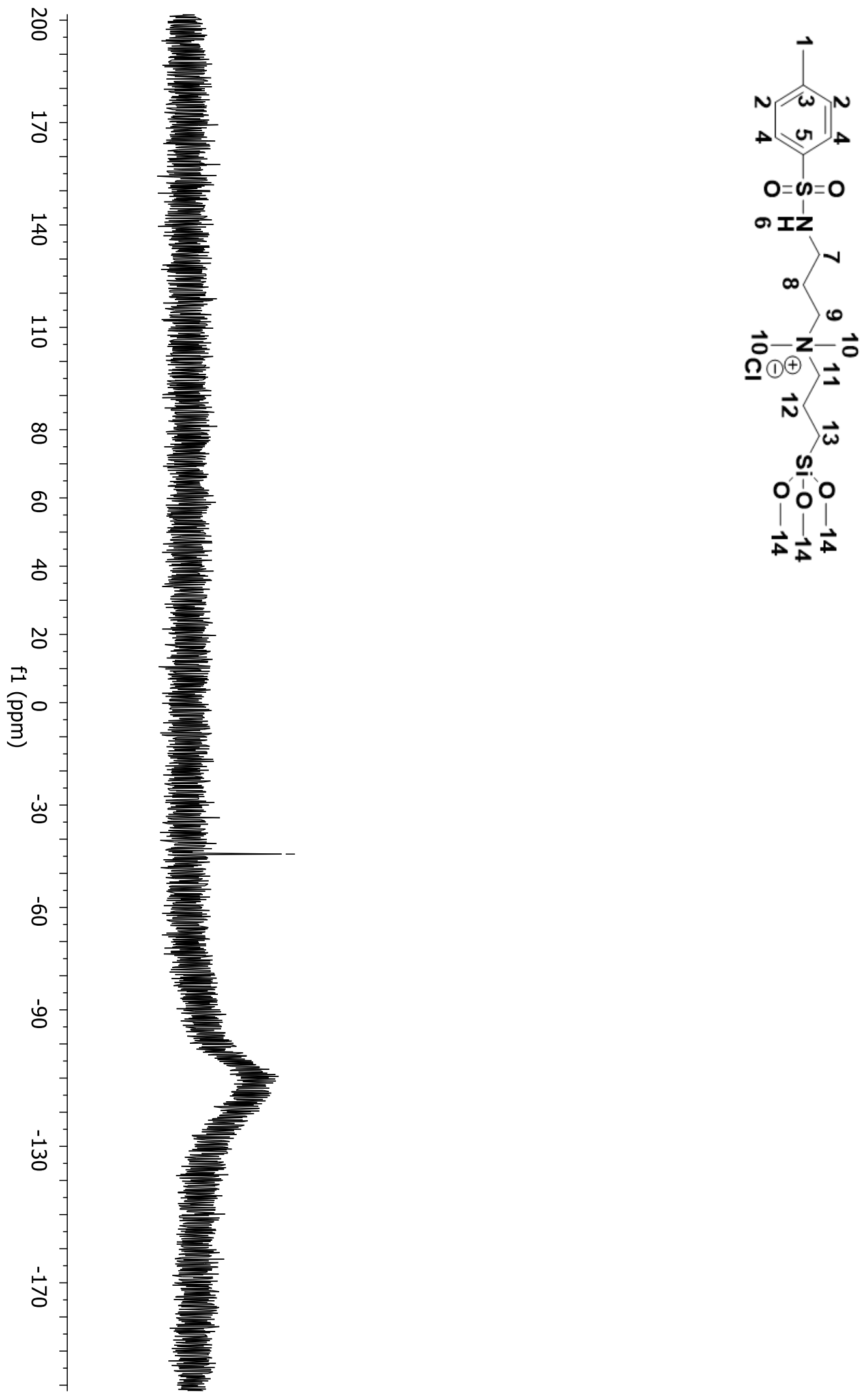

Figure A53: ${ }^{29} \mathrm{Si} \mathrm{NMR}$ spectrum of compound $2 \mathrm{~F}$ in $\mathrm{CDCl}_{3}$. 


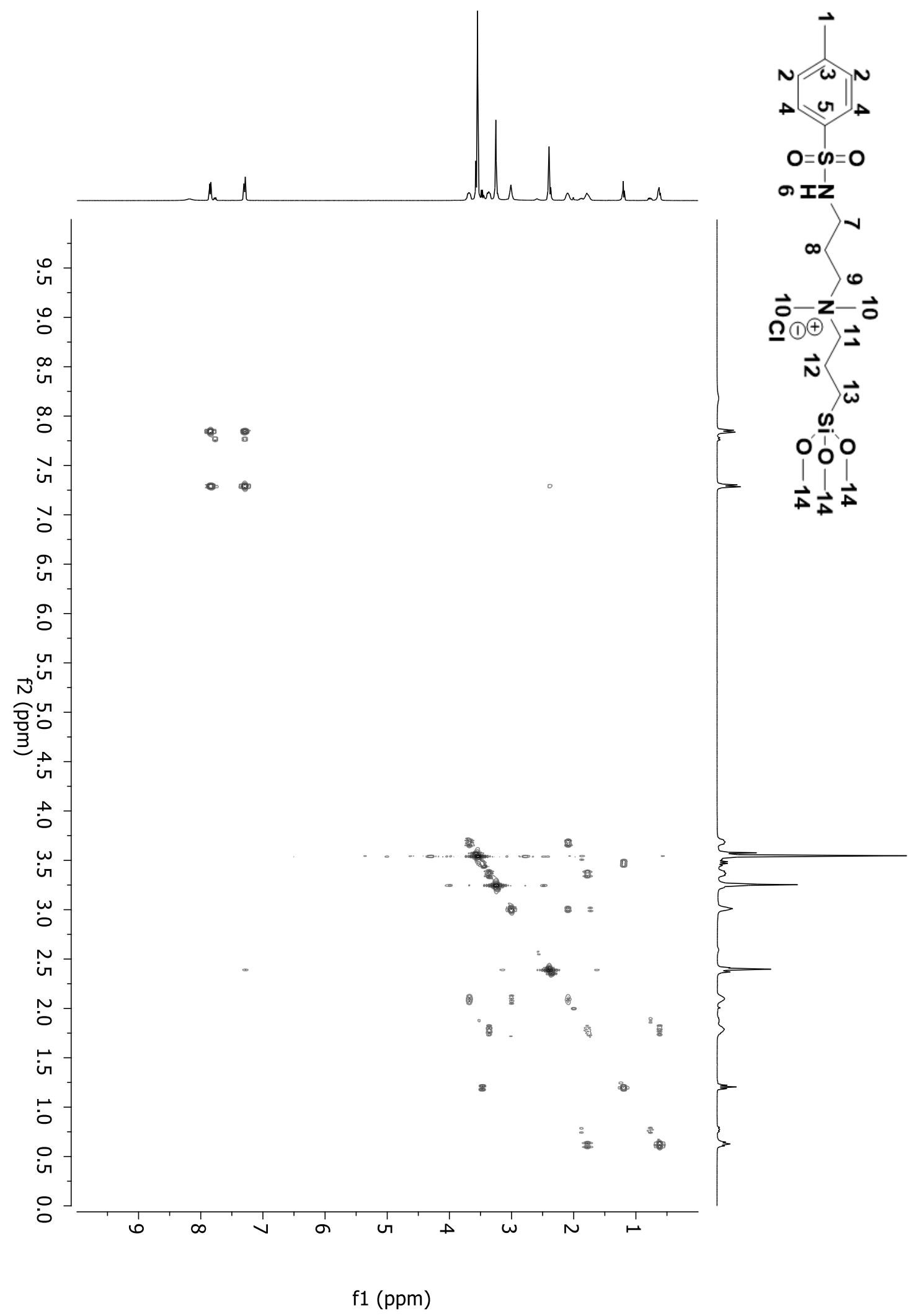

Figure A54: 2D COSY spectrum of compound $2 \mathrm{~F}$ in $\mathrm{CDCl}_{3}$. 


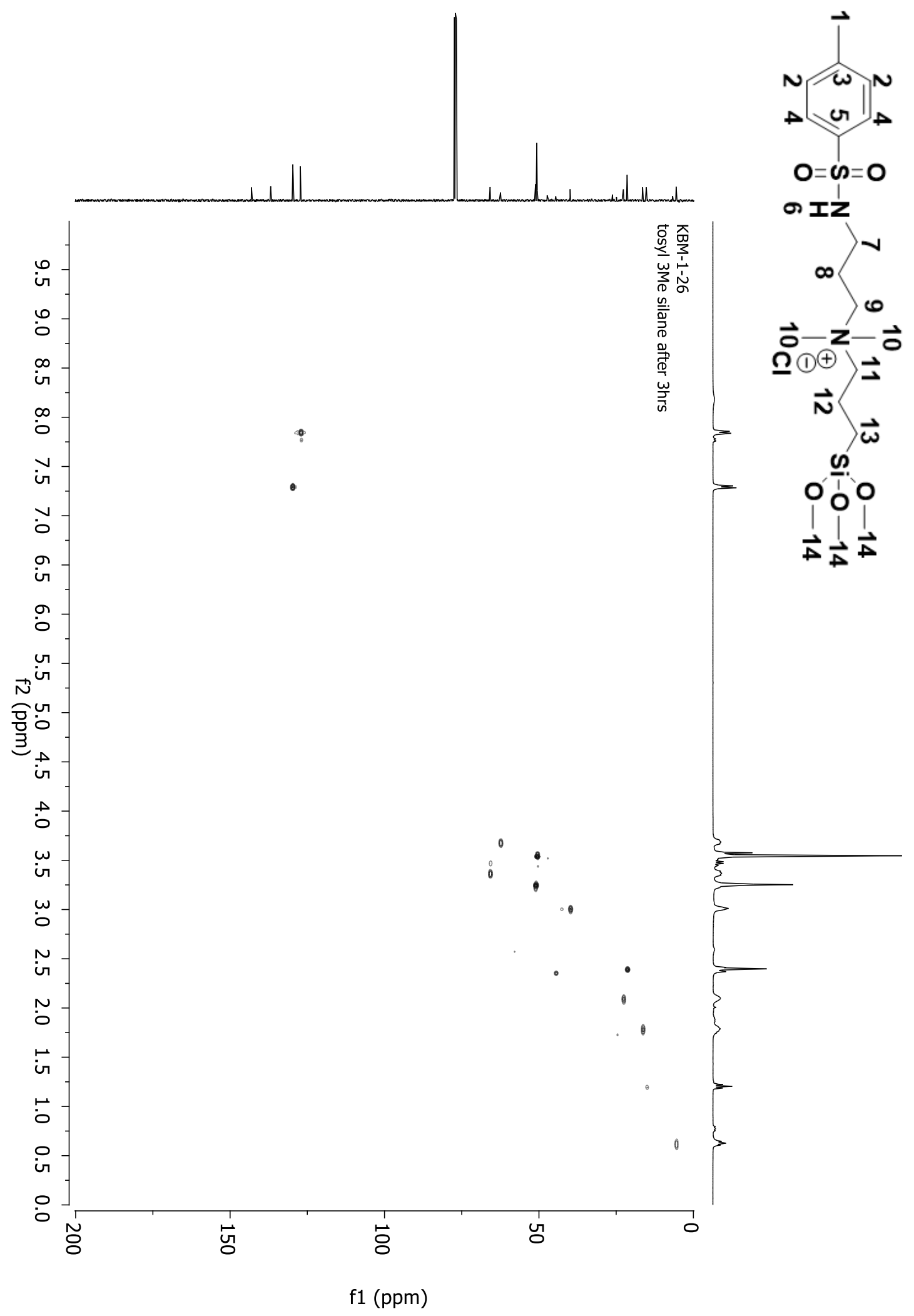

Figure A55: 2D HSQC spectrum of compound $2 \mathrm{~F}$ in $\mathrm{CDCl}_{3}$. 


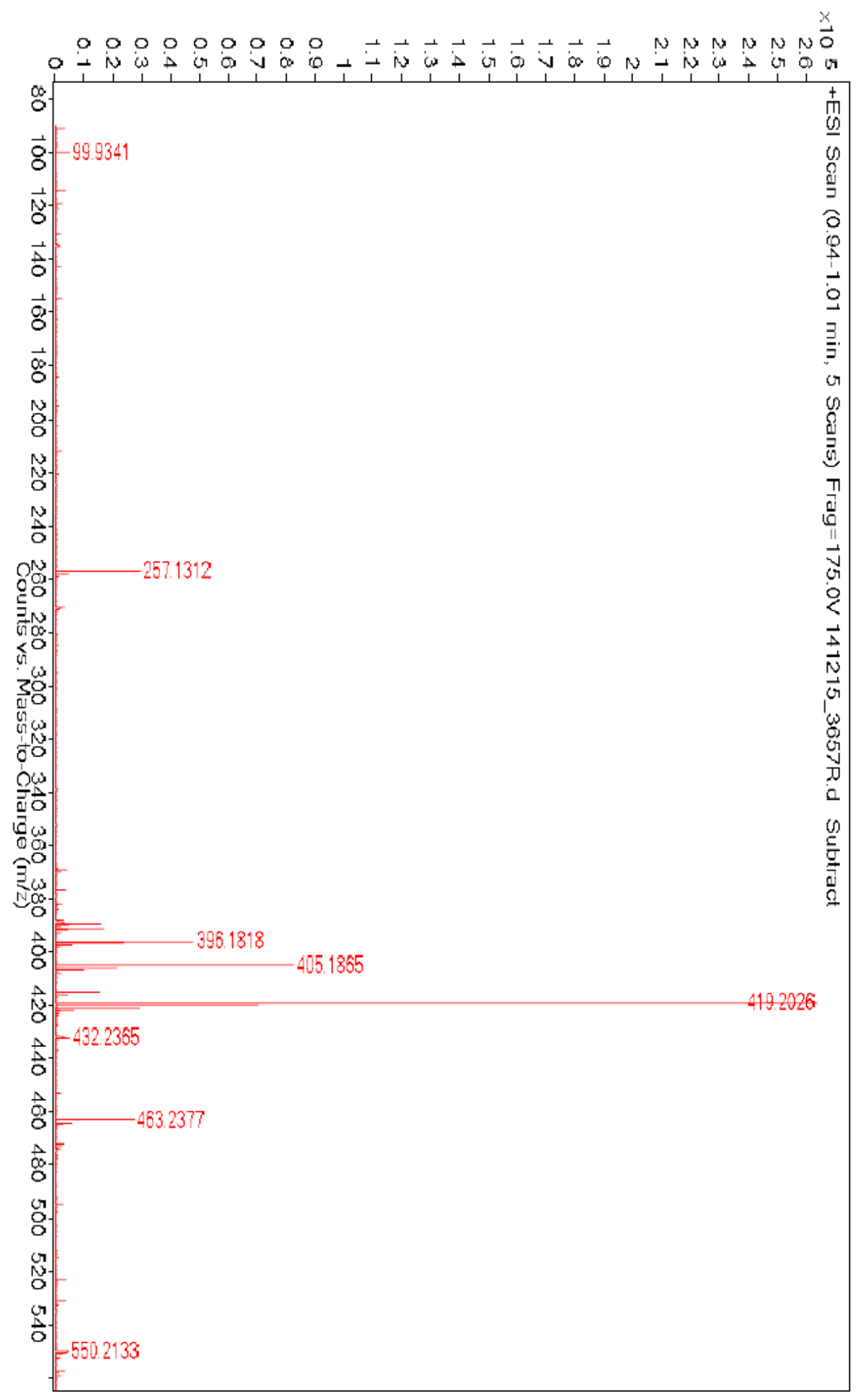

Figure A56: HRMS-ESI-TOF of compound 2F. 


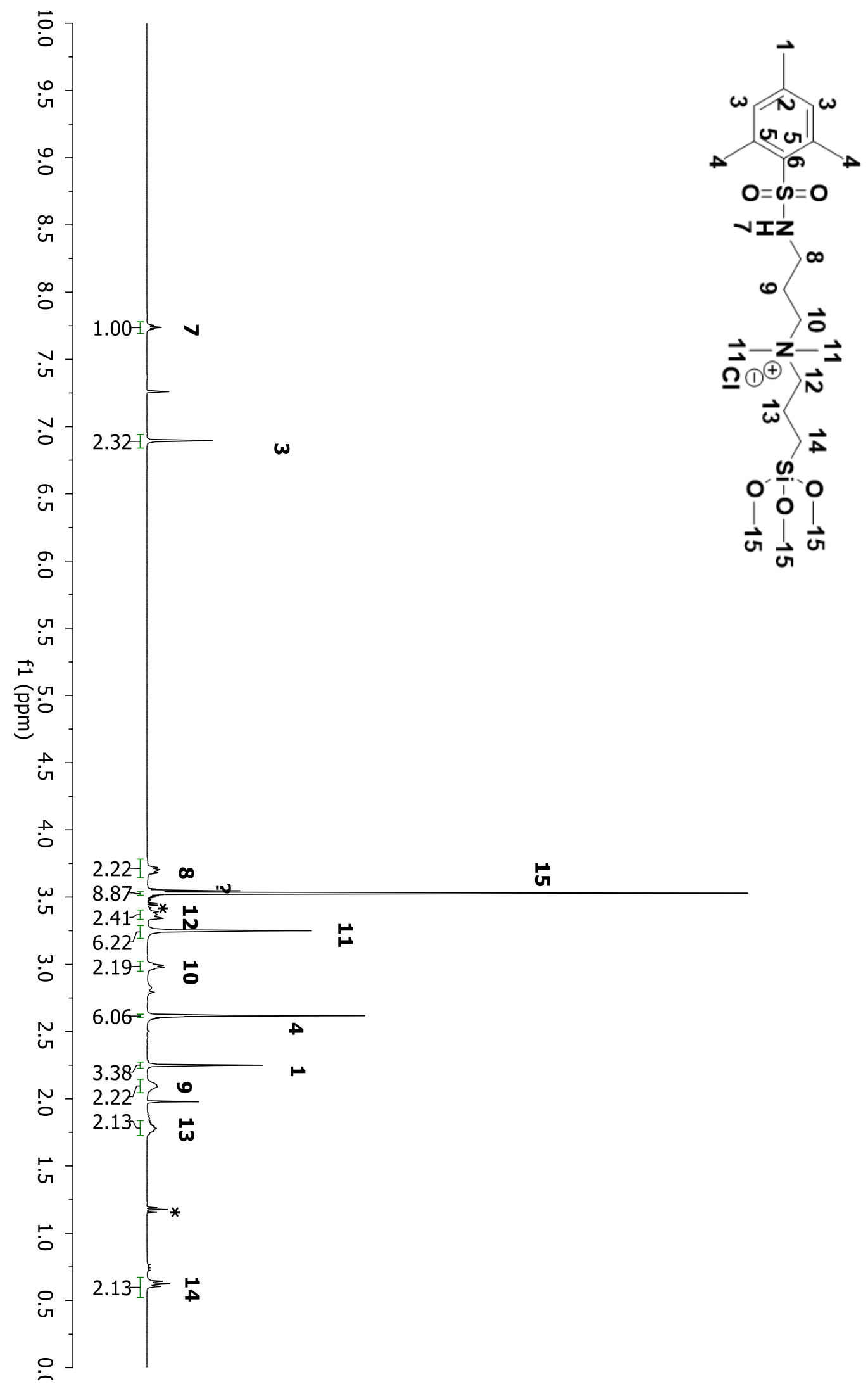

Figure A57: ${ }^{1} \mathrm{H}$ NMR spectrum of compound $\mathbf{3 F}$ in $\mathrm{CDCl}_{3}$. 


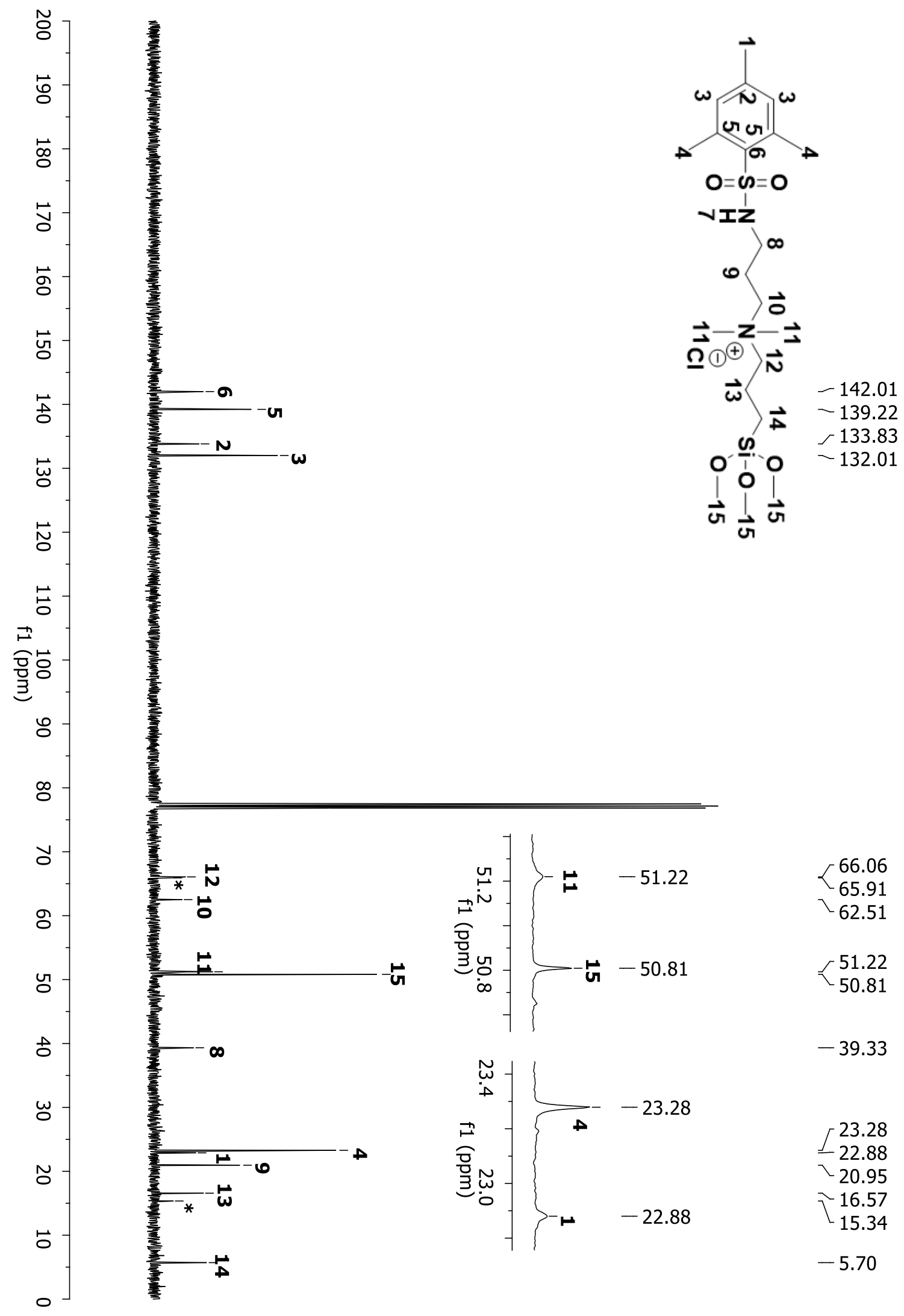

Figure A58: ${ }^{13} \mathrm{C}$ NMR spectrum of compound $\mathbf{3 F}$ in $\mathrm{CDCl}_{3}$. 

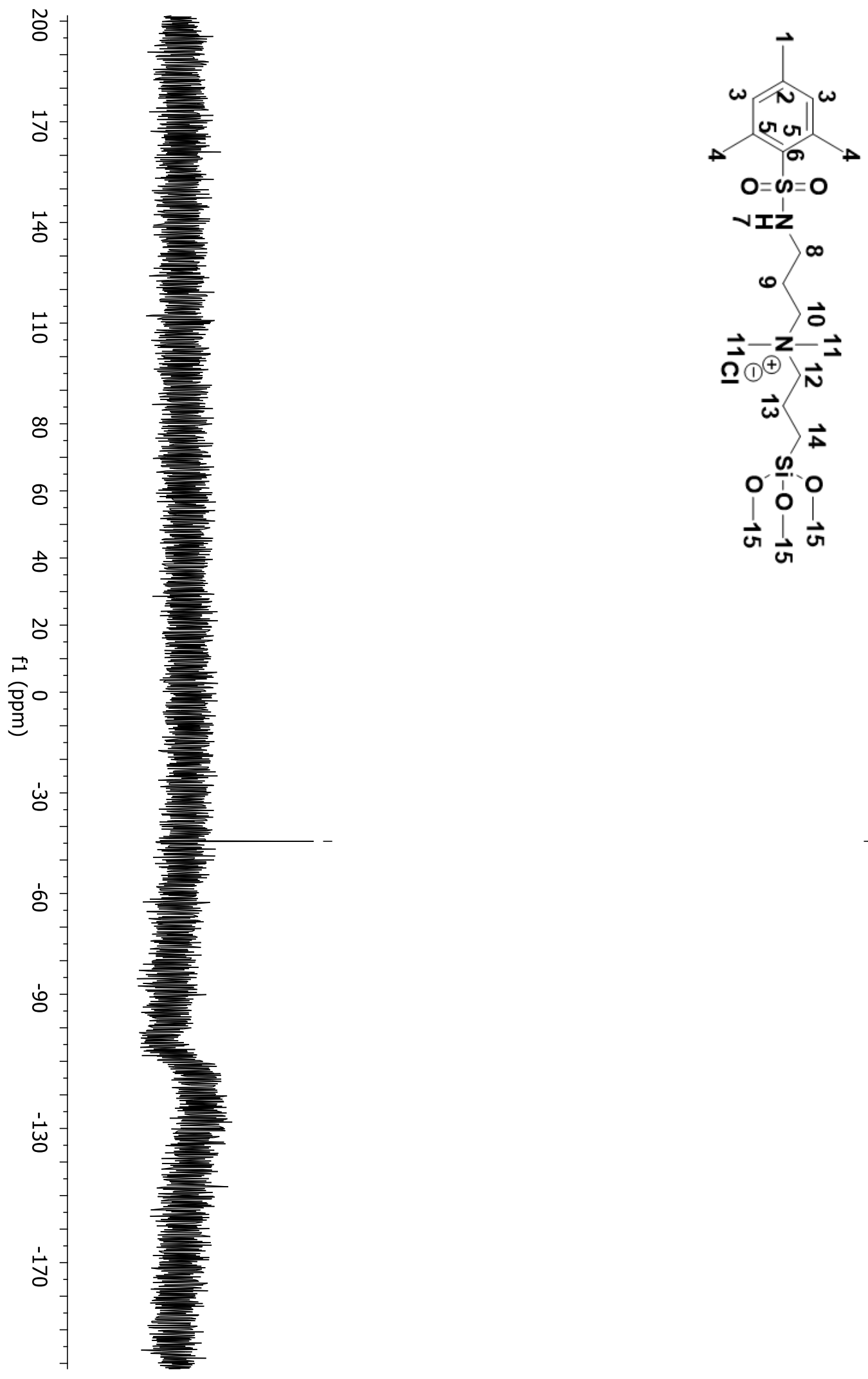

Figure A59: ${ }^{29} \mathrm{Si} \mathrm{NMR}$ spectrum of compound $\mathbf{3 F}$ in $\mathrm{CDCl}_{3}$. 


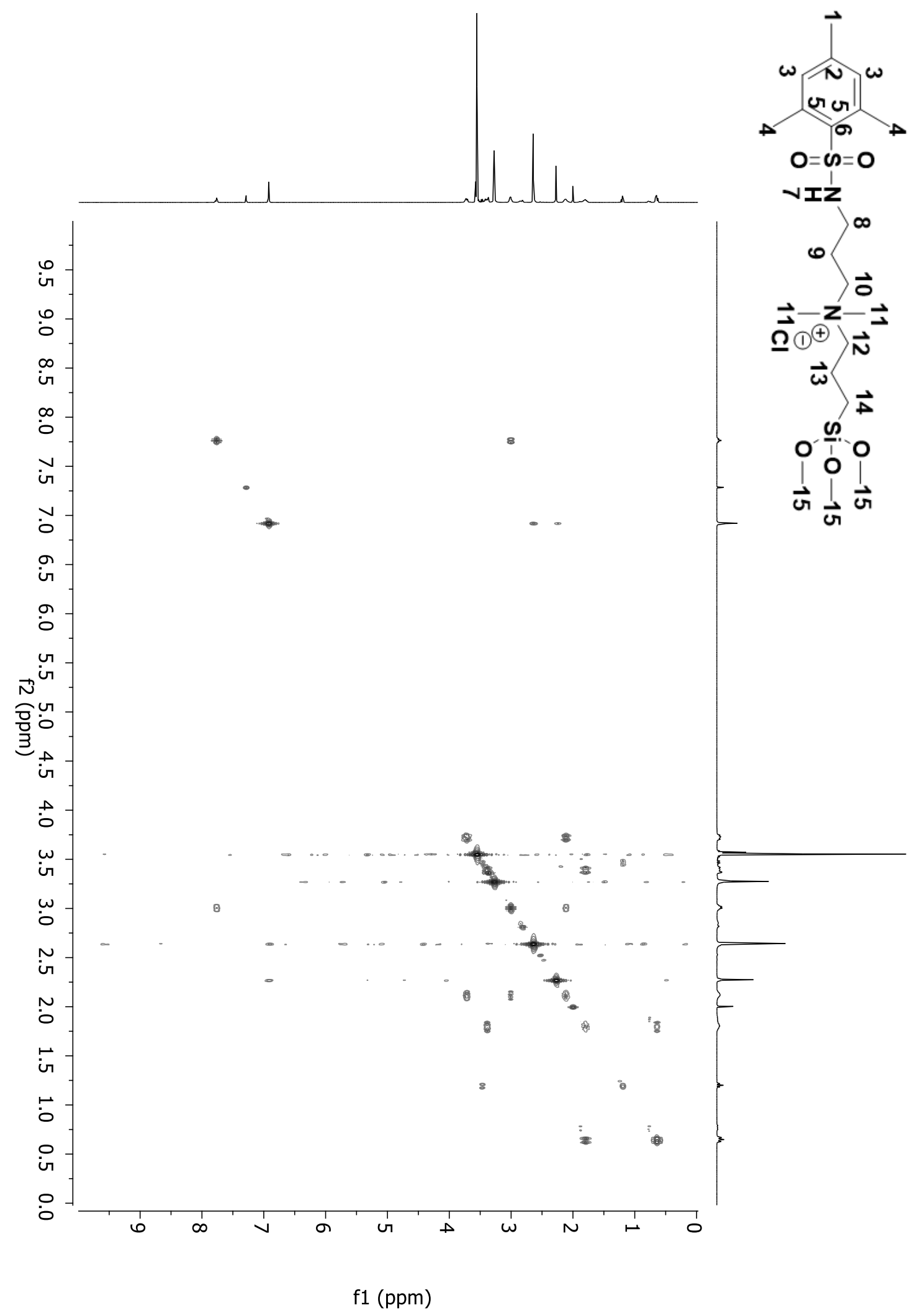

Figure A60: 2D COSY spectrum of compound $\mathbf{3 F}$ in $\mathrm{CDCl}_{3}$. 


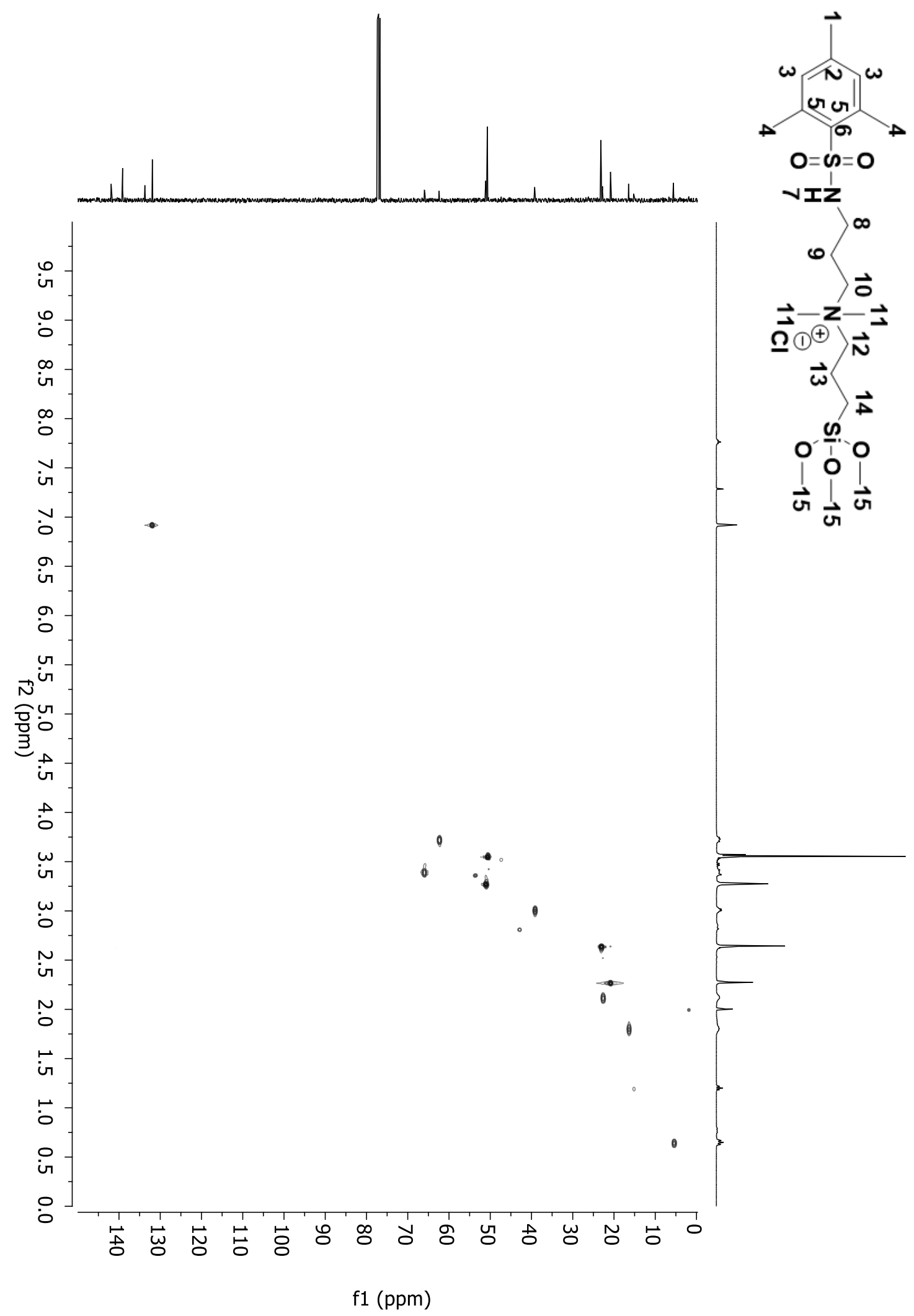

Figure A61: 2D HSQC spectrum of compound $\mathbf{3 F}$ in $\mathrm{CDCl}_{3}$. 


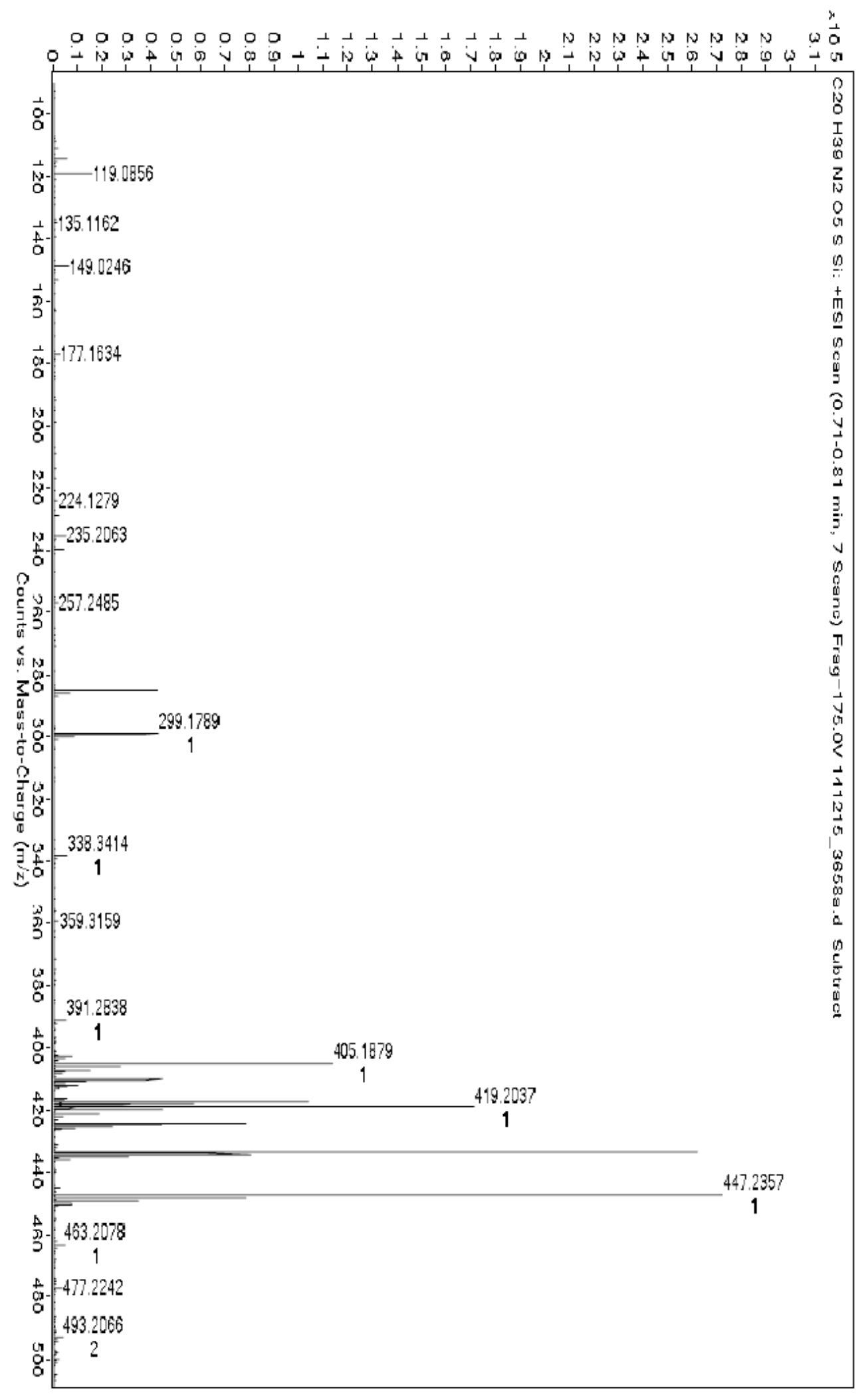

Figure A62: HRMS-ESI-TOF of compound 3F. 

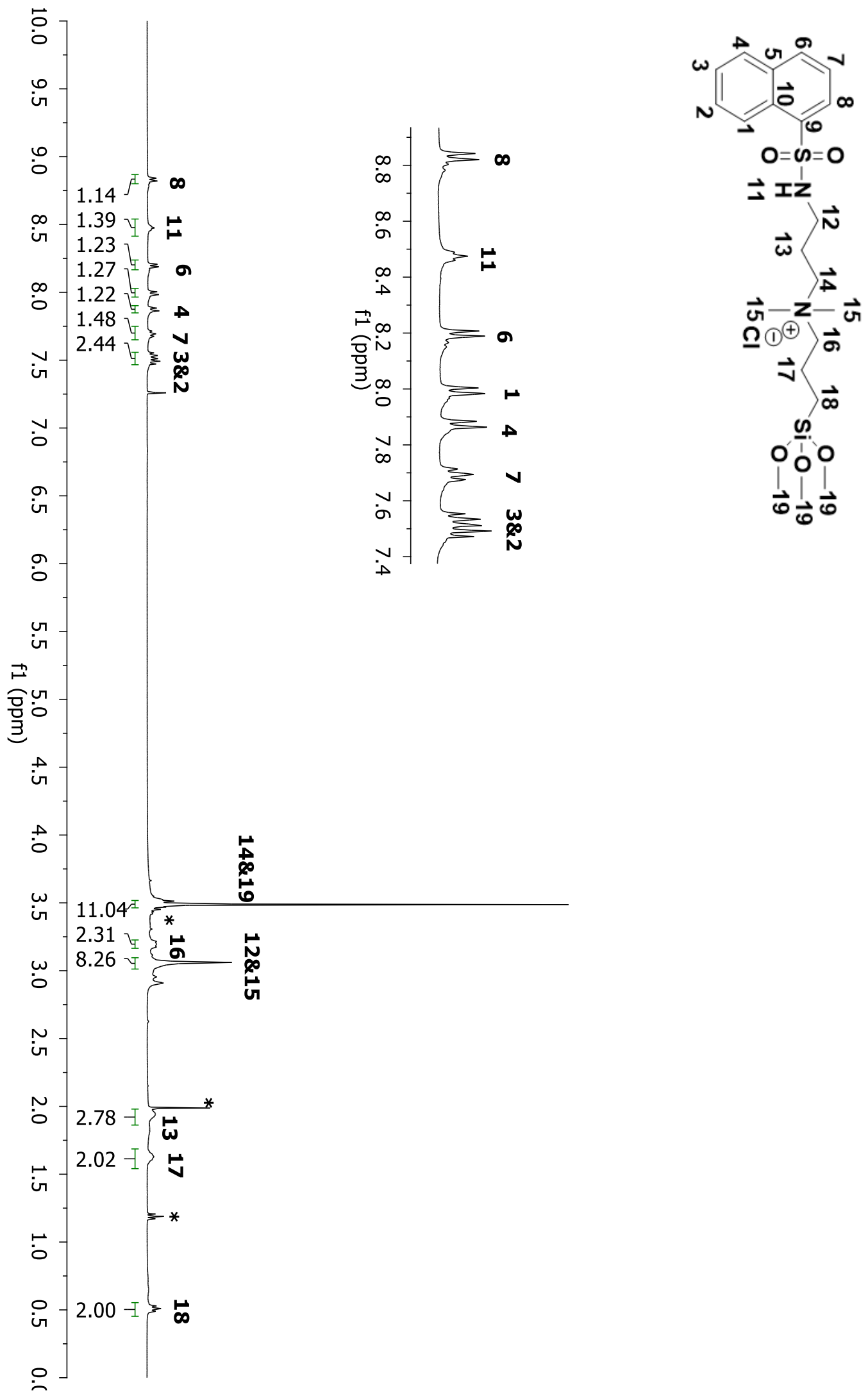

Figure A63: ${ }^{1} \mathrm{H}$ NMR spectrum of compound $\mathbf{5 F}$ in $\mathrm{CDCl}_{3}$. 


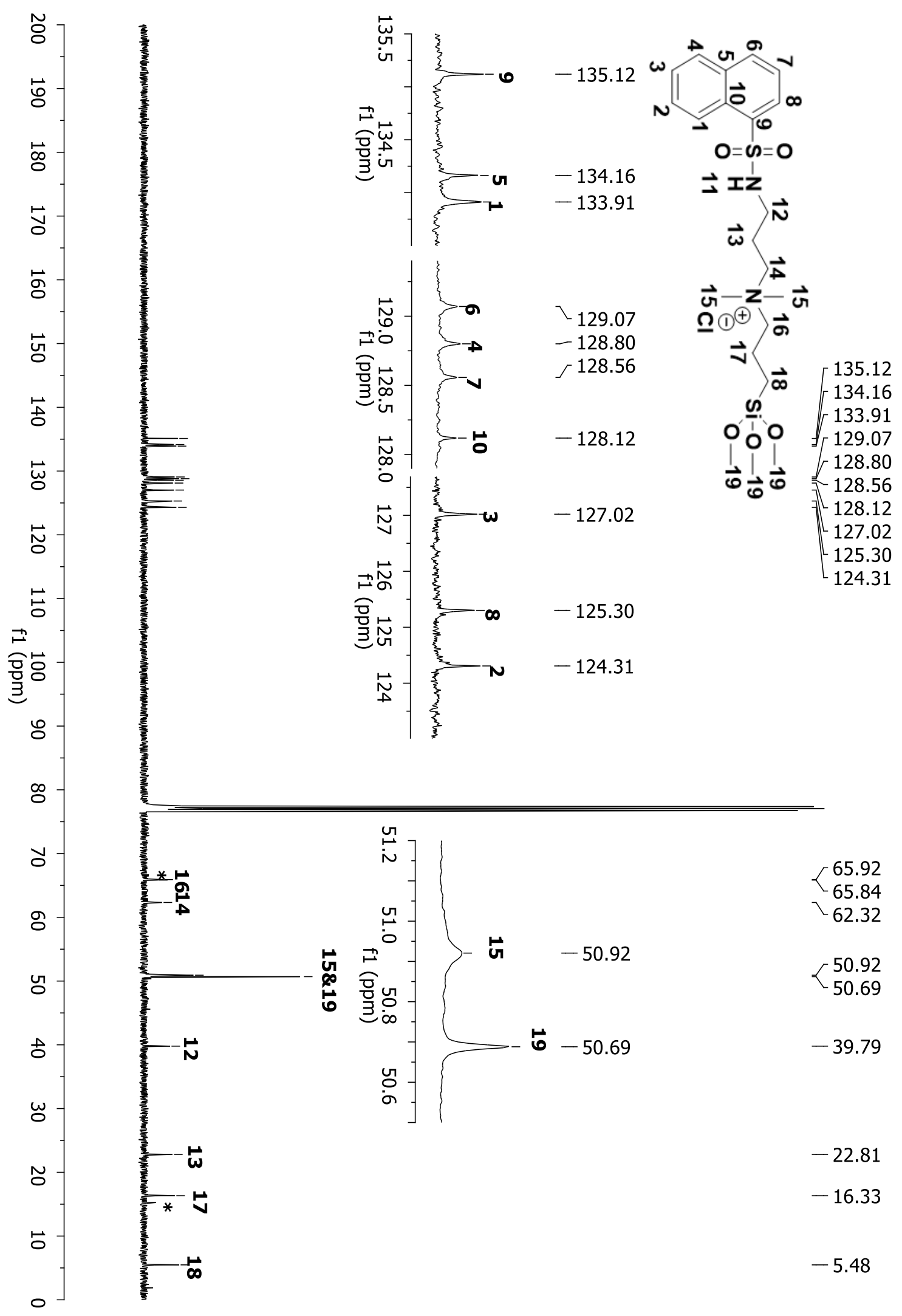

Figure A64: ${ }^{13} \mathrm{C}$ NMR spectrum of compound $5 \mathrm{~F}$ in $\mathrm{CDCl}_{3}$. 

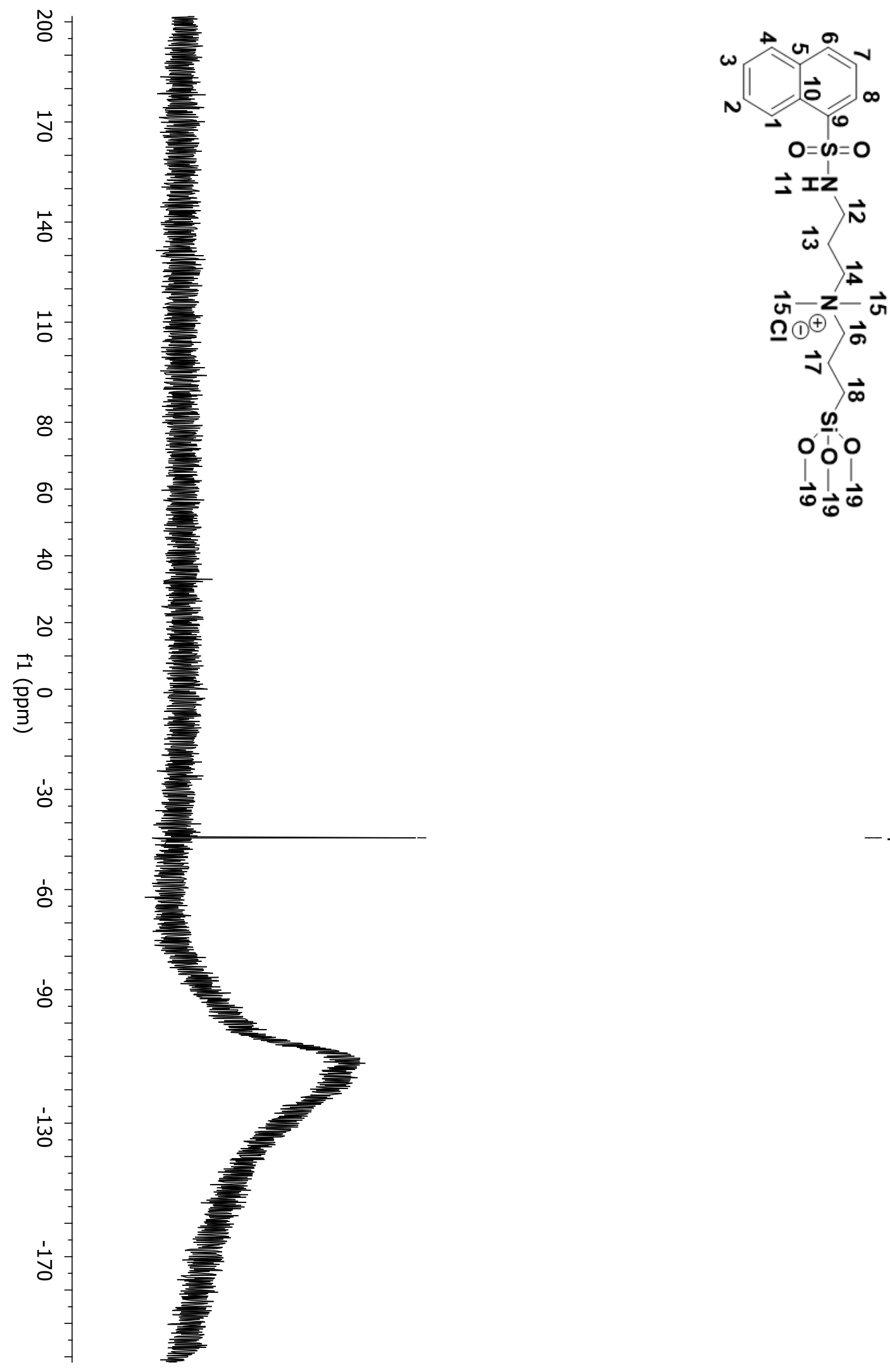

$--44.49$

Figure A65: ${ }^{29} \mathrm{Si} \mathrm{NMR}$ spectrum of compound $\mathbf{5 F}$ in $\mathrm{CDCl}_{3}$. 


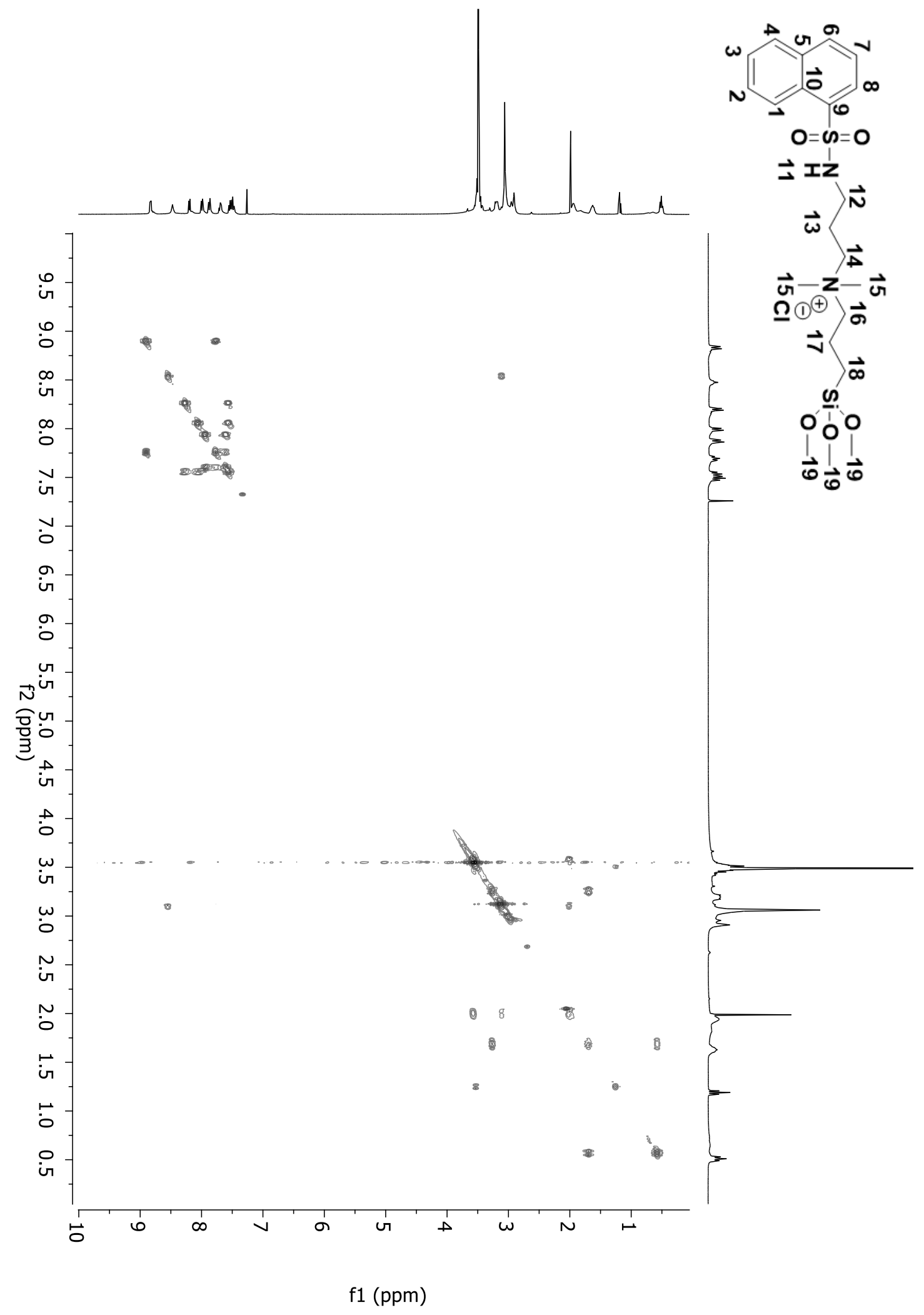

Figure A66: 2D COSY spectrum of compound $\mathbf{5 F}$ in $\mathrm{CDCl}_{3}$. 


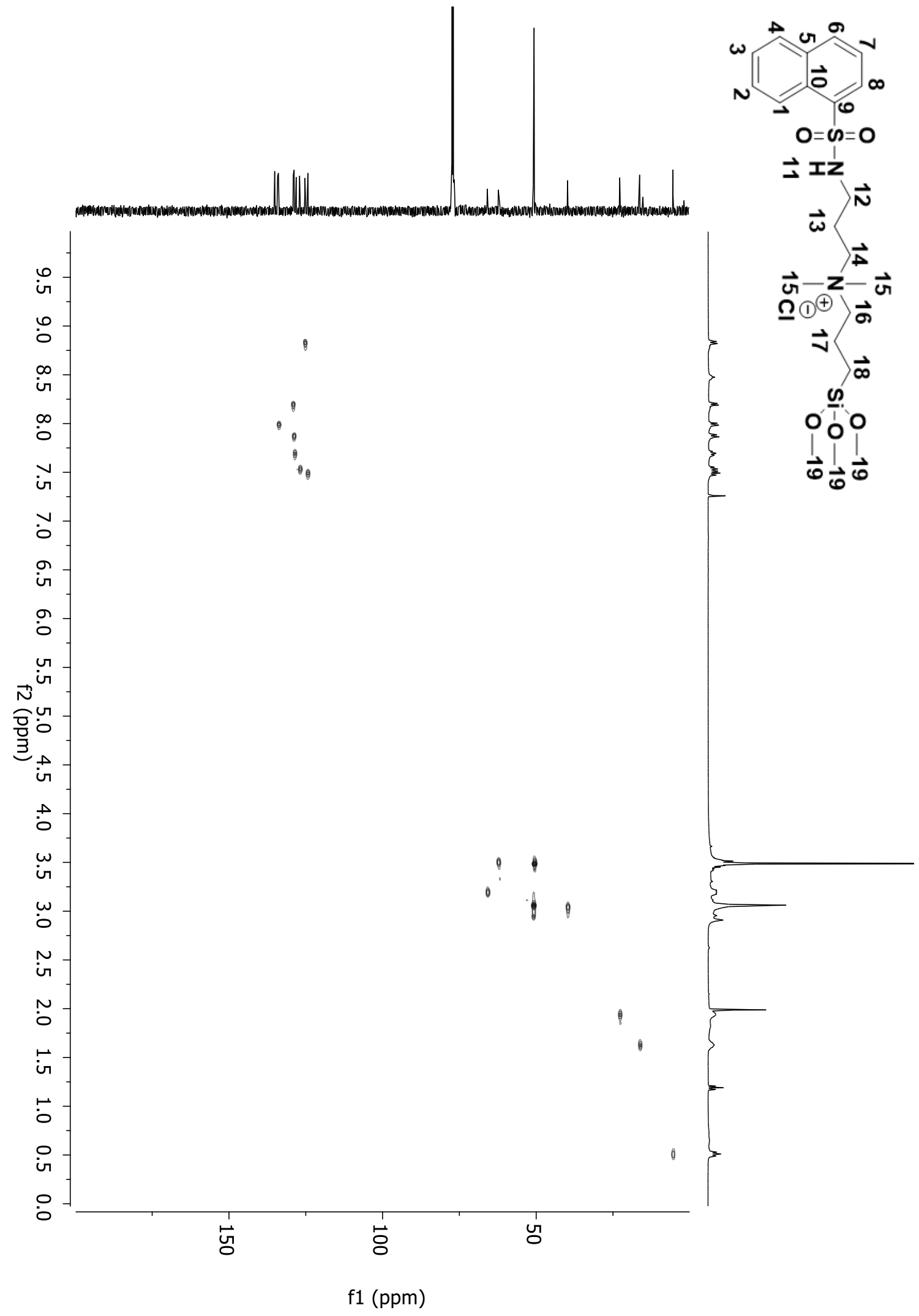

Figure A67: 2D HSQC spectrum of compound 5F in $\mathrm{CDCl}_{3}$. 


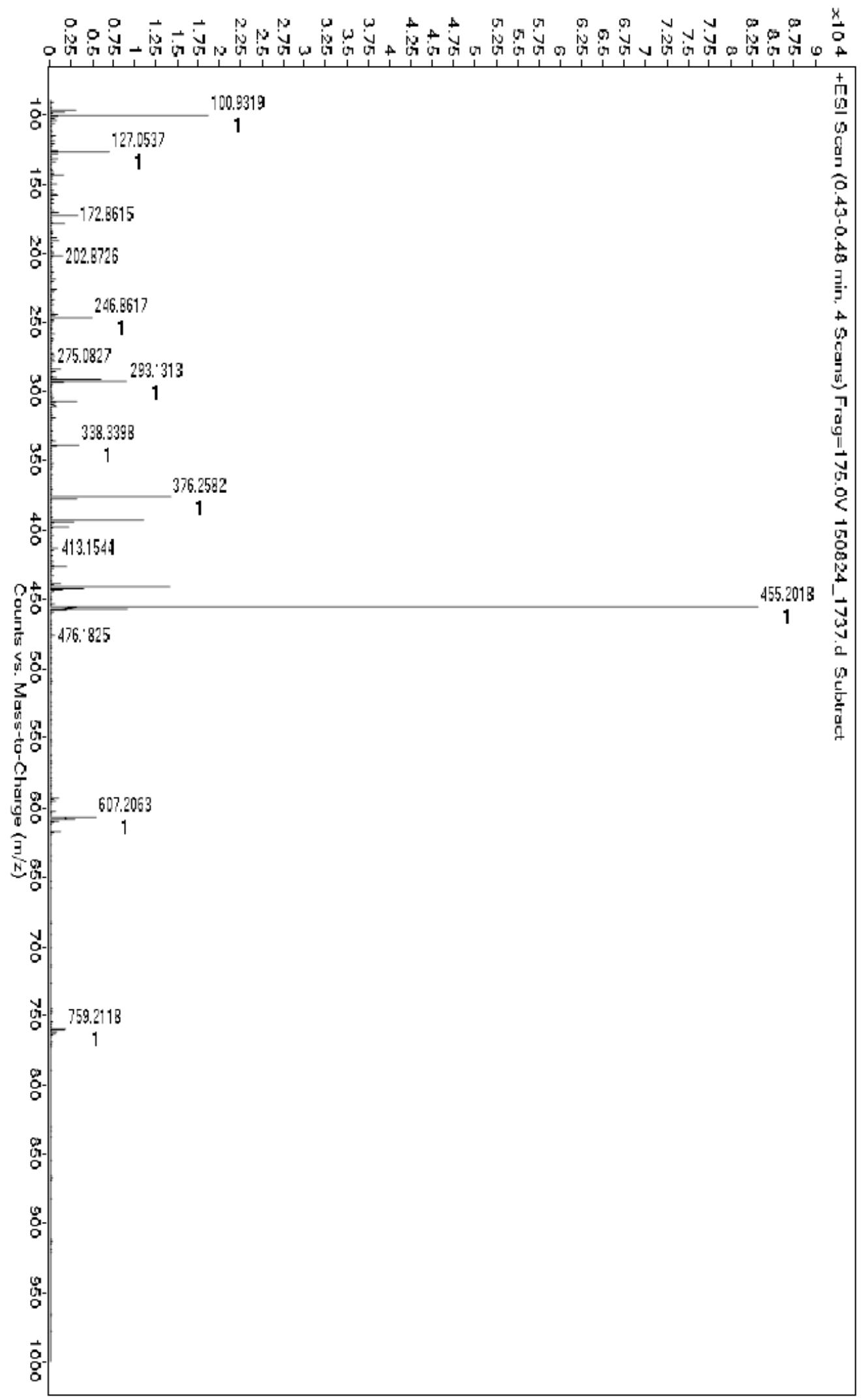

Figure A68: HRMS-ESI-TOF of compound 5F. 


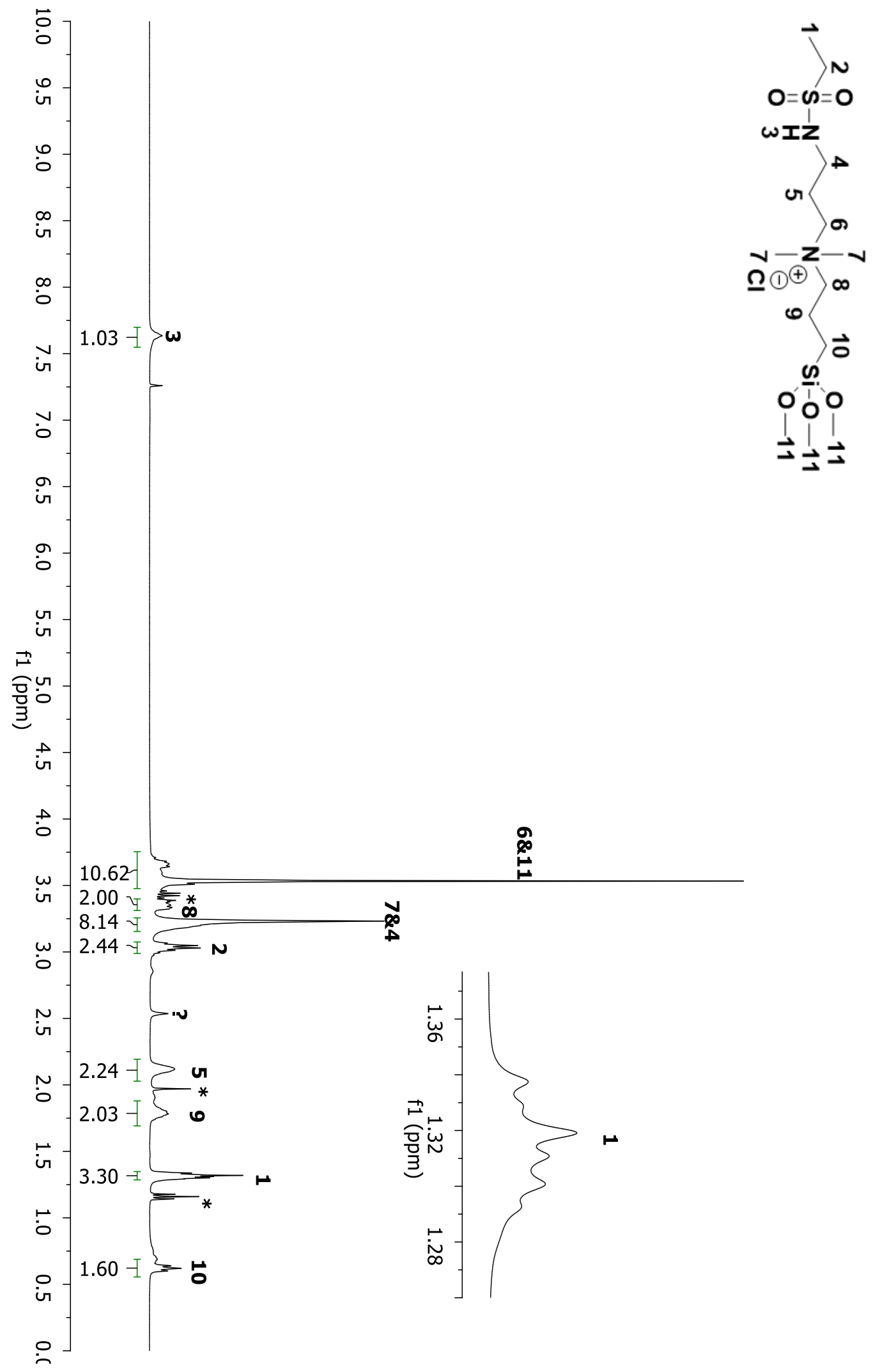

Figure A69: ${ }^{1} \mathrm{H}$ NMR spectrum of compound $7 \mathrm{~F}$ in $\mathrm{CDCl}_{3}$. 


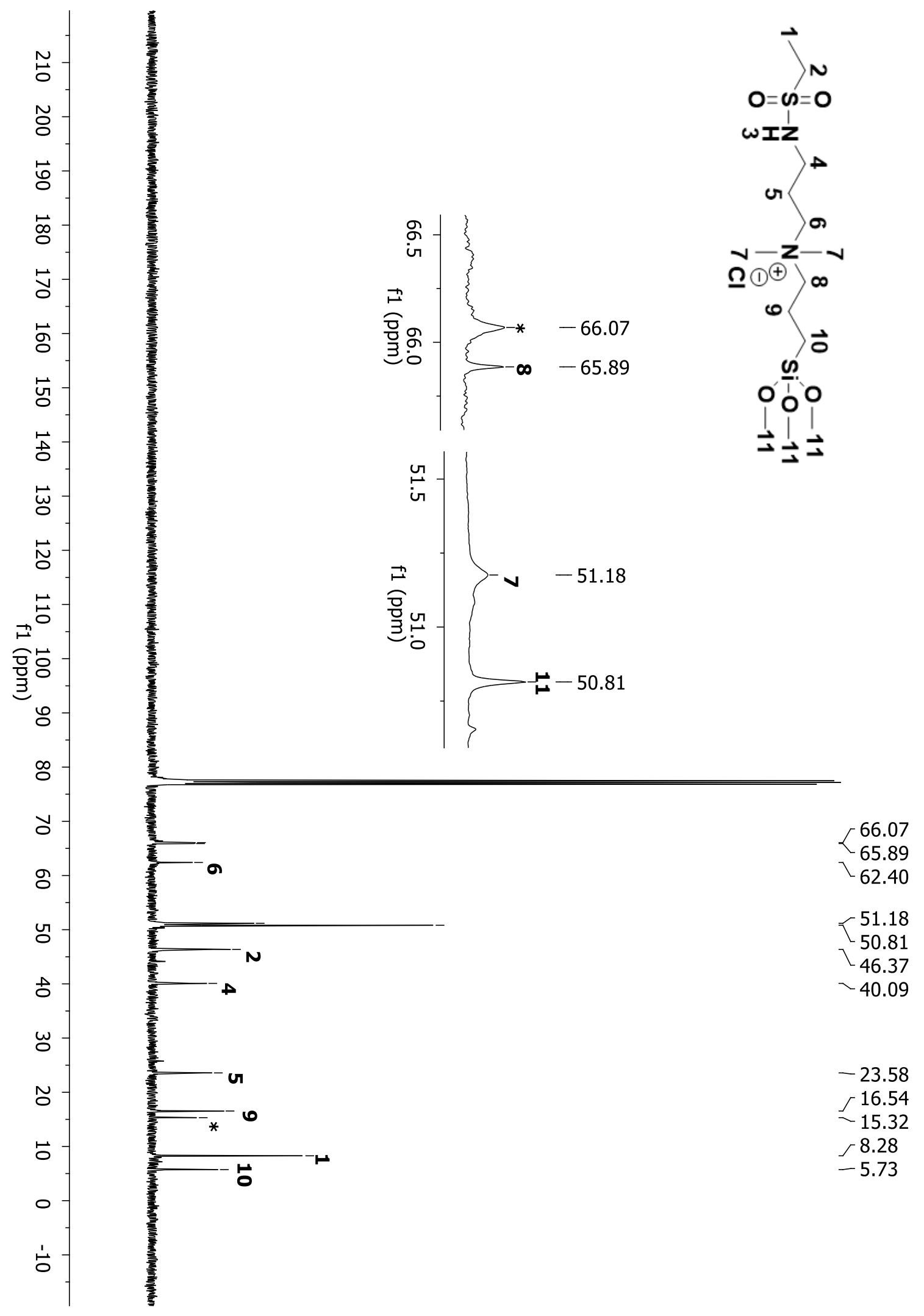

Figure A70: ${ }^{13} \mathrm{C}$ NMR spectrum of compound $7 \mathrm{~F}$ in $\mathrm{CDCl}_{3}$. 

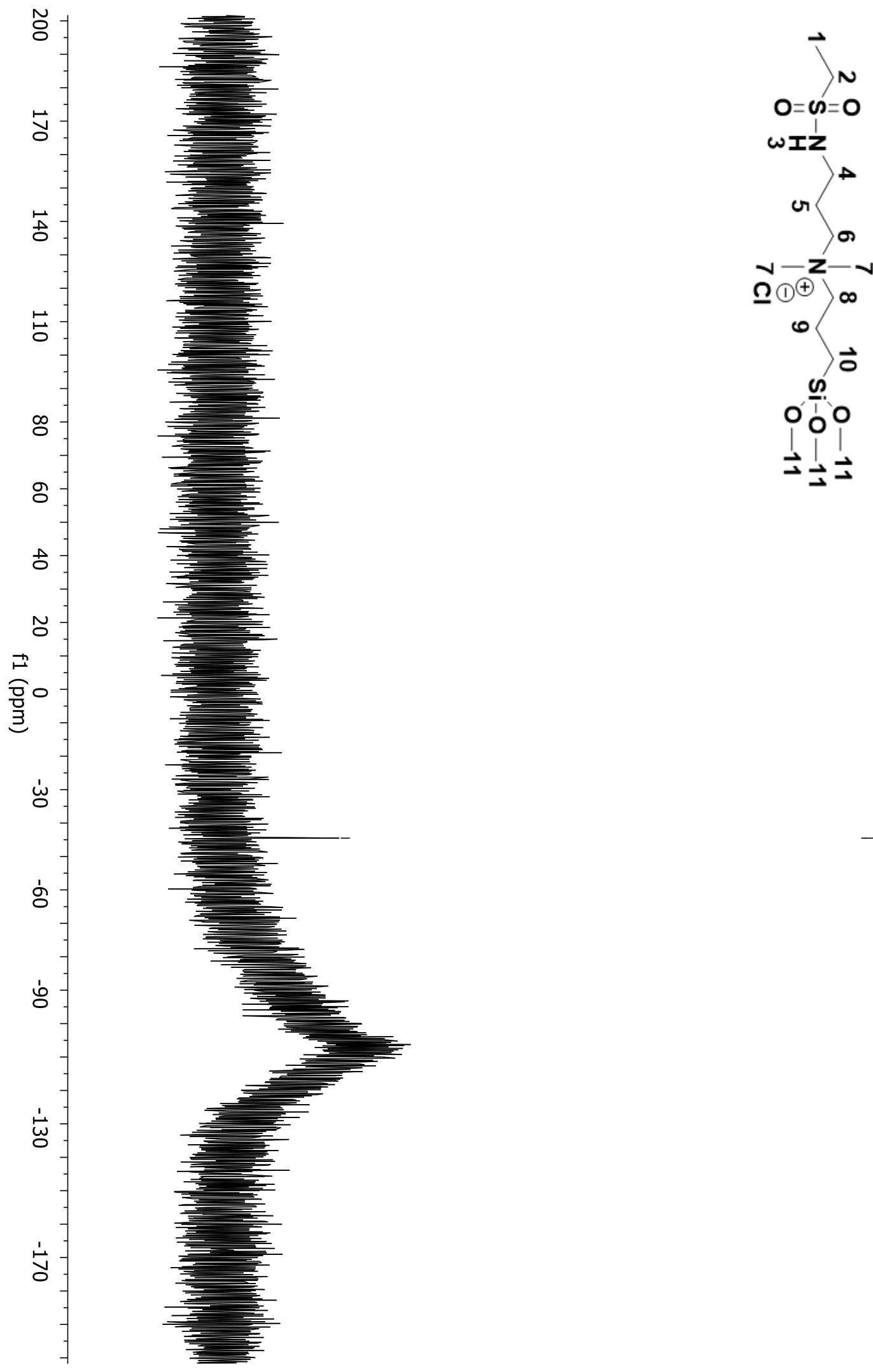

$--44.51$

Figure A71: ${ }^{29} \mathrm{Si}$ NMR spectrum of compound 7F in $\mathrm{CDCl}_{3}$. 


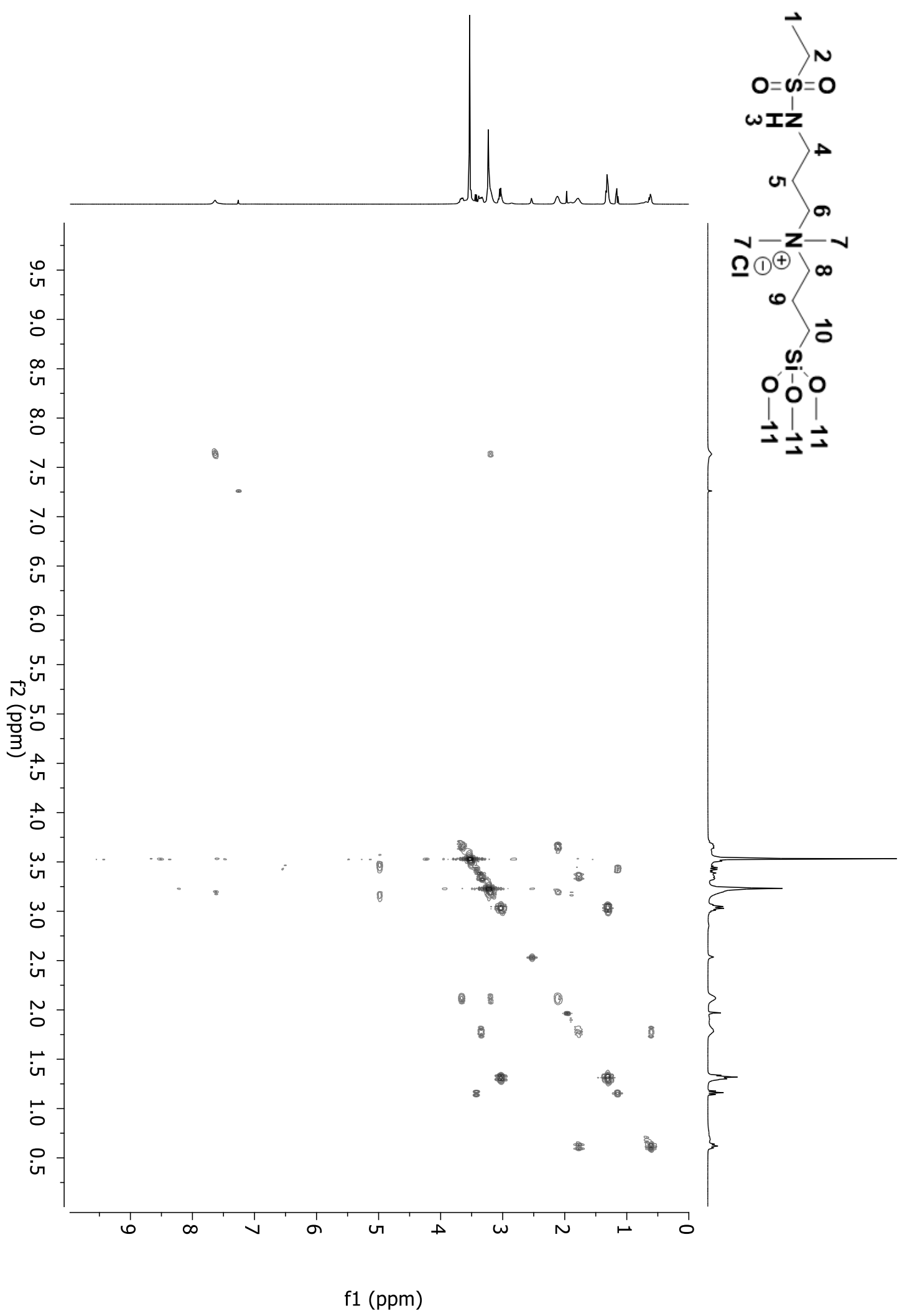

Figure A72: 2D COSY spectrum of compound $7 \mathbf{F}$ in $\mathrm{CDCl}_{3}$. 


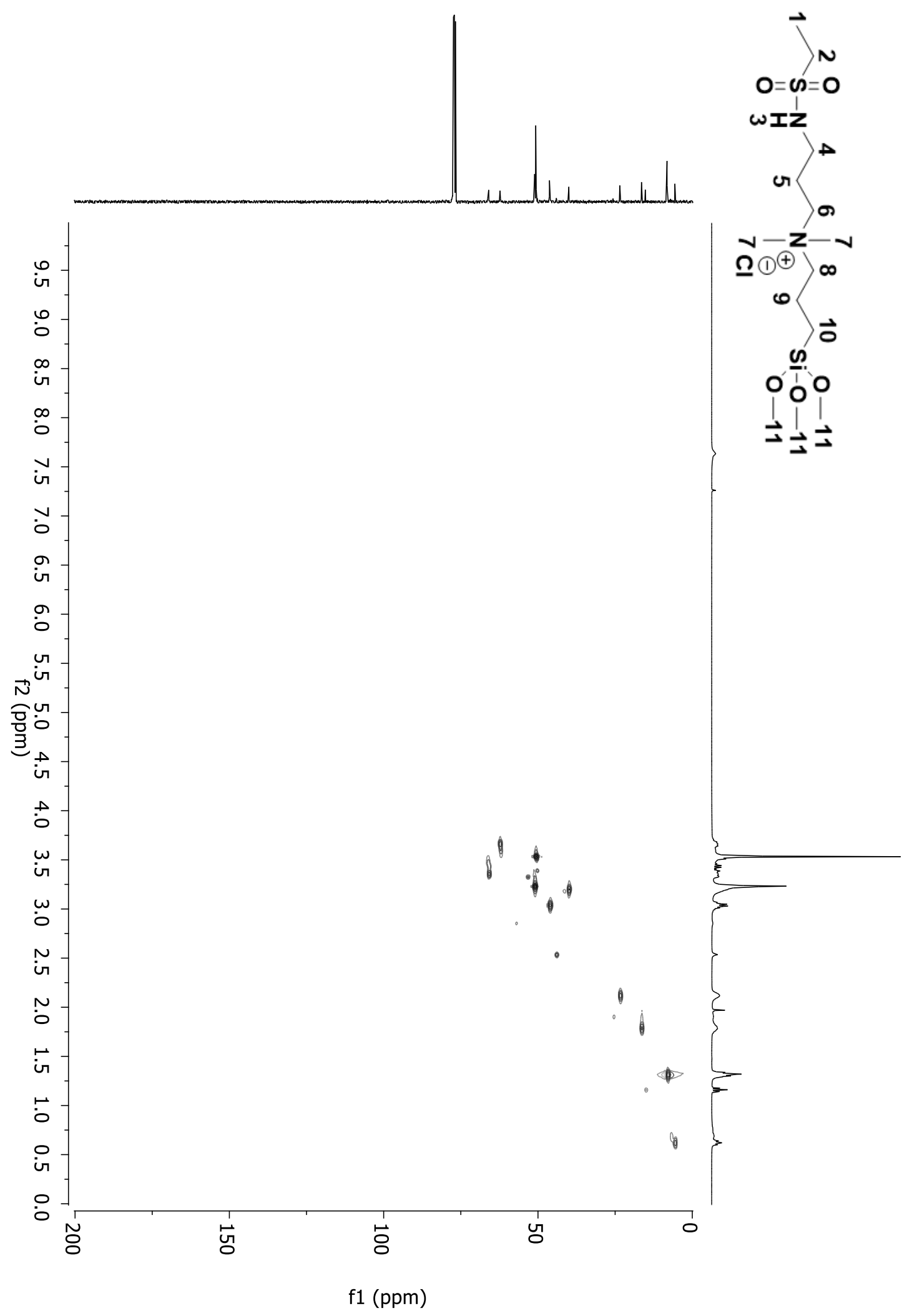

Figure A73: 2D HSQC spectrum of compound $7 \mathbf{F}$ in $\mathrm{CDCl}_{3}$. 


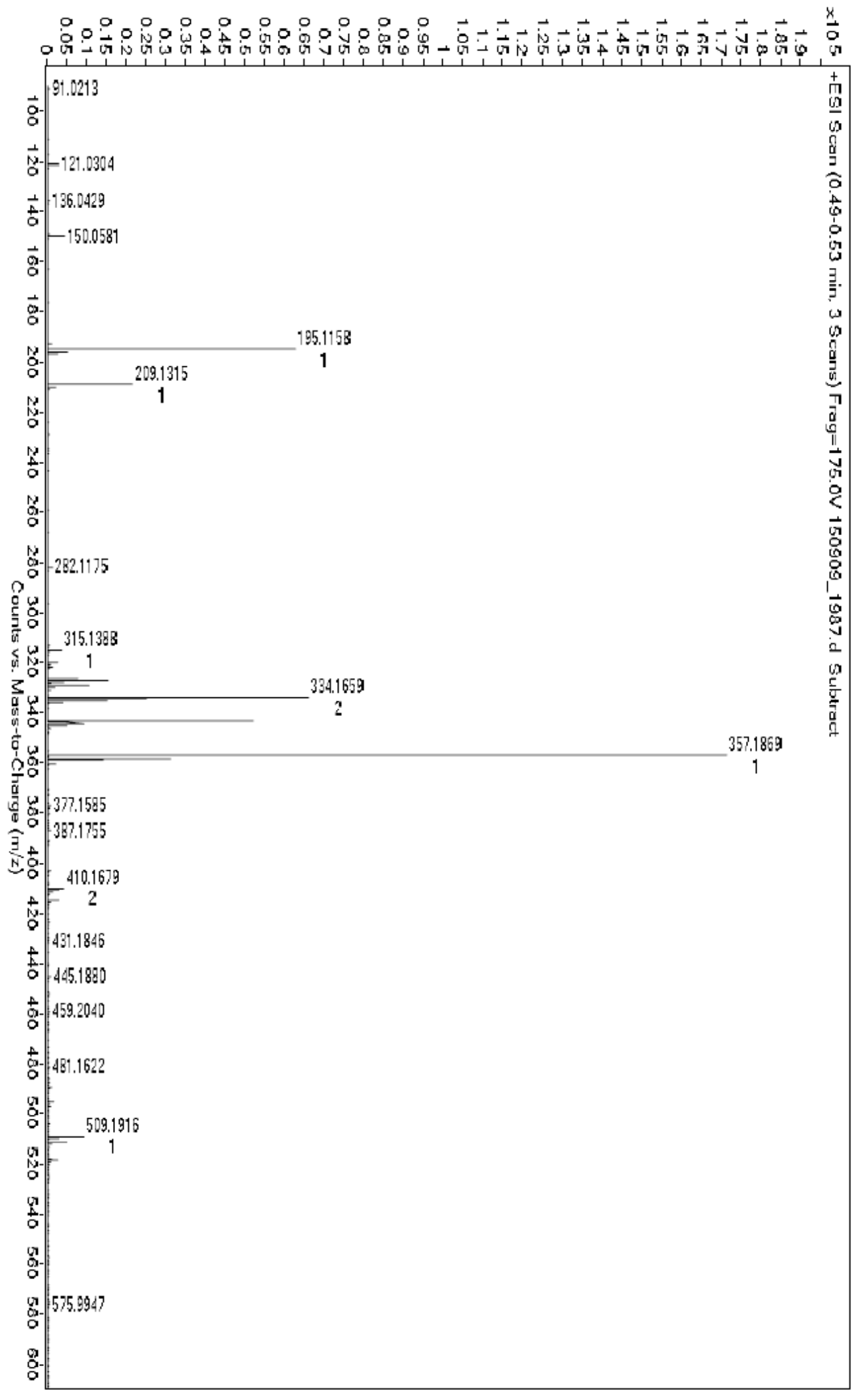

Figure A74: HRMS-ESI-TOF of compound 7F. 


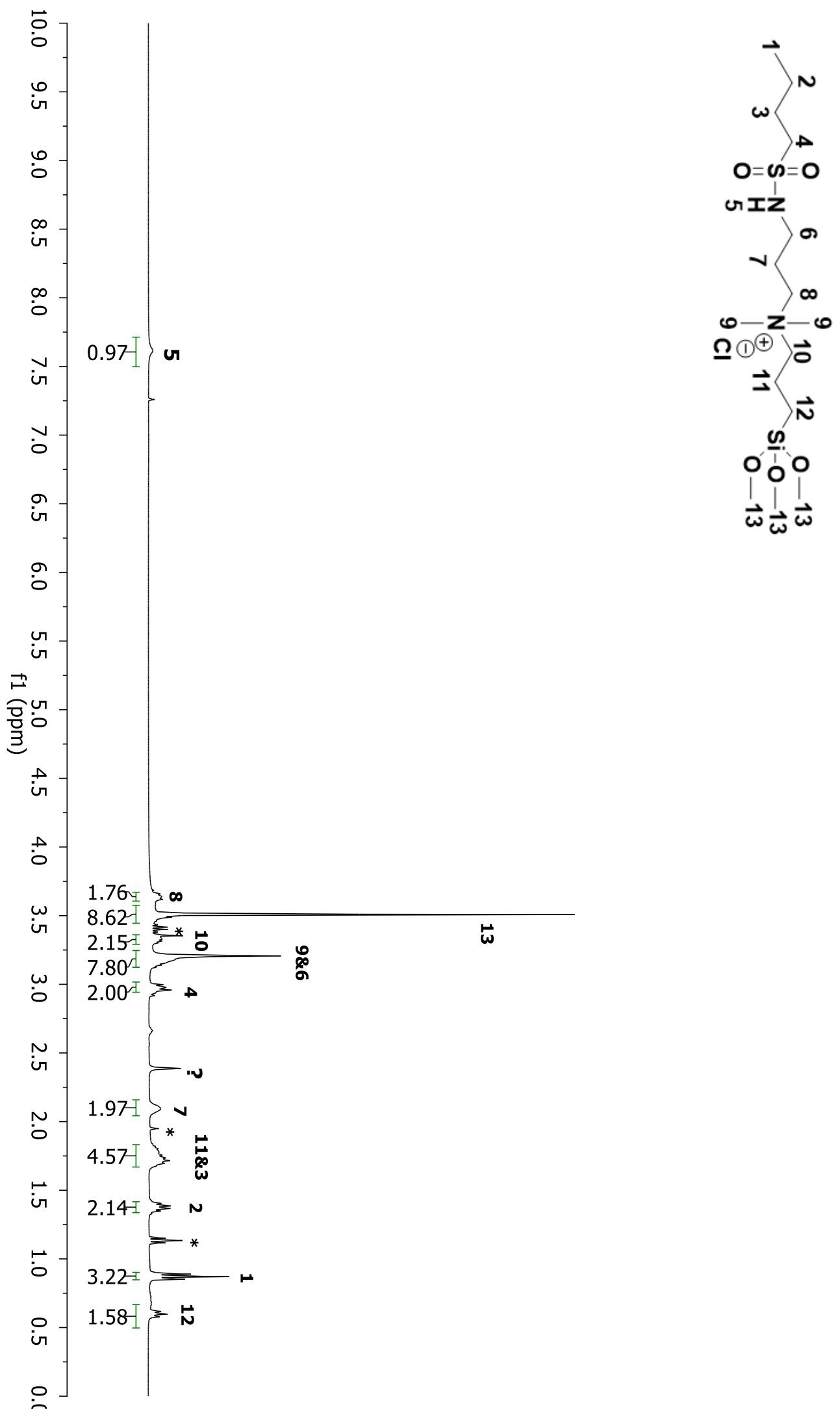

Figure A75: ${ }^{1} \mathrm{H}$ NMR spectrum of compound $\mathbf{8 F}$ in $\mathrm{CDCl}_{3}$. 

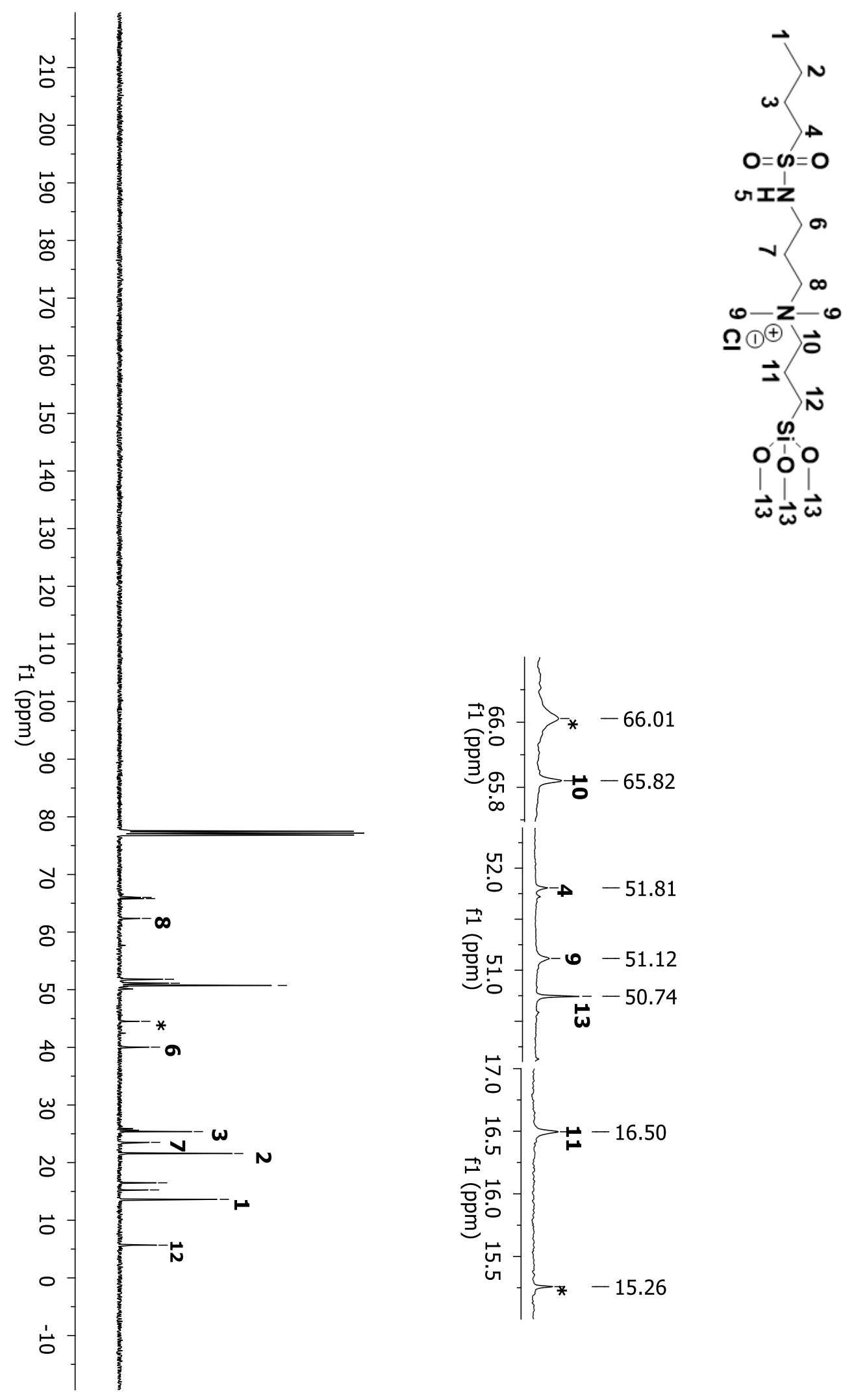

66.01

65.82

62.37

51.81

51.12

50.74

44.52

40.04

25.38

$-23.50$

21.58

16.50

15.26

13.62

5.68

Figure A76: ${ }^{13} \mathrm{C}$ NMR spectrum of compound $\mathbf{8 F}$ in $\mathrm{CDCl}_{3}$. 

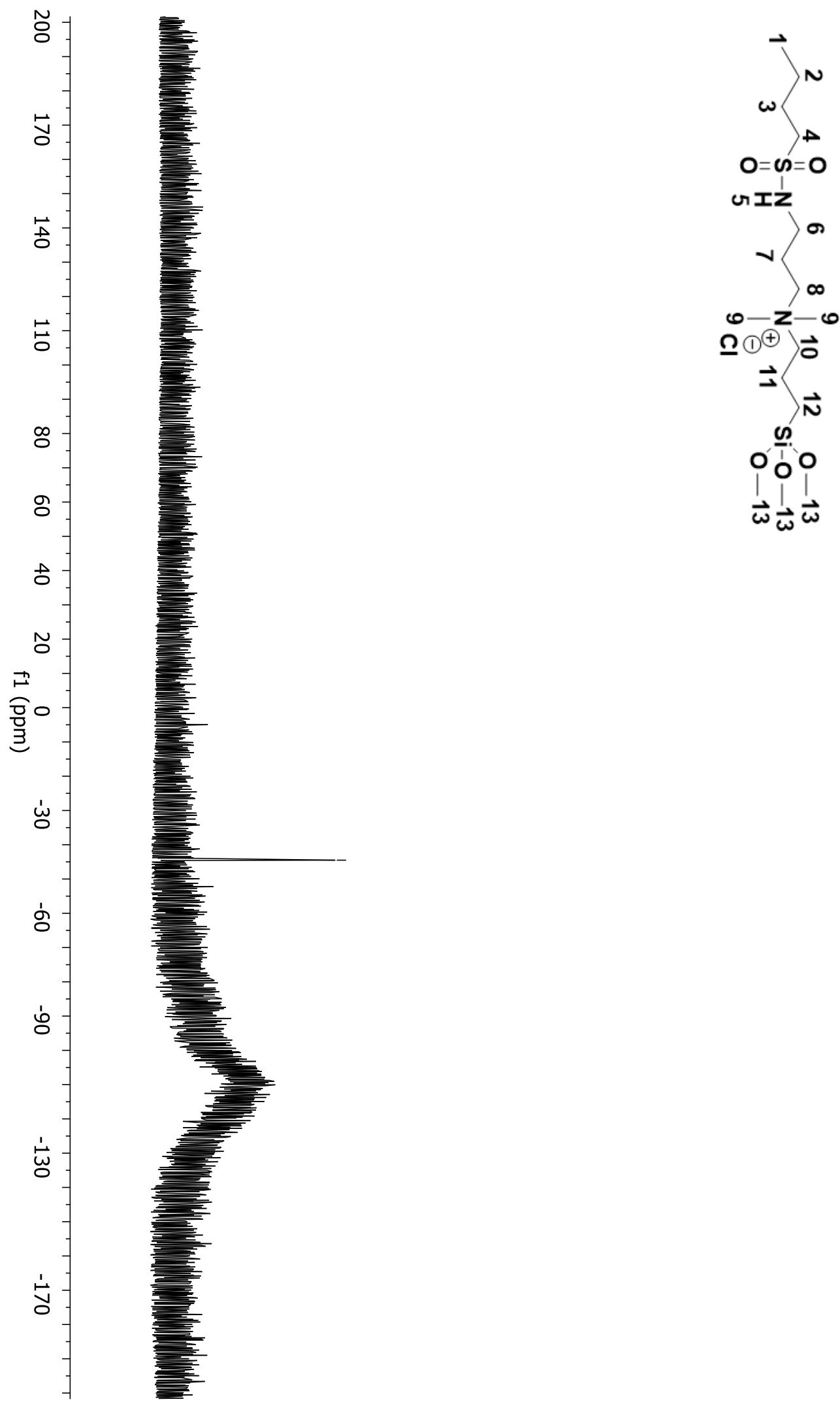

$--44.50$

Figure A77: ${ }^{29} \mathrm{Si}$ NMR spectrum of compound $\mathbf{8 F}$ in $\mathrm{CDCl}_{3}$. 


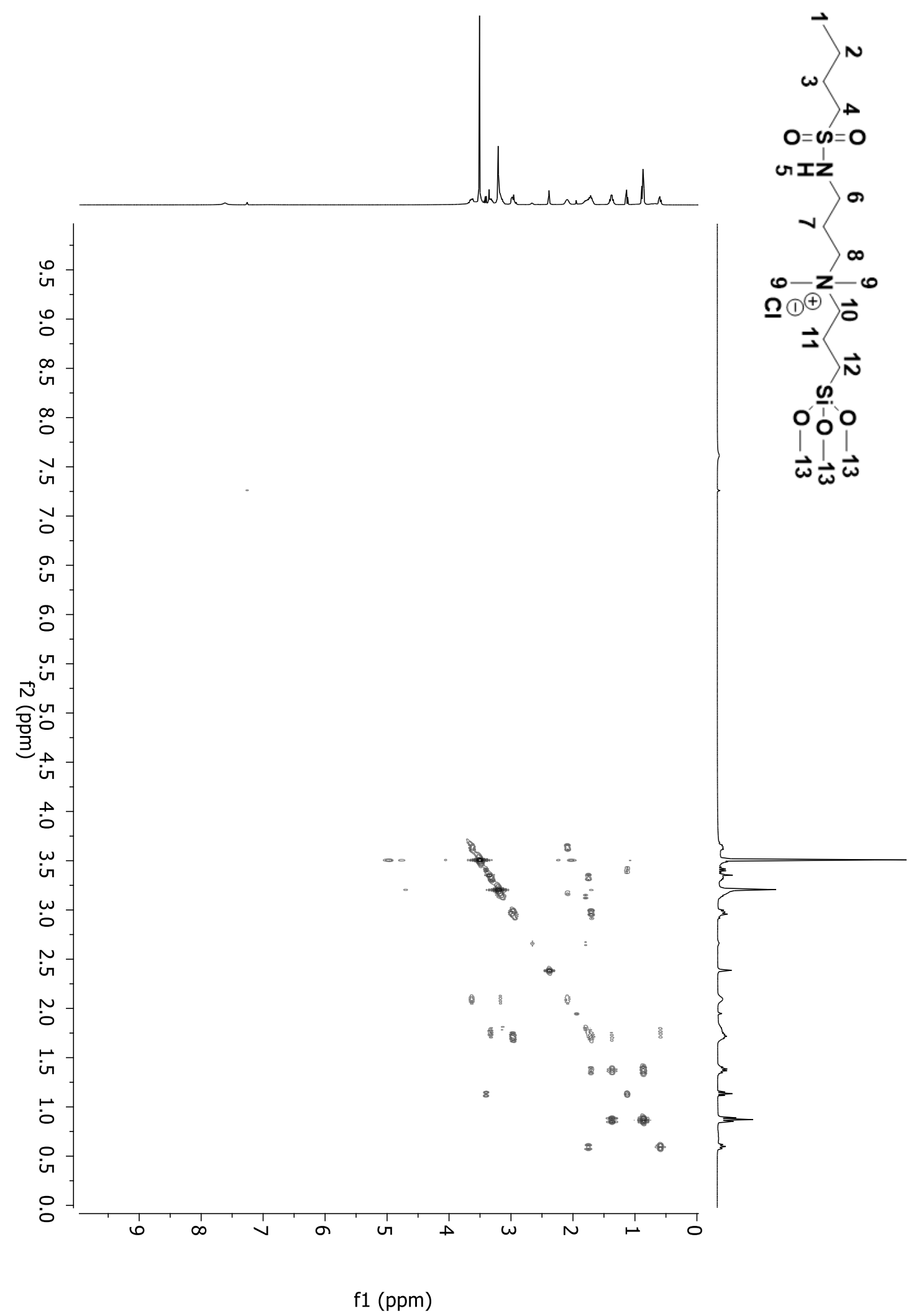

Figure A78: 2D COSY spectrum of compound $\mathbf{8 F}$ in $\mathrm{CDCl}_{3}$. 


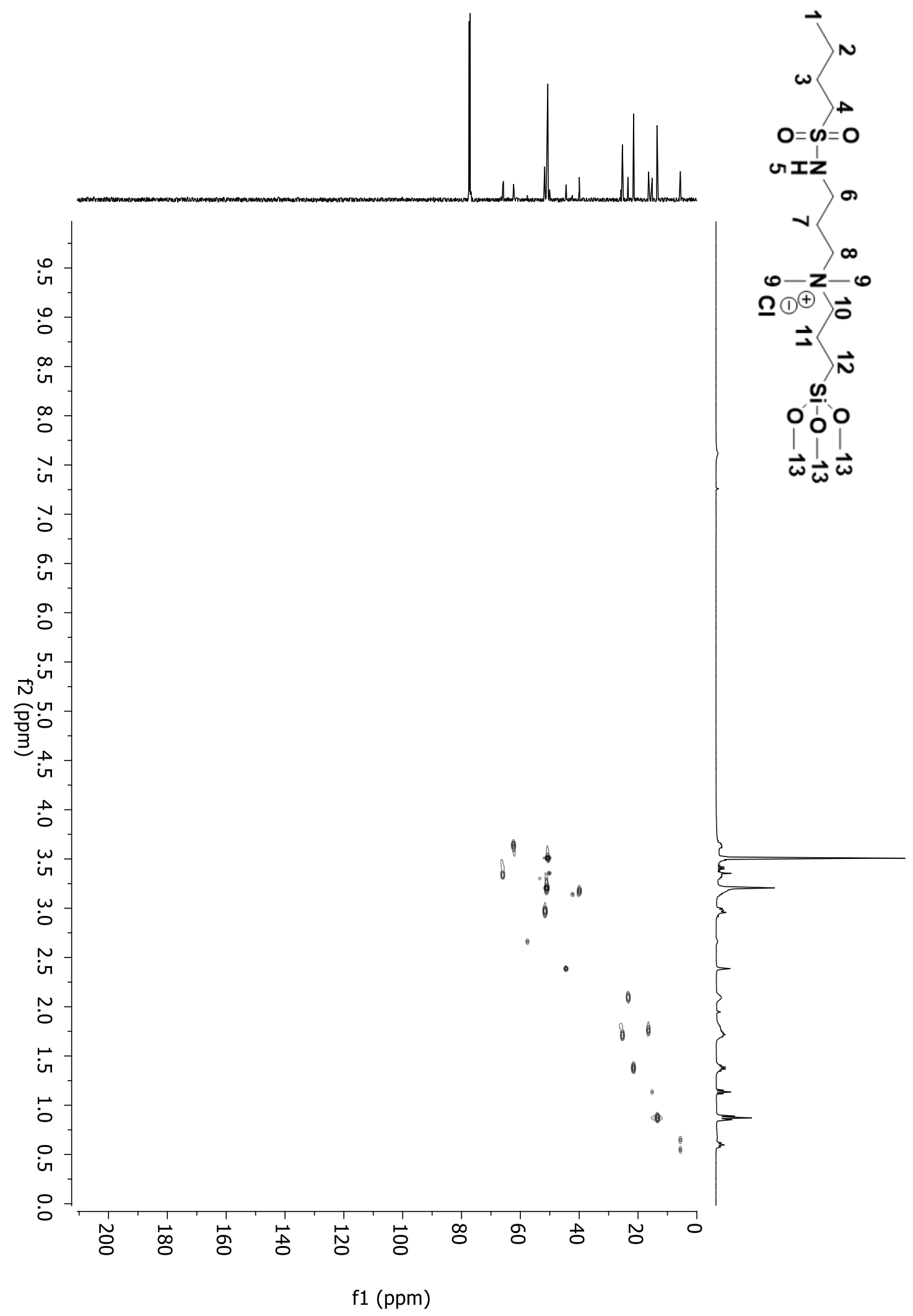

Figure A79: 2D HSQC spectrum of compound $\mathbf{8 F}$ in $\mathrm{CDCl}_{3}$. 


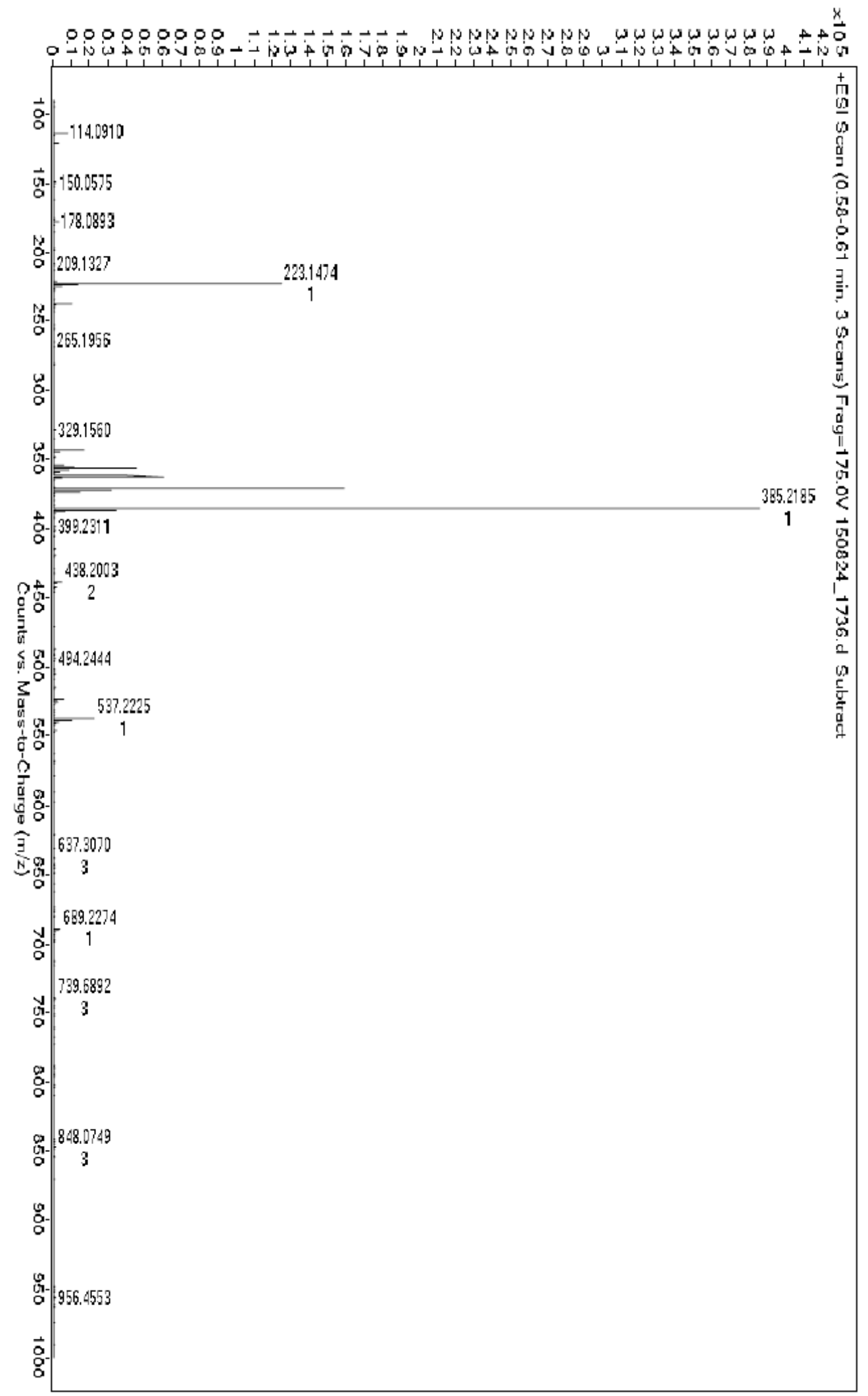

Figure A80: HRMS-ESI-TOF of compound 8F. 


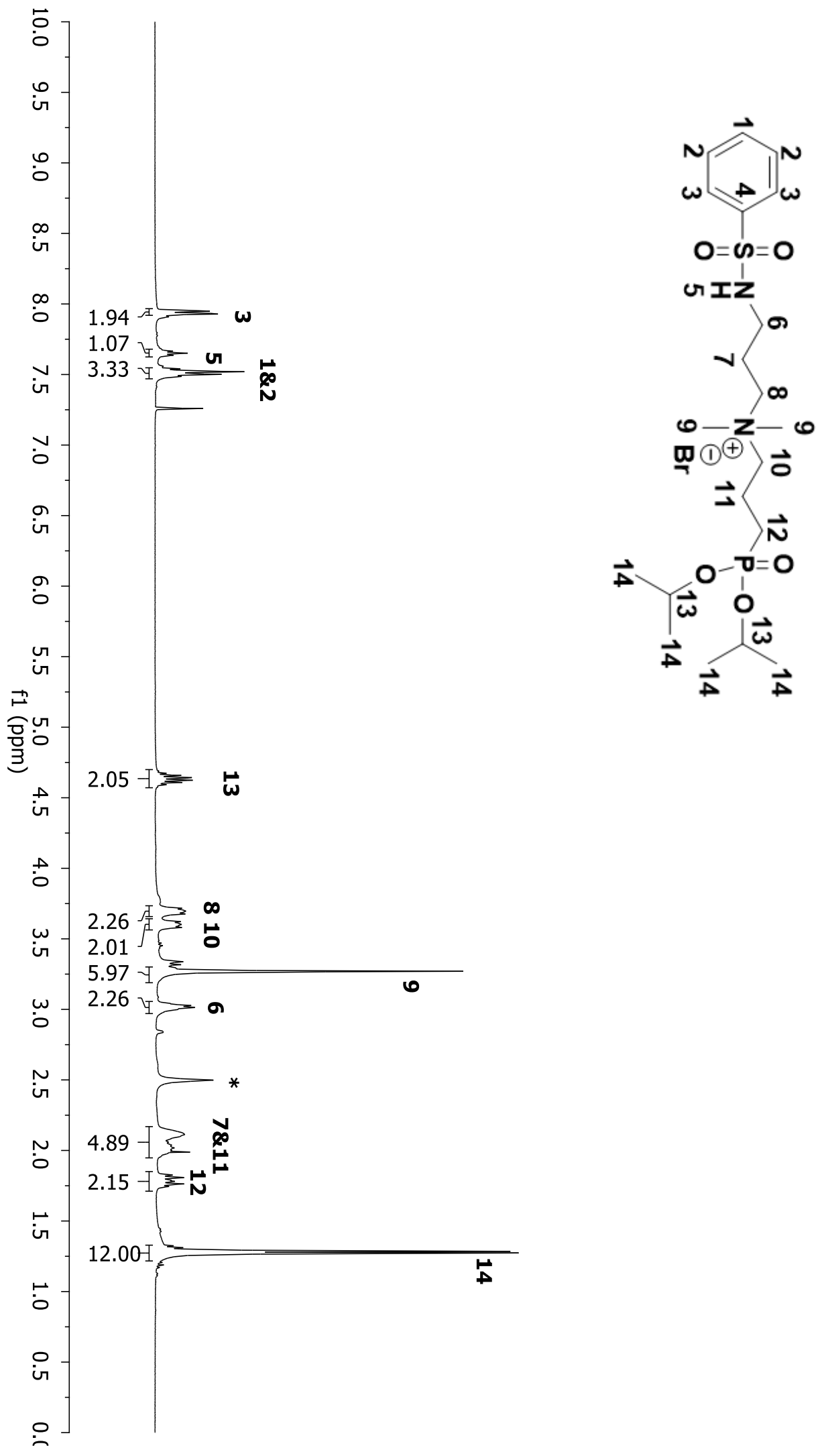

Figure A81: ${ }^{1} \mathrm{H}$ NMR spectrum of compound $1 \mathrm{H}$ in $\mathrm{CDCl}_{3}$. 


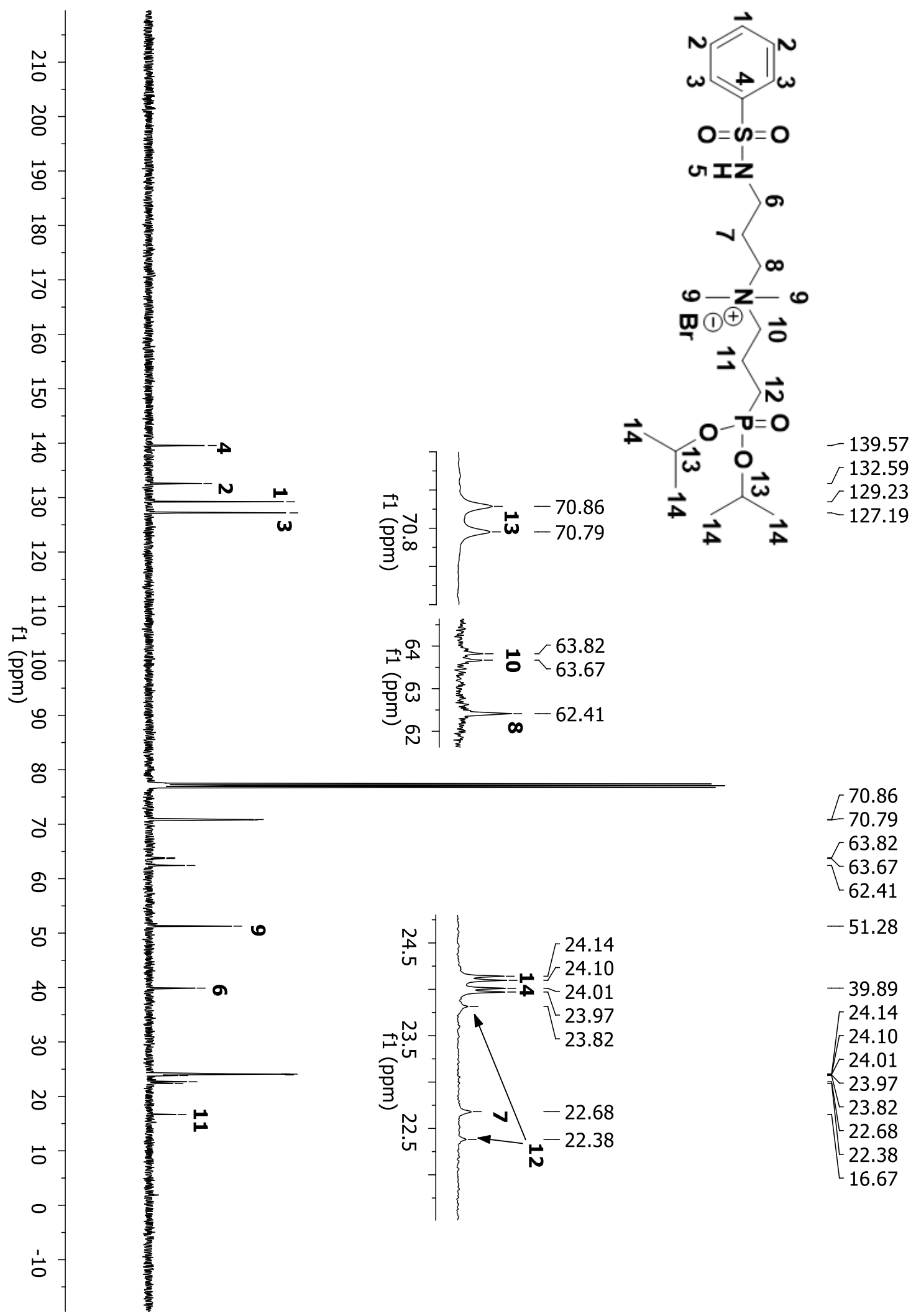

Figure A82: ${ }^{13} \mathrm{C}$ NMR spectrum of compound $\mathbf{1 H}$ in $\mathrm{CDCl}_{3}$. 


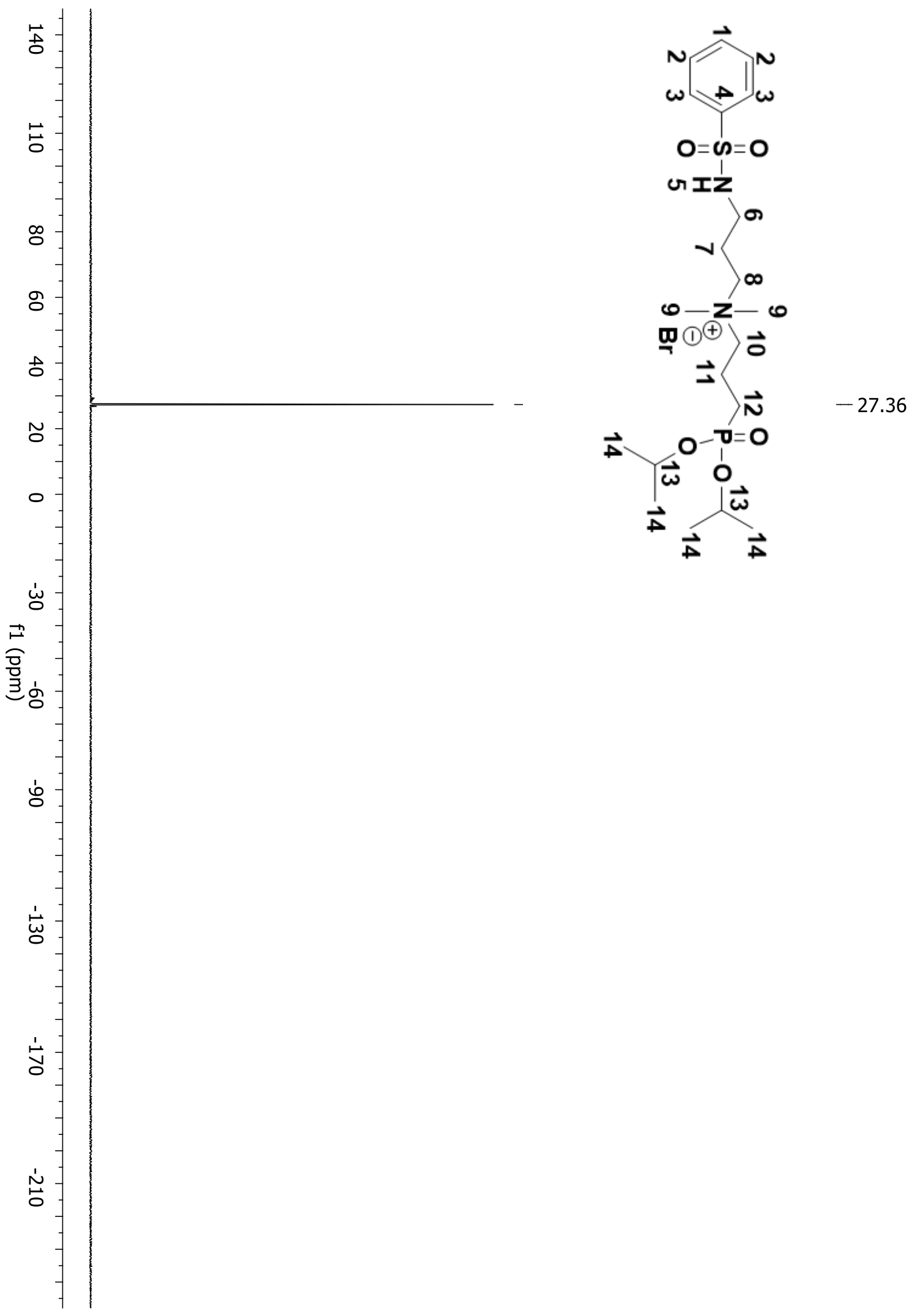

Figure A83: ${ }^{31} \mathrm{P}$ NMR spectrum of compound $\mathbf{1 H}$ in $\mathrm{CDCl}_{3}$. 


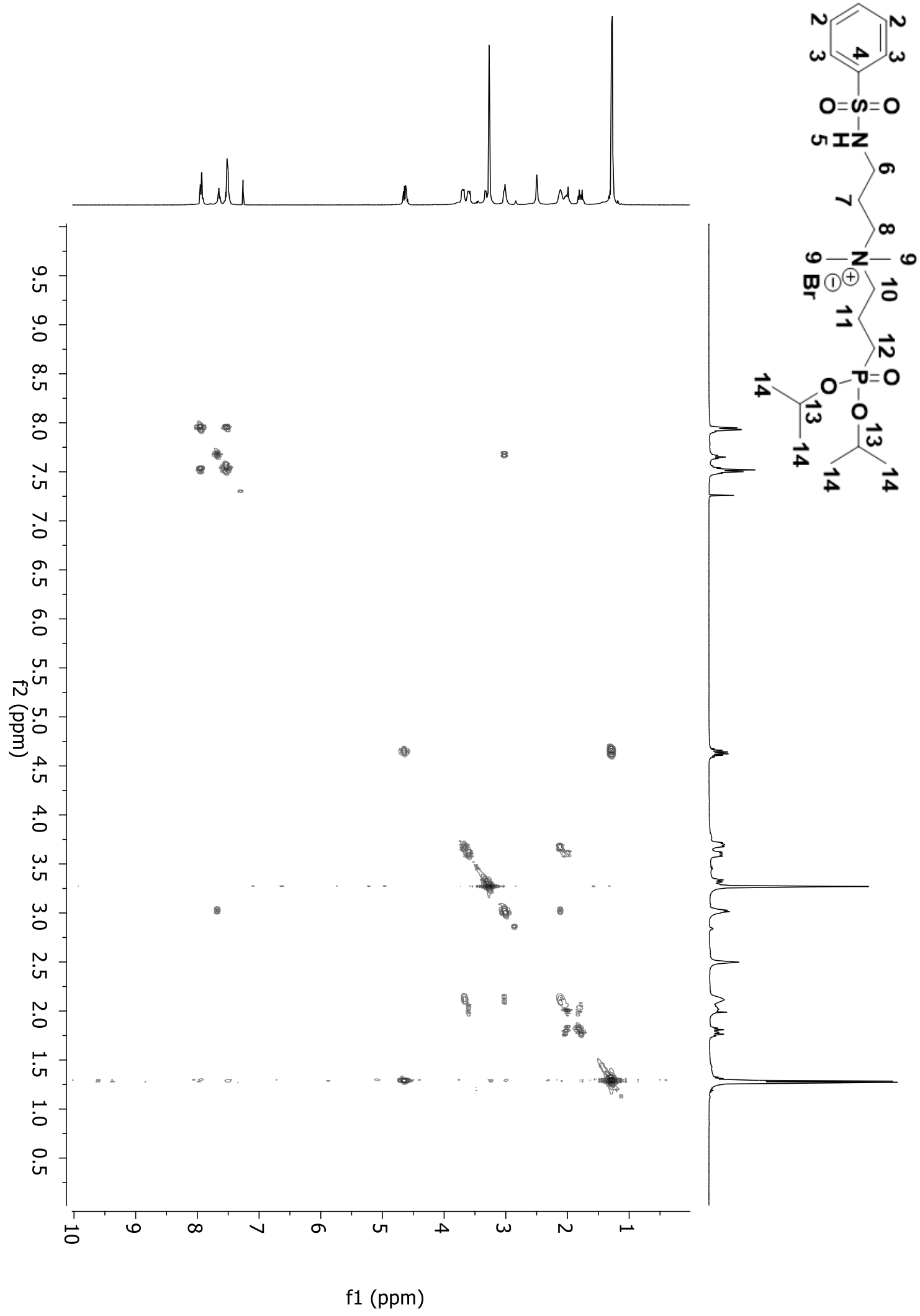

Figure A84: 2D COSY spectrum of compound $\mathbf{1 H}$ in $\mathrm{CDCl}_{3}$. 


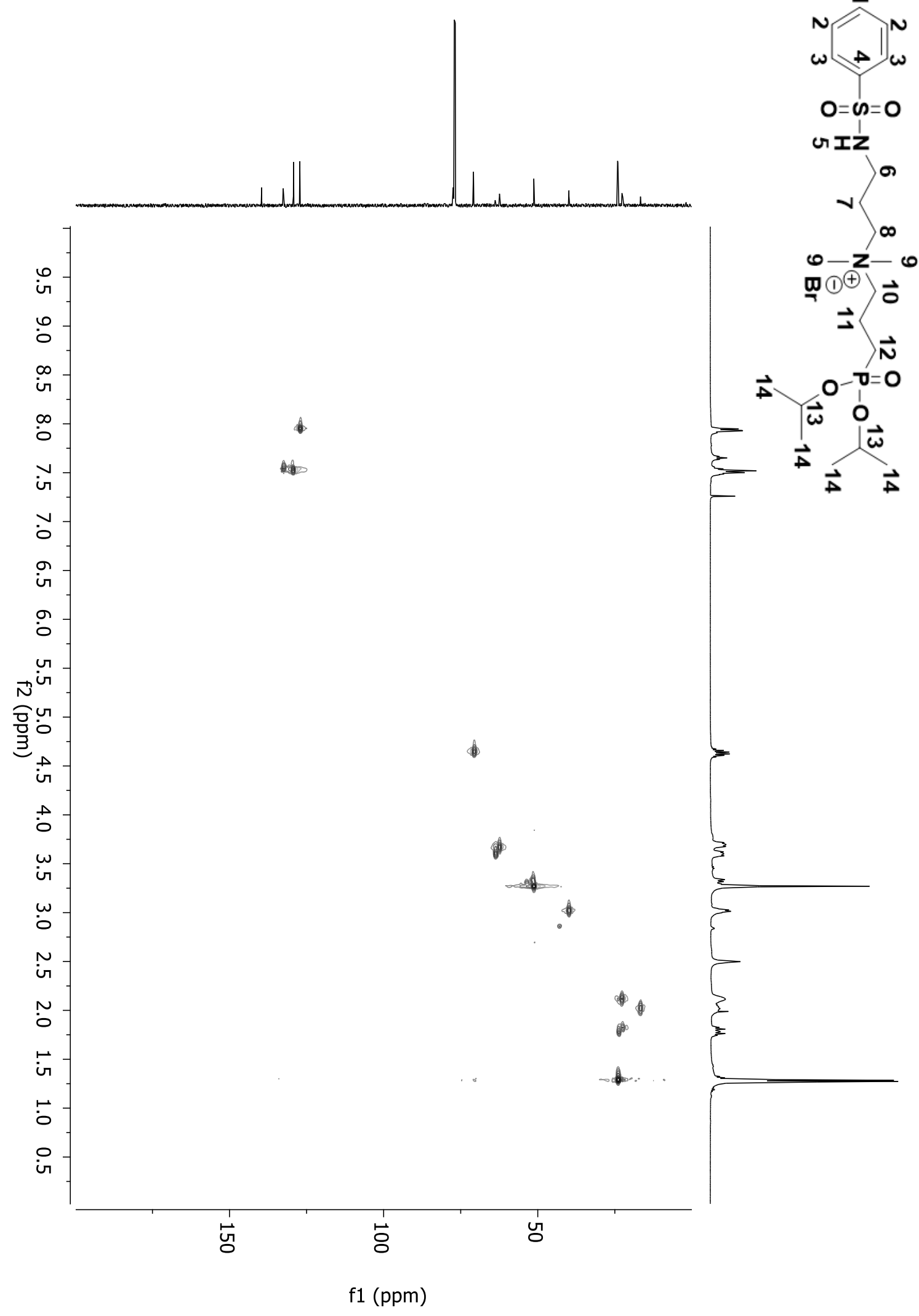

Figure A85: 2D HSQC spectrum of compound $\mathbf{1 H}$ in $\mathrm{CDCl}_{3}$. 


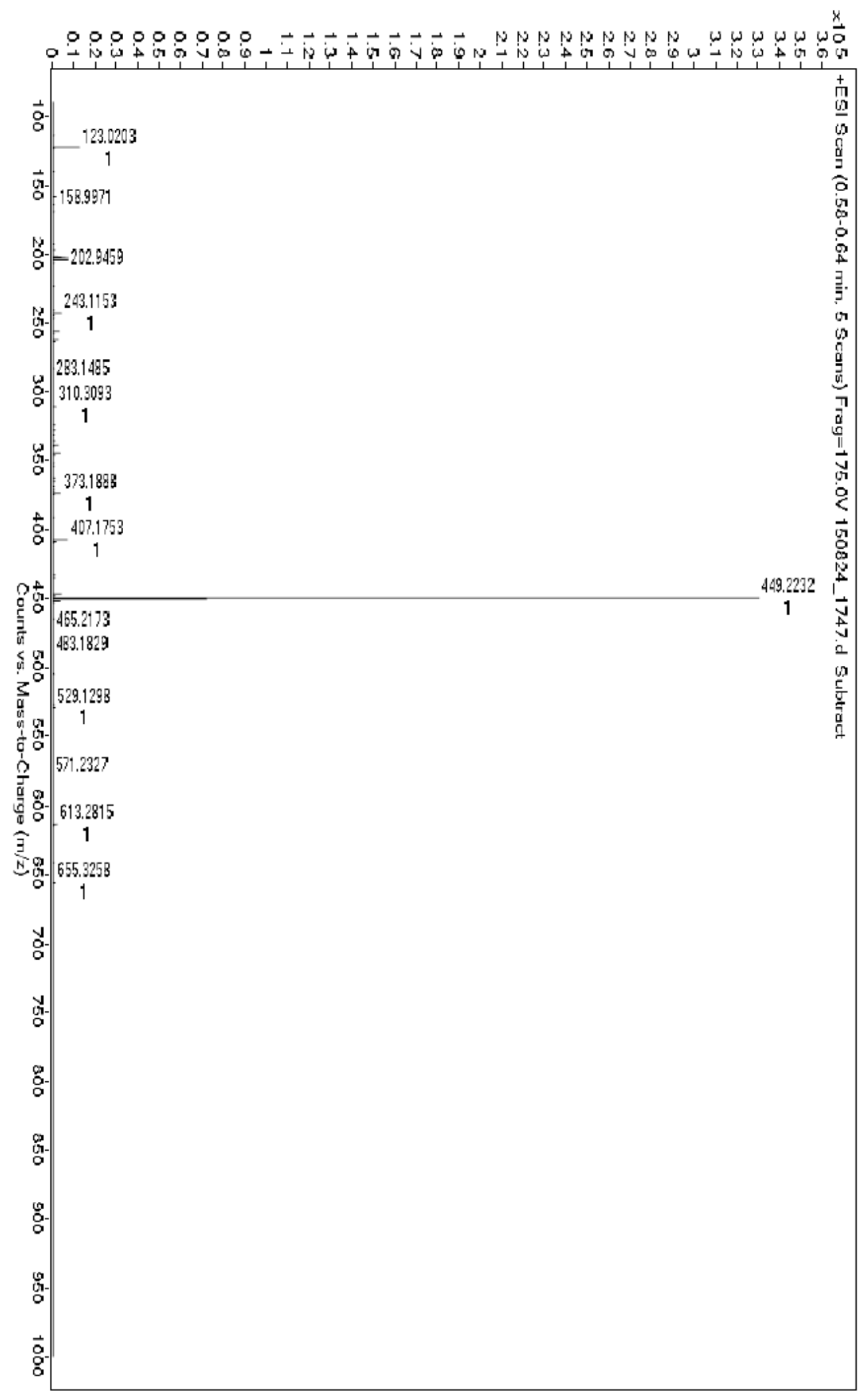

Figure A86: HRMS-ESI-TOF of compound $\mathbf{1 H .}$ 


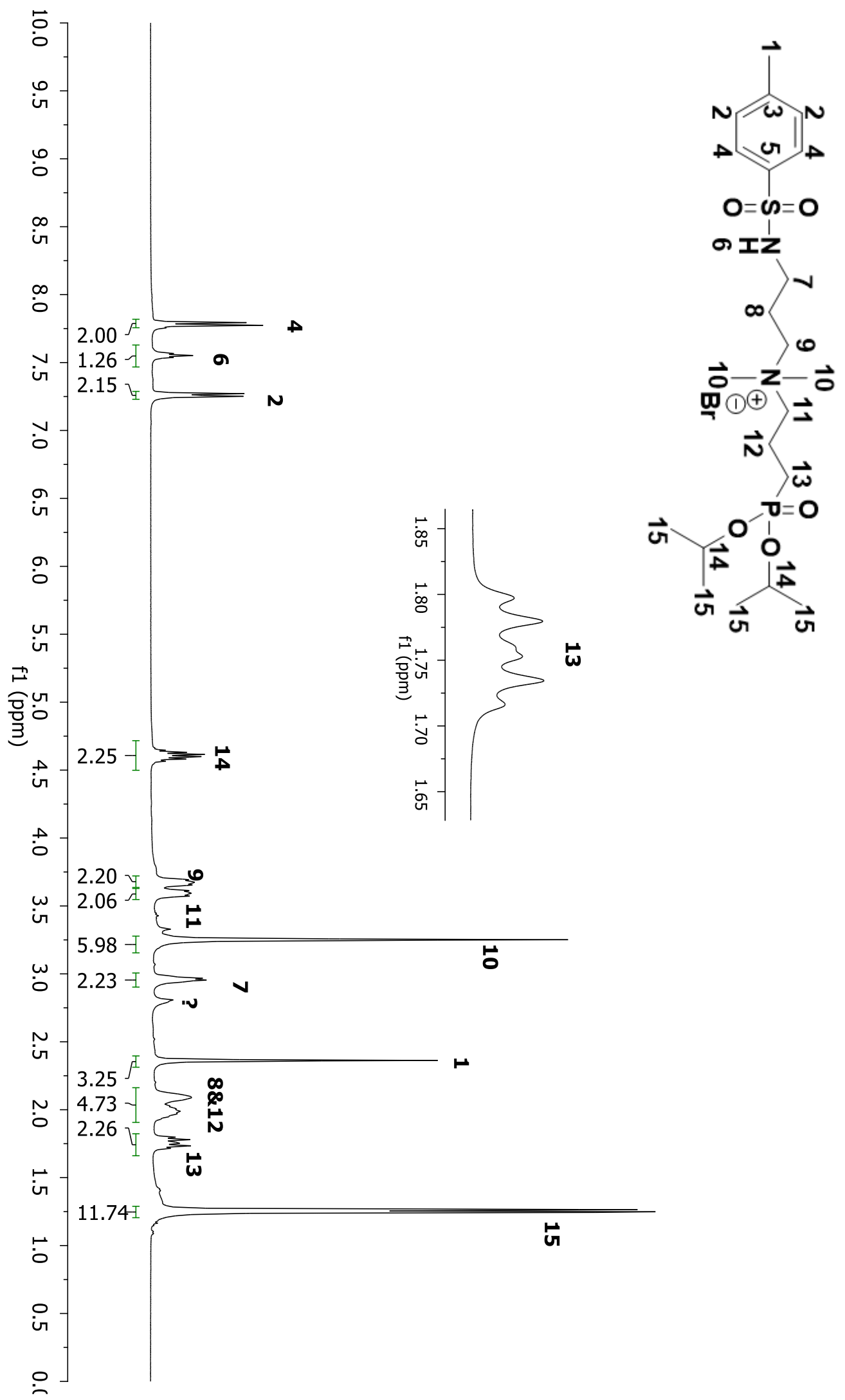

Figure A87: ${ }^{1} \mathrm{H}$ NMR spectrum of compound $\mathbf{2 H}$ in $\mathrm{CDCl}_{3}$. 


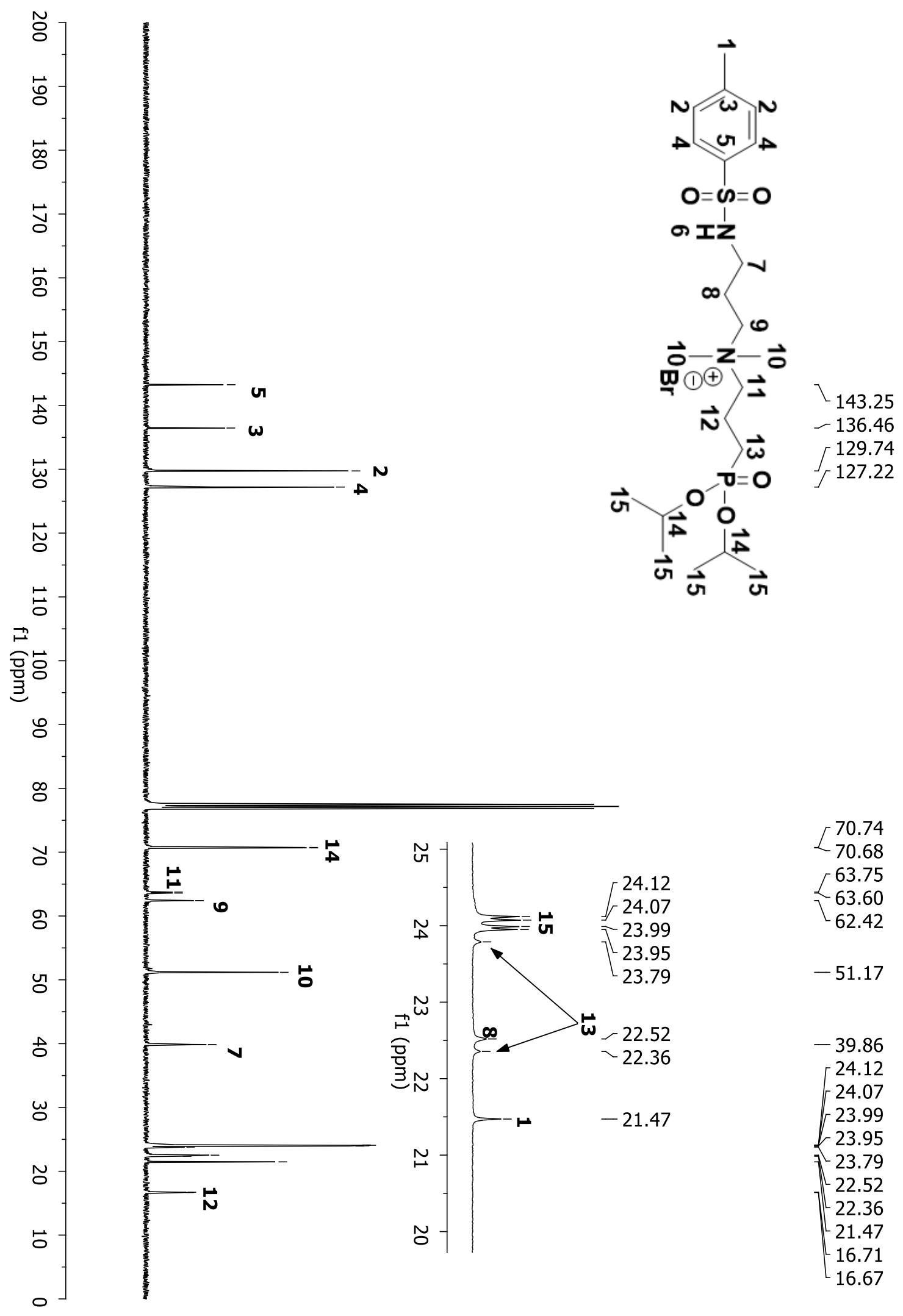

Figure A88: ${ }^{13} \mathrm{C}$ NMR spectrum of compound $2 \mathrm{H}$ in $\mathrm{CDCl}_{3}$. 


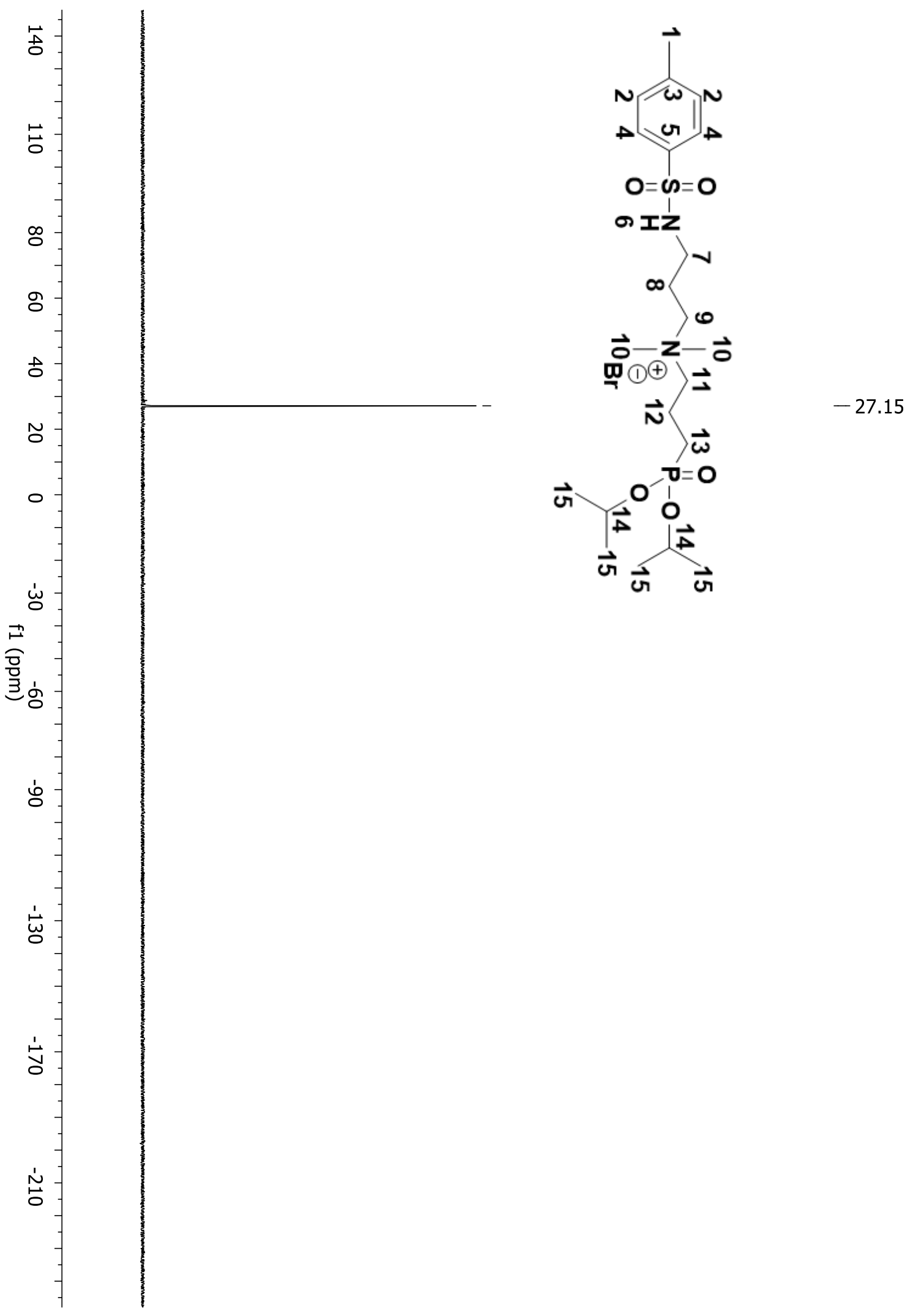

Figure A89: ${ }^{31} \mathrm{P}$ NMR spectrum of compound $\mathbf{2 H}$ in $\mathrm{CDCl}_{3}$. 


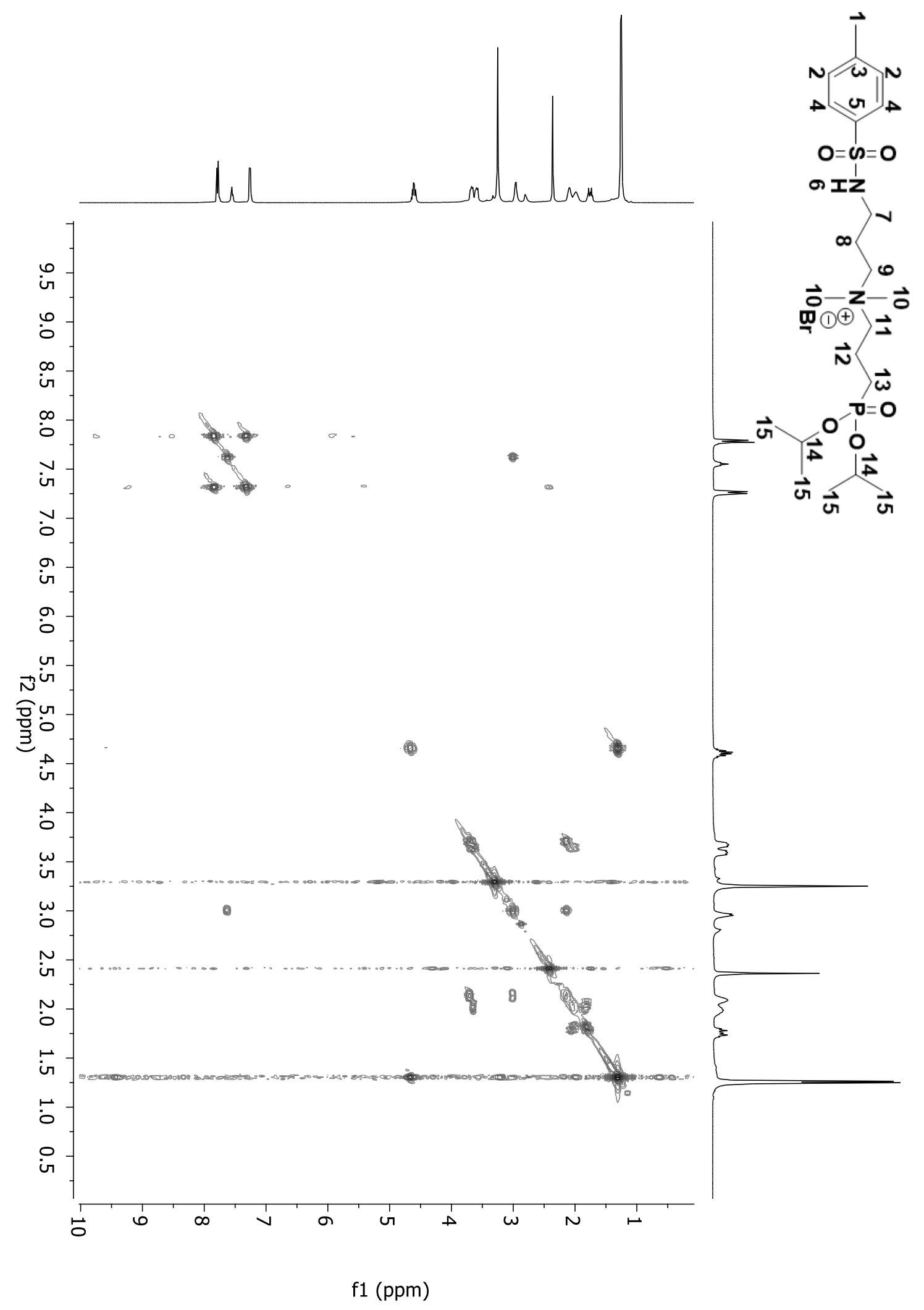

Figure A90: 2D COSY spectrum of compound $\mathbf{2 H}$ in $\mathrm{CDCl}_{3}$. 


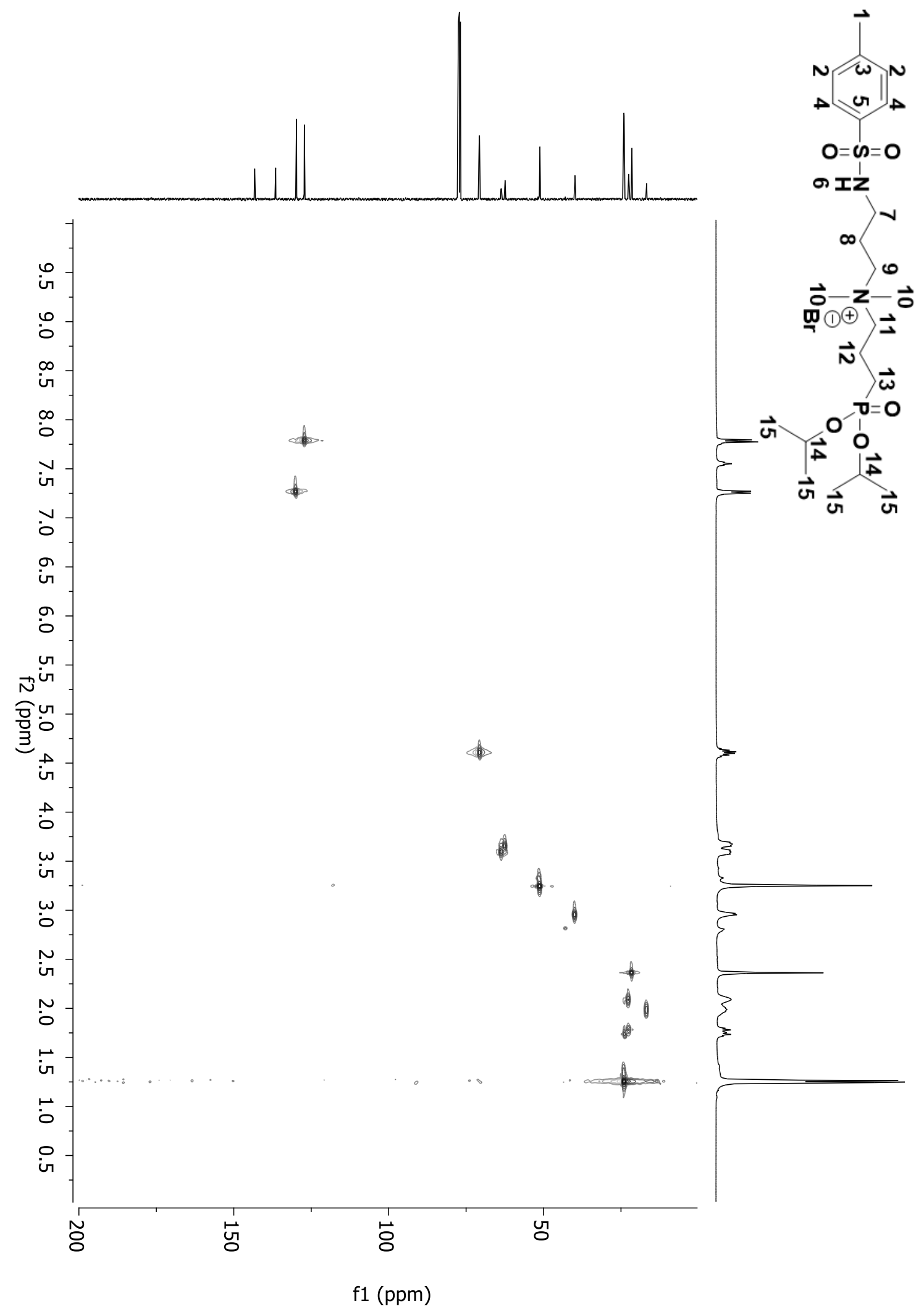

Figure A91: 2D HSQC spectrum of compound $\mathbf{2 H}$ in $\mathrm{CDCl}_{3}$. 


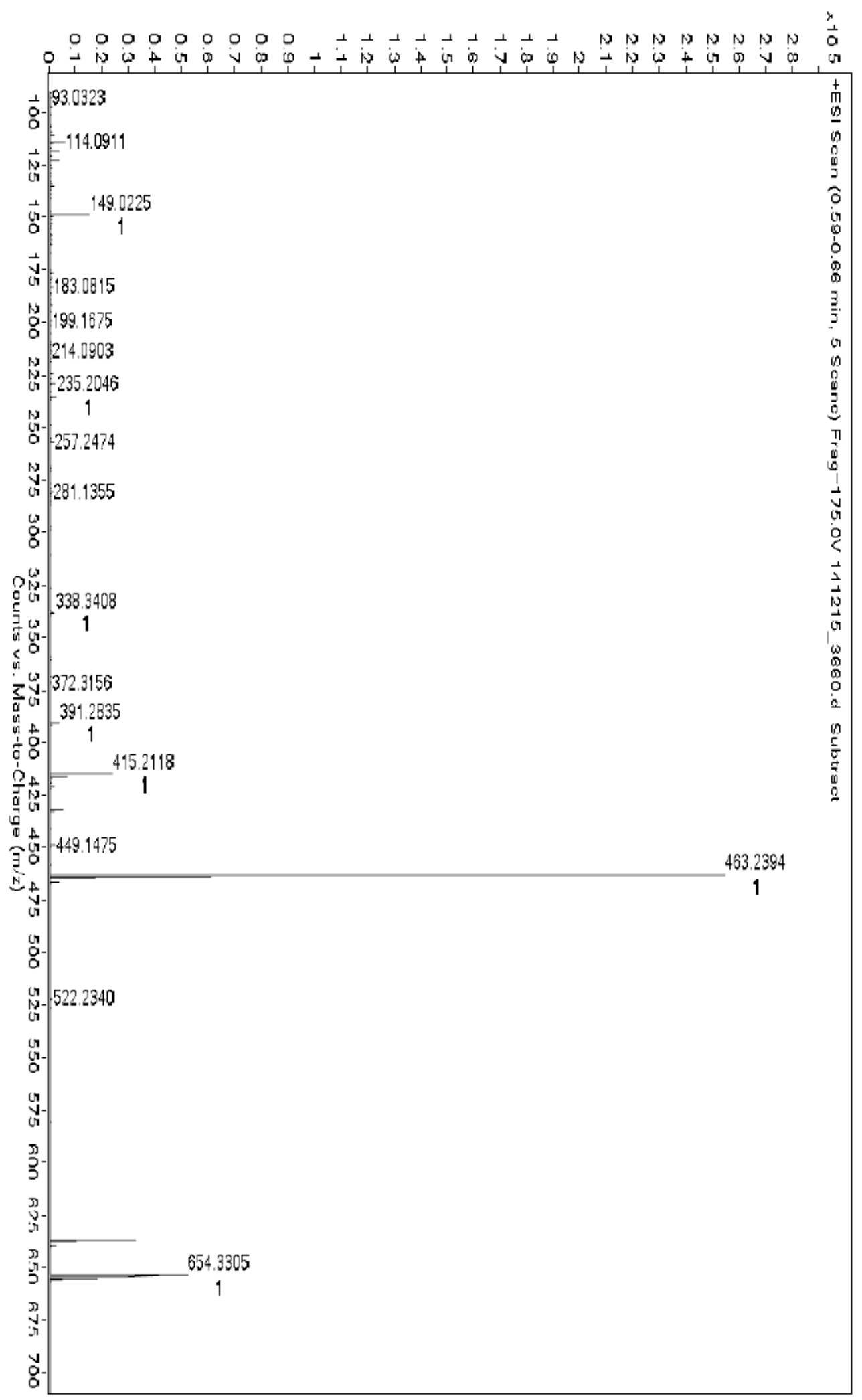

Figure A92: HRMS-ESI-TOF of compound $\mathbf{2 H}$. 


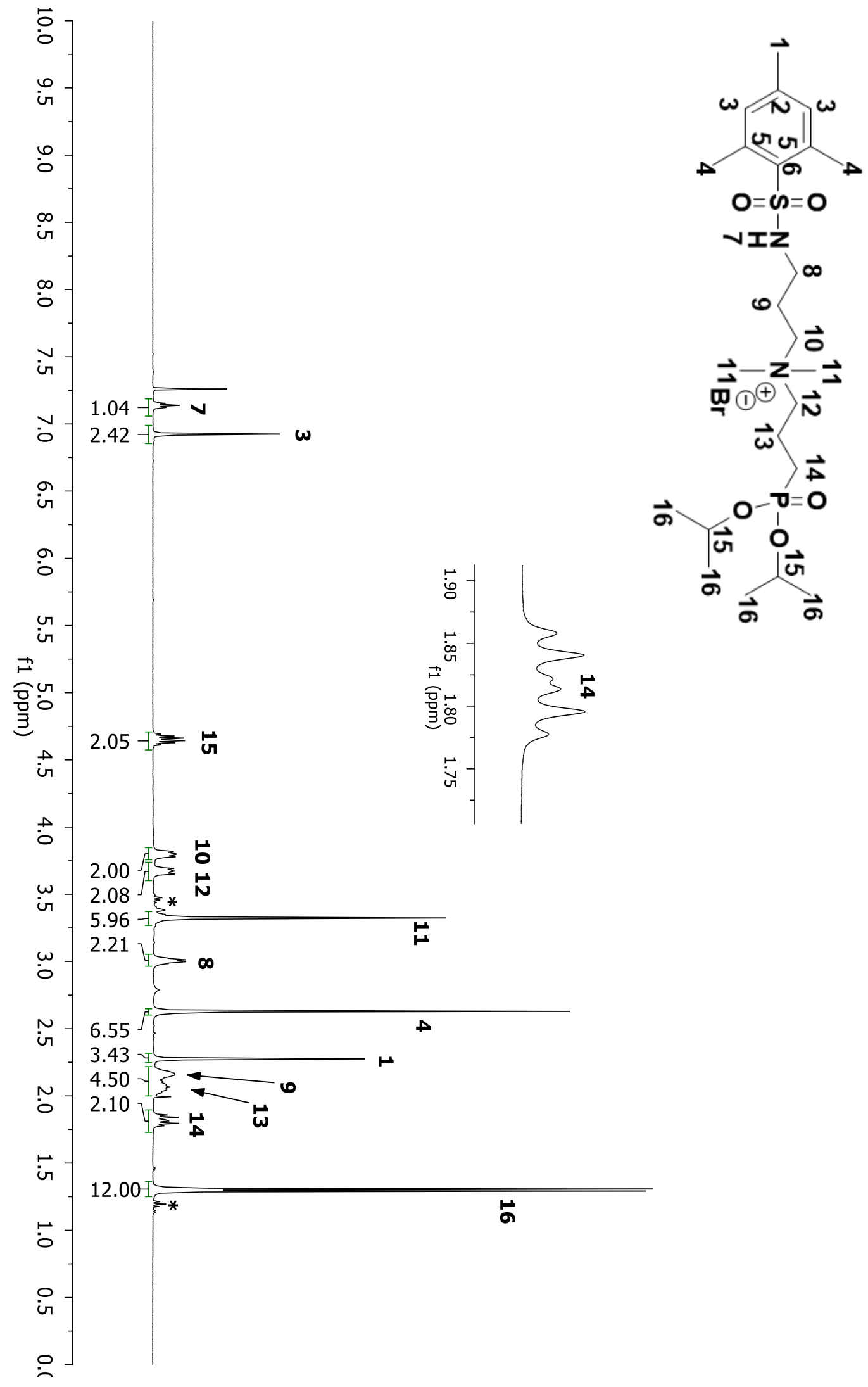

Figure A93: ${ }^{1} \mathrm{H}$ NMR spectrum of compound $3 \mathrm{H}$ in $\mathrm{CDCl}_{3}$. 


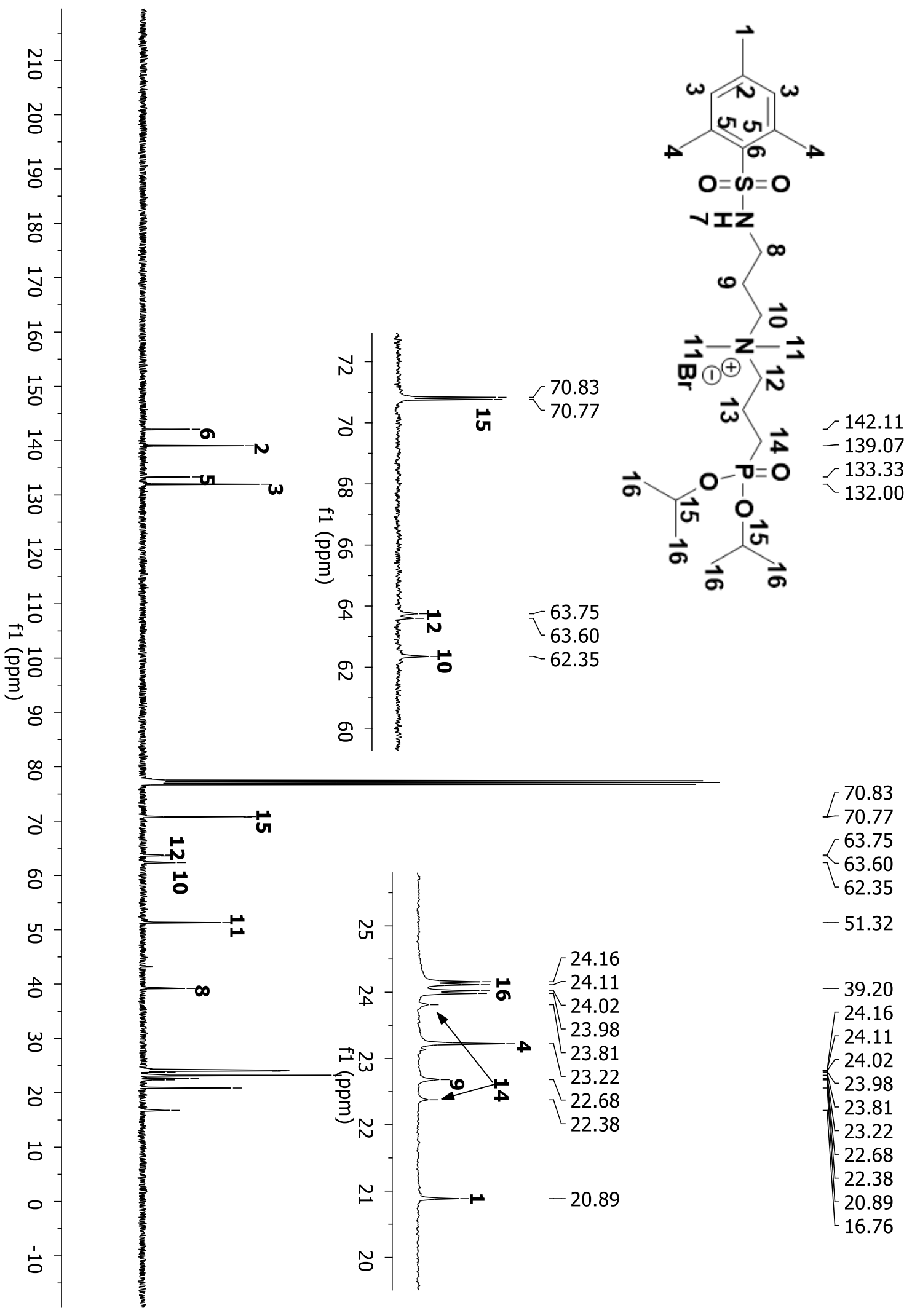

Figure A94: ${ }^{13} \mathrm{C}$ NMR spectrum of compound $3 \mathrm{H}$ in $\mathrm{CDCl}_{3}$. 


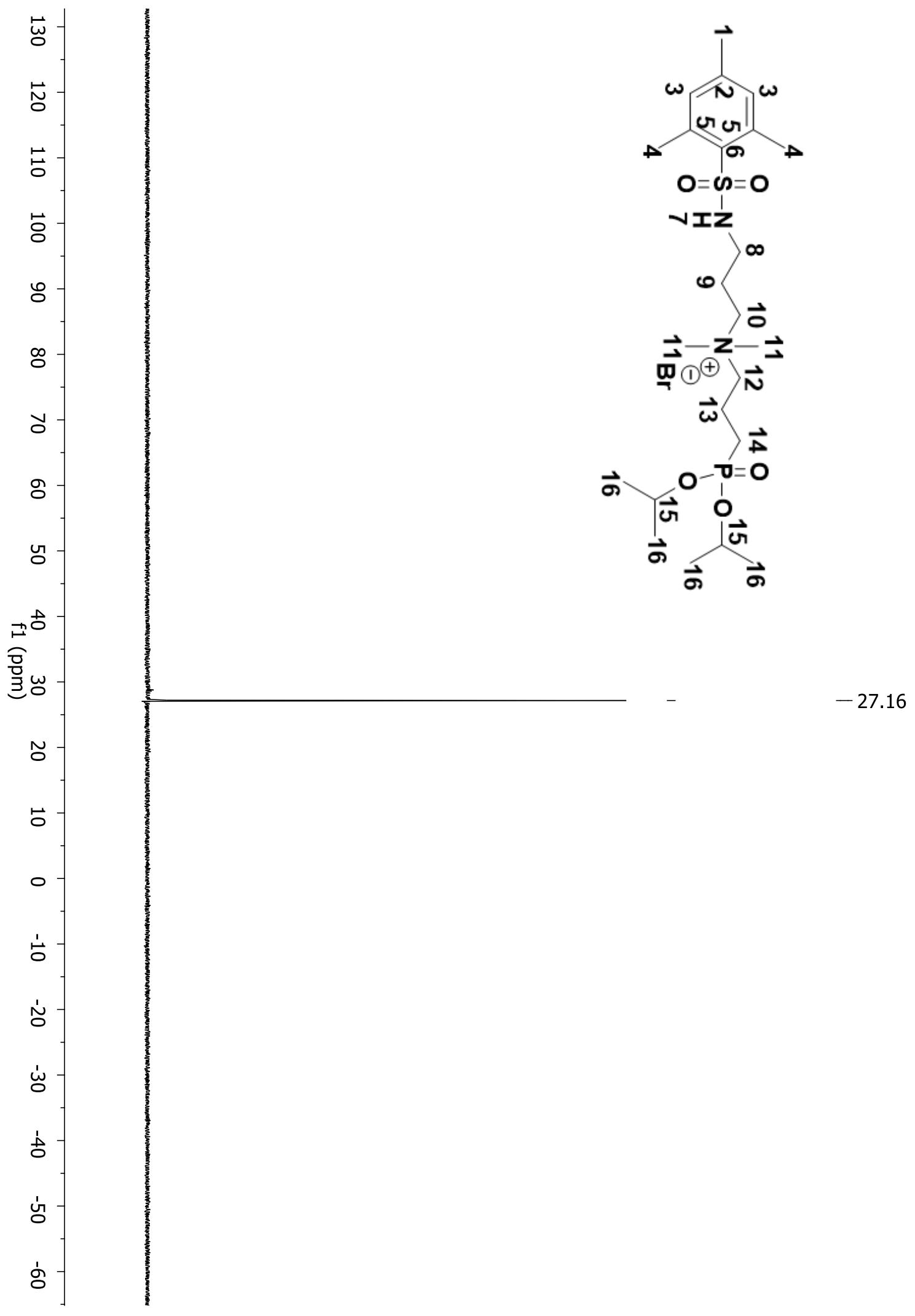

Figure A95: ${ }^{31} \mathrm{P}$ NMR spectrum of compound $\mathbf{3 H}$ in $\mathrm{CDCl}_{3}$. 


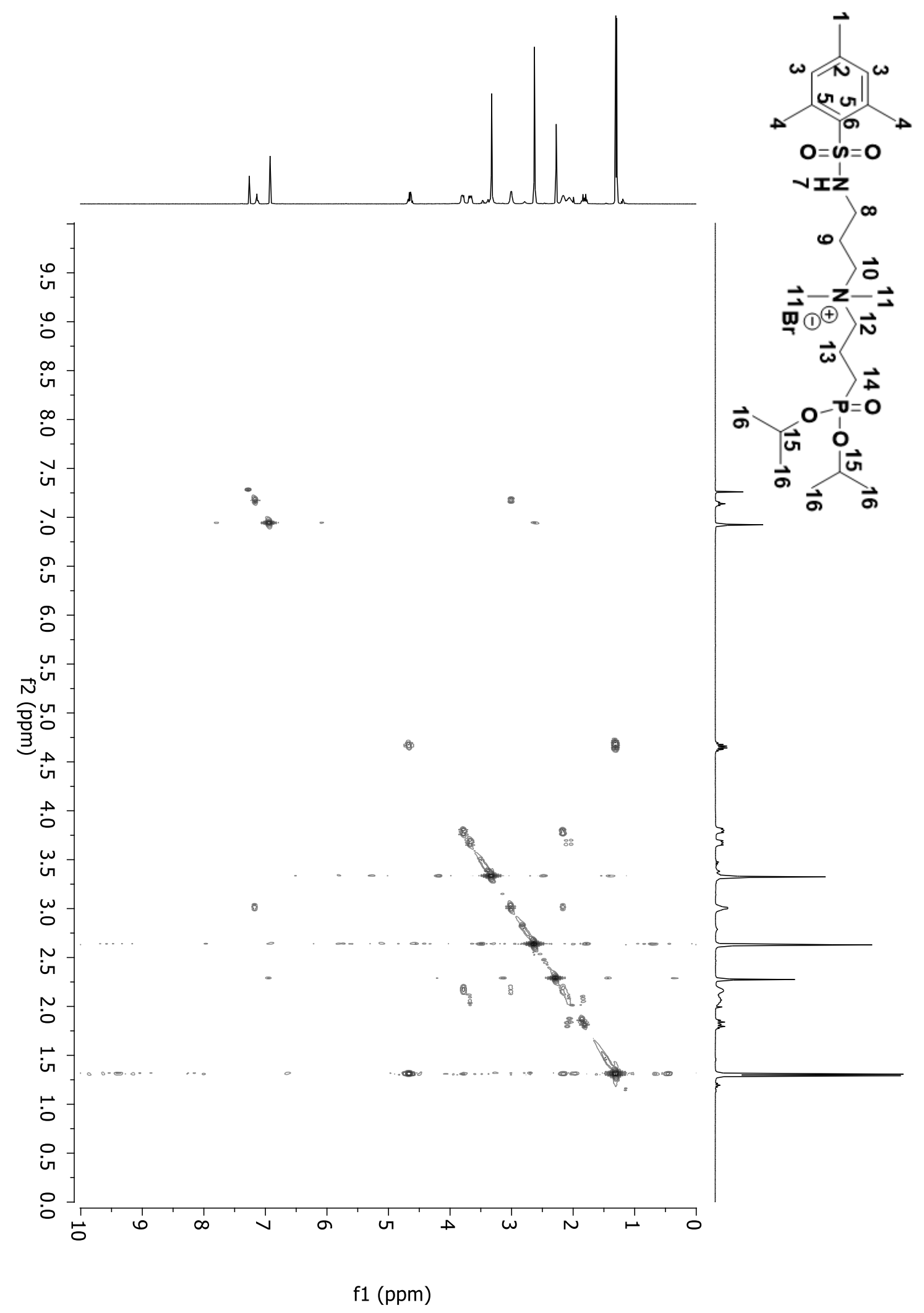

Figure A96: 2D COSY spectrum of compound $\mathbf{3 H}$ in $\mathrm{CDCl}_{3}$. 


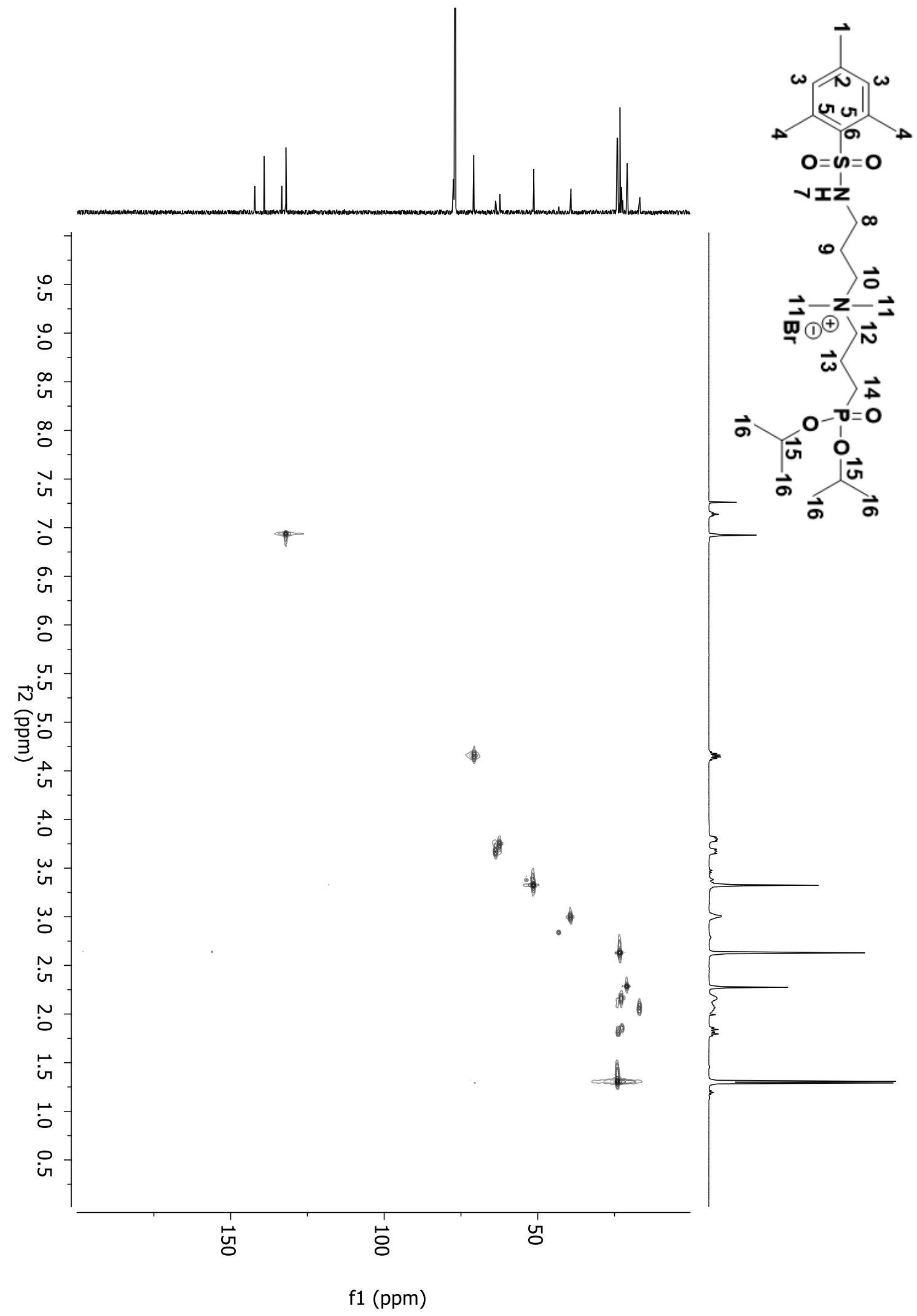

Figure A97: 2D HSQC spectrum of compound $\mathbf{3 H}$ in $\mathrm{CDCl}_{3}$. 


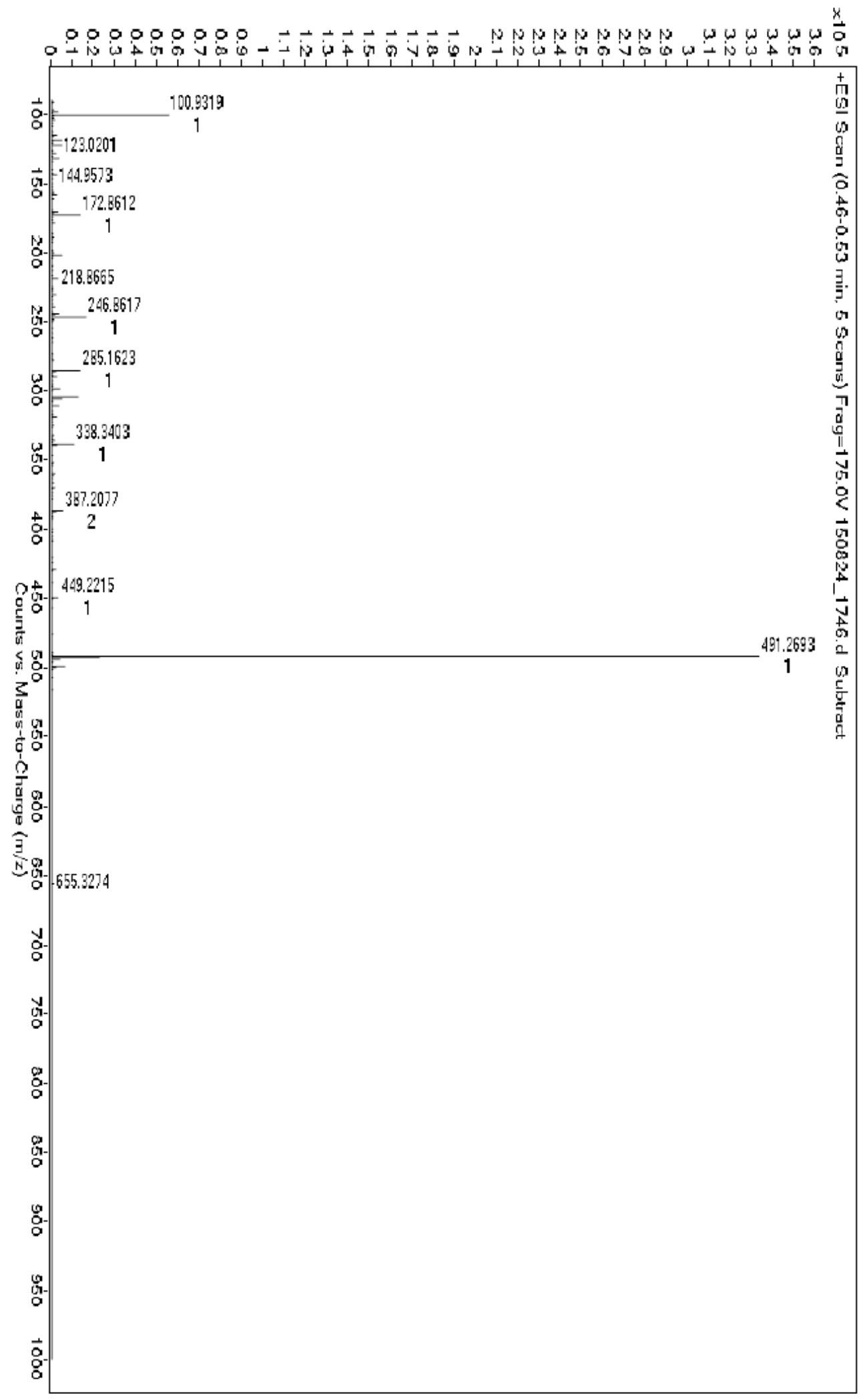

Figure A98: HRMS-ESI-TOF of compound $\mathbf{3 H}$. 


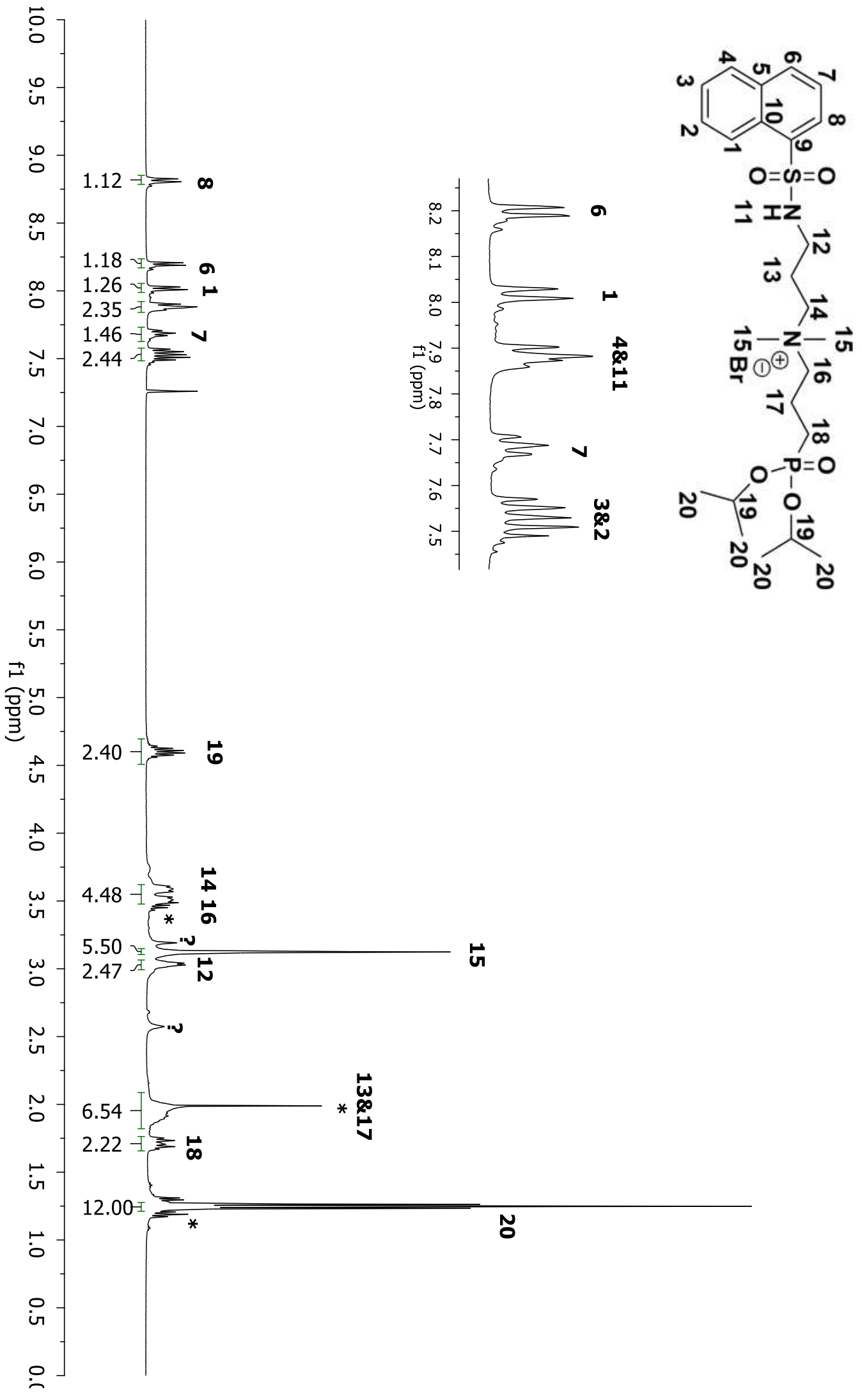

Figure A99: ${ }^{1} \mathrm{H}$ NMR spectrum of compound $5 \mathrm{H}$ in $\mathrm{CDCl}_{3}$. 


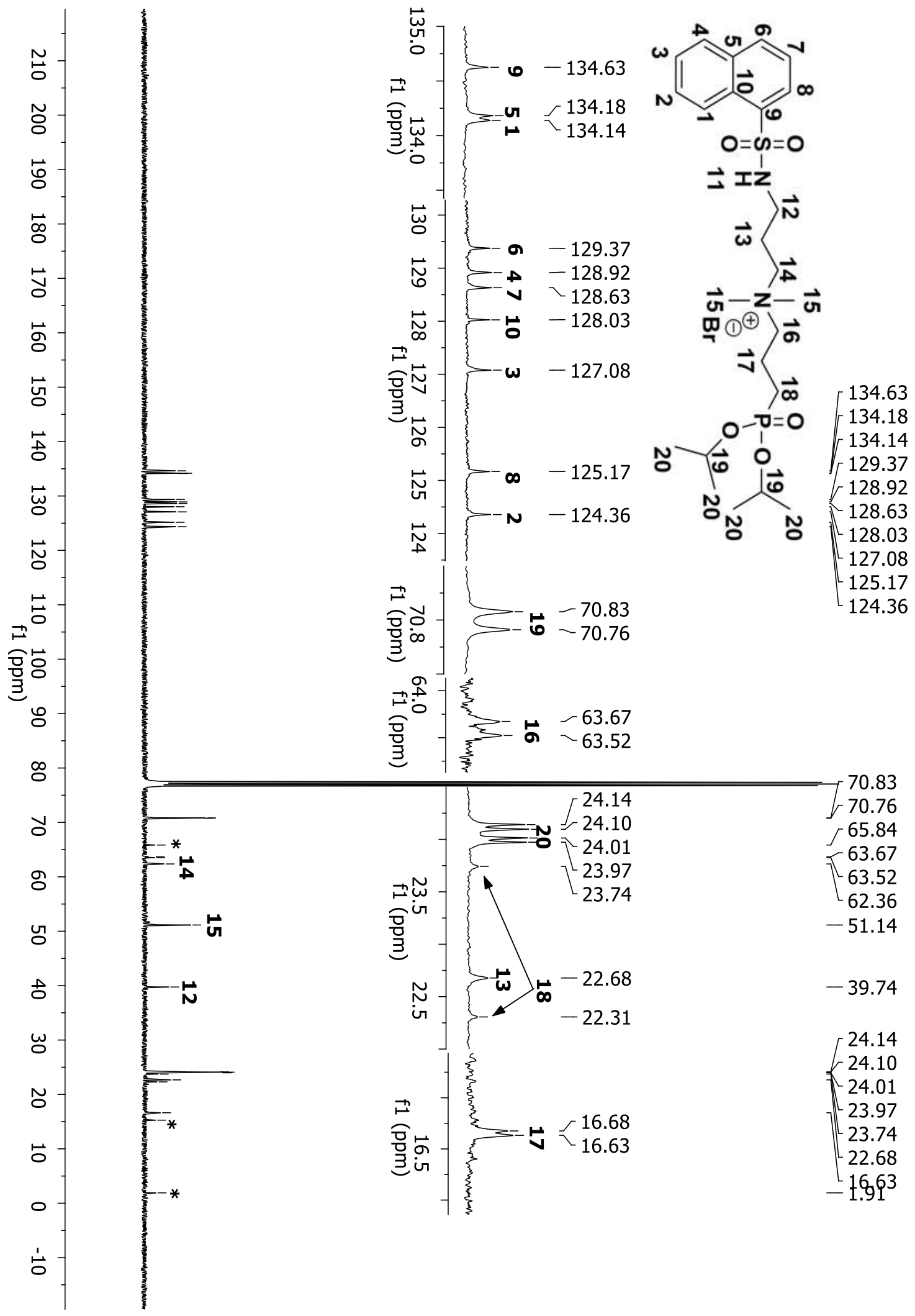

Figure A100: ${ }^{13} \mathrm{C}$ NMR spectrum of compound $5 \mathbf{H}$ in $\mathrm{CDCl}_{3}$. 


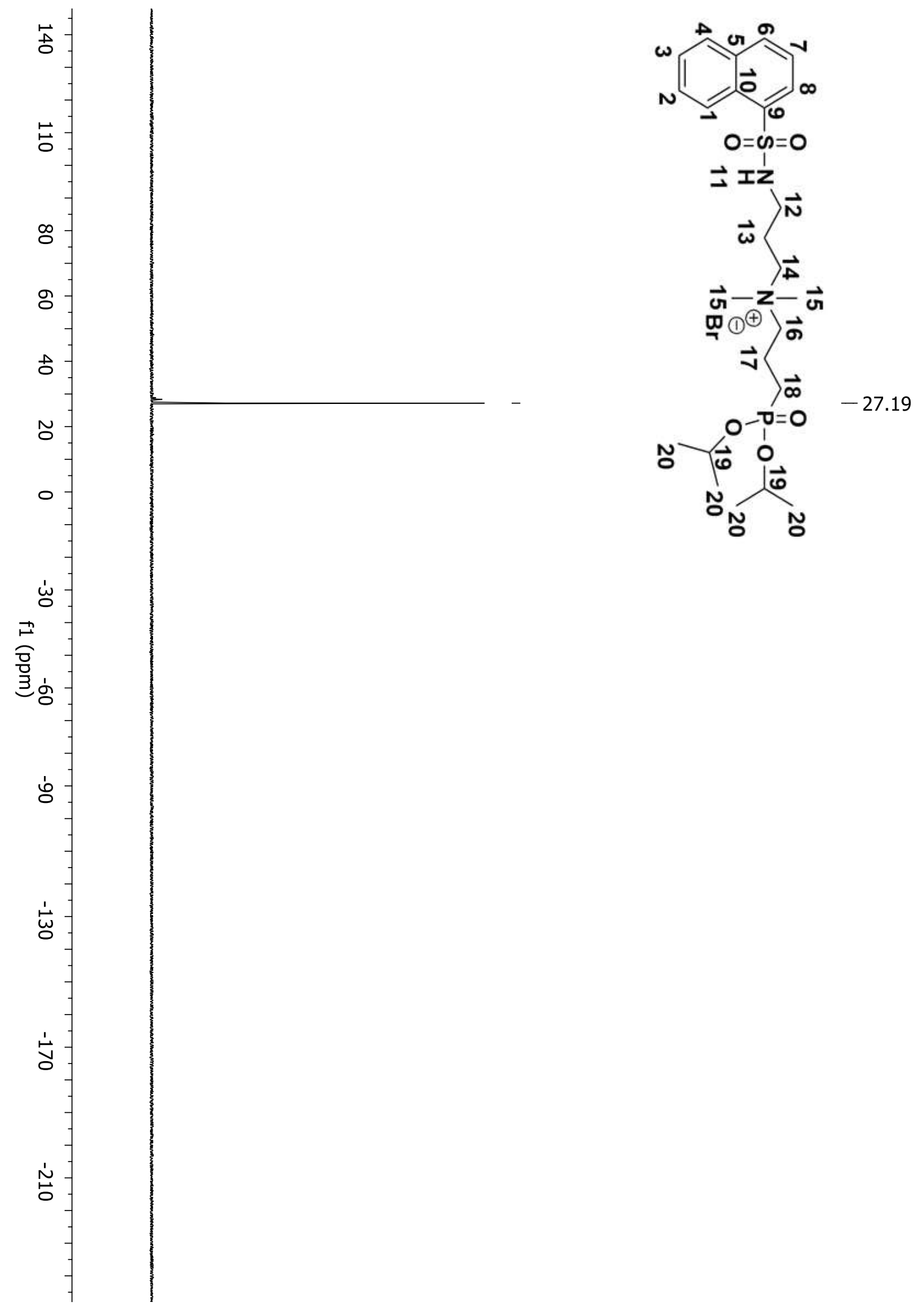

Figure A101: ${ }^{31} \mathrm{P}$ NMR spectrum of compound $5 \mathrm{H}$ in $\mathrm{CDCl}_{3}$. 


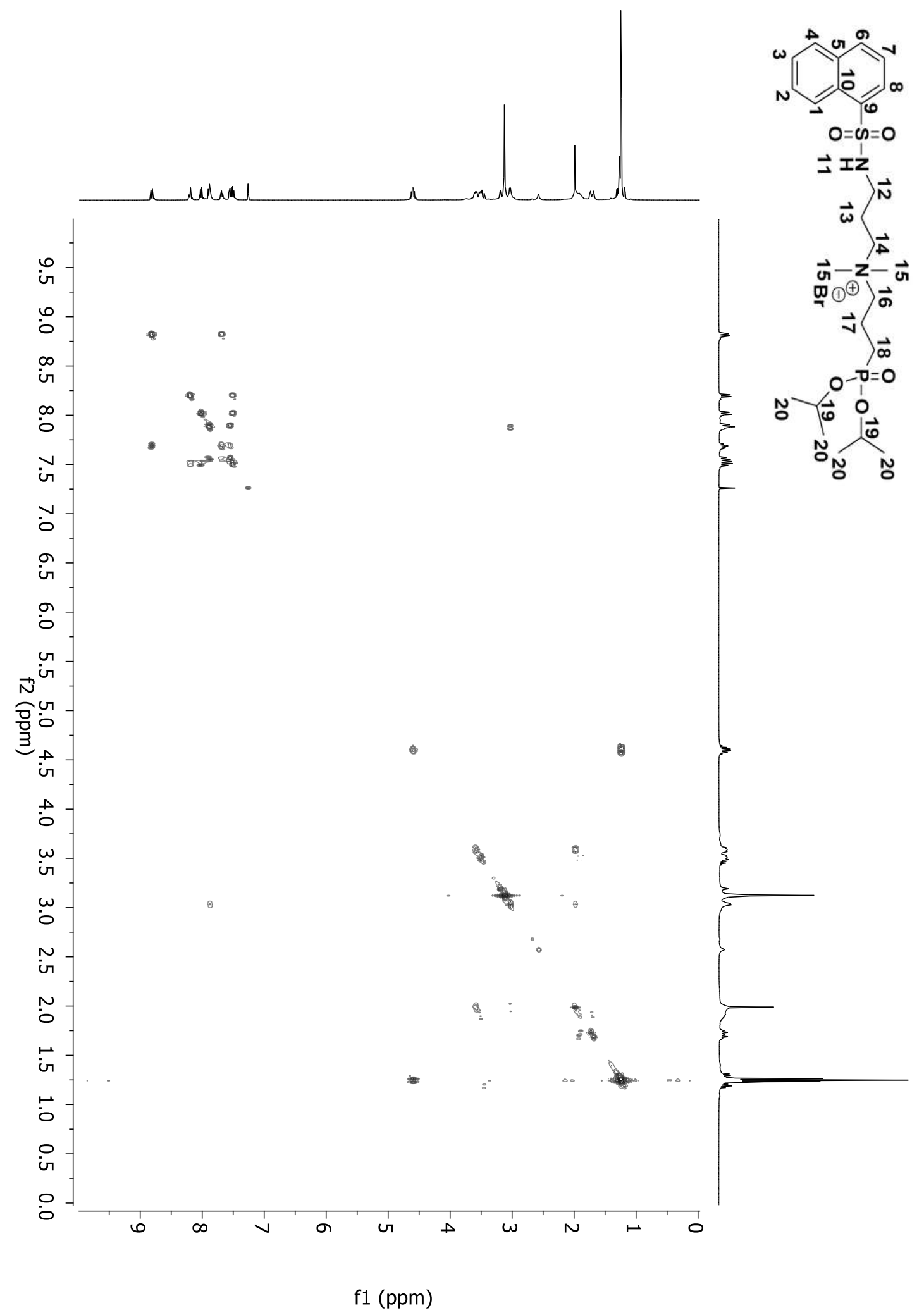

Figure A102: 2D COSY spectrum of compound $\mathbf{5 H}$ in $\mathrm{CDCl}_{3}$. 


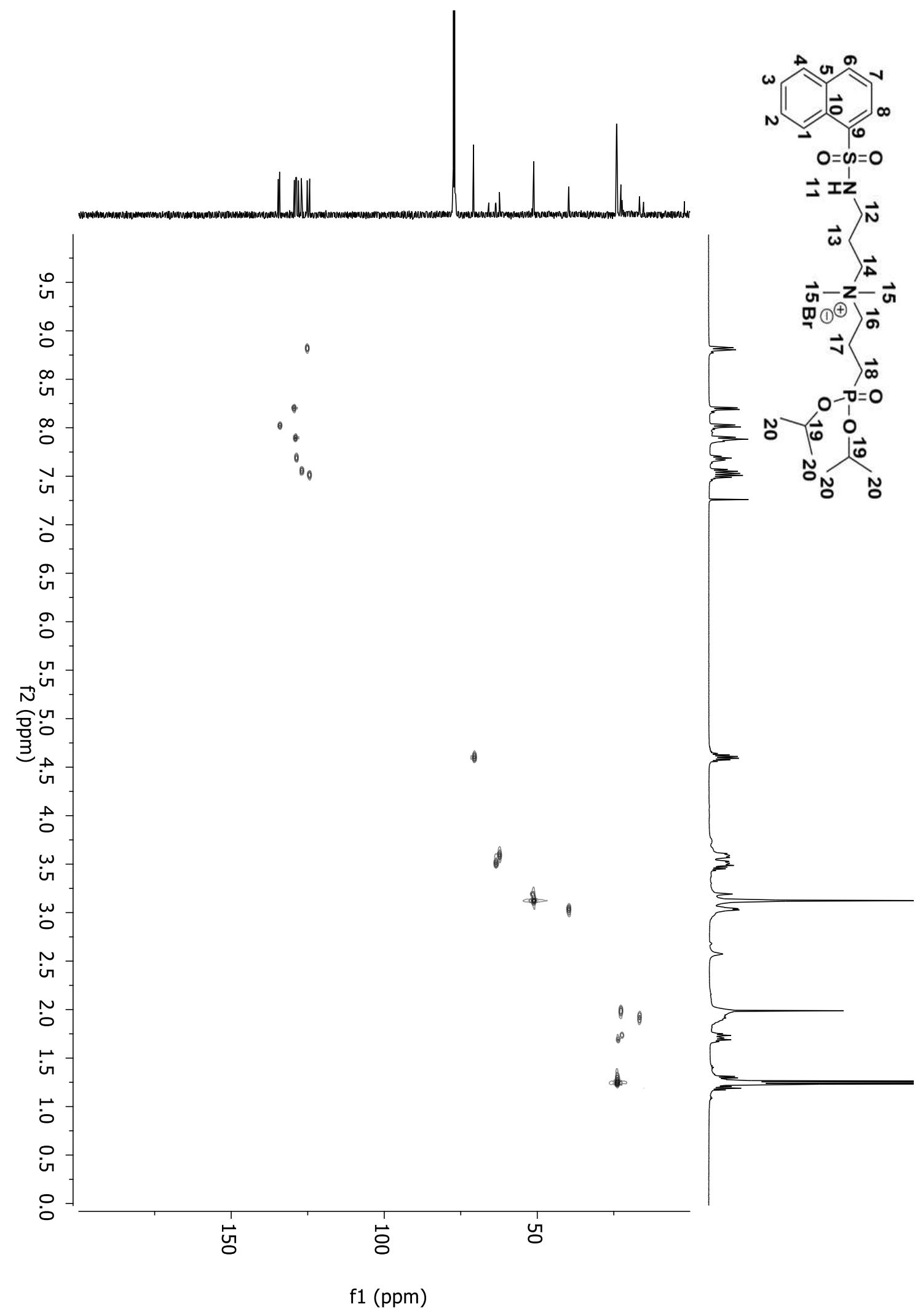

Figure A103: 2D HSQC spectrum of compound $\mathbf{5 H}$ in $\mathrm{CDCl}_{3}$. 


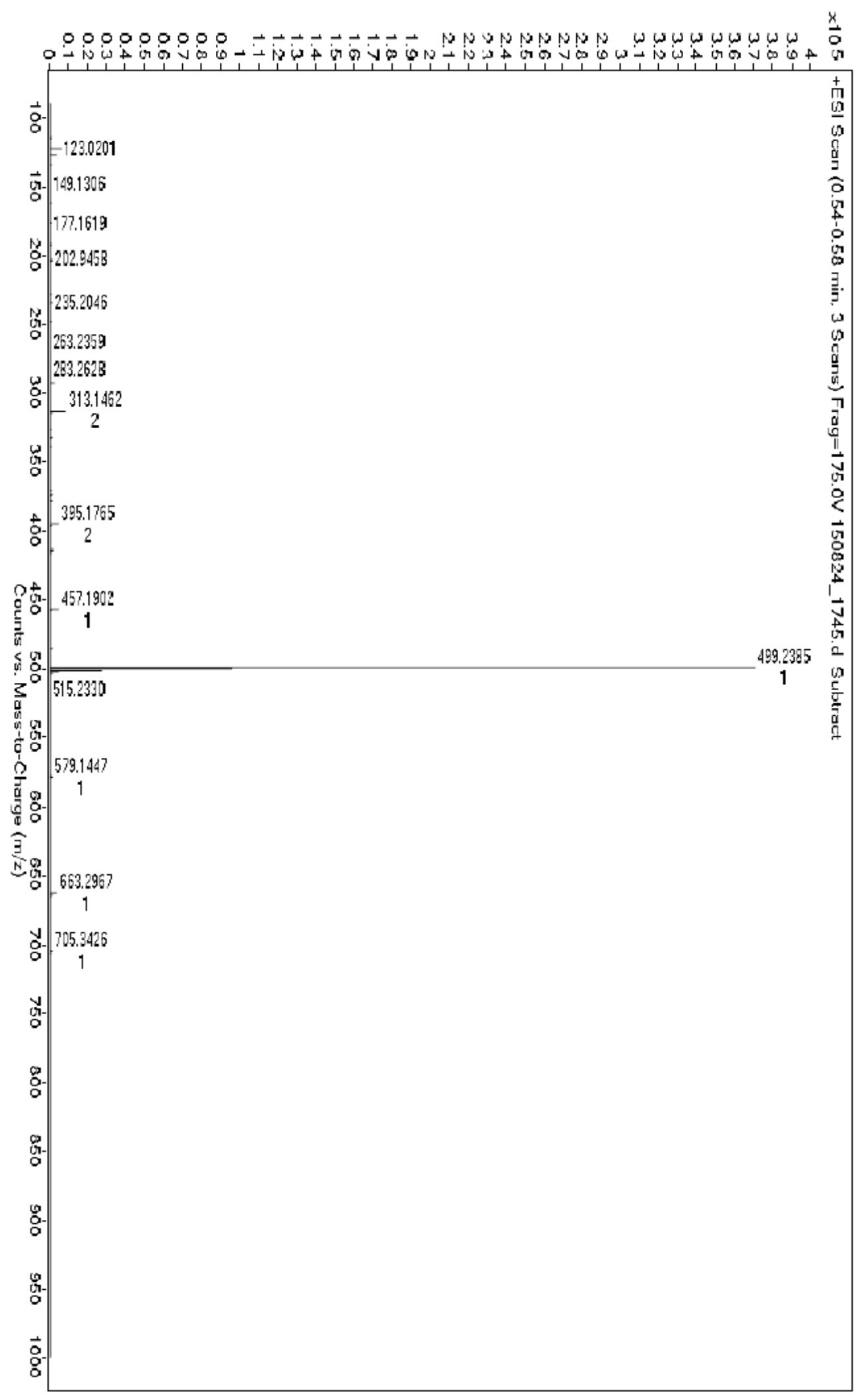

Figure A104: HRMS-ESI-TOF of compound $\mathbf{5 H}$. 


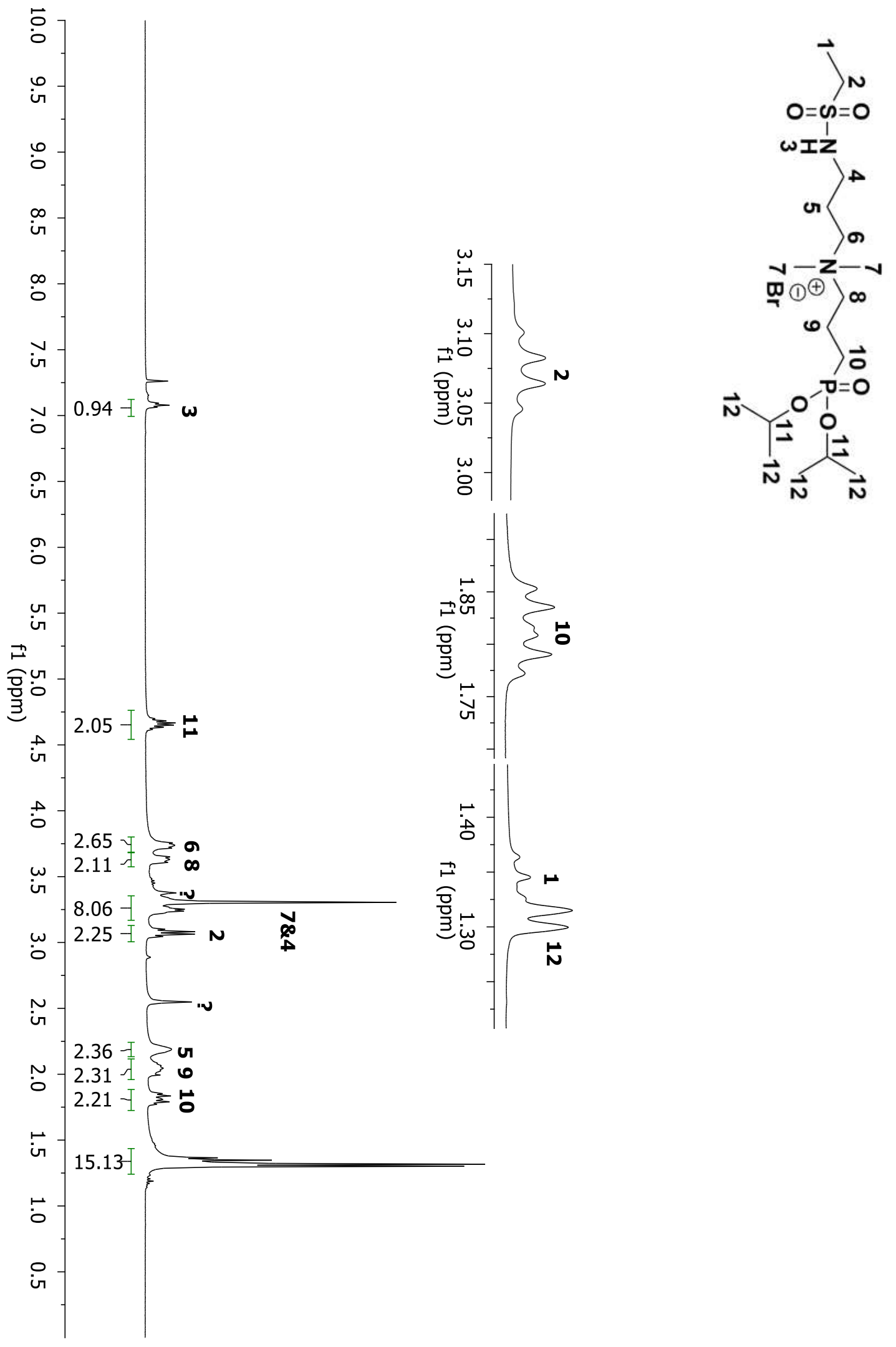

Figure A105: ${ }^{1} \mathrm{H}$ NMR spectrum of compound $7 \mathbf{H}$ in $\mathrm{CDCl}_{3}$. 


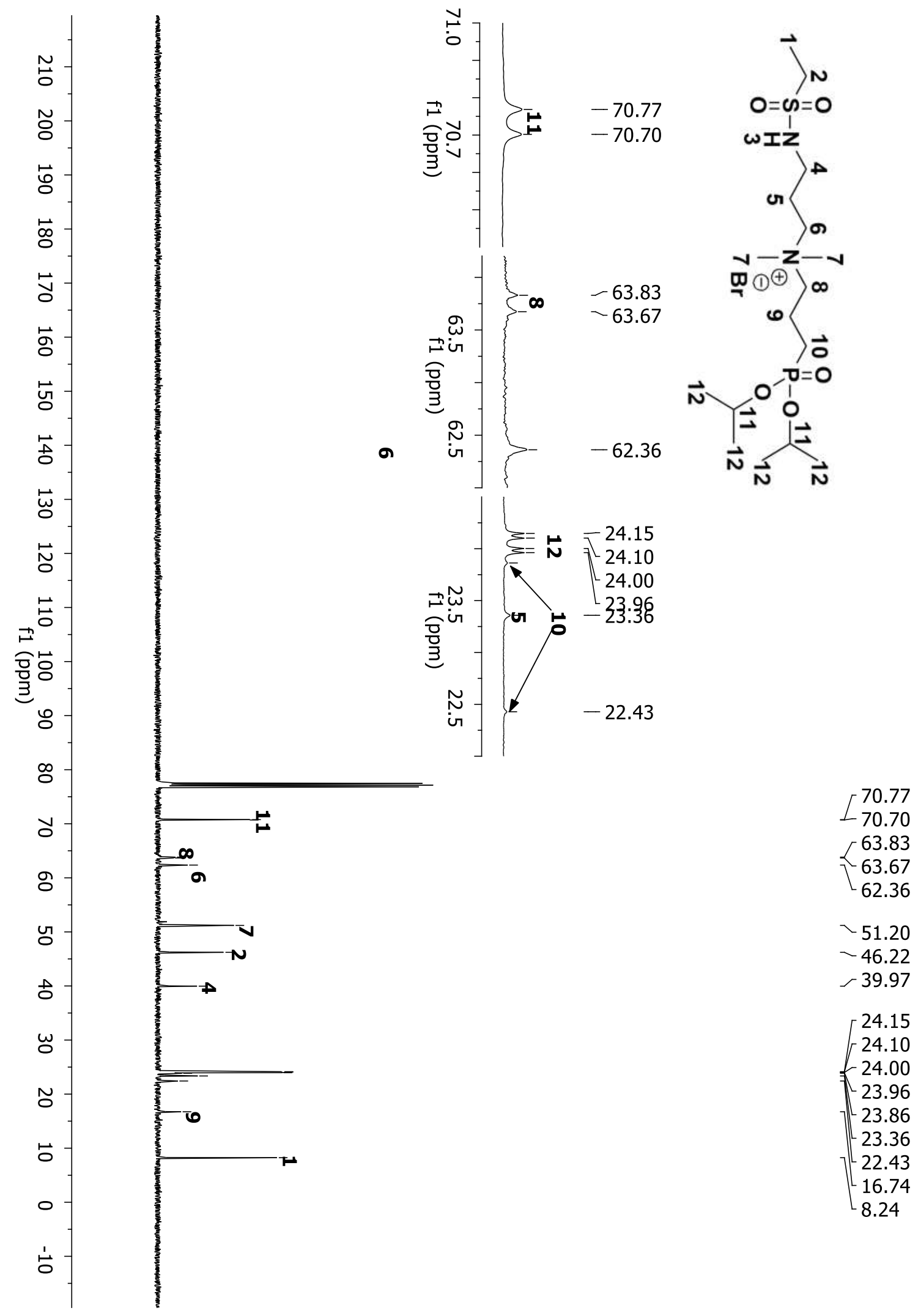

Figure A106: ${ }^{13} \mathrm{C}$ NMR spectrum of compound $7 \mathbf{H}$ in $\mathrm{CDCl}_{3}$. 


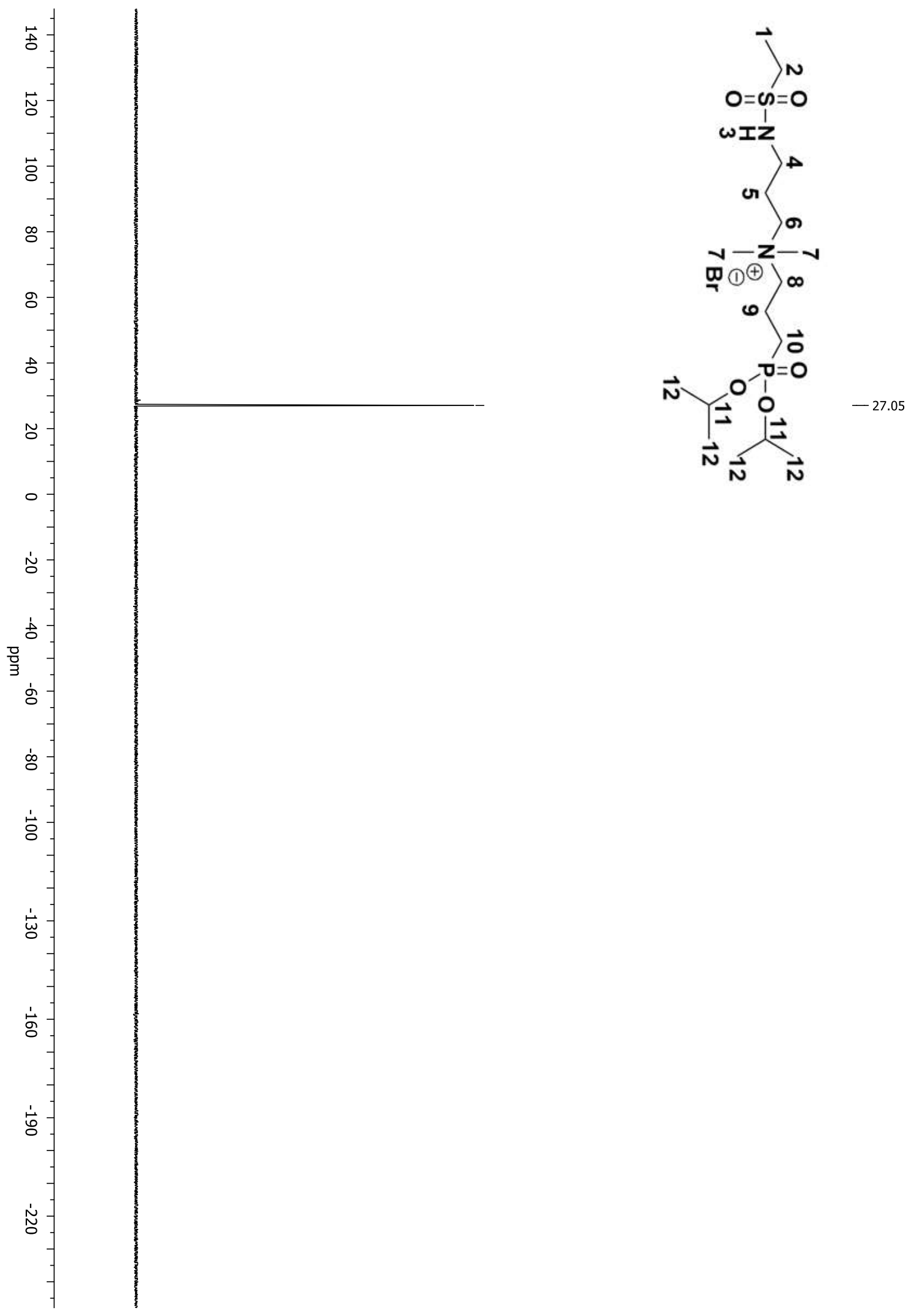

Figure A107: ${ }^{31} \mathrm{P}$ NMR spectrum of compound $\mathbf{7 H}$ in $\mathrm{CDCl}_{3}$. 


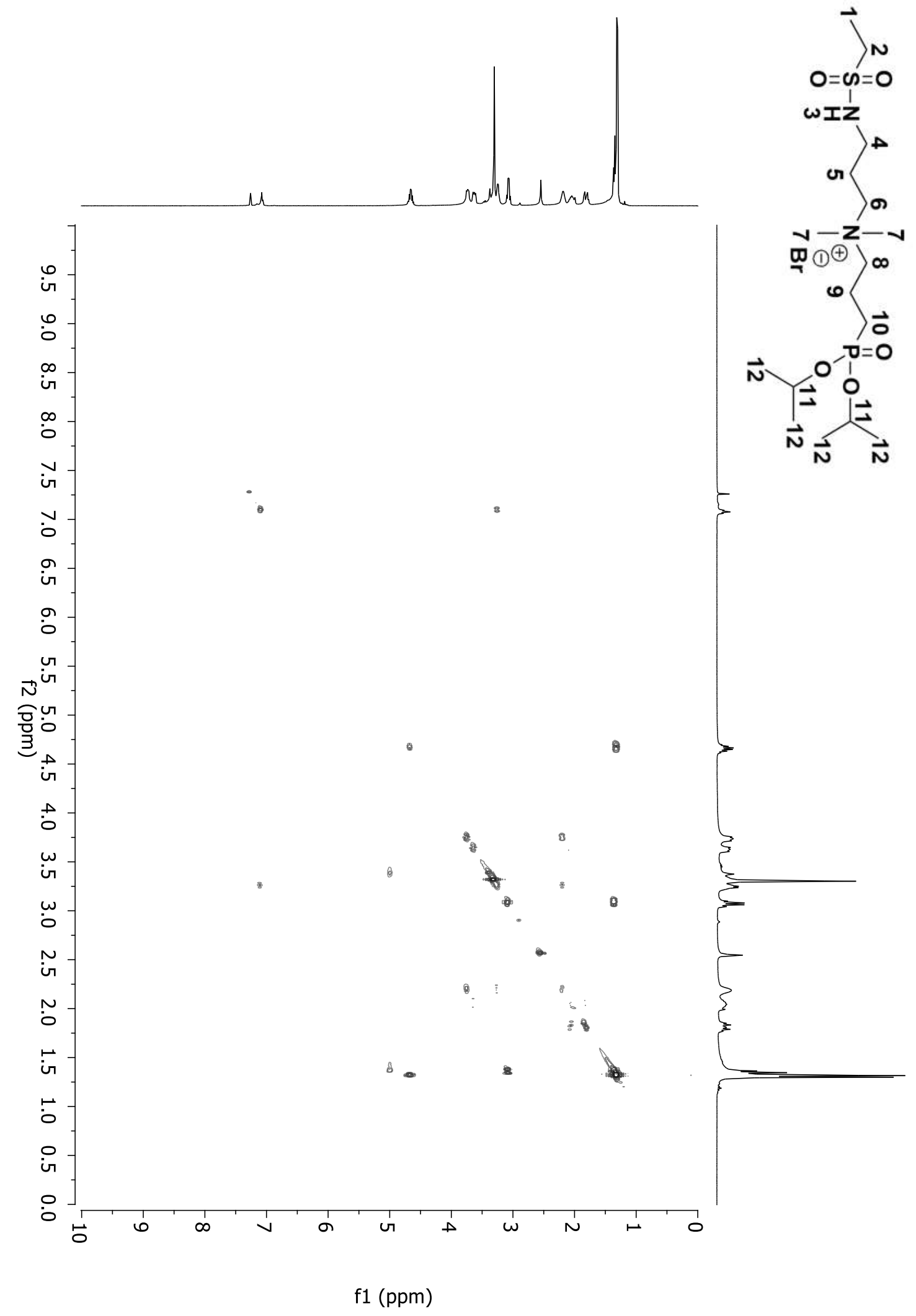

Figure A108: 2D COSY spectrum of compound $\mathbf{7 H}$ in $\mathrm{CDCl}_{3}$. 


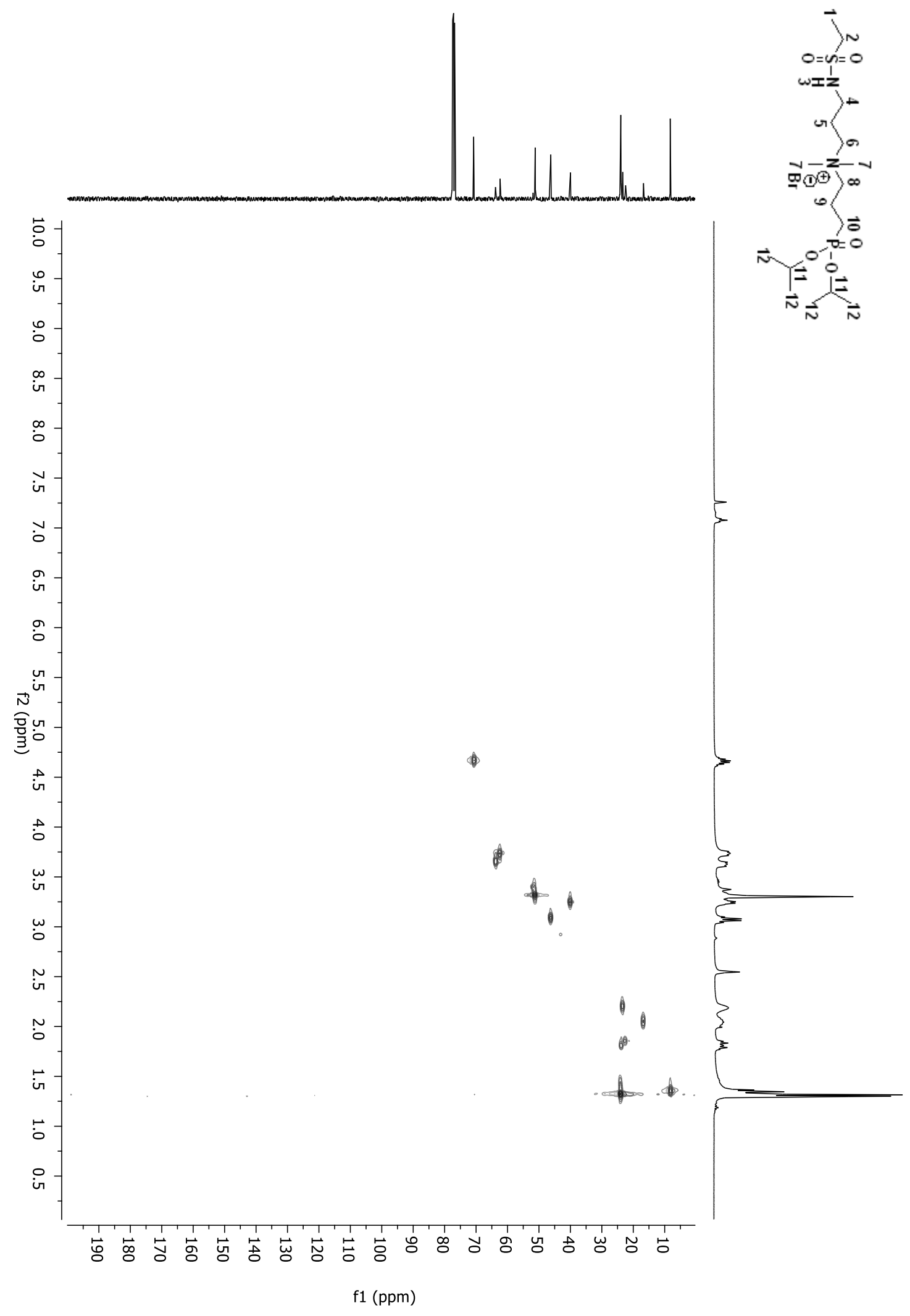

Figure A109: 2D HSQC spectrum of compound $7 \mathbf{H}$ in $\mathrm{CDCl}_{3}$. 


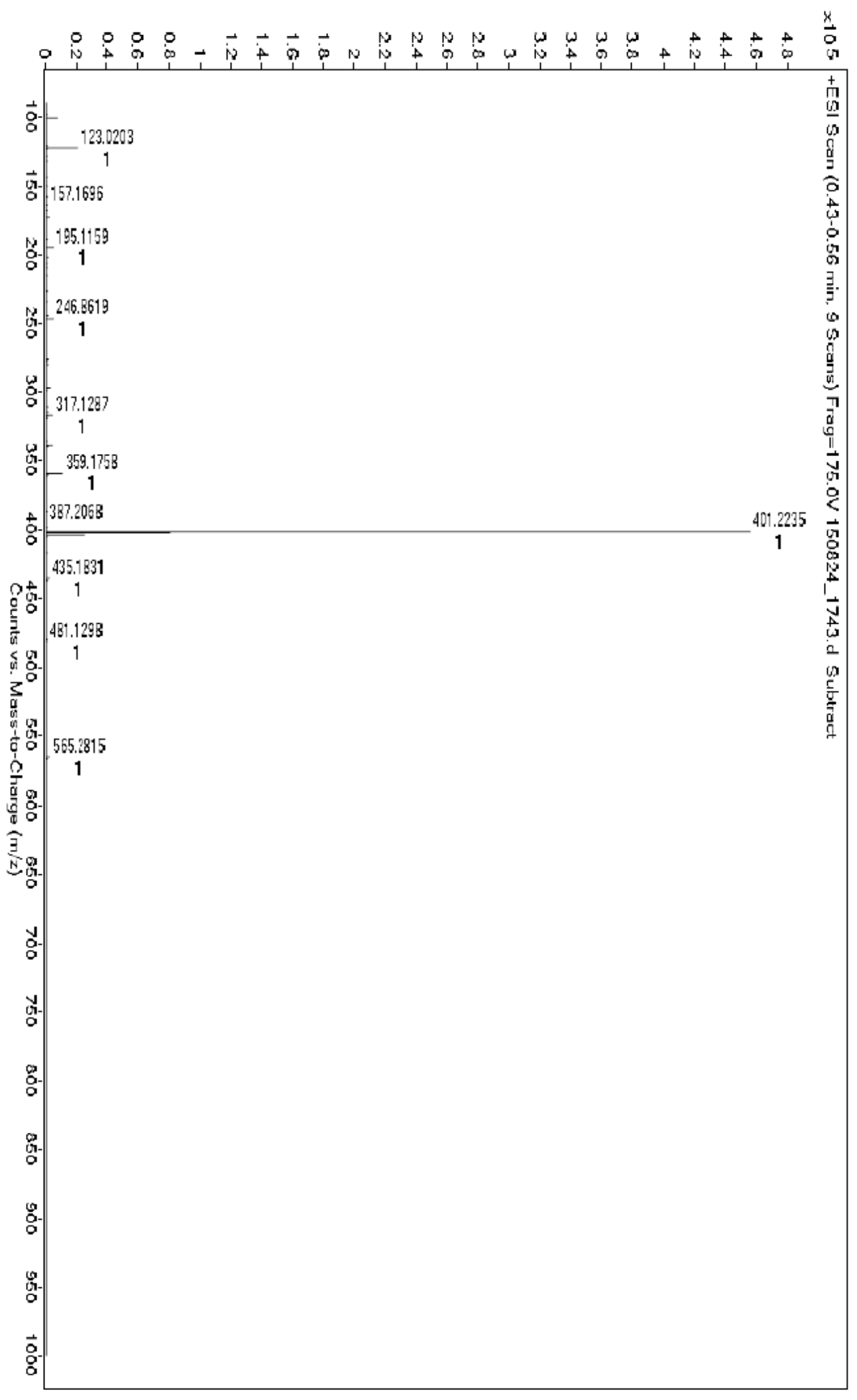

Figure A110: HRMS-ESI-TOF of compound 7H. 


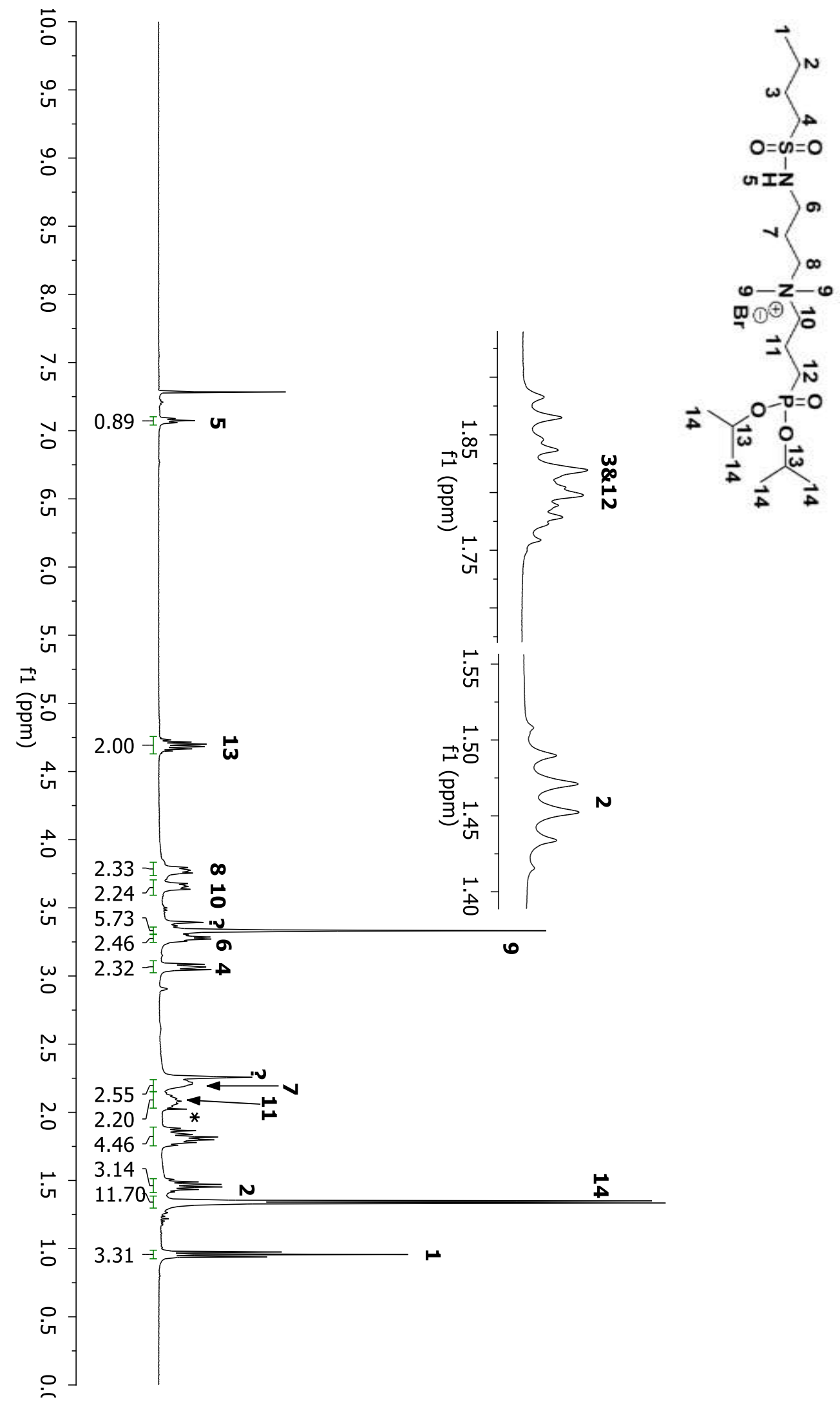

Figure A111: ${ }^{1} \mathrm{H}$ NMR spectrum of compound $\mathbf{8 H}$ in $\mathrm{CDCl}_{3}$. 


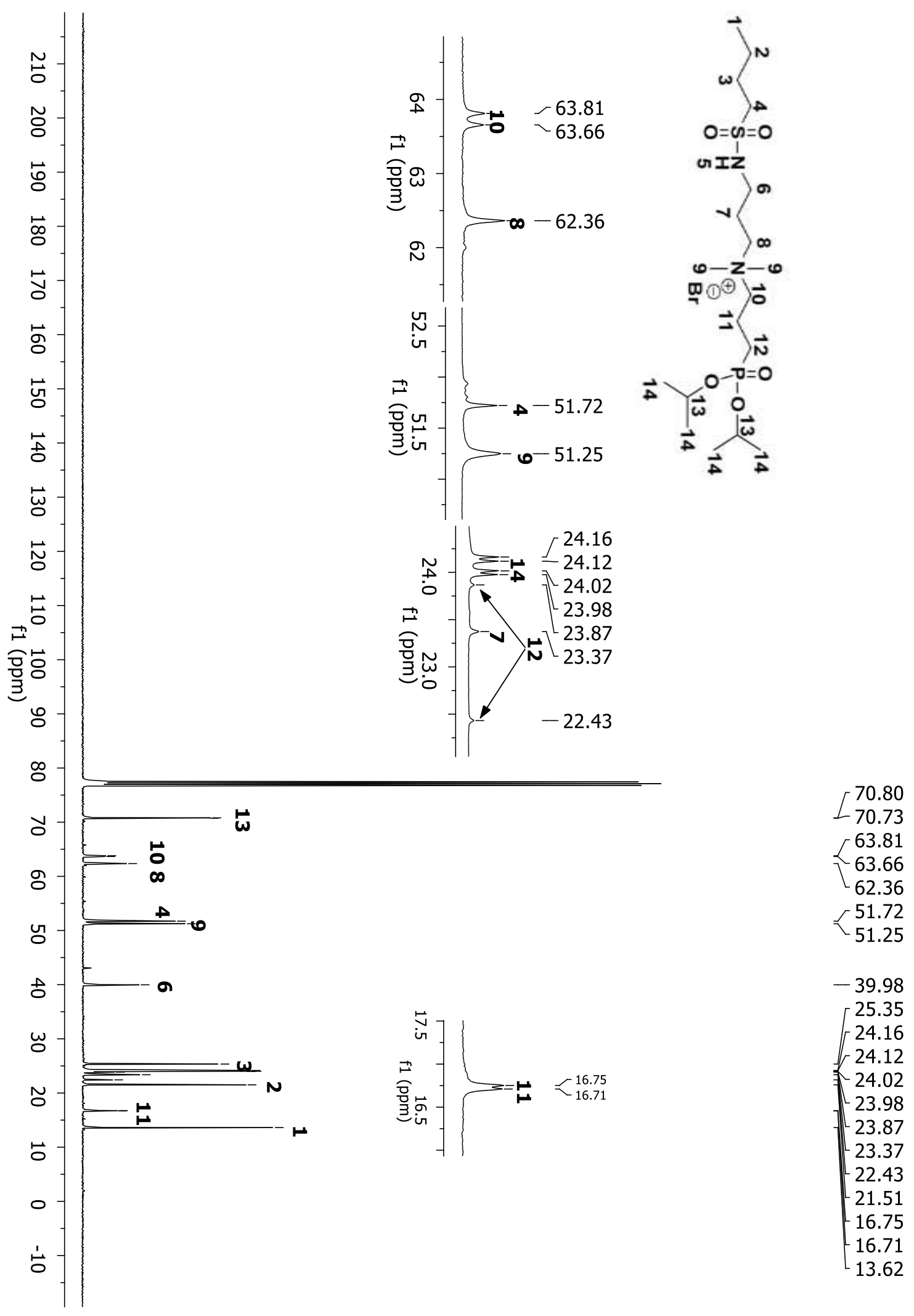

Figure A112: ${ }^{13} \mathrm{C}$ NMR spectrum of compound $8 \mathrm{H}$ in $\mathrm{CDCl}_{3}$. 


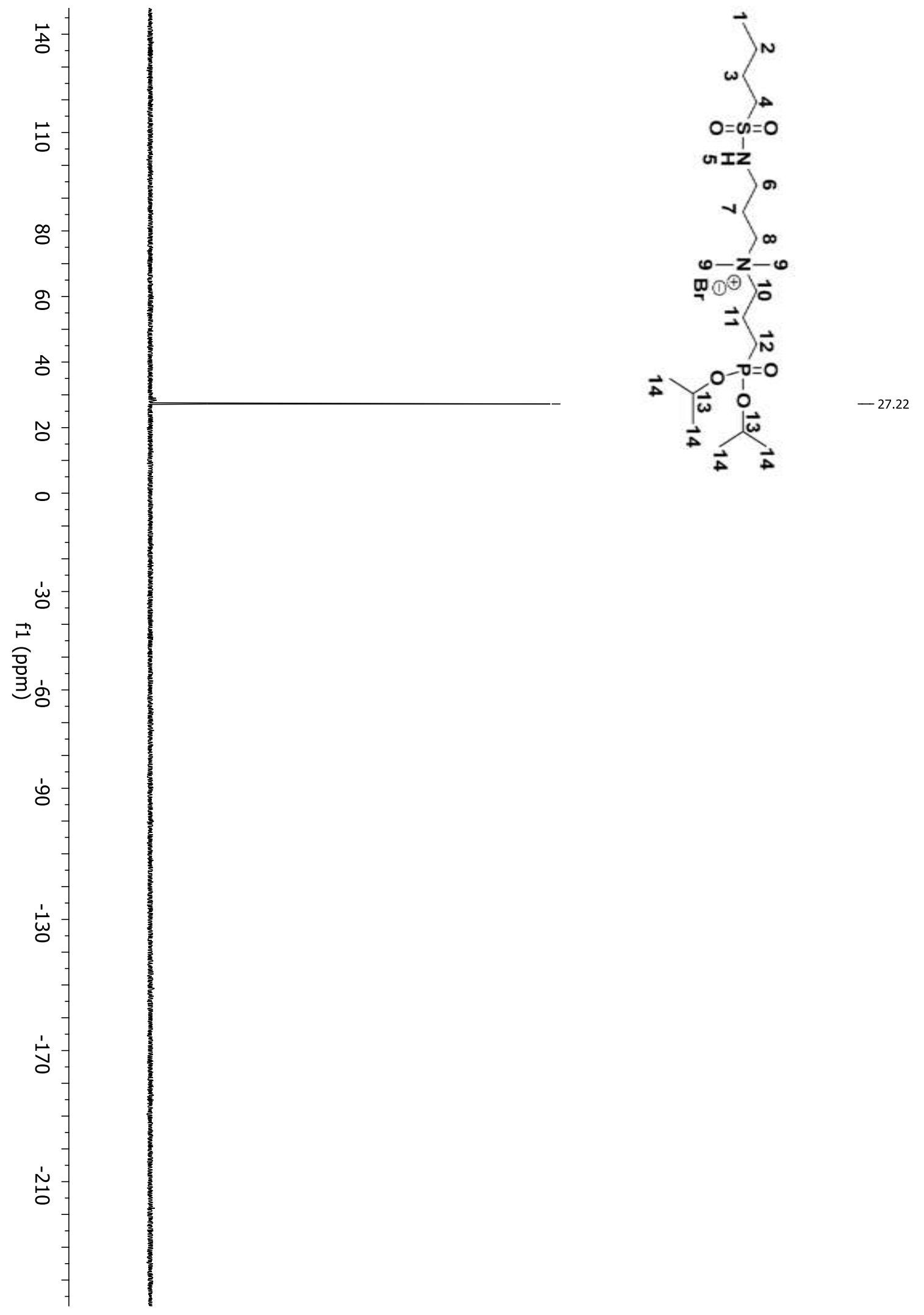

Figure A113: ${ }^{31} \mathrm{P}$ NMR spectrum of compound $\mathbf{8 H}$ in $\mathrm{CDCl}_{3}$. 


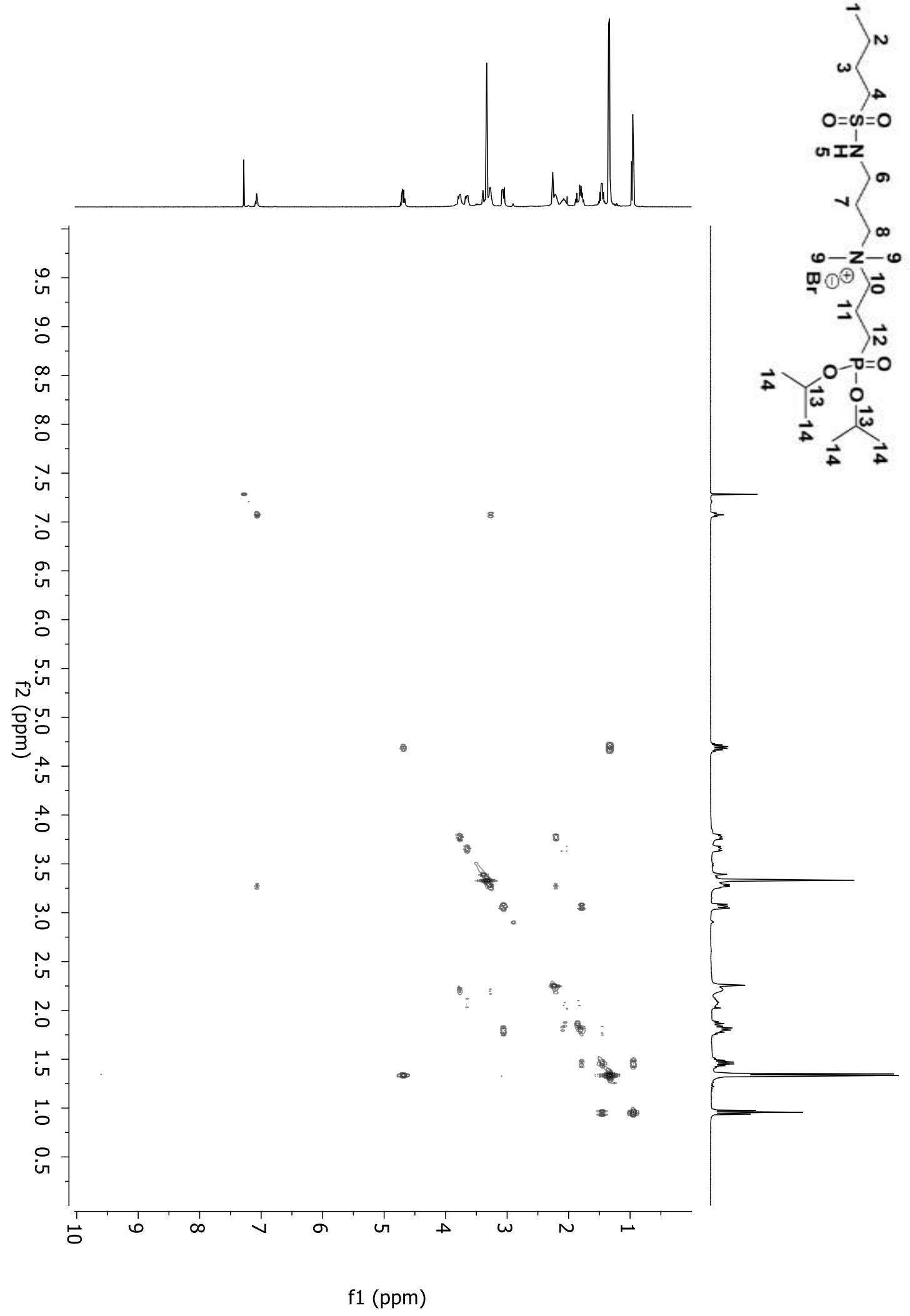

Figure A114: 2D COSY spectrum of compound $\mathbf{8 H}$ in $\mathrm{CDCl}_{3}$. 


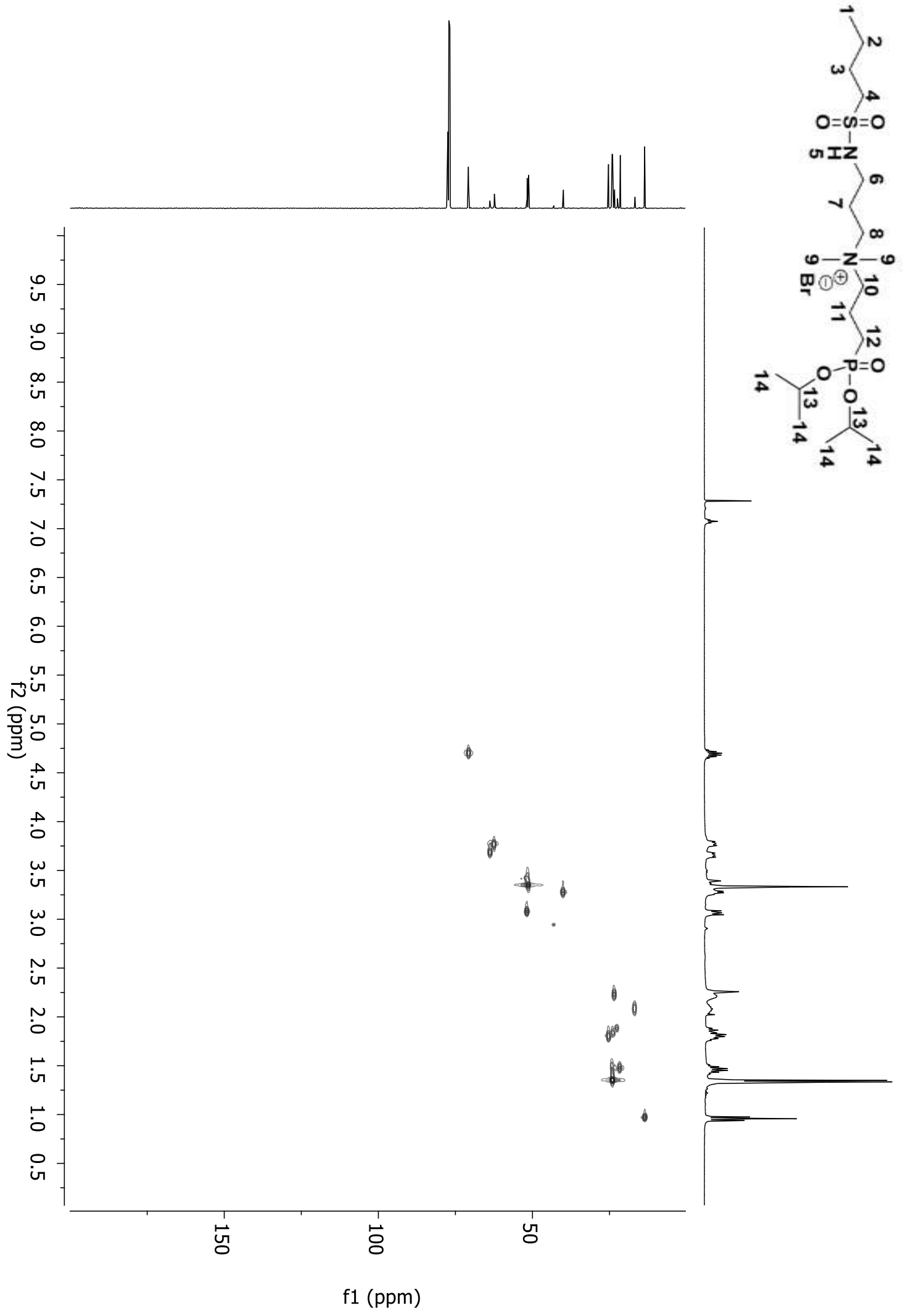

Figure A115: 2D HSQC spectrum of compound $\mathbf{8 H}$ in $\mathrm{CDCl}_{3}$. 


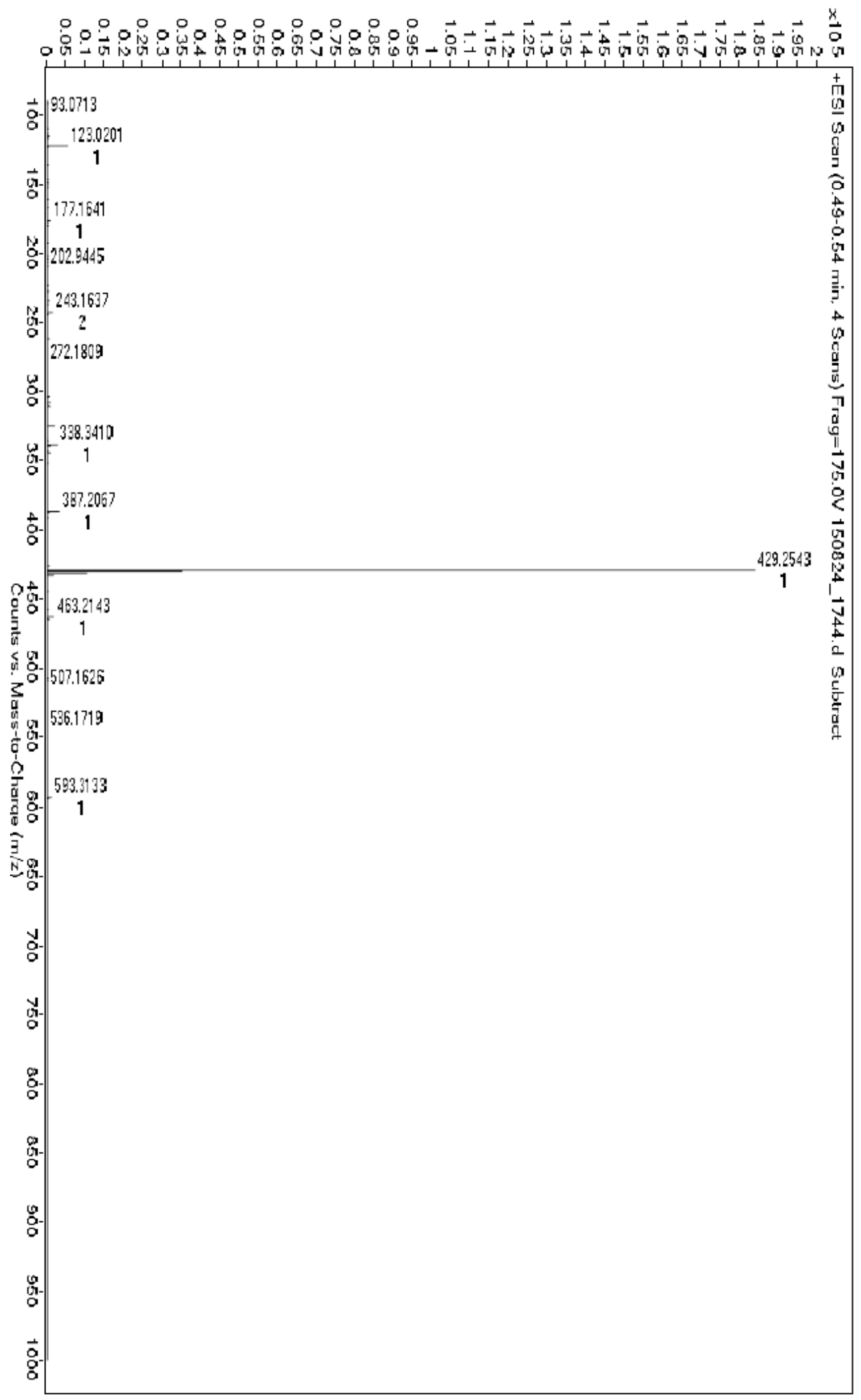

Figure A116: HRMS-ESI-TOF of compound $\mathbf{8 H}$. 


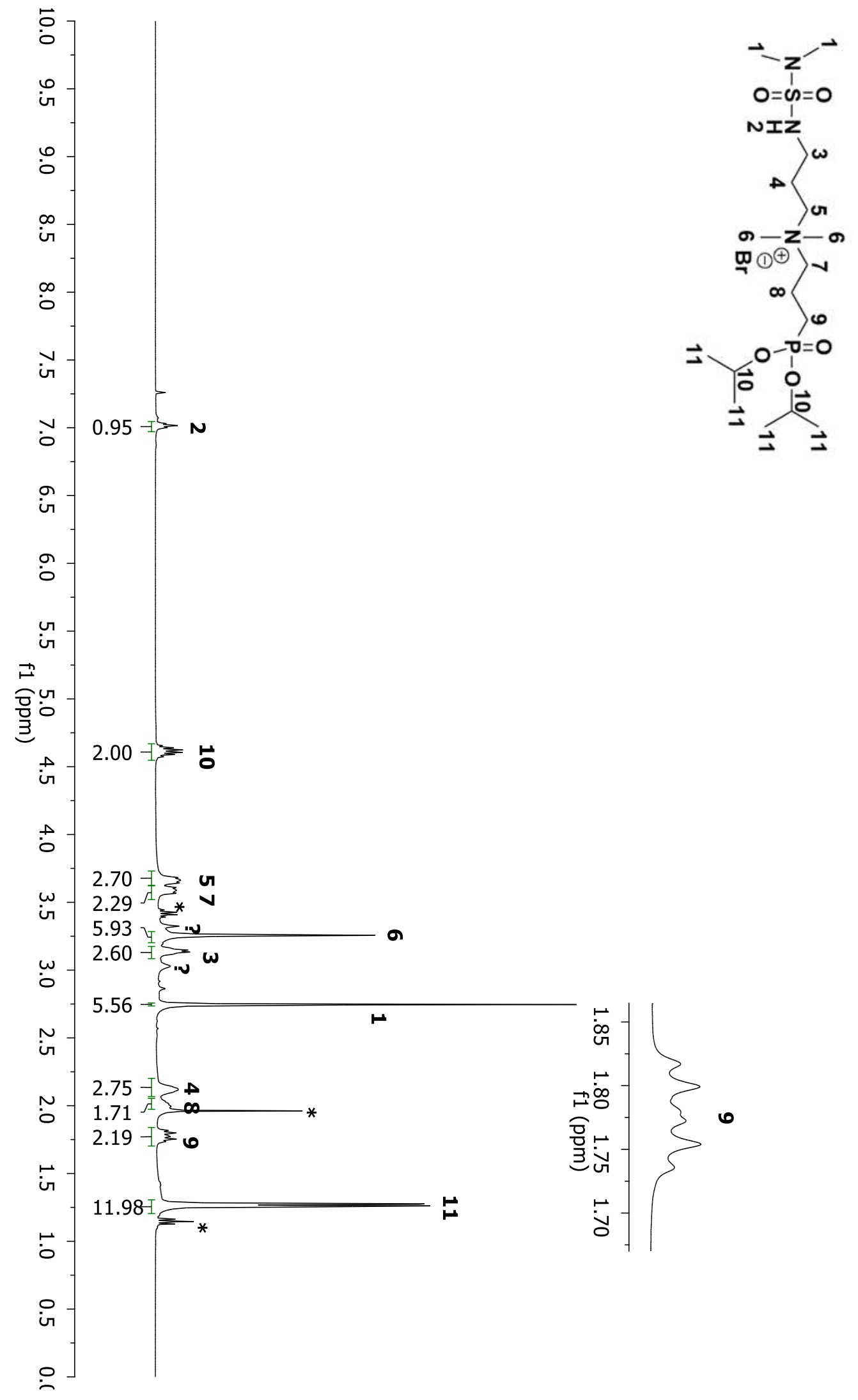

Figure A117: ${ }^{1} \mathrm{H}$ NMR spectrum of compound $9 \mathrm{H}$ in $\mathrm{CDCl}_{3}$. 


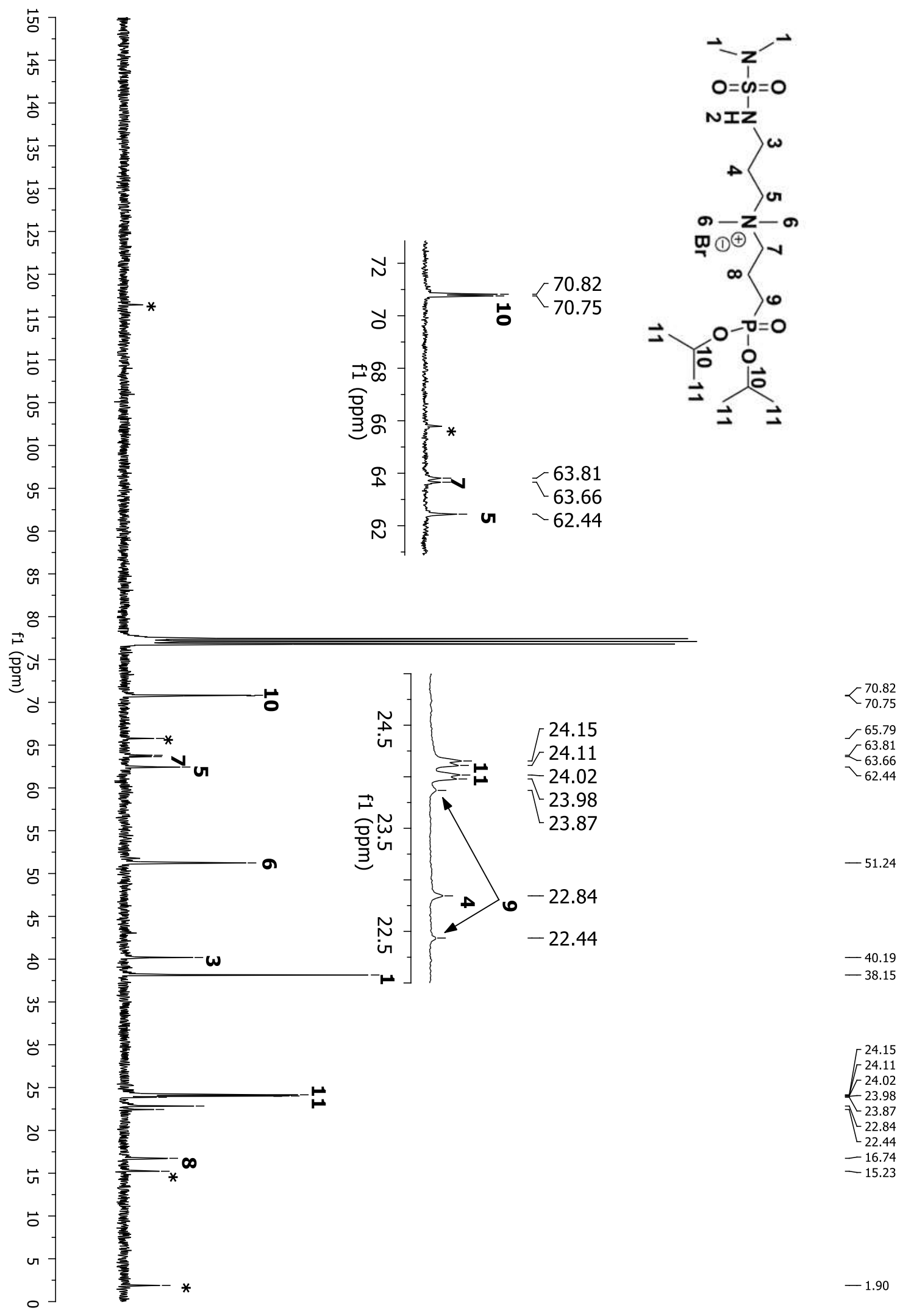

Figure A118: ${ }^{13} \mathrm{C}$ NMR spectrum of compound $9 \mathrm{H}$ in $\mathrm{CDCl}_{3}$. 


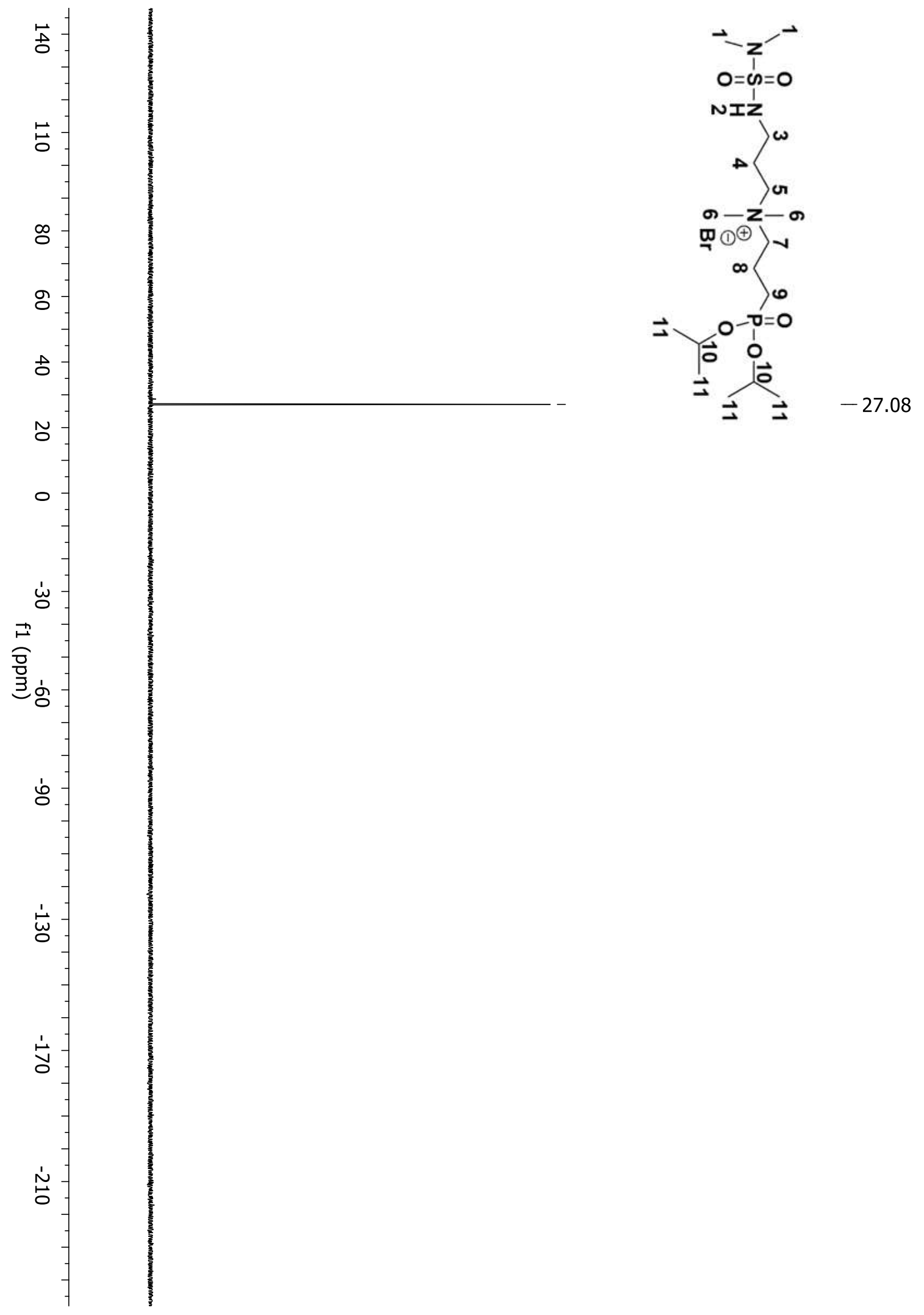

Figure A119: ${ }^{31} \mathrm{P}$ NMR spectrum of compound $9 \mathrm{H}$ in $\mathrm{CDCl}_{3}$. 


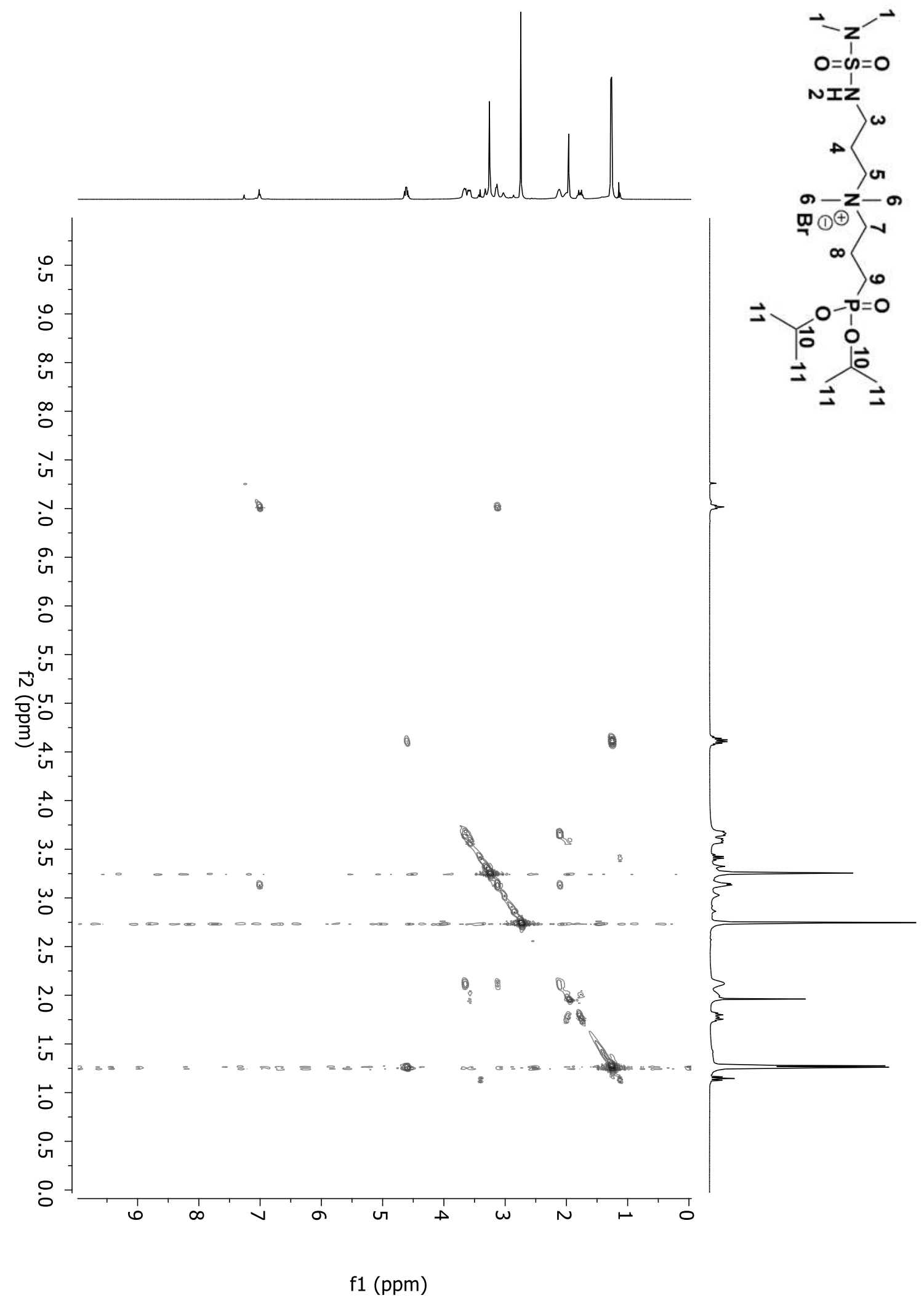

Figure A120: 2D COSY spectrum of compound $\mathbf{9 H}$ in $\mathrm{CDCl}_{3}$. 


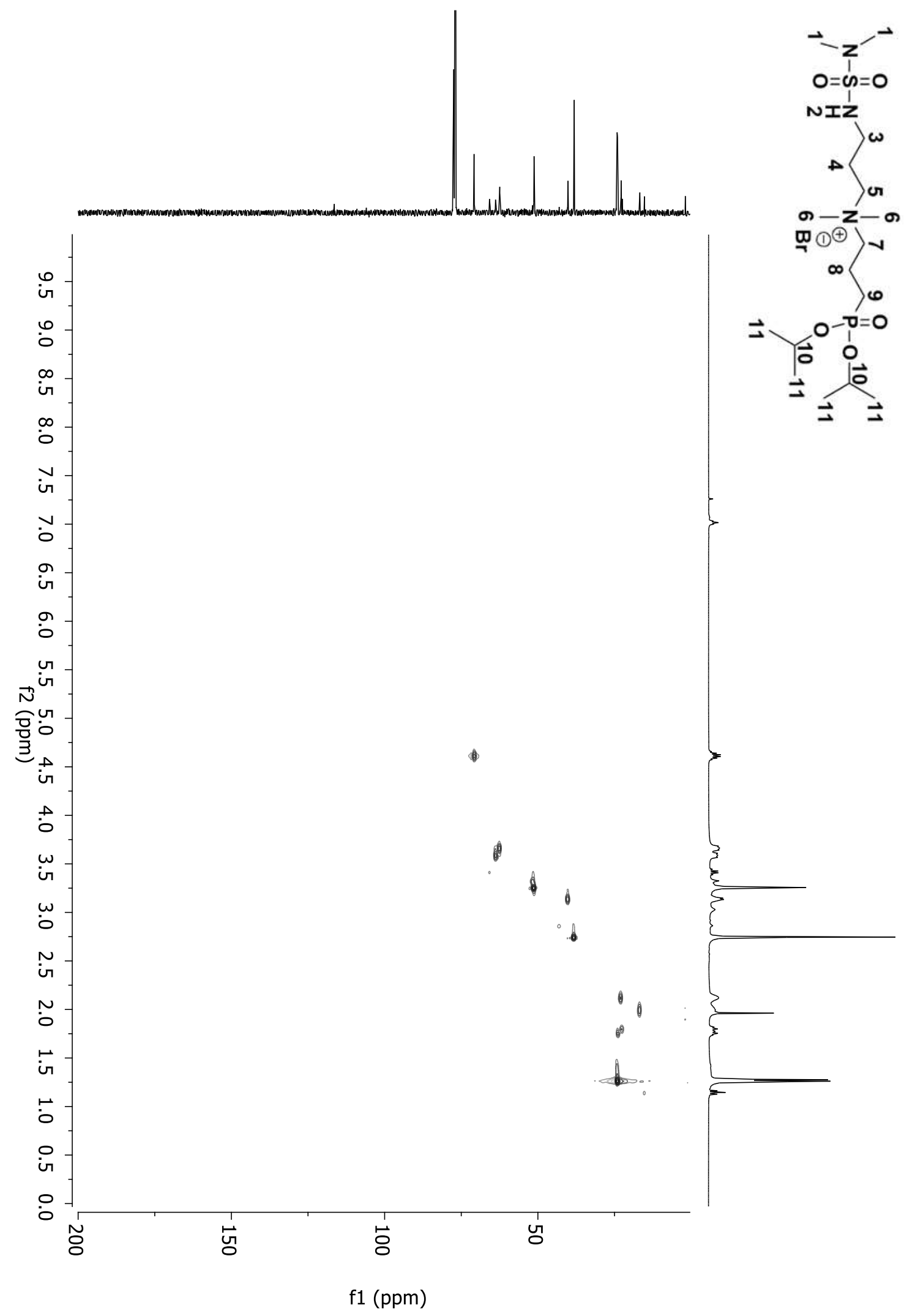

Figure A121: 2D HSQC spectrum of compound $9 \mathrm{H}$ in $\mathrm{CDCl}_{3}$. 


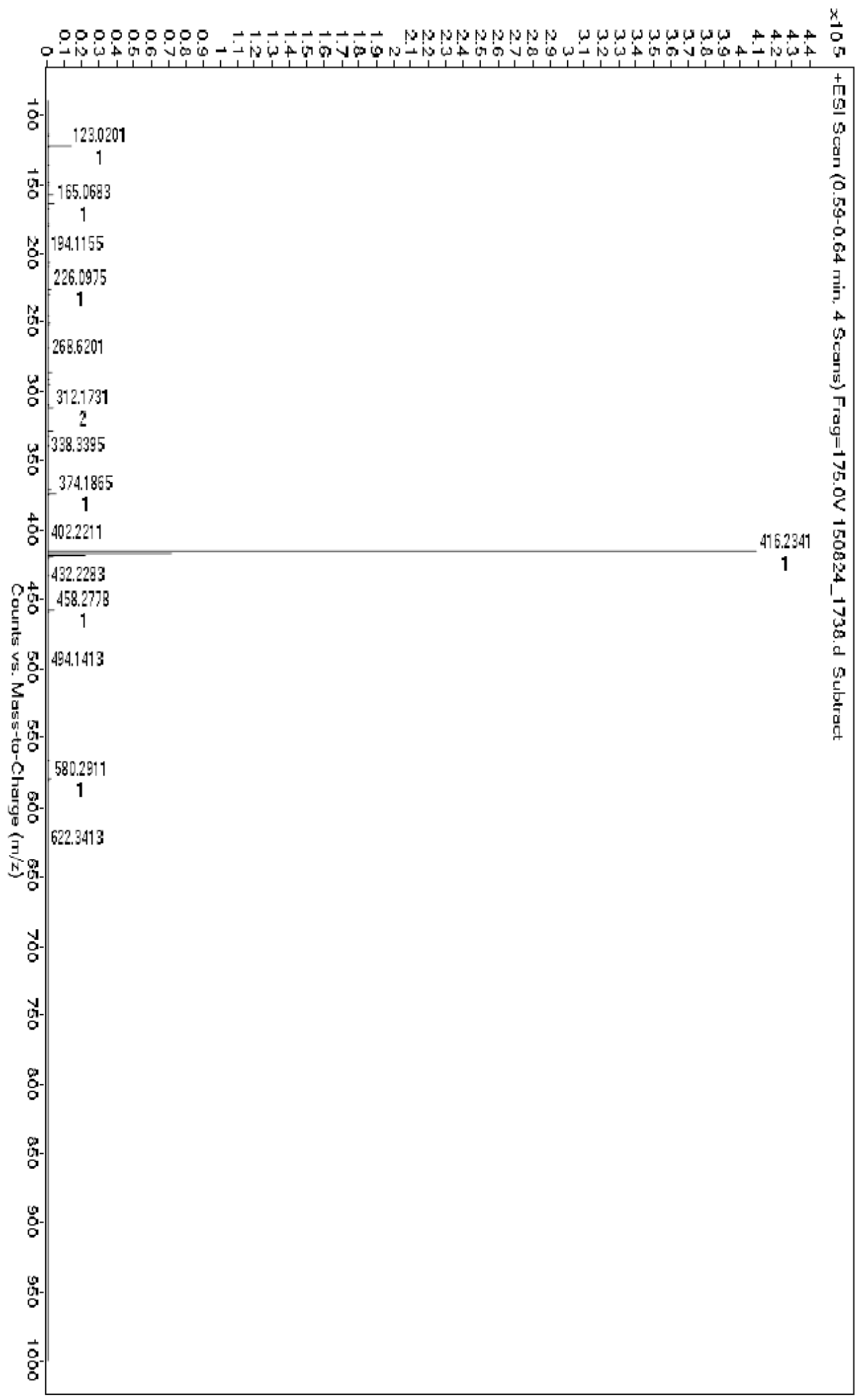

Figure A122: HRMS-ESI-TOF of compound 9H. 


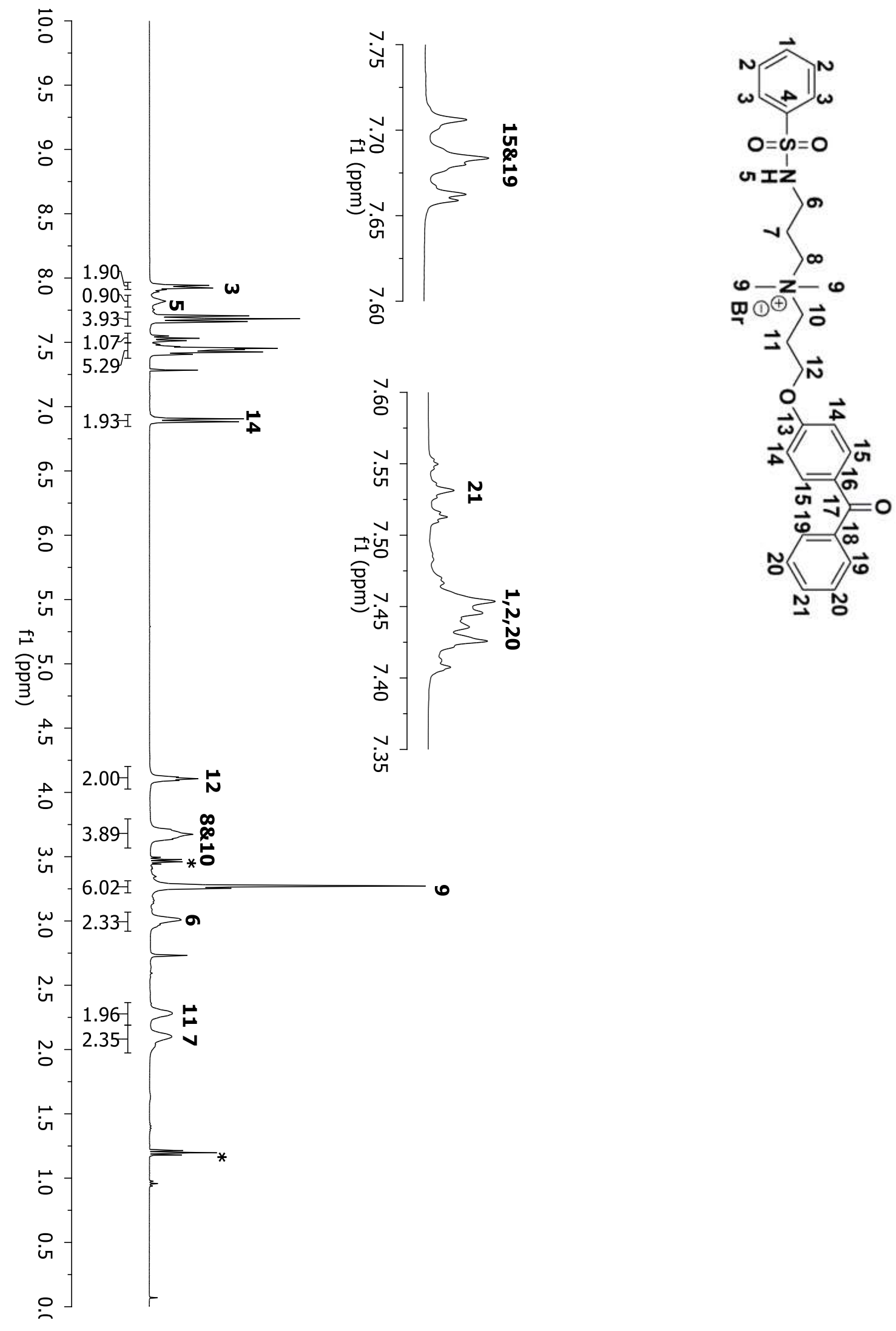

Figure A123: ${ }^{1} \mathrm{H}$ NMR spectrum of compound $\mathbf{1} \mathbf{J}$ in $\mathrm{CDCl}_{3}$. 


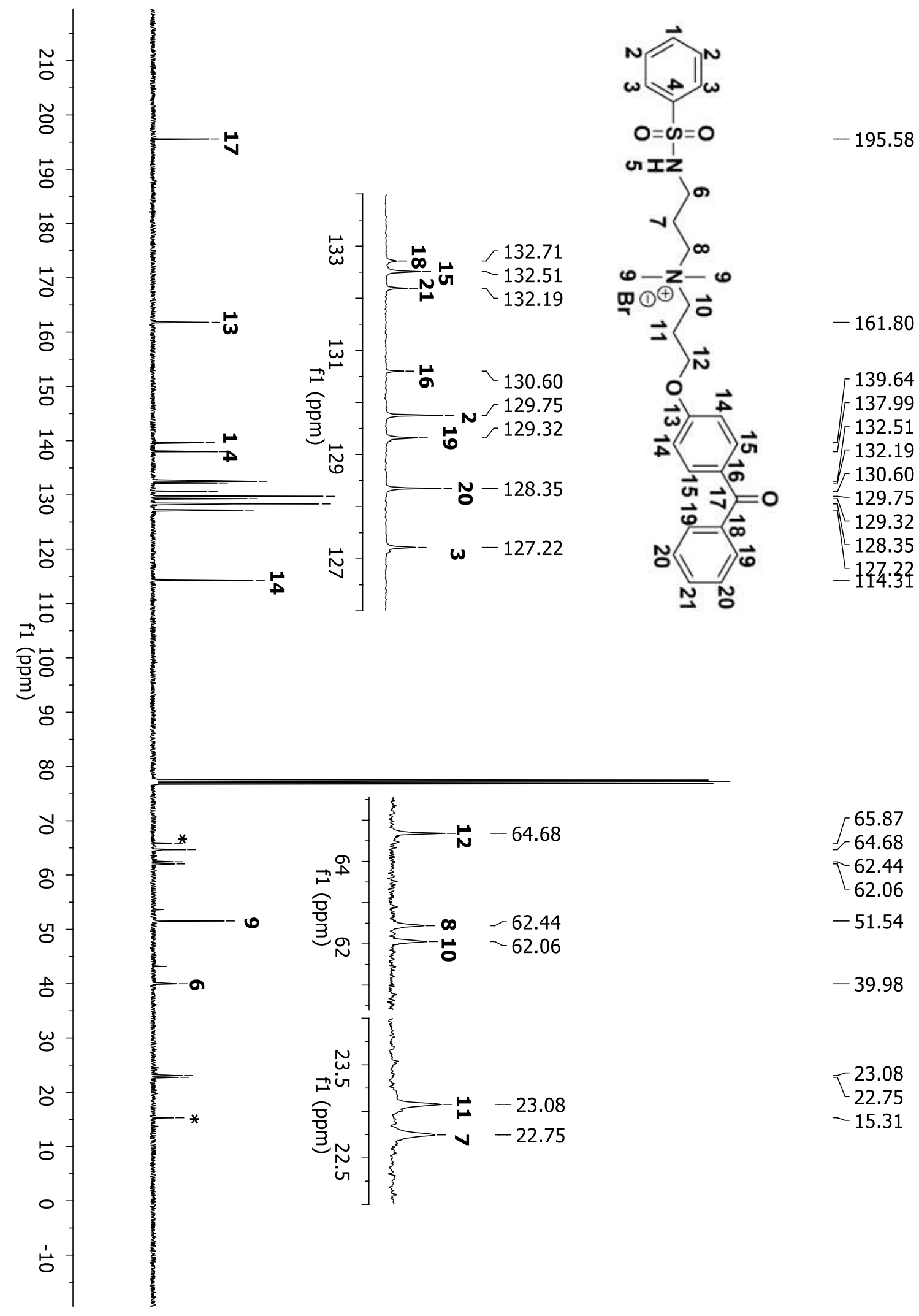

Figure A124: ${ }^{13} \mathrm{C}$ NMR spectrum of compound $\mathbf{1 J}$ in $\mathrm{CDCl}_{3}$. 


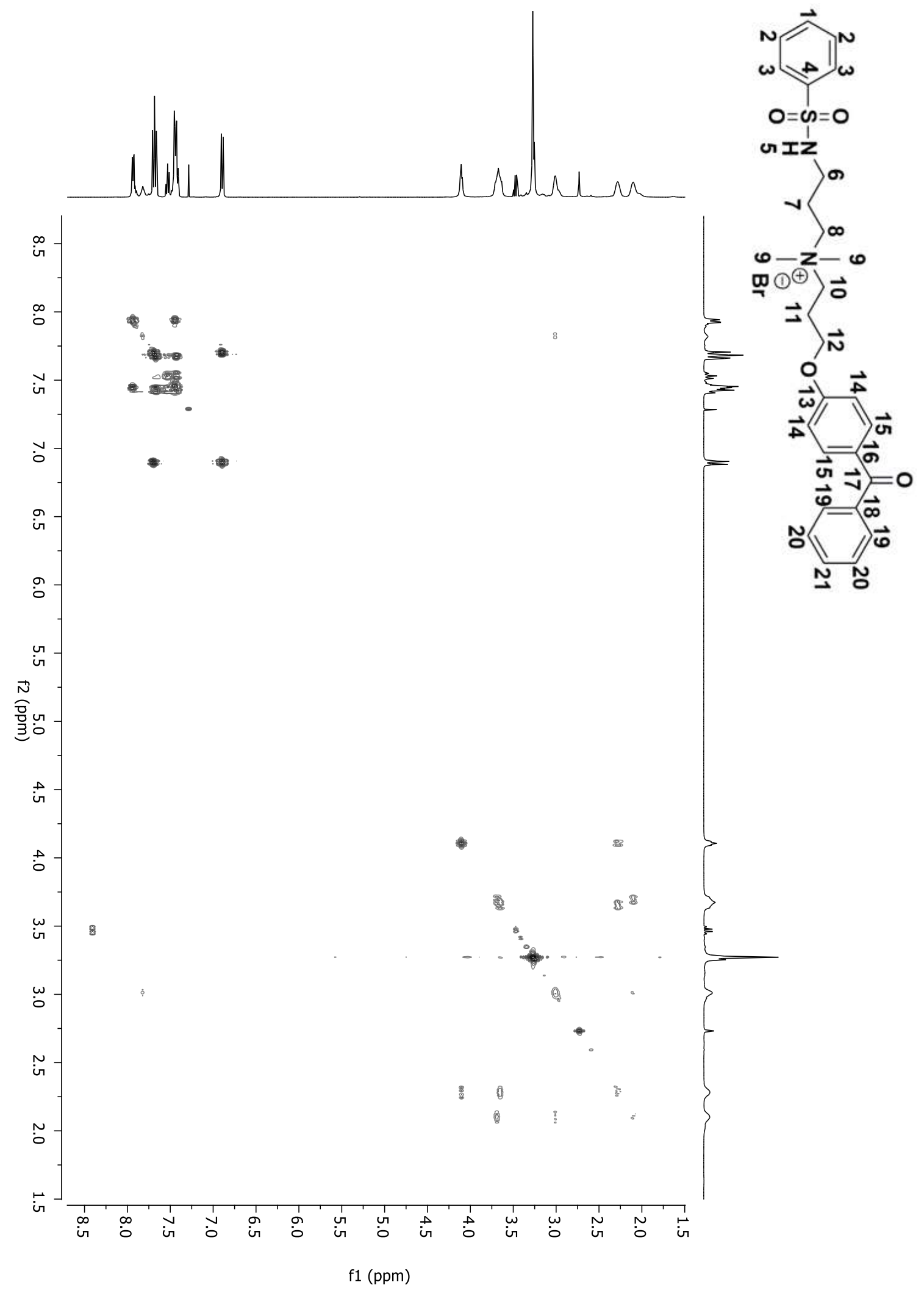

Figure A125: 2D COSY spectrum of compound $\mathbf{1 J}$ in $\mathrm{CDCl}_{3}$. 


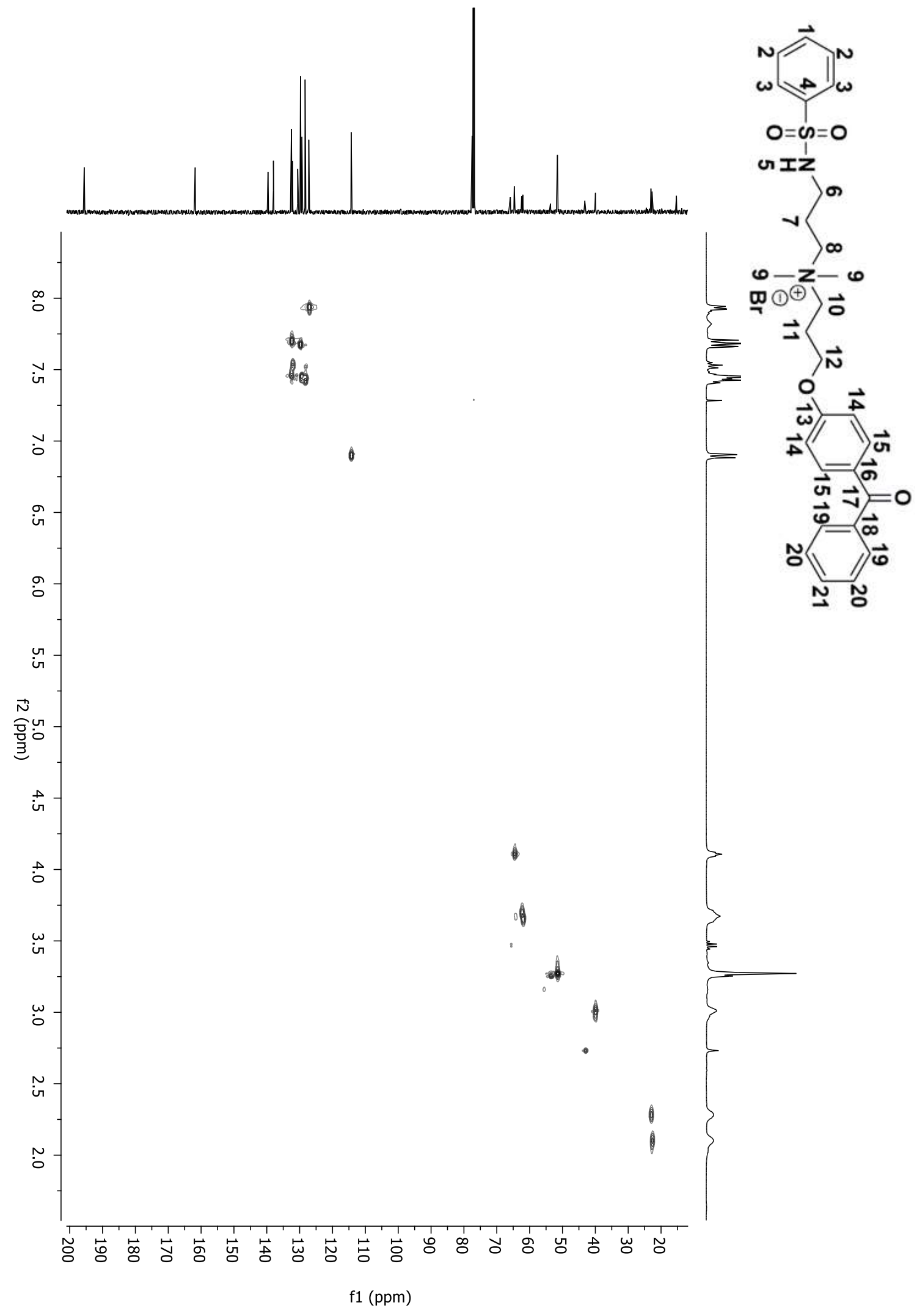

Figure A126: 2D HSQC spectrum of compound $\mathbf{1 J}$ in $\mathrm{CDCl}_{3}$. 


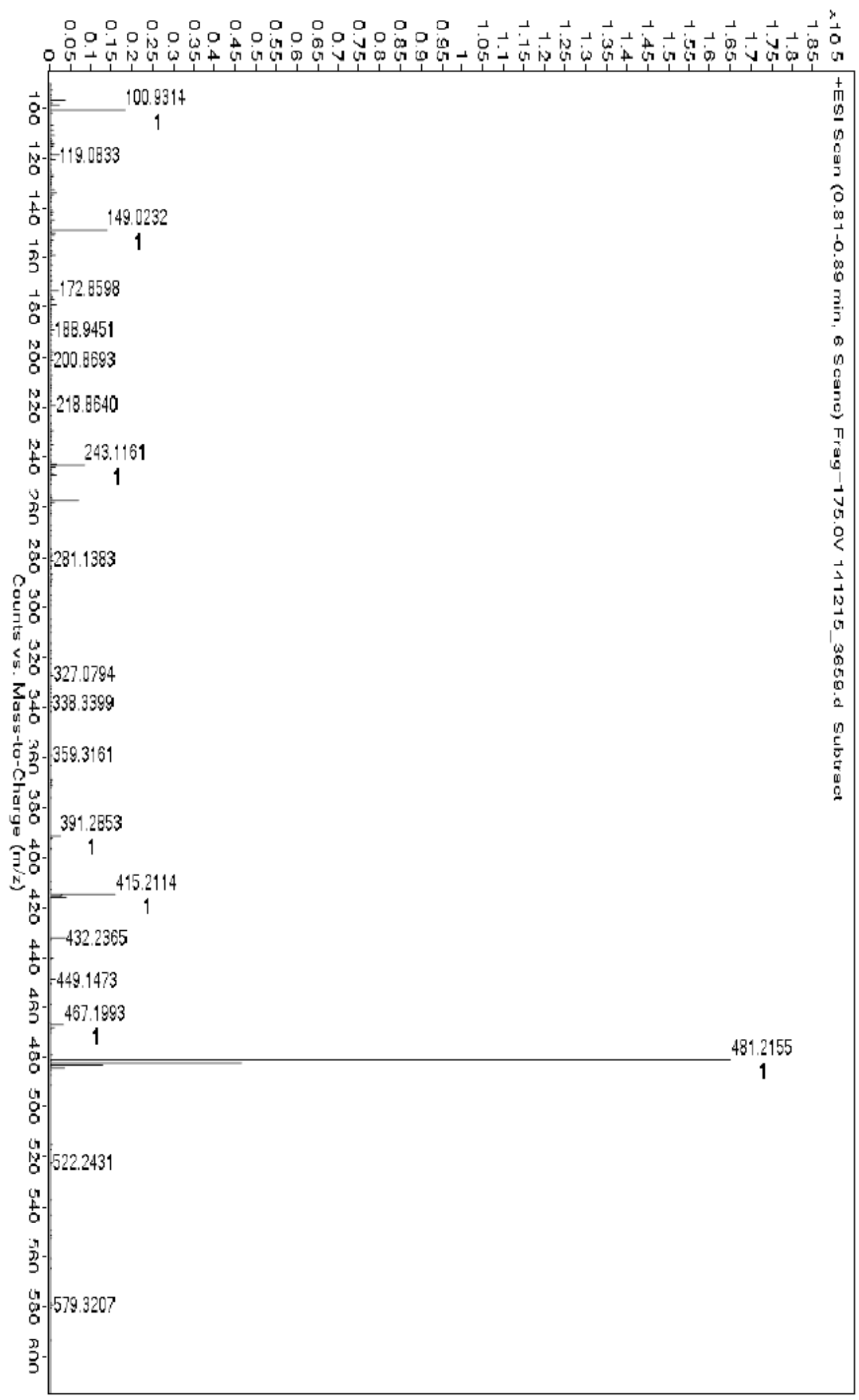

Figure A127: HRMS-ESI-TOF of compound 1J. 

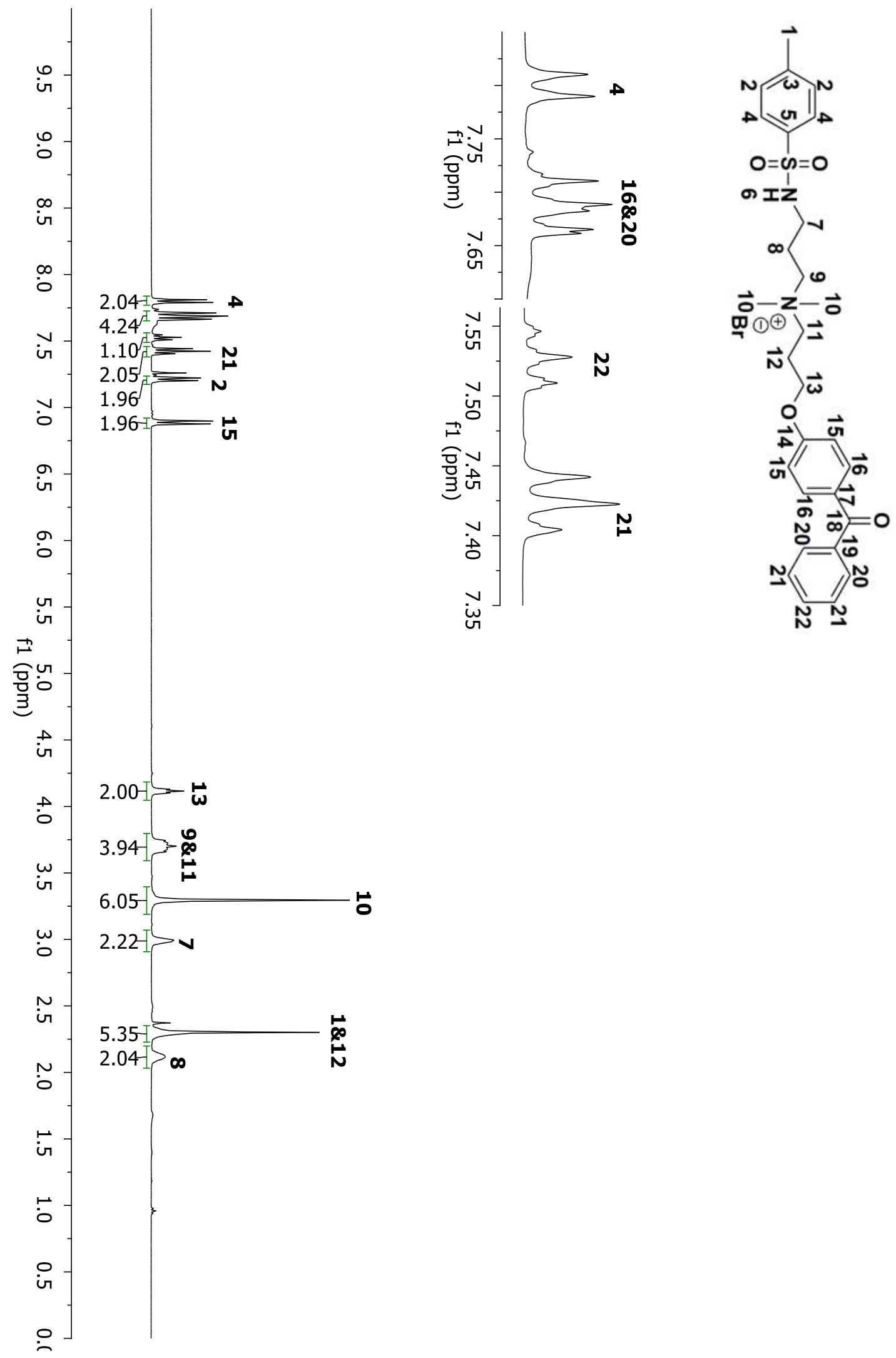

Figure A128: ${ }^{1} \mathrm{H}$ NMR spectrum of compound $\mathbf{2 J}$ in $\mathrm{CDCl}_{3}$. 


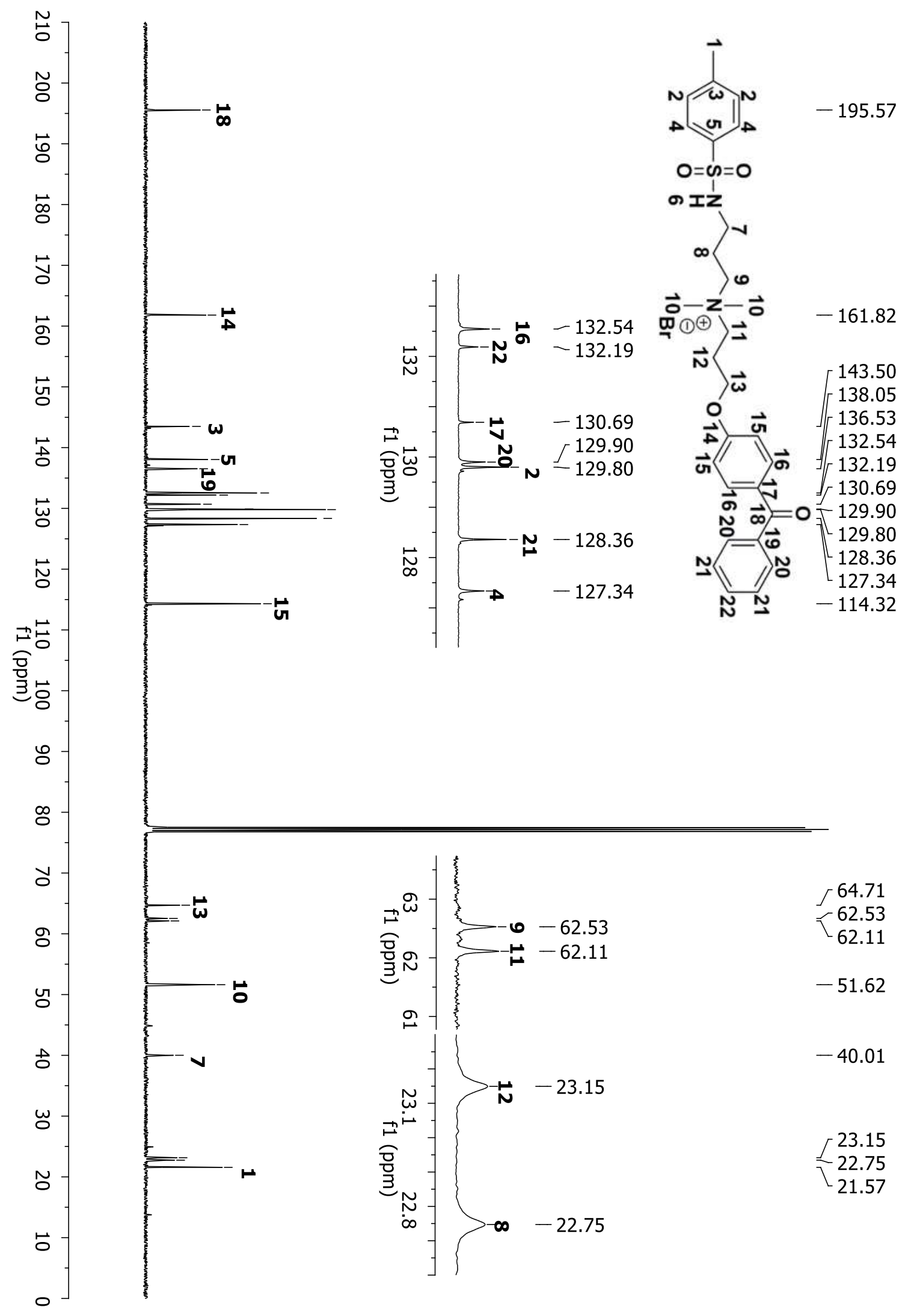

Figure A129: ${ }^{13} \mathrm{C}$ NMR spectrum of compound $\mathbf{2} \mathbf{J}$ in $\mathrm{CDCl}_{3}$. 


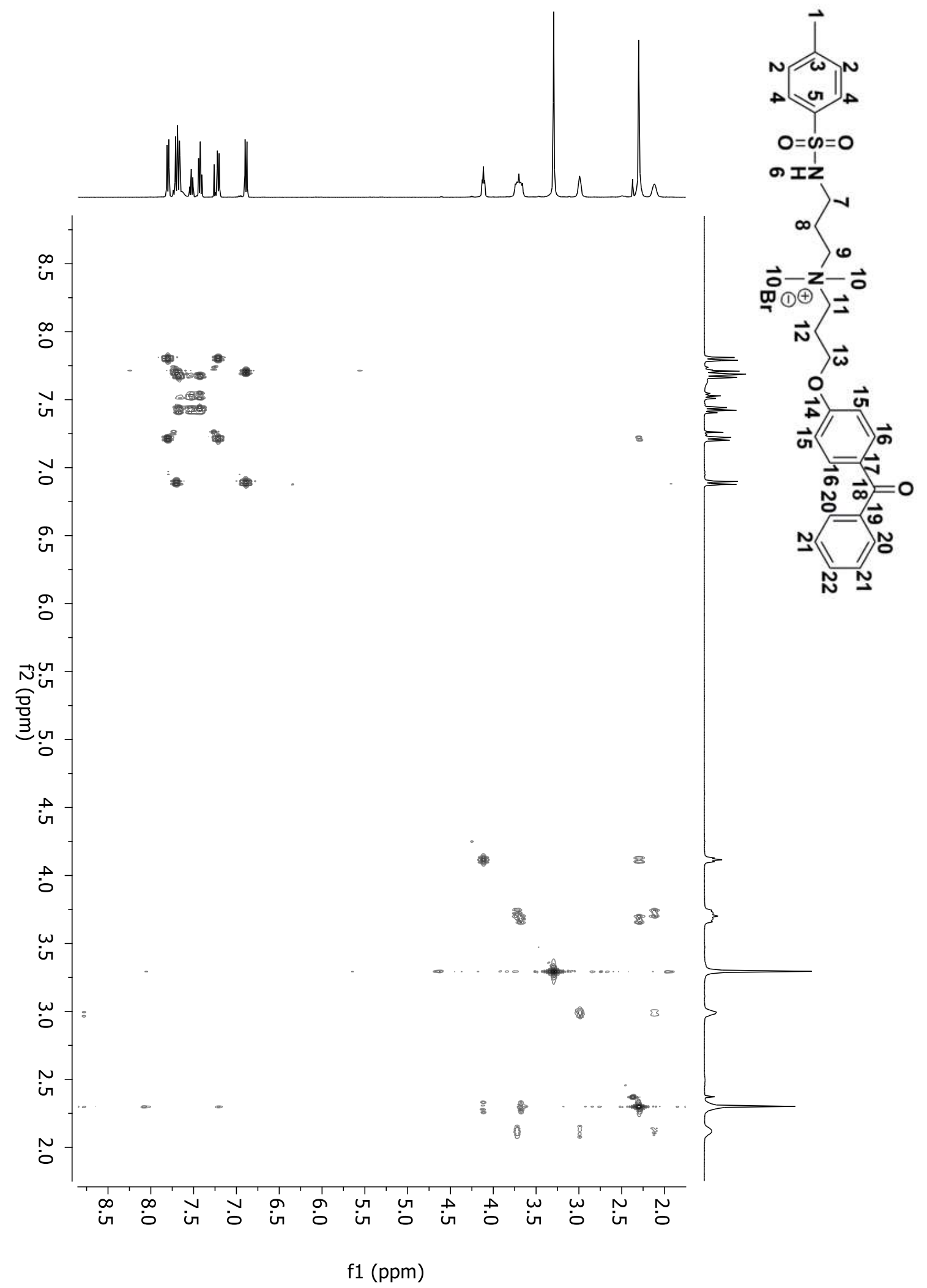

Figure A130: 2D COSY spectrum of compound $\mathbf{2} \mathbf{J}$ in $\mathrm{CDCl}_{3}$. 


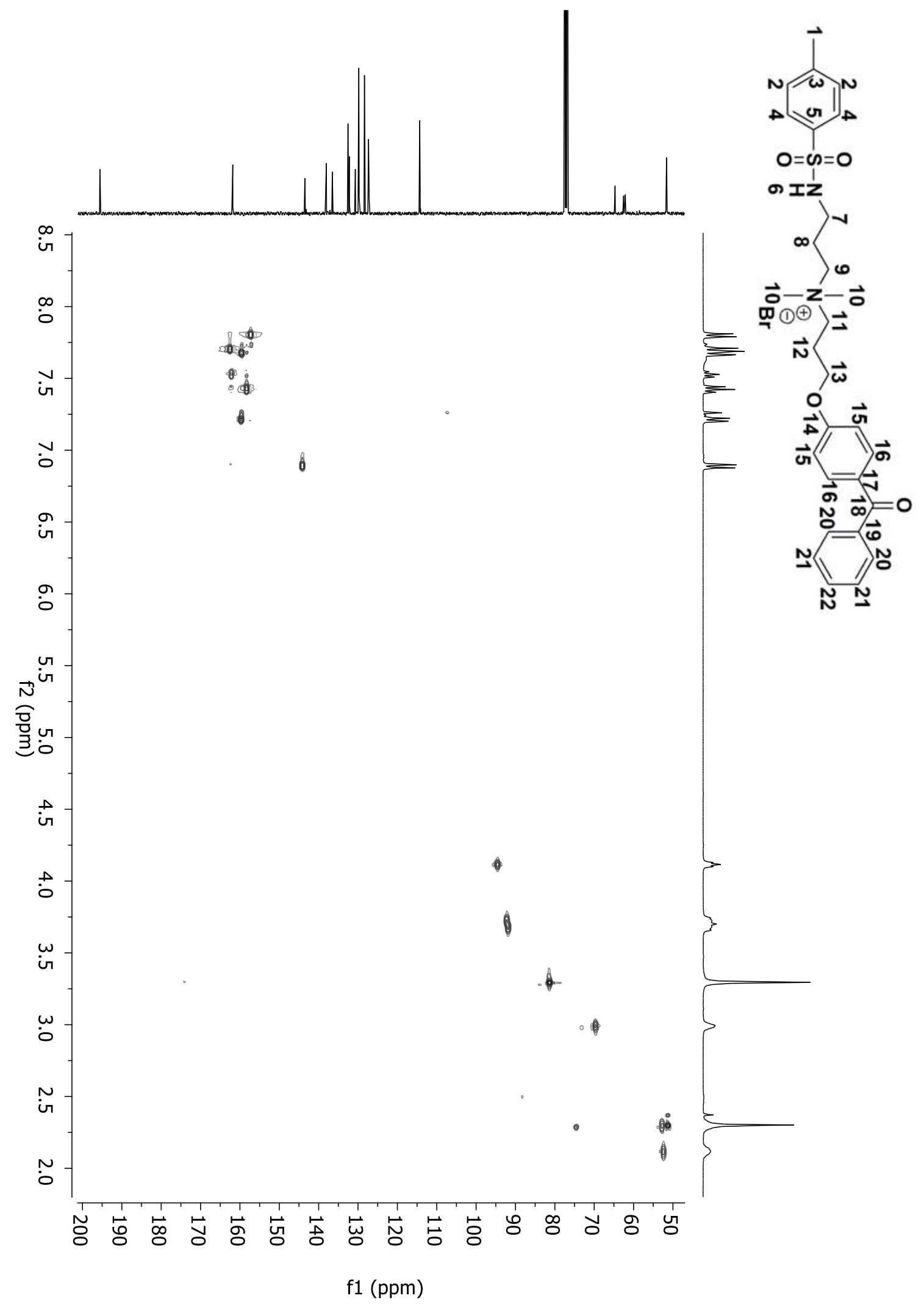

Figure A131: 2D HSQC spectrum of compound 2J in $\mathrm{CDCl}_{3}$. 


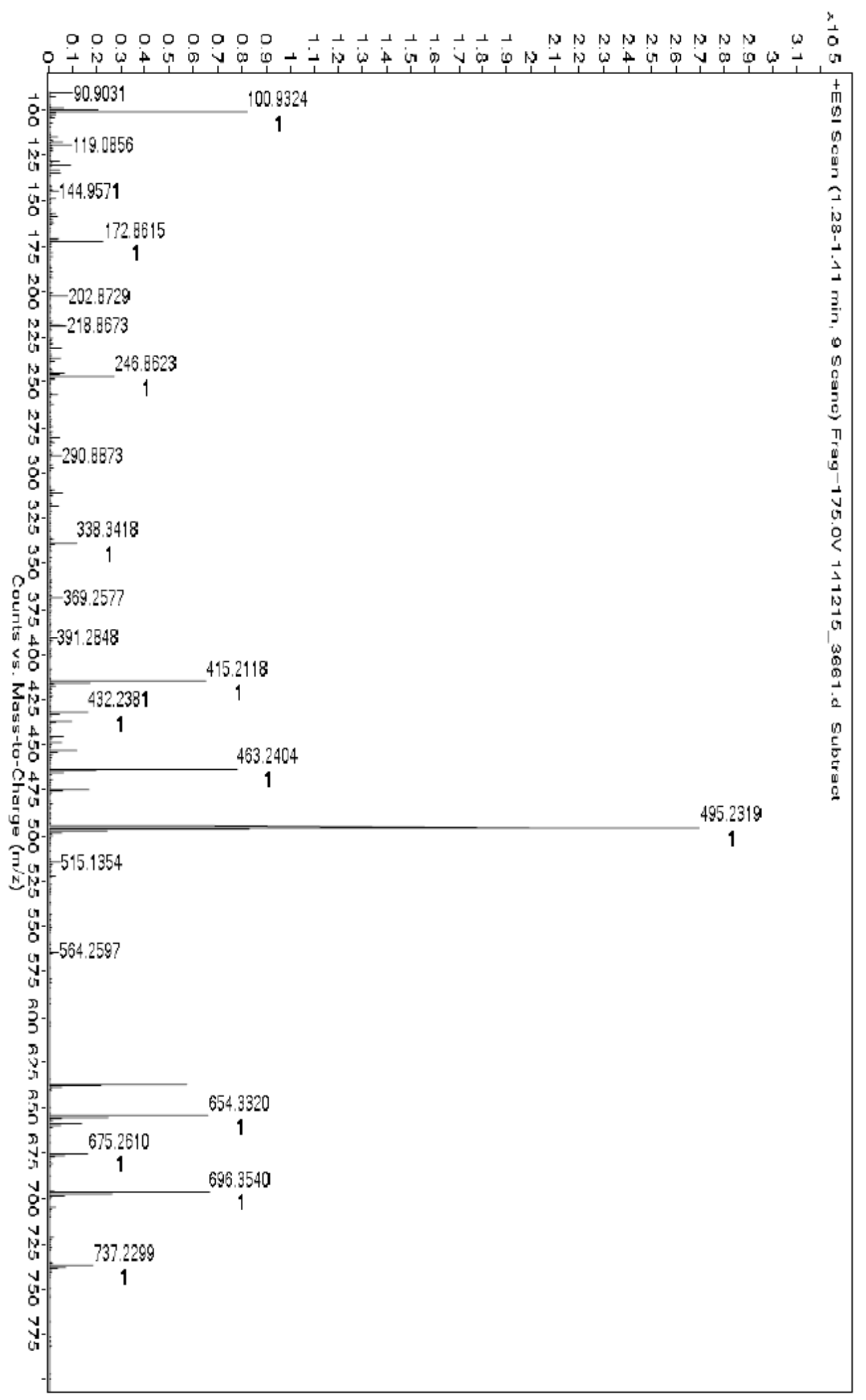

Figure A132: HRMS-ESI-TOF of compound 2J. 

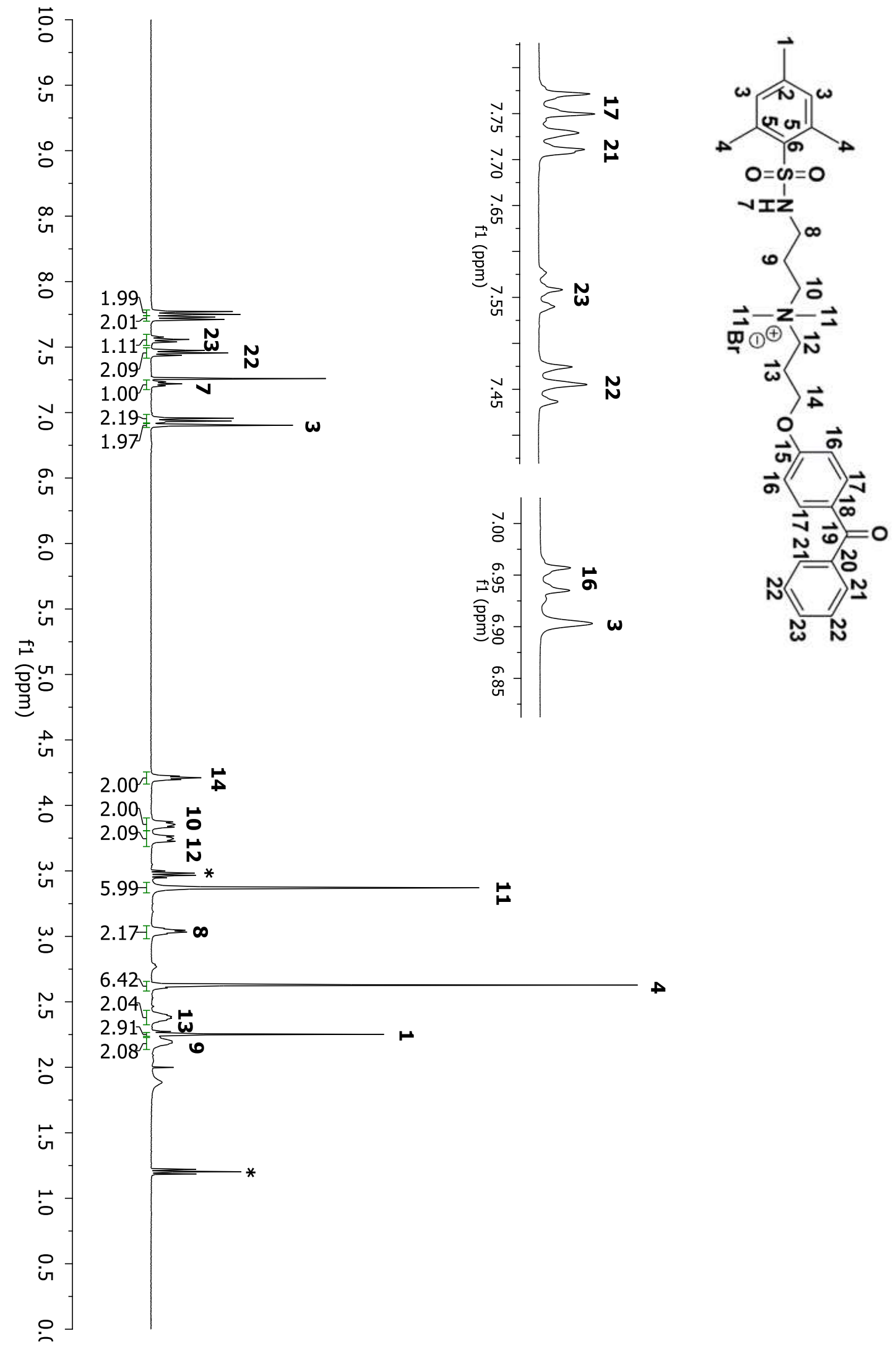

Figure A133: ${ }^{1} \mathrm{H}$ NMR spectrum of compound $\mathbf{3 J}$ in $\mathrm{CDCl}_{3}$. 


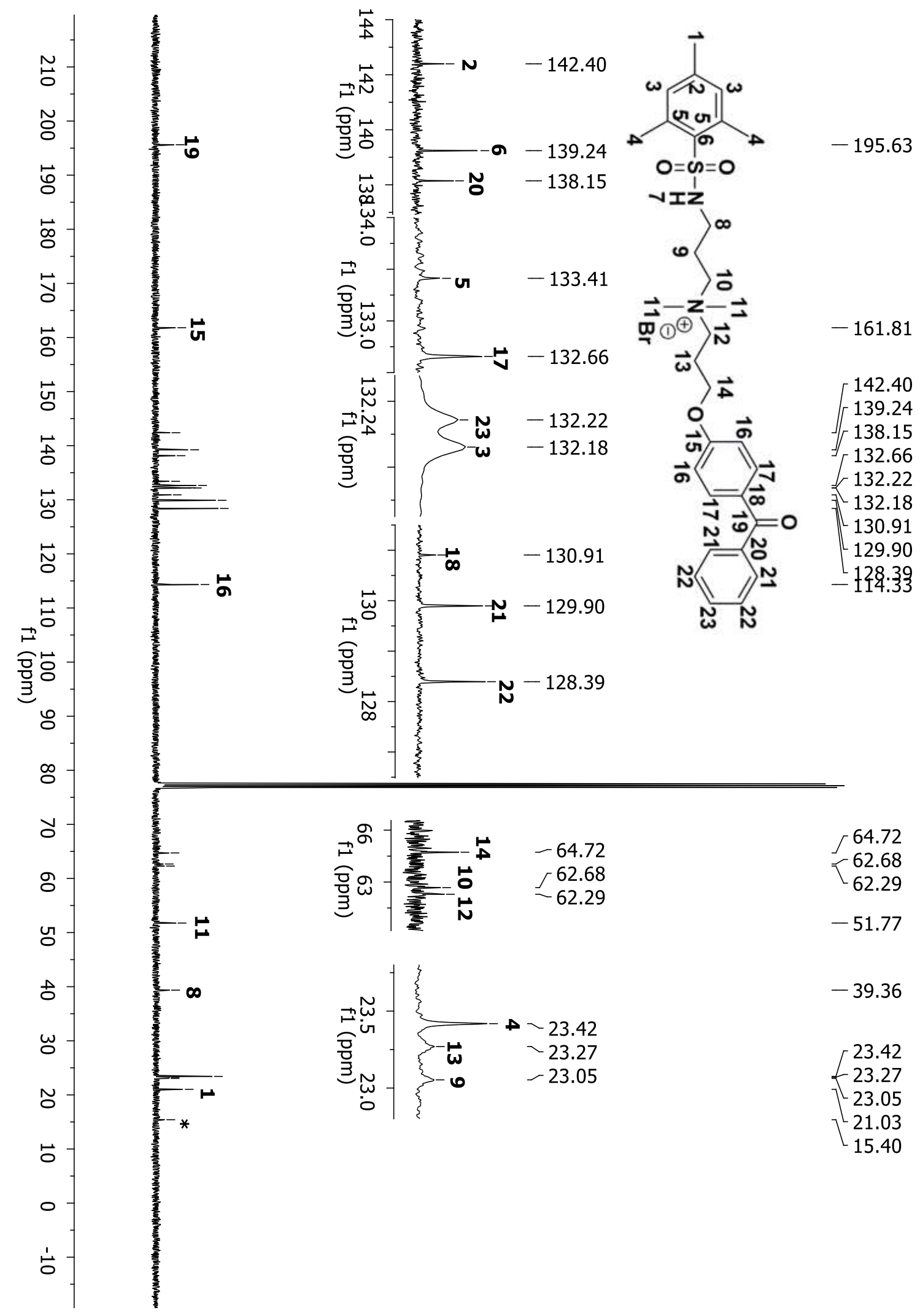

Figure A134: ${ }^{13} \mathrm{C}$ NMR spectrum of compound $3 \mathrm{~J}$ in $\mathrm{CDCl}_{3}$. 


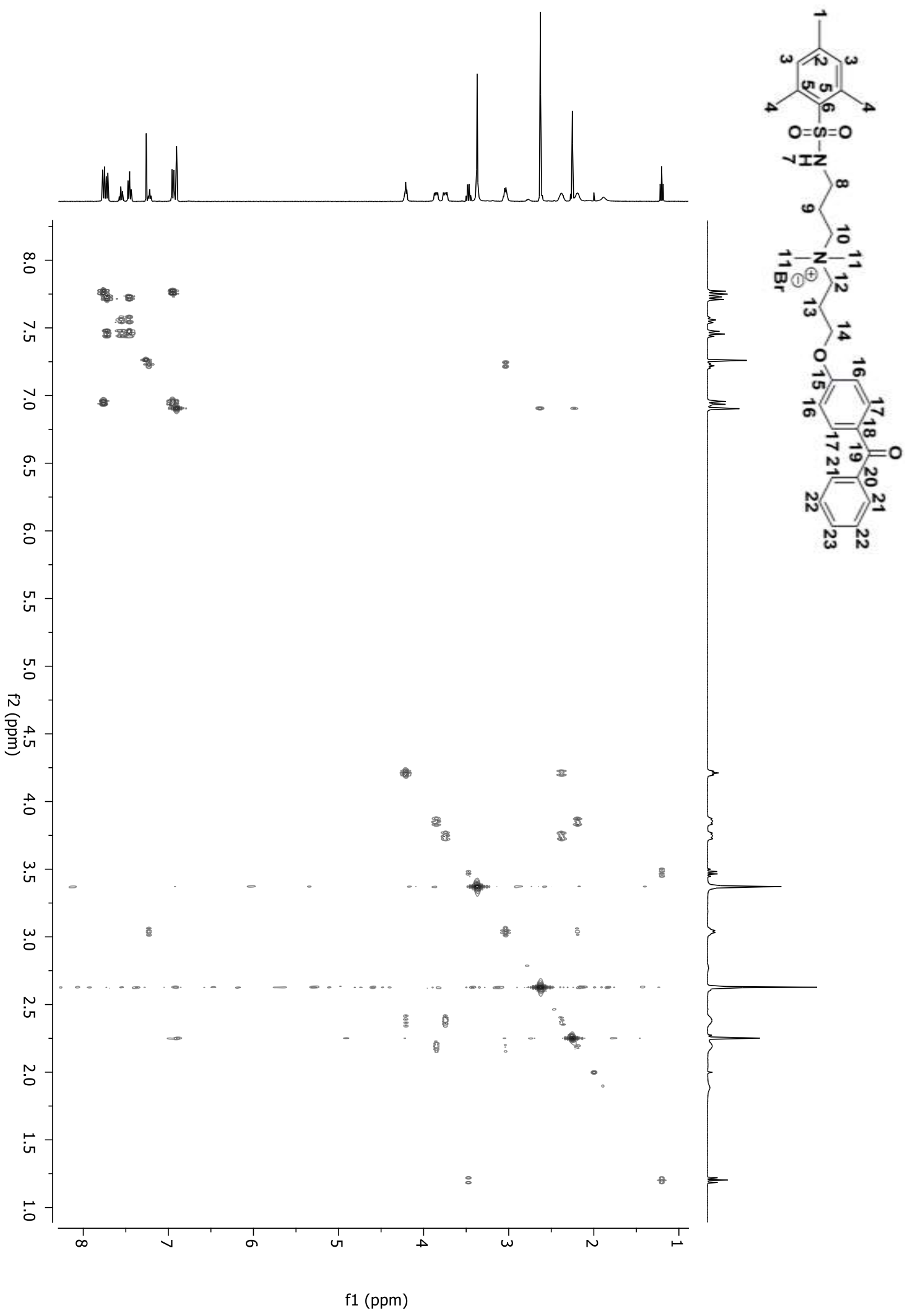

Figure A135: 2D COSY spectrum of compound 3J in $\mathrm{CDCl}_{3}$. 


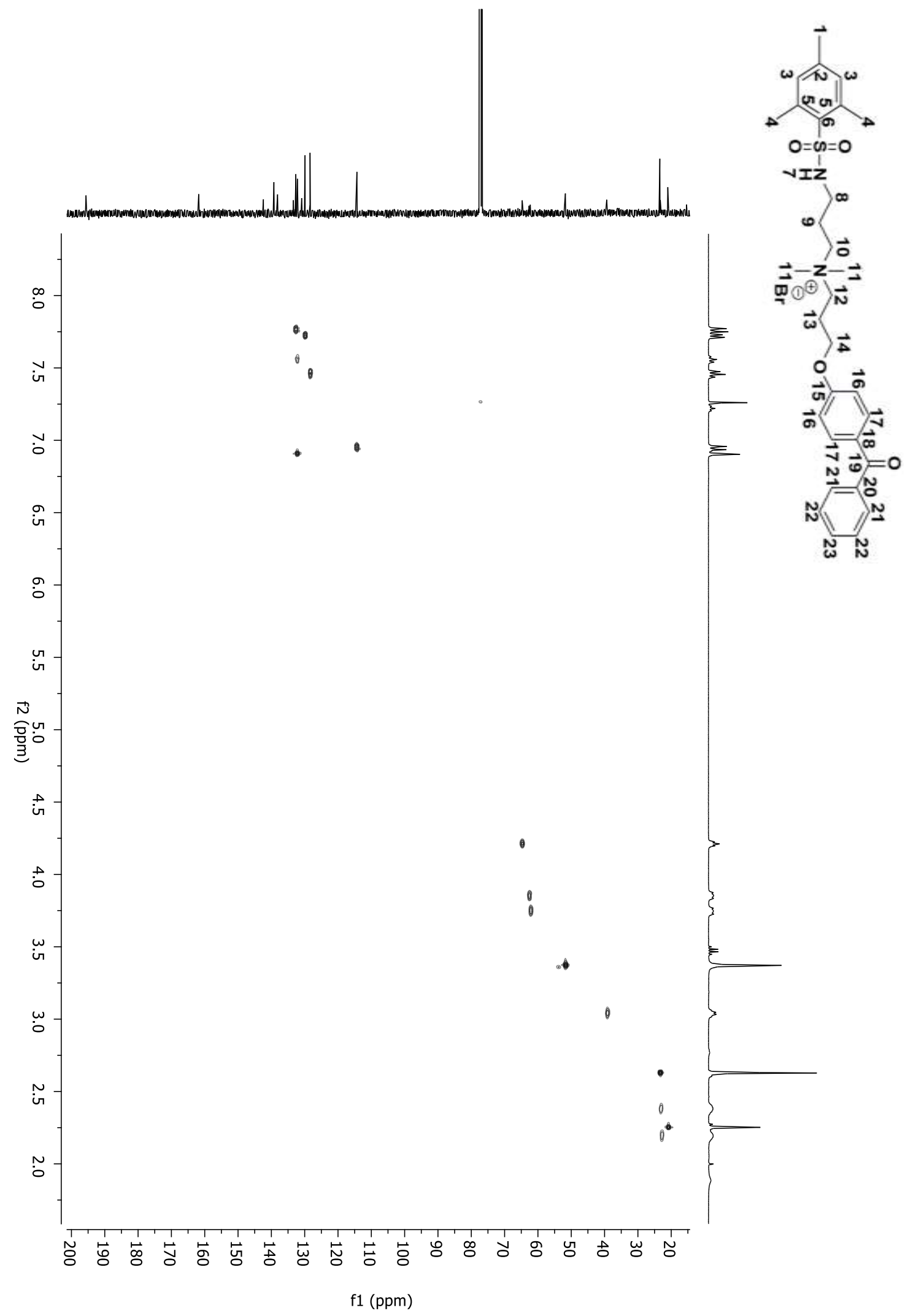

Figure A136: 2D HSQC spectrum of compound $\mathbf{3 J}$ in $\mathrm{CDCl}_{3}$. 


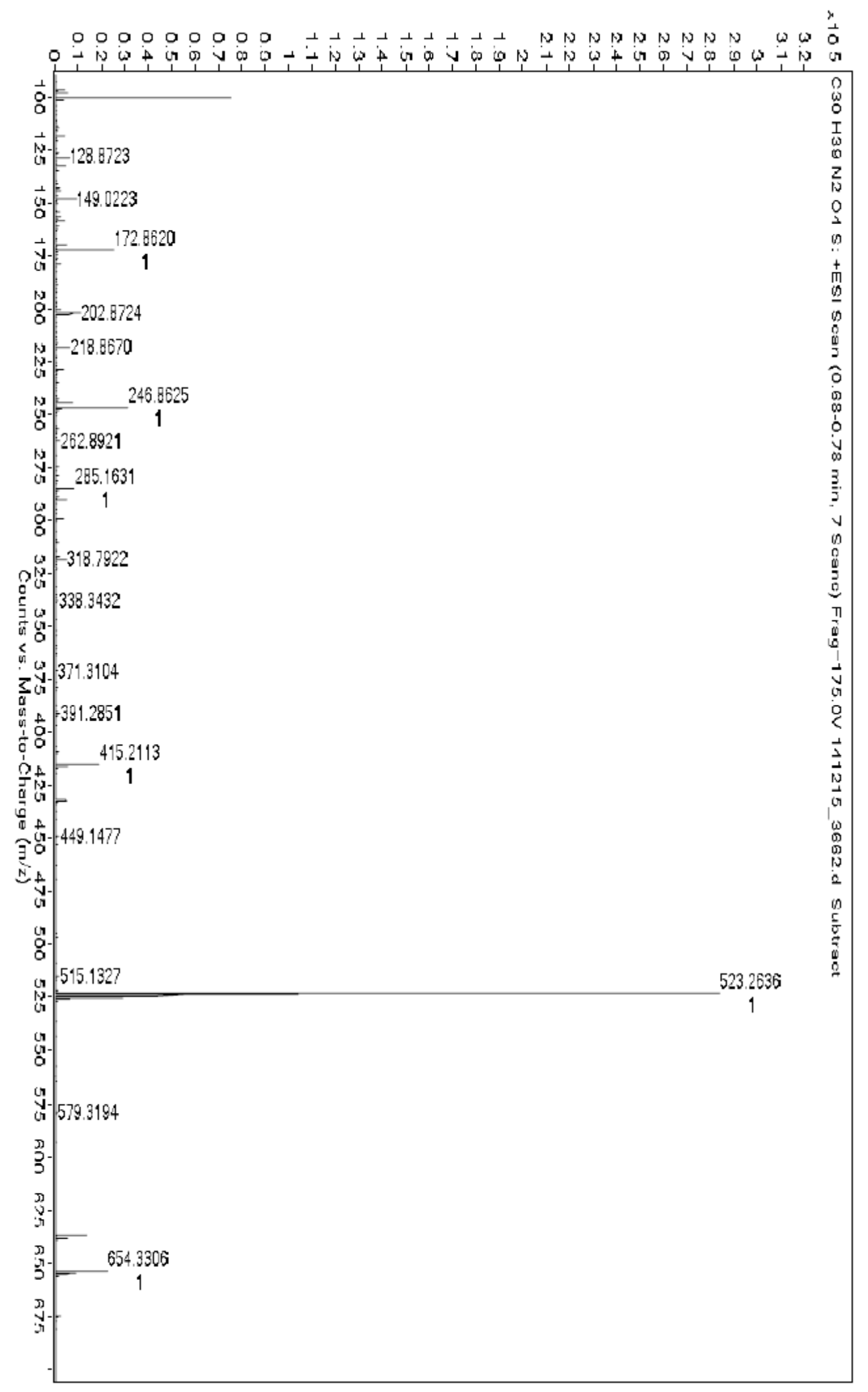

Figure A137: HRMS-ESI-TOF of compound 3J. 

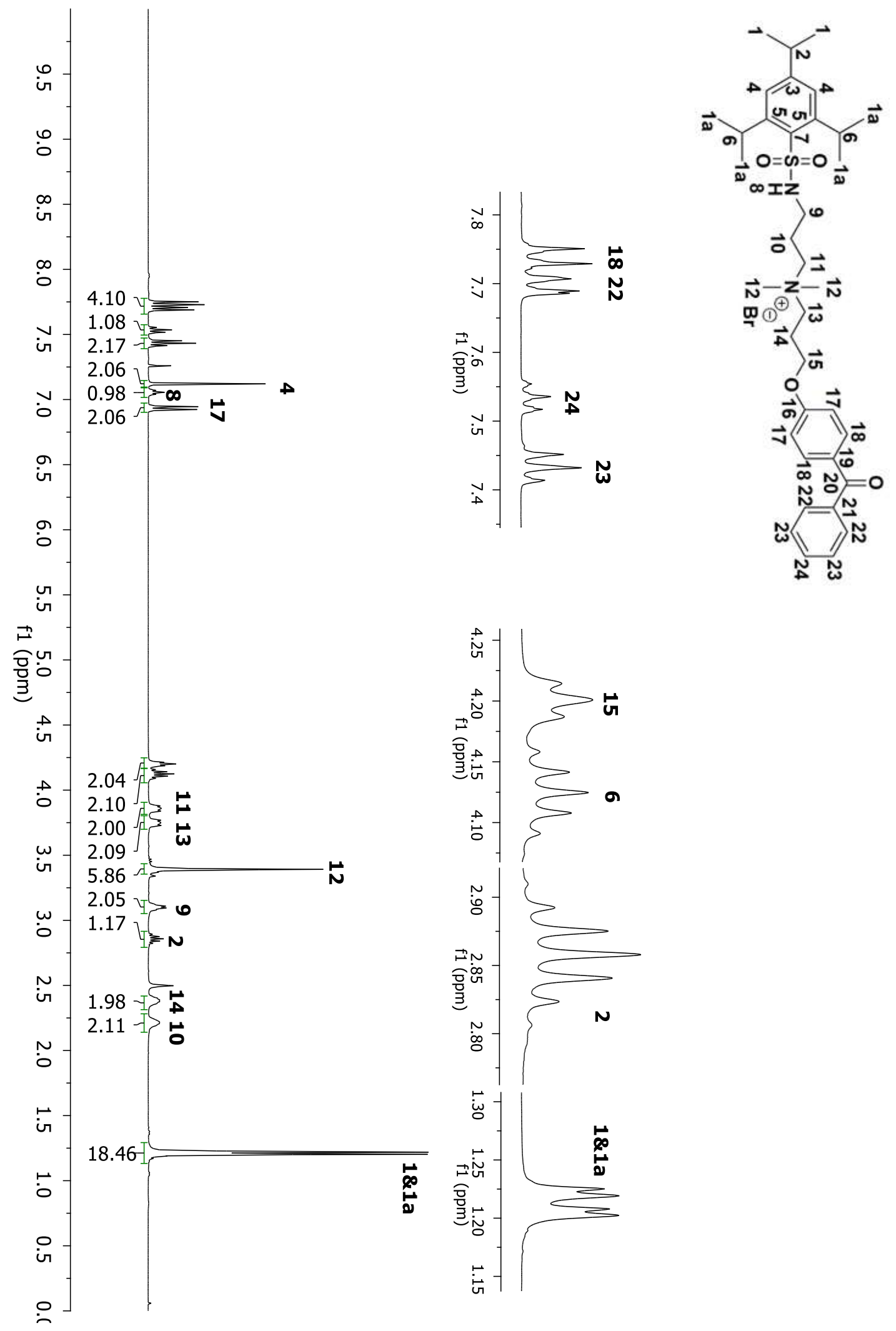

Figure A138: ${ }^{1} \mathrm{H}$ NMR spectrum of compound $4 \mathbf{J}$ in $\mathrm{CDCl}_{3}$. 


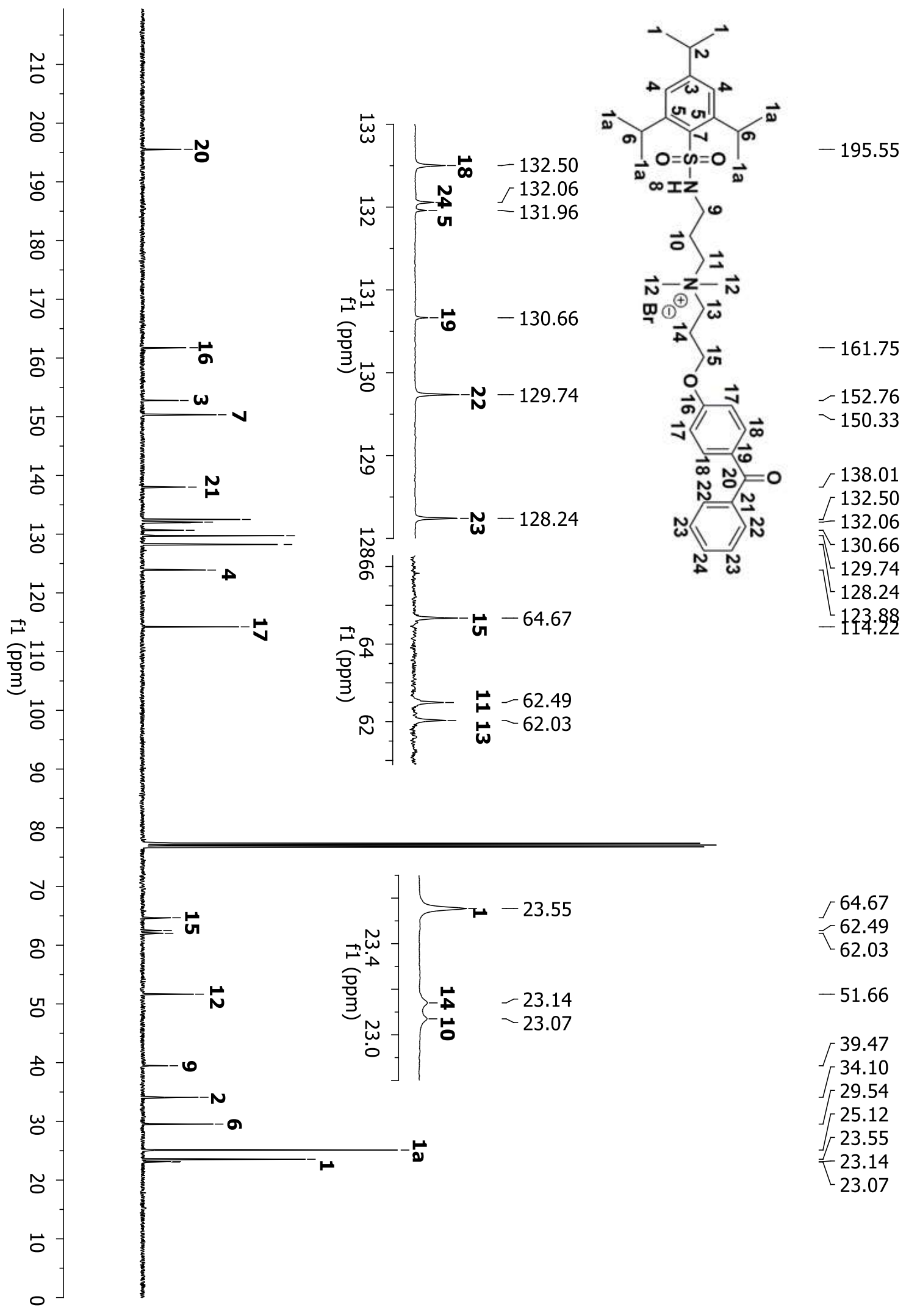

Figure A139: ${ }^{13} \mathrm{C}$ NMR spectrum of compound $\mathbf{4 J}$ in $\mathrm{CDCl}_{3}$. 


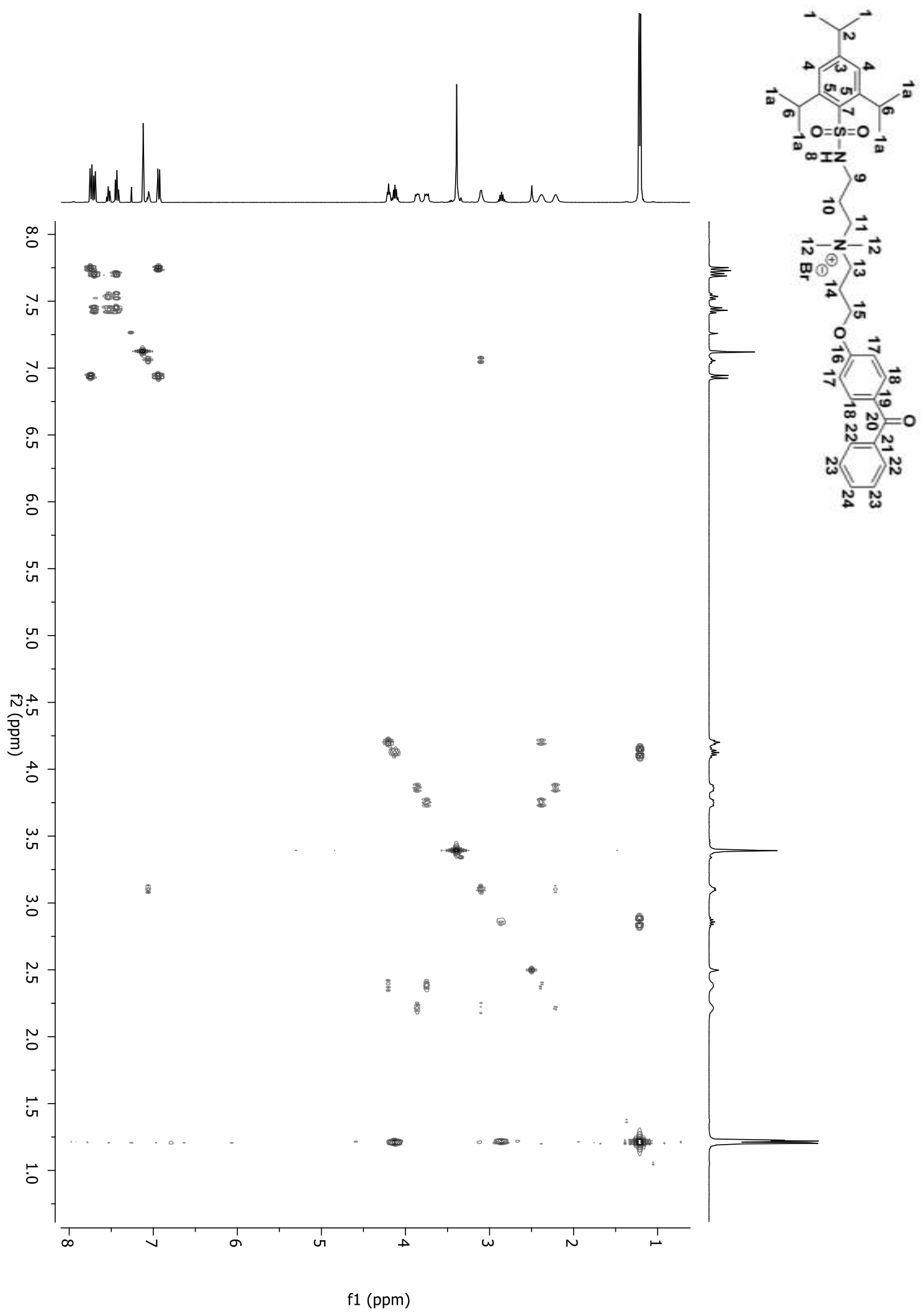

Figure A140: 2D COSY spectrum of compound $\mathbf{4 J}$ in $\mathrm{CDCl}_{3}$. 


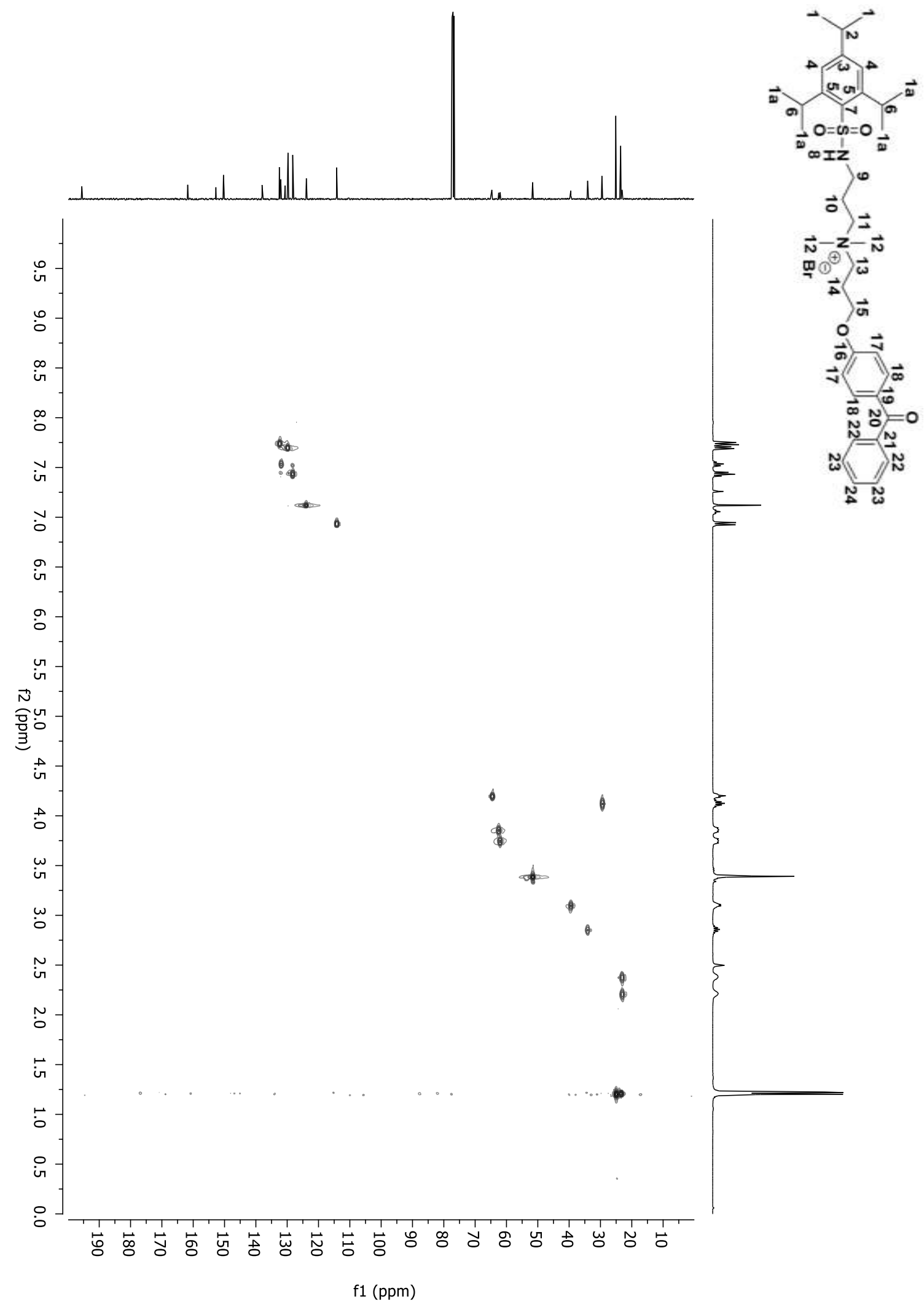

Figure A141: 2D HSQC spectrum of compound $\mathbf{4 J}$ in $\mathrm{CDCl}_{3}$. 


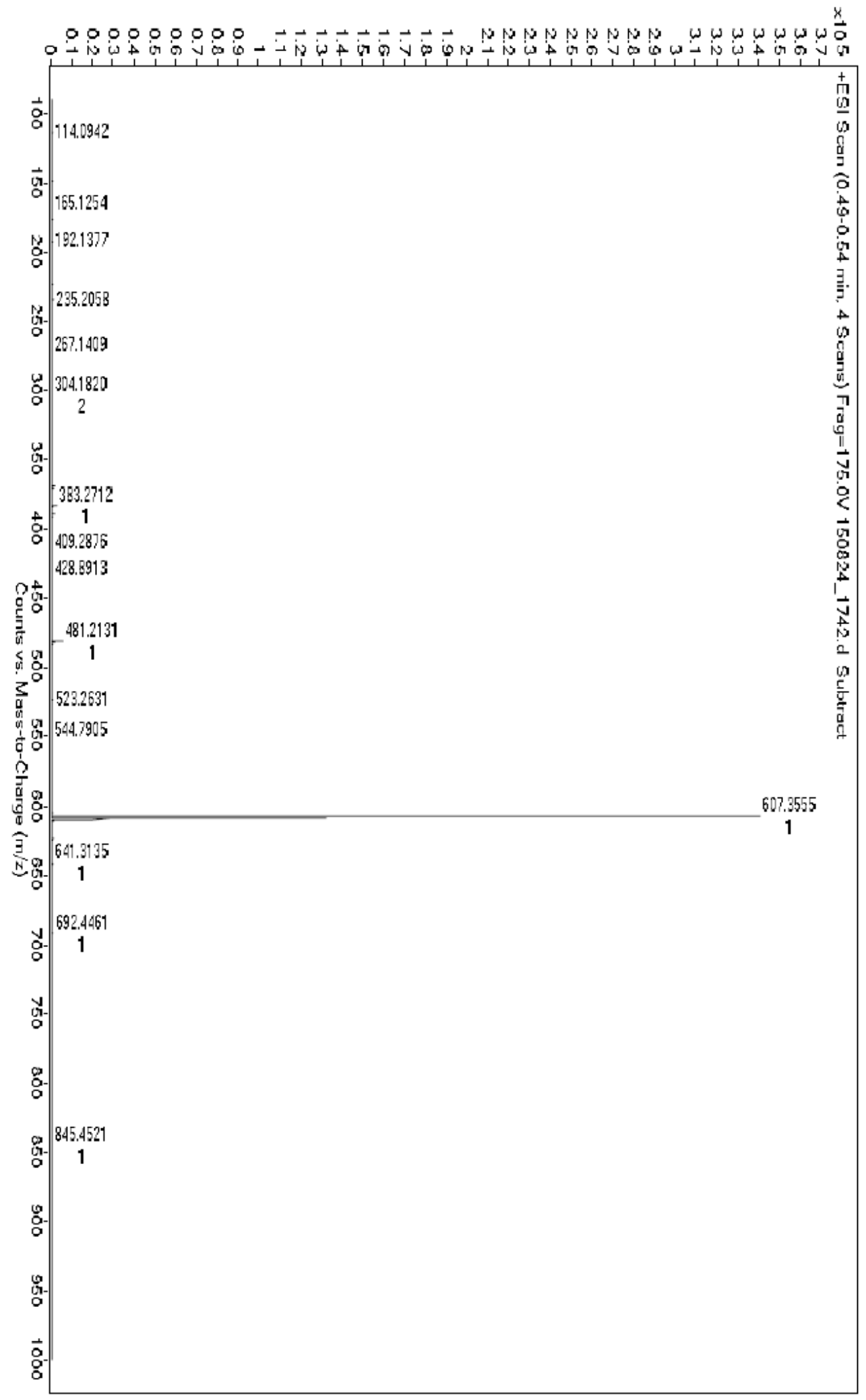

Figure A142: HRMS-ESI-TOF of compound 4J. 


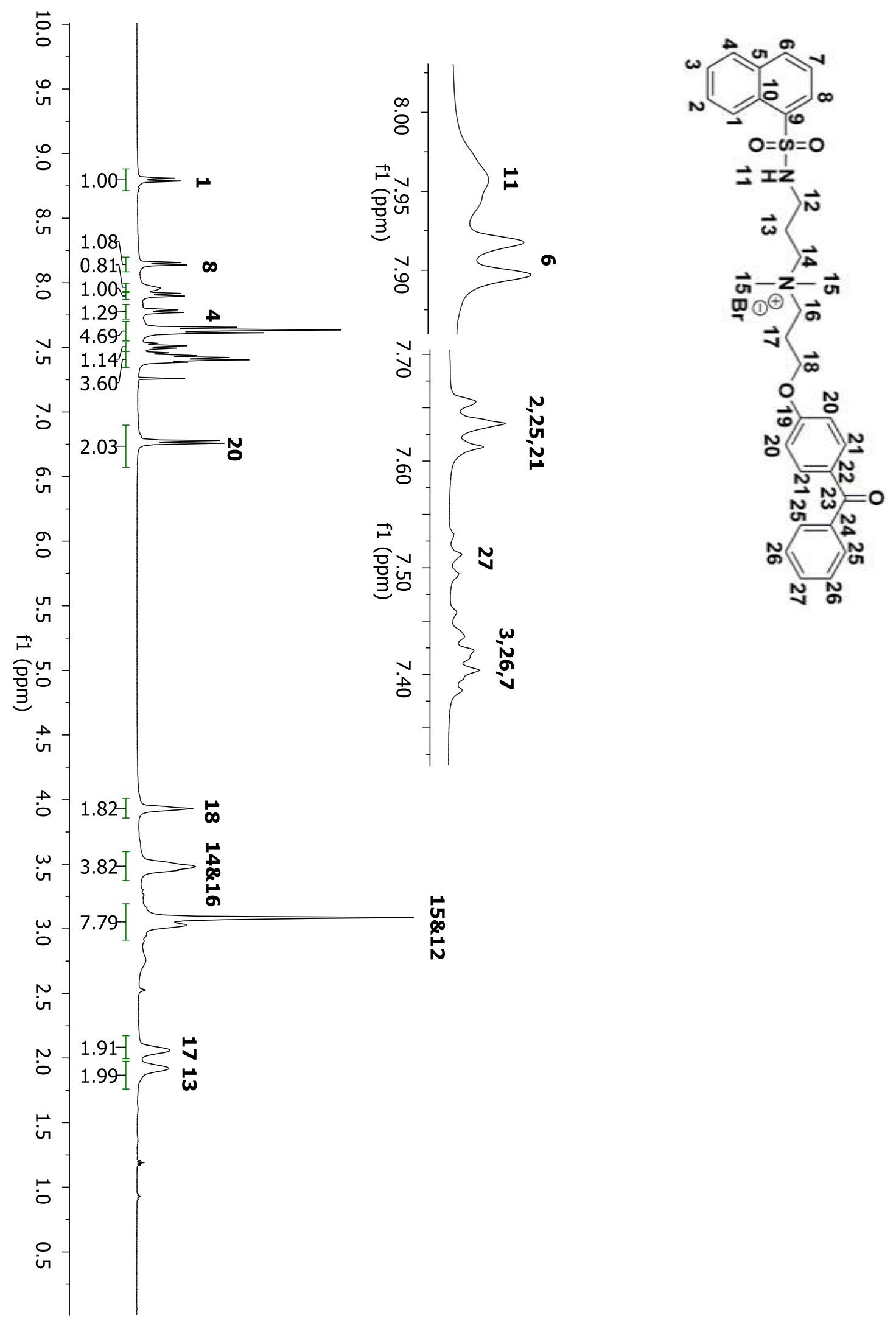

Figure A143: ${ }^{1} \mathrm{H}$ NMR spectrum of compound $\mathbf{5} \mathbf{J}$ in $\mathrm{CDCl}_{3}$. 


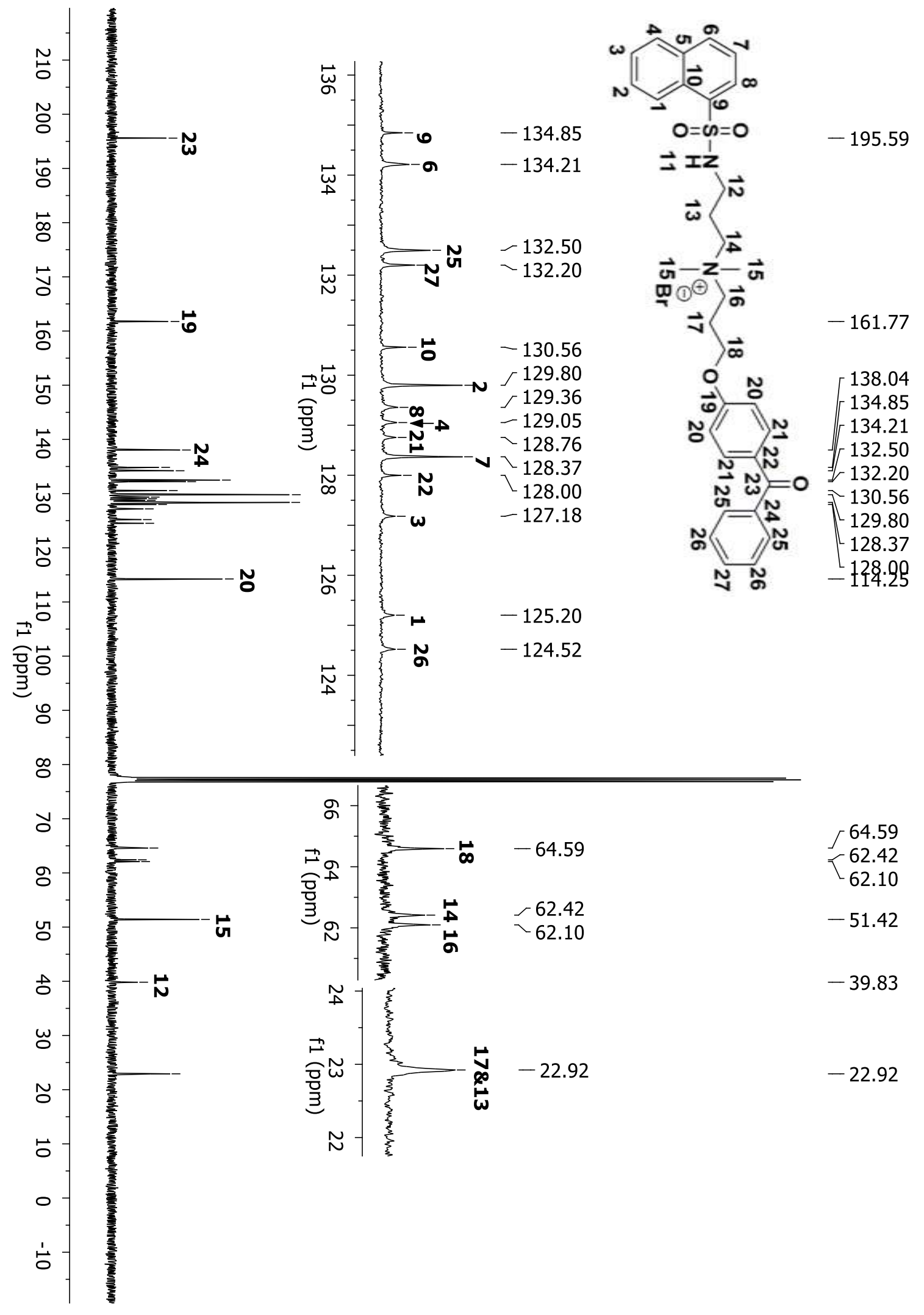

Figure A144: ${ }^{13} \mathrm{C}$ NMR spectrum of compound $\mathbf{5} \mathbf{J}$ in $\mathrm{CDCl}_{3}$. 


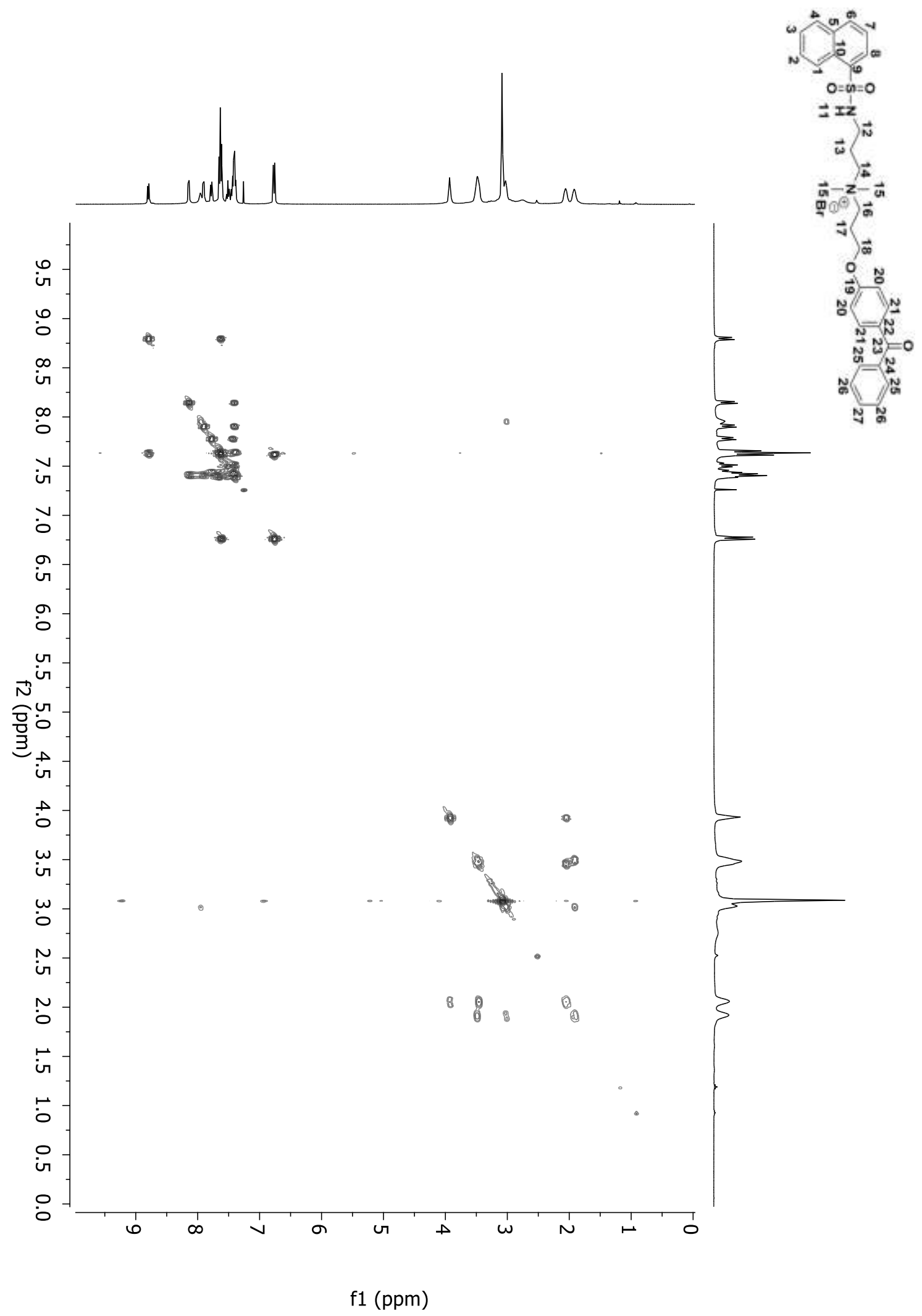

Figure A145: 2D COSY spectrum of compound $\mathbf{5 J}$ in $\mathrm{CDCl}_{3}$. 


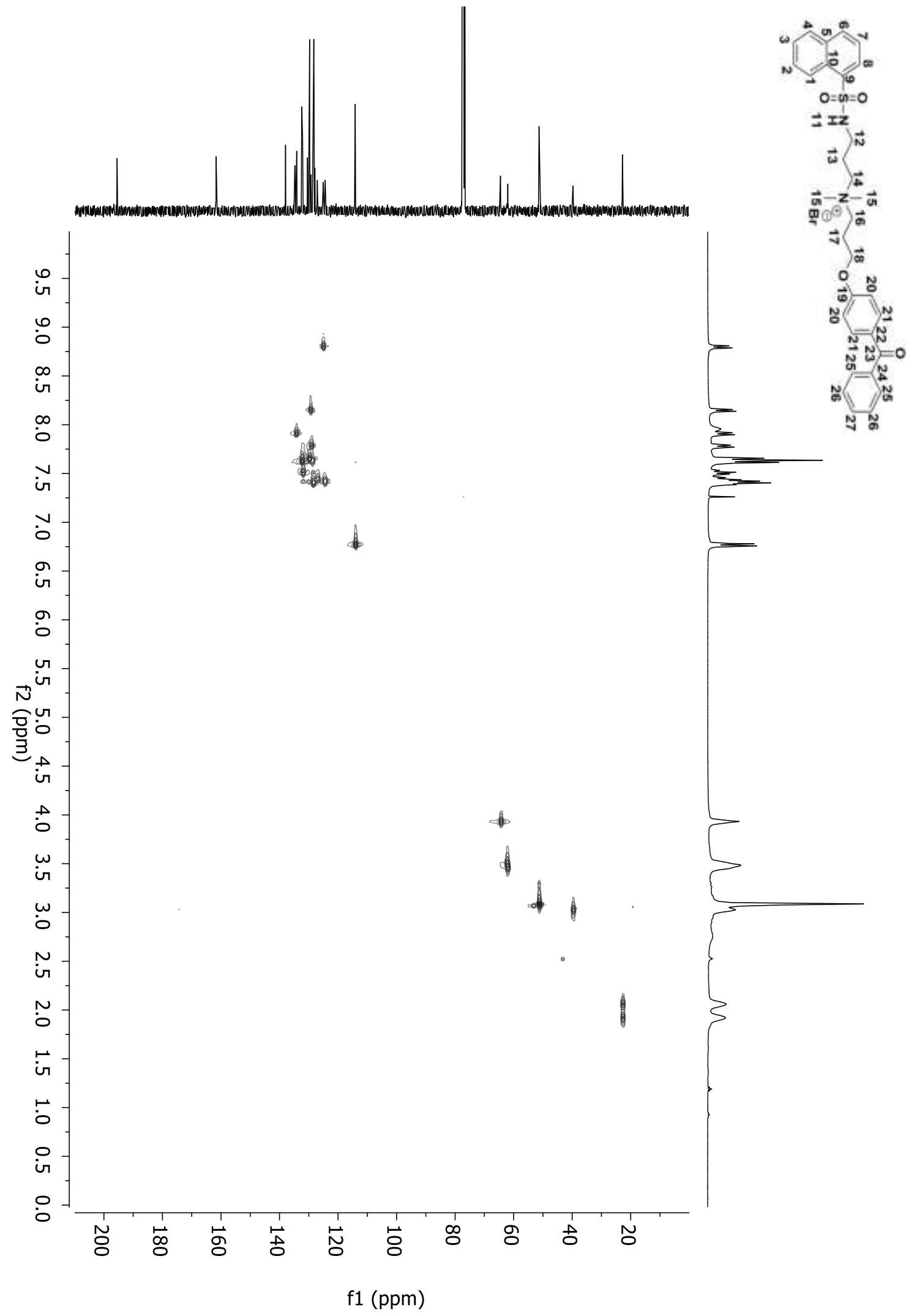

Figure A146: 2D HSQC spectrum of compound $\mathbf{5 J}$ in $\mathrm{CDCl}_{3}$. 


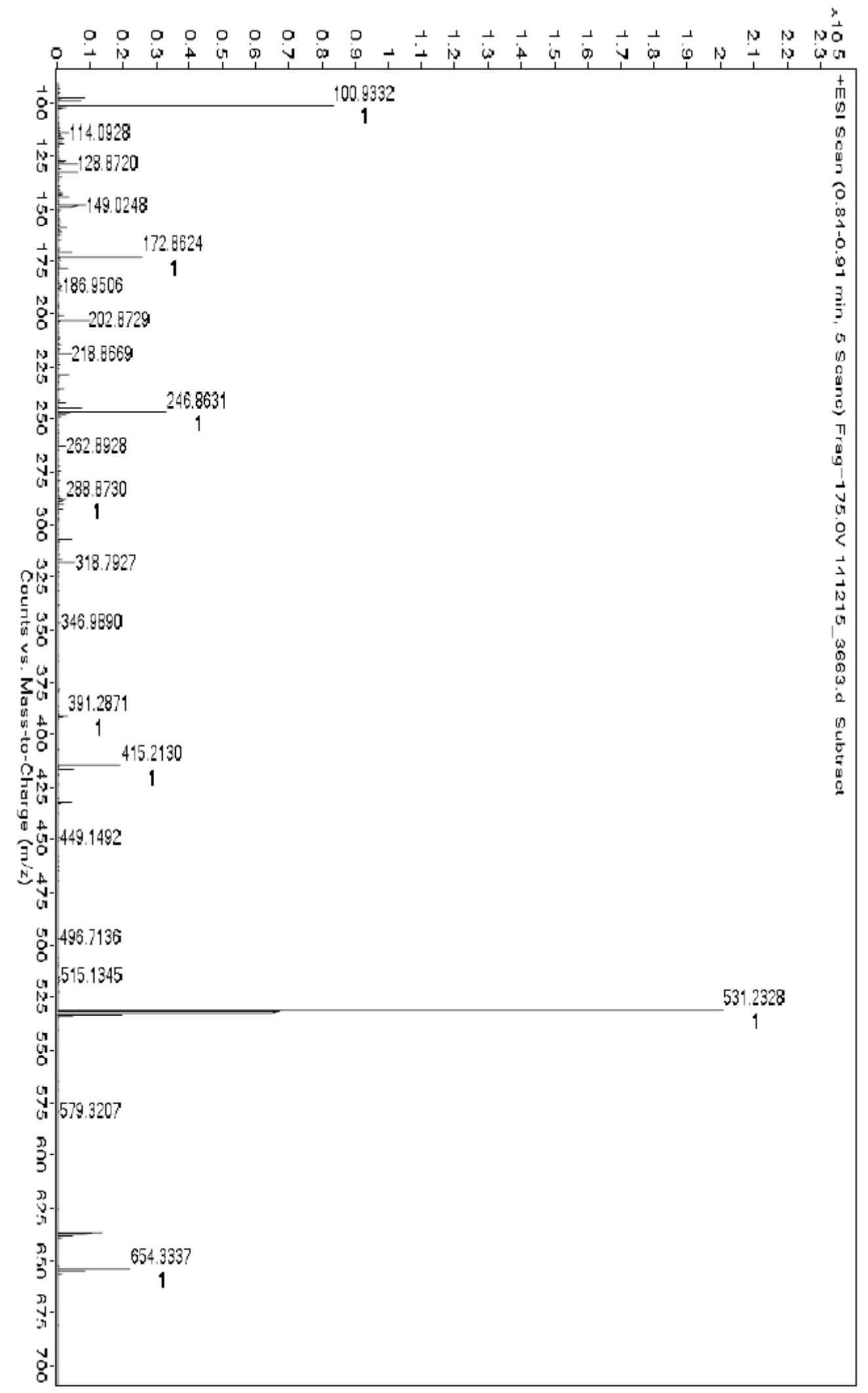

Figure A147: HRMS-ESI-TOF of compound 5J. 


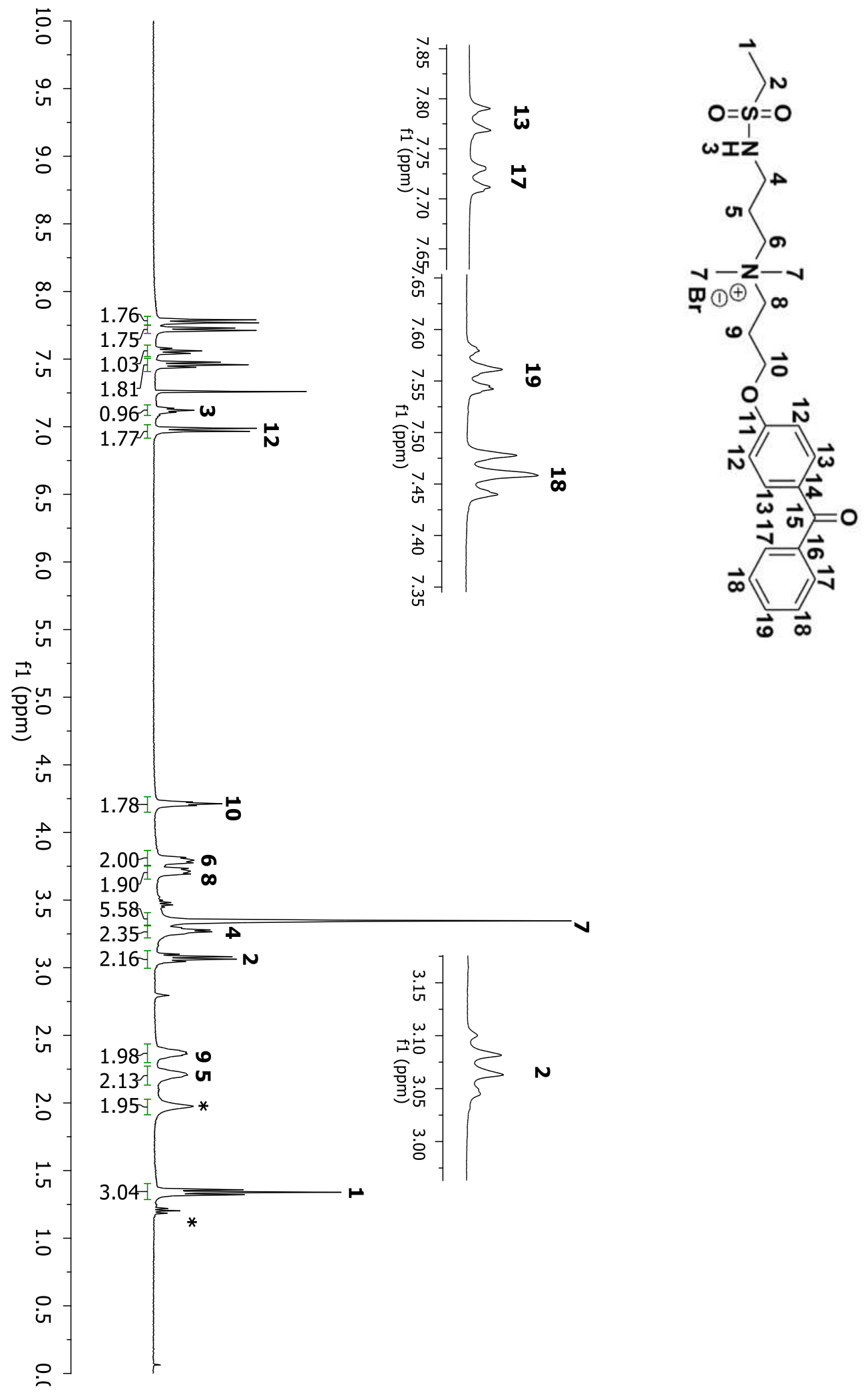

Figure A148: ${ }^{1} \mathrm{H}$ NMR spectrum of compound $7 \mathbf{J}$ in $\mathrm{CDCl}_{3}$. 


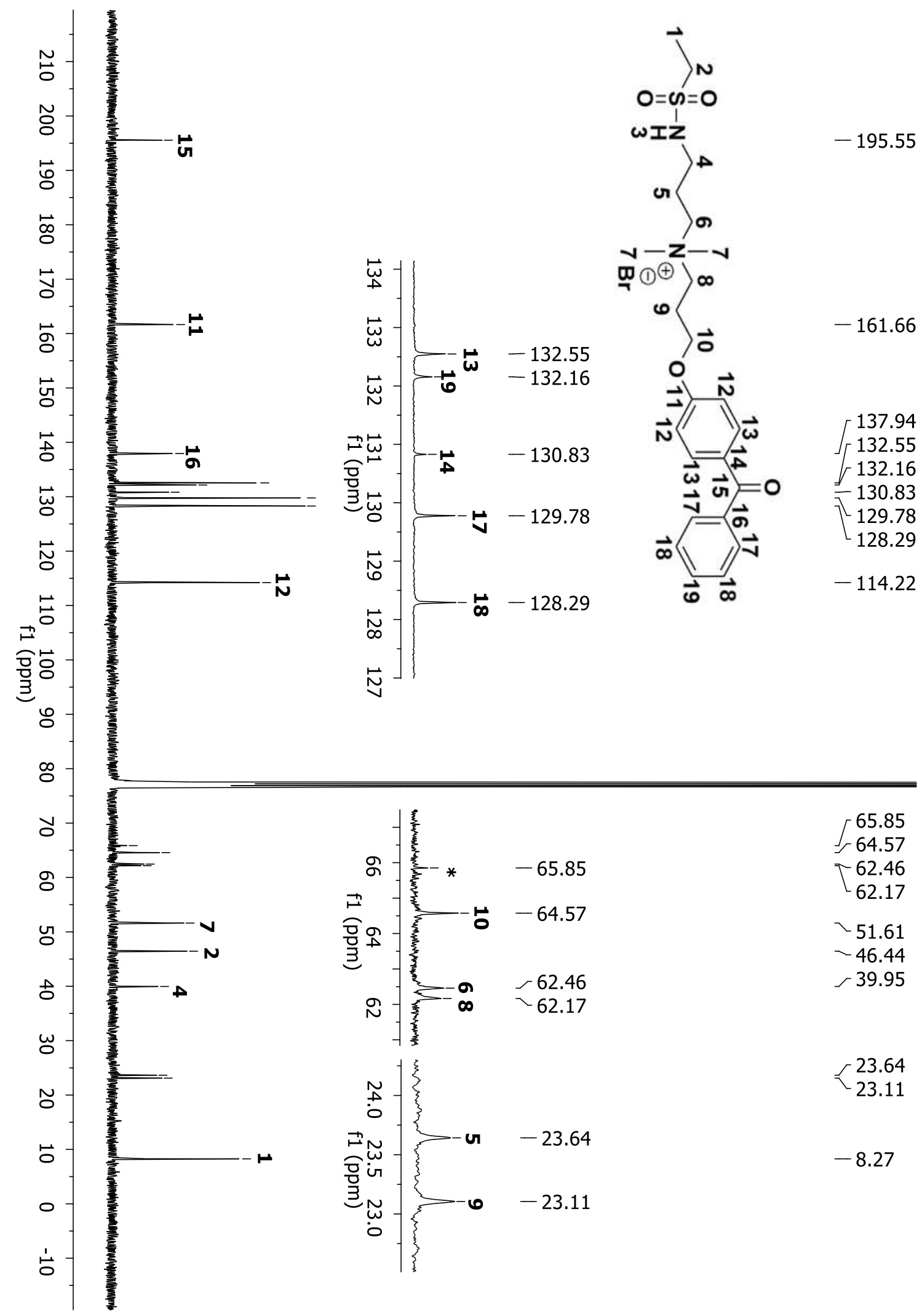

Figure A149: ${ }^{13} \mathrm{C}$ NMR spectrum of compound 7J in $\mathrm{CDCl}_{3}$. 


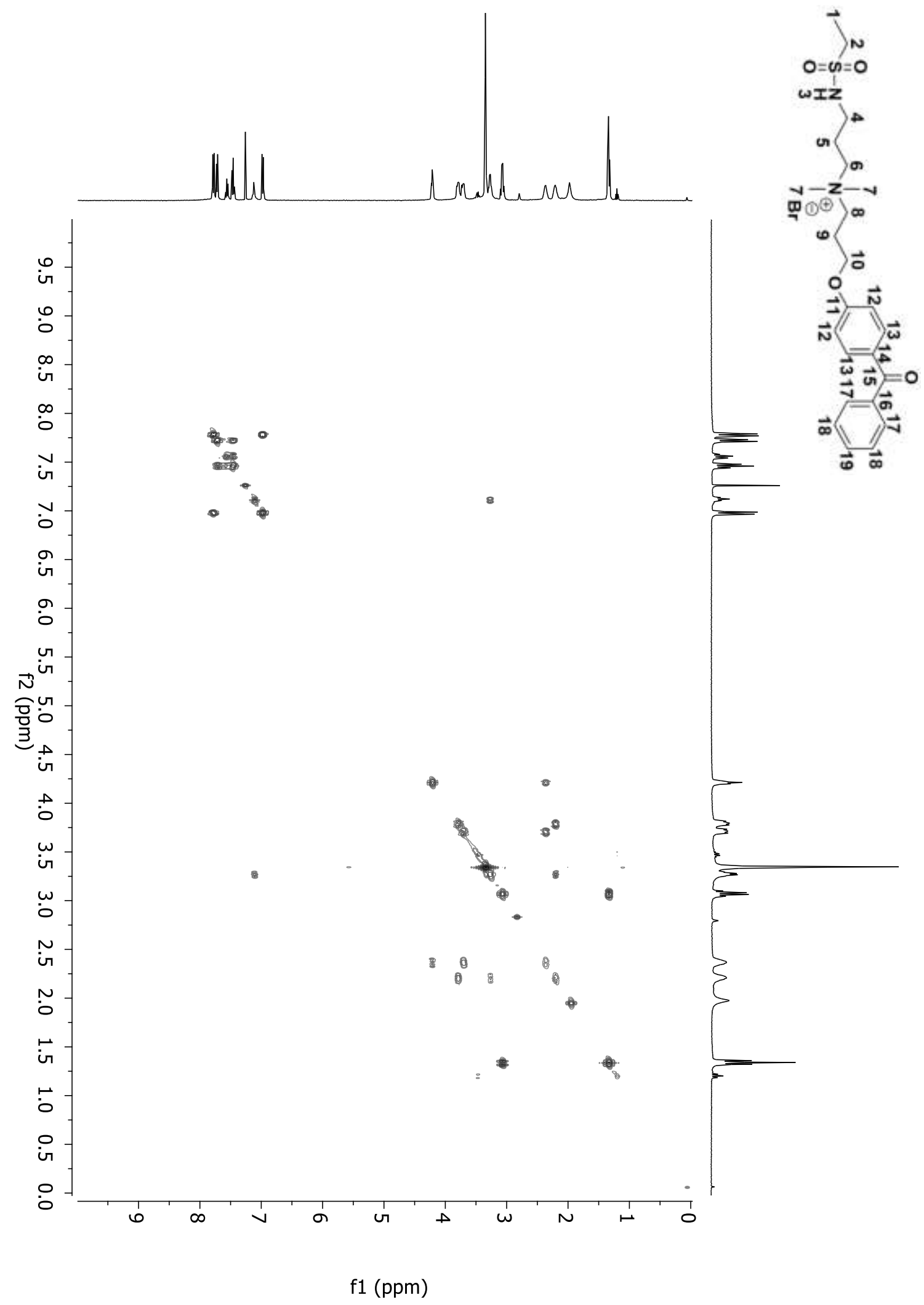

Figure A150: 2D COSY spectrum of compound $\mathbf{7} \mathbf{J}$ in $\mathrm{CDCl}_{3}$. 


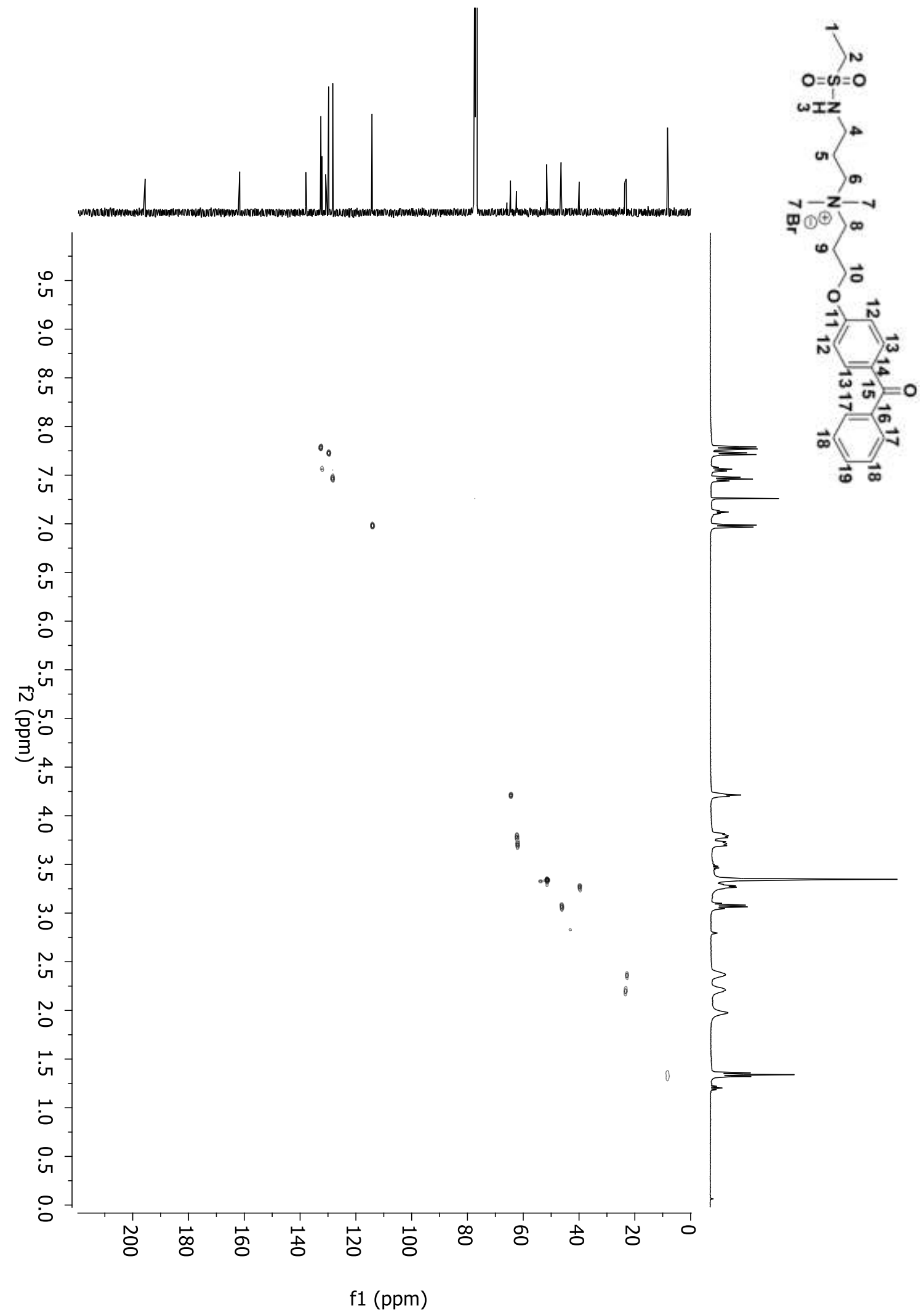

Figure A151: 2D HSQC spectrum of compound 7J in $\mathrm{CDCl}_{3}$. 


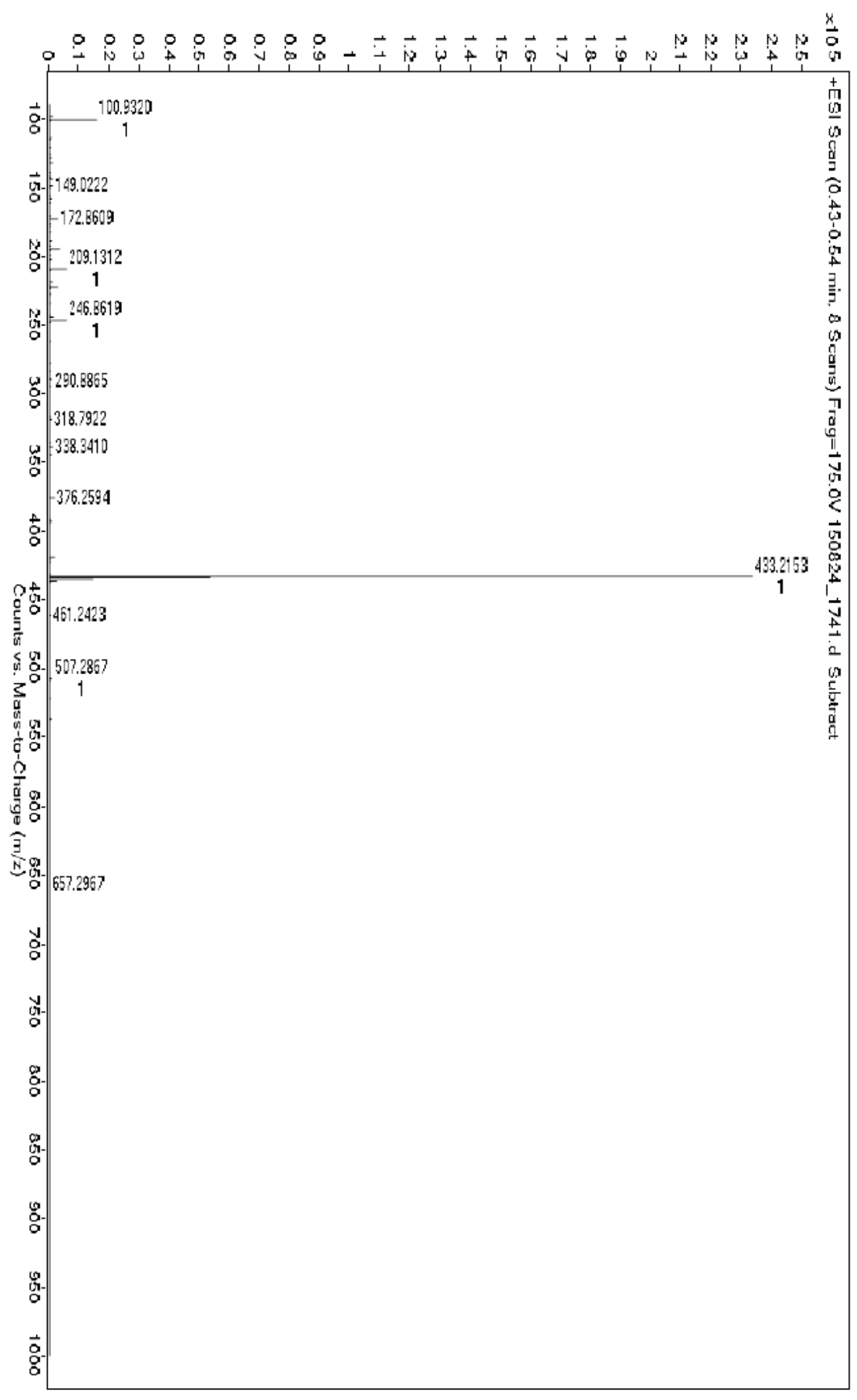

Figure A152: HRMS-ESI-TOF of compound 7J. 


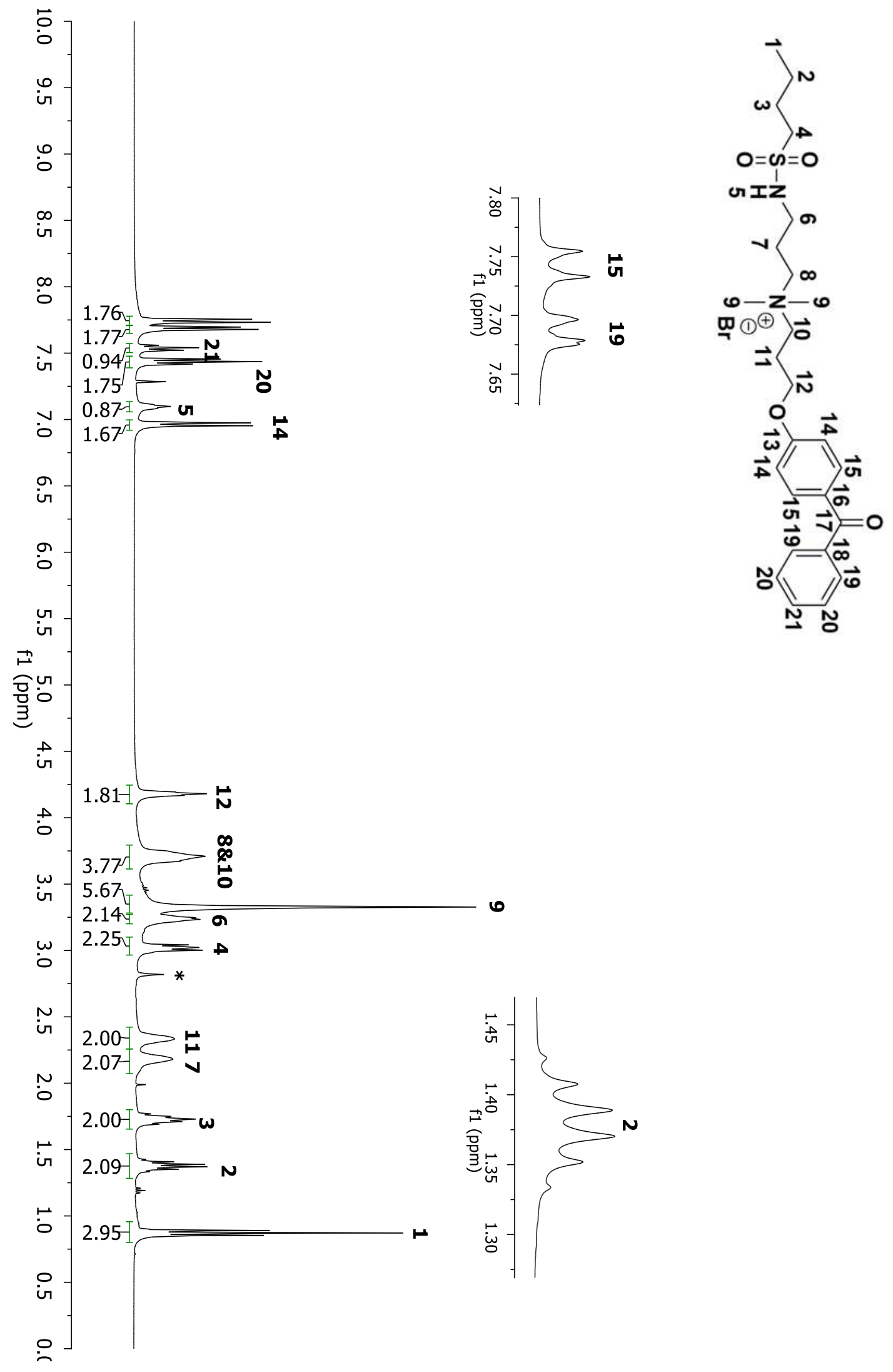

Figure A153: ${ }^{1} \mathrm{H}$ NMR spectrum of compound $\mathbf{8 J}$ in $\mathrm{CDCl}_{3}$. 


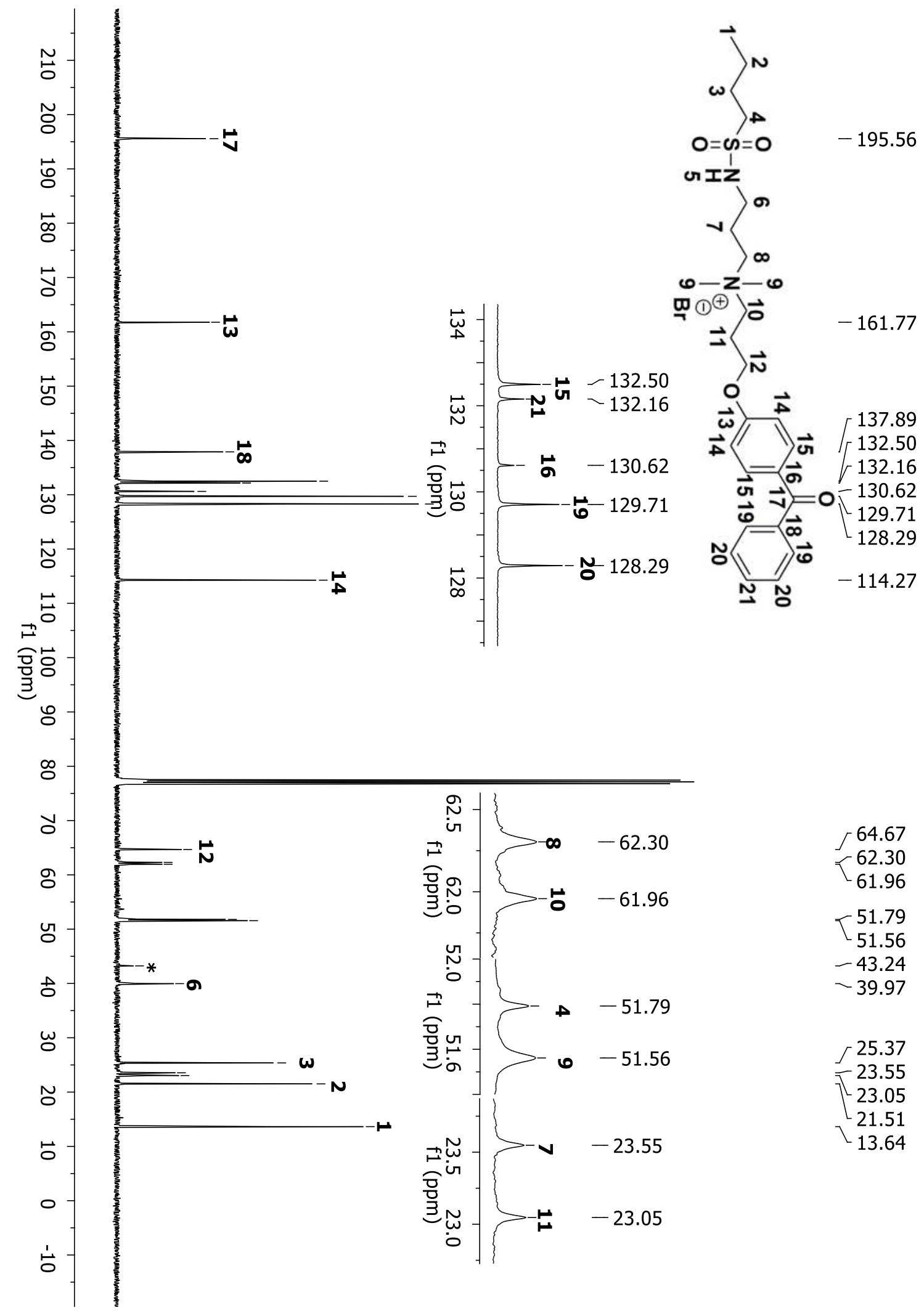

Figure A154: ${ }^{13} \mathrm{C}$ NMR spectrum of compound $8 \mathrm{~J}$ in $\mathrm{CDCl}_{3}$. 


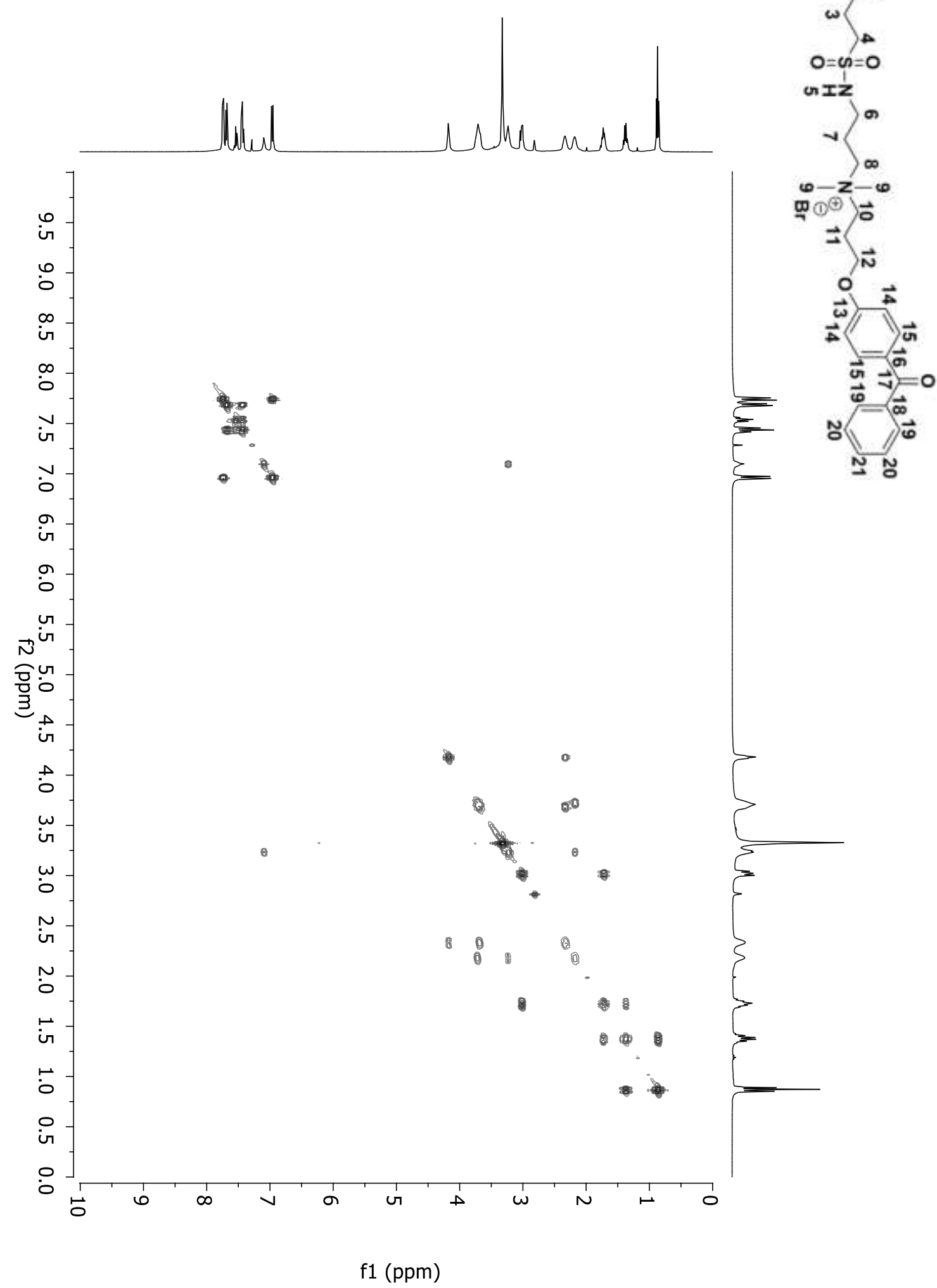

Figure A155: 2D COSY spectrum of compound $\mathbf{8 J}$ in $\mathrm{CDCl}_{3}$. 


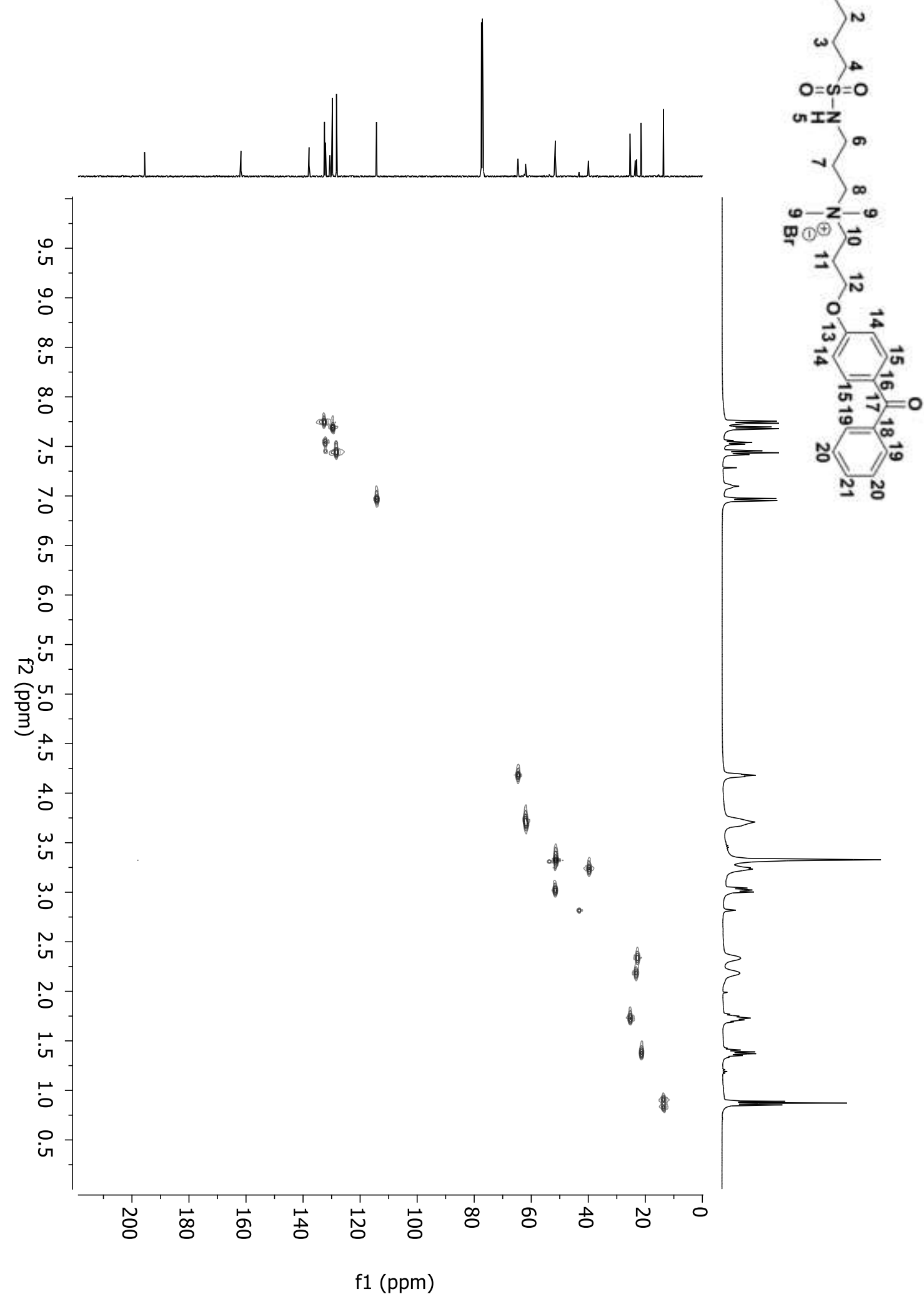

Figure A156: 2D HSQC spectrum of compound $\mathbf{8 J}$ in $\mathrm{CDCl}_{3}$. 


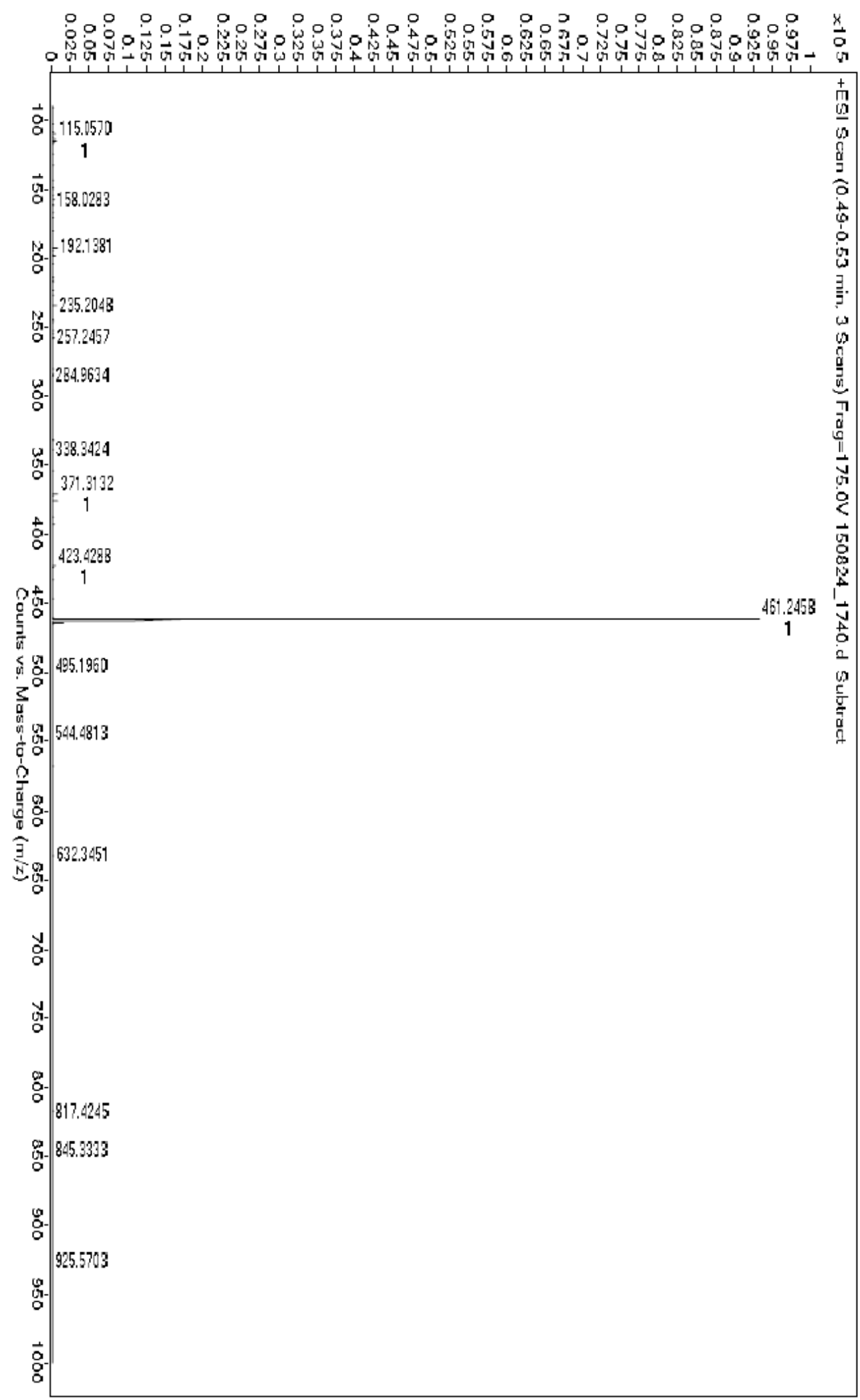

Figure A157: HRMS-ESI-TOF of compound 8J. 


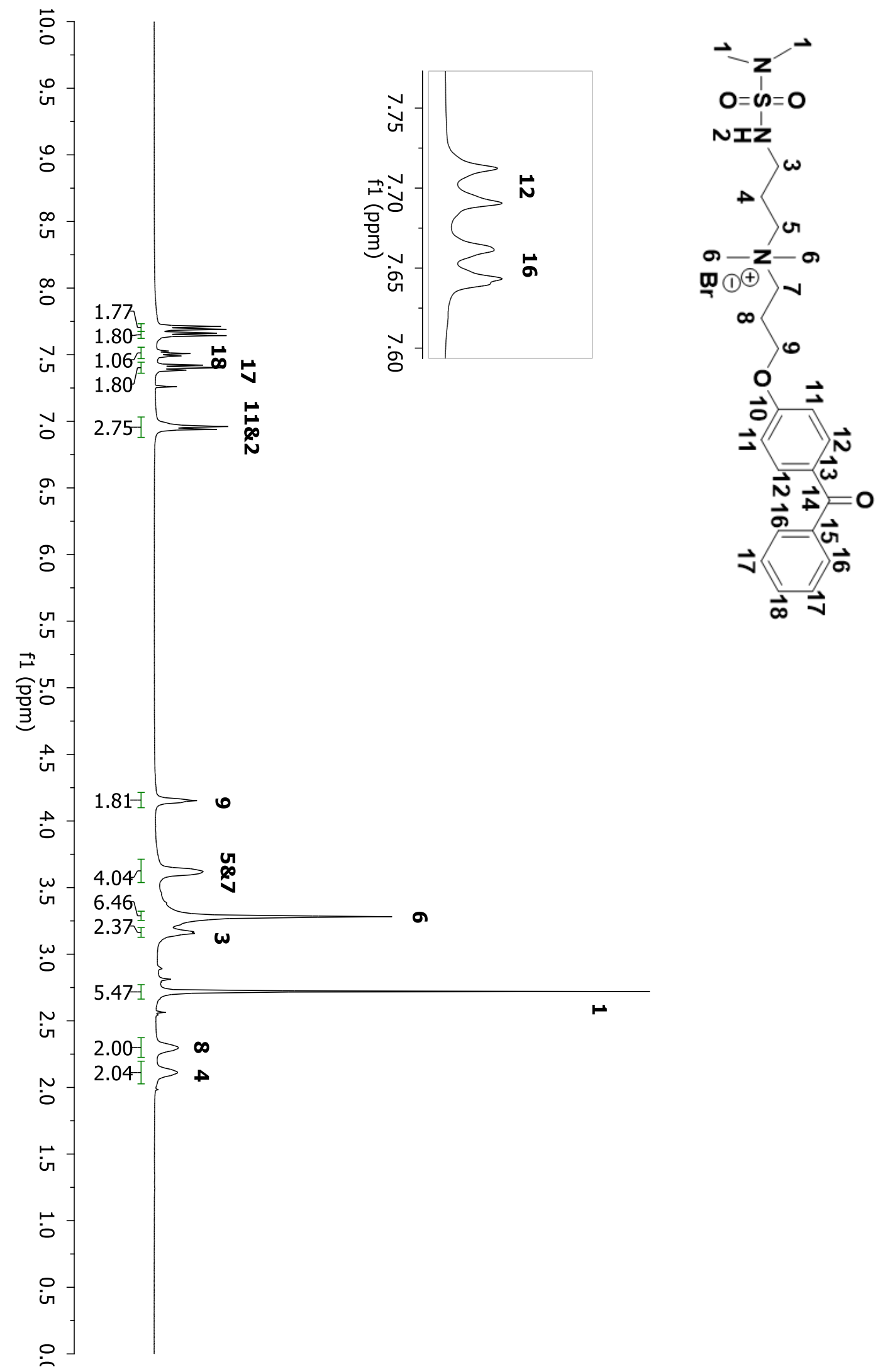

Figure A158: ${ }^{1} \mathrm{H}$ NMR spectrum of compound $9 \mathbf{J}$ in $\mathrm{CDCl}_{3}$. 


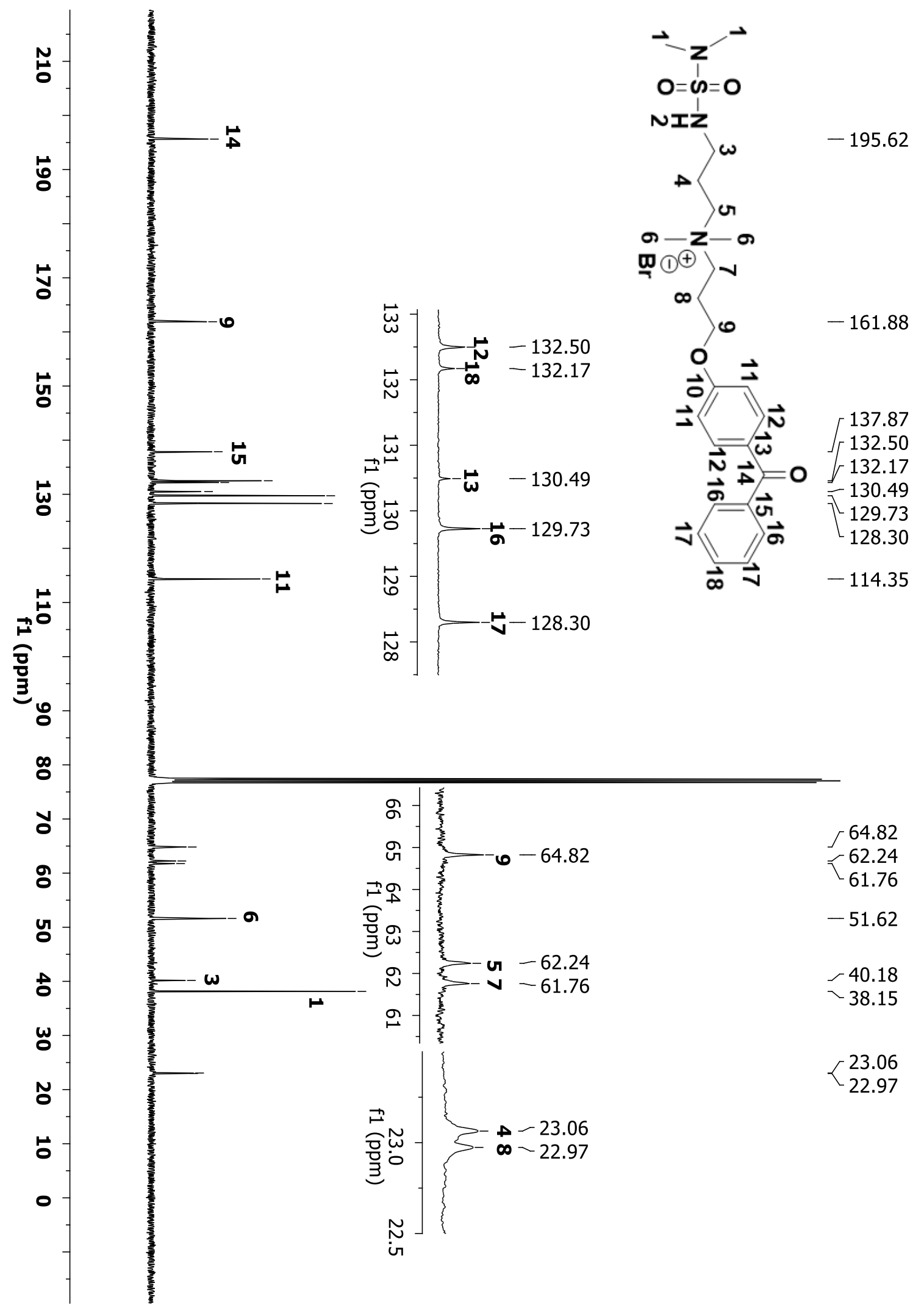

Figure A159: ${ }^{13} \mathrm{C}$ NMR spectrum of compound $9 \mathrm{~J}$ in $\mathrm{CDCl}_{3}$. 


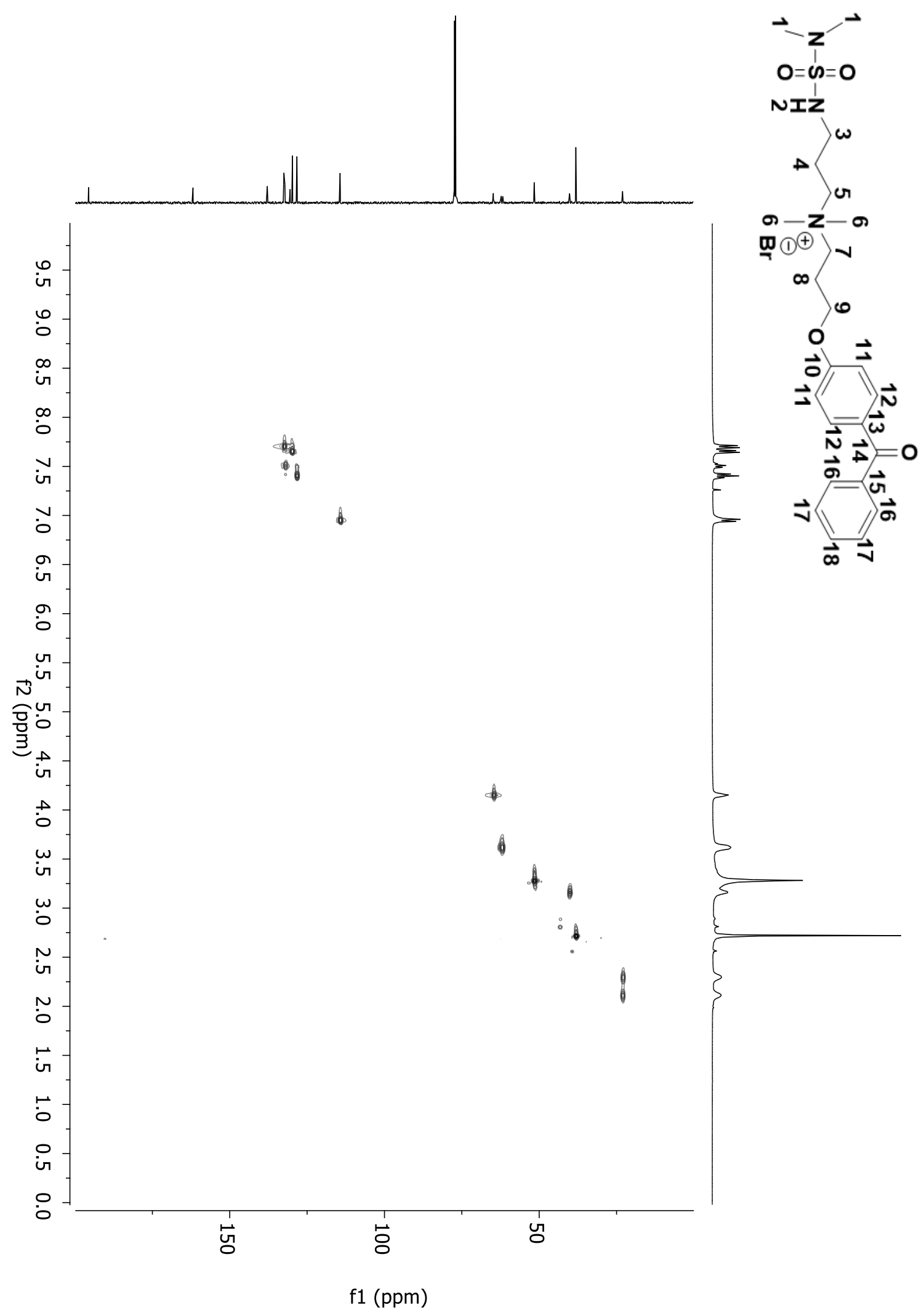

Figure A160: 2D COSY spectrum of compound $9 \mathbf{J}$ in $\mathrm{CDCl}_{3}$. 


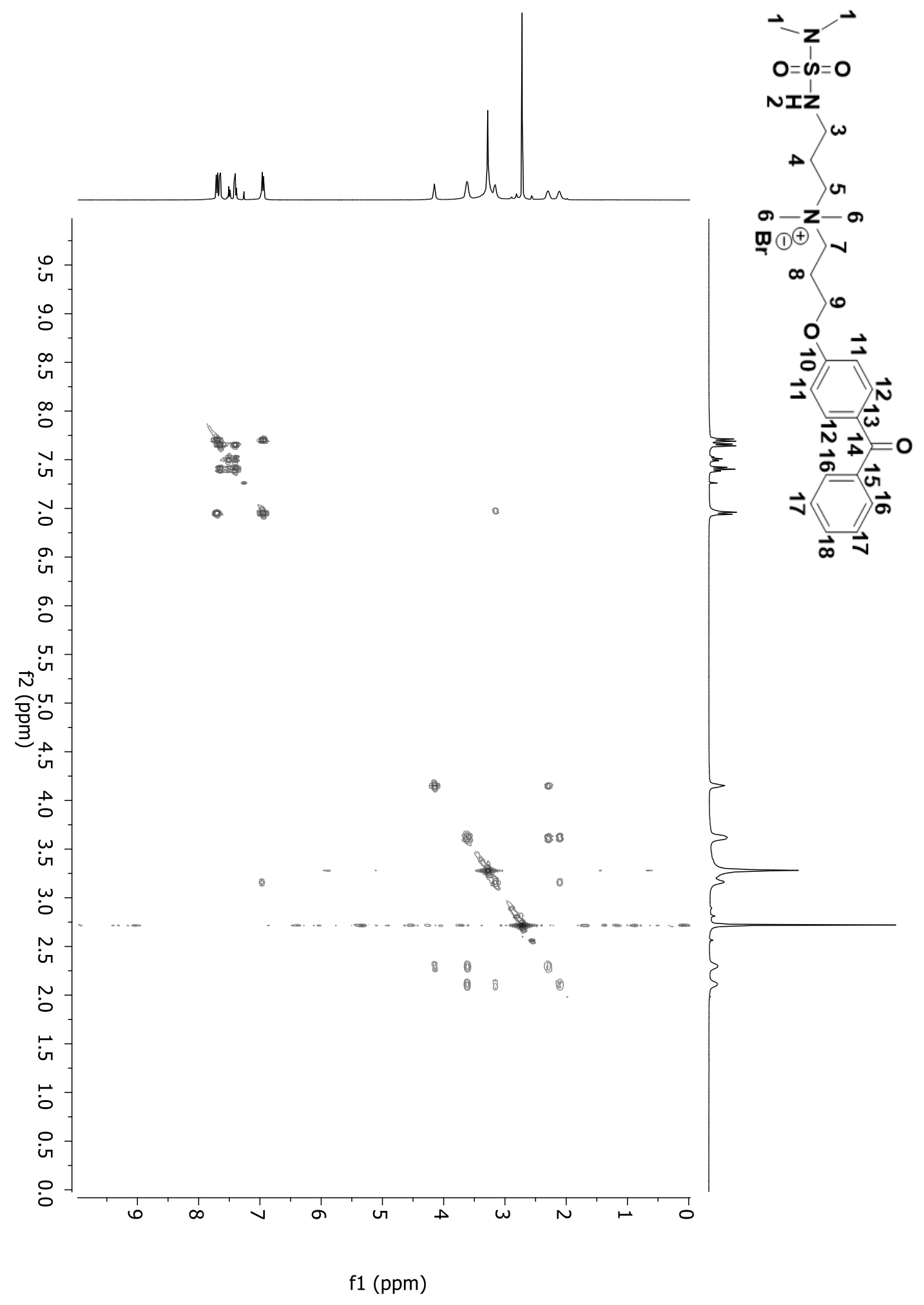

Figure A161: 2D HSQC spectrum of compound $9 \mathbf{J}$ in $\mathrm{CDCl}_{3}$. 


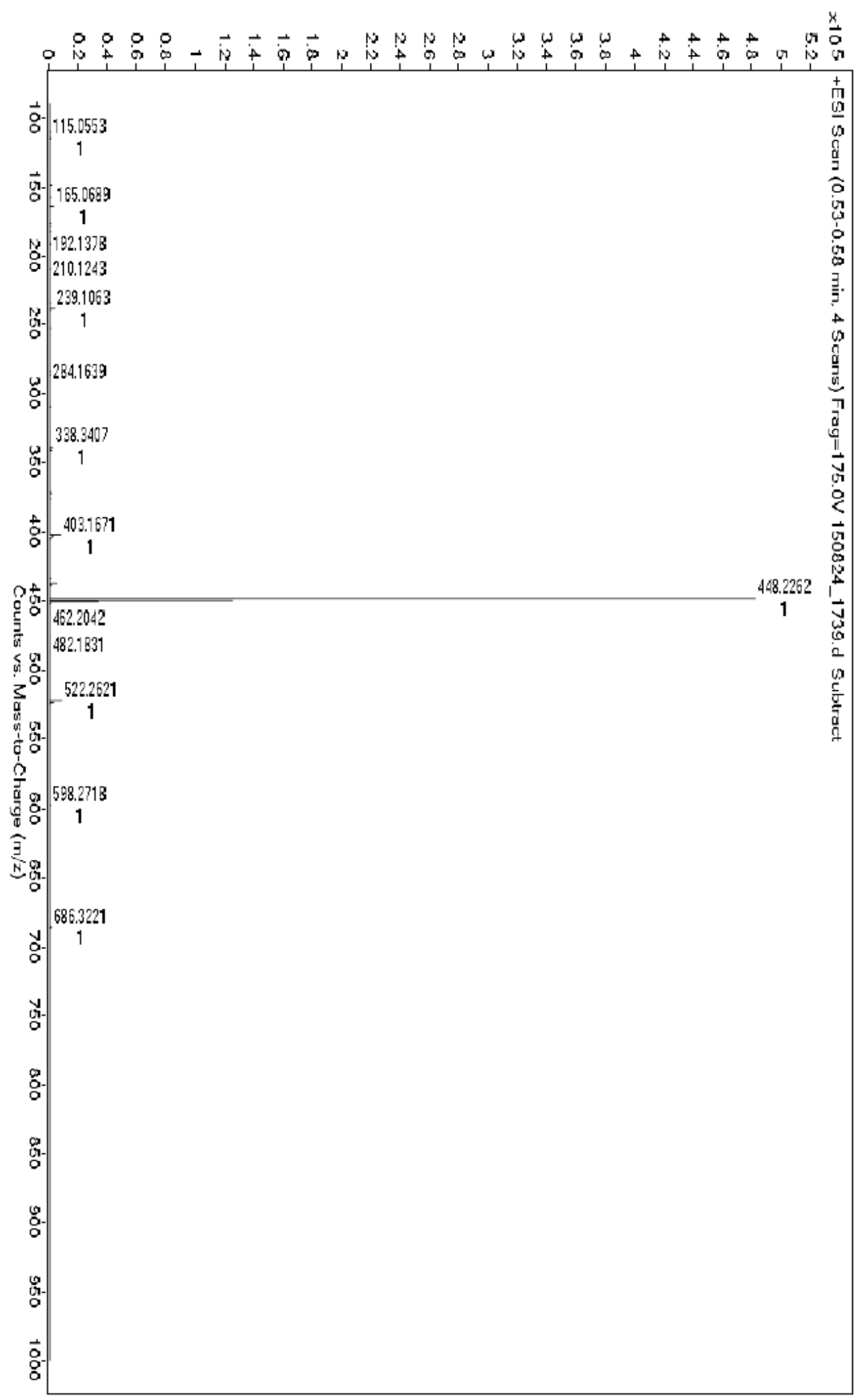

Figure A162: HRMS-ESI-TOF of compound 9J. 


\section{REFERENCES}

(1) Grass, G.; Rensing, C.; Solioz, M. Metallic copper as an antimicrobial surface. Appl. Environ. Microbiol. 2011, 77, 1541-1547 DOI: 10.1128/AEM.02766-10.

(2) Kramer, A.; Schwebke, I.; Kampf, G. How long do nosocomial pathogens persist on inanimate surfaces? A systematic review. BMC Infect. Dis. 2006, 6, 130-138 DOI: 10.1186/1471-2334-6-130.

(3) Porosa, L. M. Detection and Antimicrobial Activity of Immobilized Quaternary Ammonium Antimicrobial Monolayers on Porous and Non-porous Surfaces, Ryerson University, 2014.

(4) Ferreira, L.; Zumbuehl, A. Non-leaching surfaces capable of killing microorganisms on contact. J. Mater. Chem. 2009, 19, 7796-7806 DOI: 10.1039/b905668h.

(5) Page, K.; Wilson, M.; Parkin, I. P. Antimicrobial surfaces and their potential in reducing the role of the inanimate environment in the incidence of hospital-acquired infections. $J$. Mater. Chem. 2009, 19, 3819-3831 DOI: 10.1039/b818698g.

(6) Russell, a D. Introduction of biocides into clinical practice and the impact on antibioticresistant bacteria. Symp. Ser. Soc. Appl. Microbiol. 2002, 121S - 135S.

(7) McFee, R. B. Nosocomial or Hospital-acquired Infections: An Overview. Disease-aMonth 2009, 55, 422-438 DOI: 10.1016/j.disamonth.2009.03.014.

(8) Zoutman, D. E.; Ford, B. D.; Bryce, E.; Gourdeau, M.; Hébert, G.; Henderson, E.; Paton, $\mathrm{S}$. The state of infection surveillance and control in Canadian acute care hospitals. Am. J. Infect. Control 2003, 31, 266-273 DOI: 10.1067/mic.2003.88.

(9) G. Ducel, J. Fabry, L. N. Prevention of hospital-acquired infections. World Heal. Organ. 2002, 1-64 DOI: WHO/CDS/CSR/EPH/2002.12.

(10) McCarter, J. Prevention and Control of Hospital-acquired Infections; Toronto, Ontario, 2008.

(11) Iersel, A. Van. Infection Control: Essential for a Healthy British Columbia; Victoria, British Columbia, 2007.

(12) Ferreira, L.; Zumbuehl, A. Non-leaching surfaces capable of killing microorganisms on contact. J. Mater. Chem. 2009, 19, 7796-7806 DOI: 10.1039/b905668h.

(13) Lichter, J. A.; Van Vlietpa, K. J.; Rubner, M. F. Design of antibacterial surfaces and interfaces: Polyelectrolyte multilayers as a multifunctional platform. Macromolecules 2009, 42, 8573-8586 DOI: 10.1021/ma901356s.

(14) Kugel, A.; Stafslien, S.; Chisholm, B. J. Antimicrobial coatings produced by "tethering" biocides to the coating matrix: A comprehensive review. Prog. Org. Coatings 2011, 72, 222-252 DOI: 10.1016/j.porgcoat.2011.07.004.

(15) Cheng, G.; Zhang, Z.; Chen, S.; Bryers, J. D.; Jiang, S. Inhibition of bacterial adhesion and biofilm formation on zwitterionic surfaces. Biomaterials 2007, 28, 4192-4199 DOI: 10.1016/j.biomaterials.2007.05.041.

(16) Mistry, K. B. New Self-assembling Quaternary Ammonium Fluorescent Compounds, 
Ryerson University, Toronto, ON, 2011.

(17) Siedenbiedel, F.; Tiller, J. C. Antimicrobial polymers in solution and on surfaces: Overview and functional principles. Polymers, 2012, 4, 46-71.

(18) Tiller, J. C. Antimicrobial surfaces. Advances in Polymer Science, 2010, 240, 193-217.

(19) Perkins, John, J. Principles and Methods of Sterilization in Health Sciences, 2nd ed.; Thomas. CHarles C. Publisher, Ltd.: Pennsylvania, 1969.

(20) Sharma, V. K.; Yngard, R. A.; Lin, Y. Silver nanoparticles: green synthesis and their antimicrobial activities. Adv. Colloid Interface Sci. 2009, 145, 83-96 DOI: 10.1016/j.cis.2008.09.002.

(21) Schaeufele, P. J. Advances in quaternary ammonium biocides. J. Am. Oil Chem. Soc. 1984, 61, 387-389 DOI: 10.1007/BF02678799.

(22) Rose, S. F.; Okere, S.; Hanlon, G. W.; Lloyd, a. W.; Lewis, a. L. Bacterial adhesion to phosphorylcholine-based polymers with varying cationic charge and the effect of heparin pre-adsorption. J. Mater. Sci. Mater. Med. 2005, 16, 1003-1015 DOI: 10.1007/s10856005-4755-y.

(23) Rose, S. F.; Lewis, A. L.; Hanlon, G. W.; Lloyd, A. W. Biological responses to cationically charged phosphorylcholine-based materials in vitro. Biomaterials 2004, 25, 5125-5135 DOI: 10.1016/j.biomaterials.2003.12.016.

(24) Menschutkin, N. Ueber die Einwirkung des Chloracetyls auf phosphorige Säure. Ann. der Chemie und Pharm. 1865, 133, 317-320 DOI: 10.1002/jlac.18651330307.

(25) Reinheimer, J. D.; Harley, J. D.; Meyers, W. W. Solvent Effects in the Menschutkin Reaction. J. Org. Chem. 1963, 28, 1575-1579 DOI: 10.1021/jo01041a035.

(26) Sommer, H. Z.; Lipp, H. I.; Jackson, L. L. Alkylation of amines. General exhaustive alkylation method for the synthesis of quaternary ammonium compounds. J. Org. Chem. 1971, 36, 824-828 DOI: 10.1021/jo00805a021.

(27) Yagci, M. B.; Bolca, S.; Heuts, J. P. A.; Ming, W.; de With, G. Self-stratifying antimicrobial polyurethane coatings. Prog. Org. Coatings 2011, 72, 305-314 DOI: 10.1016/j.porgcoat.2011.04.021.

(28) Isquith, A. J.; Abbott, E. A.; Walters, P. A. Surface-bonded antimicrobial activity of an organosilicon quaternary ammonium chloride. Appl. Microbiol. 1972, 24, 859-863.

(29) Long, B.; Nikitin, K.; Fitzmaurice, D. Self-Assembly of an Electronically Switchable Rotaxane on the Surface of a Titanium Dioxide Nanoparticle. J. Am. Chem. Soc. 2003, 125, 15490-15498 DOI: 10.1021/ja037592g.

(30) Liedberg, B.; Tengvall, P. Molecular Gradients of $\omega$-Substituted Alkanethiols on Gold: Preparation and Characterization. Langmuir 1995, 11, 3821-3827 DOI: 10.1021/la00010a037.

(31) Guerrero, G.; Mutin, P. H.; Vioux, A. Anchoring of Phosphonate and Phosphinate Coupling Molecules on Titania Particles. Chem. Mater. 2001, 13, 4367-4373 DOI: $10.1021 / \mathrm{cm} 001253 \mathrm{u}$. 
(32) Hofer, R.; Textor, M.; Spencer, N. D. Alkyl Phosphate Monolayers, Self-Assembled from Aqueous Solution onto Metal Oxide Surfaces. Langmuir 2001, 17, 4014-4020 DOI: 10.1021/la001756e.

(33) Madkour, A. E.; Dabkowski, J. M.; Nusslein, K.; Tew, G. N. Fast disinfecting antimicrobial surfaces. Langmuir 2009, 25, 1060-1067 DOI: 10.1021/la802953v.

(34) Ye, Q.; Zhou, F.; Liu, W. Bioinspired catecholic chemistry for surface modification. Chem. Soc. Rev. 2011, 40, 4244-4258 DOI: 10.1039/c1cs15026j.

(35) Simoncic, B.; Tomsic, B. Structures of Novel Antimicrobial Agents for Textiles - A Review. Text. Res. J. 2010, 80, 1721-1737 DOI: 10.1177/0040517510363193.

(36) Barbey, R.; Lavanant, L.; Paripovic, D.; Schüwer, N.; Sugnaux, C.; Tugulu, S.; Klok, H. A. Polymer brushes via surface-initiated controlled radical polymerization: synthesis, characterization, properties, and applications. Chem. Rev. 2009, 109, 5437-5527 DOI: 10.1021/cr900045a.

(37) Lee, S.; Vörös, J. An Aqueous-Based Surface Modification of Poly(dimethylsiloxane) with Poly(ethylene glycol) to Prevent Biofouling. Langmuir 2005, 21, 11957-11962 DOI: 10.1021/la051932p.

(38) Papra, A.; Gadegaard, N.; Larsen, N. B. Characterization of Ultrathin Poly(ethylene glycol) Monolayers on Silicon Substrates. Langmuir 2001, 17, 1457-1460 DOI: 10.1021/la000609d.

(39) Sofia, S.; Premnath, V.; Merrill, E. Poly(ethylene oxide) Grafted to Silicon Surfaces: Grafting Density and Protein Adsorption. Macromolecules 1998, 31, 5059-5070 DOI: $10.1021 / \mathrm{ma} 9710161$.

(40) Radhakrishnan, B.; Ranjan, R.; Brittain, W. J. Surface initiated polymerizations from silica nanoparticles. Soft Matter 2006, 2, 386-396 DOI: 10.1039/b516508c.

(41) Jennings, G. K.; Brantley, E. L. Physicochemical properties of surface-initiated polymer films in the modification and processing of materials. Adv. Mater. 2004, 16, 1983-1994 DOI: $10.1002 /$ adma.200400810.

(42) Bech, L.; Elzein, T.; Meylheuc, T.; Ponche, A.; Brogly, M.; Lepoittevin, B.; Roger, P. Atom transfer radical polymerization of styrene from different poly(ethylene terephthalate) surfaces: Films, fibers and fabrics. Eur. Polym. J. 2009, 45, 246-255 DOI: 10.1016/j.eurpolymj.2008.10.031.

(43) Huang, W.; Kim, J. B.; Bruening, M. L.; Baker, G. L. Functionalization of surfaces by water-accelerated atom-transfer radical polymerization of hydroxyethyl methacrylate and subsequent derivatization. Macromolecules 2002, 35, 1175-1179 DOI: 10.1021/ma011159e.

(44) Hou, S.; Li, Z.; Li, Q.; Liu, Z. F. Poly(methyl methacrylate) nanobrushes on silicon based on localized surface-initiated polymerization. Appl. Surf. Sci. 2004, 222, 338-345 DOI: 10.1016/j.apsusc.2003.09.021.

(45) Huang, J.; Murata, H.; Koepsel, R. R.; Russell, A. J.; Matyjaszewski, K. Antibacterial Polypropylene via Surface-Initiated Atom Transfer Radical Polymerization 
Biomacromolecules. Biomacromolecules 2007, 8, 1396.

(46) Henry, R. J. The mode of action of the sulfonamides. Bacteriol. Rev. 1943, 7, 175-262.

(47) Gelmo, P. Über Sulfamide der p-Amidobenzolsulfonsäure. J. für Prakt. Chemie 1908, 77, 369-382 DOI: 10.1002/prac.19080770129.

(48) OTTEN, H. Domagk and the development of the sulphonamides. J. Antimicrob. Chemother. 1986, 17, 689-690 DOI: 10.1093/jac/17.6.689.

(49) Nunes, R. J. The Chemistry and Biological Activity of Cyclic Iminobenzenesulphonyl Derivaties, The Hatfield Polytechnic, Hertfordshire, England, United Kingdom, 1986.

(50) Trefouel, J.; Nitti, F.; Bovet, D. Action of p-aminophenylsulfamide in experimental streptococcus infections of mice and rabbits. C. R. Seances Soc. Biol. Fil. 1935, 120, 756758.

(51) Barry, R. H.; Puetzer, B. Quaternary ammonium salts of sulfanilamide derivatives. J. Am. Pharm. Assoc. 1945, 34, 244-245 DOI: 10.1002/jps.3030340908.

(52) Lawrence, C. A.; Goetchius, G. R. The antibacterial actions of quaternary ammonium sulfonamides. J. Am. Pharm. Assoc. 1948, 37, 424-428 DOI: 10.1002/jps.3030371008.

(53) Ahrq, Q.; Aik, W.; Demetriades, M.; Hamdan, M. K. K.; Bagg, E. a L.; Yeoh, K. K.; Lejeune, C.; Zhang, Z. Z.; McDonough, M. a; Schofield, C. J.; et al. Fast disinfecting antimicrobial surfaces. Polymer (Guildf). 2009, 24, 1988-1994 DOI: 10.1128/AEM.02766-10.

(54) Jansson, R. E.; O’Brien, R. N.; Visaisouk, S. Surface-functionalized biocidal polymers. US5104649A, April 14, 1992.

(55) Song, D.; Yang, J. S.; Oh, C.; Cui, S.; Kim, B. K.; Won, M.; Lee, J. I.; Kim, H. M.; Han, G. New synthetic aliphatic sulfonamido-quaternary ammonium salts as anticancer chemotherapeutic agents. Eur. J. Med. Chem. 2013, 69, 670-677 DOI: 10.1016/j.ejmech.2013.09.022.

(56) Mikláš, R.; Miklášová, N.; Bukovský, M.; Horváth, B.; Kubincová, J.; Devínsky, F. Synthesis, surface and antimicrobial properties of some quaternary ammonium homochiral camphor sulfonamides. Eur. J. Pharm. Sci. 2014, 65, 29-37 DOI: 10.1016/j.ejps.2014.08.013.

(57) Bieser, A. M.; Tiller, J. C. Mechanistic Considerations on Contact-Active Antimicrobial Surfaces with Controlled Functional Group Densities. Macromol. Biosci. 2011, 11, 526534 DOI: 10.1002/mabi.201000398.

(58) Bermingham, A.; Derrick, J. P. The folic acid biosynthesis pathway in bacteria: Evaluation of potential for antibacterial drug discovery. BioEssays 2002, 24, 637-648 DOI: 10.1002/bies.10114.

(59) Etscovitz, E. The mode of action of sulfonamides. Tufts Med. J. 1945, 13, 13-16 DOI: 10.1001/jama.1944.02850360033011.

(60) Woods, D. D. The Relation of p-aminobenzoic Acid to the Mechanism of the Action of Sulphanilamide. Br J. Exp. Pathol. 1940, 21, 74-90. 
(61) Fildes, P. A rational approach to research in chemotherapy. Lancet 1940, 235, 955-957 DOI: 10.1016/S0140-6736(00)72741-3.

(62) Speier, J. L.; Malek, J. R. Destruction of microorganisms by contact with solid surfaces. J. Colloid Interface Sci. 1982, 89, 68-76 DOI: 10.1016/0021-9797(82)90121-7.

(63) Plueddemann, E. P.; Revis, A. Organosilicon quaternary ammonium antimicrobial compounds for preservation of materials. US4866192A, September 12, 1989.

(64) Pallavicini, P.; Taglietti, A.; Dacarro, G.; Antonio Diaz-Fernandez, Y.; Galli, M.; Grisoli, P.; Patrini, M.; Santucci De Magistris, G.; Zanoni, R. Self-assembled monolayers of silver nanoparticles firmly grafted on glass surfaces: Low Ag+ release for an efficient antibacterial activity. J. Colloid Interface Sci. 2010, 350, 110-116 DOI: 10.1016/j.jcis.2010.06.019.

(65) Kickelbick, G.; Rutzinger, D.; Gallauner, T. Synthesis of Hexadentate Hexahydro-1,3,5triazine-Based Ligands and their Copper(I) Complexes. Monatshefte für Chemie / Chem. Mon. 2002, 133, 1157-1164 DOI: 10.1007/s007060200085.

(66) Sambhy, V.; Peterson, B. R.; Sen, A. Multifunctional silane polymers for persistent surface derivatization and their antimicrobial properties. Langmuir 2008, 24, 7549-7558 DOI: $10.1021 / 1 \mathrm{a} 800858 \mathrm{z}$.

(67) Porosa, L. M.; Mistry, K. B.; Mocella, A.; Deng, H.; Hamzehi, S.; Caschera, A.; Lough, A. J.; Wolfaardt, G.; Foucher, D. a. Synthesis, structures and properties of self-assembling quaternary ammonium dansyl fluorescent tags for porous and non-porous surfaces. $J$. Mater. Chem. B 2014, 2, 1509-1520 DOI: 10.1039/c3tb21633k.

(68) Walters, P. A.; Abbott, E. A.; Isquith, A. J. Algicidal activity of a surface-bonded organosilicon quaternary ammonium chloride. Appl. Microbiol. 1973, 25, 253-256.

(69) Mutin, P. H.; Guerrero, G.; Vioux, A. Hybrid materials from organophosphorus coupling molecules. J. Mater. Chem. 2005, 15, 3761 DOI: 10.1039/b505422b.

(70) Kavipriya, K.; Rajendran, S.; Sathiyabama, J.; Suriya Prabha, A. A critical review of corrosion inhibition by phosphonic acids. Eur. Chem. Bull. 2012, 1, 366-374.

(71) Porosa, L.; Wolfaardt, G.; Lough, A.; Foucher, D. Rapid Microwave-Assisted Synthesis of $\gamma$-Phosphonic Acid Quaternary Ammonium Antimicrobials for Biomedical Applications. Curr. Microw. Chem. 2015, 2, 69-82 DOI: $10.2174 / 221333560201150212112554$.

(72) Appendini, P.; Hotchkiss, J. H. Review of antimicrobial food packaging. Innov. Food Sci. Emerg. Technol. 2002, 3, 113-126 DOI: 10.1016/S1466-8564(02)00012-7.

(73) Prucker, O.; Naumann, C. a.; Rühe, J.; Knoll, W.; Frank, C. W. Photochemical attachment of polymer films to solid surfaces via monolayers of benzophenone derivatives. J. Am. Chem. Soc. 1999, 121, 8766-8770 DOI: 10.1021/ja990962+.

(74) Dhende, V. P.; Samanta, S.; Jones, D. M.; Hardin, I. R.; Locklin, J. One-step photochemical synthesis of permanent, nonleaching, ultrathin antimicrobial coatings for textiles and plastics. ACS Appl. Mater. Interfaces 2011, 3, 2830-2837 DOI: 10.1021/am200324f. 
(75) Mocella, A. UV Cured Benzophenone Terminated Quaternary Ammonium Antimicrobials for Plastics, Ryerson University, Toronto, ON, 2012.

(76) Battaglini, G. Assay of quaternary ammonium antimicrobial compounds by aqueous potentiometric titration. J. Surfactants Deterg. 2002, 5, 117-121 DOI: 10.1007/s11743002-0210-4.

(77) Chen-Yu, J. H.; Eberhardt, D. M.; Kincade, D. H. Antibacterial and Laundering Properties of AMS and PHMB as Finishing Agents on Fabric for Health Care Workers' Uniforms. Cloth. Text. Res. J. 2007, 25, 258-272 DOI: 10.1177/0887302X07303625.

(78) Deng, H. Vinyl Terminated Quaternary Ammonium Antimicrobials for Plastics and Metals, Ryerson University, Toronto, ON, 2013.

(79) Gioiello, A.; Rosatelli, E.; Teofrasti, M.; Filipponi, P.; Pellicciari, R. Building a sulfonamide library by eco-friendly flow synthesis. ACS Comb. Sci. 2013, 15, 235-239 DOI: $10.1021 / \operatorname{co} 400012 \mathrm{~m}$.

(80) Rosatelli, E.; Carotti, A.; Ceruso, M.; Supuran, C. T.; Gioiello, A. Flow synthesis and biological activity of aryl sulfonamides as selective carbonic anhydrase IX and XII inhibitors. Bioorganic Med. Chem. Lett. 2014, 24, 3422-3425 DOI: 10.1016/j.bmcl.2014.05.086.

(81) Takematsu, T.; Konnai, M.; Omokawa, H. Benzenesulfonamide derivatives. US4157257A, April 6, 1979.

(82) De Luca, L.; Giacomelli, G. An Easy Microwave-Assisted Synthesis of Sulfonamides Directly from Sulfonic Acids. J. Org. Chem. 2008, 73, 3967-3969 DOI: 10.1021/jo800424g.

(83) Ronan, E. Investigating microbial ecology at solid-air interfaces, Ryerson University, 2011.

(84) Reynaud, P.; Moreau, R. C.; Aurousseau, M.; Eyraud, H. Chemical and pharmacological study of a new class of thioamides related to procainamide: $\mathrm{N}-(\omega-$ dialkylaminoalkyl)thiobenzamides. Chim. Ther. 1971, 6, 25-41.

(85) Matsuichi, H.; Shigeru, I. Photographic developing solution composition. JP57176036A, October 29, 1982.

(86) De Vries, L. Lubricatingoil compositions. CA1072111A, December 23, 1976.

(87) Parent, M. J.; Savu, P. M.; Flynn, R. M.; Zhang, Z.; Lamanna, W. M.; Qiu, Z.-M.; Moore, G. G. I. Composition of an aqueous etching solution containing fluorinated surfactants. US20040094510A1, May 20, 2004.

(88) Vander Meer, R. K.; Lofgren, C. S.; Williams, D. F. Control of insects with fluorocarbons. US758856A0, March 14, 1986. 